\title{
MARCELO PATRÍCIO
}

\section{DIAGNÓSTICO E PROPOSTA DE MODELO DE AVALIAÇÃO OPERACIONAL PARA AUTOMAÇÃO EM TERMINAIS DE CONTÊINERES NO BRASIL}




\section{MARCELO PATRÍCIO}

\section{DIAGNÓSTICO E PROPOSTA DE MODELO DE AVALIAÇÃO OPERACIONAL PARA AUTOMAÇÃO EM TERMINAIS DE CONTÊINERES NO BRASIL}

Tese apresentada à Escola Politécnica da Universidade de São Paulo para obtenção do Título de Doutor em Engenharia

Área de Concentração:

Engenharia Naval

Orientador:

Prof. Doutor

Rui Carlos Botter

São Paulo 


\section{Catalogação-na-publicação}

\section{Patrício, Marcelo}

Diagnóstico e proposta de modelo de avaliação operacional para automação em terminais de contêineres no Brasil / $M$. Patrício. -- São Paulo, 2014. 251p.

Tese (Doutorado) - Escola Politécnica da Universidade De São Paulo. Departamento de Engenharia Naval e Oceânica.

1.Terminais de carga (Automação) - Brasil 2.Contêineres 3.Operações de transportes I. Universidade de São Paulo. Escola Politécnica. Departamento de Engenharia Naval e Oceânica. 
Às mãos de meu pai, do Alvinho, do Dr. Patrício da CODESP e do avó Dé. 


\section{AGRADECIMENTOS}

À minha mãe Edna pelo carinho e dedicação; à minha esposa Pauline e aos meus filhos Valentina (Vavá) e Pedro pelo amor e compreensão da constante ausência em virtude das minhas atividades em terminais de contêineres e Instituições de Ensino Superior nas duas últimas décadas. Aos meus avós pelos exemplos de vida.

Ao orientador Professor Doutor Rui Carlos Botter pela paciência e dedicação nas orientações.

Ao Diretor-Presidente da Brasil Terminal Portuário (BTP), o Eng. Henry James Robinson; aos amigos da Libra Terminais, em especial ao Eng. Gustavo Pecly, Eng. José Luis Soares e Roberto Lopes pela amizade, incentivo e colaboração durante o período de construção da ideia. Aos colegas "gringos" Nico Berx, Rafael Sapiña, Lawrence Henesey, Yvo Saanen, Hans Van Kerkhof cujos trabalhos acadêmicos e profissionais me auxiliaram de alguma forma.

A Lania Camilo de Oliveira em nome de quem agradecemos todos os funcionários da Escola Politécnica Naval.

A professora Valdilene Zanette Nunes pela revisão do texto; ao professor Danilo Nunes pela enorme paciência e incentivo nas atividades acadêmicas da FSV/UNIBR.

Aos colegas de turma e aos professores que direta ou indiretamente contribuíram para a realização deste trabalho.

Plagiando Carlos Drummond de Andrade, -"Obrigado, essa palavra tudo". 


\section{RESUMO}

Este trabalho apresenta um diagnóstico da questão de automação em terminais de contêineres no Brasil, assim como oferece uma proposta de um modelo que permita auxiliar a reflexão no momento da tomada de decisão na escolha da automação de equipamentos e/ou de processos que compõem as principais atividades de um terminal de contêineres. O processo de automação é recente na indústria portuária, teve seu início na década de 90 em países europeus cujos custos laborais eram altíssimos e necessitavam aumentar a produtividade e experimentar inovações. $O$ modelo apresentado pretende ser uma proposta de análise expandida, isto é, um conceito amplo, que não verifique apenas análises financeiras, mas outros aspectos pertinentes à gestão e planejamento de um terminal, indicados por meio de um conjunto de variáveis. A saber: Layout existente ou proposto do terminal, Investimento financeiro CAPEX e OPEX, Confiabilidade dos sistemas de automação, Integração com sistemas de Tecnologia da Informação e Inteligência de Equipamento, em especial com os Sistemas de Operações dos Terminais, mas conhecidos como "TOS" (Terminal Operating System), Organização do trabalho e alterações de procedimentos operacionais, Contribuição para a segurança e meio ambiente, Obrigatoriedade legal do uso de automação, Custo e Intensidade do uso de mão de obra. A contextualização do setor e evolução da automação na indústria portuária; assim como um quadro atual da situação (diagnóstico) de automação dos terminais brasileiros será apresentada. Posteriormente, a revisão bibliográfica do tema com os principais artigos nacionais e internacionais. Todo esse arcabouço busca demonstrar o hiato existente entre os estágios automatizados e não automatizados; indicar os principais entraves existentes na implantação da automação por processo existente; promover a discussão da viabilidade desses terminais entre operadores, armadores, clientes e demais intervenientes em termos de produtividade, eficiência e de custos. A delicada questão da mão de obra avulsa não foi considerada uma variável restritiva do modelo por diversas razões: pois por si só seria restrição de implantação da automação pela reserva de mercado, especialmente para avulsos; ela permeia diversos itens listados anteriormente. Ao final dessa tese, além do diagnóstico de automação no país e de uma proposta de modelo para a tomada de decisão; espera-se contribuir a pesquisa e ao ensino da engenharia e áreas de gestão indicando do grau e desenvolvimento tecnológico na área de automação especificamente para terminais de contêineres. $E$, por derradeiro, fomentar uma reflexão sobre a profundidade das mudanças operacionais e organizacionais do trabalho que podem ocorrer.

Palavras-chave: Automação, Terminais de Contêineres. 


\begin{abstract}
This study aims a diagnosis of automation in container terminals in Brazil, and offers a proposal of model that allows assist the reflection at the time of decision making in the choice of automation equipment and/or processes that compose the main activities of a container terminal. The automation process is recent into port industry, beginning in the 90s in European countries whose labor costs were very high and needed to increase productivity and test innovations. The model to be presented is intended to be a proposal for expanded analysis, ie, a wide concept, which not only make financial analysis, but others relevant to the terminal management and planning, indicated by a set of variable features. Namely: existing or proposed layout, Financial Investment CAPEX and OPEX, Reliability of automation systems, integration of Information and Intelligence hardware technology systems, in particular with the Terminal Operating System (TOS), organization of work and changes in Standards Operating Procedures, Contribution to safety and the environment, legal obligation of the use of automation, cost and intensity of use of labor. The contextualization of the sector and the evolution of automation in the port industry; as the current situation (diagnosis) of Brazilian container terminals will be presented. Subsequently, the literature review of the topic with the main national and international articles. All this framework seeks to demonstrate the gap between automated and non-automated stages; indicate the main barriers in implementation of automation for existing process; further discussion of the viability of these terminals to operators, shipowners, customers and others stakeholders in terms of productivity, efficiency and cost. The delicate issue of dock workers was not considered a restrictive variable model for several reasons: it alone would restriction deployment automation by booking deployment automation, especially for docker's pool; it permeates many items listed above. At the end of this thesis, in addition to the diagnosis of automation in the country and a proposed model for decision making; is expected to contribute to research and education in engineering and management areas indicating the degree and technological development in automation specifically for container terminals. And at last, to promote reflections on the depth of operational and organizational job changes that may occur.
\end{abstract}

Keywords: Automation, Container Terminals. 


\section{LISTA DE FIGURAS}

Figura 1 - Representação do efeito do crescimento do comércio em terminais de contêineres

Figura 2 - Imagem do Container Terminal Altenwerder (CTA) ………...................29

Figura 3 - Imagem do Euromax Terminal Rotterdam ........................................29

Figura 4 - Imagem do APM Terminals Maasvlakte II B.V .......................................31

Figura 5 - Evolução das exportações mundiais de 1950 a $2012 \ldots \ldots \ldots \ldots \ldots \ldots \ldots \ldots \ldots \ldots . . . . . . .36$

Figura 6 - Exportações brasileiras por fator agregado de 1964 à 2013 (em milhões de dólares FOB). 45

Figura 7 - Exportações brasileiras por fator agregado de 1964 à 2013 em percentual por tipo de produto 45

Figura 8 - Evolução histórica do índice de conteinerização de 1977 a 2012 _.............46

Figura 9 - Participação \% do Brasil nas Exportações e Importações Mundiais .........49

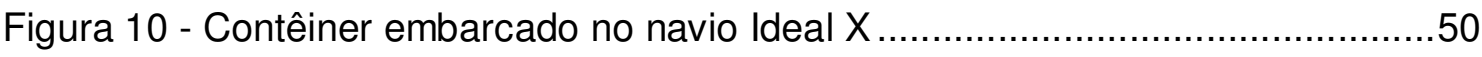

Figura 11 - Crescimento e Previsão da frota mundial de contêineres de 1990 a 2014

Figura 12 - Crescimento do Comércio Exterior e Movimentação de contêineres no Brasil versus PIB Brasil (base 100 $=1996$ )

Figura 13 - Evolução da movimentação de contêineres dos portos brasileiros (em unidades)

Figura 14 - Gráfico da evolução da movimentação de contêineres dos portos brasileiros (em unidades)

Figura 15 - Crescimento da movimentação de contêineres no Brasil em milhões de toneladas e TEUS

Figura 16 - Evolução histórica do crescimento mundial de movimentação de contêineres

Figura 17 - Projeções de Crescimento em percentual por região até 2017 57

Figura 18 - Lista dos 42 maiores portos do mundo na movimentação de contêineres

Figura 19 -Terminal de Contêineres da Margem Esquerda do Porto de Santos

(TECON)

Figura 20 - Abordagem Sistêmica de um terminal de contêineres conforme

Steenken,; Voß e Stahlbock (2004) 
Figura 21 - Abordagem Sistêmica de um terminal de contêineres conforme Monfort (2011) 64

Figura 22 - Abordagem Sistêmica de um terminal de contêineres conforme Peixoto (2005) 65

Figura 23 - Demora na atracação e produtividade no TECON em dezembro de 1995

Figura 24 - Esquema adaptado de elementos básicos da organização do trabalho na produção para operação de terminais de contêineres 68

Figura 25- Seção indicativa a meia nau do numero de Colunas (Rows) e Alturas

(Tiers)

Figura 26 - Navio convertido "Ideal X" versus o Triple-E "Maersk McKinney Moller"71 Figura 27 - Evolução dos navios porta-contêineres com dimensões, arranjos e calados. .75

Figura 28 - Crescimento do tamanho navio porta-contêineres e os valores segurados .

Figura 29 - Lista dos 20 maiores navios porta-contêineres ...................................77

Figura 30 - Navio Cap San Nicolas da Hamburg Sued .........................................78

Figura 31 - Custo de transporte entre Roterdã e Cingapura …………………........8

Figura 32 - Custo relativo por TEU resultado do aplicativo CCC da DNV .................82

Figura 33 - Tabela de equivalência de Custo de Slot .............................................. 83

Figura 34 - Evolução histórica do Preço de Bunker em US\$/tonelada........................84

Figura 35 - Consumo de Óleo combustível em função da velocidade .......................85

Figura 36 - Decréscimo da capacidade técnica na movimentação de

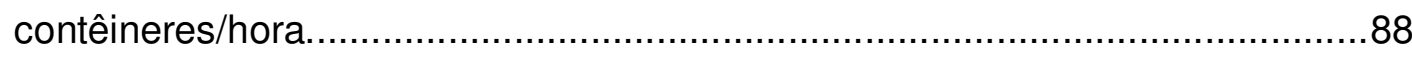

Figura 37 - Evolução dos Portêineres de 1960 - 2000 ...........................................90

Figura 38 - Ilustração de Single e Twin Picks.....................................................

Figura 39 - Ilustração de Tandem Lift e Tandem Line .........................................92

Figura 40 - Ilustração de Double e Triple Hoist .................................................92

Figura 41-llustração de Portêineres Double Trolley e de Plataforma de Lashing.....93

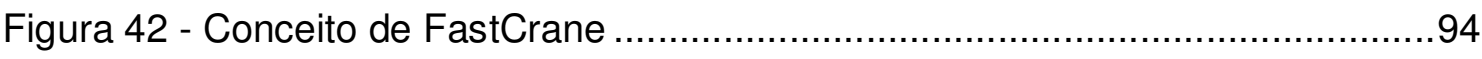

Figura 43- Conceito de Portêiner da TUDelft Transport Technologie .......................94

Figura 44 - Categorias básicas em termos de participação humana no processo ....98

Figura 45 - Ciclo do Processo de Embarque/Descarga .......................................100

Figura 46 - Marcas nos portêineres para abertura de Spreader..............................100 
Figura 47- Processo de colocação de Castanhas ou TwistLocks em contêineres de embarque 101

Figura 48- Exemplos de Tipos de TwistLocks 101

Figura 49 - Sistema de Posicionamento de Carreta através de Sensor 103

Figura 50 - Sistema Automático de Colocação e Retirada de TwistLocks ...............104

Figura 51 - Sistema Automático de Colocação e Retirada de TwistLocks 104

Figura 52 - Sistema Automático de Movimentação de TwistLocks instalado em plataforma de peação/despeação 105

Figura 53 - Plataforma de Lashing em um dos portêineres Double trolleys do

Terminal de Contêineres Burchardkai (Hamburgo) 105

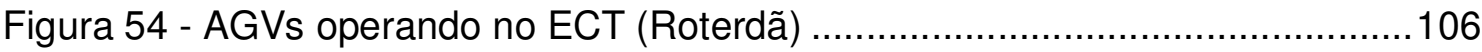

Figura 55 - AGVs operando na área de backreach do CTA (Alemanha)..... 107

Figura 56 - AGVs operando no pátio do Tobishima Pier South Side Container Terminal (Japão) 108

Figura 57 - AGVs operando no cais do Tobishima Pier South Side Container

Terminal (Japão) 108

Figura 58 - Vista aérea do Tobishima Pier South Side Container Terminal (Japão)109

Figura 59 - AGVs operando na área de Backreach no Euromax (Roterdã) ............109

Figura 60 - Ilustrações do C-AGV ..............................................................110

Figura 61- Exemplos de uso de Cassetes em operações de contêineres................110

Figura 62 - Ilustrações da manobrabilidade dos C-AGV .......................................111

Figura 63 - Exemplos de uso de Cassetes em operações de contêineres...............112

Figura 64- AutoStrad operando no Patrick Brisbane (Austrália) .............................113

Figura 65 - Desenho Ilustrativo do Quay Stack Transfer da ZPMC.........................113

Figura 66 - Protótipo do Quay Stack Transfer da ZPMC .......................................114

Figura 67 - LMTT da Noell no Eurokai Container Terminal ..................................115

Figura 68 - Portêiner sendo operado de forma remota na Alemanha (CTA) e Panamá (MIT).

Figura 69 - Tecnologias para conversão de RTG Manual para A-RTG (Automatizado)

Figura 70 - Automated Picking and Stacking Containers ("Magic eye") do A-RTG no terminal de Tobishima Pier South Side Container.

Figura 71 - Áreas de operação do A-RTG ....................................................119

Figura 72 - A-RTG no terminal de Tobishima Pier South Side Container. 
Figura 73 - Terminal Intermodal IFB Central Hub Antwerp (Bélgica) ......................120

Figura 74- Exemplo de A-RMG e ASC em zona de transferência de terminais ......121

Figura 75 - Exemplo de RMG em área de ferrovia............................................122

Figura 76 - Exemplo de quadra End-Loading no Euromax (Roterdã) .....................123

Figura 77 - Exemplo de quadra End-Loadingno TTI Algeciras (Espanha) e de

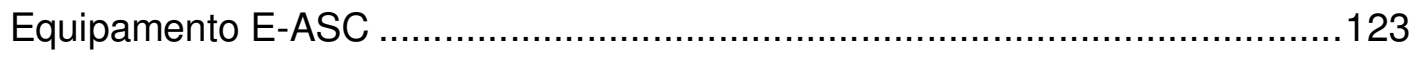

Figura 78 - Exemplo de quadra End-Loading no APTM Virginia (Estados Unidos).124

Figura 79 - Exemplo de quadra End-Loading no London Gateway (Inglaterra) ......124

Figura 80 - Exemplos de Equipamentos E-ASC no Euromax (Roterdã), Antwerp

Gateway (Deurganck Dock) (Bélgica) e CTA (Alemanha)...............................125

Figura 81 - Exemplo de quadra Side-Loading no Terminal da Hanjin New Port Co

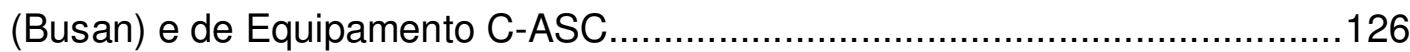

Figura 82 - Exemplos de Equipamentos C-ASC ……….................................126

Figura 83 - Vista aérea do Pasir Payang Terminal (Cingapura) e Equipamentos

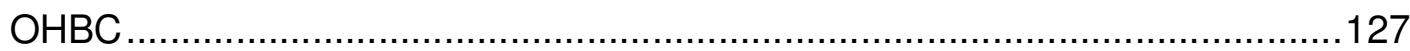

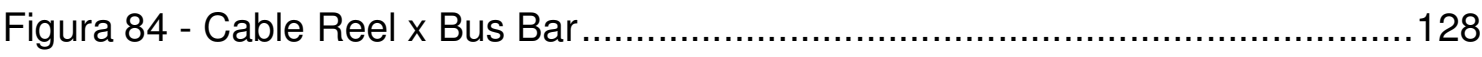

Figura 85 - Conceitos de Equipamentos de Transferência, Armazenagem e layout.

Figura 86 - High Stack System, Container Hangar e Teustack ..............................131

Figura 87 - Exemplo de CLP Siemens de portêineres .........................................133

Figura 88 - Exemplo das funções de skew e sway a bordo de navio .....................134

Figura 89 - Exemplo das funções de skew e sway em carretas ............................134

Figura 90 - Sistema de Posicionamento de Carreta através de Laser .....................135

Figura 91 - Sistema de Perfil do Navio (Ship Profilling System) ............................136

Figura 92 - Sistema de Perfil do Navio (Ship Profilling System) …........................136

Figura 93- Sistema de Perfil de Anti-Topple para RTG …...................................137

Figura 94 - Sistema de Perfil de Anti-Topple para RTG …..............................138

Figura 95 - Colocação (Aterrissagens) sobre carreta e a bordo de navio ................140

Figura 96 - Aterrissagens sobre carreta e a bordo de navio.................................141

Figura 97 - Comparação do uso do ACLAS entre operadores novatos, experientes e o sistema assistido. 142

Figura 98 - Comparação de Ergonomia entre a Cabine Fixa e o Controle Remoto 143

Figura 99- RTG Boxhunter da Konecranes ....................................................144

Figura 100 - Exemplo de OCR em Gates Cobertos e Portais ...............................146 
Figura 101 - Exemplo de Infraestrutura de Gates com OCR .................................146

Figura 102 - Exemplo de imagens "Area Scan”...............................................147

Figura 103 - Exemplos de imagens "Line Scan" ...............................................147

Figura 104 - Exemplos de imagens Line Scan diversas.......................................148

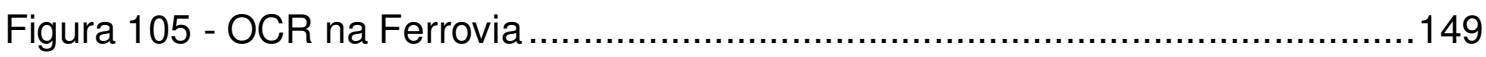

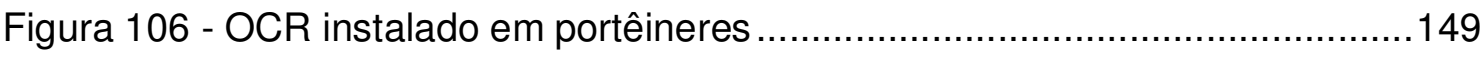

Figura 107 - Imagens de OCR instalado em portêineres .....................................150

Figura 108 - Diagramas de blocos para comparação das etapas de um processo de gate tradicional vs gate automatizado .........................................................152

Figura 109 - Gate automatizado no TPS (Chile) e London Gateway (Inglaterra) ....154

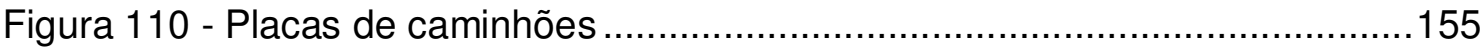

Figura 111 - Imagens das telas do OCR e resultado da vistoria automatizada.......156

Figura 112 - Imagens das telas do Sistema Visy ADDS - Active Damage Detection

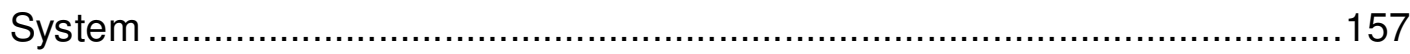

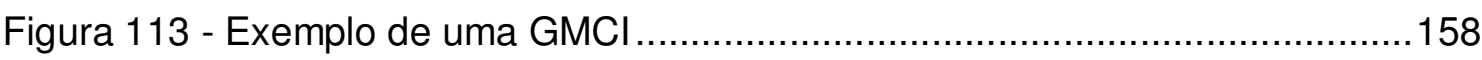

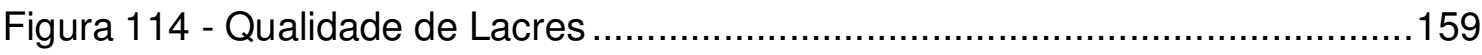

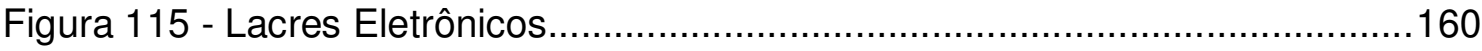

Figura 116 - Exemplo de rastreamento do container utilizando lacre eletrônico e

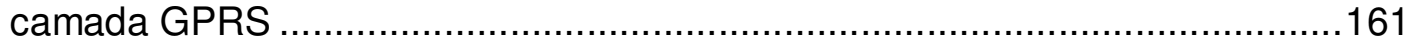

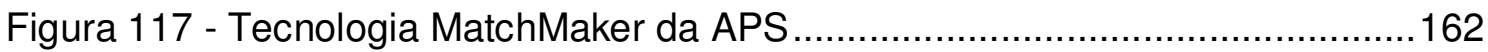

Figura 118- Identificação de carretas via RFID …………………………......162

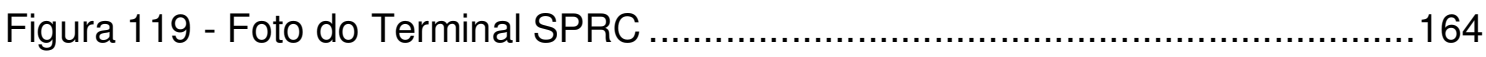

Figura 120 - Sistema de Confirmação Automatizada de Estivagem (Automated

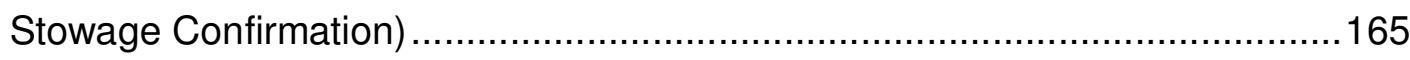

Figura 121 - Sistemas de Gerenciamento dos Equipamentos ou Crane Managemet

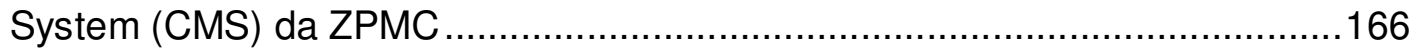

Figura 122 - Sistemas de Gerenciamento dos Equipamentos ou Crane Managemet

System (CMS) da TMEIC, com detalhe de telemetria e tendências do equipamento. 166

Figura 123 - Sistemas de Gerenciamento dos Equipamentos ou Crane Managemet System (CMS) da TMEIC para RTG. 167

Figura 124 - Modems de contêineres (ISO 10368) ………………………......168

Figura 125 - Telas do Sistema de Monitoramento de Contêineres Reefers .............168 
Figura 126 - Telas do Módulo de Planejamento da Escala do Navio e Alocação de guindastes e berço 173

Figura 127 - Tela de Overview das bays do navio 174

Figura 128 - Plano de bordo do recebido do armador e Tela de vista geral das bays do navio após aplicação dos arquivos EDI MOVINS e BAPLIE 175

Figura 129 - Tela de Alocação de Portêineres e Sequência de trabalho, detalhes do planejamento das bays 176

Figura 130 - Tela de Alocação de Portêineres e Sequencia de trabalho ................177

Figura 131 - Detalhe da representação dos guindastes .....................................178

Figura 132- Níveis de visualização do terminal, pátio, quadra, contêiner..................180

Figura 133 - Alocação e rastreamento de equipamentos no terminal ......................181

Figura 134 - Exemplo de distribuição de equipamentos com regras fixas................182

Figura 135 - Alocação e rastreamento de equipamentos no terminal .....................183

Figura 136 - Otimização de veículos através de dois tipos de Pool ........................184

Figura 137 - Áreas de Instalação de Scanners .................................................186

Figura 138 - Imagens escaneados de um contêiner com pneus ...........................186

Figura 139 - Imagens escaneados de um contêiner com um véiculo.......................187

Figura 140-Localização dos terminais que utilizam NAVIS no mundo ...................188

Figura 141 - Fotos do ECT Delta Roterdã …………….....................................190

Figura 142- TerCat ou BEST (Barcelona Europe South Terminal)........................198

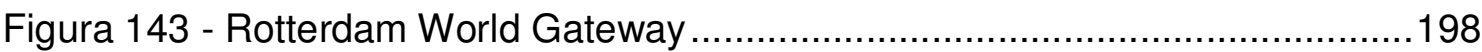

Figura 144 - Categoria de problemas de planejamento …..................................200

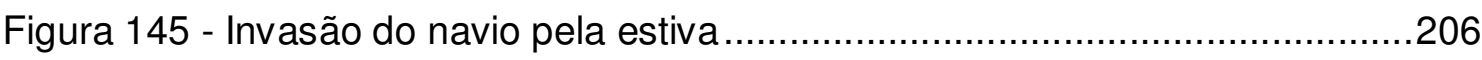

Figura 146 - Ciclo de tempo típico de portêineres ............................................208

Figura 147- Curvas de Produtividade para vários equipamentos de pátio (ASC) e

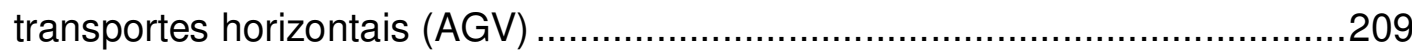

Figura 148 - Três conceitos de sistemas automatizados de armazenamento .........212

Figura 149 - Sistema de transporte de AGV Vertical (a) e Horizontal (b) ................215

Figura 150 - Contexto da tomada de decisão.................................................219

Figura 151 - Exemplos das Telas do Modelo em Excel.....................................224

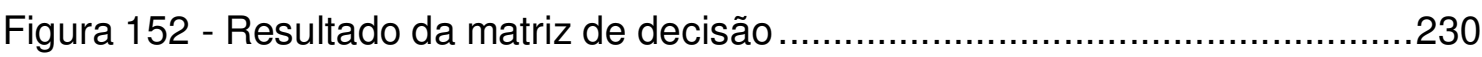

Figura 153 - Imagem do ACLAS da ABB - operador trabalhando "handsoff" .........232

Figura 154 - Características da Frota de RTG e taxa percentual de eRTG.............236 
Figura 155 - Representação do posicionamento das equipes de trabalho em regime de operação com spreader single, Tandem e Tandem Double.......................239

Figura 156 - Desenho de distância recomendada para operação de AGV e ASC

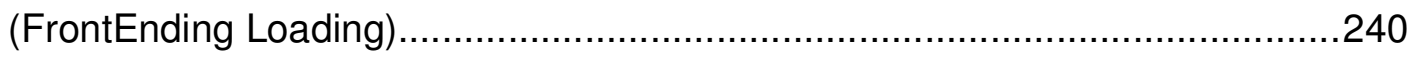

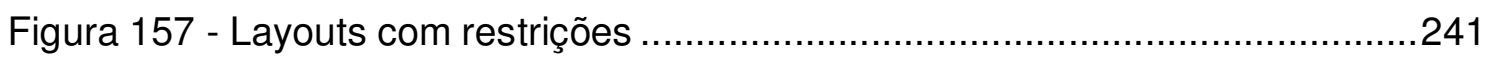




\section{LISTA DE TABELAS}

Tabela 1 - Crescimento das Exportações (FOB) no Brasil e Comércio mundial de 1950 a 2012

Tabela 2 - Crescimento das Importações no Brasil e Comércio mundial de 1950 a 2012

Tabela 3 - Ranking 2011 das maiores empresas exportadores e importadores 44

Tabela 4 - Volumes e parcela de mercado dos principais Operadores Globais de contêineres

Tabela 5 - Evolução dos navios porta-contêineres....................................................72

Tabela 6 - Evolução dos navios porta-contêineres...............................................72

Tabela 7 - Evolução dos navios porta-contêineres...................................................73

Tabela 8 - Evolução dos navios porta-contêineres em cinco categorias .....................73

Tabela 9 - Evolução dos navios porta-contêineres com dimensões e arranjos..........74

Tabela 10 - Evolução dos navios porta-contêineres com dimensões e arranjos .......74

Tabela 11 - "Cascateamento" de navios por rotas ..............................................78

Tabela 12 - Comparação de uso de recursos entre navios de 9.000 e 18.000 TEUs .88

Tabela 13 - Aumento da Potência dos Portêineres .................................................90

Tabela 14 - Dimensões básicas de portêineres em metros......................................91

Tabela 15 - Quadro resumo da revisão bibliográfica sobre planejamento de berços de atracação de Patricio (2005)

Tabela 16 - Quadro resumo da revisão de Literatura bibliográfica sobre planejamento e alocação de berços de atracação por Dragović e Park (2011).....................172

Tabela 17 - Terminais Semiautomatizados e Automatizados em Operação e Projetos Futuros 195

Tabela 18 - Benchmarking de desempenho entre terminais automatizados e convencionais

Tabela 19 - Quantidade de Terminais versus o tamanho do terminal 199

Tabela 20 - Complemento do Quadro resumo da revisão de Literatura bibliográfica sobre planejamento e alocação de berços de atracação por Dragović e Park (2011) 
Tabela 21 - Complemento do Quadro resumo da revisão de Literatura bibliográfica sobre planejamento e alocação de berços de atracação por Dragović e Park (2011) .202

Tabela 22 - Resultado de Custos e Desempenho para 04 diferentes ....................210

Tabela 23 - Resultado de Custos e Desempenho para 04 diferentes .....................213

Tabela 24 - Exemplos de técnicas para suporte a tomada de decisão ...................220

Tabela 25 - Critérios de avaliação das variáveis ...............................................227

Tabela 26 - Valor atribuído a cada uma das tecnologias/dispositivos ......................229

Tabela 27 - Comparação de consumo entre os tipos de RTG ...............................235

Tabela 28 - Tabela Diagnostico de utilização de tecnologias ...................................243 


\section{LISTA DE ABREVIATURAS E SIGLAS}

ABRATEC - Associação Brasileira dos Terminais de Contêineres de Uso Público AGV - Automated Guided Vehicle - Veículo Guiado Automaticamente ALV - Automated Lifting Vehicle - Veículo de Içamento (transporte) Automatizado APMT - A.P. Møller Terminals

ANTAQ - Agencia Nacional de Transporte Aquaviários ANVISA - Agencia Nacional de Vigilância Sanitária ASC - Automated Stacking Crane - Guindaste Automatizado de Armazenamento ATC - Automated Transfer Crane - Guindaste de Transferência Automatizado, o mesmo que ASC

BDCC - Banco de Dados Comum de Credenciamento

BIRD - International Bank for Reconstruction and Development - Banco Internacional para a Reconstrução e Desenvolvimento

BIS - Bank for International Settlements - Banco Internacional de Pagamentos

Boca - Largura do navio a meia nau.

BL - Bill of Lading - Conhecimento de Embarque ou Conhecimento Marítimo é um documento do armador preenchido pelo embarcador e assinado pelo comandante ou o agente do navio, confirmando o recebimento de determinada carga a bordo (ou para embarque) e especificando, entre outros vários detalhes, o frete pago ou a ser pago no destino. É, ao mesmo tempo, um recibo de bordo, um título de posse e uma evidência de contrato de transporte, cujas cláusulas estão incorporadas no mesmo. Bloco - É a atividade de limpeza e conservação de embarcações mercantes e de seus tanques, incluindo batimento de ferrugem, pintura, reparos de pequena monta e correlatos.

Bookings - Documento emitido pelo armador ou agente e assinado pelo embarcador, comprovando o fechamento de praça para determinado navio. É um documento provisório ao Bill of Lading, que o substituirá posteriormente. Utilizado para reserva de espaço/praça em navio

Capatazia - Consiste na movimentação de mercadoria nas instalações de uso público, nas atividades de recebimento, conferência, transporte interno, abertura de volumes para conferência aduaneira, manipulação, arrumação e entrega, bem como o carregamento e descarga de embarcações, quando efetuadas por aparelhamento portuário 
CEPAL - Comissão Econômica para a América Latina e o Caribe

CKD - Completely Knock-Down - São conjuntos de partes de automóveis criados geralmente pela fábrica matriz ou pelo seu centro de produção para exportação e posterior montagem dos veículos nos países receptores destes kits, geralmente fábricas menores ou com produção reduzida

CLP - Controlador Lógico Programável

CLT - Consolidação das Leis do Trabalho

CODESP - Companhia Docas do Estado de São Paulo

Conferência de Carga - que é a contagem de volumes, anotações de suas características, procedência ou destino, verificação do estado das mercadorias e demais serviços correlatos nas operações de carregamento e descarga de embarcações

Conserto de Carga - É o reparo e restauração das embalagens de mercadorias, nas operações de carregamento e descarga de embarcações, reembalagens, marcação, remarcação, carimbagem, etiquetagem, abertura de volumes para vistoria e posterior recomposição

CSI - Custom Security Initiative - É um programa de prevenção especifico que estabelece critérios de segurança para identificar contêineres de alto risco mediante avaliação no porto de origem, provenientes de qualquer porto do mundo com destino aos Estados Unidos, instituído pela "Custom and Border Protection" (CBP), órgão do governo americano semelhante à Aduana brasileira

CTA - Container Terminal Altenwerder (Hamburgo/Alemanha)

DGPS - Differential Global Positioning System - Sistema de Posicionamento Global Diferencial

DNV - Det Norske Veritas

DPW - Dubai Port World

DTA - Declaração de Trânsito Aduaneiro

Dweel Time - Na exportação, é o tempo de permanência do contêiner no terminal do seu recebimento até o seu embarque e, na importação, é o tempo de permanência do contêiner da descarga até a sua entrega para o importador

EADI - Estação Aduaneira do Interior, também conhecida como porto seco

ECS - Equipments Controls System - Sistema de Controle dos Equipamentos

ECT - Europe Combined Terminals

EDI - Eletronic Data Interchange - Troca Eletrônica de Dados 
Estiva - É a movimentação de mercadorias nos conveses ou porões das embarcações principais ou auxiliares (quando realizados com equipamento de bordo, ou seja, quando só se utiliza equipamentos do navio e não do porto)

Feeder - Navio de pequeno porte ou barcaça utilizada na alimentação de navios porta-contêineres

FMI - Fundo Monetário Internacional

Gates - Portões de controle de acesso de entrada e saída de caminhões para entrega ou recebimento de contêineres

GEE - Gases do Efeito Estufa

GOS - Gate Operating System - Sistema Operacional de Gates

Handling - Manuseio de carga, movimentação desta no pátio dos terminais de contêineres ou operação de descarga e embarque de navios.

$\mathrm{HPH}$ - Hutchison Port Holdings

HSS - High Stack System

ISPS Code - International Ship and Port Facility Security - Código Internacionalde Proteção à Navios e Instalações Portuárias

IMO - International Maritime Organization - Organização Marítima Internacional

ISO - International Organization for Standardization

Lashing - Atividade de peação e despeação da carga, isto é, amarração ou peação da carga

LBCT - Long Beach Container Terminal

LMCS - Linear Motor Conveyance System

LMTT - Linear Motor based Transfer Technology

MAPA - Ministério da Agricultura, Pecuária e Abastecimento

MDIC - Ministério do Desenvolvimento, Indústria e Comércio Exterior

NASDAQ - National Association of Securities Dealers Automated Quotations Associação Nacional Corretora de Valores e Cotações Automatizadas, é uma Bolsa de valores eletrônica, constituída por um conjunto de corretores conectados por um sistema de informação

NCM - Nomenclatura Comum do Mercosul, que é um Sistema Harmonizado de Designação e de Codificação de Mercadorias, ou simplesmente Sistema Harmonizado $(\mathrm{SH})$, é um método internacional de classificação de mercadorias, baseado em uma estrutura de códigos e respectivas descrições 
OCR - Optical Character Recognition - Reconhecimento Óptico de Caracteres utilizando nos Gates de entrada, scanner e equipamentos (portêineres)

OGMO - Órgão Gestor de Mão de Obra é uma entidade de utilidade pública, sem fins lucrativos, cuja atribuição exclusiva é a gestão do trabalho portuário em observância às normas do contrato, convenção ou acordo coletivo de trabalho firmado entre os sindicatos de operadores e de trabalhadores portuários

OIT - Organização Internacional do Trabalho

OMA - Organização Mundial das Aduanas

OMC - Organização Mundial do Comércio

ONU - Organização das Nações Unidas

PAC - Programa de Aceleração do Crescimento

PNSA - Plano Nacional de Segurança Aduaneira

PSA - Port Singapore Authority

RFID - Radio Frequency Identification - Identificação por Frequência de Rádio

RMG - Rail Mounted Gantry - Guindaste sobre trilhos

RTG - Rubber Tyre Gantry - Guindaste sobre pneus (Transtêineres)

SECEX - Secretária de Comércio Exterior

SEP - Secretaria de Portos

SLAM - Storage Lifecycle Automation Management

Spreader - É um dispositivo utilizado para levantar contêineres e carga unitizada. A versão para contêineres tem um mecanismo de travamento (chamado "twist lock") em cada extremidade que prende-se aos quatro cantos do contêiner e sinaliza o seu travamento

SSA - Seattle Stevedors Authority - Operador americano que atua em terminais em diversos países, tais como no Panamá, Vietnã, México e Egito

Stakeholders - Partes interessadas ou intervenientes da empresa

Tandem lift - Técnica de içamento que permite a movimentação de dois a quatro contêineres vazios um sobre o outro simultaneamente

Tandem line - Técnica de içamento que permite a movimentação de dois contêineres paralelos em colunas (rows) diferentes do navio

Terno de trabalho - Equipe de trabalhadores associada aos equipamentos que operam um navio, formada por estivadores, grupo ou conexos, operadores de guindastes, trabalhadores de capatazia e conferentes 
T.E.U - Twenty Equivalent Unit - Medida equivalente a um contêiner de 20 pés de comprimento (6 metros)

TOS - Terminal Operating System - Sistema de Operações de Terminal. Software responsável pelo Planejamento de Pátio e Navio do Terminal, assim como das atividades de Gates e Fluxo horizontal.

TPA - Trabalhador Portuário Avulso executam a movimentação de mercadorias provenientes ou destinadas do transporte aquaviário dentro da área do porto organizado

TRA - Terminal Retroportuário Alfandegado, isto é, são instalações onde, sob controle aduaneiro, são realizadas operações de desunitização de mercadorias importadas ou unitização das destinadas à exportação

Transhipment - Atividade de movimentação de contêineres de transbordo; transferência de carga

Transponder - Abreviação de Transmitter-responder, é um dispositivo de comunicação eletrônico complementar de automação e cujo objetivo é receber, amplificar e retransmitir um sinal em uma frequência diferente

Trimming - Distribuição do peso a bordo para manter o equilíbrio do navio

TUP - Terminais de Uso Privado

Twin picks - Técnica de içamento que permite a movimentação de dois contêineres lado a lado simultaneamente na mesma coluna (row) do navio

Under deck - Instrução de estivagem de container no porão do navio

ULCS - Ultra Large Container Ship.Termo utilizado para navios de contêineres acima de 14.000 TEUs. Também chamados de ULCV, VLCC ou Meganavios

ULCV - Ultra Large Container Vessels

Vigilância de Embarcações - É a atividade de fiscalização da entrada e saída de pessoas a bordo de embarcações atracadas ou fundeadas ao largo, bem como da movimentação de mercadorias nos portalós, rampas, porões, conveses, plataformas e em outros locais da embarcação

VLCC - Very Large Container Carrier

Weather deck - Instrução de estivagem de container no convés do navio ZPMC - Shanghai Zhenhua Heavy Industries Company Limited. Líder mundial da indústria de equipamentos portuários (portêineres e RTGs) 


\section{SUMÁRIO}

1 INTRODUÇÃO

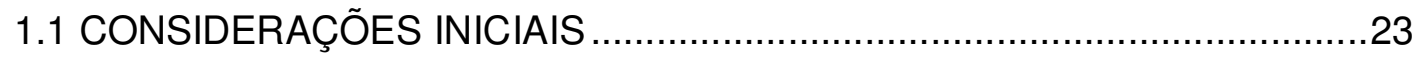

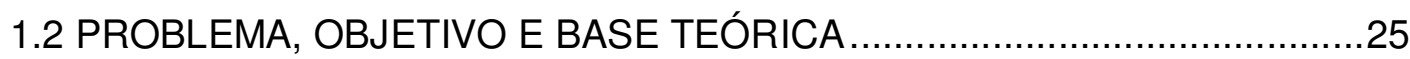

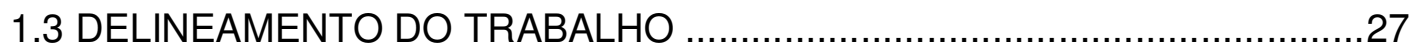

2 EVOLUÇÃO DA OPERAÇÂO PORTUÁRIA DE CONTÊINERES NO BRASIL

2.1 BREVE HISTORICO DA ECONOMIA INTERNACIONAL

2.2 EVOLUÇÃO DO COMÉRCIO INTERNACIONAL E COMÉRCIO EXTERIOR BRASILEIRO. 35

2.3 READEQUAÇÕES PERMANENTES DOS TERMINAIS DE CONTÊINERES E DA INDÚSTRIA MARÍTIMA. 60

2.4 EVOLUÇÃO DOS NAVIOS PORTA-CONTÊINERES E A BUSCA PELA

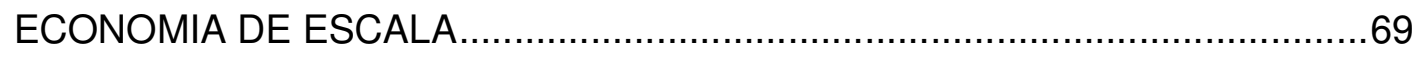

2.5 IMPACTOS NOS TERMINAIS DE CONTÊINERES E NAS SUAS OPERAÇÕES .83

3 TERMINAIS DE CONTÊINERES COMO SISTEMA DE PRODUÇÂO E DESCRIÇÂO DE TECNOLOGIAS E DISPOSITIVOS PARA AUTOMAÇÂO.....96 3.1 TERMINAIS DE CONTÊINERES COMO SISTEMA DE PRODUÇÃO..........96 3.2 COMPARAÇÕES DE PROCESSOS TRADICIONAIS VERSUS PROCESSOS AUTOMATIZADOS EM TERMINAIS DE CONTÊINERES .........99 3.2.1 PROCESSO TRADICIONAL DE EMBARQUE DE CONTÊINERES E IDENTIFICAÇÃO DAS CATEGORIAS DE PARTICIPAÇÃO HUMANA 
3.2.2 PROCESSO AUTOMATIZADO DE EMBARQUE DE CONTÊINERES E DESCRIÇÃO DAS TECNOLOGIAS PARA AUTOMAÇÃO EXISTENTES .......102 3.2.3 PROCESSO TRADICIONAL VERSUS AUTOMAÇÃO DE GATES, DESCRIÇÃO DAS TECNOLOGIAS PARA AUTOMAÇÃO EXISTENTES E

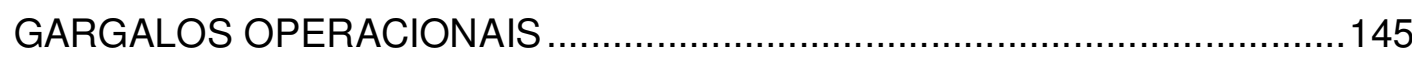

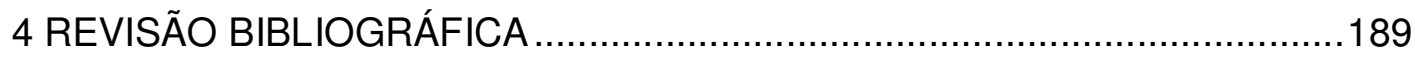

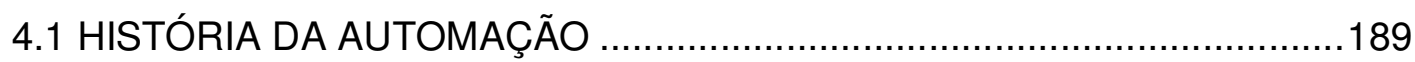

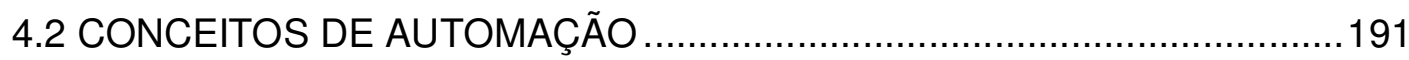

4.3 LITERATURA SOBRE AUTOMAÇÃO NA ÁREA PORTUÁRIA ..................200

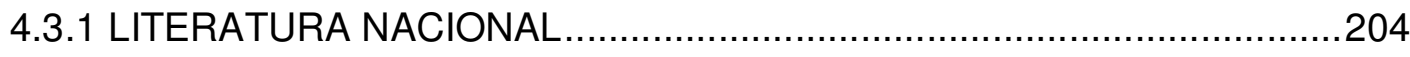

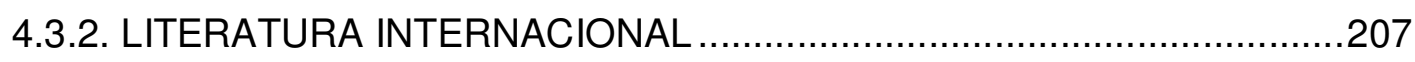

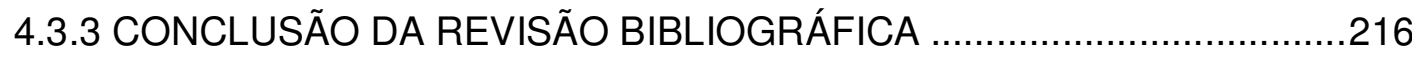

5 METOdOlOGIA, DESCRIÇÂO DO MODELO E DIAGNÓSTICO DE AUTOMAÇÂO EM TERMINAIS DE CONTÊINERES NO BRASIL....................217

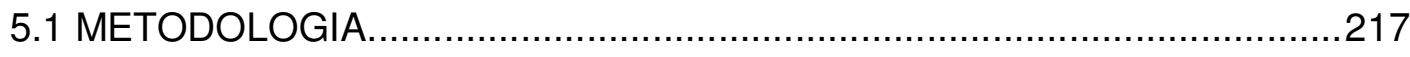

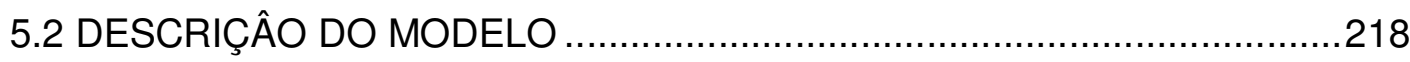

5.2.1 CONTEXTO E TÉCNICAS DE AUXILIO Á TOMADA DE DECISÂO .....218

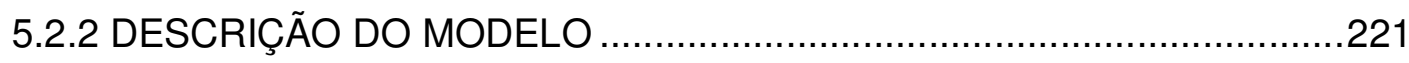

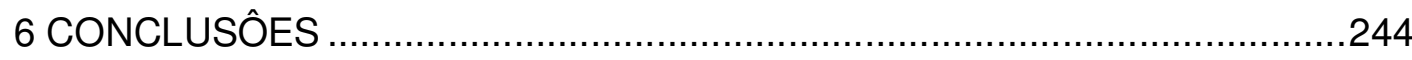

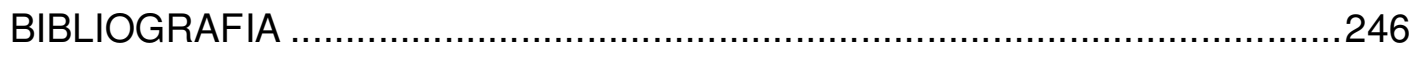

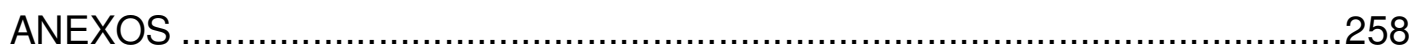




\section{INTRODUÇÃo}

\subsection{CONSIDERAÇÕES INICIAIS}

Considerado como o pai da Administração moderna, Peter Drucker disse que "Não podemos prever o futuro, mas podemos criá-lo". Essa frase parece ter sido feita para a indústria marítima e, em especial, para um segmento de transportes e de operação portuárias, o da movimentação de contêineres.

Porém, como falar de futuro sem observar o passado? Acompanhando a evolução da sociedade, percebe-se o transporte como um dos grandes fatores dessa evolução, principalmente pela facilitação do Comércio e, conforme Ballou (1993), por estender o mercado para fora das cercanias do local de produção. Aliás, difícil separar transporte de comércio e não observar as suas contribuições a diversas outras áreas do conhecimento, tais como a administração e direito, apenas para citar duas. Amaral (2004) cita que o Comércio é dinâmico desde seus primórdios e, por pressão das circunstâncias em que se desenvolveu, contribui sempre com a evolução do direito, como, por exemplo, o direito dos mercadores, a Lex Rodhia de Jactu (fenícios); a Nauticum Foenus (romanos), as leis de Wisby que em 1350 regulavam o comércio no mar Báltico; o Consulado do Mar que eram uma coletânea de costumes do comércio marítimo reunida no século XIV pela corte consular de Barcelona, ou a Lex Mercatoria no período medieval; a criação das cambiais, na criação dos bancos e das bolsas de valores e do mercado de capitais, do seguro e do crédito documentário; enfim, de um sem número de institutos jurídicos que constituíram em arcabouço do direito hodierno.

Segundo Ballou (1993), a administração de transportes é o braço operacional da função de movimentação que é realizada pela atividade logística cujo objetivo é assegurar que o serviço de transporte seja realizado de modo eficiente e eficaz. Para o autor, o transporte é, sob qualquer ponto de vista, seja militar, social ou econômico, a atividade mais importante do mundo. Lima Junior (2004) discorre na sua tese de livre docência sobre diversas versões sobre transporte de cargas e passageiros, assim como as questões de desempenho e indicadores. Nesse trabalho intitulado "Analise e avaliação do desempenho dos serviços de transporte de Carga", transporte é definido como uma atividade essencial que viabiliza a 
realização de muitas outras atividades humanas. No seu sentido amplo, transporte pode ser entendido como um facilitador das interações humanas desde a comunicação até as trocas comerciais de bens; convergindo nessa ótica as tecnologias da comunicação com as de transporte.

Figura 1 - Representação do efeito do crescimento do comércio em terminais de contêineres

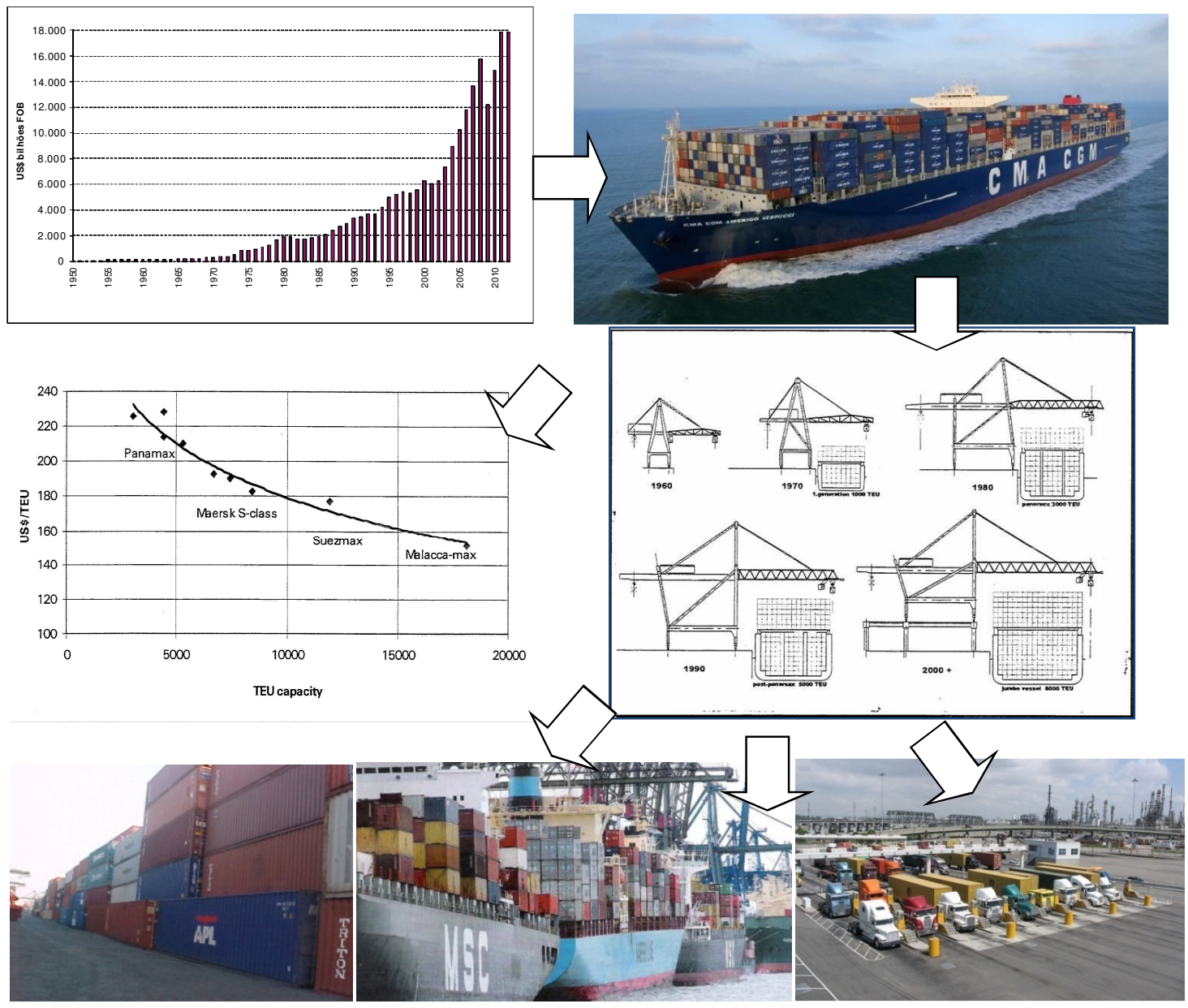

Fonte: Elaborado pelo autor

Observando as definições anteriores e realizando uma analogia para o que seria o transporte de contêineres, especificamente a operação portuária de contêineres, pode-se definir essa como sendo a fronteira tecnológica entre nações. A figura 1 demonstra que, com o crescimento do comércio internacional, ocorre necessariamente o crescimento do tamanho dos navios e o desafio da economia de escala, que, por consequência, exigem que os equipamentos portuários dedicados ao cais e a sua infraestrutura de pátio e gates (portões de acesso e controle), assim como de acessos terrestres e aquaviários, acompanhem esse crescimento 
mantendo um balanço equilibrado entre capacidade e produtividade e, obviamente, ocorre o aumenta dos problemas e complexidade das operações, o que exige uma operação cada vez mais sofisticada em termos de planejamento e disponibilidade de recursos. Lembrando que terminais estão expostos a uma multiplicidade de influências externas as quais podem causar volatilidade na utilização de seus subsistemas.

\subsection{PROBLEMA, OBJETIVO E BASE TEÓRICA}

São diversas as tecnologias e dispositivos de automação disponíveis na indústria portuária; assim como, são inúmeras as duvidas e problemas sobre os projetos de automação, tais como:

- O quê deve ser automatizado nas atividades dos terminais?

- Como deve ser implementado?

- Qual o melhor momento para automação?

- Automação restringe capacidade?

- Torna as operações inflexíveis?

- Preenche as lacunas de desempenho?

- Qual a contribuição para a não variação excessiva?

- Quais são os intervalos de confiança?

- Automação total ou parcial?

Esses problemas e duvidas são parte das decisões estratégicas e operacionais que gestores de terminais de contêineres são acometidos; contudo, essas decisões são complexas e possuem um grau de incerteza e risco, diferentes dos problemas de rotina que são conhecidos e possuem modelos ou estruturas de decisão versadas.

Dito isso, este trabalho possui dois objetivos distintos. O primeiro objetivo é desenvolver um modelo que permita auxiliar na tomada de decisão na escolha de automação de equipamentos e/ou de processos das principais atividades de um terminal de contêineres utilizando um conjunto de oito variáveis:

- Layout existente ou proposto do terminal; 
- Investimentos em CAPEX (montante de investimentos realizados em equipamentos e instalações de forma a manter a produção de um produto ou serviço ou para manter em funcionamento um negócio ou um determinado sistema) e OPEX (custo associado à manutenção dos equipamentos e aos gastos de consumíveis e outras despesas operacionais, necessários à produção e à manutenção em funcionamento do negócio ou sistema a ser desenvolvido);

- Confiabilidade dos sistemas de automação, item pouco discutido em trabalhos acadêmicos cujo foco está relacionado às operações de terminais de contêineres e praticamente a nenhuma estatística e indicadores (exemplo: Tempo Médio Entre Falhas (TMEF) ou Tempo Médio Para Reparo (TMPR)) apresentados pelos fornecedores de automação e tecnologia dos sistemas já em produção;

- Contribuições para o meio ambiente com a redução do consumo de energia elétrica, diesel e emissão de partículas poluentes e contribuições na área de segurança no trabalho com base na redução dos índices e frequência de acidentes, como, por exemplo: o Índice de Frequência de Acidentes de Trabalho (IFAT) $=$ (acidentes incapacidade/horas-homem trabalhados) x 200.000 ou Índice de Severidade de Acidentes de Trabalho $($ ISAT $)=$ (dias perdidos por incapacidade/horas-homem trabalhados $) \times$ 200.000; e nas questões de segurança patrimonial com a consequente redução das avarias a carga, contêineres e equipamentos;

- Obrigatoriedade legal do uso de automação. Como exemplo recente dessa variável, podemos indicar a Instrução Normativa $n^{\circ} 3.518 / 11$ da Receita Federal que estabelece requisitos e procedimentos para o alfandegamento de locais e recintos exige a instalação de scanners e de Dispositivos de Reconhecimento de Caracteres Óticos (OCR) para leitura da numeração dos contêineres e placas do veiculo e chassis;

- Integração com outros sistemas de Tecnologia da Informação e Inteligência de Equipamento, em especial com os Sistemas de Gerenciamento de Operações dos Terminais (TOS), presentes em praticamente todos os terminais de contêineres e sendo responsável pelo Planejamento de gates (portões de acesso de entrada e saída de veículos 
e carga), pátio e navio, de atividades tais como: reserva de espaço para contêineres, programação de entrega e recebimento, sequenciamento de descarga e embarque de navios, alocação de carretas e controle do tráfego horizontal; além do acompanhamento e confirmação das execuções dessas atividades pelos operadores de equipamentos de movimentação e de outros funcionários presentes nas operações tais como: conferente de carga/descarga, técnicos de reefers, controladores de pátio, entre outros;

- Novas formas de organização do trabalho em virtude da alteração de legislação e acordos coletivos, procedimentos operacionais, tecnologias tais como o uso de portêineres double-hoist e spreaders do tipo tandem ou gates e equipamentos não tripulados;

- Custo e uso intensivo da mão de obra e capital humano.

E o segundo objetivo, que é fomentar a reflexão sobre os entraves e profundidade das mudanças operacionais e organizacionais do trabalho que podem ocorrer.

Ainda como produto do trabalho, será apresentando um diagnóstico da situação atual de automação nos terminais de contêineres brasileiros e uma revisão bibliográfica detalhada da literatura nacional e internacional a respeito de automação para terminais de contêineres. Essa é uma contribuição à ciência enquanto conteúdo de conhecimento que se processa como resultado da articulação da teoria com a prática e ao ensino da engenharia e de outras áreas de gestão, especialmente a de gestão portuária carente de publicações técnicas de tecnologia e de engenharia.

\subsection{DELINEAMENTO DO TRABALHO}

O capítulo 1 é destinado a considerações iniciais e apresentação do problema, seguido dos objetivos e da base teórica e uma breve explicação da estrutura do trabalho.

O capítulo 2 tem como finalidade contextualizar a evolução da operação portuária de contêineres no Brasil, desde a operação controlada pelo Estado, a sua transferência para o setor privado e, principalmente, apresentar a sua atual situação, 
um benchmarking com os principais terminais e operadores globais (tais como: PSA, APMT, HPH, DPW, entre outros) e discorrer sobre os aspectos do crescimento do comércio exterior brasileiro e do comércio internacional, assim como da indústria marítima de contêineres; tais como: aumento do volume de movimentação, crescimento acelerado dos navios e seus impactos na infraestrutura e processos de terminais, na mesma linha do tempo, serão realizados apontamentos dos aspectos legais pertinentes ao setor e seus principais impactos nas operações.

Uma comparação entre um sistema de produção e um terminal de contêineres e a descrição das tecnologias de automação será apresentado no capítulo 3; seguido de uma revisão bibliográfica sobre o tema automação e tecnologia para terminais de contêineres no capítulo 4. Completando a mineração de artigos científicos, será utilizada uma rica e diversificada literatura em documentações de seminários da TOC (Terminal Operations Conference) que vem discutindo este assunto há três décadas, o proponente possui este material dessas conferências desde 1998.

Já no capítulo 5 pretende-se explicitar a metodologia cientifica, o modelo e discutir os seus resultados; e apresentar o diagnostico de automação de oito terminais de contêineres no Brasil. E, por derradeiro, a conclusão, observações e recomendações ficarão para o capítulo 6.

\section{EVOLUÇÃO DA OPERAÇÂO PORTUÁRIA DE CONTÊINERES NO BRASIL}

Neste capítulo é realizada uma apresentação da evolução da operação portuária de contêineres no Brasil e no mundo; conforme dito anteriormente, é difícil a dissociação entre transporte, economia e comércio internacional; portanto, tendo como base o crescimento econômico mundial, a evolução do comércio e do aumento de volume da carga conteinerizada, discorrer-se-á sobre a adequação da indústria marítima por meio do crescimento dos navios porta-contêineres e da busca de economia de escala para redução dos custos; os impactos nos equipamentos de movimentação de cais e pátio e nos processos e tecnologias que suportam suas operações, a infraestrutura dos terminais será evidenciada. Dessa forma, uma visão sistêmica de terminais e apresentação das suas principais características técnicas e breve perfil dos seus operadores serão realizados; assim como um benchmarking com alguns dos principais operadores globais e seus terminais. 
Figura 2 - Imagem do Container Terminal Altenwerder (CTA)

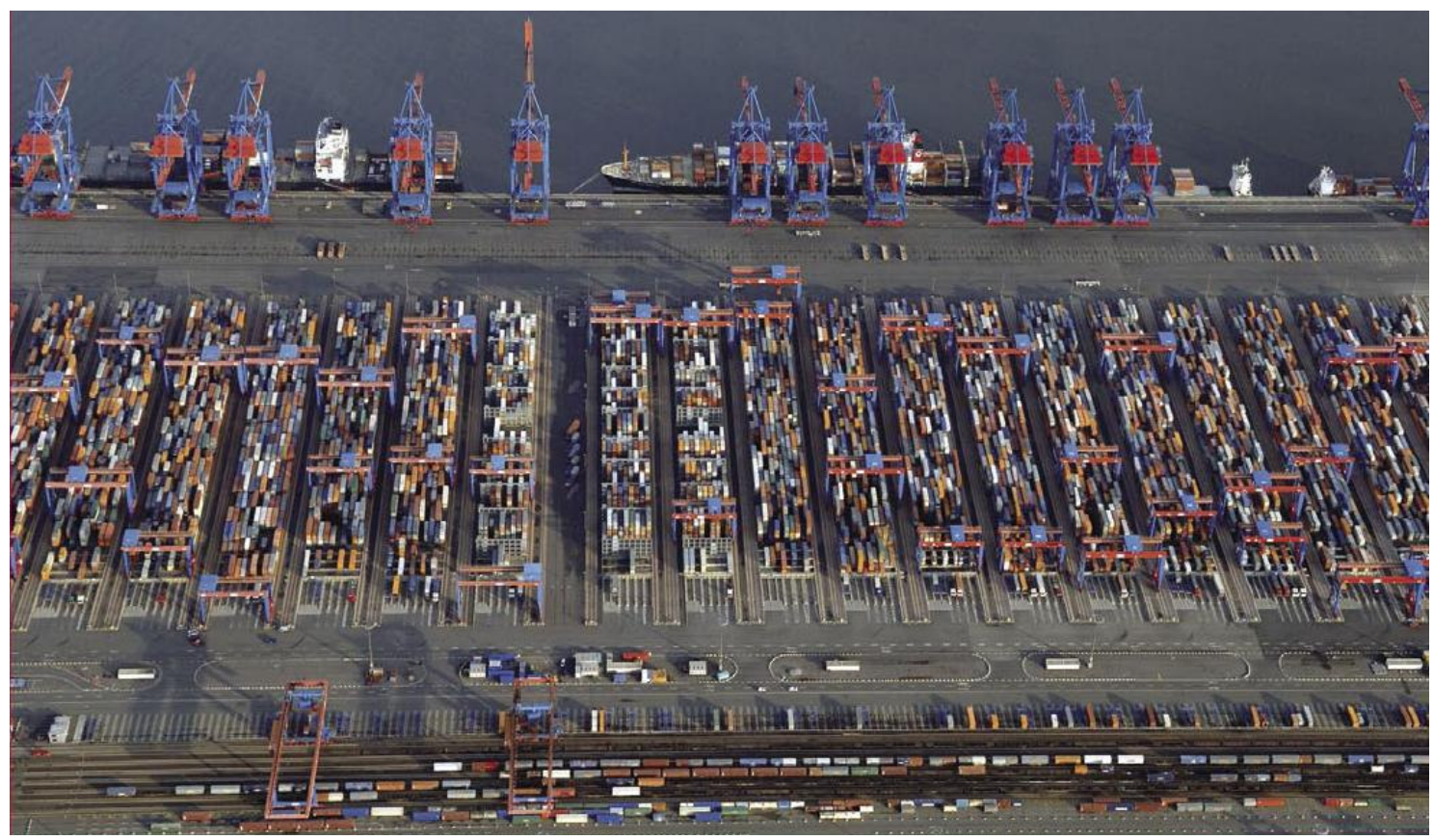

Fonte:CTA

Figura 3 - Imagem do Euromax Terminal Rotterdam

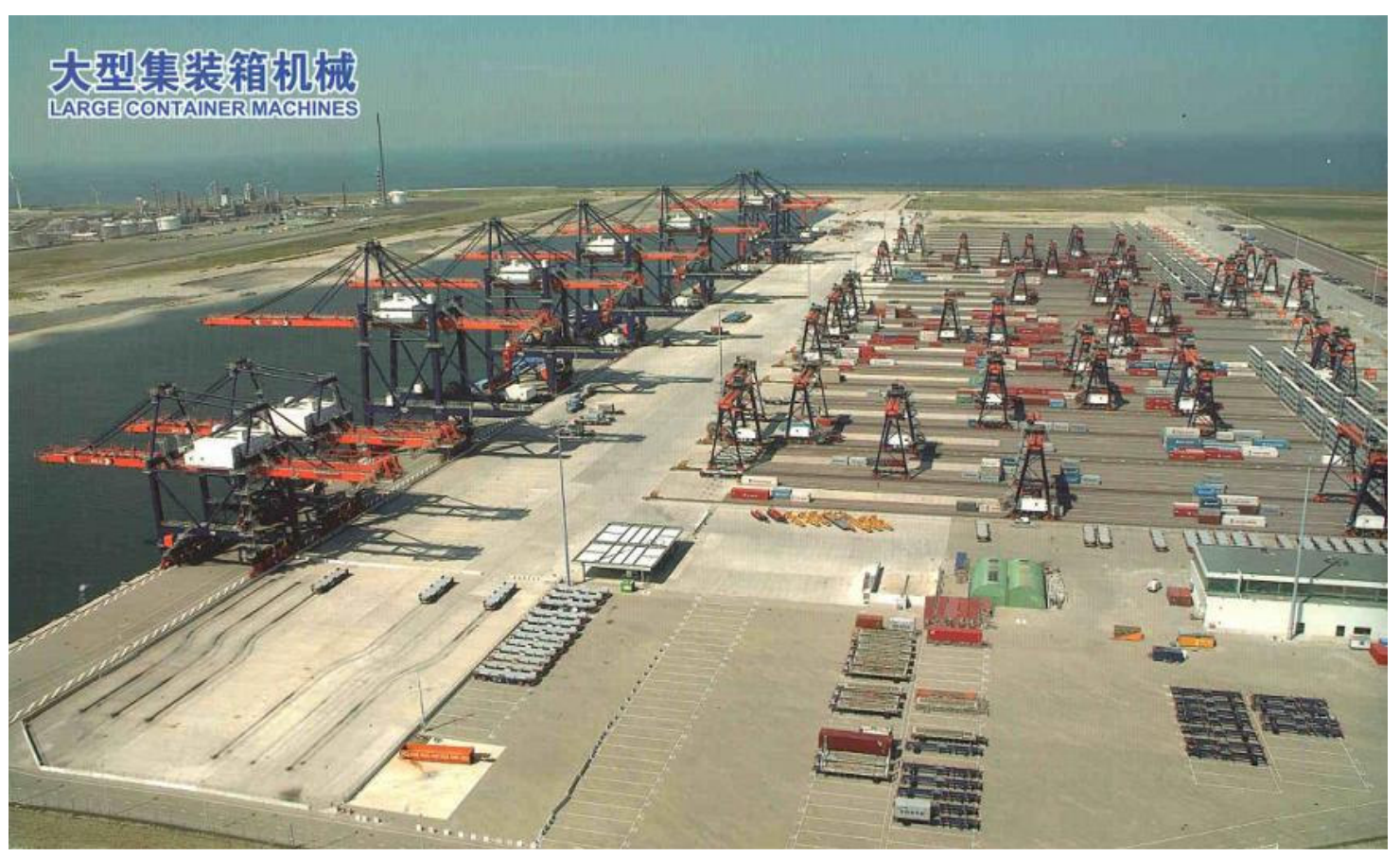

Fonte: Euromax

Apenas como uma rápida referência de terminais automatizados, os dois terminais considerados os mais automatizados em operação na Europa são: o 
Container Terminal Altenwerder (CTA) em Hamburgo na Alemanha do operador HHLA (Hamburger Hafen und LogistikAG) e o Euromax Terminal em Roterdã na Holanda do operador ECT (Europe Container Terminals) que pertence ao grupo $\mathrm{HPH}$ (Hutchison Port Holdings), conforme ilustram as figuras 2 e 3 anteriormente apresentadas.

Está em construção pela APMT em Roterdã o terminal de Maasvlakte 2, considerado o maior projeto de engenharia civil na Holanda; trata-se da construção de um novo porto e de infraestrutura de apoio em terra recuperada ao lado do terminal de Maasvlakte; A área total é de aproximadamente 167 hectares, com 2.800 metros de cais e outros 500 metros adicionais para operação de barcaças, com capacidade para 2,7 milhões de TEUs, os primeiros portêineres operados por meio de controle remoto da empresa Cargotec, guindastes para o terminal de barcaça, guindastes automatizados de pátio sobre trilhos (RMGs) da Kuenz, Guindastes para atendimentos dos ramais ferroviários na linha de cais do terminal, Veículos Guiados automatizados (AGVs) com bateria de elevação da Gottwald, estações robóticas de trocas de bateria da Gottwald, desenvolvimento conjunto dos Sistemas de Gerenciamento e Planejamento de Operações dos Terminais (TOS) e do Sistema de Controle dos Equipamentos (ECS) entre Navis (Cargotec) e TBA (Gottwald).

As construções do terminal serão realizadas conforme as regras de certificação de desempenho ambiental da Building Research Establishment Environmental Assessment Method (BREEAM) adotadas pelo Dutch Green Building Council. Outra item sustentável do terminal está relacionado a uso de eletrificação de todo os equipamentos, permitindo que o terminal seja livre de emissão de $\mathrm{CO} 2$, NOx , assim como de outras partículas. Como referência, a partir de 2009, o terminal de Maasvlakte I se tornou o primeiro terminal de contêineres do mundo alimentado por energia eólica. 
Figura 4 - Imagem do APM Terminals Maasvlakte II B.V

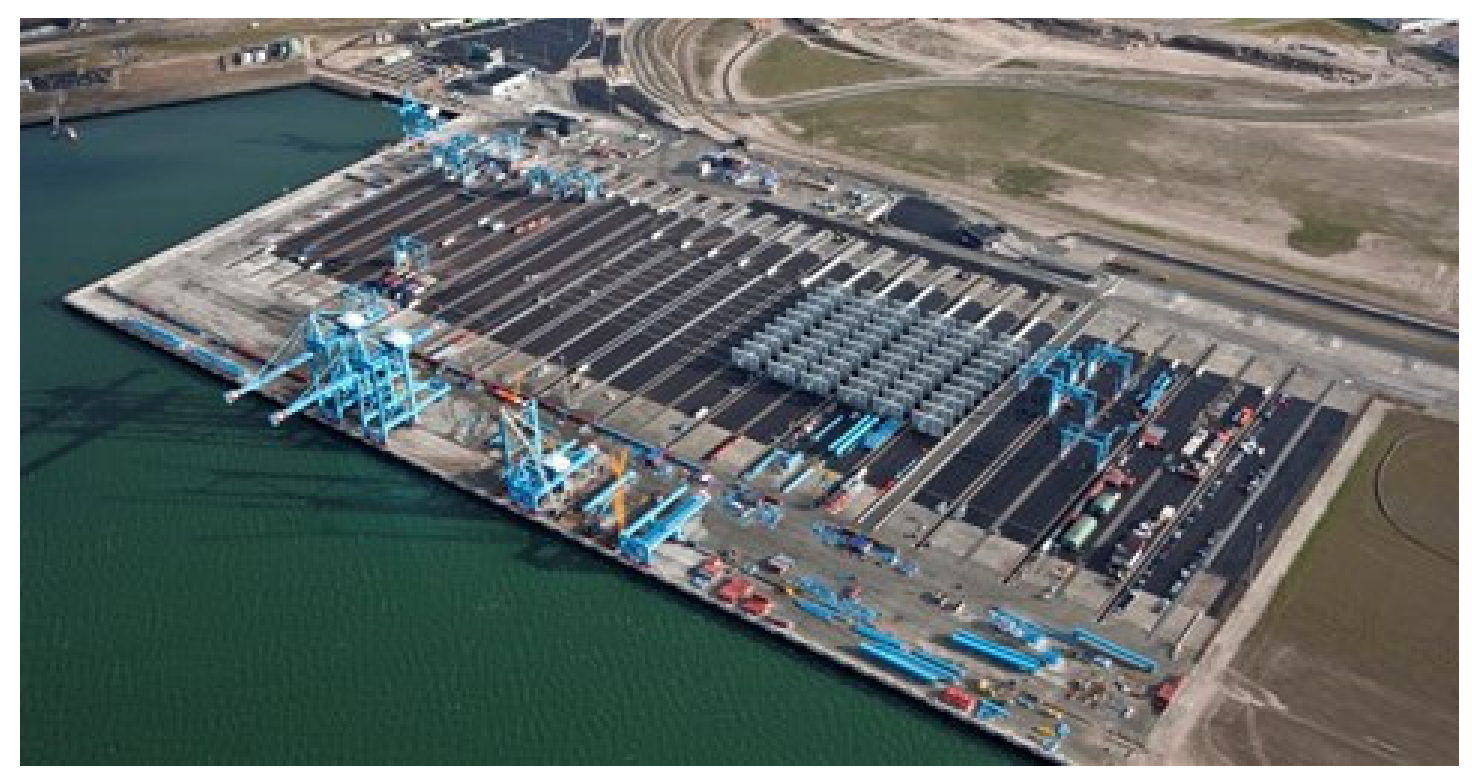

Fonte: APMT

\subsection{BREVE HISTORICO DA ECONOMIA INTERNACIONAL}

Há autores que consideram Comércio Internacional e Comércio Exterior como sinônimo, o que é natural pela relação dos temas e semelhança no conceito, nome e, por que não dizer, na prática, uma vez que as duas áreas compõem o universo normativo que define e disciplina as operações de importação e exportação. Contudo, há autores como Campoi (2008) que diferenciam esses dois conceitos, para quem o Comércio Internacional trata das questões estratégicas internacionais, tais como as operações de trocas entre países decorrentes de intercâmbio político, cultural e econômico (aplicável a mercadorias, serviços e mão de obra) e o Comércio Exterior trata das questões operacionais, isto é, dos termos, regras e normas nacionais das transações e estudos realizados no comércio internacional.

As normas de comércio internacional são um conjunto de regras criadas e disciplinadas por acordos estabelecidos entre países ou, então, são criadas por organismos internacionalmente acreditados e aderidas pelos países em todo o mundo, como as regras da Organização Mundial do Comércio (OMC). Já as normas e regras do comércio exterior são criadas para disciplinar tudo o que diz respeito à entrada no país de mercadorias procedentes do exterior (importação) e à saída de mercadorias do território nacional (exportação). Essas regras refletem não apenas 
nas questões tributárias, comerciais, financeiras, administrativas e aduaneiras, mas principalmente nas operações portuárias.

Como exemplos recentes dessas regras que afetam diretamente a infraestrutura, planejamento e a execução da operação portuária, pode-se citar a Portaria RFB $n^{\circ} 3.518$ de 30 de setembro de 2011 que estabelece requisitos e procedimentos para o alfandegamento de locais e recintos alfandegados e que determina na Seção IV no artigo 14 e na Seção VI no artigo 17 a instalação de equipamentos de inspeção não intrusiva ou Escâneres e de OCR nos Gates de entrada e saída, respectivamente; ou a Portaria $n^{\circ} 229$ de 06 de setembro de 2012 que disciplina o uso dos equipamentos de inspeção não invasiva (Escâner) de carga exigida dos recintos alfandegados jurisdicionados, em que determina que no fluxo de importação os contêineres devam ser escaneados num prazo de até 48 horas, contados da desatracação do navio, pelo recinto que realizou a operação portuária, para as cargas que armazenou, ou que permaneceram em suas dependências para serem submetidas ao regime de trânsito aduaneiro com destino a outra jurisdição; no momento da saída, pelo recinto operador, quando da transferência para outro recinto localizado nesta jurisdição ou no momento da entrada no recinto depositário que tiver o equipamento instalado, a pedido deste, e desde que garanta a inviolabilidade e rastreabilidade da carga no percurso entre o cais e suas dependências. E no fluxo de exportação, em ato contínuo, quaisquer contêineres indicados pela fiscalização aduaneira ou presentes no Custom Security Initiative (CSI); os contêineres vazios, no momento imediatamente anterior ao embarque, ou já escaneados anteriormente, desde que monitorados durante a sua permanência em área de pré-embarque para a garantia de sua inviolabilidade; os contêineres oriundos das operações de transbordo ou baldeação na qual seja necessária a transferência do contêiner para outro terminal para fins de reembarque.

Quanto ao conceito do que é Economia Internacional, Maia (2001) define esse como algo mais abrangente e que engloba o comércio internacional (exportações e importações), prestações de serviços e movimentação de capitais. Já Baumann; Canuto e Gonçalves (2004) teorizam dizendo que Economia Internacional é o campo da teoria econômica mais diretamente associada à noção de limites geográficos; ou, como o próprio nome diz, é o estudo das relações econômicas entre nações, que se divide em dois grandes ramos da Economia Internacional - a análise das relações comerciais e a análise das relações financeiras entre países. 
Segundo o economista John Kenneth Galbraith, uma das utilidades da história é que ela nos relembra o que pode acontecer novamente; observando a evolução da economia internacional a partir da Primeira Guerra Mundial, nota-se que, ao seu término em 1918, a economia dos países europeus estavam debilitadas, com seus sistemas de produção destruídos e as dividas decorrentes das despesas militares elevadas. Os países abandonam o padrão-ouro, a inflação se espalhou tal como a gripe espanhola e controles governamentais e desvalorização de moedas para tornar a exportação mais competitiva foram implantados. Surge a Liga das Nações, uma tentativa fracassada de um modelo semelhante à Organização das Nações Unidas (ONU) para preservar a paz e auxiliar no crescimento econômico; em 1930 surge a Banco Internacional de Pagamentos (BIS) para administrar os pagamentos devidos pela Alemanha a título de reparação de guerra. A maioria dos itens acima citados foram alguns dos eventos que contribuíram para que a Segunda Grande Guerra fosse deflagrada em 1939. No intervalo entre as suas grandes guerras, tivemos a Grande Depressão ou a crise de 1929, com a quebra da Bolsa de Nova lorque, que ocorreu basicamente em virtude da diminuição das exportações para a Europa, aumento dos estoques de produtos e diminuição das vendas; milhões de americanos tinham investimentos em ações dessas empresas, que em outubro de 1929, sofreram uma enorme desvalorização com reflexo no mundo todo e surgimento em 1933 do plano econômico chamado de New Deal.

Com o fim da Segunda Guerra Mundial, os Estados Unidos tornaram-se a maior potência econômica do planeta, pois novamente os meios de produção da Europa estavam destruídos, assim como o seu comércio e economia. Em 1944, com a Conferência de Bretton Woods foram apresentadas duas teses: a britânica preparada por John Maynard e atese americana aprovada de Harry D. White, que em resumo tinha por objetivo principal à volta ao padrão câmbio-ouro, sendo que a principal moeda conversível em ouro seria o dólar e, na verdade, apenas os Estados Unidos seriam obrigados a converter a sua moeda, conforme explica Luz (2010). Froyen (1999) explica que o conceito fundamental do sistema era o conjunto de taxas de câmbio fixas e o papel de moeda principal, o dólar. Outro objetivo dessa tese era definição de um sistema no qual as desvalorizações cambiais fossem eliminadas, estabelecendo paridades monetárias estáveis e ajustáveis, as quais auxiliariam na reconstrução das economias destruídas pela guerra e idealizava a criação de dois importantes órgãos: o Fundo Monetário Internacional (FMI) e o 
Banco Internacional de Reconstrução e Desenvolvimento (BIRD), que futuramente passaria a ser chamar Banco Mundial (World Bank). O conhecido Plano Marshall que foi um plano de auxilio formalizado pelos Estados Unidos ficou restrito aos países da Europa Ocidental e Turquia, tendo Inglaterra e França como os maiores beneficiários, aproximadamente $47 \%$ do total de US\$13 bilhões (atualmente esse valor seria de US\$100 bilhões).

A Crise de 1971 se deu por um processo de perda de confiança do dólar em virtude dos Balanços de Pagamentos (principalmente dos Estados Unidos) apresentarem déficits sucessivos; as taxas de juros europeias eram superiores à americana e à guerra do Vietnã; como consequência, o dólar deixou de ser conversível em ouro, os países adotaram o câmbio flutuante e o sistema cambial de Bretton Woods foi abandonado. Em 1973, segundo Yergin (2010), o petróleo havia se tornado o sangue vital das economias industriais no mundo, os países árabes reduziram a produção com o objetivo de forçar um aumento nos preços; ocorre então a primeira crise do petróleo, cujo preço do barril salta de US\$2,90 em outubro para US\$11,65 em janeiro de 1974, um aumento de mais de 400\% em apenas três meses. Já a Segunda Crise do Petróleo em 1979 ocorreu em decorrência do início de uma nova guerra e o preço do barril do petróleo em dezembro de 1979 era de US\$27,77 e no mercado livre de Amsterdã, o pico foi de US\$ 50,00.

A Crise Mexicana em 1995, seguida pela crise asiática em 1997 com início na Tailândia e reflexos em praticamente todo leste asiático, em particular Coréia do Sul, Malásia, Indonésia e Filipinas. Em 1998, o governo russo decreta moratória de 90 dias.

Em 2000 ocorre o chamado estouro da "Bolha da Internet" ou "Bolha das empresas ponto.com". Deu-se em 10 de março, quando o índice de tecnologia da Bolsa eletrônica de valores NASDAQ superou os 5.000 pontos, mais que o dobro do seu valor em apenas um ano e, em 2001, a bolha explodiu com grande parte das empresas "ponto.com" encerrando as suas atividades. Krugman (2009) indica que a Economia até o fim de julho de 2007 atravessava um dos períodos de maior prosperidade dos últimos trinta anos: as empresas nunca lucraram tanto, a China crescia acima de $10 \%$ ao ano, o Brasil exportava matéria-prima em volumes e preços recordes. Mas, a partir de 2008, a crise econômica imobiliária e financeira americana e desencadeia com a falência do banco de investimentos Lehman Brothers, em virtude de profundo desequilíbrio na oferta de créditos imobiliários. 


\subsection{EVOLUÇÃO DO COMÉRCIO INTERNACIONAL E COMÉRCIO EXTERIOR BRASILEIRO}

A partir da década de 1980, diversas mudanças das práticas econômicas e redefinições do panorama geopolítico, inicia-se o processo de globalização e, de acordo com Sirkin; Hemerling e Bhattacharya (2008) pode-se dizer que nesse momento, em virtude do alcance, a intensidade e a natureza da nova ordem, começou a ser escrito um novo capítulo da história da humanidade; a internacionalização do capital, a abertura e ampliação de mercados, a ampliação das cadeias logísticas, as questões cambiais, o incremento do fluxo internacional monetário e de mercadorias, a diversificação de produtos e pulverização de pontos de entrega, o avanço tecnológico e a difusão das informações por meio de redes, as mudanças na competitividade, o intercâmbio e a interdependência das economias nacionais, a formação de corporações transnacionais, a criação de blocos econômicos e suas implicações e os novos padrões de consumo, efeito China e surgimento dos BRICS (Brasil, Rússia, Índia, China e África do Sul) são alguns dos aspectos da nova era.

Conforme dados do Fundo Monetário Internacional (FMI), o PIB conjunto em 2013 dos cinco países que formam os chamado BRICS foi de US\$15,2 trilhões ou aproximadamente $21 \%$ da economia mundial (US\$ 71,9 trilhões). O Ministério das Relações Exteriores indica, em seu site na área de mecanismos inter-regionais, que apenas entre 2003 e 2007 o crescimento conjunto dos quatros países foi de $65 \%$ da expansão do PIB Mundial. Cabe lembrar que a África do Sul foi adicionada a esse conjunto de países emergentes somente em 2011, alterando a sigla originalmente grafada de BRIC, criada por Jim O'Neil em 2001, então economista-chefe da Goldman Sachs, e apresentada em estudo intitulado de "Building Better Global Economic BRICs".

Uma das formas de demonstrar esses efeitos são com base no aumento exponencial das exportações do comércio mundial nos últimos 30 anos, conforme a figura 5. 
Figura 5 - Evolução das exportações mundiais de 1950 a 2012

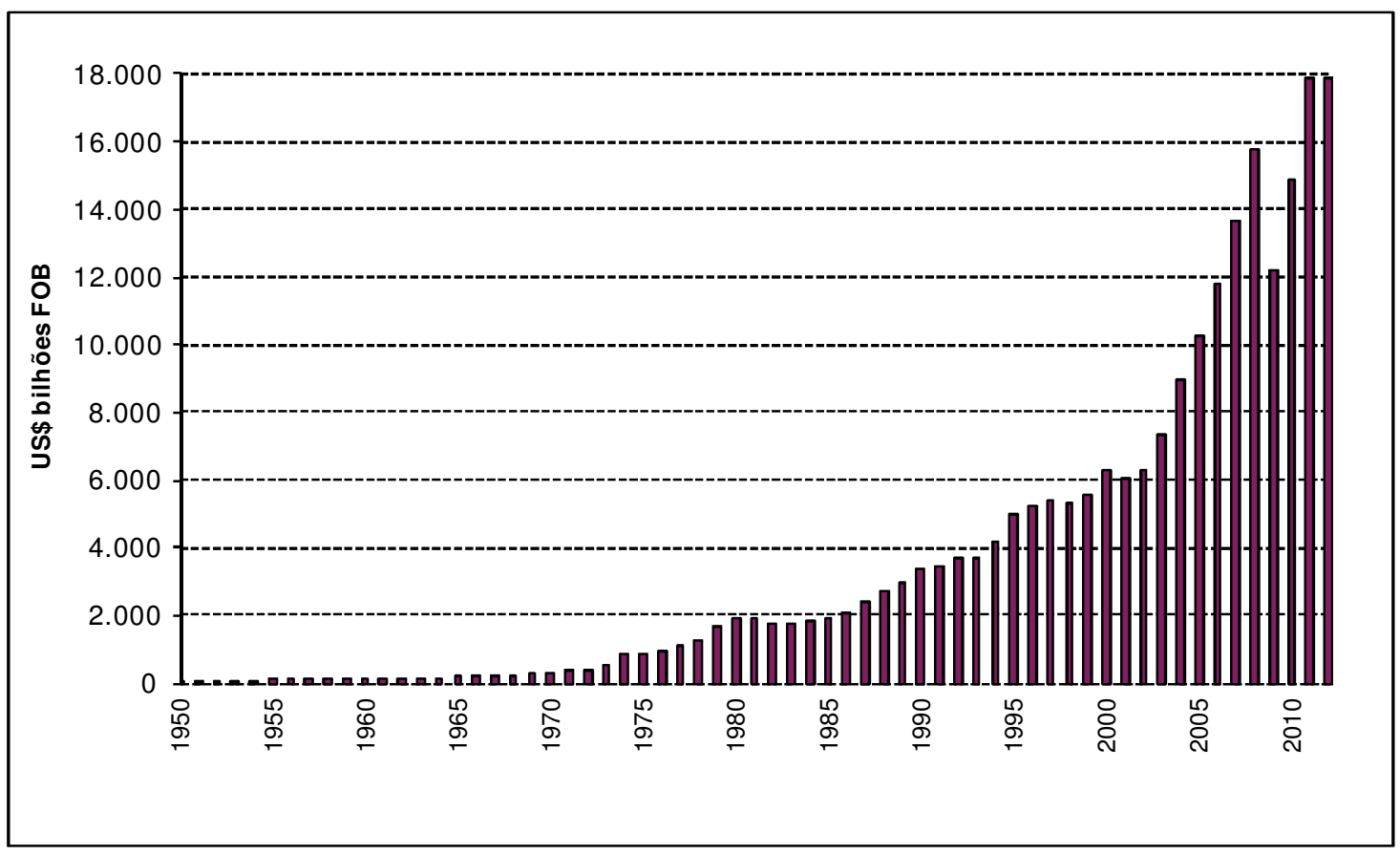

Fonte: MDIC/SECEX

A tabela 1 demonstra a evolução do comércio exterior brasileiro de 1950 a 2012, comparando os dados do Produto Interno Bruto (PIB) brasileiro, no qual se verifica um crescimento de 150 vezes no período, um salto de US $\$ 15$ bilhões para US\$ 2,2 trilhões; das exportações do país com um aumento de 240 vezes (de US\$ 1 bilhão para US\$242,6 bilhões) e das exportações mundiais na modalidade de contrato de compra e venda do tipo Free on board (FOB) ou Livre a bordo, significa que o vendedor é responsável pelo desembaraço aduaneiro e pela entrega dos bens até a transposição da murada do navio no porto de embarque, portanto, o comprador arca com os custos dos riscos de dano e perda a partir daquele ponto, conforme explica Lunardi (2001).

De forma análoga, a tabela 2 demonstra no mesmo período, os dados do PIB, das importações do país, cujo crescimento foi da mesma ordem das exportações (de US\$ 1,0 para US\$233,3 bilhões) e importação mundial na modalidade Cost, Insurance and Freight (CIF) ou Custo, Seguro e Frete, também como Lunardi (2001), o vendedor entrega a carga quando elas transpõem a murada do navio; porém o vendedor deve pagar os custos e o frete necessário até o porto de destino designado e obter o seguro marítimo contra perda e avarias. 
Completando a informação acima e listando apenas os dez principais países com que o Brasil possui maiores relações comercial na exportação temos:

1. China,

2. Estados Unidos,

3. Argentina,

4. Holanda,

5. Suíça,

6. Alemanha,

7. Japão,

8. Chile,

9. Bélgica, e

10. Itália.

Enquanto na Importação temos uma inversão entre o primeiro e o segundo colocado da exportação, isto é,

1. Estados Unidos,

2. China,

3. Argentina,

4. Alemanha,

5. Coreia do Sul,

6. Nigéria,

7. Japão,

8. França,

9. Itália, e

10. Chile. 
Tabela 1 - Crescimento das Exportações (FOB) no Brasil e Comércio mundial de 1950 a 2012

\begin{tabular}{|c|c|c|c|c|c|c|c|c|c|}
\hline \multirow[b]{2}{*}{ Período } & \multicolumn{3}{|c|}{ P I BBRASIL } & \multicolumn{4}{|c|}{ EXP BRASIL (FOB) } & \multicolumn{2}{|c|}{$\begin{array}{c}\text { EXPORTAÇÃO } \\
\text { MUNDIAL } \\
\text { (FOB) }\end{array}$} \\
\hline & US\$ bi & $\begin{array}{c}\text { Tx. } \\
\text { Real } \\
\%\end{array}$ & $\begin{array}{l}\text { Abert. } \\
\text { Econ /1 }\end{array}$ & US\$ bi & $\begin{array}{c}\text { Var. } \\
\%\end{array}$ & $\begin{array}{c}\mathrm{Pa} \\
\mathrm{B} / \mathrm{A}\end{array}$ & $\begin{array}{l}\mathrm{t} . \% \\
\mathrm{~B} / \mathrm{C}\end{array}$ & US\$ bi & $\begin{array}{c}\text { Var. } \\
\%\end{array}$ \\
\hline 1950 & 15,0 & 6,7 & 15,3 & 1,4 & 23,6 & 9,0 & 2,37 & 57,2 & - \\
\hline 1951 & 18,6 & 4,6 & 18,7 & 1,8 & 30,6 & 9,5 & 2,28 & 77,5 & 35,5 \\
\hline 1952 & 21,9 & 7,6 & 14,3 & 1,4 & $-19,8$ & 6,5 & 1,90 & 74,5 & $-3,9$ \\
\hline 1953 & 12,4 & 4,5 & 21,7 & 1,5 & 8,5 & 12,4 & 2,04 & 75,5 & 1,3 \\
\hline 1954 & 11,2 & 7,9 & 26,5 & 1,6 & 1,5 & 13,9 & 2,01 & 77,8 & 3,0 \\
\hline 1955 & 11,4 & 8,7 & 22,2 & 1,4 & $-8,9$ & 12,5 & 1,68 & 84,8 & 9,0 \\
\hline 1956 & 14,6 & 2,5 & 17,3 & 1,5 & 4,1 & 10,1 & 1,57 & 94,5 & 11,4 \\
\hline 1957 & 21,1 & 8,4 & 12,7 & 1,4 & $-6,1$ & 6,6 & 1,37 & 101,6 & 7,5 \\
\hline 1958 & 12,2 & 10,5 & 19,8 & 1,2 & $-10,7$ & 10,2 & 1,29 & 96,5 & $-5,0$ \\
\hline 1959 & 15,3 & 9,5 & 16,3 & 1,3 & 3,1 & 8,4 & 1,25 & 102,4 & 6,1 \\
\hline 1960 & 17,1 & 9,6 & 15,0 & 1,3 & $-1,0$ & 7,4 & 1,11 & 114,5 & 11,8 \\
\hline 1961 & 17,2 & 8,7 & 15,6 & 1,4 & 10,6 & 8,1 & 1,17 & 119,7 & 4,5 \\
\hline 1962 & 20,0 & 6,5 & 12,6 & 1,2 & $-13,5$ & 6,1 & 0,97 & 125,1 & 4,5 \\
\hline 1963 & 24,0 & 0,4 & 11,3 & 1,4 & 15,8 & 5,9 & 1,02 & 137,3 & 9,8 \\
\hline 1964 & 21,7 & 3,6 & 11,6 & 1,4 & 1,7 & 6,6 & 0,93 & 153,9 & 12,1 \\
\hline 1965 & 22,8 & 2,4 & 11,1 & 1,6 & 11,5 & 7,0 & 0,96 & 167,0 & 8,5 \\
\hline 1966 & 28,5 & 6,8 & 10,7 & 1,7 & 9,2 & 6,1 & 0,95 & 183,5 & 9,9 \\
\hline 1967 & 31,3 & 4,4 & 9,9 & 1,7 & $-5,0$ & 5,3 & 0,86 & 192,6 & 5,0 \\
\hline 1968 & 34,1 & 9,7 & 10,9 & 1,9 & 13,7 & 5,5 & 0,83 & 225,8 & 17,2 \\
\hline 1969 & 37,4 & 9,4 & 11,5 & 2,3 & 22,9 & 6,2 & 0,89 & 258,4 & 14,4 \\
\hline 1970 & 42,6 & 10,4 & 12,3 & 2,7 & 18,5 & 6,4 & 0,91 & 299,7 & 16,0 \\
\hline 1971 & 49,2 & 11,4 & 12,5 & 2,9 & 6,0 & 5,9 & 0,86 & 335,9 & 12,1 \\
\hline 1972 & 58,8 & 11,9 & 14,0 & 4,0 & 37,4 & 6,8 & 1,00 & 399,9 & 19,1 \\
\hline 1973 & 84,1 & 13,9 & 14,7 & 6,2 & 55,3 & 7,4 & 1,11 & 556,1 & 39,1 \\
\hline 1974 & 110,4 & 8,1 & 18,7 & 8,0 & 28,3 & 7,2 & 0,96 & 829,1 & 49,1 \\
\hline 1975 & 129,9 & 5,2 & 16,1 & 8,7 & 9,0 & 6,7 & 1,02 & 850,7 & 2,6 \\
\hline 1976 & 154,0 & 10,3 & 14,6 & 10,1 & 16,8 & 6,6 & 1,06 & 958,7 & 12,7 \\
\hline 1977 & 177,2 & 4,9 & 13,6 & 12,1 & 19,7 & 6,8 & 1,12 & $1.086,3$ & 13,3 \\
\hline 1978 & 201,2 & 5,0 & 13,1 & 12,7 & 4,4 & 6,3 & 1,01 & $1.257,6$ & 15,8 \\
\hline 1979 & 223,5 & 6,8 & 14,9 & 15,2 & 20,4 & 6,8 & 0,94 & $1.625,0$ & 29,2 \\
\hline
\end{tabular}




\begin{tabular}{|c|c|c|c|c|c|c|c|c|c|}
\hline \multirow[b]{2}{*}{ Período } & \multicolumn{3}{|c|}{ P I BBRASIL } & \multicolumn{4}{|c|}{ EXP BRASIL (FOB) } & \multicolumn{2}{|c|}{$\begin{array}{l}\text { EXPORTAÇÃO } \\
\text { MUNDIAL (FOB) }\end{array}$} \\
\hline & US\$ bi & $\begin{array}{c}\text { Tx. } \\
\text { Real } \\
\%\end{array}$ & $\begin{array}{l}\text { Abert. } \\
\text { Econ/1 }\end{array}$ & US\$ bi & $\begin{array}{l}\text { Var. } \\
\%\end{array}$ & $\begin{array}{l}\text { Par } \\
\text { B/A }\end{array}$ & $\begin{array}{l}. \% \\
B / C\end{array}$ & US\$ bi & $\begin{array}{c}\text { Var. } \\
\%\end{array}$ \\
\hline 1980 & 237,8 & 9,2 & 18,1 & 20,1 & 32,1 & 8,5 & 1,04 & $1.940,8$ & 19,4 \\
\hline 1981 & 258,6 & $-4,3$ & 17,6 & 23,3 & 15,7 & 9,0 & 1,21 & $1.924,2$ & $-0,9$ \\
\hline 1982 & 271,3 & 0,8 & 14,6 & 20,2 & $-13,4$ & 7,4 & 1,14 & $1.765,5$ & $-8,2$ \\
\hline 1983 & 189,5 & $-2,9$ & 19,7 & 21,9 & 8,5 & 11,6 & 1,26 & $1.734,5$ & $-1,8$ \\
\hline 1984 & 189,7 & 5,4 & 21,6 & 27,0 & 23,3 & 14,2 & 1,47 & $1.840,6$ & 6,1 \\
\hline 1985 & 211,1 & 7,9 & 18,4 & 25,6 & $-5,1$ & 12,1 & 1,37 & $1.872,0$ & 1,7 \\
\hline 1986 & 257,8 & 7,5 & 14,1 & 22,3 & $-12,8$ & 8,7 & 1,09 & $2.046,4$ & 9,3 \\
\hline 1987 & 282,4 & 3,6 & 14,6 & 26,2 & 17,3 & 9,3 & 1,09 & $2.401,1$ & 17,3 \\
\hline 1988 & 305,7 & $-0,1$ & 15,8 & 33,8 & 28,8 & 11,1 & 1,23 & $2.742,0$ & 14,2 \\
\hline 1989 & 415,9 & 3,2 & 12,7 & 34,4 & 1,8 & 8,3 & 1,15 & $2.981,5$ & 8,7 \\
\hline 1990 & 469,3 & $-4,3$ & 11,1 & 31,4 & $-8,6$ & 6,7 & 0,93 & $3.395,6$ & 13,9 \\
\hline 1991 & 405,7 & 1,0 & 13,0 & 31,6 & 0,7 & 7,8 & 0,92 & $3.446,1$ & 1,5 \\
\hline 1992 & 387,3 & $-0,5$ & 14,5 & 35,8 & 13,2 & 9,2 & 0,97 & $3.676,7$ & 6,7 \\
\hline 1993 & 429,7 & 4,9 & 14,9 & 38,6 & 7,7 & 9,0 & 1,05 & $3.675,4$ & 0,0 \\
\hline 1994 & 543,1 & 5,9 & 14,1 & 43,5 & 12,9 & 8,0 & 1,04 & $4.203,3$ & 14,4 \\
\hline 1995 & 770,4 & 4,2 & 12,5 & 46,5 & 6,8 & 6,0 & 0,93 & $5.020,1$ & 19,4 \\
\hline 1996 & 840,3 & 2,2 & 12,0 & 47,7 & 2,7 & 5,7 & 0,91 & $5.249,5$ & 4,6 \\
\hline 1997 & 871,3 & 3,4 & 12,9 & 53,0 & 11,0 & 6,1 & 0,98 & $5.430,1$ & 3,4 \\
\hline 1998 & 844,0 & 0,0 & 12,9 & 51,1 & $-3,5$ & 6,1 & 0,96 & $5.350,7$ & $-1,5$ \\
\hline 1999 & 586,8 & 0,3 & 16,6 & 48,0 & $-6,1$ & 8,2 & 0,86 & $5.560,0$ & 3,9 \\
\hline 2000 & 645,0 & 4,3 & 17,2 & 55,1 & 14,8 & 8,5 & 0,88 & $6.276,9$ & 12,9 \\
\hline 2001 & 553,8 & 1,3 & 20,6 & 58,3 & 5,7 & 10,5 & 0,97 & $6.022,2$ & $-4,1$ \\
\hline 2002 & 504,4 & 2,7 & 21,4 & 60,4 & 3,7 & 12,0 & 0,96 & $6.310,4$ & 4,8 \\
\hline 2003 & 553,6 & 1,1 & 22,0 & 73,2 & 21,1 & 13,2 & 0,99 & $7.377,9$ & 16,9 \\
\hline 2004 & 663,8 & 5,7 & 24,0 & 96,7 & 32,1 & 14,6 & 1,08 & $8.973,4$ & 21,6 \\
\hline 2005 & 882,4 & 3,2 & 21,8 & 118,5 & 22,6 & 13,4 & 1,16 & $10.230,9$ & 14,0 \\
\hline 2006 & $1.088,8$ & 4,0 & 21,0 & 137,8 & 16,3 & 12,7 & 1,17 & $11.825,1$ & 15,6 \\
\hline 2007 & $1.366,5$ & 6,1 & 20,6 & 160,6 & 16,6 & 11,8 & 1,17 & $13.685,7$ & 15,7 \\
\hline 2008 & $1.650,9$ & 5,2 & 22,5 & 197,9 & 23,2 & 12,0 & 1,25 & $15.800,7$ & 15,5 \\
\hline 2009 & $1.625,6$ & $-0,3$ & 17,3 & 153,0 & $-22,7$ & 9,4 & 1,25 & $12.232,4$ & $-22,6$ \\
\hline 2010 & $2.143,9$ & 7,5 & 17,9 & 201,9 & 32,0 & 9,4 & 1,35 & $14.903,1$ & 21,8 \\
\hline 2011 & $2.475,1$ & 2,7 & 19,5 & 256,0 & 67,4 & 10,3 & 1,43 & $17.852,3$ & 45,9 \\
\hline 2012 & $2.253,1$ & 0,9 & 20,7 & 242,6 & 20,1 & 10,8 & 1,36 & $17.852,0$ & 19,8 \\
\hline
\end{tabular}

Fonte: SECEX/MDIC 
Tabela 2 - Crescimento das Importações no Brasil e Comércio mundial de 1950 a 2012

\begin{tabular}{|c|c|c|c|c|c|c|c|}
\hline \multicolumn{4}{|c|}{ P I BBRASIL } & \multicolumn{2}{|c|}{$\begin{array}{l}\text { IMP BRASIL } \\
\text { (CIF) }\end{array}$} & \multicolumn{2}{|c|}{$\begin{array}{l}\text { IMPORTAÇÃO } \\
\text { MUNDIAL (CIF) }\end{array}$} \\
\hline Período & US\$ bi & $\begin{array}{c}\text { Tx. } \\
\text { Real } \\
\%\end{array}$ & $\begin{array}{c}\text { Abert. } \\
\text { econ. } \\
/ 1\end{array}$ & US\$ bi & $\begin{array}{c}\text { Var. } \\
\%\end{array}$ & US\$ bi & $\begin{array}{l}\text { Part.\% } \\
\text { E/F }\end{array}$ \\
\hline 1950 & 15,0 & 6,7 & 15,3 & 1,0 & - & 59,6 & 1,68 \\
\hline 1951 & 18,6 & 4,6 & 18,7 & 1,9 & 90,0 & 82,3 & 2,31 \\
\hline 1952 & 21,9 & 7,6 & 14,3 & 1,9 & 0,0 & 81,4 & 2,33 \\
\hline 1953 & 12,4 & 4,5 & 21,7 & 1,2 & $-36,8$ & 77,4 & 1,55 \\
\hline 1954 & 11,2 & 7,9 & 26,5 & 1,5 & 25,0 & 80,4 & 1,87 \\
\hline 1955 & 11,4 & 8,7 & 22,2 & 1,2 & $-20,0$ & 90,3 & 1,33 \\
\hline 1956 & 14,6 & 2,5 & 17,3 & 1,1 & $-8,3$ & 99,4 & 1,11 \\
\hline 1957 & 21,1 & 8,4 & 12,7 & 1,4 & 27,3 & 109,1 & 1,28 \\
\hline 1958 & 12,2 & 10,5 & 19,8 & 1,3 & $-7,1$ & 101,8 & 1,28 \\
\hline 1959 & 15,3 & 9,5 & 16,3 & 1,3 & 0,0 & 108,1 & 1,20 \\
\hline 1960 & 17,1 & 9,6 & 15,0 & 1,4 & 7,7 & 121,1 & 1,16 \\
\hline 1961 & 17,2 & 8,7 & 15,6 & 1,4 & 0,0 & 126,8 & 1,10 \\
\hline 1962 & 20,0 & 6,5 & 12,6 & 1,4 & 0,0 & 133,9 & 1,05 \\
\hline 1963 & 24,0 & 0,4 & 11,3 & 1,4 & 0,0 & 145,8 & 0,96 \\
\hline 1964 & 21,7 & 3,6 & 11,6 & 1,2 & $-14,3$ & 162,1 & 0,74 \\
\hline 1965 & 22,8 & 2,4 & 11,1 & 1,0 & $-16,7$ & 176,1 & 0,57 \\
\hline 1966 & 28,5 & 6,8 & 10,7 & 1,4 & 40,0 & 193,7 & 0,72 \\
\hline 1967 & 31,3 & 4,4 & 9,9 & 1,7 & 21,4 & 213,2 & 0,80 \\
\hline 1968 & 34,1 & 9,7 & 10,9 & 2,1 & 23,5 & 237,0 & 0,89 \\
\hline 1969 & 37,4 & 9,4 & 11,5 & 2,3 & 9,5 & 269,4 & 0,85 \\
\hline 1970 & 42,6 & 10,4 & 12,3 & 2,8 & 21,7 & 314,4 & 0,89 \\
\hline 1971 & 49,2 & 11,4 & 12,5 & 3,7 & 32,1 & 345,8 & 1,07 \\
\hline 1972 & 58,8 & 11,9 & 14,0 & 4,8 & 29,7 & 406,7 & 1,18 \\
\hline 1973 & 84,1 & 13,9 & 14,7 & 7,0 & 45,8 & 561,3 & 1,25 \\
\hline 1974 & 110,4 & 8,1 & 18,7 & 14,2 & 102,9 & 824,6 & 1,72 \\
\hline 1975 & 129,9 & 5,2 & 16,1 & 13,6 & $-4,2$ & 869,9 & 1,56 \\
\hline 1976 & 154,0 & 10,3 & 14,6 & 13,7 & 0,7 & 975,2 & 1,40 \\
\hline 1977 & 177,2 & 4,9 & 13,6 & 13,3 & $-2,9$ & $1.116,8$ & 1,19 \\
\hline 1978 & 201,2 & 5,0 & 13,1 & 15,1 & 13,5 & $1.292,0$ & 1,17 \\
\hline 1979 & 223,5 & 6,8 & 14,9 & 19,8 & 31,1 & $1.630,3$ & 1,21 \\
\hline
\end{tabular}




\begin{tabular}{|c|c|c|c|c|c|c|c|}
\hline \multicolumn{4}{|c|}{ P I BBRASIL } & \multicolumn{2}{|c|}{$\begin{array}{l}\text { IMP BRASIL } \\
\text { (CIF) }\end{array}$} & \multicolumn{2}{|c|}{$\begin{array}{l}\text { IMPORTAÇÃO } \\
\text { MUNDIAL (CIF) }\end{array}$} \\
\hline Período & $\begin{array}{l}\text { US\$ bi } \\
(A)\end{array}$ & $\begin{array}{l}\text { Tx. } \\
\text { real } \\
\%\end{array}$ & $\begin{array}{c}\text { Abert. } \\
\text { econ. } \\
/ 1\end{array}$ & $\begin{array}{l}\text { US\$ bi } \\
(\mathrm{E})\end{array}$ & $\begin{array}{c}\text { Var. } \\
\%\end{array}$ & $\begin{array}{l}\text { US\$ bi } \\
(\mathrm{F})\end{array}$ & $\begin{array}{l}\text { Part.\% } \\
\text { E/F }\end{array}$ \\
\hline 1980 & 237,8 & 9,2 & 18,1 & 25,0 & 26,3 & $2.006,3$ & 1,25 \\
\hline 1981 & 258,6 & $-4,3$ & 17,6 & 24,1 & $-3,6$ & $1.990,0$ & 1,21 \\
\hline 1982 & 271,3 & 0,8 & 14,6 & 21,1 & $-12,4$ & $1.860,3$ & 1,13 \\
\hline 1983 & 189,5 & $-2,9$ & 19,7 & 16,8 & $-20,4$ & $1.800,2$ & 0,93 \\
\hline 1984 & 189,7 & 5,4 & 21,6 & 15,2 & $-9,5$ & $1.918,4$ & 0,79 \\
\hline 1985 & 211,1 & 7,9 & 18,4 & 14,3 & $-5,9$ & $1.942,1$ & 0,74 \\
\hline 1986 & 257,8 & 7,5 & 14,1 & 15,6 & 9,1 & $2.121,3$ & 0,74 \\
\hline 1987 & 282,4 & 3,6 & 14,6 & 16,6 & 6,4 & $2.484,6$ & 0,67 \\
\hline 1988 & 305,7 & $-0,1$ & 15,8 & 16,1 & $-3,0$ & $2.834,7$ & 0,57 \\
\hline 1989 & 415,9 & 3,2 & 12,7 & 19,9 & 23,6 & $3.068,3$ & 0,65 \\
\hline 1990 & 469,3 & $-4,3$ & 11,1 & 22,5 & 13,2 & $3.550,0$ & 0,63 \\
\hline 1991 & 405,7 & 1,0 & 13,0 & 23,0 & 1,9 & $3.632,0$ & 0,63 \\
\hline 1992 & 387,3 & $-0,5$ & 14,5 & 23,1 & 0,5 & $3.881,0$ & 0,59 \\
\hline 1993 & 429,7 & 4,9 & 14,9 & 27,7 & 20,3 & $3.875,0$ & 0,72 \\
\hline 1994 & 543,1 & 5,9 & 14,1 & 36,0 & 29,8 & $4.428,0$ & 0,81 \\
\hline 1995 & 770,4 & 4,2 & 12,5 & 54,1 & 50,4 & $5.283,0$ & 1,02 \\
\hline 1996 & 840,3 & 2,2 & 12,0 & 56,8 & 4,9 & $5.544,0$ & 1,02 \\
\hline 1997 & 871,3 & 3,4 & 12,9 & 63,3 & 11,4 & $5.737,0$ & 1,10 \\
\hline 1998 & 844,0 & 0,0 & 12,9 & 61,1 & $-3,4$ & $5.681,0$ & 1,08 \\
\hline 1999 & 586,8 & 0,3 & 16,6 & 51,9 & $-15,1$ & $5.921,0$ & 0,88 \\
\hline 2000 & 645,0 & 4,3 & 17,2 & 59,1 & 13,8 & $6.724,0$ & 0,88 \\
\hline 2001 & 553,8 & 1,3 & 20,6 & 58,6 & $-0,7$ & $6.483,0$ & 0,90 \\
\hline 2002 & 504,4 & 2,7 & 21,4 & 49,7 & $-15,2$ & $6.742,0$ & 0,74 \\
\hline 2003 & 553,6 & 1,1 & 22,0 & 50,9 & 2,3 & $7.867,0$ & 0,65 \\
\hline 2004 & 663,8 & 5,7 & 24,0 & 66,4 & 30,6 & $9.568,0$ & 0,69 \\
\hline 2005 & 882,4 & 3,2 & 21,8 & 77,6 & 16,9 & $10.866,0$ & 0,71 \\
\hline 2006 & $1.088,8$ & 4,0 & 21,0 & 95,8 & 23,5 & $12.459,0$ & 0,77 \\
\hline 2007 & $1.366,5$ & 6,1 & 20,6 & 126,6 & 32,1 & $14.325,0$ & 0,88 \\
\hline 2008 & $1.650,9$ & 5,2 & 22,5 & 182,4 & 44,0 & $16.566,0$ & 1,10 \\
\hline 2009 & $1.625,6$ & $-0,3$ & 17,3 & 133,7 & $-26,7$ & $12.776,0$ & 1,05 \\
\hline 2010 & $2.143,9$ & 7,5 & 17,9 & 191,5 & 43,3 & $15.504,0$ & 1,24 \\
\hline 2011 & $2.475,1$ & 2,7 & 19,5 & 237,0 & 77,3 & $18.487,0$ & 1,28 \\
\hline 2012 & $2.253,1$ & 0,9 & 20,7 & 233,3 & 21,8 & $18.567,0$ & 1,26 \\
\hline
\end{tabular}

Fonte: SECEX/MDIC 
Completam as fontes das tabelas anteriores: dados de exportação e importação Brasileira são da Secretária de Comércio Exterior do Ministério do Desenvolvimento, Indústria e Comércio (SECEX/MDIC) e Receita Federal do Brasil do Ministério da Fazenda (RFB/MF); os dados do PIB são do Banco Central (BACEN) e do Comércio Mundial são da OMC. Comparando apenas os dados da última década de atuação do país, é possível verificar que o Brasil cresceu e mudou, ocupando novos espaços no comércio internacional e ganhando relevância nas discussões na OMC; onde o atual diretor geral é o brasileiro Roberto Azevedo, cujo principal desafio será desbloquear as negociações da Rodada do Desenvolvimento de Doha iniciadas em 2001 e suspensas em 2008 para liberalização do comércio mundial. Cabe destacar dois fatores importantes nas exportações brasileiras, a saber:

- A existência de uma pauta diversificada de produtos e

- Não dependência de um único parceiro comercial.

O Brasil sempre teve uma pauta exportadora concentrada basicamente em um único produto; pode-se dizer que se iniciou no comércio internacional no período pré-colonial (1500 a 1531), com exportação de madeira Pau-Brasil para a Europa; ou após o período colonial, quando o Brasil exportava cana de açúcar (entre os séculos XV e XVI), Ouro (século XVIII), café (1727 até hoje) e borracha (1879 e, posteriormente, entre 1942 - 1945). Atualmente, o Brasil tem uma pauta exportadora diversificada, sendo que 25 produtos representam aproximadamente $57 \%$ das vendas externas; sendo esses: minério de ferro, petróleo, soja e farelo de soja, carne bovina e de frango, aviões, automóveis e peças para automóveis (CKD), café cru em grão, produtos semimanufaturados de ferro ou aço, ferro fundido bruto, ferros-liga, pastas químicas de madeira, açúcar de cana (bruto), tratores e veículos de carga, óleos comestíveis, fumos em folhas, aparelhos transmissores ou receptores e componentes, álcool etílico, motores geradores e transformadores elétricos e suas partes, óleo de soja bruto, produtos laminados planos de ferro ou aço, calçados e suas partes ou componentes.

$\mathrm{Na}$ importação, os 15 principais produtos importados pelo Brasil são: combustíveis e lubrificantes, equipamentos mecânicos, equipamentos elétrico e eletrônico, automóveis e partes, químicos orgânicos e inorgânicos, plásticos, instrumentos de ótica e precisão, farmacêuticos, fertilizantes, borrachas, cereais e 
produtos de moagem, cobre, aeronaves e peças, filamentos e fibras sintéticas e artificiais.

O que é possível notar de ambas as listas de produtos apresentados é que boa parte desses produtos pode ser contêinerizada, destacando que o contêiner não se limita apenas aos produtos manufaturados e semimanufaturados, mas também aos produtos básicos agrícolas, tais como o café que tem $100 \%$ de sua produção exportada através em contêineres; o açúcar foi o segundo produto mais exportado em 2012 pelo maior terminal de contêineres do porto de Santos e do país - a Santos-Brasil. Em 2013, ocorreu um aumento da produção de açúcar da ordem de $4,7 \%$, totalizando 37,7 milhões de toneladas e mantida oferta de etanol para atender demanda norte-americana.

Há diversos experimentos em andamento na contêinerização da soja, produto o qual o Brasil é o segundo maior produtor mundial com 81,5 milhões de toneladas (atrás dos Estados Unidos com 82,6 milhões), mas com uma produtividade superior de $2.939 \mathrm{Kg} / \mathrm{hectare}$ (contra $2.679 \mathrm{Kg} /$ hectare dos Estados Unidos). Observando-se apenas a produtividade dos estados do Paraná e Mato Grosso esse número sobe $3.348 \mathrm{Kg} / \mathrm{hectare}$ com uma produção conjunta de 39,4 milhões de toneladas, ou seja, 48,3 \% da safra 2012/2013 conforme dados da Companhia Nacional de Abastecimento (CONAB) e da Empresa Brasileira de Pesquisa Agropecuária (EMBRAPA).

Em virtude do crescimento da exportação de frutas e, principalmente, de carne bovina e de frango em todas as suas categorias (in natura, industrializada, miúdos, salgadas e tripas), os terminais de contêineres de forma geral ampliaram seu número de tomadas elétricas disponíveis em suas áreas destinadas a contêineres refrigerados - os chamados Reefers - com a finalidade de atender a esse crescimento.

A tabela 3 a seguir apresenta a lista das maiores empresas exportadoras e importadoras que operam no comércio brasileiro. Entre os segmentos e empresas identificam-se frequentes usuários de contêineres como o setor automobilístico com a CAOA Hyundai, Fiat, Ford, GM, Wolkswagen e outras montadoras conhecidas; ou gingantes da área alimentícia como a JBS, Brasil Foods e Sadia, essas principais clientes das áreas de contêineres refrigerados dos armadores e terminais. 
Tabela 3 - Ranking 2011 das maiores empresas exportadores e importadores

\begin{tabular}{c|cc}
\hline Ranking & Exportadores & Importadores \\
\hline 1 & Vale & Petrobras \\
2 & Petrobras & CISA Trading \\
3 & Bunge Alimentos & Samsung da Amazônia \\
4 & Samarco Mineração & Embraer \\
5 & Embraer & Braskem \\
6 & Cargill Agrícola & Volkswagen do Brasil \\
7 & ADM do Brasil & REFAP \\
8 & Braskem & CAOA \\
9 & Sadia & Ford Brasil \\
10 & Louis Dreyfus Brasil & Toyota Brasil \\
11 & JBS & FIAT \\
12 & Brasil Foods (BRF) & Arcelormittal Brasil \\
13 & Coopersucar & Renault do Brasil \\
14 & Thyssenkrupp CSA & Peugeot-Citröen do \\
& & Brasil \\
15 & Arcelormittal Brasil & Bunge Fertilizantes \\
16 & Volkswagen do Brasil & Cotia Vitória Serviços e \\
17 & Cia. Bras. de Metalurgia e Mineração & Comércio \\
18 & General Motors do Brasil & Syngenta \\
19 & Caterpillar Brasil & Mercedes-Benz do \\
20 & Raízen & Brasil \\
21 & Fibria Celulose & Fertilizantes Heringer \\
22 & Seara Alimentos & Paranapanema \\
23 & FIAT & Usiminas \\
24 & Raízen Combustíveis & Mosaic Fertilizantes do \\
25 & Brasil \\
\hline & Cord Brasil & BASF \\
\hline & Thyssenkrupp CSA \\
\hline
\end{tabular}

Fonte: Anuário 2012 - Análise Brasil Global

A figura 6 apresenta a evolução dos produtos básicos, semimanufaturados e manufaturados das exportações brasileiras de 1964 a 2013 em milhões de dólares FOB. Nota-se o forte crescimento das exportações de manufaturados e de produtos básicos; observa-se também que desde o início da década de 80 , os produtos manufaturados tiveram uma maior participação na pauta de exportação, contudo, a partir de 2010, os produtos básicos superam os manufaturados na pauta. Corrobora com essa afirmação o gráfico da figura 7 que apresenta a participação em percentual das exportações brasileiras por fator agregado no mesmo período, no qual os produtos básicos e manufaturados respondem por $85,4 \%$, sendo $46,7 \%$ de produtos básicos e $38,7 \%$ dos manufaturados. 
Figura 6 - Exportações brasileiras por fator agregado de 1964 à 2013 (em milhões de dólares FOB)

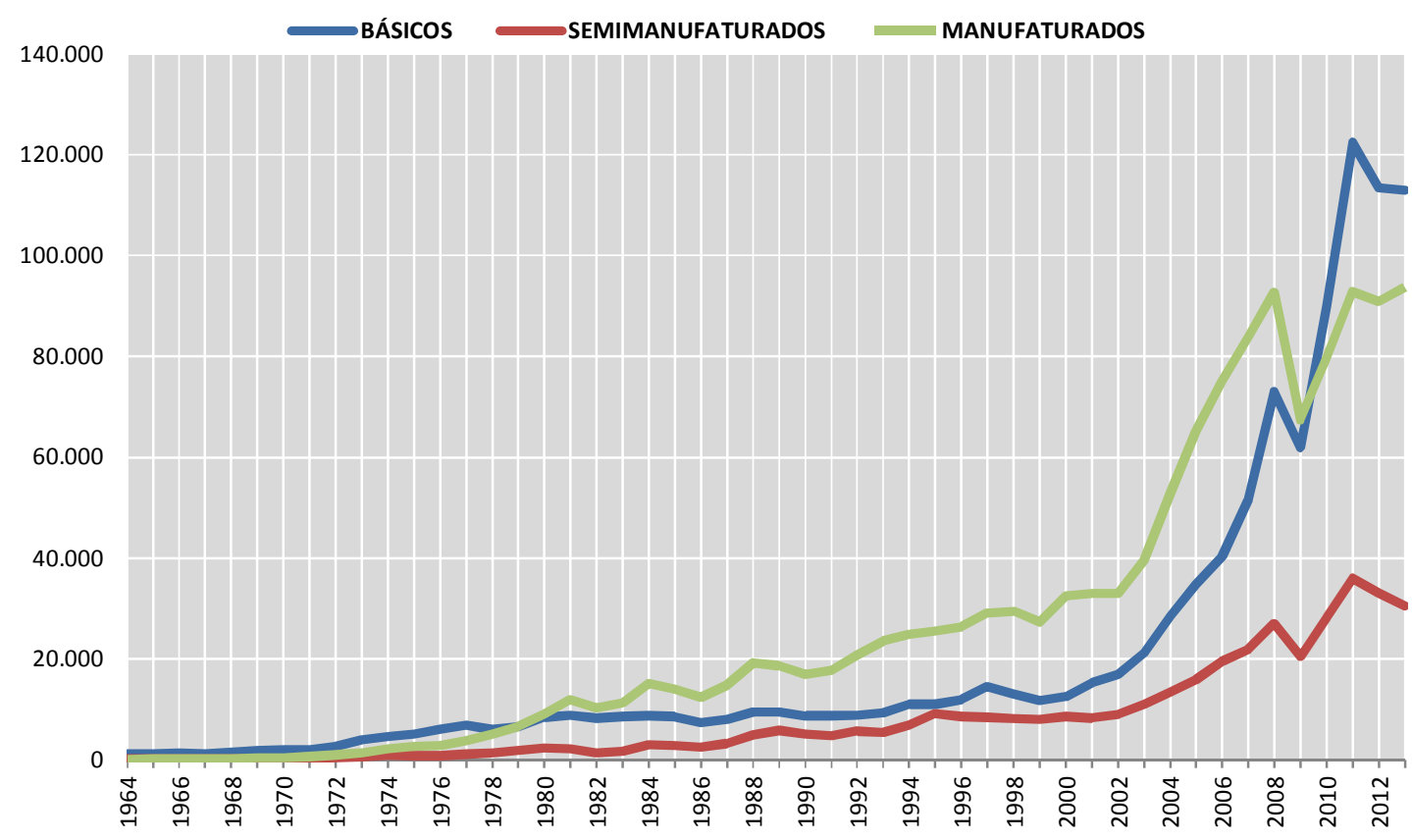

Fonte: MDIC/SECEX

Figura 7 - Exportações brasileiras por fator agregado de 1964 à 2013 em percentual por tipo de produto

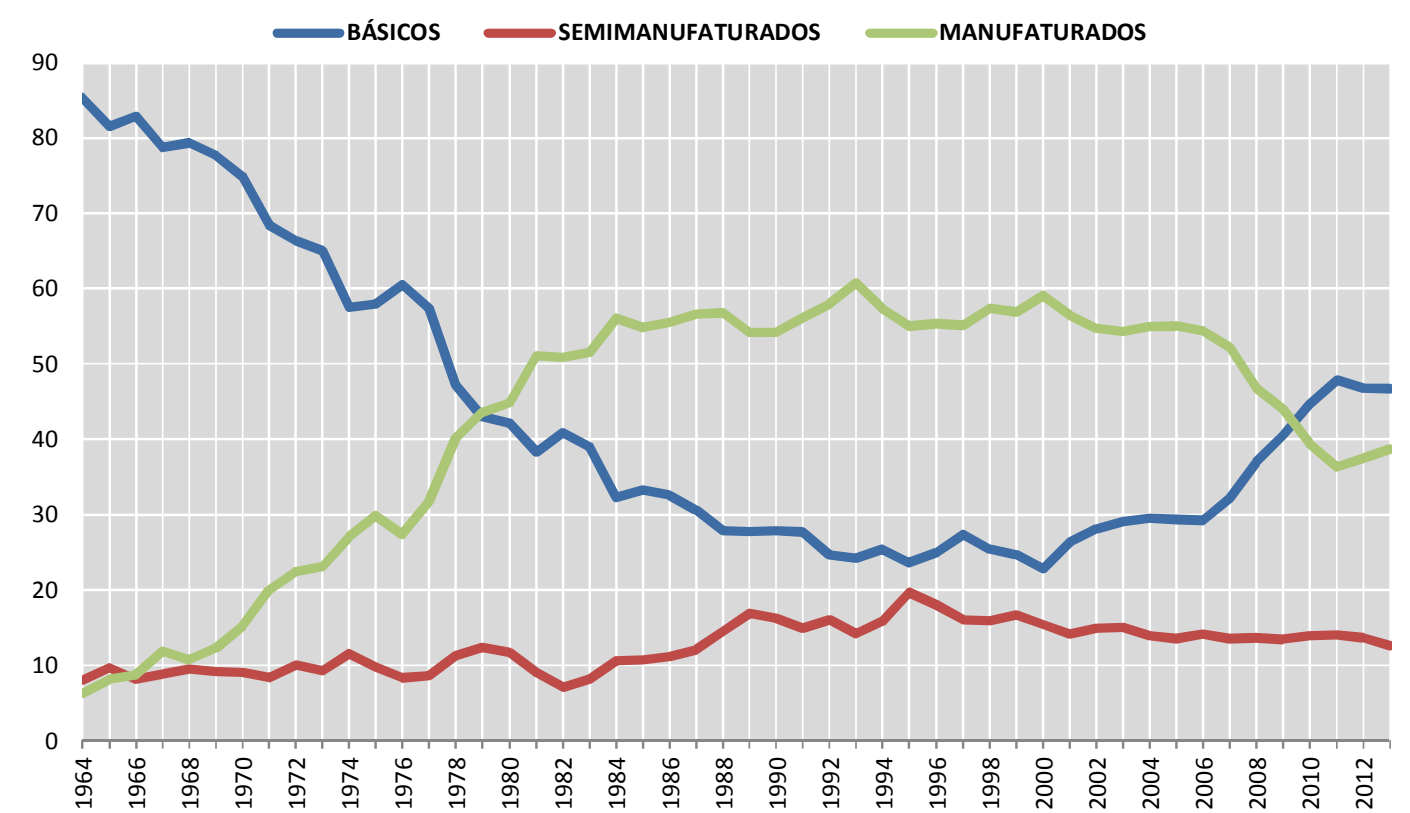

Fonte: MDIC/SECEX 
Conforme Baumann, Canuto e Gonçalves (2004) nota-se que o comércio internacional tem se caracterizado de forma crescente pela participação de produtos industrializados na pauta de exportação, tanto para os países desenvolvidos (superando $80 \%$ em 2000) quanto para os países em desenvolvimento (na faixa de 70\%); apesar de serem números médios, esses números refletem situações individuais de países com graus diferenciados de dependência em relação à exportação de produtos primários.

No Brasil, dados do CEPAL de 2003 indicam que a composição de exportação de produtos industrializados era de 80\% em 1999 e a importação de $86,6 \%$. Há um estudo elaborado pela Louis Berger e Internave para a Companhia Docas do Estado de São Paulo (CODESP) que indicava em 85,6\% a participação relativa das cargas conteinerizada e solta na movimentação de carga geral do porto de Santos entre 1999 - 2008. Fonseca (2013) apresenta a evolução histórica do índice de conteinerização desde 1977, o qual atinge 66\% em 2012, ilustrado na figura 8. Apesar de diferentes fontes e momentos, pode-se ajuizar o índice de conteinerização na faixa de $70 \%$.

Figura 8 - Evolução histórica do índice de conteinerização de 1977 a 2012

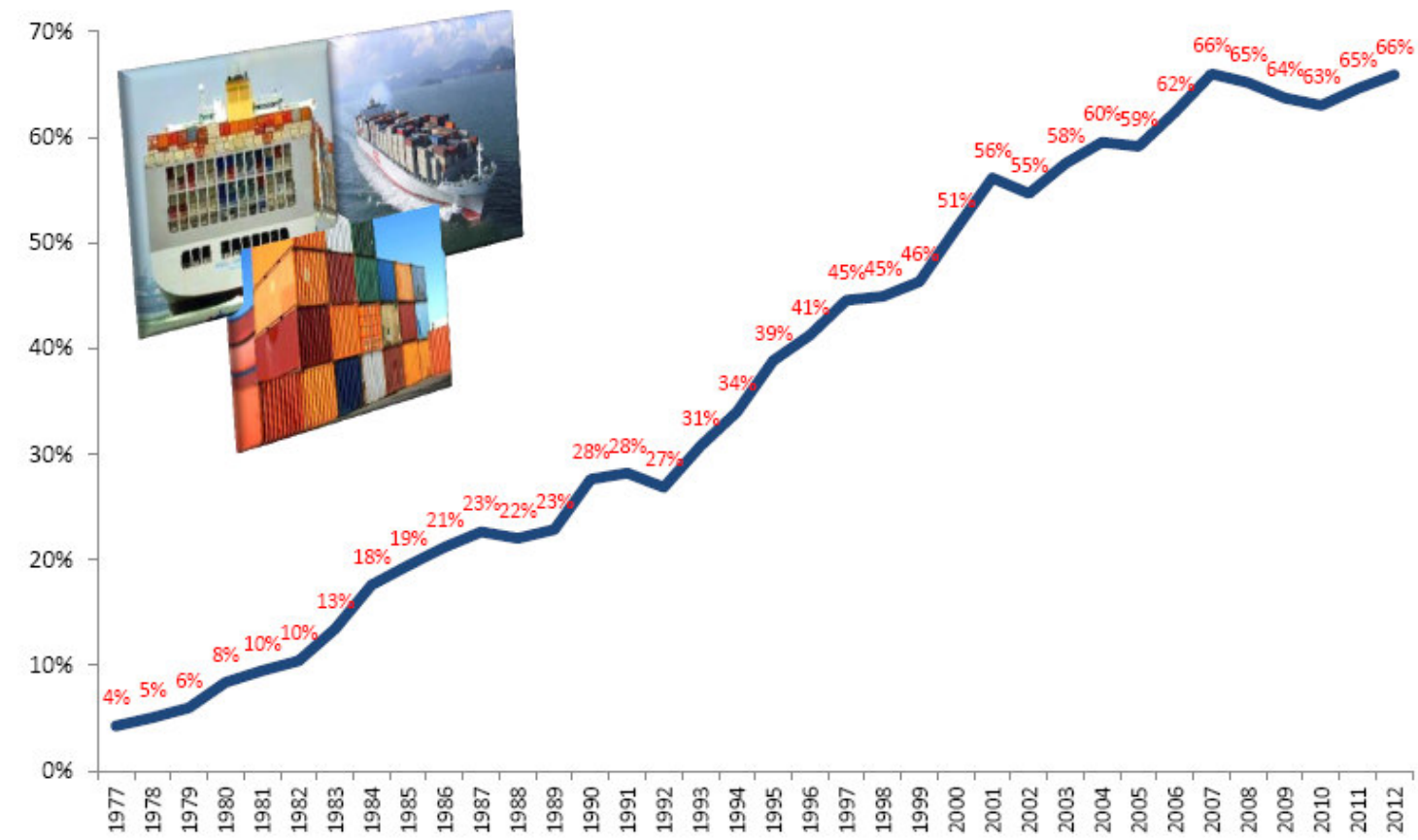

Fonte: ANTAQ - base de dados interna 
Com base no gráfico da figura 8, é possível relacionar o índice de conteinerização com marcos regulatório e início de operação de terminais, como, por exemplo:

- Em agosto de 1981, a inauguração do Terminal de Contêineres da Margem Esquerda do porto de Santos (TECON) que foi o primeiro terminal de contêineres no Brasil (hoje Santos-Brasil, empresa responsável por movimentar aproximadamente $22 \%$ dos contêineres do país.) o índice era de 10\%;

- Em 1988, com a promulgação da Constituição Federal do Brasil que legislava com base nos artigos $21^{\circ}, 22^{\circ} \mathrm{e} 175^{\circ}$ sobre a competência da exploração dos portos, o índice atingira 22\%;

- Com o índice em 31\%, foi sancionada a Lei 8.630 de 1993 ou Lei de modernização dos portos, a qual dispunha sobre o regime jurídico da exploração dos portos organizados e das instalações portuárias;

- Em novembro de 1995, quando o Terminal 37 (T-37) do Grupo Libra inicia as suas operações, o índice era de 41\%. O T37 foi o primeiro terminal privativo pós-lei 8.630/93;

- Em 2001, a criação da Agência Nacional de Transporte Aquaviários (ANTAQ) com base na lei 10.233, com a finalidade de fiscalização e regulação do sistema portuário, o índice supera os 50\%;

- A Secretária Especial de Portos (SEP) criada pela Lei 11.518 de 2007, com a competência para definir políticas, diretrizes e investimentos públicos para os portos encontra o índice em 66\%;

- No final de 2012, inicia-se a discussão da Medida Provisória 595, que em junho de 2013 é convertida na Lei 12.815 que dispõe sobre a exploração direta e indireta pela União de portos e instalações portuárias e sobre as atividades desempenhadas pelos operadores portuários, revogando a lei de 1993. Ainda em 2013, iniciam suas operações os dois maiores projetos de terminais do porto de Santos e do país, a Brasil Terminal Portuário (BTP) e a Embraport, o índice se aproxima da ordem de $70 \%$. 
Essas informações preliminares sobre a economia e comércio exterior brasileiro são importantes para demonstrar o crescimento do valor agregado de nossas exportações com produtos industrializados, mas também a tendência e principalmente o potencial da conteinerização. Como referência, estudo recente do Instituto de Logística e Supply Chain (ILOS), intitulado "Portos 2021 - Avaliação de demanda e capacidade do Segmento Portuário de Contêineres" foi identificado um volume potencial por tipo de carga baseado na Nomenclatura Comum do Mercosul (NCM) que possuem no mínimo $10 \%$ de seu volume transportado em contêineres. A Carga Geral possui $96 \%$ do seu volume já movimentado em contêineres, porém graneis sólidos e líquidos possuem 53\% e 38\% respectivamente contêinerizados, ou seja, ainda há oportunidades; sendo os principais produtos identificados como: açúcar, celulose, suco de laranja, siderúrgicos e fertilizantes.

O Relatório de Competitividade Global 2012/13 do Fórum Econômico Mundial indica que o fim de entraves e remoção de barreiras ao comércio exterior, como a burocracia e a falta de infraestrutura, acrescentaria US\$ 2,6 trilhões de dólares ao PIB Mundial, considerando o PIB Mundial de 2012 de US\$ 71,2 trilhões, isso representa um acréscimo de $3,7 \%$ nas exportações globais. $O$ Brasil teria um aumento de $30 \%$ nas exportações e um acréscimo de 3,6\% no PIB. Contudo, o mesmo estudo aponta um indicador preocupante, a qualidade da infraestrutura portuária brasileira, classificada em $135^{\circ}$ entre 144 países, com 2,6 pontos, quando a média mundial foi de 4,3 pontos. Itens como a dificuldade de acessos (rodoviários e ferroviários) aos portos, profundidade limitada de acesso e berços, somados ao alto tempo médio de espera para atracação dos navios e as baixas disponibilidades de terminais marítimos especializados contribuíram fortemente para essa avaliação negativa do sistema portuário brasileiro.

Quanto à participação do Brasil nas exportações e importações mundiais demonstrados na figura 9, apesar da relativa queda na participação mundial, o gráfico demonstra algo mais importante para as atividades de terminais de contêineres, que é a necessidade constante de planejamento do espaço de pátio em virtude da alternação de perfil exportador para importador, e vice versa, aumentando e/ou diminuindo o chamado "Allotment" (número de posições (slots) no pátio), destinados a um determinado serviço que sofreu acréscimo ou perda de carga ou, ainda, remanejar as janelas de atracação em virtude do aumento da prancha 
média/movimentação de contêineres de uma escala/serviço, ou aumento do porte do navio.

Figura 9 - Participação \% do Brasil nas Exportações e Importações Mundiais

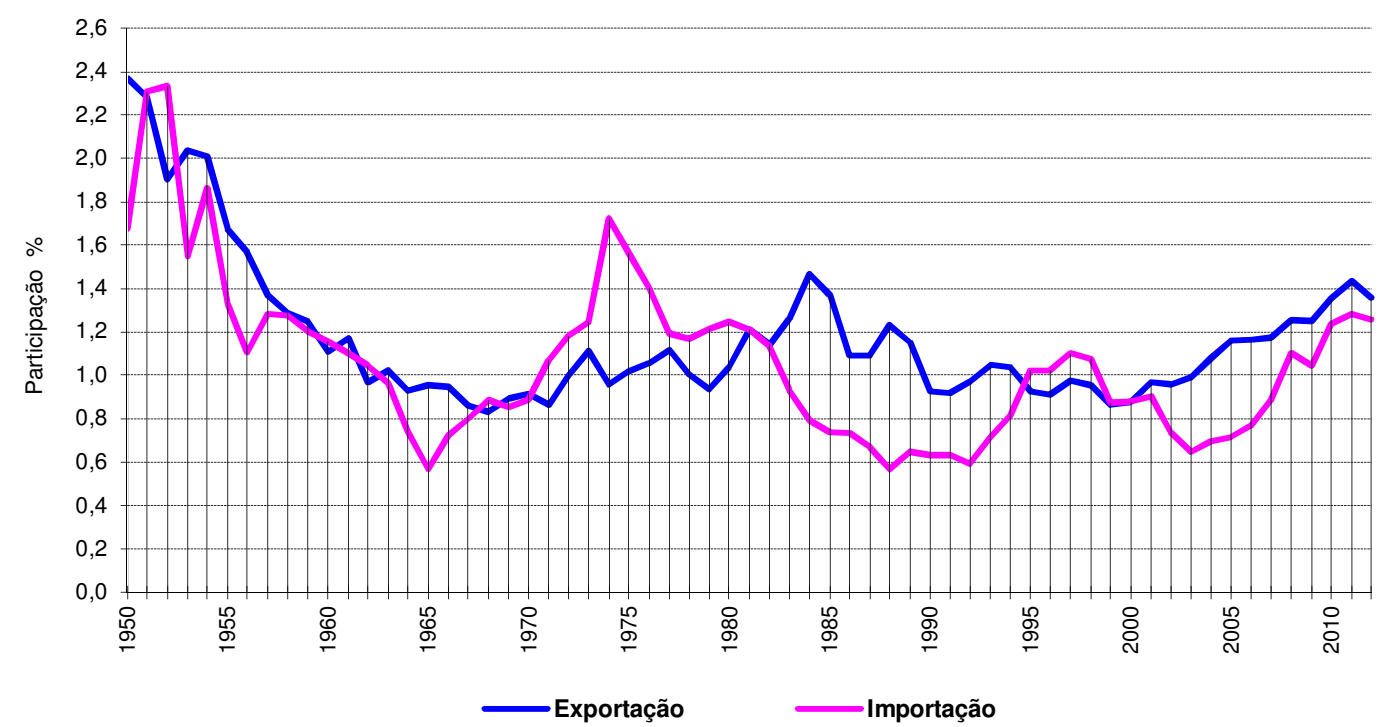

Fonte: SECEX/MDIC

\subsection{EVOLUÇÃO E PERSPECTIVAS DA MOVIMENTAÇÃO DE CONTÊINERES NO MUNDO E NO BRASIL}

Pode-se afirmar, sem medo de errar, que do ponto de vista do comércio mundial e do transporte, nenhuma invenção teve mais impacto do que o contêiner. Levinson (2006) indica que o contêiner tornou o transporte marítimo mais barato e alterou o formato da economia mundial; enquanto Peters (2001) afirma que a indústria de transporte do contêiner auxiliou o processo de globalização facilitando o fluxo de comércio das zonas de produção de baixo custo para os mercados consumidores ao redor do mundo. É difícil indicar exatamente a data da criação do contêiner; Carvalho (2012) indica que a ideia de transportar mercadorias de uma caixa, com a finalidade de facilitar as trocas comerciais, não foi uma inovação; há relatos de 1792 do transporte de caixas na Inglaterra com a finalidade de facilitar a integração entre as carroças e trens; datam de 1911 registros da ideia de unitização de carga em contêineres por meio de um anúncio da revista National Geographic conforme Faria (2000); Indicações de 1920 de contêineres utilizados exclusivamente no transporte ferroviário; na Segunda Guerra Mundial, o governo americano passou 
a utilizar caixas de tamanho padrão com a finalidade de aumentar a velocidade e a eficiência no embarque, descarga e distribuição das cargas.

Em 1937, enquanto aguardava a carga de seu caminhão ser lentamente retirada pelos estivadores, Malcon $P$. McLean, concluiu que a operação seria muito mais rápida se a carreta pudesse ser colocada diretamente sobre o navio; porém, somente no início de 1950, decidiu fazê-lo de forma comercial e, em 1953, desenvolveu planos para transportar caminhões de sua empresa em navios ao longo da costa atlântica dos EUA (Carolina do Norte para Nova lorque), porém os chamados "trailerships" se mostraram ineficientes em virtude do desperdício de espaço de carga potencial a bordo do navio. McLean, então, modificou seu conceito original para carregar apenas os contentores ou baús com as peças, não os chassis completos nos navios. A figura 10 registra em 26 de abril de 1956 o içamento a bordo de 58 contêineres (35') no navio Ideal X atracado no porto de Newark em Nova Jersey, conforme Levinson (2006).

\section{Figura 10 - Contêiner embarcado no navio Ideal X}

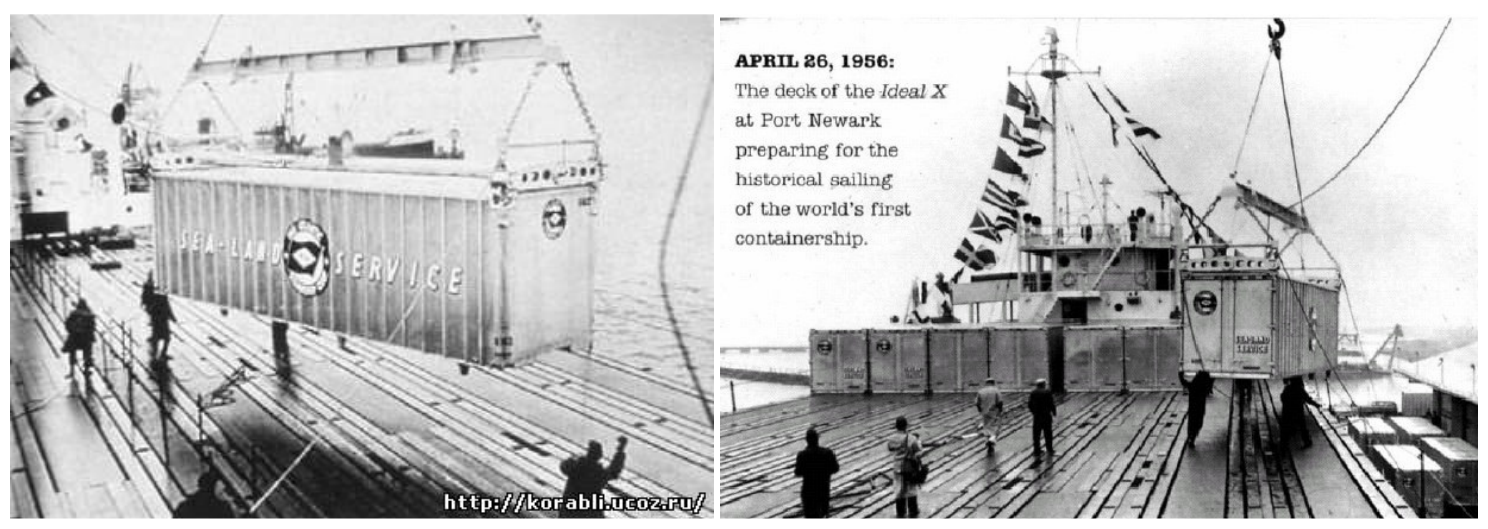

Fonte: www.korably.net

Na década de 1950, os processos de mecanização total passaram a figurar na indústria marítima; contudo, a chamada mecanização nada mais era do que a inclusão de mais guindastes e de correias transportadoras mecânicas e outras formas de usar mais máquinas para mover cargas soltas e uso da paletização.

O conceito de McLean, de automatização na movimentação do contêiner, foi um passo inicial para a revolução do transporte de carga e do que seria a conteinerização na operação portuária. A questão da redução do custo da movimentação é outro fator fundamental da criação do contêiner; em 1956, a maior 
parte da carga nos navios era embarcada e descarregada pelos estivadores de forma manual e, o que custava cerca de US\$ 5,86/tonelada; com o uso dos contêineres, esse custo foi drasticamente reduzido para US\$ 0,16/tonelada. Em 1961, a Organização Internacional para a Padronização ou International Organization for Standardization (ISO) definiu o tamanho padrão de contêineres, sendo que o de 20 pés de comprimento (6 metros) tornou-se o tamanho de referência para toda a indústria marítima.

Não se sabe exatamente o número de contêineres existente no mundo atualmente, mas, de acordo com World Container Census 2012 da Drewry Maritime Container Research, a frota mundial de contêineres cresceu mais de $400 \%$ nos últimos 20 anos, sendo 5,3\% em 2012, o que adiciona mais 1,6 milhões de TEU a um número estimado de 32,9 milhões de unidades.

Figura 11 - Crescimento e Previsão da frota mundial de contêineres de 1990 a 2014

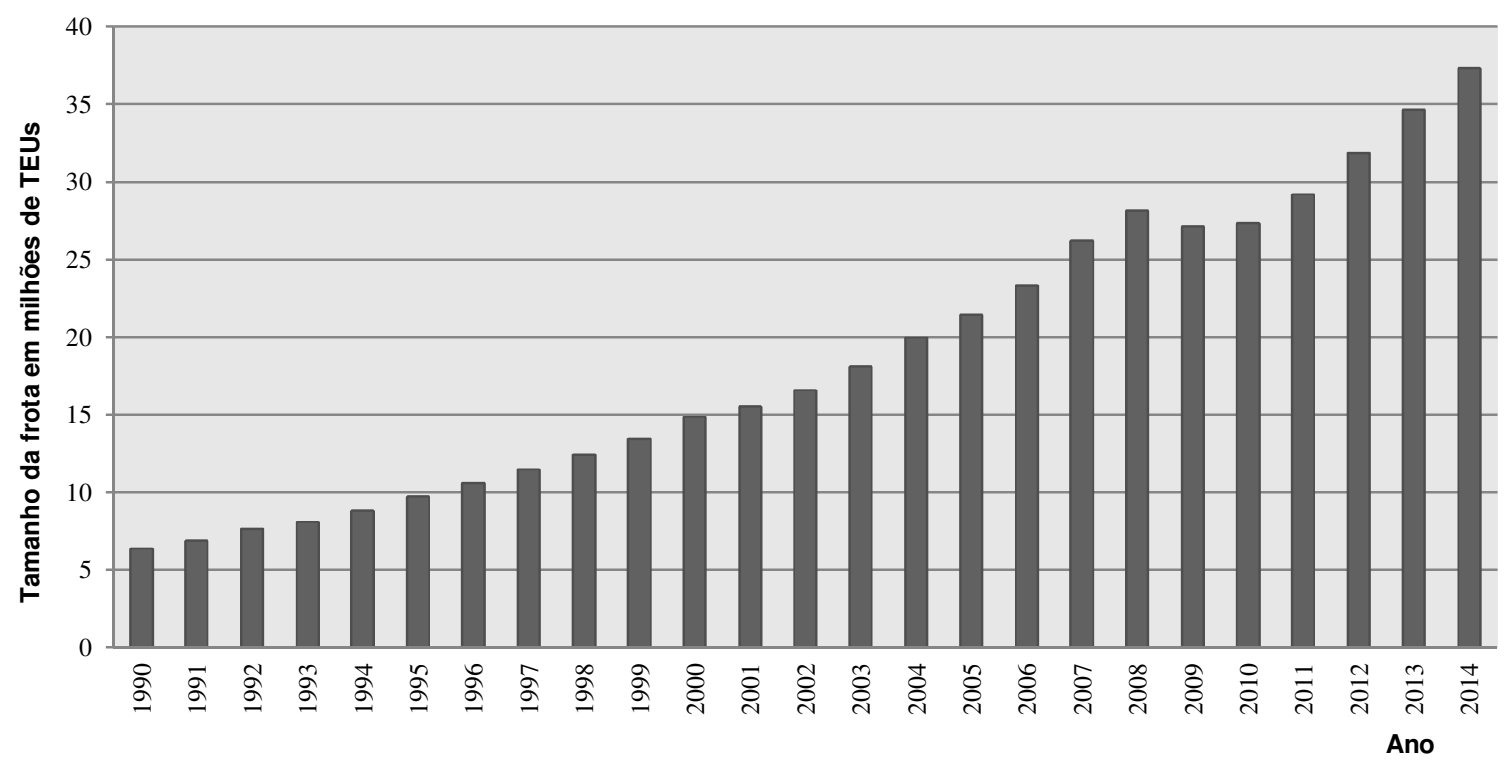

Fonte: World Container Census 2012

Davidson (2014) indica o tamanho da indústria de contêiner global com uma movimentação total de contêineres de aproximadamente 640 milhões de TEUs/ano, mais de 5.000 portêineres ao redor do mundo e cerca de 600 quilômetros de berços, em 700 terminais especializados na movimentação de contêineres e mais outros 600 terminais multi-propósito (multi-purpose) e instalações para operação Roll on Roll off (RO-RO). A estimativa de receita é de US\$ 48 bilhões e EBITDA de US\$11 bilhões (aproximadamente 22\%). 
De acordo com a publicação World Top Container Ports 2013 da "Container Management" (revista especializada do setor de contêineres que publica anualmente os dados de movimentação consolidada dos principais portos mundiais), apenas os 120 primeiros portos no mundo movimentaram em 2012 o volume de aproximadamente 514,2 milhões de TEUs (Twenty Equivalent Units ou Unidade Equivalente de 20'), uma variação de 21,5 milhões de TEUs e $4,38 \%$ superior a 2011. Como referência, apenas os cinco primeiros portos do mundo (Shangai, Cingapura, Hong Kong, Shenzhen e Busan) movimentaram 127,2 milhões de TEUS.

Patricio (2005) indica que a indústria marítima, em especial o mercado de transporte de cargas em contêineres, foi o que mais cresceu e continuará crescendo, principalmente em razão dos seguintes fatores: a contínua expansão da conteinerização nos países desenvolvidos e em desenvolvimento; o aumento do comércio de mercadorias de maior valor agregado e industrializadas; a intensificação do processo de globalização e o crescimento no tamanho dos navios e consequente aumento de transbordo e dos serviços de navios feeder. Contudo, cabe completar com novos fatores tais como: o fato de diversas indústrias multinacionais estarem instaladas no país, o que obriga que o Brasil se integre às cadeias de suprimentos globais; a migração de alguns commodities e produtos básicos para o contêiner; a diversificação de mercados (isto é, produtos e serviços a novos segmentos de mercado não previstos anteriormente) e produtos (adição de novos produtos ou serviços para expansão da oferta de negócios nos mercados já existentes); pulverização dos pontos de entrega; o aumento de terminais especializados no manuseio de contêineres e o aumento da demanda contratada.

Em especial nos países em desenvolvimento, já existe uma demanda contratada. Usando o Brasil como exemplo: grandes eventos esportivos (pontuais, é verdade!) como Copa do Mundo e Jogos Olímpicos; entretanto, há eventos permanentes, como a ascensão das chamadas classes C, D e E, no qual se estima que 13 milhões ascendam à classe $C$ e outros sete milhões alcançaram as classes $A$ e $\mathrm{B}$ nos próximos anos; aumento do poder aquisitivo devido à estabilidade econômica; à questão do pré-sal e cadeia de suprimentos do setor; ao investimento em infraestrutura seja com base na iniciativa privada ou nos Programas de Aceleração do Crescimento (PAC), foram investidos no PAC 1 de acordo com a Casa Civil da Presidência da República entre 2007 e 2010 cerca de $R \$$ 657,4 
bilhões e no PAC 2 entre 2011 e 2014 está previsto R\$ 955 bilhões e outros R\$ 631,4 bilhões após 2014 .

Observando o gráfico da figura 12, verifica-se o crescimento do Comércio Exterior do Brasil e movimentação de contêineres no país versus o PIB brasileiro; nota-se que o a movimentação de contêineres no país cresceu de forma superior ao PIB e ao próprio Comércio Exterior. Na figura 13 é apresentada a evolução da movimentação de contêineres em unidades dos portos brasileiros entre 2000 a 2013, assim como a evolução percentual de crescimento anual.

Figura 12 - Crescimento do Comércio Exterior e Movimentação de contêineres no Brasil versus PIB Brasil (base 100=1996)

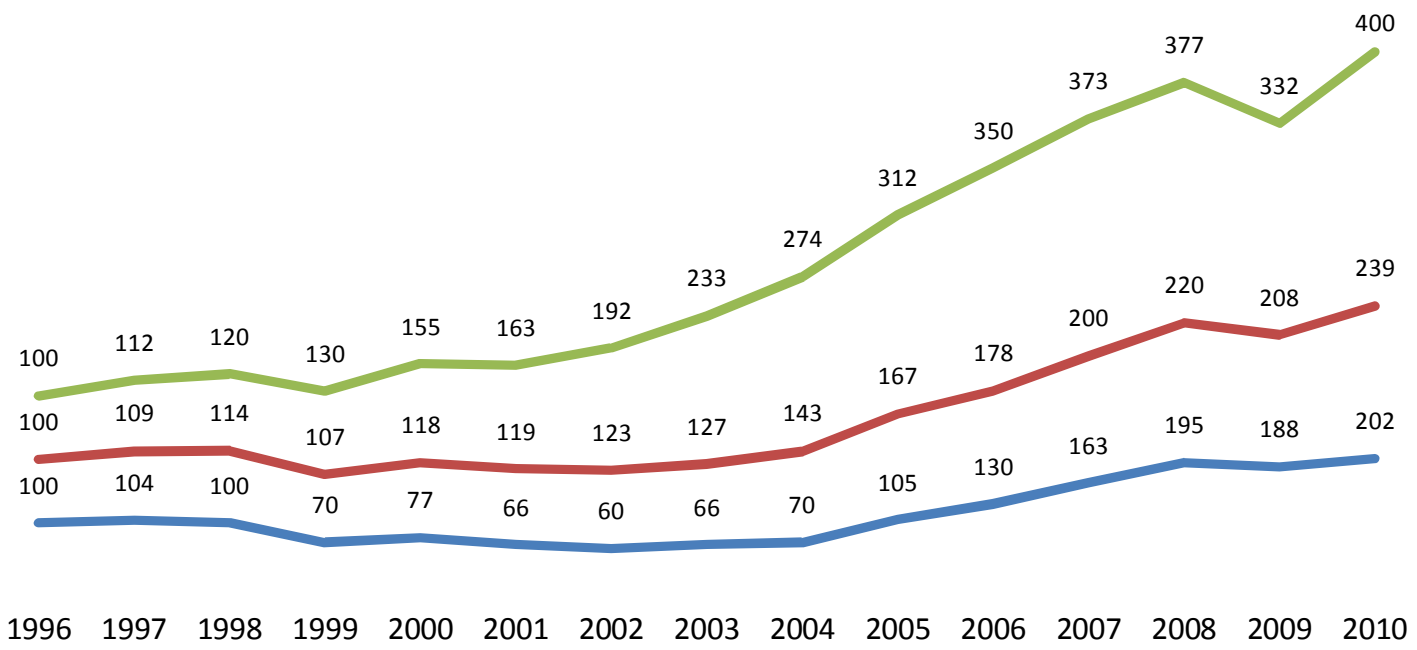

$\longrightarrow$ PIB Comercio Exterior Brasileiro $\longrightarrow$ Movimentação de Contêineres

Fonte: Apresentação do Grupo Libra no CHT 2012

Figura 13 - Evolução da movimentação de contêineres dos portos brasileiros (em unidades)

\begin{tabular}{|c|c|c|c|c|c|c|c|c|c|c|c|c|c|c|}
\hline Porto & 2000 & 2001 & 2002 & 2003 & 2004 & 2005 & 2006 & 2007 & 2008 & 2009 & 2010 & 2011 & 2012 & 2013 \\
\hline Santos & 772.760 & 713.740 & 836.511 & 1.037 .271 & 1.247 .112 & 1.478 .428 & 1.603 .868 & 1.654 .713 & 1.743 .412 & 1.469 .151 & 1.762 .205 & 1.915 .292 & 2.013 .922 & 2.177 .307 \\
\hline Itajai & 103.626 & 142.191 & 192.506 & 268.160 & 318.240 & 364.883 & 472.417 & 390.394 & 396.287 & 346.479 & 565.017 & 594.486 & 616.580 & 670.988 \\
\hline Rio Grande & 193.764 & 220.571 & 272.904 & 324.015 & 350.646 & 374.190 & 369.362 & 388.320 & 372.811 & 394.005 & 408.835 & 395.218 & 388.904 & 400.677 \\
\hline Paranagua & 146.933 & 166.841 & 156.046 & 182.648 & 224.969 & 245.669 & 296.919 & 348.000 & 356.577 & 367.798 & 399.590 & 313.245 & 452.753 & 452.872 \\
\hline Rio de Janeiro & 170.337 & 187.352 & 200.516 & 235.969 & 255.723 & 236.505 & 260.232 & 290.575 & 289.059 & 244.536 & 299.623 & 321.160 & 352.626 & 349.201 \\
\hline Itaguai & 2.503 & 10.864 & 12.994 & 7.644 & 89.665 & 126.094 & 194.867 & 174.865 & 213.272 & 154.289 & 196.267 & 216.420 & 216.460 & 257.045 \\
\hline Vitoria & 68.043 & 69.128 & 99.511 & 123.259 & 157.208 & 175.051 & 197.903 & 207.234 & 197.773 & 165.420 & 184.737 & 204.393 & 193.478 & 208.254 \\
\hline São Francis & 110.286 & 112.658 & 159.986 & 173.121 & 168.410 & 146.414 & 128.772 & 201.500 & 175.288 & 152.478 & 118.802 & 177.112 & 281.832 & 333.150 \\
\hline Salvador & 63.031 & 68.005 & 87.446 & 108.012 & 121.788 & 141.267 & 163.834 & 165.715 & 150.497 & 144.263 & 186.283 & 167.286 & 174.487 & 186.415 \\
\hline Manuas & 53.475 & 64.035 & 76.497 & 66.491 & 64.146 & 130.000 & 143.093 & 174.570 & 189.330 & 190.000 & 238.646 & 393.065 & 297.059 & 325.662 \\
\hline Suape & 42.172 & 47.767 & 69.555 & 37.303 & 87.263 & 111.668 & 128.237 & 163.500 & 201.562 & 167.870 & 226.538 & 284.124 & 265.415 & 269.405 \\
\hline Pecém & 0 & 0 & 12.265 & 7.311 & 46.067 & 57.812 & 70.627 & 77.689 & 60.575 & 88.301 & 111.334 & 120.788 & 103.448 & 93.485 \\
\hline Fortaleza & 46.886 & 56.170 & 47.537 & 53.202 & 59.343 & 46.326 & 44.408 & 80.689 & 41.201 & 33.000 & 46.855 & 46.514 & 50.242 & 54.802 \\
\hline Belem & 29.463 & 28.762 & 32.768 & 29.958 & 52.337 & 30.946 & 32.463 & 43.465 & 27.479 & 18.363 & 22.377 & 17.787 & 13.355 & 0 \\
\hline Vila do Conde & 0 & 0 & 0 & 1.834 & 9.530 & 20.668 & 19.363 & 17.690 & 14.498 & 17.605 & 21.527 & 20.756 & 22.494 & 24.155 \\
\hline imbituba & 0 & 0 & 0 & 0 & 0 & 0 & 0 & 0 & 0 & 0 & 0 & 0 & 0 & 11.462 \\
\hline Outros & 54.450 & 63.947 & 44.798 & 90.486 & 32.855 & 49.498 & 63.823 & 88.205 & 89.213 & 28.620 & 23.438 & 28.573 & 32.078 & 41.079 \\
\hline \multirow[t]{2}{*}{ Brasil } & 1.857 .729 & 1.952 .031 & 2.301 .840 & 2.786 .684 & 3.285 .302 & 3.735 .419 & 4.190 .188 & 4.467.124 & 4.518 .834 & 3.982 .178 & 4.812 .074 & 5.216 .219 & 5.475 .133 & 5.855 .959 \\
\hline & $16,10 \%$ & $5,08 \%$ & $17,92 \%$ & $21,06 \%$ & $17,89 \%$ & $13,70 \%$ & $12,17 \%$ & $6,61 \%$ & $1,16 \%$ & $-11,88 \%$ & $20,84 \%$ & $8,40 \%$ & $4,96 \%$ & $6,96 \%$ \\
\hline
\end{tabular}


Observa-se que o crescimento médio do volume de contêineres no Brasil ao ano foi de $10,1 \%$, mesmo considerando os anos de desaceleração pela crise financeira de 2008 e 2009; descartando-se apenas o ano de 2009, esse indicador sobe para $12,0 \%$. O crescimento anualizado da movimentação somado supera 150\% nos últimos 13 anos; no mesmo período de acordo com a Associação Brasileira dos Terminais de Contêineres de Uso Público (ABRATEC) foram realizados investimentos em obras civis, aquisição de equipamentos de movimentação e treinamento e especialização da mão de obra da ordem de US\$2,8 bilhões. Adicionando os investimentos realizados pelos terminais da EMBRAPORT e BTP que não são associadas à ABRATEC, esse número se aproxima de US\$ 5 bilhões. Como referência, o PIB brasileiro cresceu no mesmo período 3,5\%, com o maior índice atingindo 7,5\% em 2010, e o menor em 2009 com -0,3\%.

Nota-se, no gráfico da figura 14, que a maioria dos portos brasileiros encontra-se abaixo da faixa de 500.000 mil unidades de movimentação anual; exceção apenas dos portos de Santos com 2,1 milhões e Itajaí (somado o volume de Navegantes) com 670 mil unidades.

Figura 14 - Gráfico da evolução da movimentação de contêineres dos portos brasileiros (em unidades)

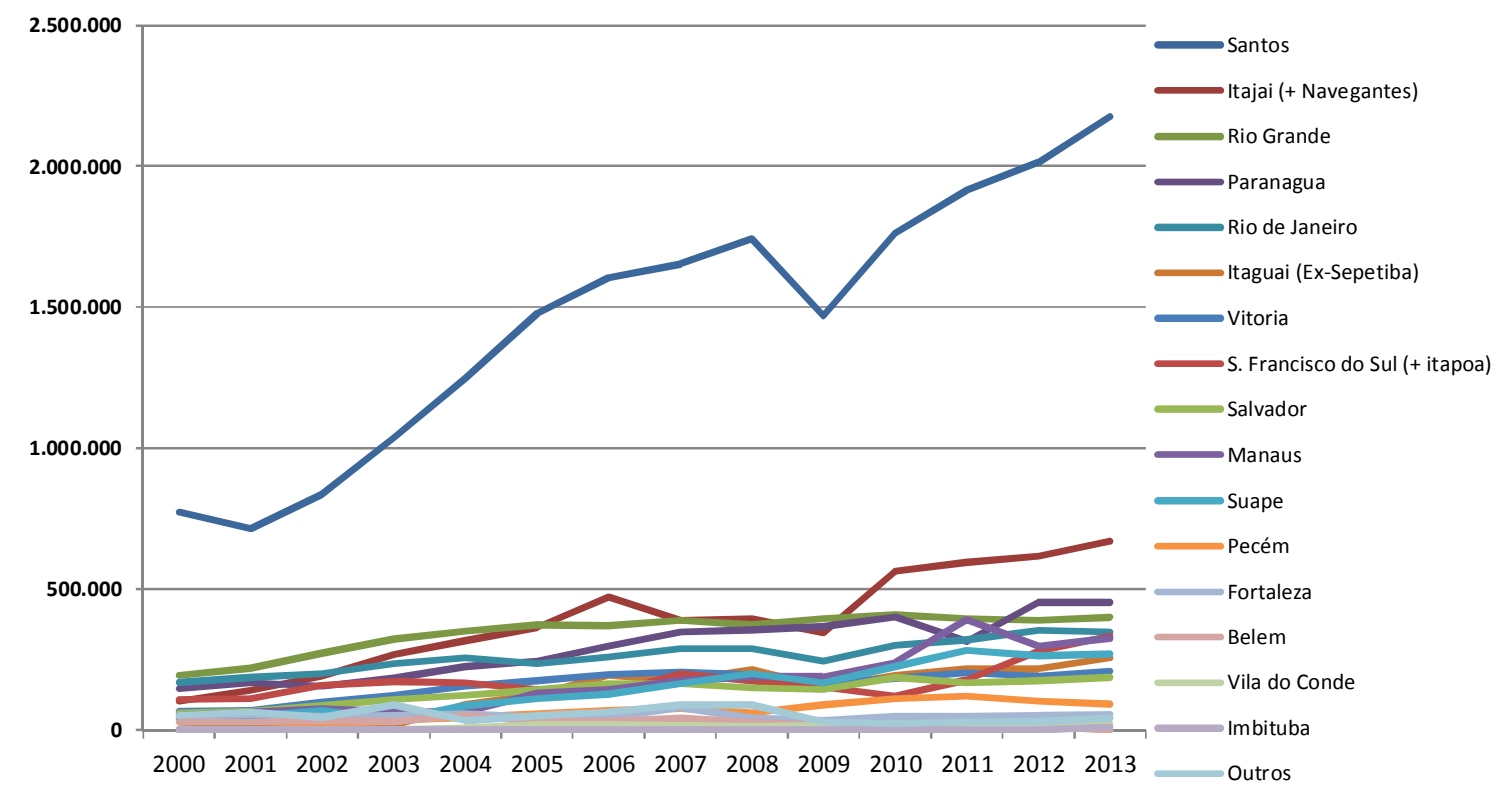

Fonte: Elaborado pelo autor com dados da ABRATEC 
Entretanto, é emblemático o crescimento da movimentação nos diversos portos listados nas figuras 13 e 14; em praticamente uma década, os portos de Rio Grande e Rio de Janeiro dobraram a sua movimentação, os portos de Santos, Paranaguá, Salvador, Vitória e São Francisco do Sul (adicionada à movimentação de Itapoá) tiveram as suas movimentações triplicadas; enquanto Suape, Manaus e Itajaí (somado o volume de Navegantes, do terminal da Portonave) sextuplicaram seus volumes. E há casos especiais como Pecém e Itaguaí (antigo porto de Sepetiba) que praticamente não existiam 10 anos atrás e operações incipiente em Vila do Conde e Imbituba.

A evolução do crescimento da movimentação geral dos portos brasileiros em milhões de toneladas e TEUs é ilustrada na figura 15. A relação entre os contêineres de 40' (12 metros) e de 20' (6 metros), o chamado "fator TEU" tem sido historicamente de 1,5. No ano de 2012 foram movimentados 5,47 milhões de unidades que multiplicadas por 1,5 atingem os 8,2 milhões de TEUs. Esse fator varia conforme o trafego ou serviço, por exemplo: os navios que escalam Costa Oeste Americana e Extremo Oriente possuem uma parcela maior em contêineres de 40'; ou no caso dos contêineres do tipo refrigerado, os quais são na sua totalidade de 12 metros. Em 2013, a movimentação atingiu 5,8 milhões de unidades, o equivalente a 8,7 milhões de TEUs.

Figura 15 - Crescimento da movimentação de contêineres no Brasil em milhões de toneladas e TEUS

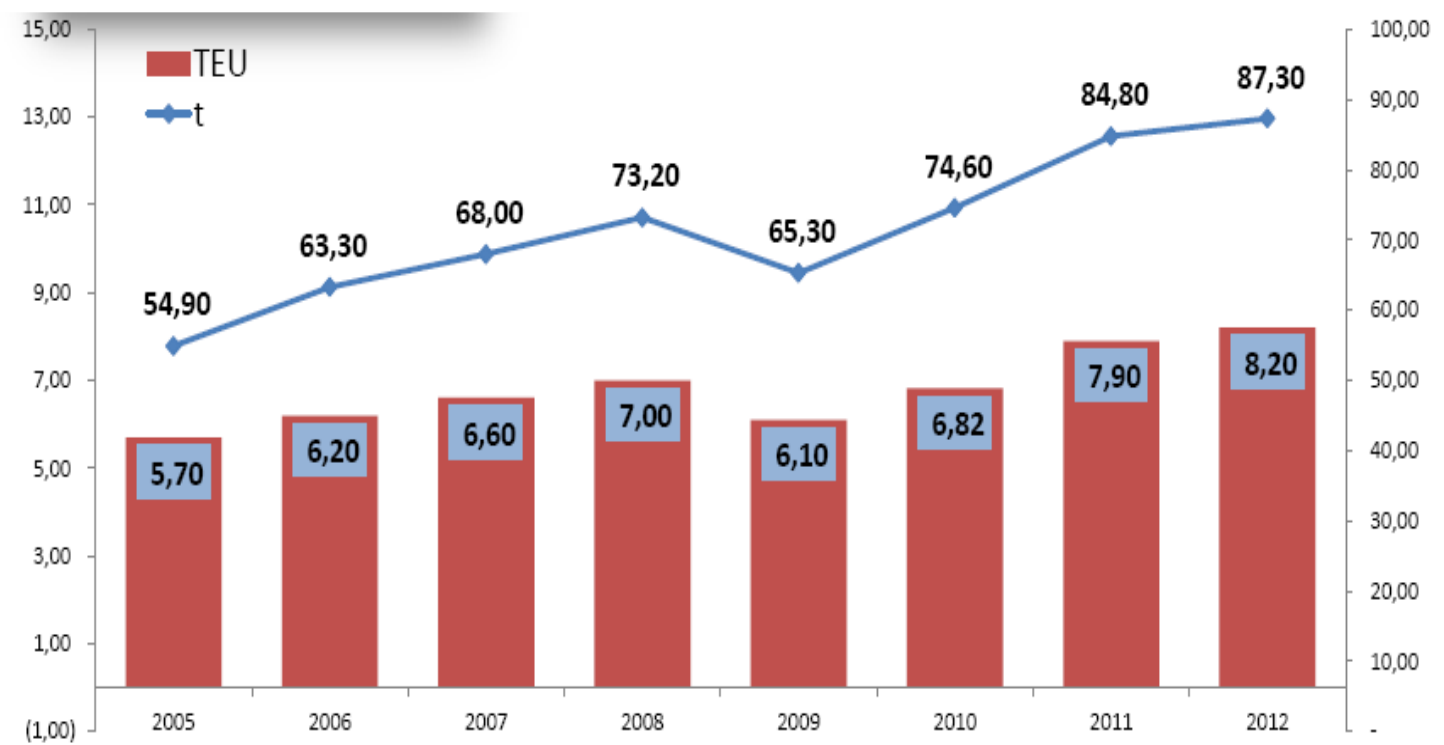

Fonte: Anuário Estatístico 2012 da ANTAQ 
De acordo a ANTAQ, foram movimentados pelos Portos e Terminais de Uso Privado (TUP) 904 milhões de toneladas, sendo 588 milhões de toneladas escoados por meio dos TUPs, isto é, 65\% e 316 milhões por portos, o equivalente a 35\%.

$\mathrm{Na}$ figura 16 verifica-se que durante os últimos 30 anos o mercado global de contêineres cresceu em média na faixa entre $5 \%$ a $10 \%$ anuais e em 15 oportunidades esses valores ultrapassaram os 10\%; exceções apenas em 4 anos, a saber: 1982 que o crescimento foi de 4,6\% e em 2009, ano da crise financeira global durante a qual o mundo amargou uma queda próxima de $10 \%$, esse foi o único número indicador negativo entre 1980 e 2013 e, a partir de 2012, quando se estabelece um novo panorama e regras globais.

Figura 16 - Evolução histórica do crescimento mundial de movimentação de contêineres

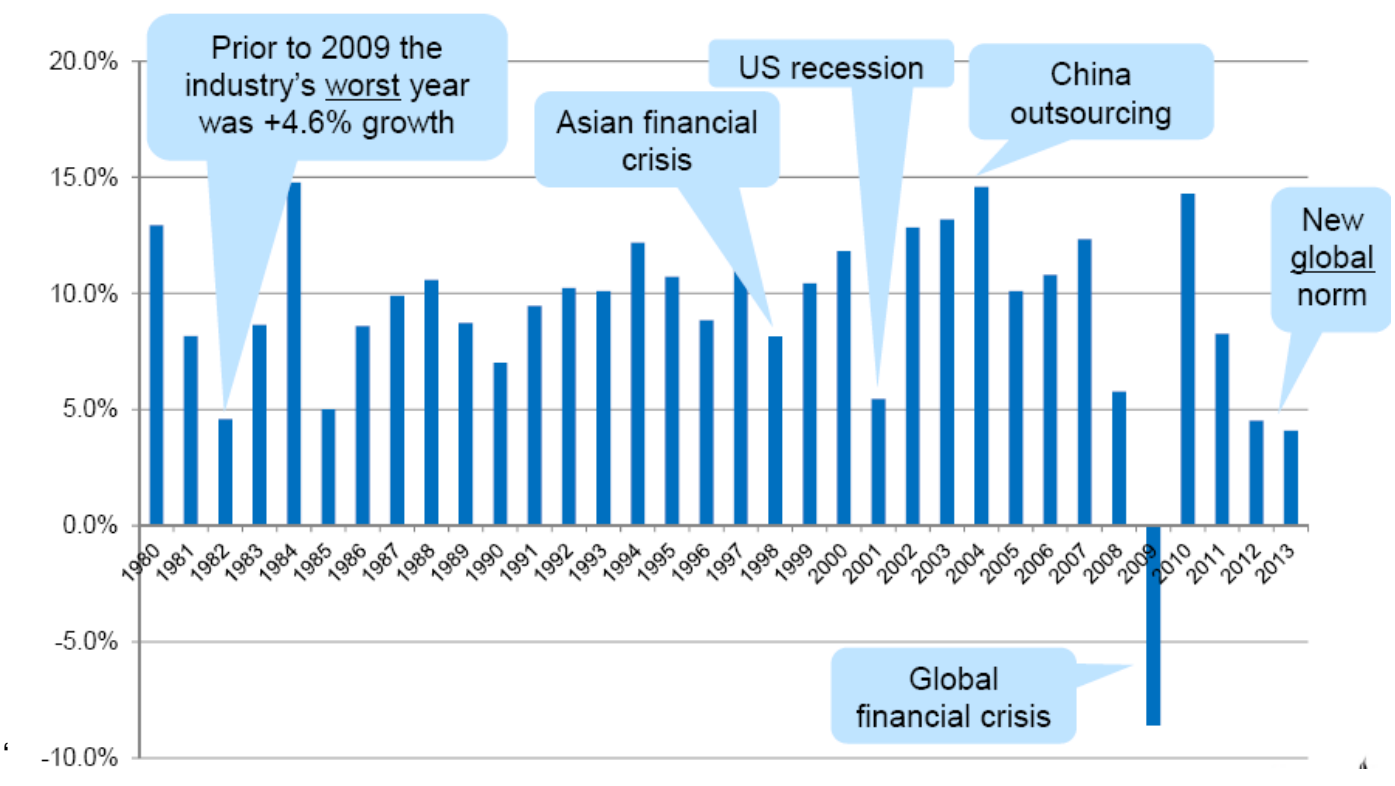

Fonte: Drewry Maritime Advisors

Na sequência, a figura 17 apresenta as projeções de crescimento por região até 2017, na qual se prevê que o mundo continue crescendo ao ritmo de $5 \%$, com destaque para o Leste Europeu com número próximo a 8\%, seguidos do Extremo Oriente, da América Latina e África com índices de 6\%. Coincidentemente, essas regiões são as mesmas dos países que formam o chamado BRICS. 
Figura 17 - Projeções de Crescimento em percentual por região até 2017

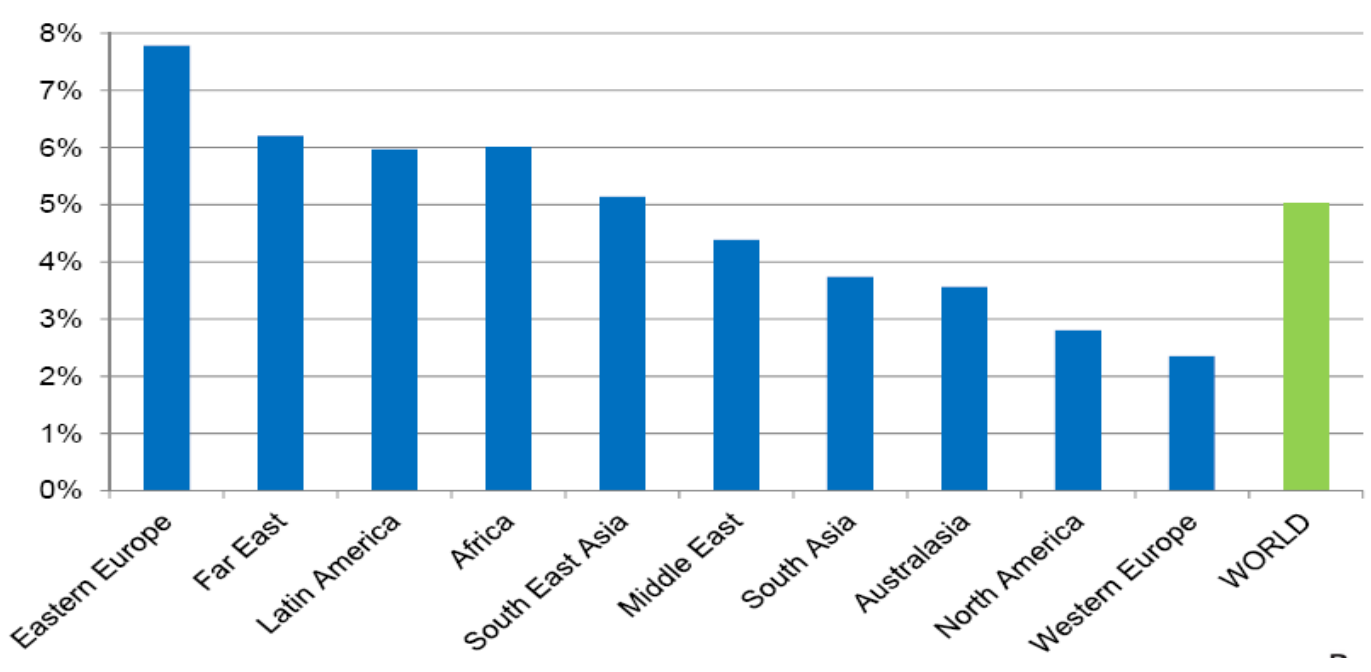

Fonte: Drewry Maritime Advisors

Mudando do universo de projeções para mundo de números reais de 2012, o ranking dos 120 principais portos na movimentação de contêineres listados na figura 18; o porto de Santos, o primeiro porto brasileiro aparece na 42a posição; o outro porto brasileiro que aparece nessa lista é o porto de Itajaí (e Navegantes) na $108^{\circ}$ posição.

Desponta nessa lista o fato de nove dos dez primeiros portos no mundo serem da região do Extremo Oriente (China, Coreia e Cingapura) sendo eles: Shanghai, Cingapura, Hong Kong, Shenzhen, Busan, Ningbo-Zhoushan, Guangzhou, Qingdao e Tianjai, todos com movimentações superiores a 12 milhões de TEUs. Conforme relatado anteriormente, todos os portos brasileiros juntos movimentaram 8,7 milhões de TEUs em 2013. Nota-se, ainda, que sete dos nove portos listados anteriormente são chineses; destacando o crescimento de três outros portos chineses, Dailan (17a posição) com $27 \%$ de expansão e movimentação de ordem de 8 milhões de TEUs, e Yingkou (27a posição) com 20\% com 4,8 milhões de TEUs e Taicang (34a posição) com 31\% e 4 milhões de TEUs.

O primeiro porto europeu e americano que aparecem na lista são: Roterdã, na 11a posição próximos dos 12 milhões de TEUs, e Los Angeles, na 16a posição com 8 milhões de TEUs. Enquanto os primeiros portos da América Latina aparecem na 40a e 41ạ posição, ambos no Panamá, sendo o porto de Colon e Balboa respectivamente, com movimentação na ordem 3,5 milhões de TEUs. 
Os destaques negativos ficam por conta de Port Said no Egito que perdeu 10 posições, com uma redução de $16 \%$ de volume, o que corresponde a 675.303 TEUs no ranking de 2011 para 2012, em virtude da crise política que enfrenta, a qual acaba refletindo na economia do país. E do porto de Hong Kong que perdeu 1,3 milhão de TEUs ou uma redução de $5 \%$ de sua movimentação, essa em virtude da acirrada competição entre os portos da região.

Figura 18 - Lista dos 42 maiores portos do mundo na movimentação de contêineres

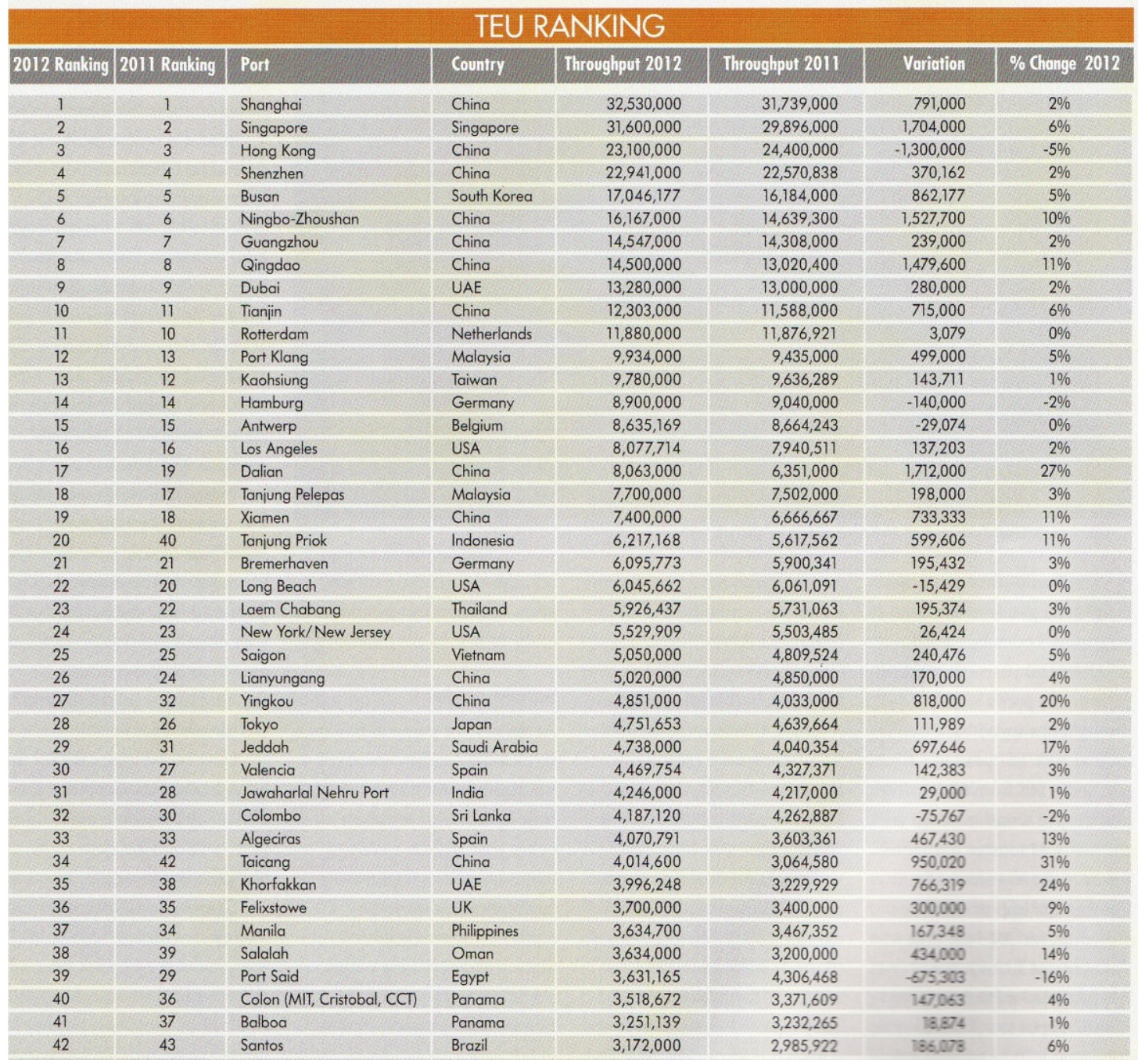

Fonte: World Top Container Ports 2013 - Container Management

O relatório anual "Global Container Terminal Operators 2012" da Drewry Maritime Research estima que metade dos terminais de contêineres do mundo movimenta menos de 100.000 TEUS/ano e estes estão sob gestão do setor público; embora, significativamente, menos de $20 \%$ possua capacidade superior a 500.000 
TEUS/ano. Esse mesmo relatório indica que 22,6\% da movimentação mundial é realizada pelo setor publico; ficando $77,4 \%$ do volume restante operado pelo setor privado. A Drewry faz uma divisão da parte privada entre o que operadores globais ou internacionais e operadores privativos. Dessa forma, têm-se 50,2\% da movimentação de contêineres operados pelos chamados operadores globais; $24,2 \%$ pelos operadores privativos e há, ainda, aproximadamente $3 \%$ movimentados por uma categoria intitulada "outros", cujo controle não é claro.

A tabela 4 apresenta o ranking dos principais operadores globais com suas respectivas movimentações e parcela do mercado mundial.

Tabela 4 - Volumes e parcela de mercado dos principais Operadores Globais de contêineres

\begin{tabular}{c|lcc}
\hline Ranking & \multicolumn{1}{|c}{ Operador Global } & $\begin{array}{c}\text { Movimentação em } \\
\text { milhões de TEUs }\end{array}$ & Parcela \% \\
\hline 1 & Hutchison Port Holdings & 71,8 & 12,2 \\
2 & APM Terminals & 63,7 & 10,8 \\
3 & PSA International & 57,1 & 9,7 \\
4 & DP World & 54,1 & 9,2 \\
5 & COSCO Group & 53,2 & 9,0 \\
6 & Terminal Investment Limited & 23,1 & 3,9 \\
7 & China Shipping Terminal & 18,8 & 3,2 \\
& Development & & \\
8 & Eurogate & 12,9 & 2,2 \\
9 & Hanjin & 10,0 & 1,7 \\
10 & SSA Marine/Carrix & 9,7 & 1,6 \\
11 & Evergreen & 9,1 & 1,5 \\
12 & CMA/CGM Link & 8,1 & 1,4 \\
13 & HHLA & 7,1 & 1,2 \\
14 & NYK & 6,6 & 1,1 \\
15 & APL/NOL & 6,3 & 1,1 \\
16 & Yang Ming & 5,9 & 1,0 \\
17 & OOCL & 5,6 & 1,0 \\
18 & ICTSI & 5,2 & 0,9 \\
19 & K Line & 4,5 & 0,8 \\
20 & MOL & 3,4 & 0,6 \\
21 & Hyundai & 2,7 & 0,5 \\
22 & Grup TCB & 2,6 & 0,4 \\
\hline
\end{tabular}

Fonte: Drewry Shipping Consultants

Alguns desses operadores globais estão presentes em terminais no país, tais como: o ICTSI no Terminal de Contêineres de Suape, o Grup TCB no Terminal de Contêineres de Paranaguá (TCP), a APMT em Pecém e Itajaí, a TIL na Portonave em Navegantes e ambas mais recentemente em Santos na BTP; assim como a 
DPW no terminal da Embraport. Os demais operadores de terminais de contêineres no Brasil são empresas ou grupos brasileiros, como o Grupo Libra (grupo controlado pela família Torrealba) que opera o Terminal 37 em Santos e T1-Rio de Janeiro; o Grupo Batistella e a LogZ em Itapoá com participação da Aliança, Grupo Ecorodovias no Ecoporto (antigo TECONDI), o Grupo Wilson Sons (grupo de investidores liderados pela família Salomon) nos terminais de Rio Grande e Salvador e a MultiTerminais nos terminais em Santos e Rio de Janeiro. Há também a forte presença de privates equits na composição acionária dos terminais, tais como o Advent Internacional em Paranaguá e o Grupo Oppportunity (por meio de International Market Investments C.V) no terminal da Santos-Brasil, entre outros.

Baseado no crescimento apresentado da economia, do comércio internacional e da conteinerização em um cenário de rápidas mudanças e de obsolescência, os terminais precisam de adequação; ou melhor, de readequação permanente. Thomas (2001) explica que a indústria marítima já sofreu diversas adequações quando: os armadores alteraram o transporte regular de longo curso com a formação de alianças e aquisições; quando realizou alteração na rotação de navios e portos de escala; com o crescimento dos navios; com o surgimento de novos equipamentos de movimentação e operação e, consequentemente, alteração nos terminais, nas práticas comerciais e procedimentos alfandegários, em virtude de novos sistemas de Tecnologia da Informação e Comunicação; com novos aspectos laborais e de segurança no trabalho; quesitos de meio-ambiente; de segurança da carga e cadeia segura e implantação do Código de Proteção de Embarcações e Instalações Portuárias, mas conhecido como ISPS Code; e completando, inserção da automação.

\subsection{READEQUAÇÕES PERMANENTES DOS TERMINAIS DE CONTÊINERES E DA INDÚSTRIA MARÍTIMA}

Os primeiros contêineres movimentados na América do Sul ocorreram no porto de Santos em 1966, dois contêineres foram descarregados para testes pela empresa Moore McComark Lines e foram movimentados por uma cábrea (guindaste flutuante para cargas pesadas) pela inexistência de equipamentos e terminais apropriados de acordo com Machado (2012). Essa situação estendeu-se durante toda a década de 70 no porto santista e no país, pois conforme citado anteriormente, 
o primeiro terminal especializado de contêineres no Brasil foi inaugurado somente em agosto de 1981, com a operação de 93 contêineres do navio Calandrini do Lloyd Brasileiro. A figura 19 ilustra o terminal a época.

Figura 19 -Terminal de Contêineres da Margem Esquerda do Porto de Santos (TECON)

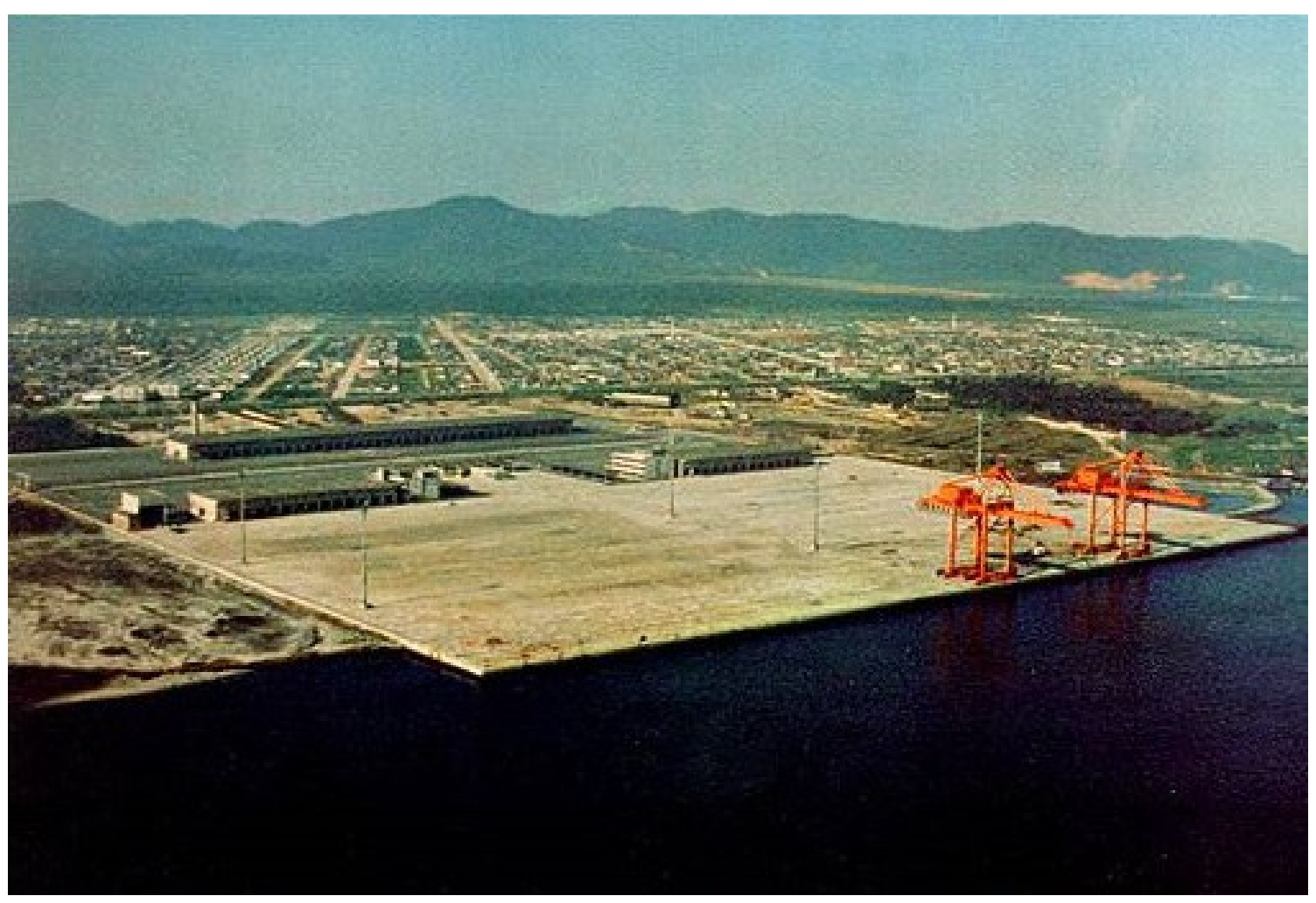

Fonte: http://www.novomilenio.inf.br/santos/

Sobre a infraestrutura implantada para conteinerização no Brasil, Robinson (1985) afirmou que essa nascera "inadequada e deficiente" para atendimento das exigências dos armadores. Passadas quase três décadas, Salgado (2012) discorreu no $1^{0}$ fórum de contêineres sobre a questão da "adequação permanente" dos terminais e demonstra como a atividade portuária é de capital-intensiva e que a infraestrutura e equipamentos ensejam altos custos fixos. Ele apresentou os seguintes desafios:

- Economias de escala, por meio das quais o custo unitário será reduzido na proporção do número de contêineres movimentados, amortizando os altos custos fixos num volume maior de contêineres movimentados;

- Economias de escopo, isto é, o custo de produção unitário será reduzido quando o serviço é prestado em conjunto com outro, de forma que a 
oferta de um mitigue o custo do outro (trade-offs ou compensação de custos);

- Economias de densidade, por meio de ganhos econômicos decorrentes da agregação de consumidores vis à vis ao fator tempo. Na atividade portuária, há um ganho crescente de produtividade verificado quanto maior for o numero de berços de um mesmo terminal, pois menor será a ociosidade de cada berço e mais fácil será a distribuição, no tempo, dos navios por berço.

Além desses desafios, Salgado (2012) apresentou parâmetros físicos que determinam a capacidade de um terminal de contêineres, a saber: Capacidade de atendimento dos "gates", Capacidade de "pátio" e Capacidade de operações de carga e descarga dos "berços".

Esses parâmetros de capacidade citados anteriormente são os mesmos que compõem uma estrutura clássica ou tradicional de terminal, retratados por diversos autores, como Casaca (2005) que descreve uma estrutura abrangente de terminal portuária como subsistemas de portões (Gates) de acesso rodoviário e ferroviário, pátios de armazenagem e berços ou Steenken; Voß e Stahlbock (2004), que de forma mais detalhada define um terminal de contêineres como um sistema aberto identificado por meio de três subsistemas ou áreas de operações (área de operações intermodal de caminhões e vagões, área de armazenagem de contêineres e área de operações de navios), e com duas interfaces externas, sendo a primeira a interface de operações de costado com as operações de embarque e descarga dos navios e, a segunda, uma interface das operações de retaguarda de recebimento e entrega de contêineres de/para caminhões e vagões. A figura 20 representa essa abordagem sistêmica. 
Figura 20 - Abordagem Sistêmica de um terminal de contêineres conforme Steenken,; Voß e Stahlbock (2004)

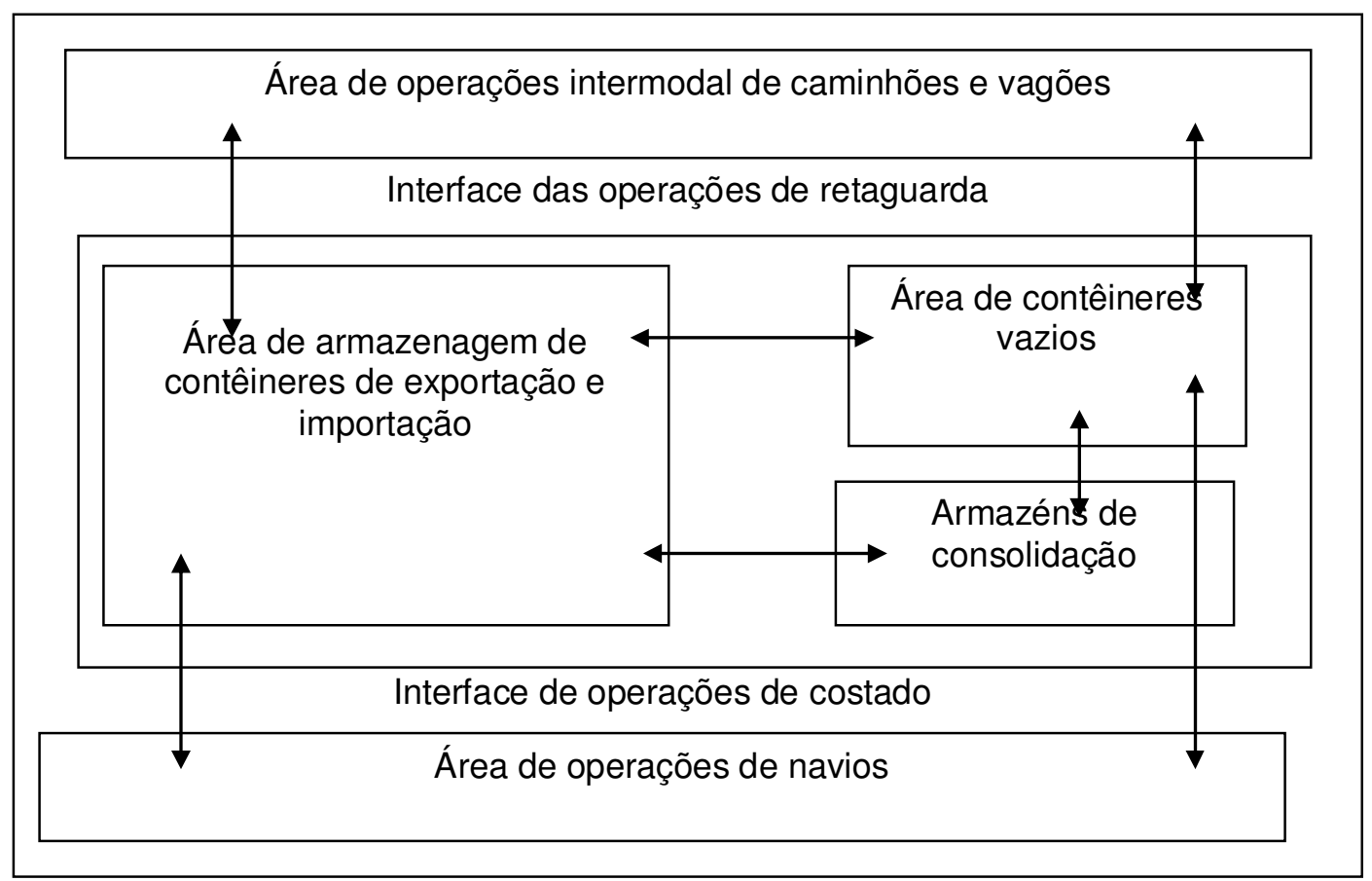

Fonte: Elaborado pelo autor

Sistema similar é descrito por Monfortet al (2011) e representado na figura 21, no qual um terminal é um sistema integrado com conexões físicas e informacionais com as redes de transportes terrestres e marítimas e para análise considera quatro subsistemas:

- Subsistema (1) de Embarque, Descarga e de atracação de navios responsável pela interface marítima com todos os aspectos de infraestrutura, equipamentos e relações com os agentes envolvidos;

- Subsistema (2) de Armazenagem para depósito temporário dos contêineres e mercadorias e sua disposição depende de fatores como o fluxo de comércio, do tipo da carga, do tempo de permanência (dwell time), dos equipamentos de movimentação e lógica operacional;

- Subsistema (3) de Recebimento e Entrega, o qual é integrado ao sistema de Gates para caminhões e vagões;

- Subsistema (4) de Interconexões que assegura a movimentação e transferências entre os subsistemas anteriores, portanto, compreende a solução tecnológica adotada em cada terminal para a movimentação física e informacional necessária. 
Figura 21 - Abordagem Sistêmica de um terminal de contêineres conforme Monfort (2011)

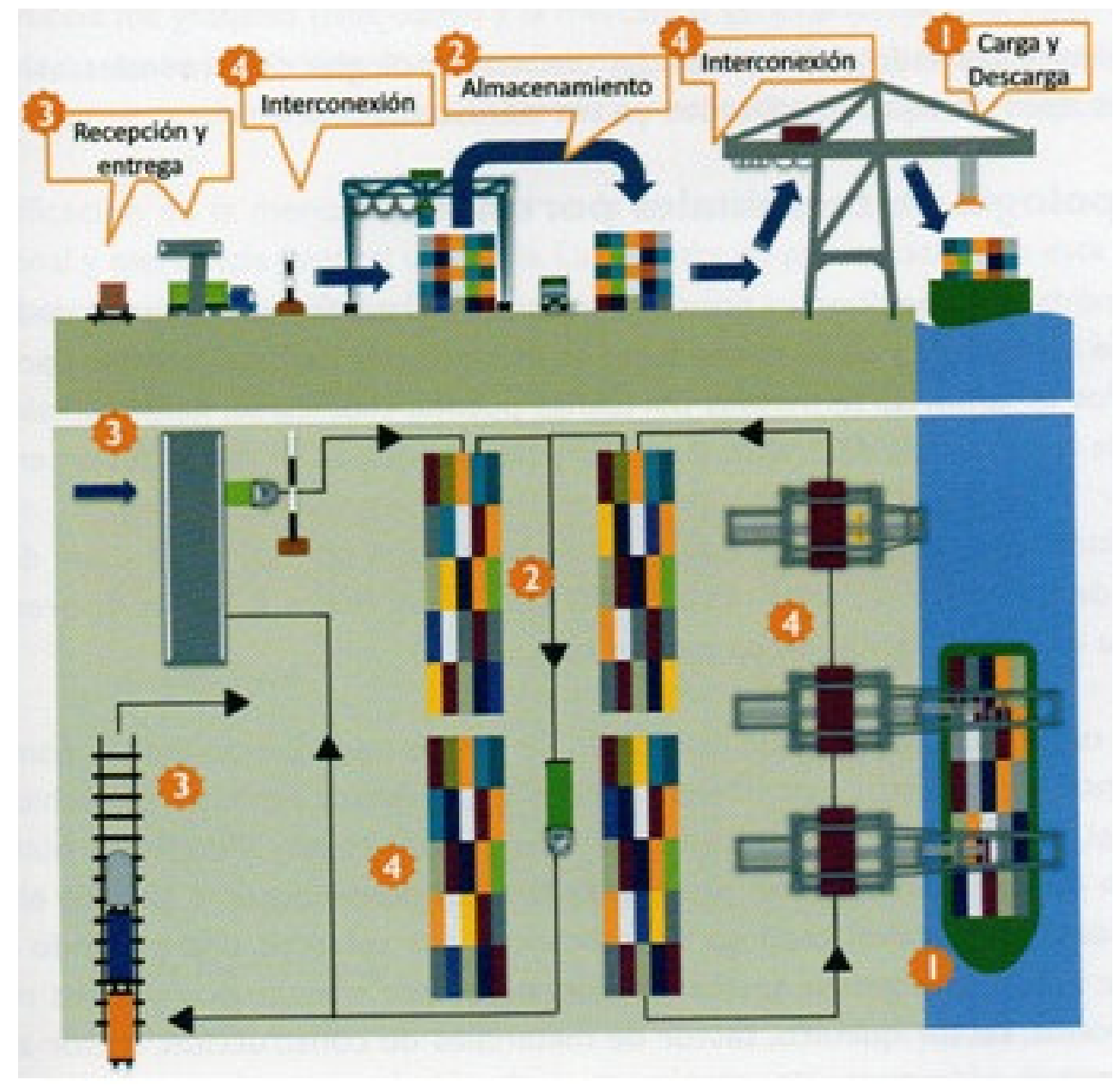

Fonte: Monfort (2011)

Peixoto (2005) apresenta um modelo de caracterização sistêmica de um terminal de contêineres, ilustrada na figura 22, formado por cinco subsistemas, a saber:

- Subsistema Costado dedicado à chegada e à atracação de navios;

- Subsistema Operações de descarga e embarque de contêineres dos navios;

- Subsistema Fluxo de transferência de contêineres entre o costado e pátio (usualmente chamado de "retaguarda");

- Subsistema Armazenagem para recebimento e posicionamento dos contêineres; e, 
- Subsistema Transbordo (Gates) responsável pela intermodalidade do transporte.

Figura 22 - Abordagem Sistêmica de um terminal de contêineres conforme Peixoto (2005)

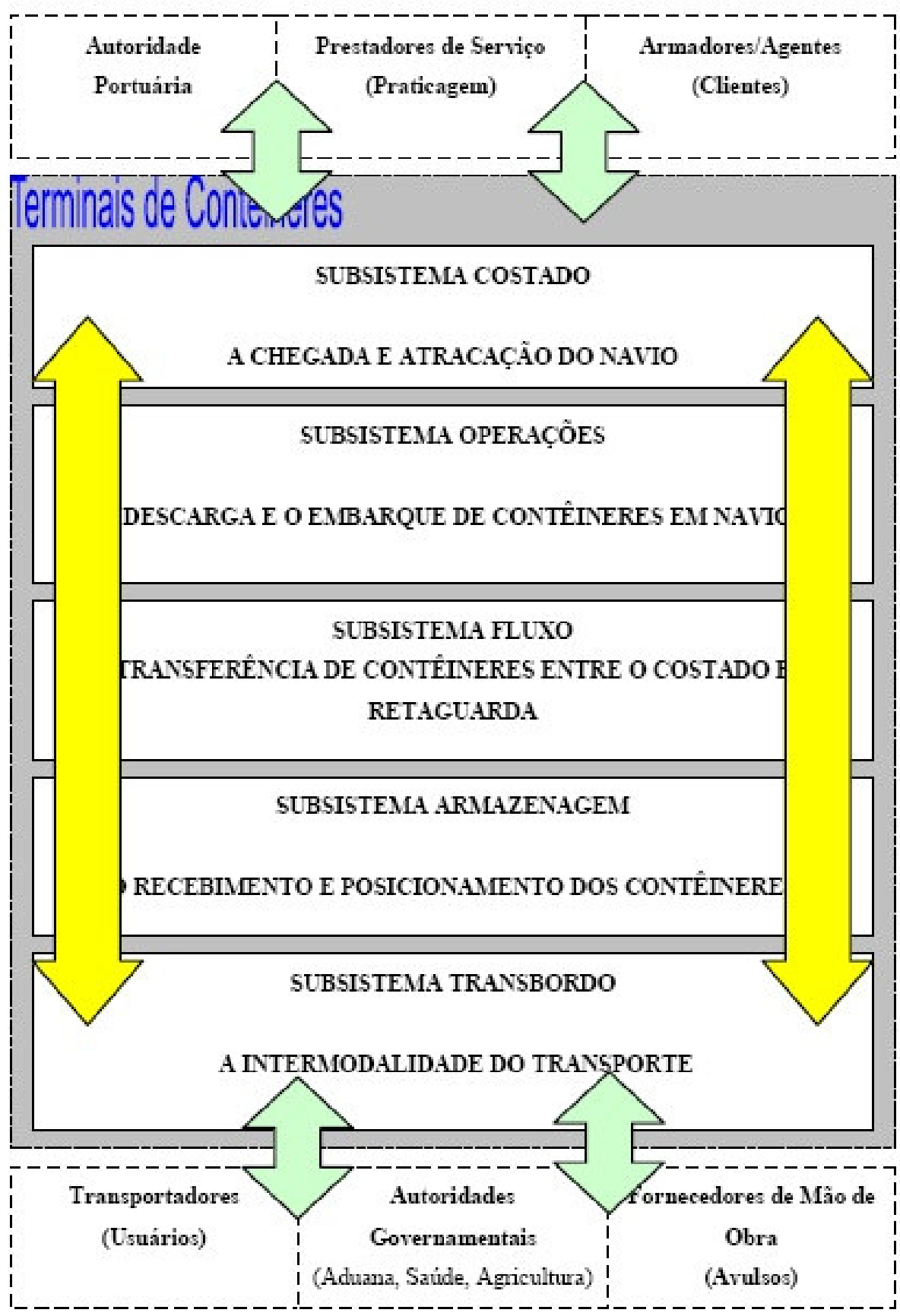

Fonte: Peixoto (2005)

Monfortet al (2011) apontam que, independente do modelo, cada subsistema conta com diferentes elementos relacionados entre si, como: a Infraestrutura, a 
Superestrutura (Equipamentos) e o Sistema de Operações do Terminal ou Sistema de Planejamento e Gerenciamento das Operações (TOS).

Atualizando, Patricio e Botter (2012) indicam que a evolução do setor de terminais de contêineres no Brasil pode ser feita com base na seguinte leitura de suas fases:

- Fase 0 de Contágio (antes de 1980): Não havia terminais especializados, começam as operações com contêineres no Brasil de forma bastante incipiente e precária;

- Fase 1 de Iniciação (1980 a 1995/1996): A operação portuária era realizada pelo governo por meio das Companhias Docas, com baixíssimo nível de serviço (8,36 movimentos por hora/navio no único terminal especializado do país com utilização de portêineres), tempo de espera para atracação de navios bastantes altos (6,16 dias de espera para atracar), altos custos operacionais, sem concorrência, e, na maioria das vezes, com a utilização dos recursos de bordo (guindastes) dos navios, conforme ilustrado na figura 23 ;

Figura 23 - Demora na atracação e produtividade no TECON em dezembro de 1995

\begin{tabular}{|c|c|c|c|c|c|}
\hline $\begin{array}{c}1995 \\
\text { Més/Month }\end{array}$ & $\begin{array}{c}\text { Total } \\
\text { Navios/Ships }\end{array}$ & $\begin{array}{c}\text { Total } \\
\text { Units/Unidades }\end{array}$ & $\begin{array}{c}\text { Aver. units p/ship } \\
\text { Média un.p/navio }\end{array}$ & $\begin{array}{c}\text { Aver. days wait. p/ship } \\
\text { Média dia esp. p/navio }\end{array}$ & $\begin{array}{c}\text { Aver. moves p/hr p/ship } \\
\text { Média mov. p/h p/navio }\end{array}$ \\
\hline JAN & 50 & 17.349 & 347 & 1.96 & 10.20 \\
\hline FEV & 40 & 17.414 & 435 & 2.00 & 9.19 \\
\hline MAR & 29 & 13.931 & 480 & 6.41 & 8.36 \\
\hline APRIL & 36 & 18.876 & 524 & 4.50 & 9.29 \\
\hline MAY & 34 & 16.641 & 489 & 4.66 & 9.27 \\
\hline JUN & 37 & 16.614 & 449 & 5.16 & 11.49 \\
\hline JUL & 37 & 16.681 & 451 & 4.70 & 10.37 \\
\hline AUG & 41 & 16.513 & 403 & 6.16 & 9.30 \\
\hline SEP & 40 & 14.862 & 372 & 1.58 & 14.68 \\
\hline OCT & 50 & 18.104 & 362 & 1.66 & 13.00 \\
\hline NOV & 52 & 18.409 & 354 & 1.54 & 13.85 \\
\hline DEZ & 50 & 17.653 & 353 & 1.13 & 14.00 \\
\hline
\end{tabular}

Fonte: Centro Nacional de Navegação Transatlântica (CNNA)

- A Fase 2 de Transferência (1995/96 a 2013): Período compreendido entre dois marcos regulatórios, das leis $8.630 / 93$ e 12.815/13, no qual ocorre a transferência das operações para iniciativa privada e os 
primeiros ciclos de aportes de altos investimentos dos arrendatários na aquisição de equipamentos de movimentação (portêineres, transtêineres, Reach-stacker, empilhadeiras de pequeno porte, caminhões e terminal tractors); reformas e ampliação das estruturas existente de cais e pátio; investimento em tecnologia como sistemas de gerenciamento, ferramentas de planejamento, sistemas integrados; segurança aduaneira e das instalações em atendimento ao ISPS Code; programas ambientais; treinamento e gestão e mudança organizacional e de cultura nas atividades portuárias, em especial da segurança no trabalho. Apesar de o primeiro marco regulatório ser datado de maio de 1993, considera-se novembro de 1995 como a data inicial dessa transferência, pois é a data que marca o início das operações do Terminal 37 do Grupo Libra, primeiro terminal arrendado no formato da nova lei;

- A Fase 3 de Adequação (a partir de 2013): Período de incerteza em face do novo marco regulatório, e de adequação em virtude da competição anunciada com entrada de novos operadores globais como DPW (acionista da Embraport) e da APMT e TIL (acionistas da BTP); alteração da composição de ternos de trabalhos nas operações de navios com composição mista entre trabalhadores avulsos (TPAs) e trabalhadores vinculados (CLTs) nas operações de estiva e capatazia;

- A Fase 4 de Automação (Onda futura): Eletrificação e automação de equipamentos, revisão obrigatória dos processos, aumento significativo dos indicadores de performance e segurança, redução de OPEX e, principalmente, a questão de organização do trabalho, a qual deve ser entendida em função de três elementos: Pessoas, Equipamentos e Materiais em Transformação. Adaptando da produção para operações em terminais de contêineres, temos o esquema da figura 24. 
Figura 24 - Esquema adaptado de elementos básicos da organização do trabalho na produção para operação de terminais de contêineres

\section{Pessoas}
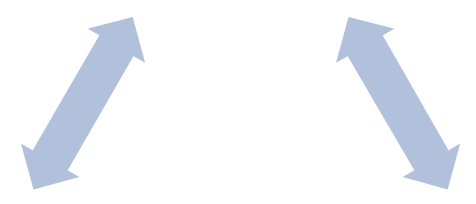

\section{Equipamentos}

\section{Serviços de \\ movimentação \\ de contêineres}

Fonte: Elaborado pelo autor

Segundo informações da ABRATEC, foram notórias as ações e providências tomadas pelos terminais privativos durante as Fases 2 e 3 para atender ao crescimento da demanda e elevar os índices de crescimento de desempenho. A quantidade de contêineres movimentada passou de 1.857 .729 unidades em 2000 para 5.855.959 unidades em 2013; um crescimento de mais de $350 \%$ na quantidade de contêineres movimentados desde 1997; um aumento médio de produtividade de 525\%; investimentos de US $\$ 2,8$ bilhões entre 1997 a 2011, na construção de obras físicas, aquisição de modernos equipamentos e especialização de mão de obra. Abaixo, algumas das principais ações:

- Aumento da capacidade nominal e operacional de armazenamento;

- Uso de equipamentos de movimentação que permitam maior adensamento das pilhas nos pátios de armazenamento;

- Redução do Dwell Time, isto é, do tempo de permanência de contêineres no pátio desde a sua entrada até a sua saída, tanto na exportação, como na importação;

- Aumento da capacidade de recebimento e entrega de contêineres por meio dos seus Gates;

- Melhoria e regularidade do desempenho das operações de costado; 
- Solicitação do aumento do número médio de contêineres por escala e, consequentemente, o aumento do número de contêineres movimentados por tampa removida;

- Alteração do nível de serviço exigido pelos clientes, especialmente pelos armadores, que atualmente determinam o nível de serviço que deve ser oferecido pelo terminal;

- Uso intensivo de ferramentas de tecnologia da informação para planejamento e gestão das atividades administrativas e operacionais de terminais de contêineres;

- Discussão de simplificação dos processos aduaneiros;

- Maior acompanhamento sobre a chegada de navios e distribuição de janelas de tempo de atracação para evitar congestionamentos;

- Cumprimento das Janelas de Atracação de navios.

A Fase 4 intitulada de "Fase da Automação" em terminais de contêineres exigirá um novo ciclo de altos investimentos e diversas situações precisam ser cuidadosamente discutidas e preparadas, em especial a questão de revisão de processos e organização do trabalho.

Ainda sobre as adequações do setor citadas anteriormente por Thomas (2001) e indicação de instrumento para se alcançar economia de escala, tem-se o crescimento e o aumento da capacidade dos navios e adaptação dos terminais de contêineres para atingir a produtividade necessária para essas operações.

\subsection{EVOLUÇÃo dOS NAVIOS PORTA-CONTÊINERES E A BUSCA PELA ECONOMIA DE ESCALA}

Os navios porta-contêineres evoluíram rapidamente desde a primeira viagem entre Nova lorque e Houston do navio tanque convertido Ideal X em 1956, com 135 $\mathrm{m}$ de comprimento e capacidade para 500 TEUs, até a viagem inaugural do primeiro navio da série "Triple-E" do armador dinamarquês Maesk Lines, o M.V Maersk Kinney Moller em agosto de 2013, com 400 metros de comprimento (LOA) e 59 metros de largura ou "Boca" (Breadth) e com capacidade para 18.200 TEUs (sendo 
10.600 TEUs nos conveses e 7.600 TEUs nos porões), 23 colunas (Rows) e 10 Alturas (Tiers) no convés, conforme demonstra a Figura 25 da seção a meia nau.

Figura 25- Seção indicativa a meia nau do numero de Colunas (Rows) e Alturas (Tiers)

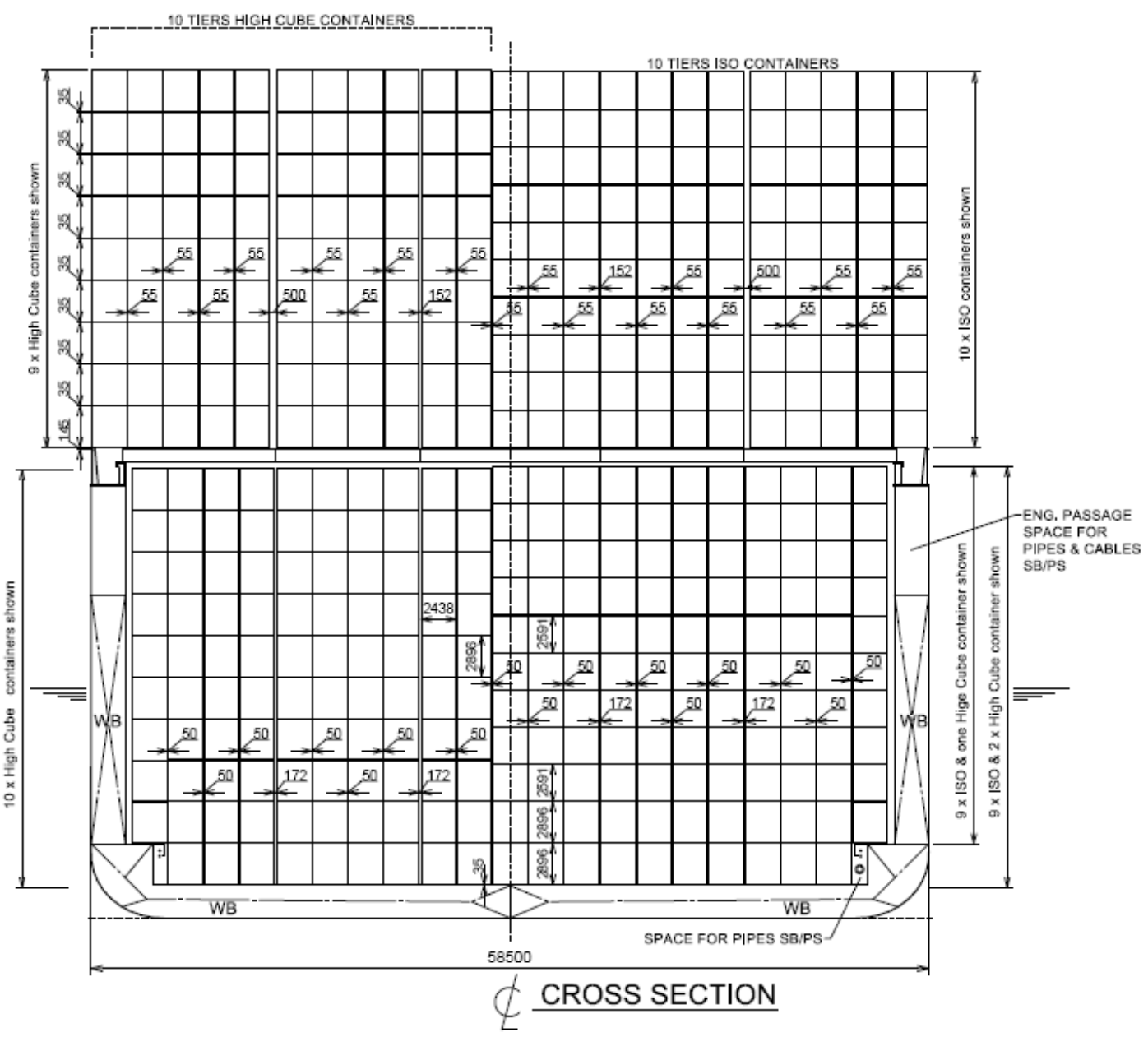

Fonte: DNV Offshore Containers

A propósito, o nome Triple-E é derivado de três princípios: Economia de escala, Eficiência Energética, Eficiência Ambiental (EEconomy of scale, Ennergy efficient and Environmentally improved); essa classe de navio vem sendo construída pelo estaleiro da Daewoo Shipbuilding and Marine Engineering (DSME) na Coreia do Sul, com custo de US\$190 milhões por navio; e o que comprova esses princípios são as comparações de indicadores como: a redução de emissão de $\mathrm{CO}_{2}$ do TripleE é $20 \%$ menor do que da classe antecessora de navios - a "E-Class", também da Maersk Line, onde o navio mais conhecido dessa classe foi o Emma Maersk com 15.000 TEUs de capacidade e 397 metros de comprimento (LOA), lançado em 2006; 
essa eficiência aumenta para 50\% quando compara-se o Triple-E com a média de navios nas rotas da Europa-Ásia; a redução de 37\% no consumo de combustível em virtude de um sistema de recuperação de calor do motor principal e pelo sistema de redução de velocidade (Slow steaming) de 2 motores de 32 Megawatts (43.000 hp) com um sistema de dois hélices a uma velocidade de 19 nós (equivalente a 35 $\mathrm{Km} / \mathrm{h})$.

Nesses quase 60 anos de intervalo entre os navios Ideal $X$ e o Triple-E Maersk McKinney Moller, a figura 26 ilustra ambos os navios; estabeleceram-se diversas classificações e tabelas de evoluções das gerações e crescimento dos navios porta-contêineres disponíveis na literatura; e, discussões sobre o tamanho ideal de navio, e real economia destes.

Figura 26 - Navio convertido "Ideal X” versus o Triple-E "Maersk McKinney Moller"
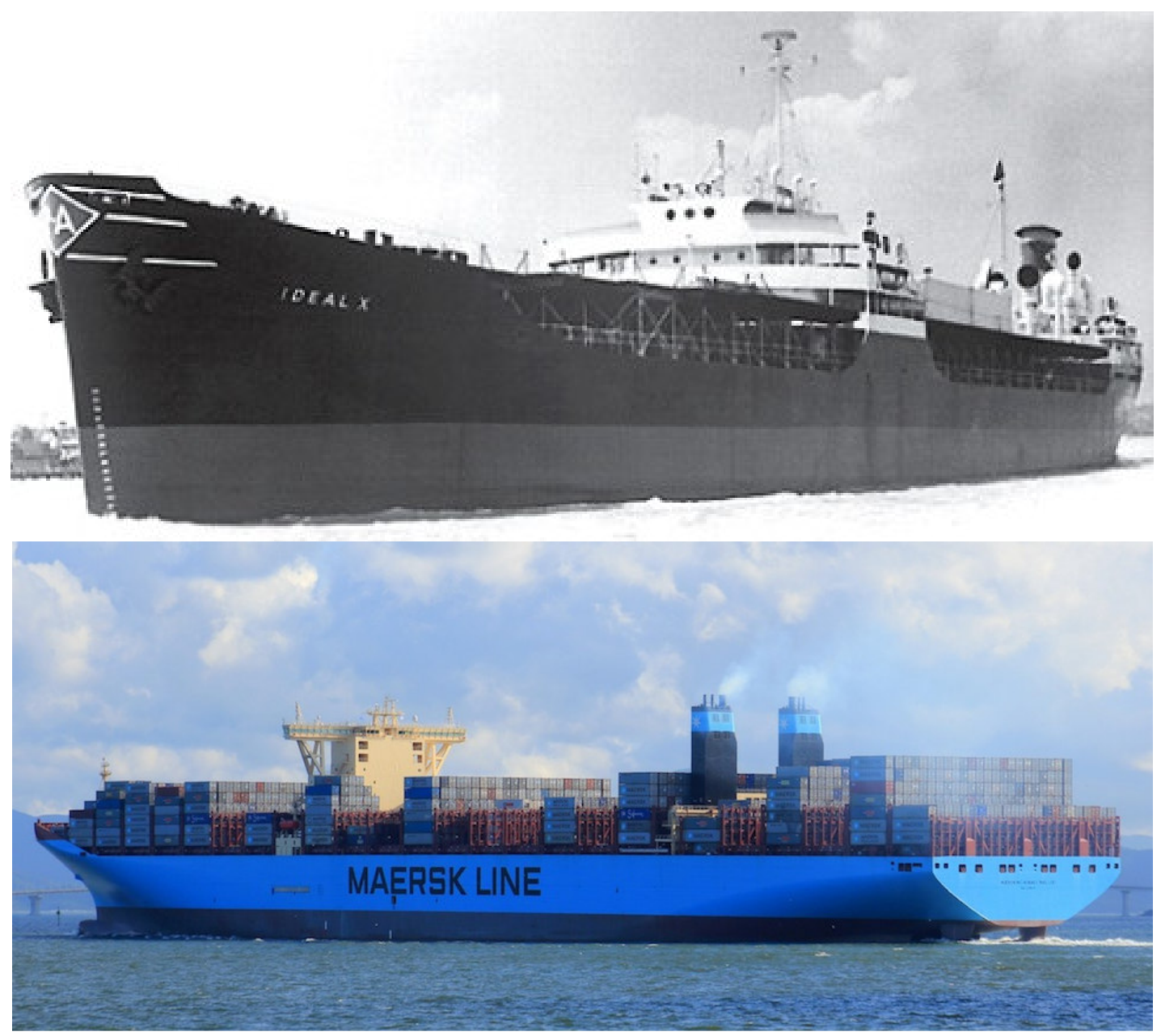

Fonte: www.korably.net e Maersk Line 
Por exemplo, a tabela 5 ilustra a evolução dos navios porta-contêineres conforme Alderton (1999). Nota-se que a 6ª geração de navios indicada pelo autor era para navios maiores ou da ordem de 8.000 TEUs.

Tabela 5 - Evolução dos navios porta-contêineres

\begin{tabular}{|c|c|c|c|}
\hline Data & Geração & $\begin{array}{c}\text { Capacidade } \\
\text { (TEUs) }\end{array}$ & $\begin{array}{l}\text { Comprimento } \\
\text { (metros) }\end{array}$ \\
\hline $1960-1970$ & 1a Geracão & $<1.000$ & 180 \\
\hline $1970-1980$ & $2^{a}$ Geração & 2.000 & 215 \\
\hline 1985 & 3ª Geração & $3.000-4.000$ & $260-280$ \\
\hline 1988 & 4ª Geração & $4.000-5.000$ & $275-305$ \\
\hline \multirow[t]{2}{*}{1995} & 5a Geração & $>6.000$ & 310 \\
\hline & 6ª Geração & $>8.000$ & 338 \\
\hline
\end{tabular}

Fonte: Alderton(1999)

Foltz; Sandpearl e Urriola (2001) apresentaram a classificação de navios com cinco gerações (ver tabela 6) e indicavam a 5 $5^{\text {a }}$ geração como o limite de capacidade realística, pois, para baixas velocidades e menor consumo, 8.000 TEUs precisaria de apenas um motor; enquanto a próxima geração de navio de 14.000 TEUs necessitaria de dois motores para atingir velocidades médias semelhantes.

Tabela 6 - Evolução dos navios porta-contêineres

\begin{tabular}{|c|c|c|}
\hline Data & Geração & Capacidade (TEUs) \\
\hline Pré 1960 - 1970 & 1a Geração & 1.703 \\
\hline $1970-1980$ & $2^{a}$ Geração & 2.305 \\
\hline 1985 & 3ª Geração & 3.220 \\
\hline $1986-2000$ & 4ª Geração & 4.848 \\
\hline $2000-?$ & 5a Geração & 7.598 \\
\hline
\end{tabular}

Fonte: Foltz; Sandpearl; Urriola (2001)

Davidson (2004) explica, a partir de uma comparação do tamanho médio em capacidade de TEUs dos navios e dos maiores navios existente, a tendência dos navios Ultra Large Container Vessels (ULCV), ou Very Large Container Carrier (VLCC) ou também chamados de Mega Container Ships. A tabela 7 apresenta essa comparação. Contudo, há autores que apresentam classificações com a $7^{\mathfrak{a}}$ e $8^{\underline{a}}$ geração de navios porta contêineres com 14.000 e 19.200 TEUs respectivamente. 
Tabela 7 - Evolução dos navios porta-contêineres

\begin{tabular}{c|cc}
\hline Data & $\begin{array}{c}\text { Média da capacidade } \\
\text { dos navios (em TEUs) }\end{array}$ & $\begin{array}{c}\text { Navio com maior capacidade no } \\
\text { mundo (em TEUs) }\end{array}$ \\
\hline 1980 & 975 & 3.057 \\
1990 & 1.355 & 4.409 \\
2000 & 1.741 & 7.200 \\
2004 & 1.999 & 8.063 \\
\hline
\end{tabular}

Fonte: Drewry Shipping Consultancy

Nesse trabalho, Davidson (2004) afirmava que o tamanho médio dos navios continuaria a aumentar em médio prazo; os navios de 5.000 a 8.000 TEUs se tornariam os Boeings 747 nas rotas de leste a oeste da indústria marítima, enquanto os menores que 3.500 TEUs seriam cascateados para linhas regionais; que os navios de 8.000 a 10.000 TEUs seriam comuns na indústria marítima e, finalmente, que navios com $12.500 \mathrm{TEUs} \mathrm{seriam} \mathrm{os} \mathrm{de} \mathrm{maior} \mathrm{capacidade.}$

Tozer e Penfold (2001) de forma semelhante indicam que, baseados nas informações de mercado e infraestrutura portuária existente, o tamanho ideal de navios do tipo ULCS seria de 10.700 a 12.500 TEUs no intervalo de 5 a 10 anos e que esses navios geram consideráveis reduções de custos, com velocidades de 23 a 24 nós com um motor e que poderiam ser movimentados economicamente nos terminais.

Wijnolst e Waals (2000) divergem da previsão anteriores de Davidson e de Tozer e Penfold, pois, com base no crescimento do comércio, especialmente no eixo Norte da Europa para o Extremo Oriente, indicavam que 2010 seria o ano de introdução dos navios do tipo Malacca-max de ordem de 18.000 TEUs e, de forma simplificada, indicavam cinco Classes de navios, mostrados na tabela 8.

Tabela 8 - Evolução dos navios porta-contêineres em cinco categorias

\begin{tabular}{l|c}
\hline Classes & Capacidade (em TEUs) \\
\hline Panamax & 4.800 \\
Post-Panamax & 6.600 \\
Maersk S-Class & 8.700 \\
Suez Max & 11.989 \\
Malacca-max & 18.154 \\
\hline
\end{tabular}

Fonte: Wijnolst e Waals (2000)

Ashar (2000) escreve sobre o que ele chamou de uma evolução e quatro revoluções da navegação regular, na qual a evolução refere-se ao crescimento 
gradual em tamanho dos dois maiores componentes do sistema, isto é, navio e portos; Em seguida, descreve sobre as quatro revoluções, a saber: a primeira revolução é a transferência do navio para o cais (ship-to-shore transfer) e a própria invenção do contêiner; a segunda revolução trata da transferência intermodal de navio para a ferrovia (ship-to-rail transfer); a terceira revolução ou revolução do transbordo (transshipment) é a transferência navio para navio (ship-to-ship) e a quarta revolução do estabelecimento de um novo padrão de serviço. Nesse estudo, apresentou-se uma tabela com as dimensões e arranjos de cinco classes de navios, conforme a tabela 9. Semelhante classificação com sete categorias é apresentada na tabela 10.

Tabela 9 - Evolução dos navios porta-contêineres com dimensões e arranjos

\begin{tabular}{l|ccc}
\hline Classes & $\begin{array}{c}\text { Capacidade em } \\
\text { TEUs }\end{array}$ & $\begin{array}{c}\text { Dimensões em } \\
\text { metros (LOA x Boca } \\
\text { x Calado) }\end{array}$ & $\begin{array}{c}\text { Arranjo de Colunas } \\
\text { (convés } \times \text { porão } x \\
\text { transversal) }\end{array}$ \\
\hline Panamax & 4.000 & $294 \times 33 \times 12$ & $8 \times 5 \times 13$ \\
Post-Panamax I & 4.000 & $275 \times 39 \times 12,7$ & $8 \times 5 \times 15$ \\
Post Panamax II & 6.000 & $348 \times 42 \times 14$ & $9 \times 6 \times 17$ \\
Double Wide & 15.000 & $400 \times 69 \times 14$ & $10 \times 6 \times 28$ \\
Mallacca-max & 18.000 & $400 \times 60 \times 21$ & $12 \times 8 \times 23$ \\
\hline
\end{tabular}

Fonte: Ashar (2000)

Tabela 10 - Evolução dos navios porta-contêineres com dimensões e arranjos

\begin{tabular}{|c|c|c|c|}
\hline Classes & $\begin{array}{c}\text { Capacidade em } \\
\text { TEUs }\end{array}$ & $\begin{array}{c}\text { Dimensões em } \\
\text { metros (LOA x Boca } \\
\text { x Calado) } \\
\end{array}$ & Exemplos \\
\hline $\begin{array}{l}\text { Small Feeder } \\
\text { Feeder } \\
\text { Feederrmax } \\
\text { Panamax } \\
\text { Post Panamax }\end{array}$ & $\begin{array}{c}<1.000 \\
1.001-2.000 \\
2.001-3.000 \\
3.001-5.100 \\
5.101-10.000\end{array}$ & $294 \times 32 \times 12$ & $\begin{array}{c}\text { MV Trans Atlantic } \\
\text { Providence Bay } \\
\text { COSCO } \\
\text { Guangzhou Class }\end{array}$ \\
\hline $\begin{array}{l}\text { New Panamax } \\
\text { Ultra Large } \\
\text { Container Vessel }\end{array}$ & $\begin{array}{c}10.000-14.500 \\
>14.501\end{array}$ & $\begin{array}{c}366 \times 49 \times 15,2 \\
>366 \times 49 \times 15,2\end{array}$ & E-Class, Triple-E \\
\hline
\end{tabular}

Fonte: DNV offshore containers

Há diversas outras categorizações de navios na literatura como o da figura 27 que relaciona também em sete categorias as classes ou gerações de navios, a sua 
capacidade, o arranjo de colunas (rows), e inclui informações sobre o calado necessário para esses navios.

Figura 27 - Evolução dos navios porta-contêineres com dimensões, arranjos e calados
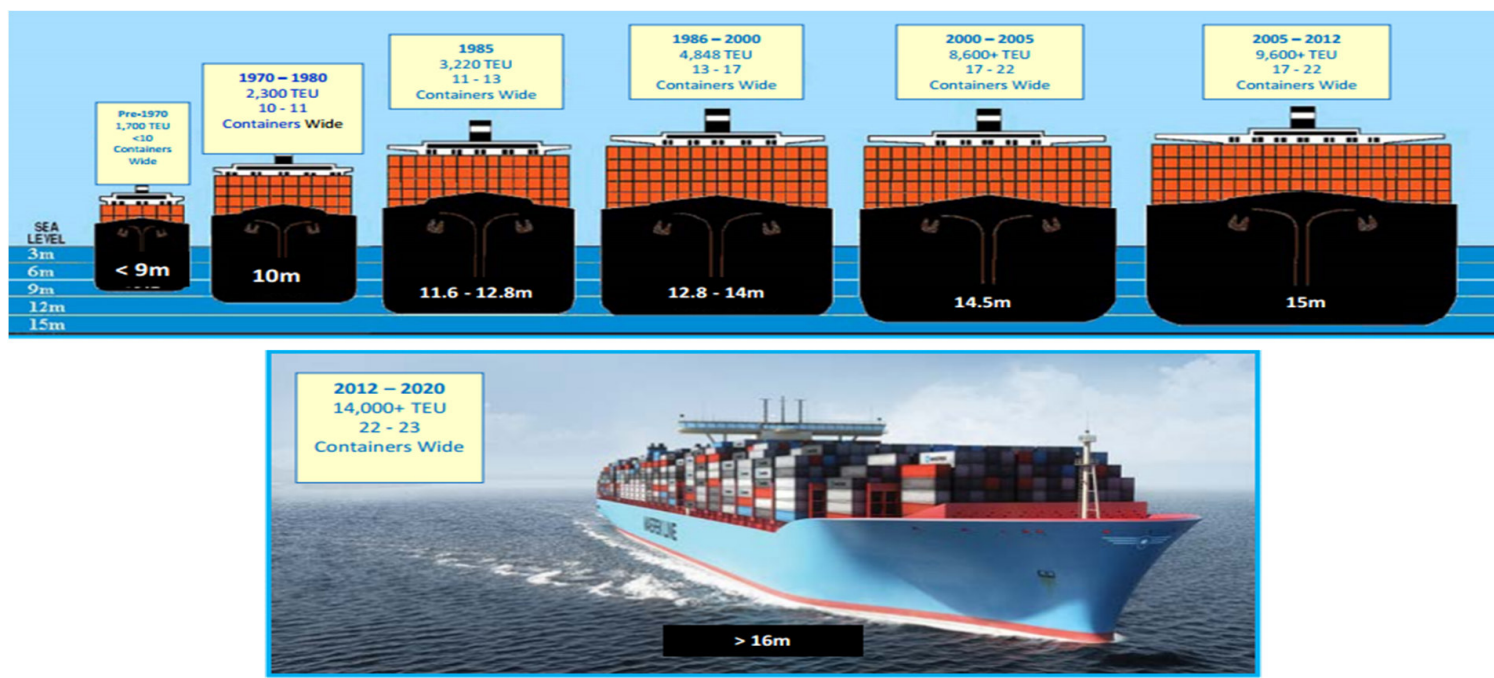

Esse último atributo, juntamente com a dimensão de equipamentos e das dimensões e capacidade construtiva do cais, é um dos itens mais restritivos das operações portuárias, pois, além do calado, exige a distância de quilha livre (Clearance keel) que é a distância entre o ponto mais baixo do casco do navio e do fundo do canal, estuário ou berço.

Contudo, a barreira de capacidade de 18.000 TEUs deverá em breve ser superada, está prevista a entrega de um navio de 19.000 TEUs para novembro de 2014 para o armador China Shipping Company Lines (CSCL) e, de acordo com pesquisa da empresa de seguros Allianz, a classe de navios de 24.000 TEUs deverá se tornar realidade nos próximos cinco anos. No relatório anual intitulado de "Safety and Shipping Review 2014", a Allianz apresenta uma preocupação com o aumento do custo do seguro em virtude do aumento do risco e de preocupações sobre a dificuldade de salvamento e regras de segurança. Outrossim, apresenta a indicação de seguro por classe de navio, como ilustra a figura 28. 
Figura 28 - Crescimento do tamanho navio porta-contêineres e os valores segurados

Fully cellular (1970-) $1,000-2,500$ teu $215 \times 20 \times 10 m-\$ 8 m$ to $\$ 12 m$
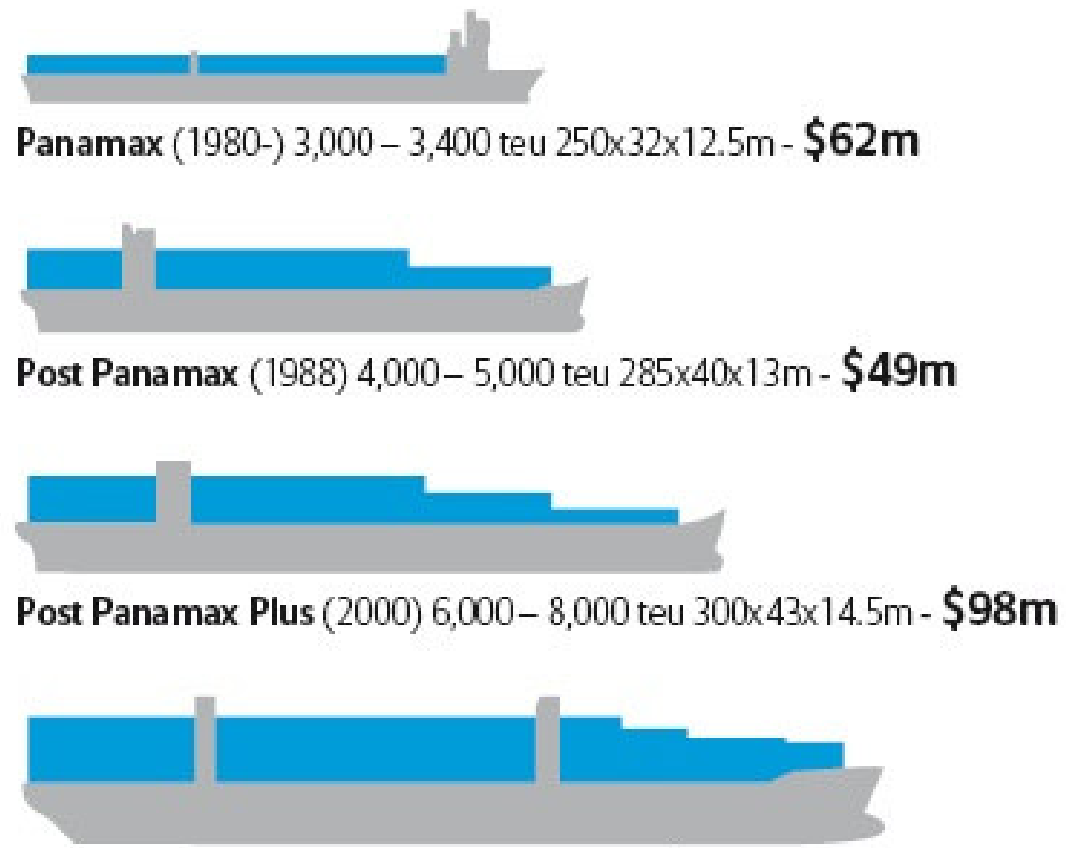

Triple E(2013) 18,000 teu $400 \times 59 \times 15.5 m-\$ 140 m$

Fonte: Allianz

Essa tendência de crescimento dos navios, que inicialmente ocorrem na rota do norte da Europa para o Extremo Oriente, espalhou-se para outras rotas como Ásia - Mediterrâneo ou Ásia - Oriente Médio; assim como foi pulverizada entre os armadores, conforme lista de 20 navios apresentados na figura 29. Nota-se o pioneiro nessa questão de meganavios, o armador dinamarquês Maersk Lines com as classes "E-Class" e "Triple-E" de 14.770 TEUs e 18.270 TEUs, respectivamente, seguidos pelo armador francês CMA-CGM com o "Explorer Class" de 16.000 TEUs (navios CMA-CGM Marco Polo e CMA-CGM Julio Verne), e pelos chineses com a classe "CSCL Star" para 14.100 TEUs.

Apenas como referência, a CMA-CGM possui $20 \%$ da frota em TEUs em navios entre 7.500 e 9.999 TEUs e outros $20 \%$ em navios maiores que 10.000 TEUs, e 55\% da frota de navios com menos de 5 anos. Apesar de não aparecer na lista a MSC possui navios da classe de 14.000 TEUs como MSC Paloma, MSC Daniela, MSC Gaia, MSC Danit entre outros. 
Figura 29 - Lista dos 20 maiores navios porta-contêineres

\begin{tabular}{|c|c|c|c|c|c|c|}
\hline & Name & Built & Length overall (m/ft) & Maximum TEU & GT & Owner \\
\hline 1 & Maersk Mc-Kinney Moler & 2013 & $398 / 1,306$ & 18,270 & 174,500 & Maersk (Denmark) \\
\hline 2 & Majestic Maersk & 2013 & $398 / 1,306$ & 18,270 & 174,500 & Maersk (Denmark) \\
\hline 3 & Mary Maersk & 2013 & $398 / 1,306$ & 18,270 & 174,500 & Maersk (Denmark) \\
\hline 4 & Marie Maersk & 2013 & $398 / 1,306$ & 18,270 & 174,500 & Maersk (Denmark) \\
\hline 5 & CMA CGM Marco Polo & 2012 & $396 / 1,299$ & 16,020 & 175,343 & CMA CGM (France) \\
\hline 6 & $\begin{array}{l}\text { CMA CGM Alexander von } \\
\text { Humboldt }\end{array}$ & 2013 & $396 / 1,299$ & 16,020 & 153,022 & CMA CGM (France) \\
\hline 7 & CMA CGM Jules Verne & 2013 & $396 / 1,299$ & 16,020 & 153,022 & CMA CGM (France) \\
\hline 8 & Emma Maersk & 2006 & $397.7 / 1,305$ & 15,500 & 151,687 & Maersk (Denmark) \\
\hline 9 & Estelle Maersk & 2006 & $397.7 / 1,305$ & 15,500 & 151,687 & Maersk (Denmark) \\
\hline 10 & Eleonora Maersk & 2007 & $397.7 / 1,305$ & 15,500 & 151,687 & Maersk (Denmark) \\
\hline 11 & Evelyn Maersk & 2007 & $397.7 / 1,305$ & 15,500 & 151,687 & Maersk (Denmark) \\
\hline 12 & Ebba Maersk & 2007 & $397.7 / 1,305$ & 15,500 & 151,687 & Maersk (Denmark) \\
\hline 13 & Elly Maersk & 2007 & $397.7 / 1,305$ & 15,500 & 151,687 & Maersk (Denmark) \\
\hline 14 & Edith Maersk & 2007 & $397.7 / 1,305$ & 15,500 & 151,687 & Maersk (Denmark) \\
\hline 15 & Eugen Maersk & 2008 & $397.7 / 1,305$ & 15,500 & 151,687 & Maersk (Denmark) \\
\hline 16 & CSCL Star & 2010 & $366 / 1,201$ & 14,074 & 165,300 & CSCL (China) \\
\hline 17 & CSCL Saturn & 2011 & $366 / 1,201$ & 14,074 & 158,000 & CSCL (China) \\
\hline 18 & CSCL Mercury & 2011 & $366 / 1,201$ & 14,074 & 155,470 & CSCL (China) \\
\hline 19 & CSCL Mars & 2011 & $366 / 1,201$ & 14,074 & 150,853 & CSCL (China) \\
\hline 20 & CSCL Uranus & 2012 & $366 / 1,201$ & 14,074 & 150,853 & CSCL (China) \\
\hline
\end{tabular}

Fonte: DNV Offshore Containers

Duas implicações comuns do crescimento de navios são: o "cascateamento" global de navios nas rotas comerciais existentes e o impacto na infraestrutura e custos dos portos e dos terminais.

Clarke (2014) define cascateamento de navios como duas formas de Transferência:

1. A transferência de navios de um serviço originalmente projetado para outros serviços que utilizavam navios menores ou

2. A transferência de navios maiores para aumento da capacidade daquele serviço de um dado serviço para a redução de custo por TEU e uso de navios relativamente novos que sejam redundantes. 
E indica que os Serviços que possuem chance de sofrerem cascateamento são aqueles em que os navios estão com alta taxa de utilização; cuja previsão de crescimento foi antecipada ou possuem potência de transhipment.

De acordo com dados da Drewry de setembro de 2013, os maiores navios em circulação por rota estão listados na Tabela 11.

Tabela 11 - "Cascateamento" de navios por rotas

\begin{tabular}{l|c}
\hline Rota & Maior navio na rota (em TEUs) \\
\hline Ásia - Norte da Europa & 18.270 \\
Ásia - Mediterrâneo & 14.000 \\
Ásia - Costa Oeste EUA & 13.100 \\
Ásia - Costa Leste da América do Sul & 9.669 \\
Europa - Costa Leste da América do Sul & 8.762 \\
Ásia - Costa Oeste da América do Sul & 9.178 \\
Ásia - Oriente Médio & 14.074 \\
Europa - África do Sul - Ásia & 12.552 \\
\hline
\end{tabular}

Fonte: Drewry Shipping Consultancy

Atualmente, na rota da Europa para a Costa Leste da América do Sul, os maiores navios em operação são do armador Hamburg Sud, o Cap San Raphael e Cap San Nicolas, ambos com capacidade de 9.600 TEUs, 2.100 tomadas para contêineres reefers, 333,3 metros de LOA e calando 14 metros, conforme ilustra a figura 30.

Figura 30 - Navio Cap San Nicolas da Hamburg Sued

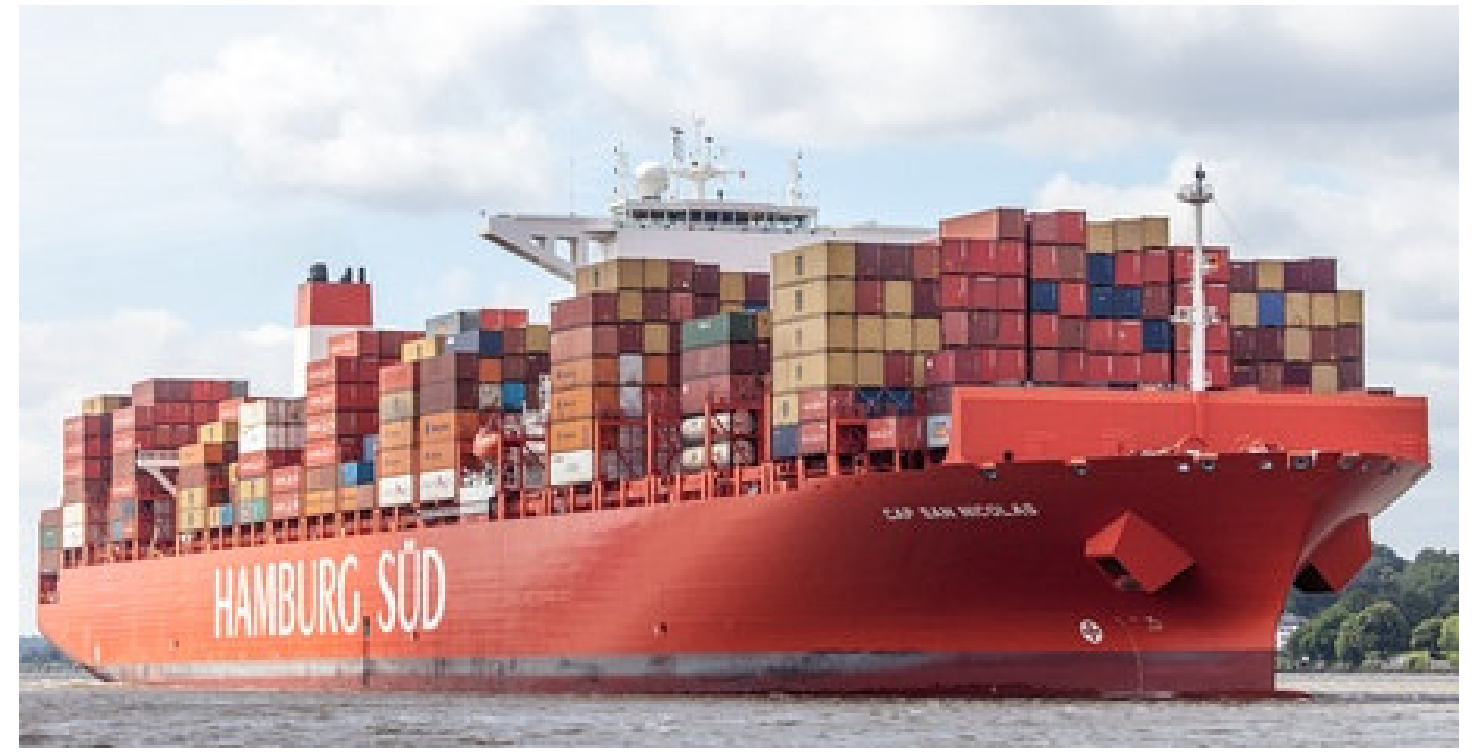

Fonte: Hamburg Sued 
Há uma discussão permanente sobre a real economia na operação dos meganavios porta-contêineres. Stopford (2002) indica estudos acadêmicos que contrariam a ideia de economia dessas classes de navios, como, por exemplo, a classe Malacca-max, tais como: o estudo Economies of Containership Size: a New Evaluation de Seok-Mia Lin (1994) que conclui que os benefícios desses navios ainda não estão totalmente aparentes, ou o artigo de Gilman (1998), Size Economics and Network Efficiency in Large Conteinershipso qual conclui que a economia inicial é irrisória.

Stopford (2002) também discorre sobre a real necessidade do crescimento dos navios porta-contêineres, indicando que esses têm causado controvérsias na indústria marítima, especialmente para os terminais de contêineres e armadores que necessitarão realizar novos e vultosos investimentos e ressalta, ainda, que nem todos concordam que esses tipos de navios são o que mercado realmente necessita por razões como:

- A Economia de escala diminui acima de 3.000 TEU e sobre 8.000 TEU as economias se tornam pequenas;

- Há significantes gastos em dragagem, com congestionamentos, distribuição de carga dos portos concentradores (hub) e uma série de dificuldades logísticas;

- Antecipação de investimento na aquisição de portêineres maiores ou necessidade de retrofit dos equipamentos existentes e consequente redução do ciclo de vida dos mesmos;

- Há economias em transformar e atualizar o tamanho dos navios nos tráfegos pequenos e médios;

- O tráfego mundial está crescendo, o que favorece navios de tamanho médio;

- O negócio dominado pelos operadores logísticos prefere a flexibilidade oferecida por navios menores.

Retomando Clarke (2014), o autor indica que um navio de 8.000 TEUs navegando com $60 \%$ de utilização terá o mesmo custo/TEU milha do que um navio antigo de 4.500 TEUs com 90\% de utilização; situação semelhante para os navios de 18.000 TEUs (com utilização de $60 \%$ ) terão o mesmo custo/TEU milha do que um 
navio de 8.000 TEUs (com 90\% de utilização). Ponderações das quais Wijnost e Waals (2000) discordaram e indicavam um horizonte de 10 anos para as soluções das restrições técnicas, de infraestrutura, operacionais, financeiras e comerciais atingissem as condições ideais e demostravam por meio da figura 31, que traduz o custo por slot para custos por TEU para uma "pernada", isto é, uma viagem entre Roterdã e Cingapura e demonstra que a economia de escala de grandes navios, como Suezmax ou Malacca-max, fica evidente. O custo por TEU em um navio Malacca-max é 30 \% menor que em um navio do tipo Panamax e a redução do custo total é de aproximadamente $16 \%$ para os navios de 8.000 TEUs, o que representa um diferencial competitivo.

Figura 31 - Custo de transporte entre Roterdã e Cingapura

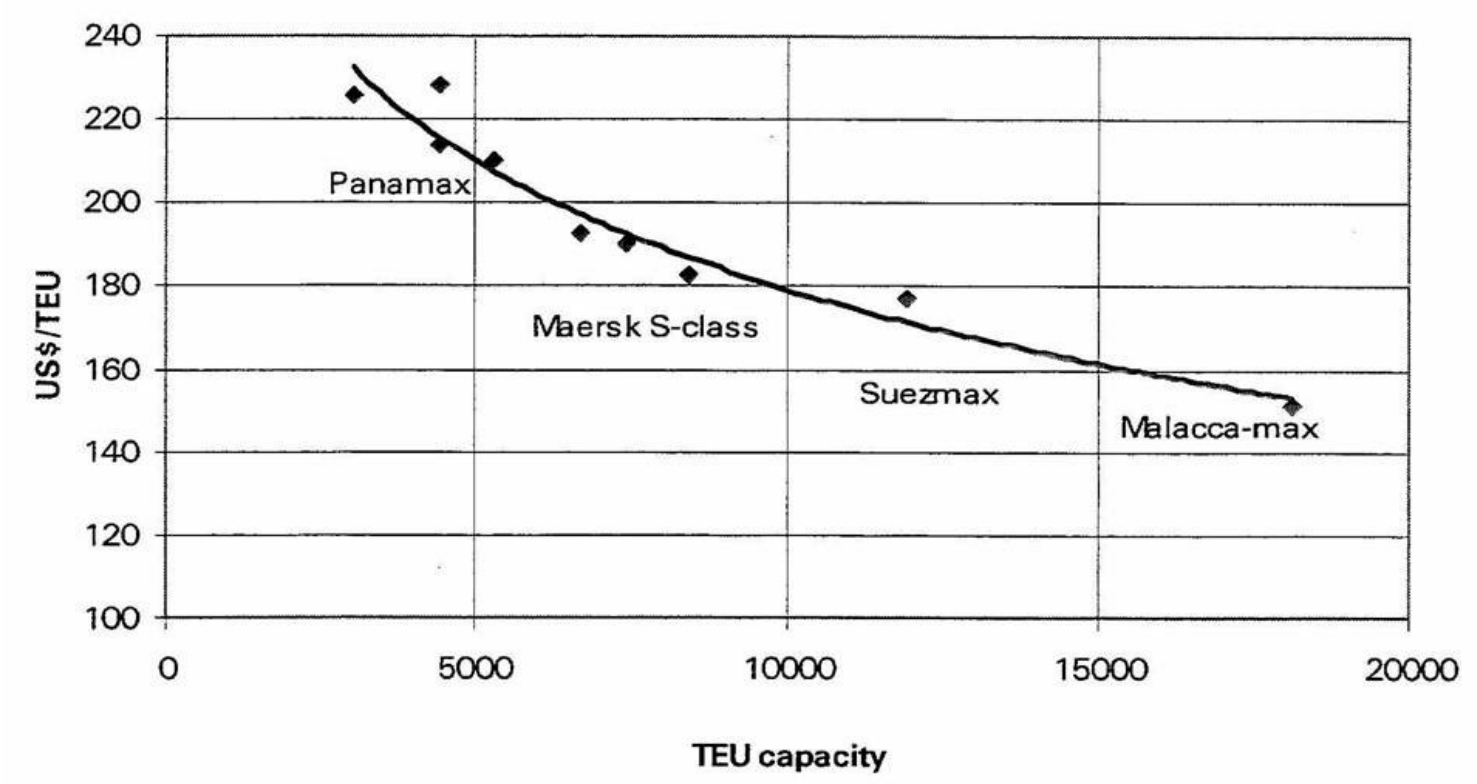

Fonte: Wijnolst e Waals (2000)

Grimstad e Neumann-Larsen (2013), em uma publicação da Det Norske Veritas (DNV), apresentam os resultados da investigação das tendências de custos/TEU para uma série de navios de 14.000 TEUs, 16.000 TEUs, 18.000 TEUs e 21.000 TEUs por meio de uma abordagem simples e de uma aplicação denominada de "Container Cost Calcullator" (CCC) .

A aplicação inclui dados de desempenho dos navios, como a relação velocidade-força-deslocamento, produtividade dos portos, custos de capital (CAPEX) e operacionais (OPEX) e custos relacionados à viagem e a taxas portuárias 
diversas. Esses dados foram selecionados a partir de estudos conceituais da DNV e projetos e, assim, não correspondem necessariamente a navios existentes ou a dados publicados; apesar disso, demonstraram ser bastante fieis a realidade, embora não necessariamente capture todos os pontos das operações de ULCS ou dos terminais de contêineres.

E, embora seja um modelo simples, esse se mostrou capaz de identificar três tendências interessantes, a saber:

1) Não foi uma surpresa encontrar que o custo por TEU está fortemente relacionado à utilização do navio; mas foi interessante observar que a diferença de custo por slot não é muito grande na comparação das classes de navios, isto é, se a utilização for reduzida em 3 a $5 \%$, a vantagem de custos de um navio da categoria maior seguinte se equilibra;

2) A paridade de custos do slot entre os navios de 14.000 e 21.000 TEUs corresponde até $12 \%$ de diferença na utilização, a diferença reduz conforme a taxa de utilização é menor. Isso significa que seria preciso 5.000 TEUs adicionais por viagem para os navios de 21.000 TEUs comparados com14.000 TEUs a fim de ter o mesmo custo de slot.

3) Velocidade lenta (Slow steaming) e consumo mais baixo não parecem contribuir muito para a redução do custo por slot; a utilização do navio precisa se manter tão alta quanto para navios pequenos.

Lembram também outros dois itens: que os navios deverão navegar sempre cheios para serem rentáveis, independente do seu tamanho e que o número de portos por trecho (ou pernada) de longo curso não devem ser muitos, pois qualquer ganho potencial em utilização pode ser rapidamente consumido pelos custos extras e tempo nas diversas operações dos portos. Resumidamente, indicam que a economia de escala para os meganavios não é necessariamente tão significante quanto apregoado.

A figura 32 apresenta os resultados dos custos de slot (US\$/TEU) para as diferentes classes de navios e variação da utilização. As curvas formam calculadas para velocidade média de 18 nós. 
Figura 32 - Custo relativo por TEU resultado do aplicativo CCC da DNV

\section{Relative cost per TEU (slot cost)}

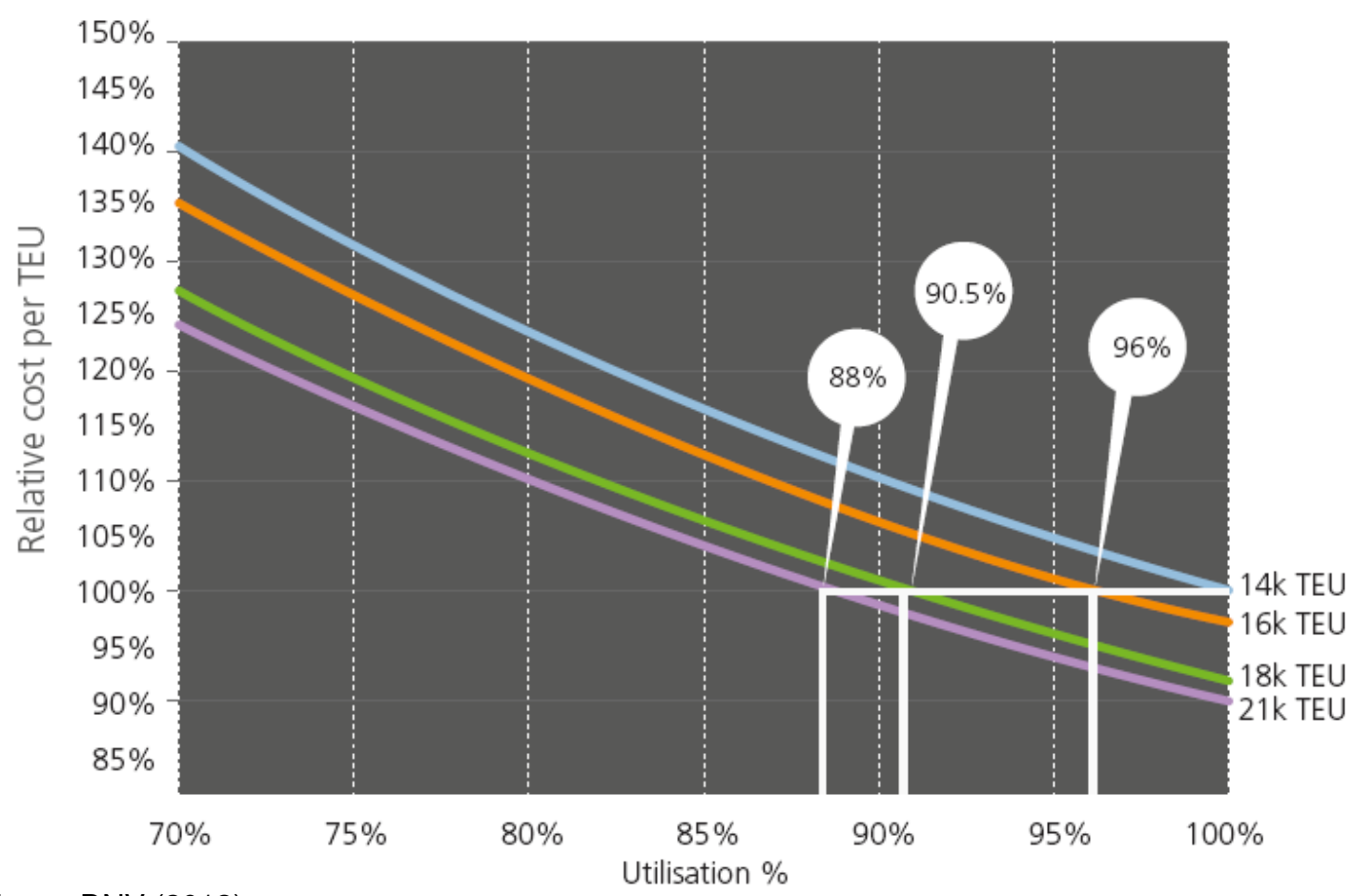

Fonte: DNV (2013)

A figura 33, a seguir, apresenta uma tabela de custo de equivalência, cujos dados demonstram o desenvolvimento de custos vis-à-vis, a dimensão do navio em dois eixos de comparação. Interpretando a tabela linha a linha, e referenciando a linha de $100 \%$ de utilização, a tabela mostra que o custo de slot de um navio de 21.000 TEUs é $89 \%$ do custo de um navio de 14.000 TEUs; e, quando analisamos coluna a coluna, o custo do slot aumenta conforme diminui a utilização do navio; tomando-se a coluna do navio de 14.000 TEUs como exemplo, reduzindo a utilização de $100 \%$ para $75 \%$ o custo por slot sofre um aumento de $31 \%$. 
Figura 33 - Tabela de equivalência de Custo de Slot

\begin{tabular}{|c|c|c|c|c|c|}
\hline & & \multicolumn{4}{|c|}{ Vessel Size } \\
\hline & & 14,000 TEU & 16,000 TEU & 18,000 TEU & 21,000 TEU \\
\hline \multirow{6}{*}{ 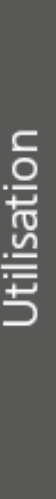 } & $100 \%$ & $100 \%$ & $97 \%$ & $91 \%$ & $89 \%$ \\
\hline & $95 \%$ & $105 \%$ & $101 \%$ & $96 \%$ & $94 \%$ \\
\hline & $90 \%$ & $110 \%$ & $106 \%$ & $101 \%$ & $98 \%$ \\
\hline & $85 \%$ & $117 \%$ & $112 \%$ & $106 \%$ & $103 \%$ \\
\hline & $80 \%$ & $123 \%$ & $119 \%$ & $112 \%$ & $109 \%$ \\
\hline & $75 \%$ & $131 \%$ & $126 \%$ & $119 \%$ & $116 \%$ \\
\hline
\end{tabular}

Fonte: DNV (2013)

\subsection{IMPACTOS NOS TERMINAIS DE CONTÊINERES E NAS SUAS OPERAÇÕES}

Na mesma publicação da DNV anteriormente citada, há um artigo de Vallø (2013) que trata sobre a adequação dos terminais a esses meganavios e como os terminais têm sido forçados a continuar a investir enormes quantidades em infraestrutura e equipamentos de forma a garantir as operações dos clientes armadores.

Como principais itens da lista estão: a questão de aquisição de portêineres que alcancem pelo menos 23 colunas (rows); aumento da capacidade de pátio e não apenas em espaço, mas melhores equipamentos de manuseio com maior capacidade de altura combinados com melhorias dos sistemas de TI ou automação; navios de 400 metros têm se mostrado um desafio para a utilização ótima de berço, em recentes operações de navios como Emma Maersk e CMA CGM Marco Polo demonstram que a combinação do planejamento de "janela de tempo" (Time windows) com alto grau de acuracidade das escalas não permite otimização de berços. A realidade de aplicação da velocidade reduzida ou inferiores à velocidade de projeto (Slow steaming) melhorou indiretamente a confiabilidade das escalas, 
pois eventuais atrasos nas operações portuárias podem ser recuperados na navegação acelerando a velocidade.

Um parêntese sobre velocidade de navios, desde 2005 que os armadores têm diminuído as velocidades médias gradualmente; conforme Brandão (2013) não se trata de um novo conceito, mas tornou-se prática no transporte marítimo, motivado principalmente pela elevação do preço de óleo combustível (bunker), o qual pode atingir em navios porta-contêineres metade dos custos operacionais.

O preço de bunker em 1999 era de US\$ 73,28 /ton., enquanto em 2013 o valor foi de US\$679,47/ton., ou seja, um aumento de mais de 8 vezes; conforme demonstra o gráfico da figura 34 e há projeções que indicam que esse valor, acompanhando a tendência do preço de barril de petróleo em 2023, supere o valor de US\$1.000,00/ton.

Figura 34 - Evolução histórica do Preço de Bunker em US\$/tonelada

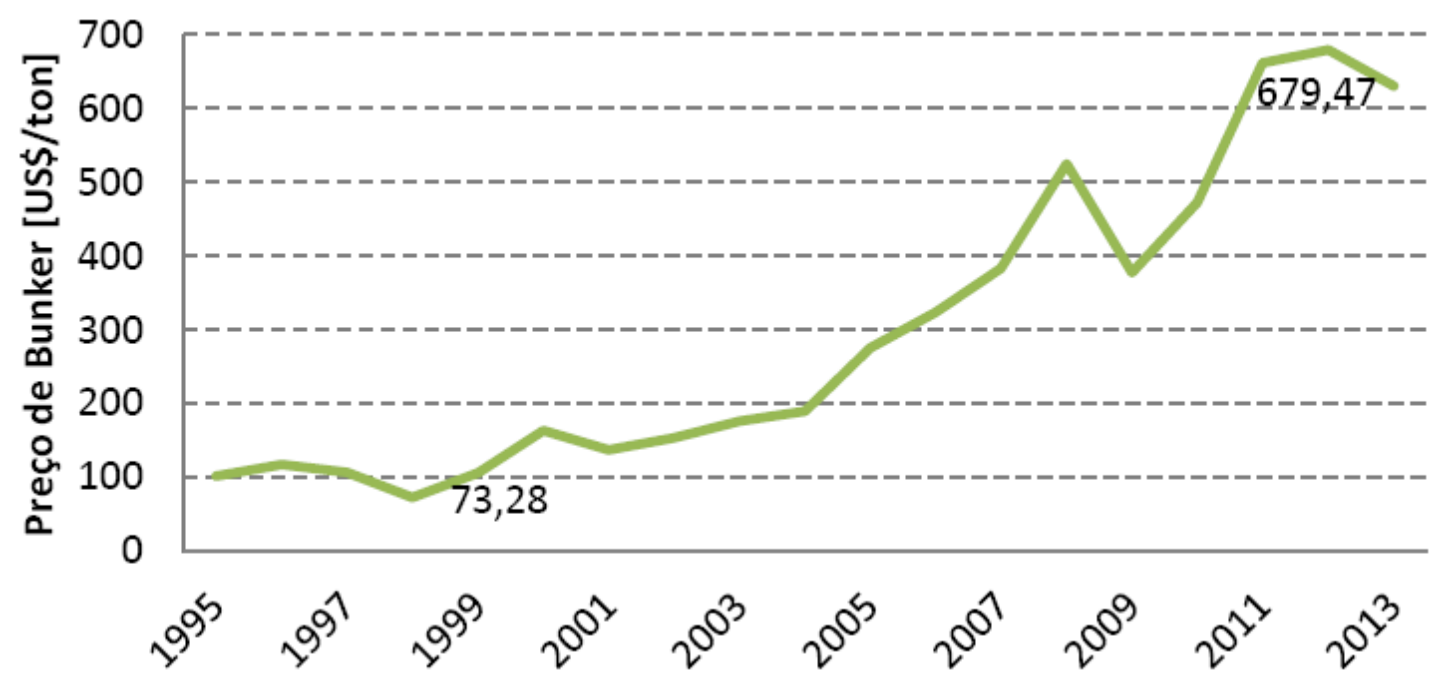

Fonte: BR (2013)

Os navios da armadora alemã Hamburg Sued têm reduzido suas velocidades de 20 nós para 16 nós na classe "Santa" (cujas principais características são: 7.100 TEUs, 300 metros de LOA, boca de 42,8 metros e calado máximo de 13,5 metros) e isso gerou uma economia de cerca de $40 \%$ de combustível, conforme gráfico ilustrado na figura 35. 
Figura 35 - Consumo de Óleo combustível em função da velocidade

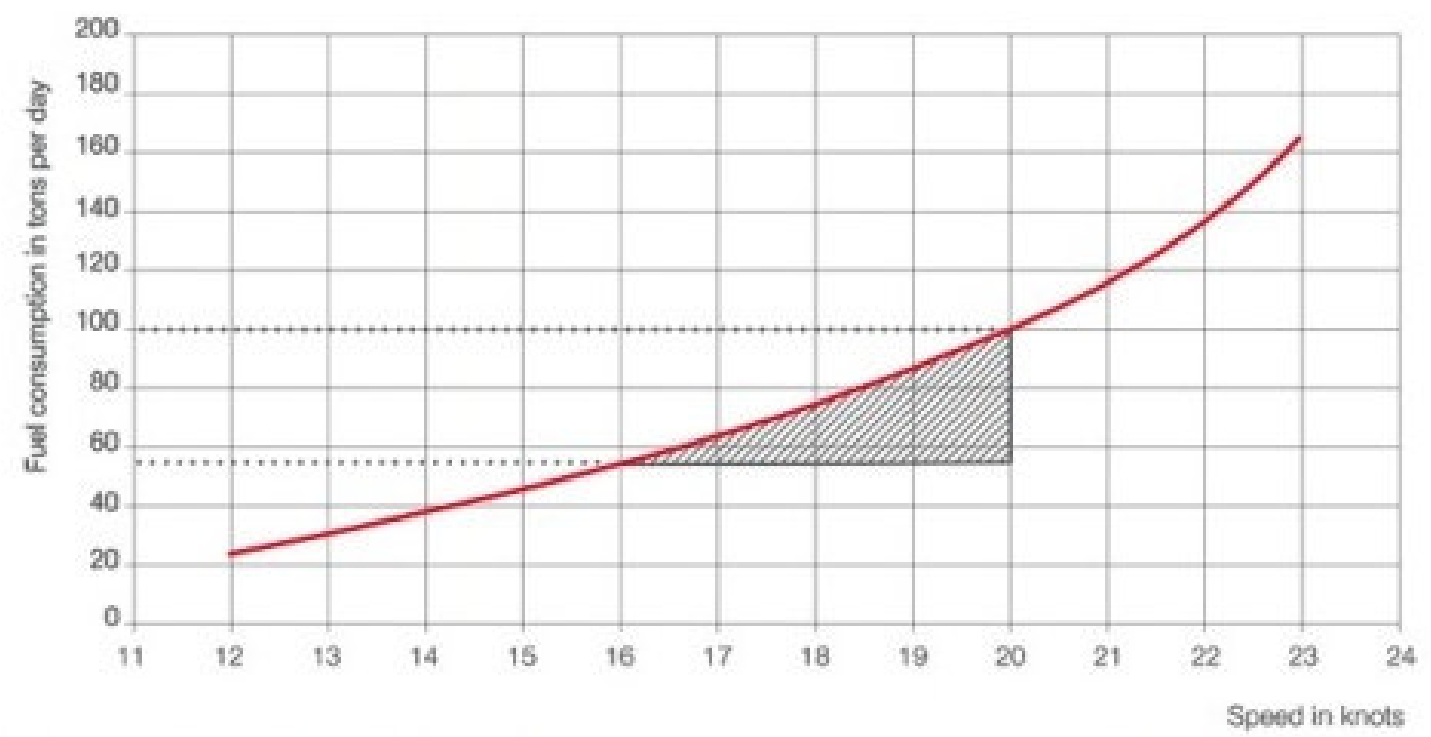

Fonte: Hamburg Sued

Outros fatores indicados por Brandão (2013) são a necessidade de redução de emissão de gases poluentes, especialmente $\mathrm{CO}_{2}$, e a absorção da frota mercante disponível durante períodos de desaceleração da economia.

Retomando Vallø (2013) sobre a questão de adequação, ele indica que a alocação de um alto número de portêineres, trabalhando por várias horas na mesma bay em virtude do volume, ocorre uma redução do custo por movimento para o terminal, enquanto o armador salva tempo, para recuperar eventuais atrasos operacionais na navegação; entretanto, indica que é difícil indicar porcentagens dessas economias nos ganhos de produtividade, mas estima valores na ordem de 3 a $5 \%$.

Ainda sobre portêineres, Vallø indica que diversos terminais já realizaram pedidos e instalações de portêineres para 24 a 25 colunas (rows) e 10 alturas (layers) no convés e com velocidades de trolley mais elevadas, exceção feita para os términos de curso na lança e trecho de elevação ou momento quando em operação dentro da cela (cellguide), itens ajustáveis na programação dos Controladores Lógicos Programáveis (CLP).

Rijsenbrij (2001) trata sobre os altos investimentos para adequação e atendimento em longo prazo das demandas em portos e terminais para operação de navios da faixa de 15.000 a 18.000 TEUs; para os portos indica que o canal de acesso deverá prover profundidades da ordem de 23 a 25 metros em virtude da 
quilha livre (keel clearance), o que acarretaria o aumento de depósito da sedimentação de material e necessidade de dragagem regular adicional; maiores bacias de manobras e evolução, assim como rebocadores mais potentes em termos de bolloard pull. Os cais irão precisar de um novo sistema de defensa (fender) e de cabeços de amarração (quay bollard); ainda sobre cais, os mesmos precisarão de redesenho, em virtude das forças e esforços dos navios, efeito dos motores laterais dos navios (bow and heck thrustors); fundações mais robustas para portêineres maiores e mais pesados, os quais necessitarão de fornecimento redundante de energia.

Considera para terminais que a produtividade de berço deverá ser da ordem de 275 a 375 movimentos/hora, seis ternos (portêineres) performando 60 a 65 movimentos/hora, o que exige uma produtividade técnica de projeto do equipamento de 100 movimentos/hora, assumindo uma estadia de 24 horas do navio no terminal, $1 / 3$ da capacidade do navio entre operações de descarga e embarque e com 22 horas efetivas de operação devem ser realizados cerca de 8.000 movimentos.

O aumento das operações de transbordo (Transhipment) acarreta uma maior movimentação interna do terminal, como, por exemplo: o reposicionamento de contêineres nas pilhas e decisões do tipo "último-minuto" para distribuição dos portos; melhora no processo e sistema de planejamento de navios em virtude do aumento considerável de volume, assim como de operações complexas de conexões com outros modais (serviços de barcaça e trens); ampliação da capacidade de pátio para absorção do volume considerado de descarga, além de espaço excedente para casos de atraso dos navios por: mau tempo ou perda de janela de atracação em portos a montante ou jusante da costa, entre outros.

Atenção especial deve ser dada também às áreas de pátio destinadas aos contêineres refrigerados (Reefers), carga perigosa, com excessos (altura, largura e comprimento) e carga geral solta ("Caixarias" e Carga de projeto); permanece a necessidade de peação e despeação, pois navios sem tampas (Hatchcoverless) continuam raros; de forma geral deverá ser dada mais ênfase às operações ininterruptas por meio de monitoramento constante dos objetivos e metas definidas e uma abordagem industrial na solução de problemas; provavelmente o aumento das demandas de pico deverão exigir equipes de trabalho mais flexíveis; necessidade do aumento da eficiência dos terminais satélites ou de apoio, os quais são conectados operacionalmente com os terminais marítimos e, por derradeiro, o alto rendimento de 
operações exigirá menos variabilidade de desempenho e não somente nas operações de cais, mas para as operações de transporte interno, operação de pátio e processos de gates, com todas as operações físicas suportadas por eventos via EDI para controle logístico. Portanto, um campo fértil para estímulo do aumento da aplicação de automação, ainda que parcial.

Contrapondo Rijsenbrij (2001), de forma bastante pragmática, Ward (2012) relata o desafio operacional de movimentar 6.000 movimentos em 24 horas em navios de 15.000 a 18.000 TEUs em cada fluxo do terminal e suas consequências.

O fluxo de navio indica que a produtividade estimada deve ser de 250 movimentos/hora e faz uma relação com o Dwell time típico dos terminais americanos; no fluxo de pátio indica os volumes de transação de gates deve ser de 340 transações/hora para uma operação uniforme de 24 horas, no caso dos gates trabalharem apenas 16 horas esse volume sobe para 560 transações/hora.

Ainda no fluxo de pátio e distribuição de equipamentos, indica um número de 22 RTGs na importação, com produtividade de 20 movimentos/hora para atendimento do navio e outros 10 movimentos/hora para atendimento dos gates, na exportação indica o uso de equipamentos do tipo top-picks (como Reach-stackers) num total de 18 equipamentos, performando 20 movimentos/hora para atender navio ou gates e estabelece uma máquina para cada 100 metros de extensão de quadra e cerca de 400 caminhões circulando ao mesmo tempo para atender às demandas do lado de mar e terra.

Em outro estudo, Rijsenbrij (2002) discorre sobre o decréscimo da capacidade técnica na movimentação de contêineres/hora, de acordo com o tipo do navio, nesse estudo é indicado que quanto maior o arranjo do navio, maiores são as perdas. 
Figura 36 - Decréscimo da capacidade técnica na movimentação de contêineres/hora

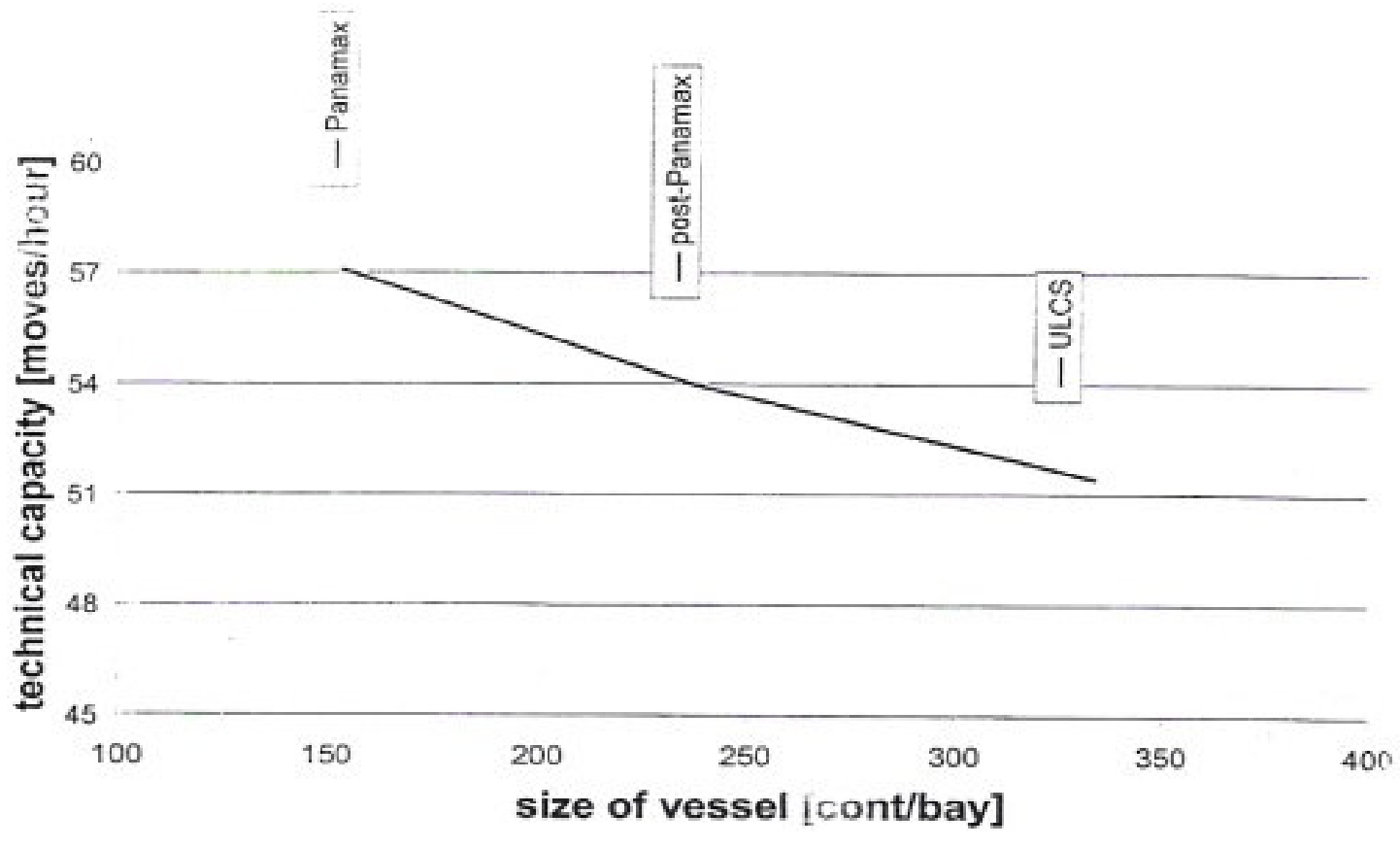

Fonte: Rijsenbrij (2002)

Uma comparação dos efeitos entre a operação de navios de 9.000 TEUs versus navios de 18.000 TEUs nos terminais, na condição Ceteris Paribus, isto é, analisando a influência de um fator sobre outro e mantidas as condições inalteradas das variáveis foi realizada por Koegeboehn (2014). A Tabela 12 apresenta a comparação.

Tabela 12 - Comparação de uso de recursos entre navios de 9.000 e 18.000 TEUs

\begin{tabular}{l|ccc}
\hline Variável & $\begin{array}{c}\text { Navios } \\
9.000 \text { TEUs }\end{array}$ & $\begin{array}{c}\text { Navios18.000 } \\
\text { TEUs }\end{array}$ & Variação \\
\hline Pico no pátio & 1,2 & 1,36 & $+13,3 \%$ \\
Slots de pátio & 14.525 & 16.340 & $+12,5 \%$ \\
Portếineres & 5 & 9 & $+80 \%$ \\
Transtêineres & 17 & 30 & $+76,5 \%$ \\
Caminhõ̃es & 27 & 46 & $+70,4 \%$ \\
Utilização dos portêineres & $59,5 \%$ & $33,1 \%$ & $-44,4 \%$ \\
Utilização dos Transtêineres & $46,1 \%$ & $36,2 \%$ & $-21,5 \%$ \\
Equipe & 1 & 1,47 & $+46,9 \%$ \\
Custo operacional por/contêiner & & & \\
Custo total por/contêiner & 1 & 1,5 & $+50,1 \%$ \\
\hline
\end{tabular}

Fonte: HPC - Hamburg Port Consulting GMbH 
Observa-se que os picos para esses meganavios são maiores, assim como a utilização de recursos, por exemplo:

- Equipamentos de movimentação de cais (portêineres),

- Pátio (transtêineres), e,

- Transferência (caminhões e terminal tractors).

E os custos com mão de obra avulsa e própria acompanham a adição desses recursos, mesmo que os volumes de movimentação sejam mantidos; em contrapartida, não há garantias de aumento da eficiência operacional na utilização dos recursos e redução do custo por contêiner.

A variável mais afetada é a necessidade de incremento de portêineres, os quais podem apresentar limitações técnicas, tais como: não alcançar transversalmente determinadas colunas (rows) do navio ou atingir as últimas alturas (layers ou tiers) dos contêineres no convés ou as primeiras alturas do porão.

Esses equipamentos possuem vida útil de aproximadamente 15 a 20 anos e estruturas de cais de 50 anos ou mais, o que exige uma longa projeção sobre quando ocorrerá o impacto do tamanho dos navios. Tal evolução dos navios deve ser avaliada no momento da compra ou troca de equipamento, para que não ocorra o subdimensionamento e, consequentemente, restrições de utilização.

A figura 37 apresenta a evolução dos portêineres desde 1960, na qual se nota o aumento de bitola entre "pernas" do equipamento, aumento do cumprimento da lança para cima do navio (Front-reach) e para trás do equipamento (Back-reach); enquanto a tabela 13 apresenta o aumento de potência do motor (Hoist HP) e velocidade de elevação (Hoist speed) e trolley (Trolley speed) de cinco gerações de portêineres adaptado de Rudolf III (2001). 
Figura 37 - Evolução dos Portêineres de 1960 - 2000
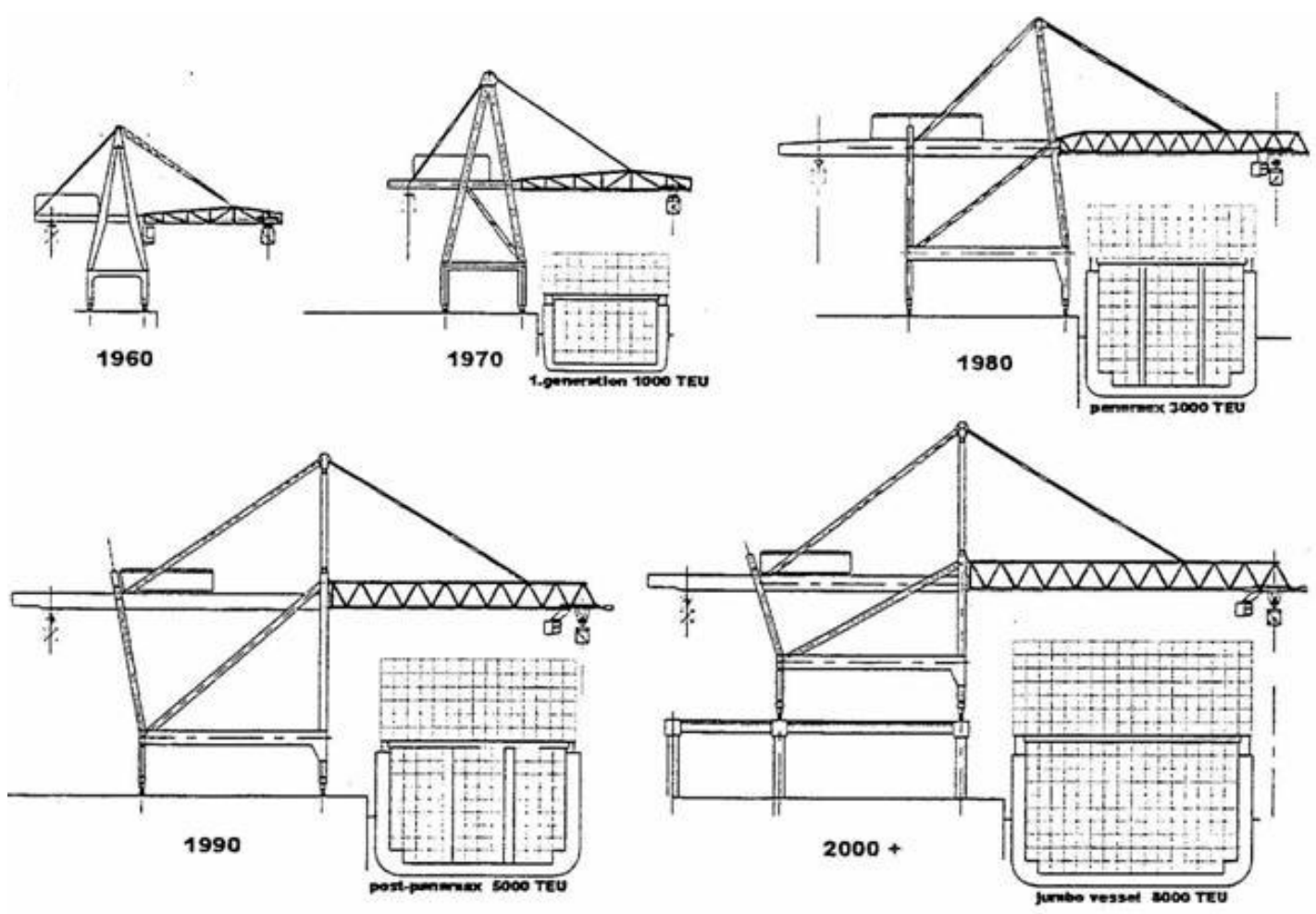

Fonte: Wijnolst e Waals (2000)

Tabela 13 - Aumento da Potência dos Portêineres

\begin{tabular}{|c|c|c|c|c|}
\hline $\begin{array}{c}\text { Geração } \\
\text { dos } \\
\text { Portêineres }\end{array}$ & $\begin{array}{l}\text { Velocidade de } \\
\text { elevação } \\
\text { Ft } / \mathrm{min}(\mathrm{m} / \mathrm{min})\end{array}$ & $\begin{array}{c}\text { Potência de Elevação } \\
\text { (HP) }\end{array}$ & $\begin{array}{c}\text { Velocidade de } \\
\text { Trolley } \\
\text { Ft/min (m/min) }\end{array}$ & $\begin{array}{l}\text { Potência do } \\
\text { Trolley (HP) }\end{array}$ \\
\hline $1^{\underline{a}}$ & $100(30,4)$ & 250 & $400(121,9)$ & 40 \\
\hline $2^{\mathrm{a}}$ & $130(39,6)$ & 400 & $500(152,4)$ & 100 \\
\hline $3^{\mathrm{a}}$ & $150(45,7)$ & 500 & $550(167,6)$ & 175 \\
\hline $4^{\mathrm{a}}$ & $175(53,3)$ & 650 & $600(182,8)$ & 200 \\
\hline $5^{\mathrm{a}}$ & $245(74,6)$ & 1000 & $800(243,8)$ & 250 \\
\hline
\end{tabular}

Fonte: adaptado de Rudolf III (2001)

Há outras classificações e caracterização de equipamentos com base em suas dimensões e no tipo de classe de navio, como ilustrado na Tabela 14; que relaciona o cumprimento de lança frontal (Front-reach) e traseiro (Back-reach), distância entre pernas (Rail gauge) e ambas as alturas de elevação (Lift Height): sobre o trilho (Above rail) e abaixo do trilho (Below rail). 
Tabela 14 - Dimensões básicas de portêineres em metros

\begin{tabular}{|c|c|c|c|c|}
\hline Classe de Navio & $\begin{array}{l}\text { Alcance } \\
\text { Frontal }\end{array}$ & $\begin{array}{c}\text { Distância entre } \\
\text { pernas }\end{array}$ & Alcance traseiro & $\begin{array}{c}\text { Altura de } \\
\text { Elevação } \\
\text { (Acima / Abaixo } \\
\text { do trilho) }\end{array}$ \\
\hline Feeder & $29-30$ & $15,2-30,4$ & 10 & 25 \\
\hline Panamax & $30-43$ & $15,2-30,4$ & 15 & $33 / 25$ \\
\hline Post Panamax & $45-56$ & $15,2-30,4$ & 25 & 42 /23 \\
\hline $\begin{array}{l}\text { Super Post } \\
\text { Panamax }\end{array}$ & $60-73,7$ & $18,2-42,6$ & 25 & $46,4 / 23,5$ \\
\hline
\end{tabular}

Fonte: Fundacion ValenciaPort a partir de dados dos fabricantes

Como exemplo de portêineres adquiridos recentemente no país, citamos os da BTP, que possuem como características: 65 metros de lança frontal, 25 metros de lança traseira, distância entre pernas de 30,4 metros, Altura de elevação acima dos trilhos de 41 metros e 17 metros abaixo do trilho; em termos de velocidades possui $240 \mathrm{~m} / \mathrm{min}$ de velocidade de trolley, e de Elevação $90 \mathrm{~m} / \mathrm{min}$ quando carregado e $180 \mathrm{~m} / \mathrm{min}$ com Spreader vazio. Quanto à capacidade de içamento, temos 50 toneladas quando trabalhando com um contêiner por vez (single), em twin 65 toneladas e sem o Spreader, diretamente no "gancho", atinge-se 100 toneladas.

As figuras de 38 a 40 ilustram as técnicas de içamento, tais como: Single e Twin picks (Figura 38), Tandem lift e Tandem line (Figura 39), Double e Triple hoist (Figura 40).

Figura 38 - Ilustração de Single e Twin Picks

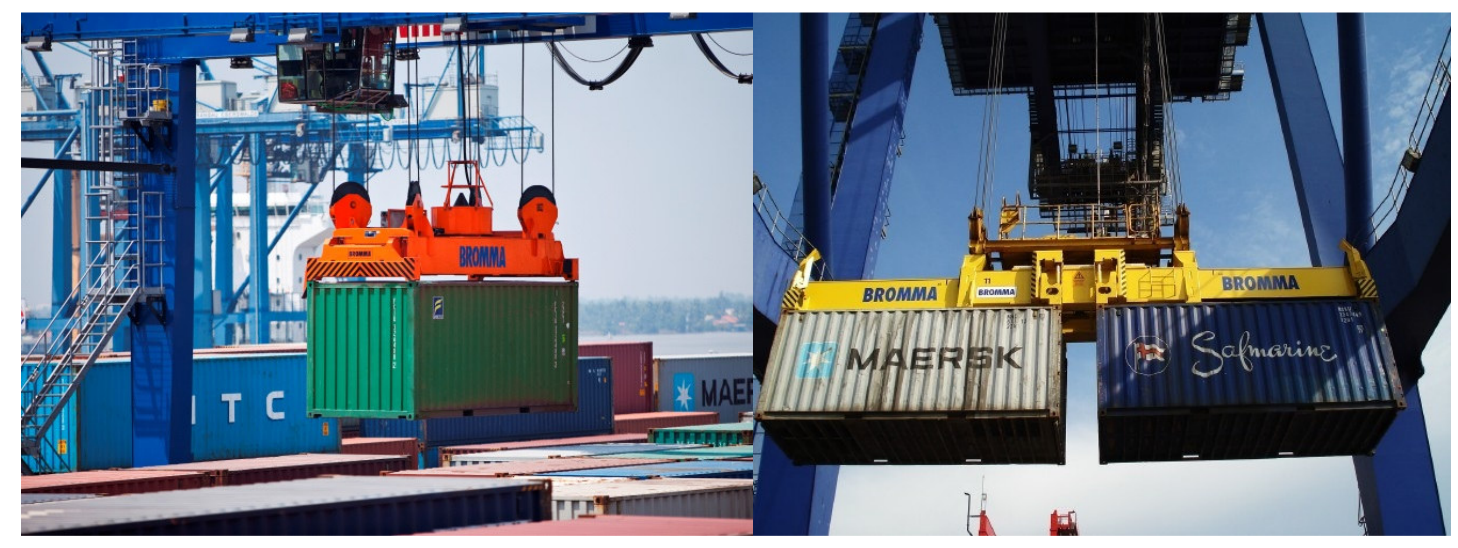

Fonte: Catálogo de spreader da Bromma 
Figura 39 - Ilustração de Tandem Lift e Tandem Line

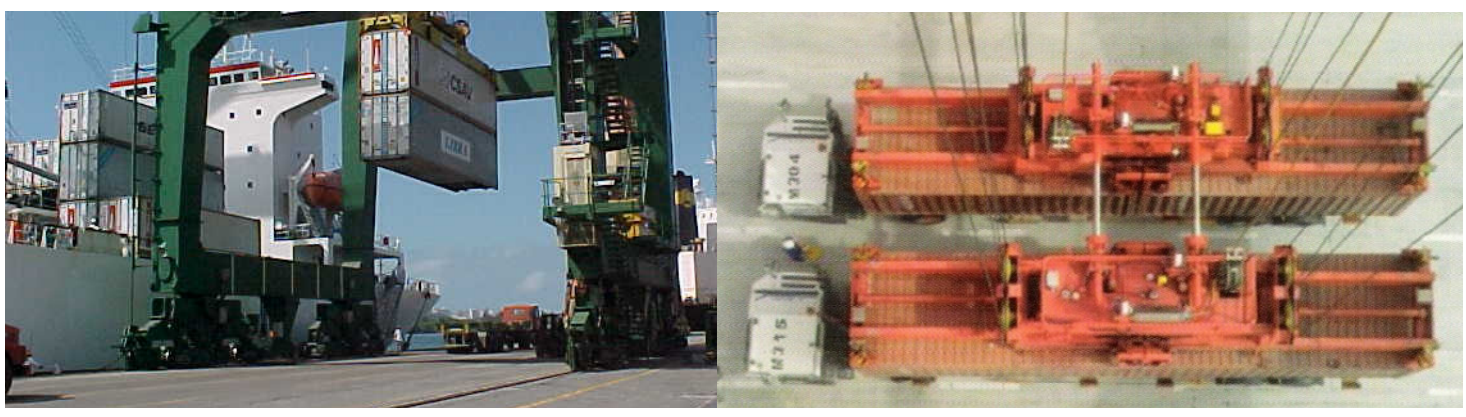

Fonte: Foto tirada pelo autor e Catálogo de fabricante de equipamentos ZPMC

Figura 40 - Ilustração de Double e Triple Hoist

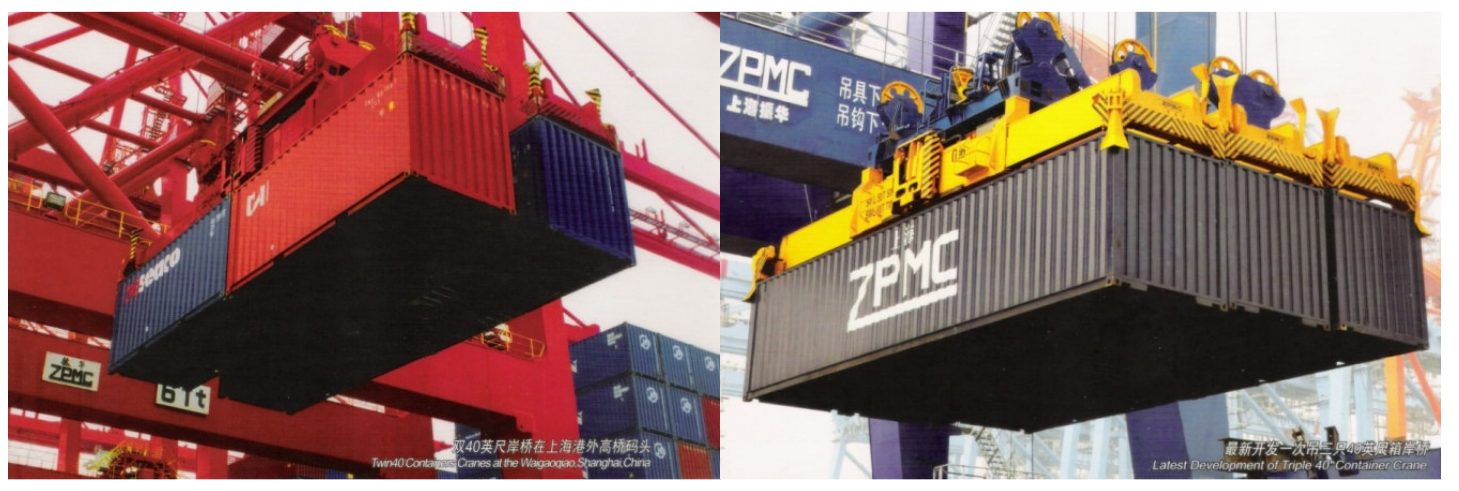

Fonte: Catálogo de fabricante de equipamentos ZPMC

Exceção feita às técnicas de içamento Single (padrão) e Twins Picks; as demais técnicas elencadas ainda sofrem desconfiança por parte de alguns operadores portuários sobre o ganho efetivo da movimentação simultânea. Provavelmente, pelo fato dessas novas técnicas de içamento, onde é possível embarcar ou descarregar combinações de contêineres do tipo: 2 x 40'; 3 x 40'; 4 x 20' ou 6 x 20' exigirem uma revisão dos processos e reorganização do trabalho, pois impacta diretamente no planejamento do navio e sequenciamento do embarque e descarga, planejamento do pátio, fluxo e posicionamento das carretas nas linhas de atendimento dos portêineres, localização e movimentação dos trabalhadores de capatazia e conferência embaixo dos equipamentos para atividades de colocação e retirada de castanhas (twist locks), registro de lacres e confirmação do embarque e descarga por meio de coletores de dados ou de forma automatizada a partir de OCR nos equipamentos.

Essas atividades apontadas no parágrafo anterior são realizadas na sua maioria manualmente em todos os terminais brasileiros; portanto, todo o ganho 
decorrente das novas técnicas de içamento e melhoria de equipamentos podem ser perdidos em virtude da operação manual com intervenção humana; certamente, podemos indicar que algumas dessas atividades seriam potencializadas se fossem realizadas de forma automatizada.

Os terminais que possuem Sistemas de Planejamento de Terminal (TOS) podem realizar os sequenciamentos de embarque e descarga de forma automática, por meio de algoritmos que cruzam as informações do plano de bordo e navio (carga em trânsito), contêineres a serem descarregados e posição de estivagem (Stowposition) dos contêineres de embarque, enviado pelo armador a partir de arquivos de Troca Eletrônica de Dados (EDI) MOVINS e BAPLIE com a distribuição e posição dos contêineres no pátio; contudo, é uma função ou módulo do sistema normalmente subutilizado.

$\mathrm{E}$, finalizando a questão dos equipamentos de cais do tipo portêineres, a figura 41 ilustra um portêiner do tipo Double trolley com uma plataforma de peação/despeação traseira (Lashing platform rear) do fabricante ABB.

Figura 41-Ilustração de Portêineres Double Trolley e de Plataforma de Lashing

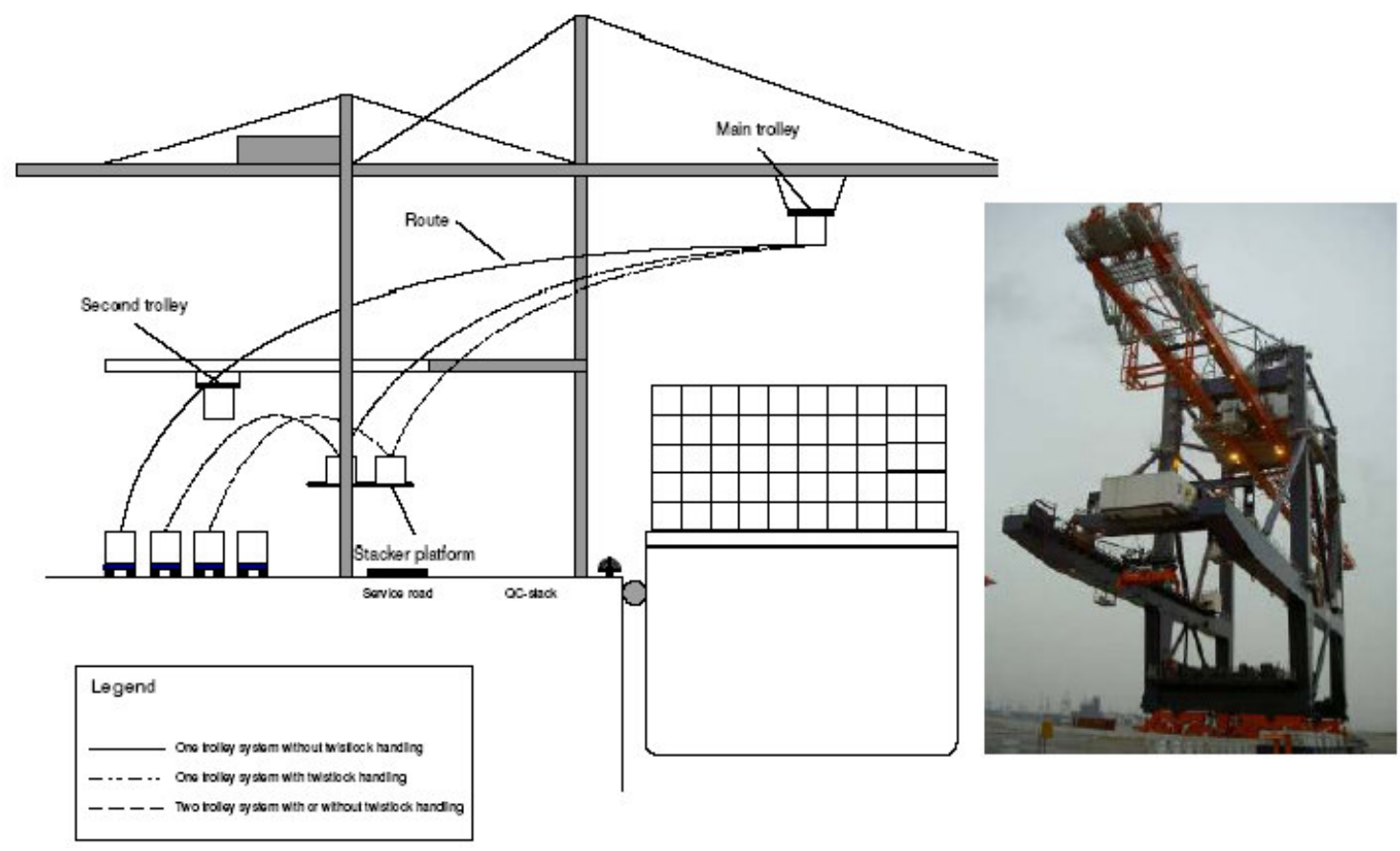

A figura 42 ilustra um conceito inovador de projeto de portêineres, o FastCrane da APMT, que objetiva um salto qualitativo na produtividade do terminal, dobrando o número de guindastes que trabalham em navios maiores; pois trata-se 
de uma estrutura suspensa sobre grandes vigas horizontais levantada a 50 metros acima do nível do cais e apoiado por quadros intermediários, os quais eliminam a restrição de espaçamento mínimo de uma bay entre dois portêineres, em virtude da distância entre bumpers (protetores) dos equipamentos.

Figura 42 - Conceito de FastCrane

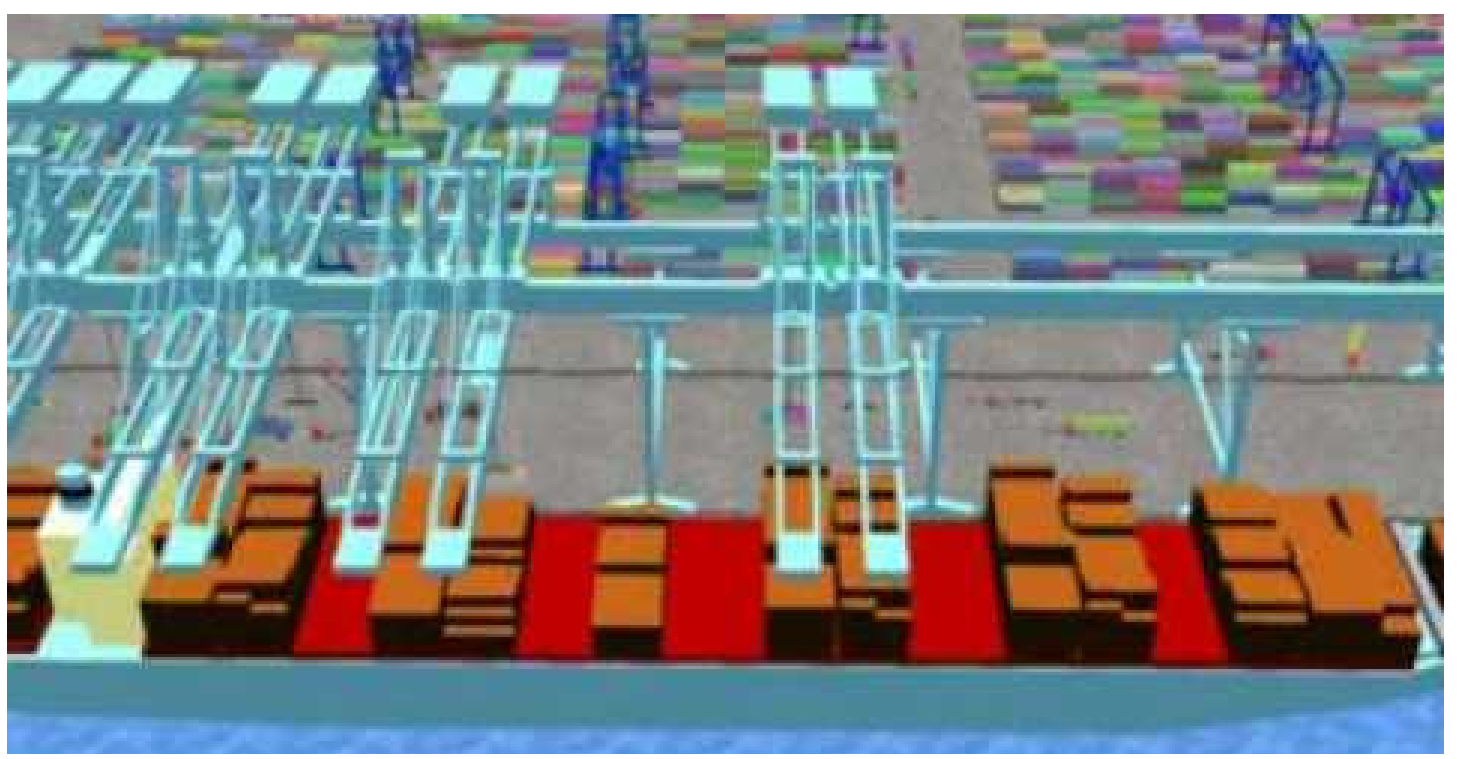

Fonte: APMT

Ainda tratando de conceitos inovadores, a figura 43 desenha um portêiner com capacidade de produção de 100 movimentos/hora.

Figura 43- Conceito de Portêiner da TUDelft Transport Technologie

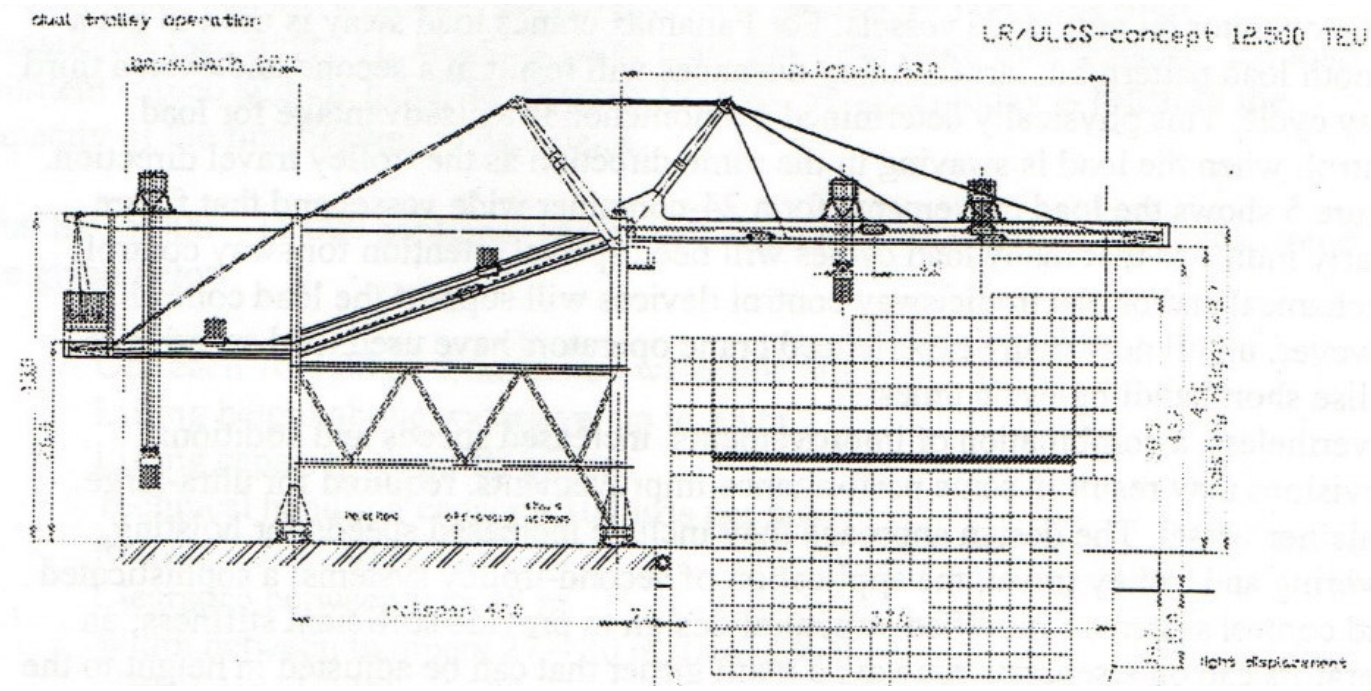

Fonte: Rijsenbrij (2001) 
Uma comparação de terminais de contêineres com sistemas de produção, e descrição dos tipos de equipamentos de movimentação e tecnologias de automação serão tratados mais adiante no capitulo 3 . 


\section{TERMINAIS DE CONTÊINERES COMO SISTEMA DE PRODUÇÂO E DESCRIÇÂO DE TECNOLOGIAS E DISPOSITIVOS PARA AUTOMAÇÂO}

\subsection{TERMINAIS DE CONTÊINERES COMO SISTEMA DE PRODUÇÃO}

Moreira (2000) explica um Sistema de Produção como um conjunto de atividades e operações inter-relacionadas envolvidas na produção de bens (indústria) ou serviços; indicando que o sistema não age sozinho e nem de forma isolada, sendo suscetíveis às influências internas e externas da organização, as quais podem afetar o seu desempenho. Complementando, as influências dos chamados Stakeholders nas operações dos terminais portuários, especialmente de contêineres são representativas; fazem parte desse grupo: SEP, ANTAQ, Autoridade Portuária, Receita Federal, ANVISA, MAPA, Marinha, Exército, Praticagem, Armadores, Agentes, Transportadoras Rodoviárias, Transportadores ferroviários, Órgãos ambientais anuentes (IBAMA, CETESB), Prefeituras, Importadores, Exportadores, Despachantes, Prefeituras, Companhias de Engenharia de tráfego, ONGs, Concorrentes, entre outros.

Groover (2011) resumidamente define um Sistema de Produção como um conjunto de pessoas, equipamentos e procedimentos organizados para realizar as operações de produção de uma empresa. E indica que esses sistemas são divididos em dois níveis ou categorias, isto é: Instalações (a fábrica, os equipamentos e a forma como estão organizados) e Sistemas de Apoio à Produção (conjunto de procedimentos utilizados no suporte da produção e solução de problemas técnicos e logísticos).

Fundamentado nas definições anteriores, podemos considerar um terminal de contêineres como um sistema de produção e defini-lo como um complexo industrial orientado por processos ao desempenho operacional com a missão de ser uma interface eficiente e econômica. E, com a mesma divisão de níveis, a saber: Instalações (o cais, o pátio, os gates, seus equipamentos de movimentação (portêineres, RTGs,) e Sistemas de Apoio à Operação (conjunto de procedimentos e instruções de trabalho, também conhecidos como Standard Operating Procedures (SOPs) e do Sistema de Operacional do Terminal ou Terminal Operating System, doravante denominada simplesmente TOS, utilizados no suporte das atividades de 
planejamento, controle e gerenciamento das operações de navio e pátio; o qual será tratado de forma mais detalhada nesse trabalho).

Nos sistemas de produção, as instalações incluem também o layout da fábrica, que se refere à organização física dos equipamentos; os quais normalmente estão dispostos em grupos lógicos de trabalho e trabalhadores. Em um terminal de contêineres, não é diferente, o layout do terminal, localização das quadras, sentido das portas dos contêineres, fluxos no cais e pátio, localização de escâneres e balanças, estrutura dos gates e áreas de acomodação de veículos, largura das ruas de fluxos, linhas de atendimento de veículos nos RTGs, linhas de passagem e atendimento embaixo dos portêineres, área de back-reach (atrás) dos portêineres para colocação de tampas, arranjo das equipes de trabalhos e composição dos ternos de trabalhadores são itens fundamentais para o nível de serviço do sistema.

O trabalhador portuário sempre foi uma discussão difícil, delicada e com avanços lentos no decorrer dos últimos anos, resultado principalmente da fórmula vigente do trabalho portuário e do uso do Trabalhador Portuário Avulso (TPA) nas atividades de Capatazia, Estiva, Conferência de Carga, Conserto de Carga, Vigilância das embarcações e o Bloco; e porque não dizer da própria origem das atividades de movimentação portuária, que se confundem com as próprias origens do trabalho humano e que está presente nas sociedades humanas desde o aparecimento das cidades (PINTO; FLEURY, 2004). Com o decorrer do tempo, um conjunto de fatores econômico-sociais e as características do trabalho portuário contribuíram para que as operações portuárias fossem feitas, exclusivamente, por determinadas categorias de trabalhadores, as quais conquistaram direitos assentados em normas legais, inclusive, em convenções da Organização Internacional do Trabalho (OIT), como exemplo, a Convenção № 137 que versa sobre as Repercussões Sociais dos Novos Métodos de Manipulação de Cargas nos Portos visando à proteção do trabalhador portuário diante de todo o processo de redução dos quadros, flexibilização e automação que marcou a Europa a partir da década de 1970.

Aliás, sobre a convenção anteriormente mencionada e proteção contra a automação, Basilio (2009) indica que com a promulgação da lei 8.630/93, a chamada lei de modernização dos portos, o Brasil ratificou a mencionada convenção por meio do Decreto oㅜ 1.574/95, portanto, integrando a nossa legislação ordinária desde então; e que no Capítulo II, artigo $7^{\circ}$, inciso XXVII da Constituição Federal de 
1988 consta o texto de proteção em face da automação, na forma da Lei. Recentemente, no porto de Santos, começou o sistema de alocação de ternos de trabalhos mistos (avulsos e vinculados no sistema das Consolidações das Leis do Trabalho (CLT)) nas atividades de estivagem a bordo de navios e capatazia.

Há três categorias básicas em termos de participação humana nos processos produtivos, conforme ilustra a figura 44.

a) Sistemas de trabalho manual;

b) Sistemas trabalhador-máquina e

c) Sistemas automatizados.

Figura 44 - Categorias básicas em termos de participação humana no processo

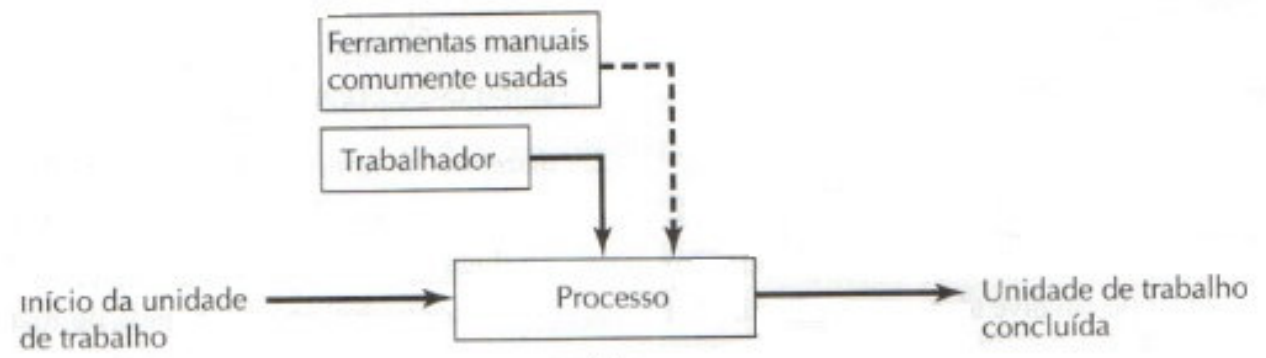

(a)

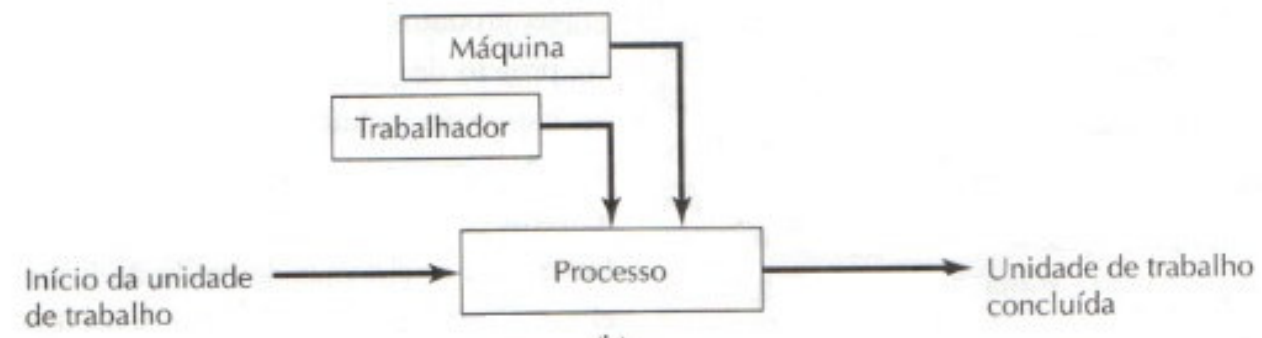

(b)

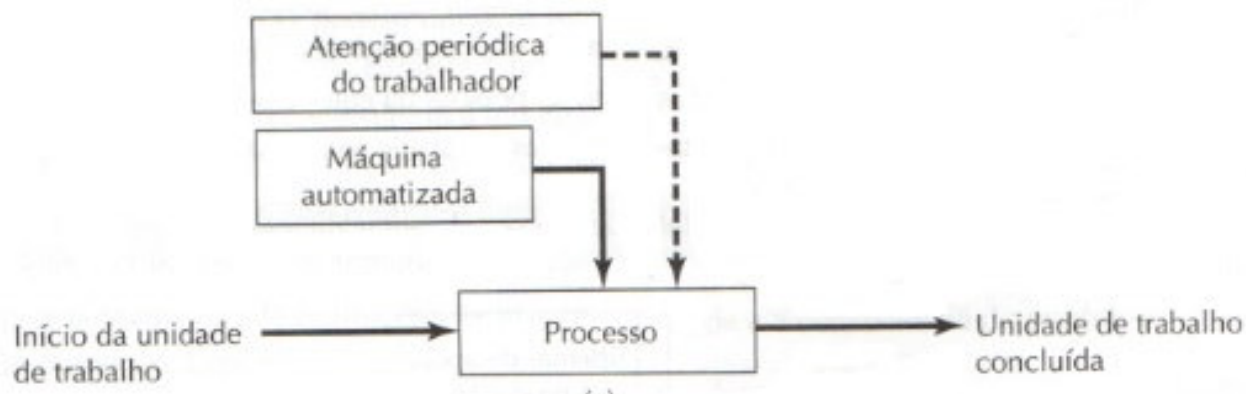

(c)

Fonte: Groover (2011)

Descrevendo os sistemas de trabalho manual (a) são aqueles formados por um ou mais trabalhadores que executam uma ou mais tarefas sem ajuda de 
ferramentas motorizadas; por exemplo, um inspetor de qualidade utilizando um micrometro para medir uma peça. Um trabalhador operando um torno em uma ferramentaria é um exemplo do sistema trabalhador-máquina (b) que é um dos mais utilizados e consiste na combinação de um ou mais trabalhadores e um ou mais equipamentos. E, finalmente, os sistemas automatizados (c) são aqueles, os quais um processo é executado por uma máquina sem a participação direta de um trabalhador humano.

\subsection{COMPARAÇÕES DE PROCESSOS TRADICIONAIS VERSUS PROCESSOS AUTOMATIZADOS EM TERMINAIS DE CONTÊINERES}

A partir da descrição do processo tradicional de embarque de contêineres, será realizada uma comparação com o mesmo processo de forma automatizada; permitindo identificar e descrever as principais tecnologias de automações existentes em terminais automatizados e semiautomatizados.

\subsubsection{PROCESSO TRADICIONAL DE EMBARQUE DE CONTÊINERES E IDENTIFICAÇÃO DAS CATEGORIAS DE PARTICIPAÇÃO HUMANA}

Tomando a operação de embarque de contêineres no cais como um exemplo de um processo operacional, seguindo o processo pela ordem da Figura 45, tem-se:

- Etapa 1 - O embarque do contêiner;

- Etapa 2 - A atividade de capatazia e conferência;

- Etapa 3 - A transferência ou transporte horizontal cais-pátio e

- Etapa 4 - O recebimento/entrega no pátio/pilha.

Nesse processo de embarque, observam-se as três categorias básicas em termos de participação humana nos processos produtivos, descritas anteriormente no item 3.1 e ilustrado na figura 45. 
Figura 45 - Ciclo do Processo de Embarque/Descarga

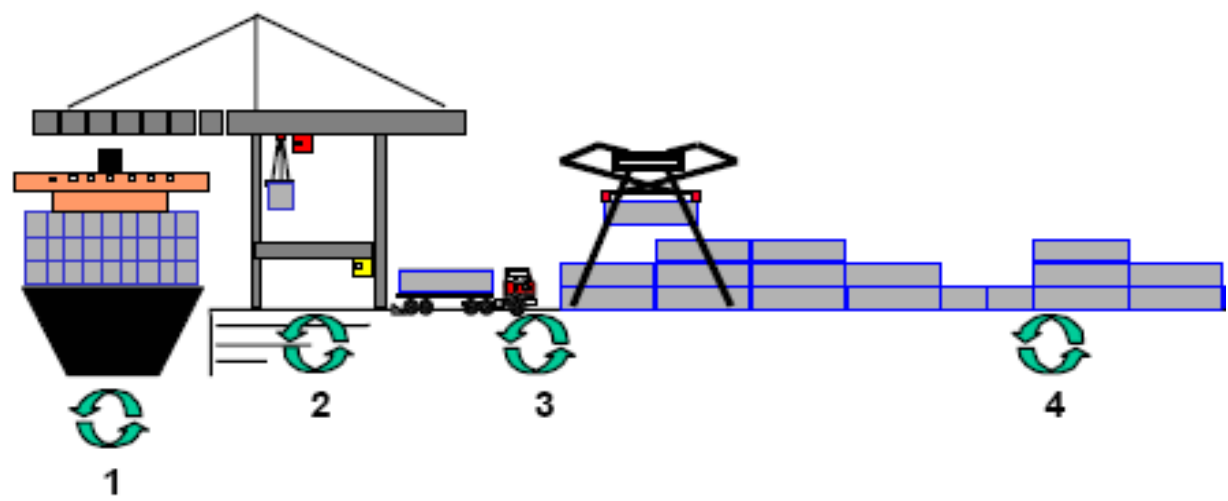

A figura 46 também ilustra o processo de embarque em Twin (dois contêineres de 20') realizado pelo operador de portêiner (Etapa 1), representando dessa forma o sistema trabalhador-máquina.

Figura 46 - Marcas nos portêineres para abertura de Spreader

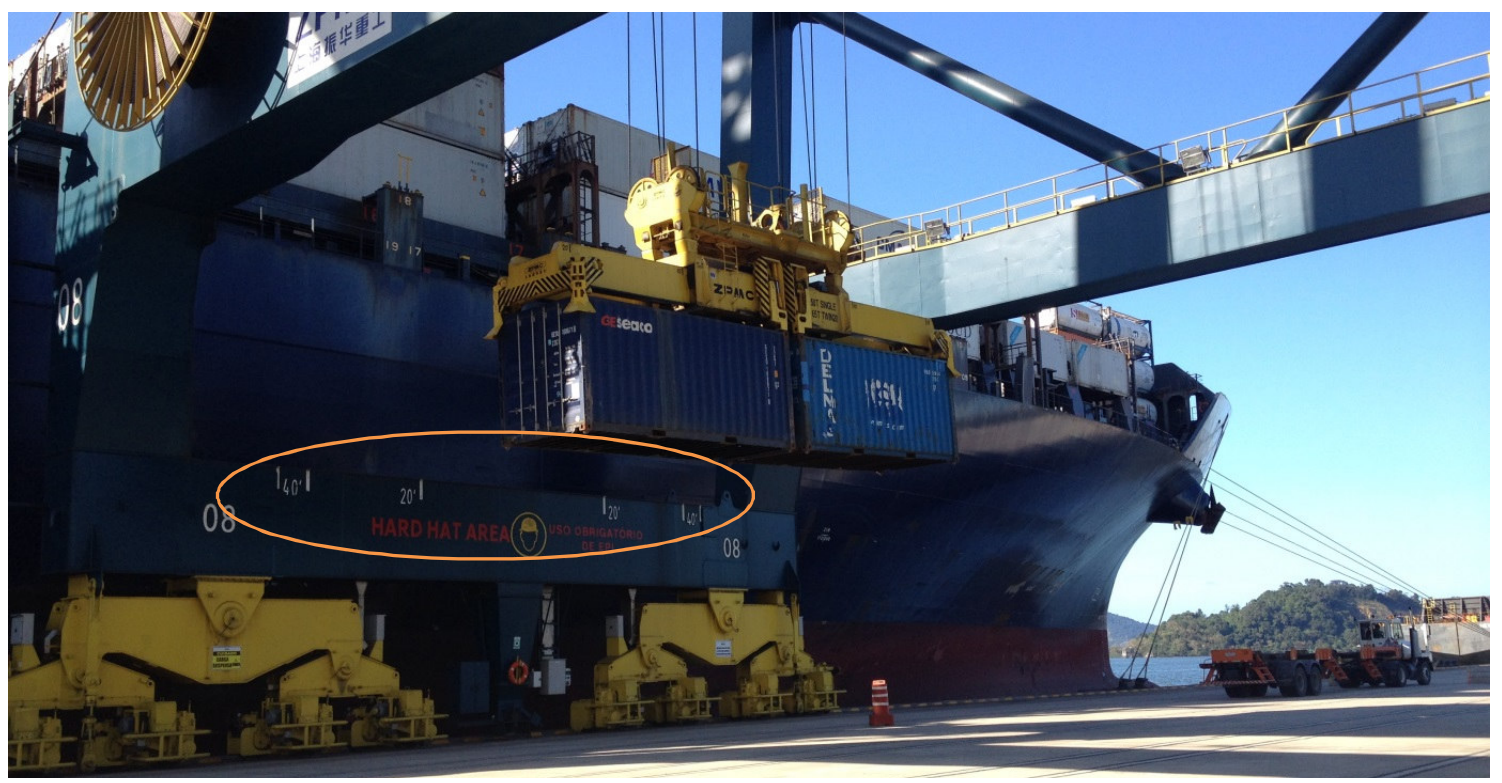

Fonte: Fotos do acervo do Autor

Considerando o processo de embarque, no qual o trabalhador de capatazia (Etapa 2) realiza normalmente duas tarefas independentes, a primeira de auxiliar no posicionamento da carreta corretamente no alinhamento da faixa de atendimento e de abertura do Spreader, para em seguida colocar os diferentes tipos de castanhas ou Twistlock, o que representa o sistema de trabalho manual, uma vez que ambas as atividades são feitas manualmente e sem uso de ferramenta; em alguns casos 
utilizam cones para marcação do posicionamento da carreta ou orientação por meio de marcas pintadas na perna dos portêineres (ver figura 46).

$\mathrm{Na}$ figura 47 observa-se o trabalho de capatazia em terra, na colocação de Twistlocks nos contêineres que serão embarcados, conforme plano de bordo, peação (Lashing) e determinação da tripulação do navio. Essa atividade é costumeiramente supervisionada por um conferente de carga, que aponta o tipo de Twistlock que deve ser colocado no contêiner; conferentes de carga também possuem a função de registro do embarque e descarga do contêiner, assim como registro dos números de lacres dos contêineres e avarias.

Figura 47- Processo de colocação de Castanhas ou TwistLocks em contêineres de embarque

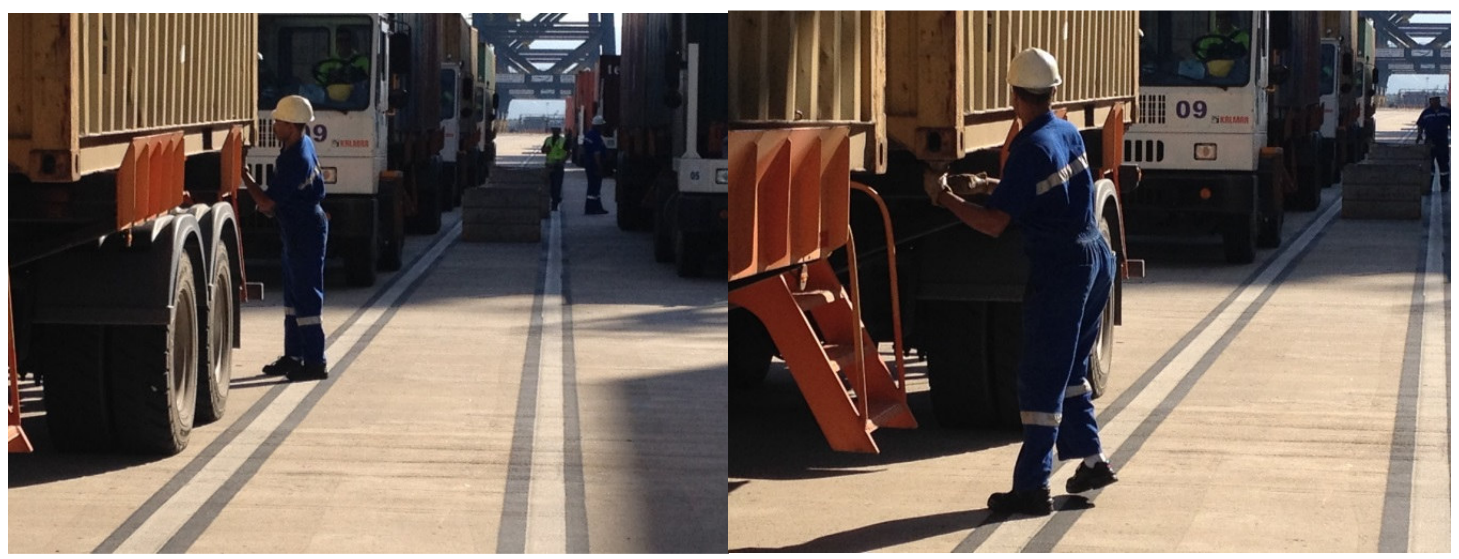

Fonte: Fotos do acervo do Autor

A figura 48 ilustra alguns tipos de TwistLocks existentes nas operações de navios.

Figura 48- Exemplos de Tipos de TwistLocks
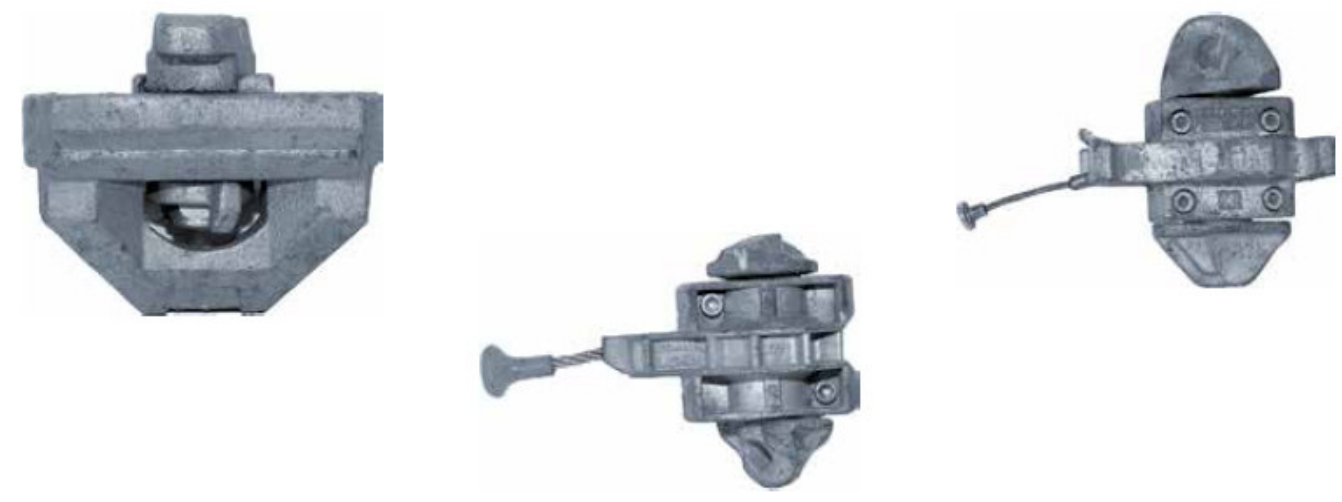
Completa esse processo o transporte horizontal cais-pátio realizado pelos motoristas de caminhões (Etapa 3) e o carregamento pelos operadores de RTG (Etapa 4) no pátio, outros dois exemplos de sistema trabalhador-máquina.

E mesmo em sistemas de operação tradicional, é possível identificar sistemas automatizados; há nos portêineres uma série de dispositivos, como o CLP, o qual executa funções de "automação menor", tais como: redução de velocidade do Trolley do equipamento, conforme velocidade do vento, e redução da velocidade de elevação de acordo com a distância do container do chassi da carreta, apenas para citar duas.

\subsubsection{PROCESSO AUTOMATIZADO DE EMBARQUE DE CONTÊINERES E DESCRIÇÃO DAS TECNOLOGIAS PARA AUTOMAÇÃO EXISTENTES}

Todas as etapas do processo de embarque de contêiner descritas anteriormente são passíveis de automação. Iniciando pela mais simples: o posicionamento da carreta presente na Etapa 2.

Esse processo poderia ser executado por meio de tecnologias conhecidas e experimentadas na indústria portuária, as quais são chamadas de Sistema de Posicionamento de Carreta (Truck Positioning System ou Trailer Positioning System) que consiste no uso de sensores, lasers e lâmpadas indicativas de posicionamento instaladas nas pernas dos portêineres (e no chassi dos equipamentos), em locais de fácil visualização, para orientação do local correto de parada pelo motorista. Ver figura 49. 
Figura 49 - Sistema de Posicionamento de Carreta através de Sensor

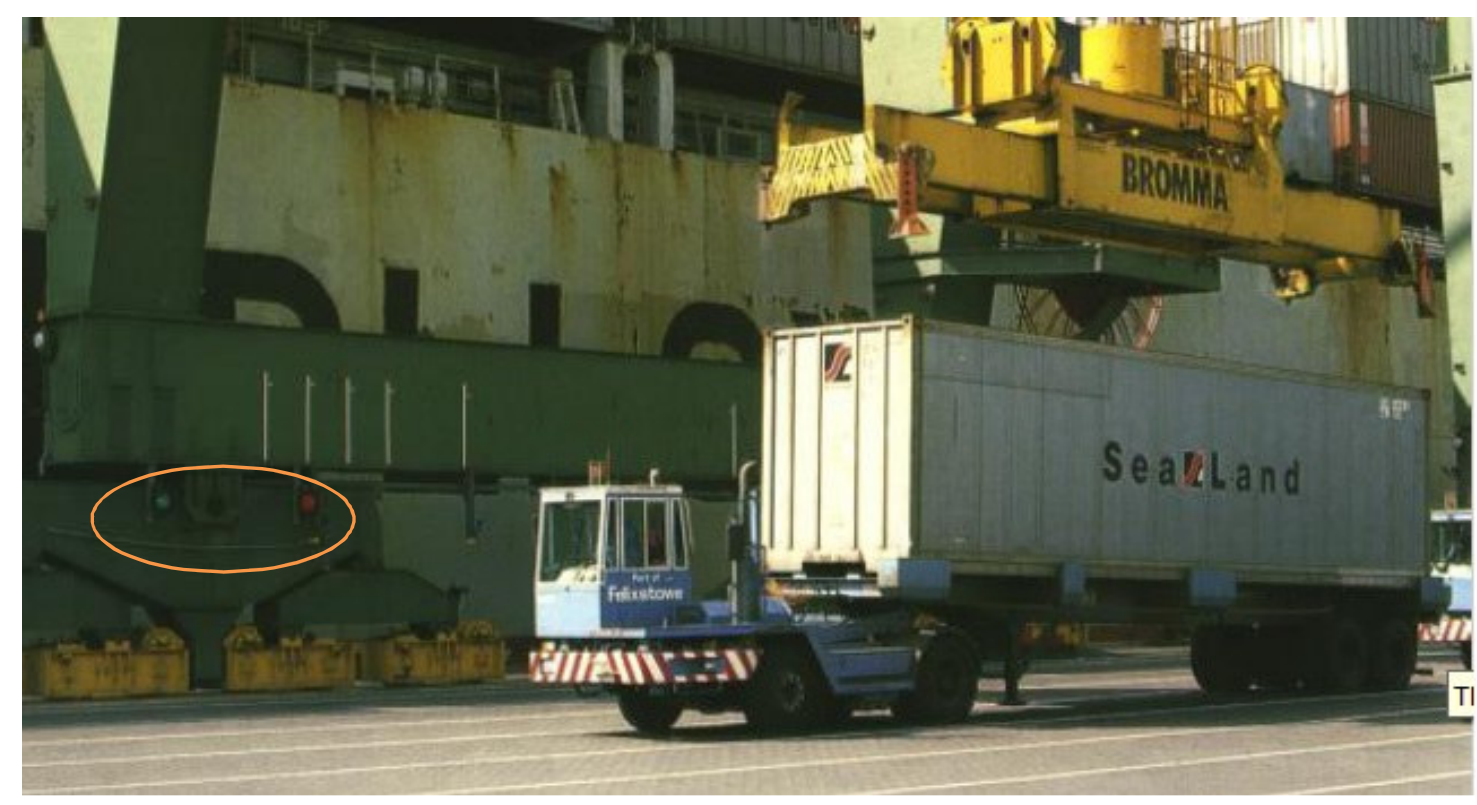

Fonte: Catálogo da ITS

O processo seguinte, presente na Etapa 2, é a colocação e retirada de TwistLocks, realizada por meio de Sistema Automático de Colocação e Retirada de TwistLocks (Automatic TwistLock Handling System), ilustrado nas figuras 50 e 51 . Trata-se de nova tecnologia em fase de experimentação e aprovação pela indústria. Esse sistema objetiva finalizar com uma operação manual intermediaria entre operação do portêiner e a transferência para o transporte horizontal.

Comparando tempos entre o sistema manual e o automatizado, o tempo para remoção e colocação de quatro Twistlocks em um container de 40' (12 metros) utilizando dois funcionários de capatazia (um de cada lado do contêiner) é aproximadamente 20 segundos; com o uso desse sistema o tempo despenca para próximo de zero e há a questão relevante de segurança do trabalhador e de possibilidade de integração com outros dispositivos, como balanças.

Porém, possui algumas desvantagens: não opera $100 \%$ dos tipos de Twistlocks existentes, a faixa indicada pelo fabricante BROMMA é de $95 \%$ e há questão de layout de equipamentos, esse sistema foi desenvolvido para Straddle Carriers ou Auto Straddle Carrier (ver equipamento na figuras 50) ou para portêineres que possuem plataforma de Peação/Despeação (Lashing Plataform, disponível nas figuras 52 e 53). 
Figura 50 - Sistema Automático de Colocação e Retirada de TwistLocks

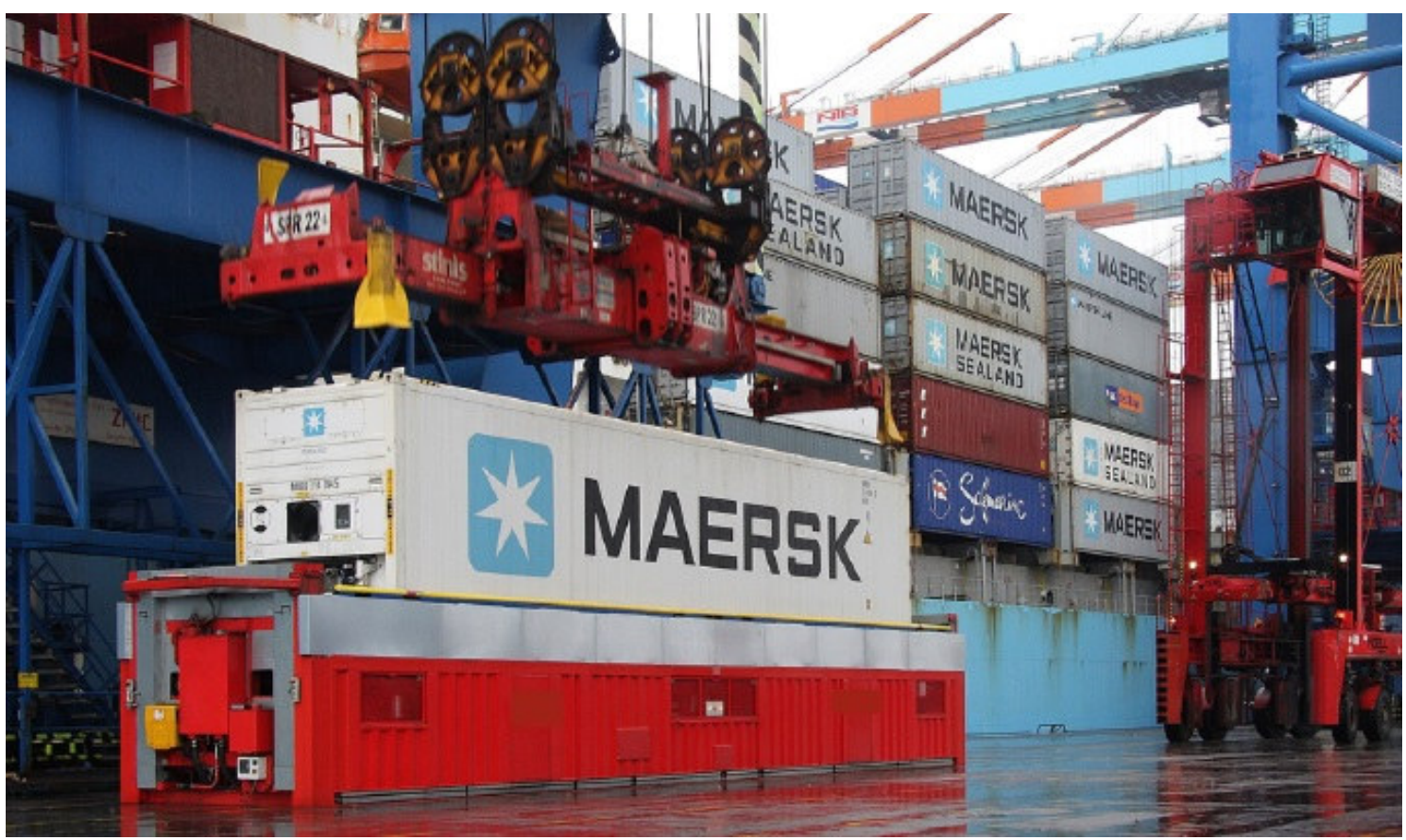

Fonte: Catálogo da Bromma e KALP Technology GmbH

Outro exemplo desse sistema (ilustrado na figura 51) é da empresa inglesa RAM Spreaders que admite uma redução de $75 \%$ da carga de trabalho manual. O sistema é composto de estrutura metálica que suporta os contêineres, e um sistema de guias de posicionamento de precisão dos contêineres e um computador integrado para acionamento dos módulos pelo operador.

Figura 51 - Sistema Automático de Colocação e Retirada de TwistLocks

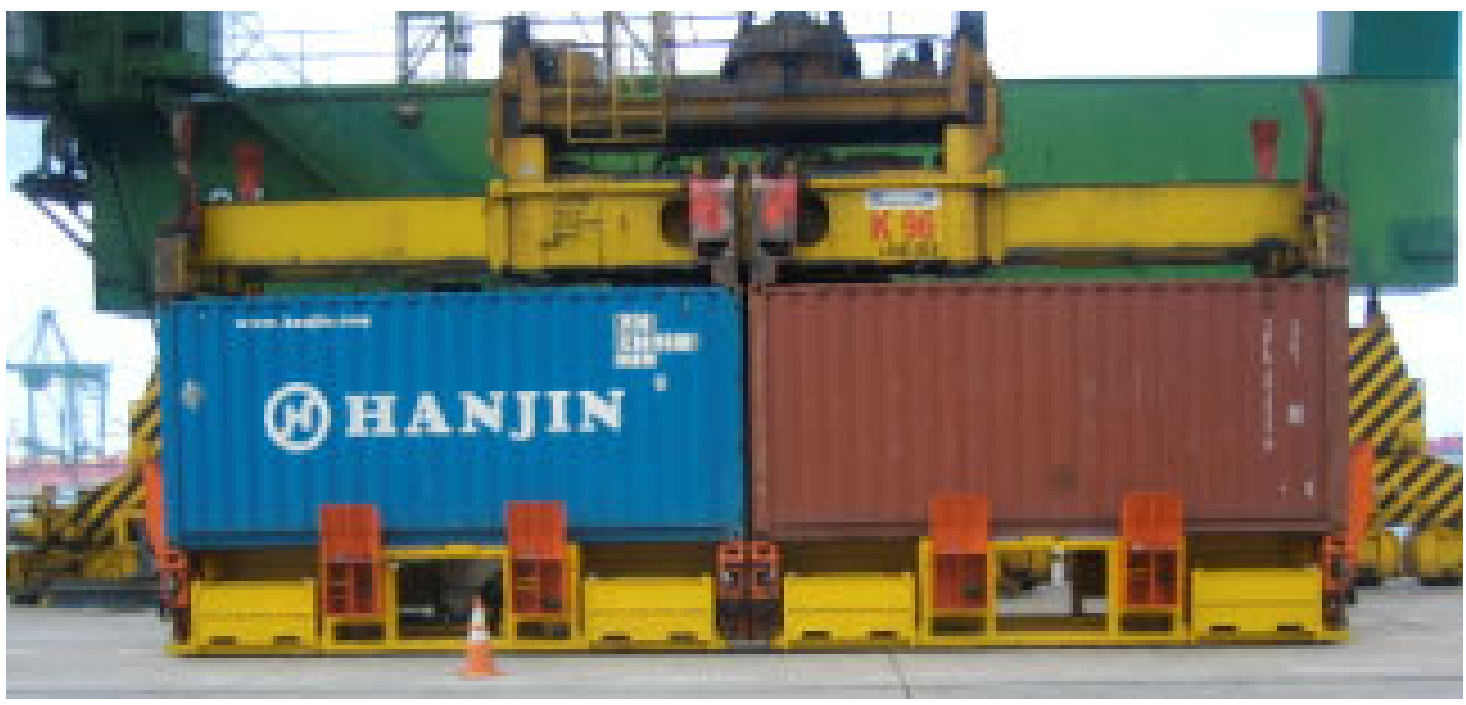

Fonte: RAM Spreaders 
Figura 52 - Sistema Automático de Movimentação de TwistLocks instalado em plataforma de peação/despeação

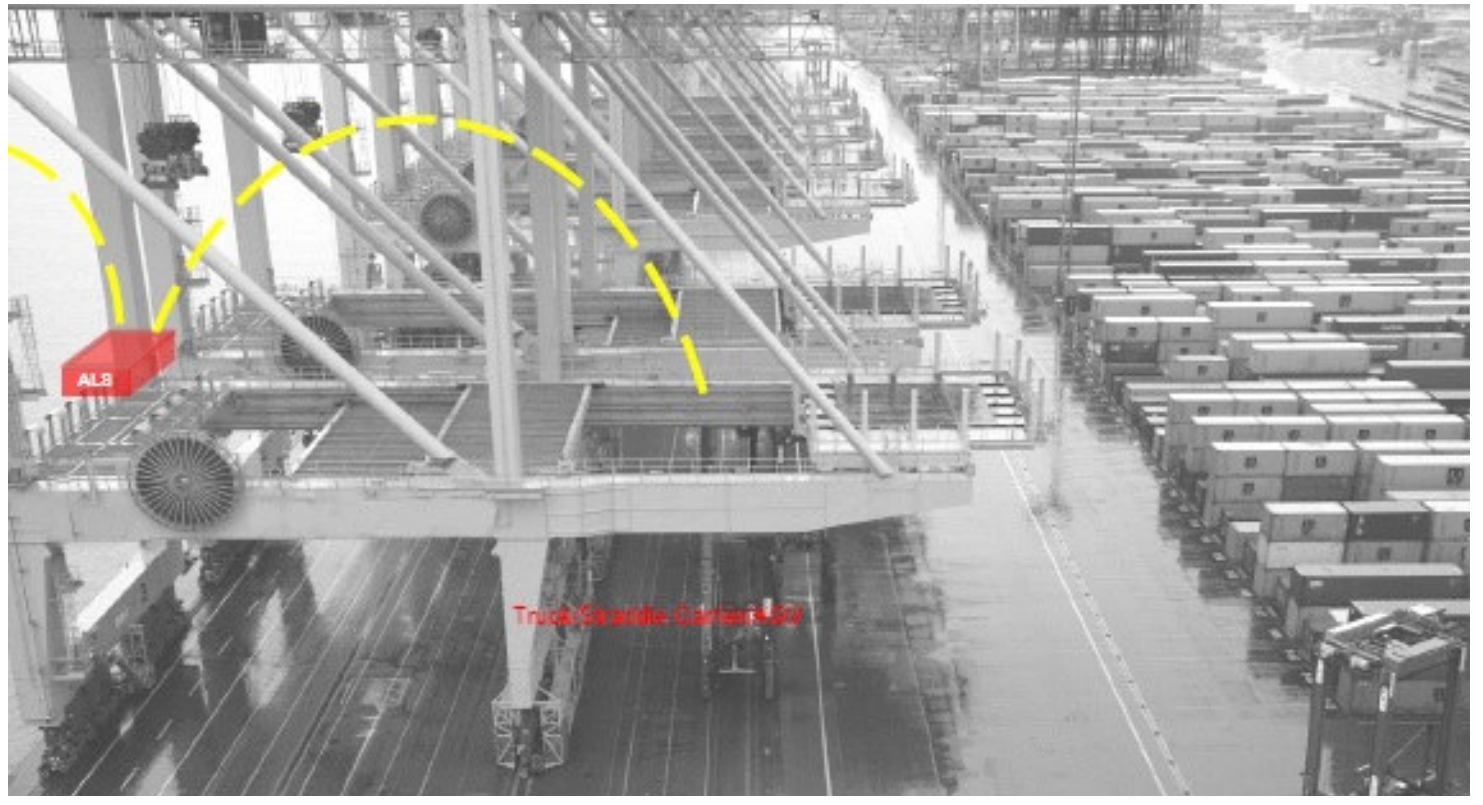

Fonte: Catálogo da Bromma e KALP Technology GmbH

Figura 53 - Plataforma de Lashing em um dos portêineres Double trolleys do Terminal de Contêineres Burchardkai (Hamburgo)

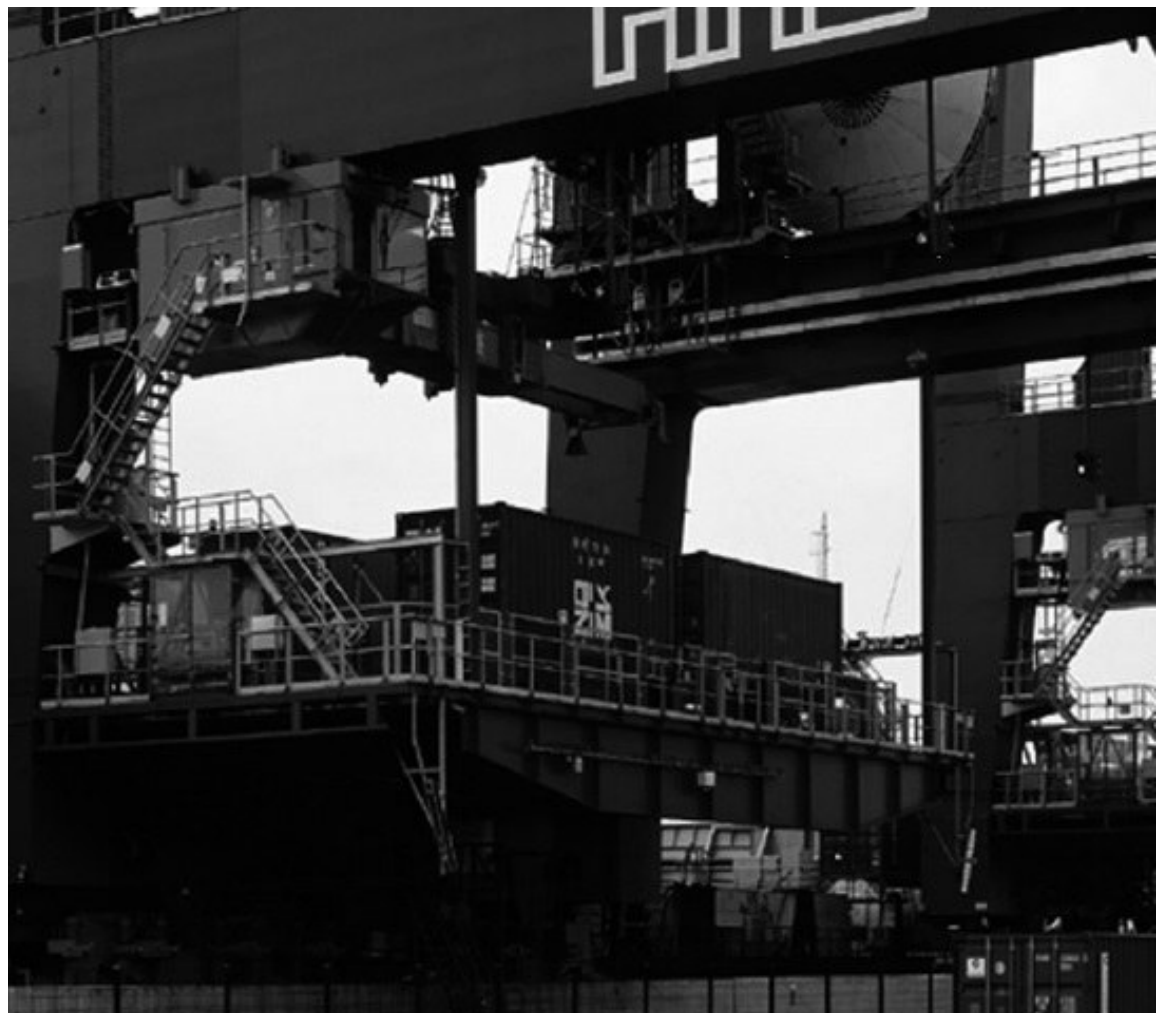

Fonte: Catálogo da Bromma e KALP Technology GmbH 
Ainda integrante do processo na Etapa 2 , há as atividades de conferência de carga (registro do embarque e descarga do contêiner, números de lacres e avarias) que podem ser substituídos pelo uso de OCR nos portêineres e de tecnologia de lacres eletrônicos. Essas tecnologias serão descritas posteriormente, ao descrever suas aplicações nos processos de Gates.

Seguindo para a Etapa 3 do processo, a transferência ou transporte horizontal cais-pátio; etapa essa por onde se iniciaram as discussões e projetos de automação.

Conforme Dobner (2014), o desenvolvimento dos primeiros Veículos Guiados Automaticamente (AGVs) iniciaram com a Gottwald (hoje empresa integrante do grupo TEREX) em parceria com o ECT de Roterdã, entre os anos de 1987 a 1992; tendo a primeira operação comercial iniciada em 1993, com 48 AGVs do tipo dieselhidráulico para 40 toneladas, velocidade de 3 metros/segundo (aproximadamente 11 $\mathrm{Km} / \mathrm{h}$ ) e posicionamento via transponders em único eixo de direção (ver figura 54).

Figura 54 - AGVs operando no ECT (Roterdã)

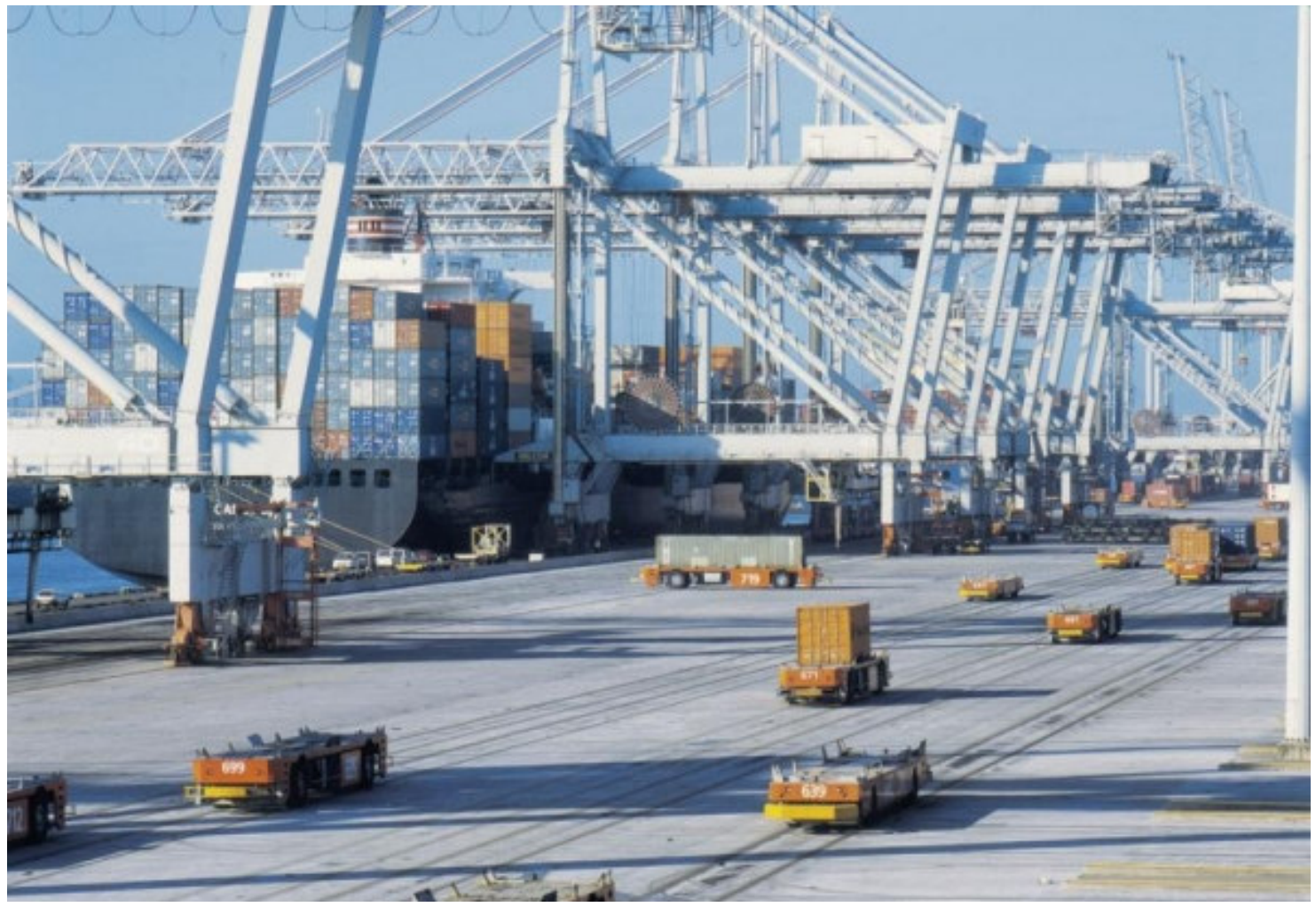

Fonte: Porttechnology Magazine 
Em 2002, após nove anos de operação, uma segunda geração de AGVs é lançada com melhorias significativas nas operações do CTA da Alemanha, tais como: alteração para diesel-elétrico; operação automatizada do lado de terra na área de backreach dos portêineres, operação de Twins (2 × 20') para 60 toneladas e a possibilidade de mudança de faixa ou linhas de movimentação. (vide figura 55).

Figura 55 - AGVs operando na área de backreach do CTA (Alemanha)
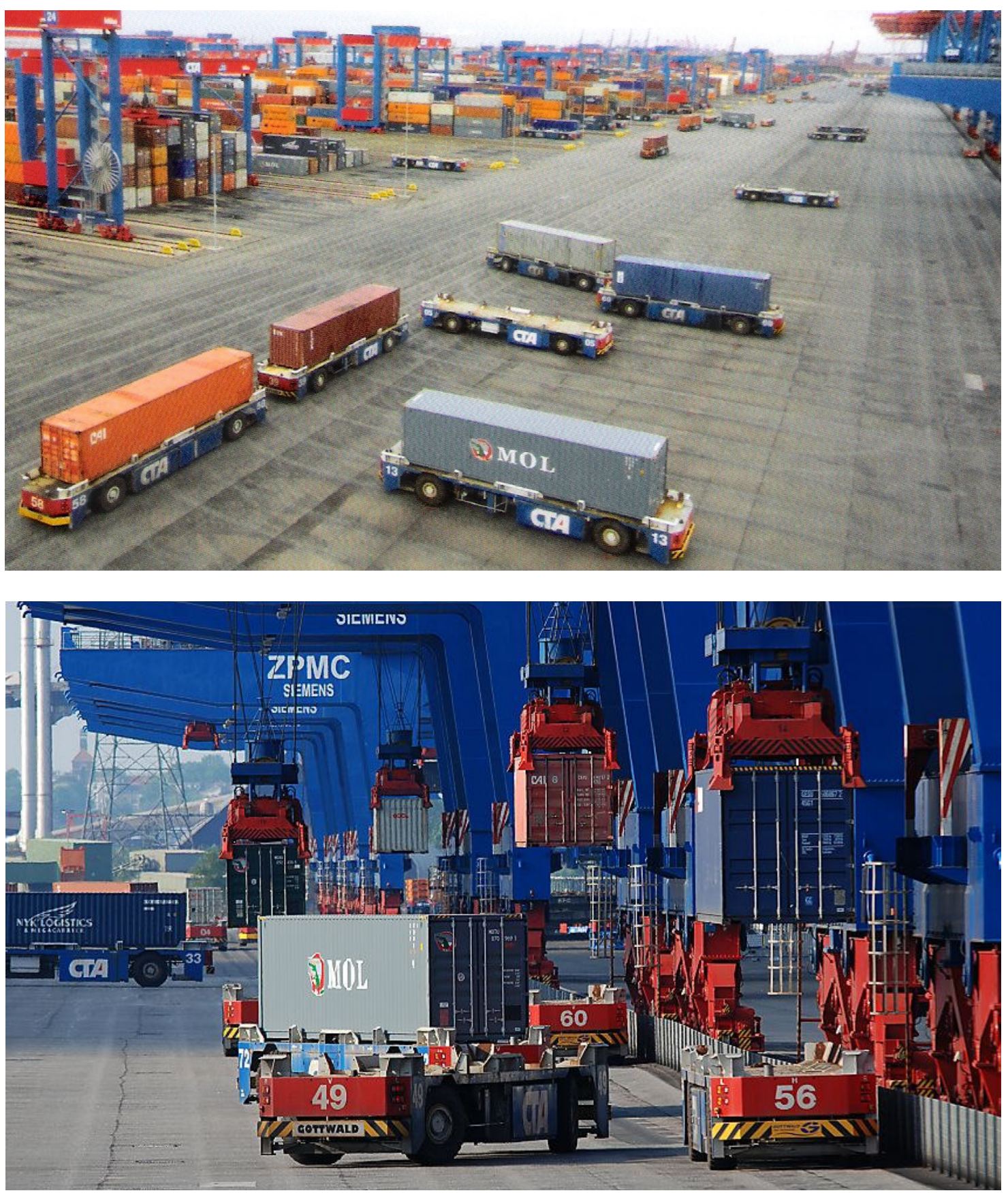

Fonte: CTA 
Em 2005, acontece a primeira operação de AGVs fora da Europa, o Tobishima PierSouth Side Container Terminal no Japão, com 33 AGVs dieselelétricos, de capacidade para 40 toneladas, construídos pela Toyota e conectados aos portêineres por meio de um sistema inovador de semiautomação de RTGs. Ver figuras 56 e 57.

Figura 56 - AGVs operando no pátio do Tobishima Pier South Side Container Terminal (Japão)

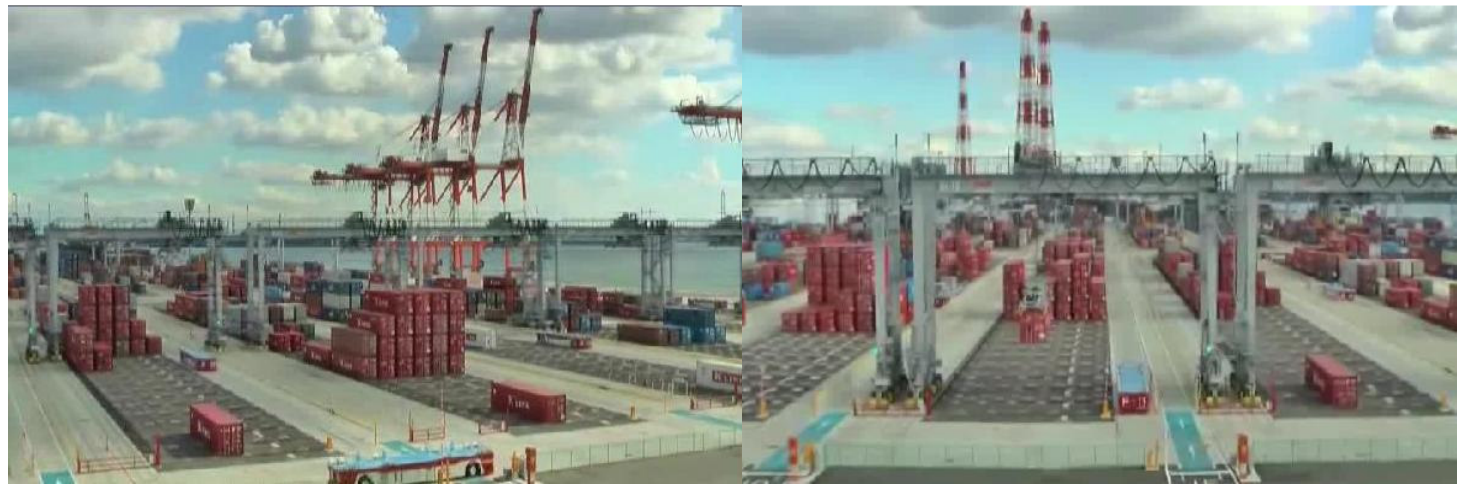

Fonte: Nagoya Port Terminal Corporation

Figura 57 - AGVs operando no cais do Tobishima Pier South Side Container Terminal (Japão)

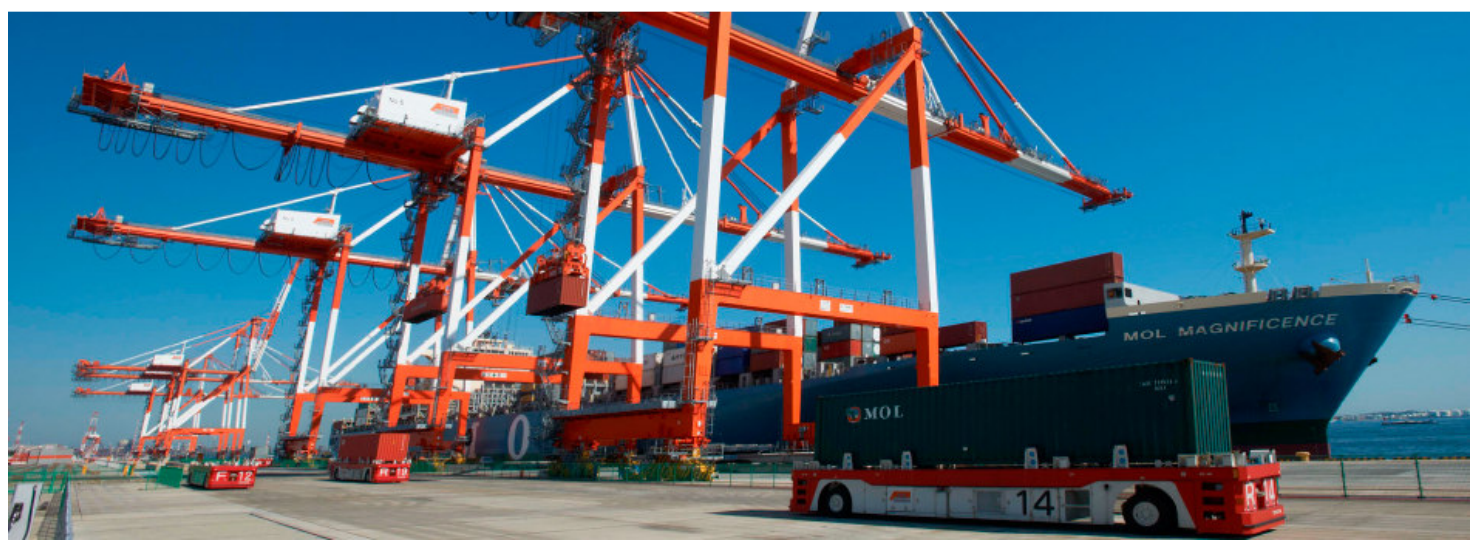

Fonte: Nagoya Port Terminal Corporation

A figura 58 demonstra uma vista aérea do Terminal de Tobishima. Enquanto a figura 59 apresenta o Euromax, outro terminal do grupo ECT (anteriormente mostrado na Figura 3), que possui, desde 2008, operação automatizada no backreach dos portêineres, sendo 96 AGVs, com velocidade de 6 metros/segundo (equivalente a $21,6 \mathrm{Km} / \mathrm{h}$ ) e capacidade para 60 toneladas. 
Figura 58 - Vista aérea do Tobishima Pier South Side Container Terminal (Japão)

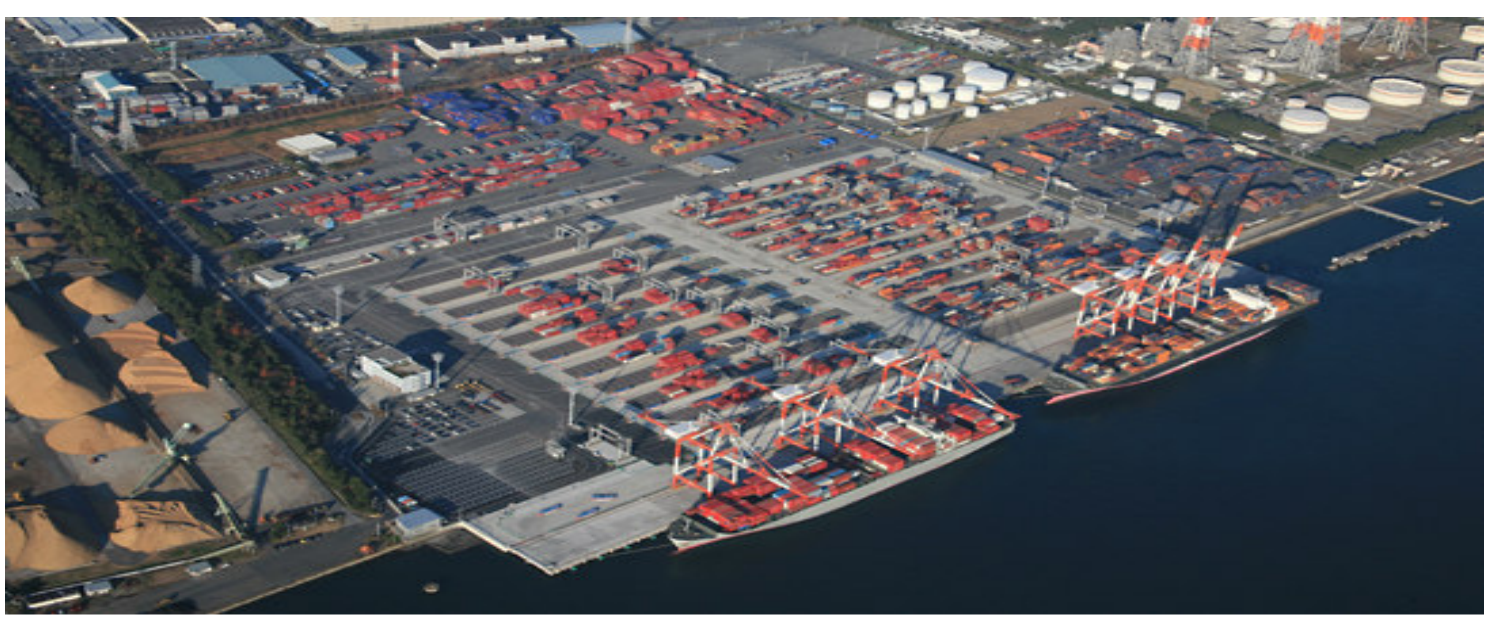

Fonte: Nagoya Port Terminal Corporation

Figura 59 - AGVs operando na área de Backreach no Euromax (Roterdã)

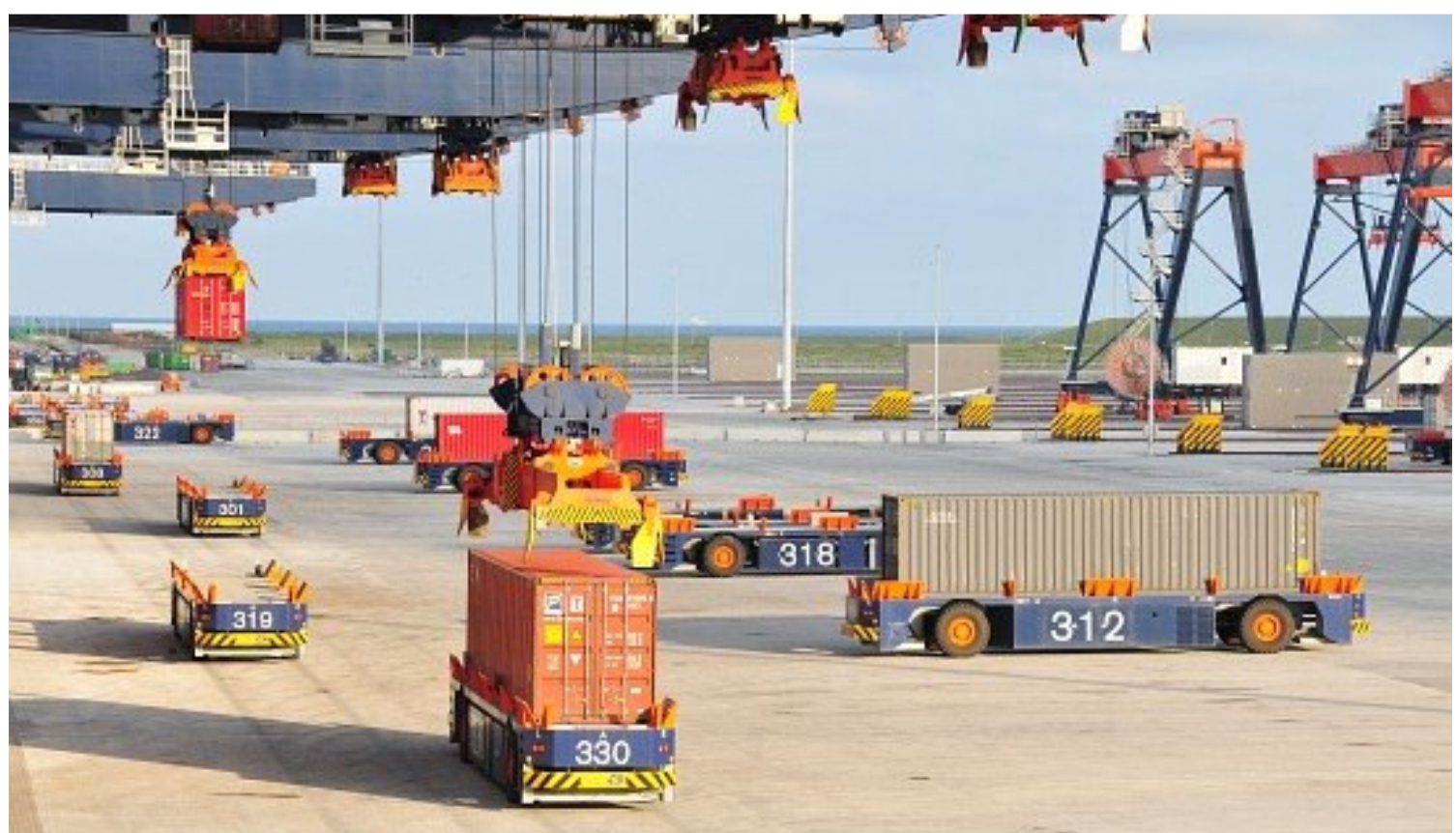

Fonte: Euromax

A partir de 2011, surge uma nova geração de AGV movidos à bateria, começam a ser utilizado em terminais como o CTA na Alemanha e LBCT nos Estados Unidos, o objetivo é a redução dos custos de energia e manutenção, emissão zero de poluentes, diminuição dos ruídos e utilização de energia renovável.

Há outro modelo de AGV chamado de C-AGV ou Cassete-AGV (figura 60), são veículos com capacidade de carga de 61 toneladas; e que pode transportar cassetes (figura 61) com contêineres de 40 pés (Double deck) ou dois contêineres 
de 20 pés (Twins). As principais melhorias estão relacionadas à manobrabilidade do veículo, com base na incorporação de eixos individuais acionados eletricamente e direcionais que permitem que o C-AGVs mova-se em qualquer direção e gire 360 graus. Isso aumenta a versatilidade e flexibilidade da AGV, minimizando o congestionamento no cais. Novos projetos permitem que o C-AGV possa entrar e sair tanto de forma transversal e longitudinal (figura 62), que permite a dissociação no cais, que é a chave para a eficiência de movimentação de carga do sistema.

Figura 60 - Ilustrações do C-AGV
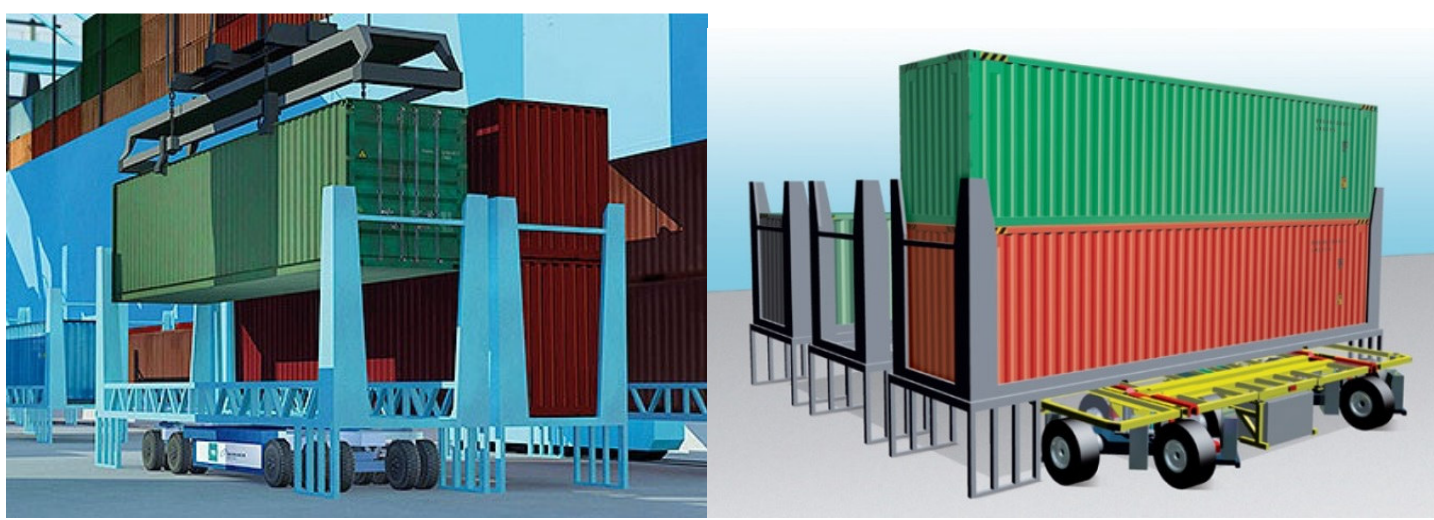

Fonte: TTS

Figura 61- Exemplos de uso de Cassetes em operações de contêineres

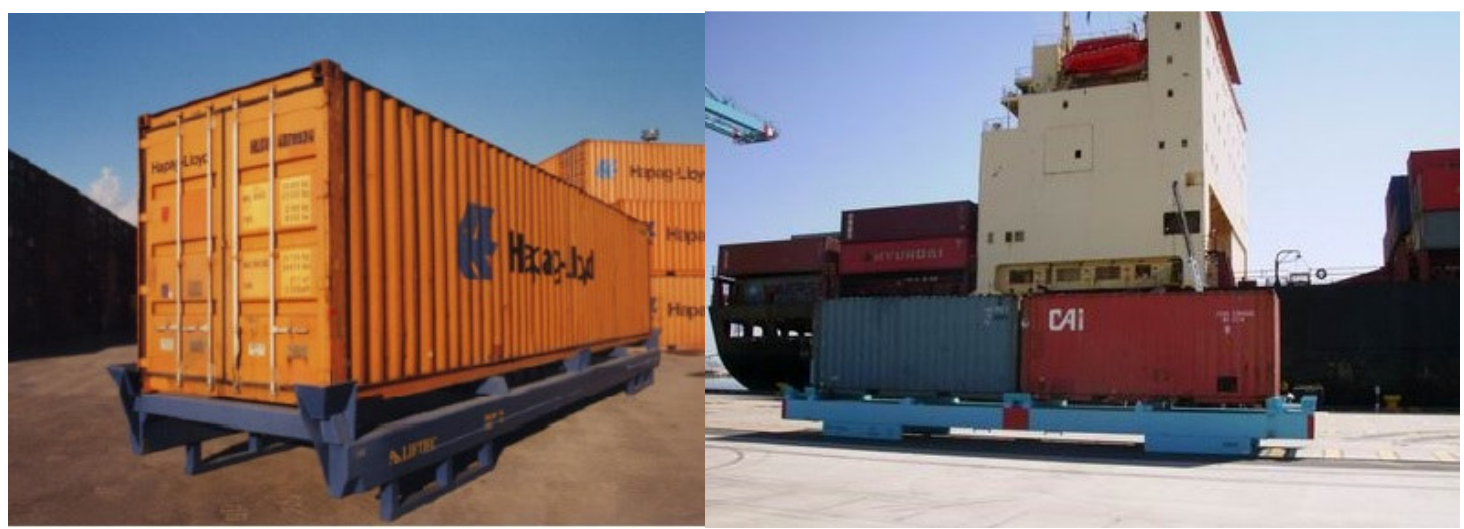

Fonte: TTS 
Figura 62 - llustrações da manobrabilidade dos C-AGV
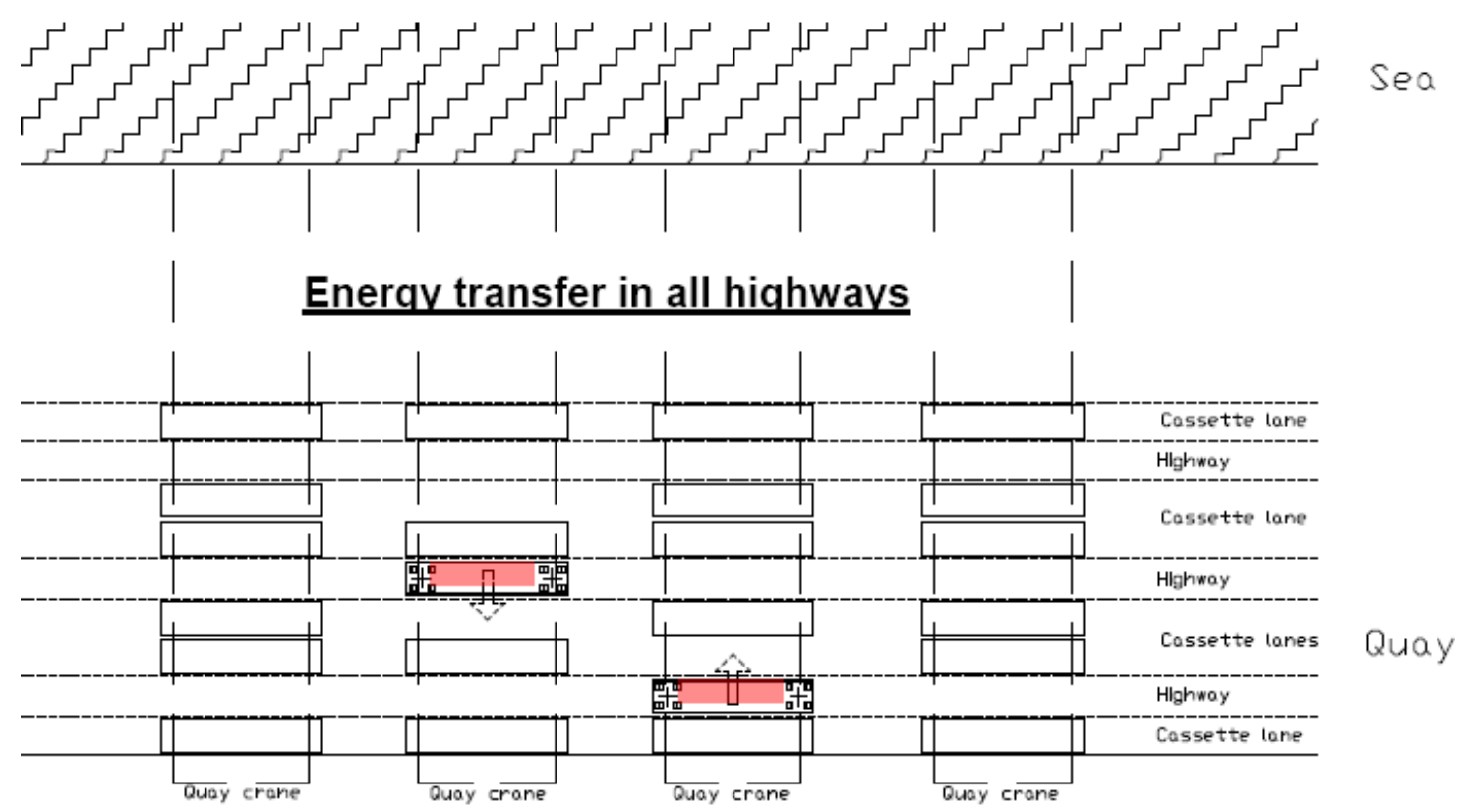

AGV entering/exiting from the front/rear
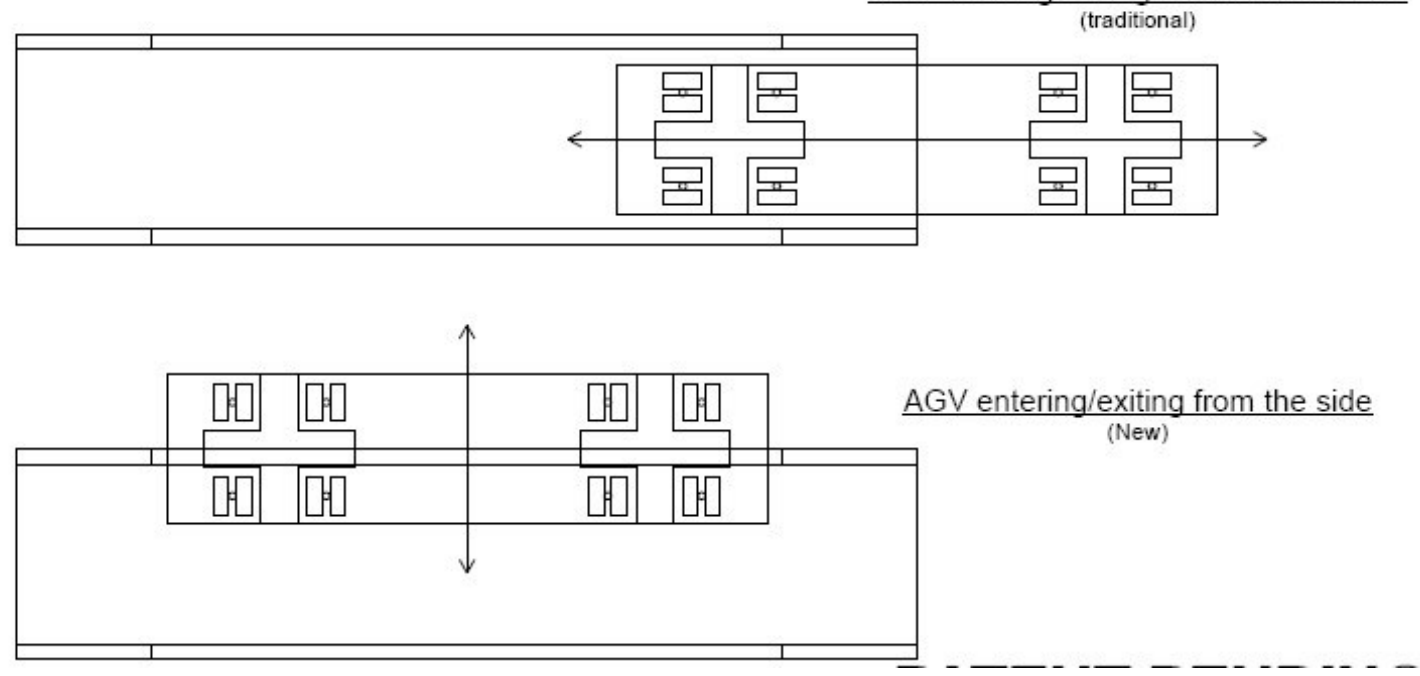

Fonte: TTS

E, para finalizar os modelos de AGV, há o sistema chamado de Battery-Lift AGV com operação conjunta com Racks, sistema que será utilizado no Maasvlakte 2 em Roterdã; trata-se da combinação do uso de baterias com um sistema de mesa de elevação; dessa forma o AGV não precisa esperar os equipamentos de pátio para ser atendido; ele deixa o contêiner sobre o rack (figura 63), ficando livre para assumir um novo movimento; a capacidade é de 70 toneladas e a velocidade permanece em 6 metros/segundo . 
Figura 63 - Exemplos de uso de Cassetes em operações de contêineres

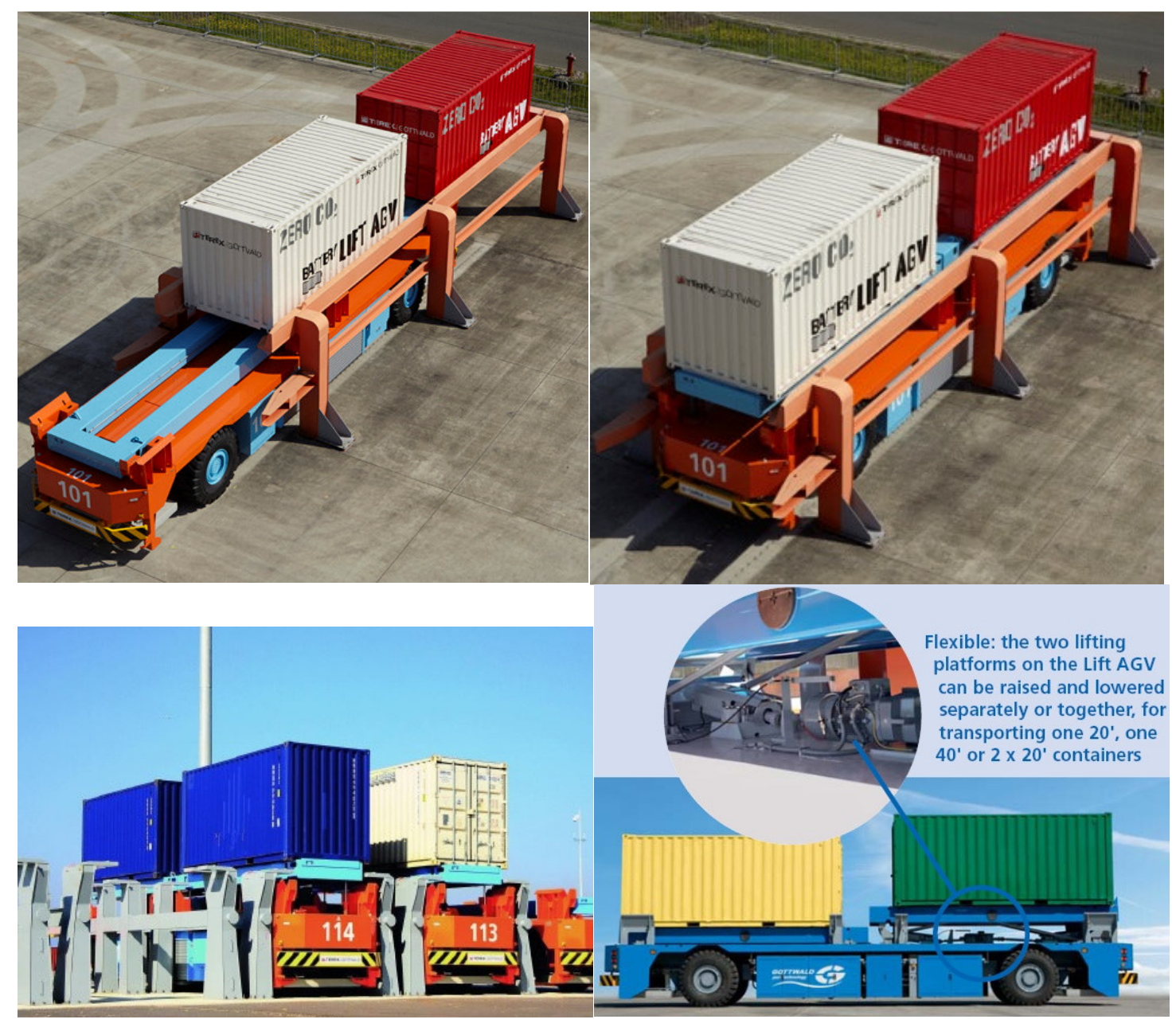

Fonte: TTS

Pode-se afirmar que a operação de terminais Totalmente Automatizados (Full Automated) exige o uso de AGVs ou, alternativamente, de Automated Lifting Vehicle (ALV) ou Auto Straddle Carriers (Autostrad) (figura 64).

Esse último equipamento pode ser encontrado no Patrick AutoStrad Terminal no Porto de Brisbane na Austrália, desde 2007, e caracteriza-se por um sistema de navegação redundante, composto de um Sistema de Posicionamento Global Diferencial (DGPS) e Laser; possui uma baixa capacidade de empilhamento (1 sobre 2), e de produtividade, com aproximadamente 9 movimentos/hora. 
Figura 64- AutoStrad operando no Patrick Brisbane (Austrália)

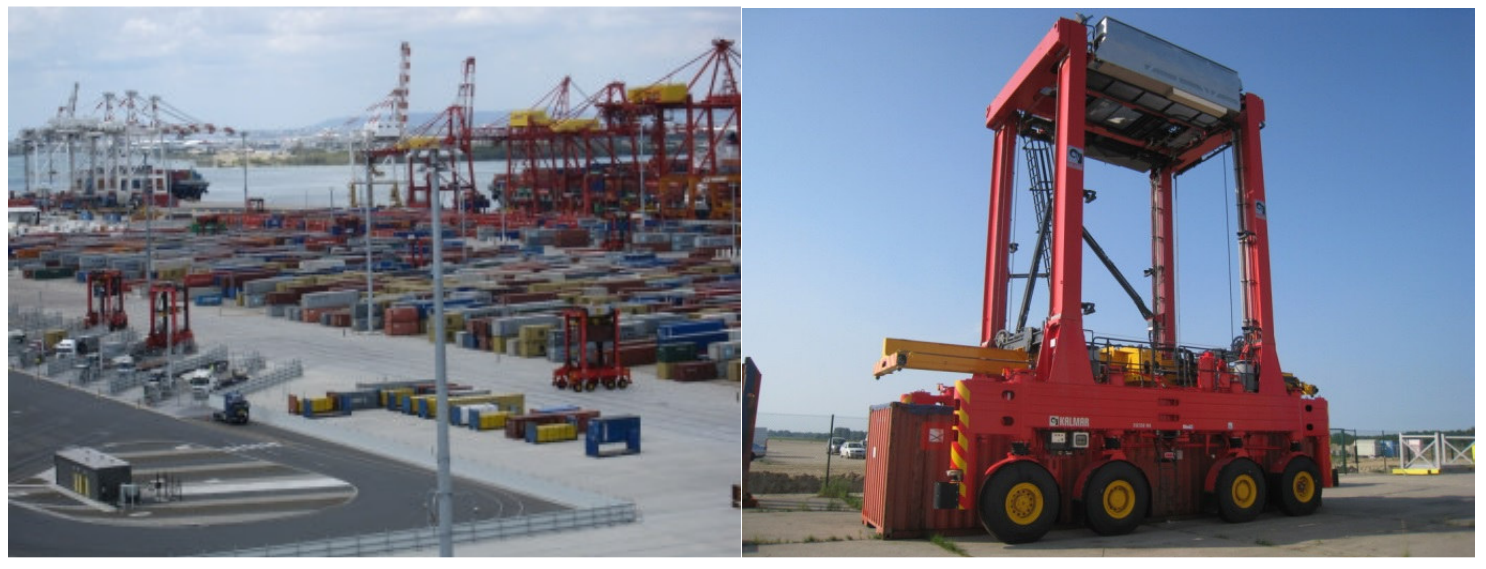

Fonte: Patrick Brisbane Terminal

O sofisticado equipamento desenvolvido pela ZPMC, o Sistema Transferidor de Cais-Pátio (Quay-Stack Transfers System) é o que atende à Etapa 1 de embarque e à Etapa 4 de Armazenagem do contêiner. A figura 65 ilustra o projeto, enquanto a figura 66 o protótipo montado na ilha Changxing, base de fabricação da empresa.

Figura 65 - Desenho llustrativo do Quay Stack Transfer da ZPMC

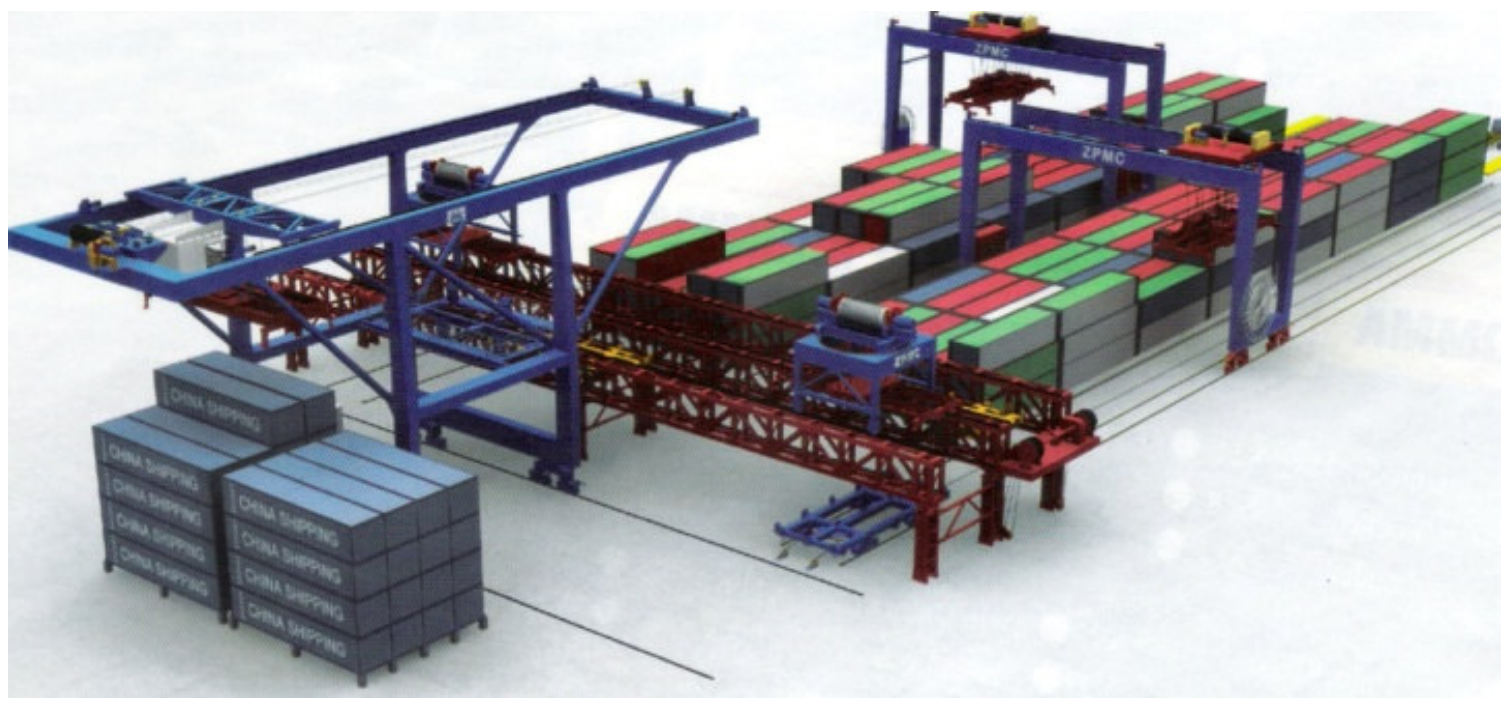

Fonte: Catalogo ZPMC 
Figura 66 - Protótipo do Quay Stack Transfer da ZPMC
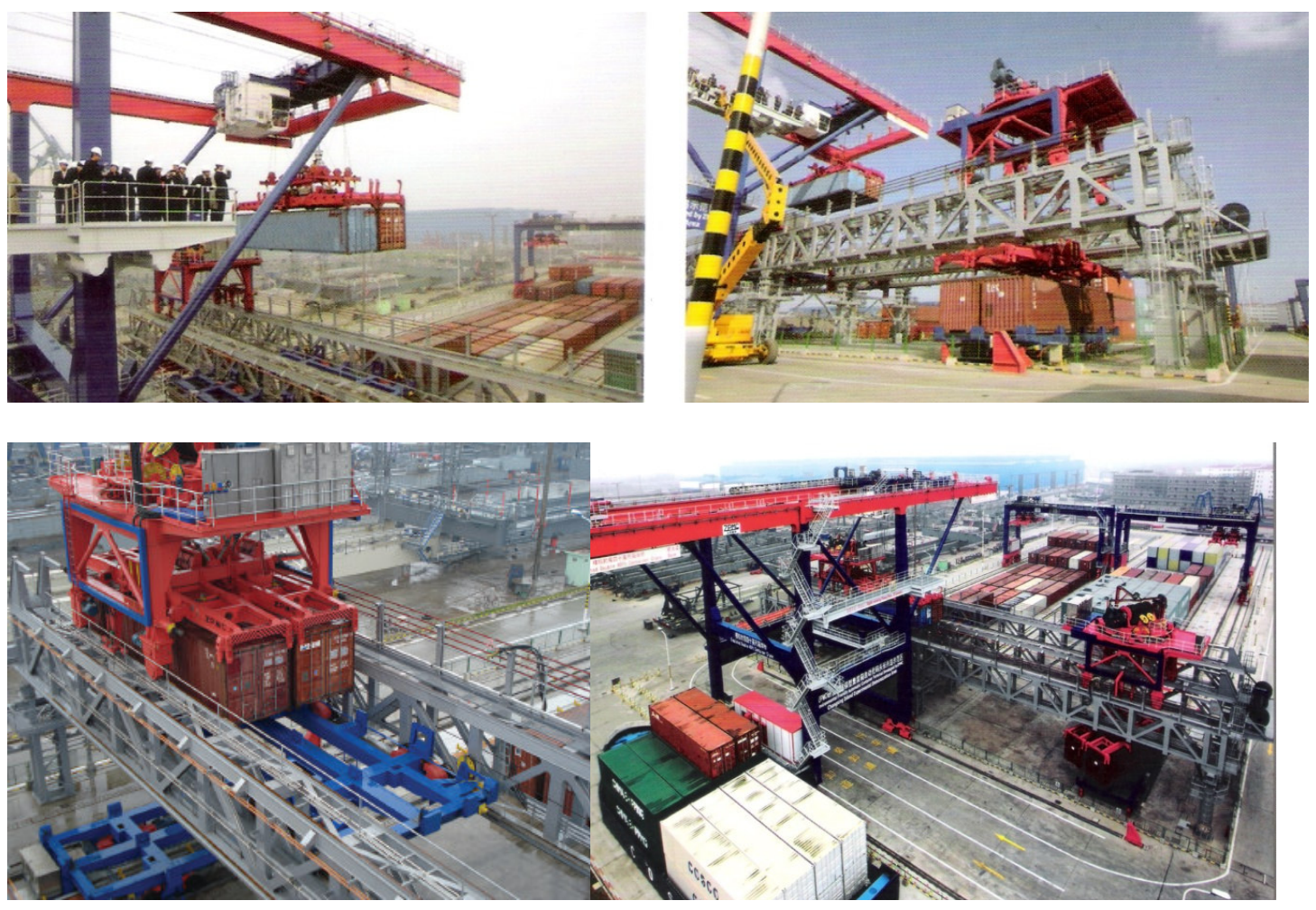

Fonte: Catálogo ZPMC

A filosofia básica desse sistema é a utilização de duas plataformas ou veículos sobre trilhos: a primeira plataforma elevada na área de backreach do portêiner recebe o contêiner para, em seguida, girar $90^{\circ}$ e abaixá-lo para a segunda plataforma de movimentação no nível do piso, quando ocorre a transferência para os Sistemas Automatizados de Armazenamento de Contêineres ou Guindastes de Pátio Automatizados (Automated Stacking Cranes (ASC)).

Contudo, o conceito não é inovador, pois a empresa Preussag Noell desenvolveu na década de 90 , conforme ilustra a figura 67 , um sistema piloto com a Hamburg Docks e Eurokai, denominado Linear Motor based Transfer Technology (LMTT), em uma tradução livre, Plataforma de Transporte com Motores em Linha. A ideia consiste em uma unidade de transporte de contêineres para a ligação do cais-pátio através de um sistema de trilhos paralelos e perpendiculares entre si, com as plataformas projetadas para fazer curvas em ângulo reto através de um conjunto duplo de rodas, sendo as plataformas acionadas por meio de motores síncronos lineares isentos de contato, os quais são distribuídos ao longo da unidade de acordo com a exigência de força motriz. 
Figura 67 - LMTT da Noell no Eurokai Container Terminal

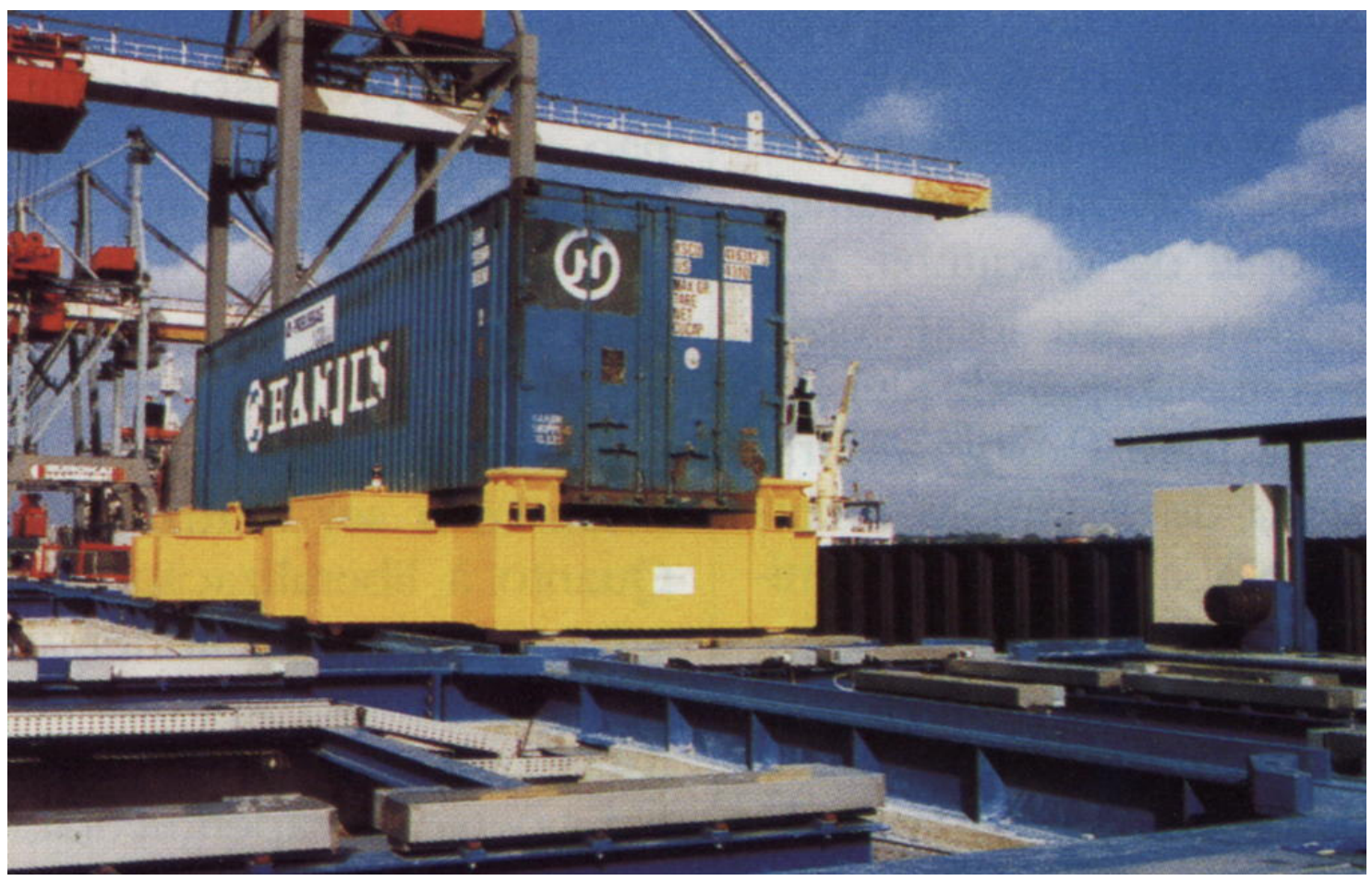

Fonte: World CargoNews

Retomando a Etapa 1, a figura 68 ilustra a operação de portêineres com uso de operadores de forma remota, isto é, operando o sistema a distância e não mais nas cabines fixas do equipamento. Interessante notar a possibilidade de 0 trabalhador operar mais de um equipamento simultaneamente.

Figura 68 - Portêiner sendo operado de forma remota na Alemanha (CTA) e Panamá (MIT)

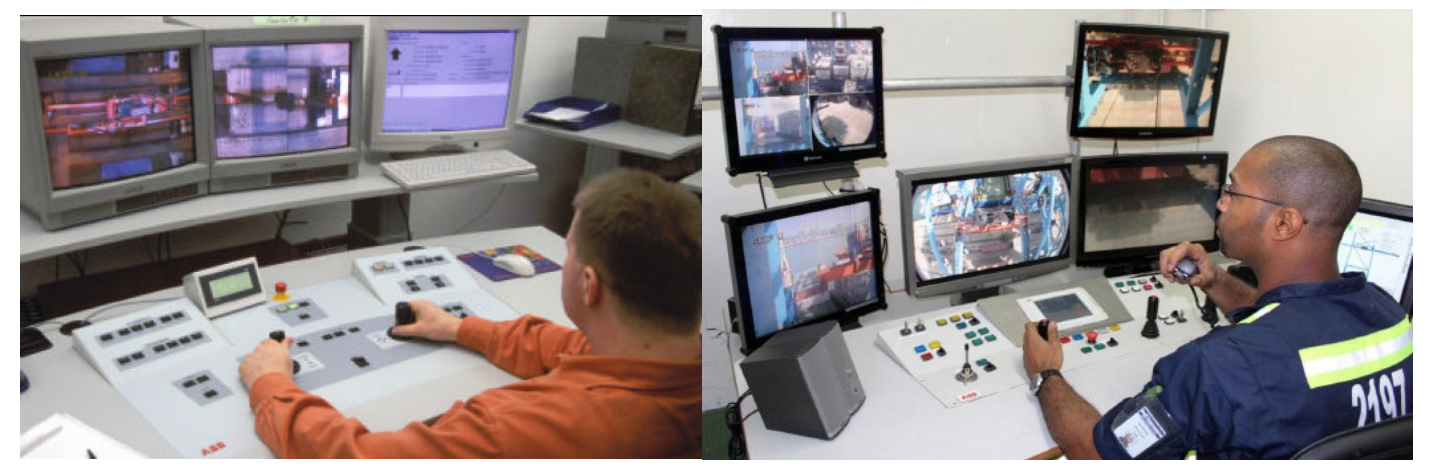

Fonte: Catálogo ABB

Finalizando a Etapa 4, serão apresentados cinco Sistemas Automatizados de Armazenamento de Contêineres. A saber: 
- A-RTG - Automated RTG;

- A-RMG - Automated RMG

- ASC - Automated Stacking Crane

- E-ASC - End-Loading ASC

- C-ASC - Cantilever ASC (Side-loading); e,

- OHBC - Overhead Bridge Crane.

O equipamento mais adotado no armazenamento de contêineres em pátios de terminais são os Transtêineres sobre Pneus ou Rubber Tired Gantry, ou apenas RTG. Trata-se de equipamento versátil em configuração (exemplo: 7 lastros $\times 6+1$ alturas); atendimento por sobre os lastros; capacidade de adensamento de quadra, diminuindo o fator de comprometimento das quadras e permite alteração entre bloco/quadras.

Esse equipamento sobre pneus tem sofrido diversas inserções tecnológicas que permitem a sua automação, apesar de algumas desvantagens quando comparados com os equipamentos sobre trilhos (RMG e ASC), tais como: a deformação dos pneus; aumento da propensão a vibrações e dificuldades para exato posicionamento.

Gylling (2014) indica que 18 RTG do fabricante Konecranes foram convertidos de manual para automatizado no terminal da DPWorld em Yarimca (Turquia) e lista que os dispositivos tecnológicas (ver Figura 69) para essa conversão foram:

- Auto-Steering

- Dispositivo que auxilia o RTG a não sair do alinhamento das pistas e utiliza a tecnologia de GPS criando "trilhos virtuais";

- Auto TOS Reporting,

- Dispositivo de integração com o sistema de planejamento de pátio do TOS, previne erros na movimentações;

- Auto-Truck Guiding,

- Dispositivo de alinhamento do caminhão na linha de atendimento do equipamento,

- Auto-positioning, 
- Outro dispositivo integrado com o sistema de planejamento de pátio do TOS e tecnologia GPS converte as tradicionais posições de pátio do tipo quadra/bay/coluna/altura em latitude e longitude;

- Stack Collision Prevention

- Dispositivo de laser 3D que verifica o perfil da pilha, prevenindo colisões;

- Truck Lift Prevention

- Dispositivo que auxilia na prevenção de içamento de veículos cujos contêineres ainda estejam presos aos pinos (locks) do veículo.

Figura 69 - Tecnologias para conversão de RTG Manual para A-RTG (Automatizado)
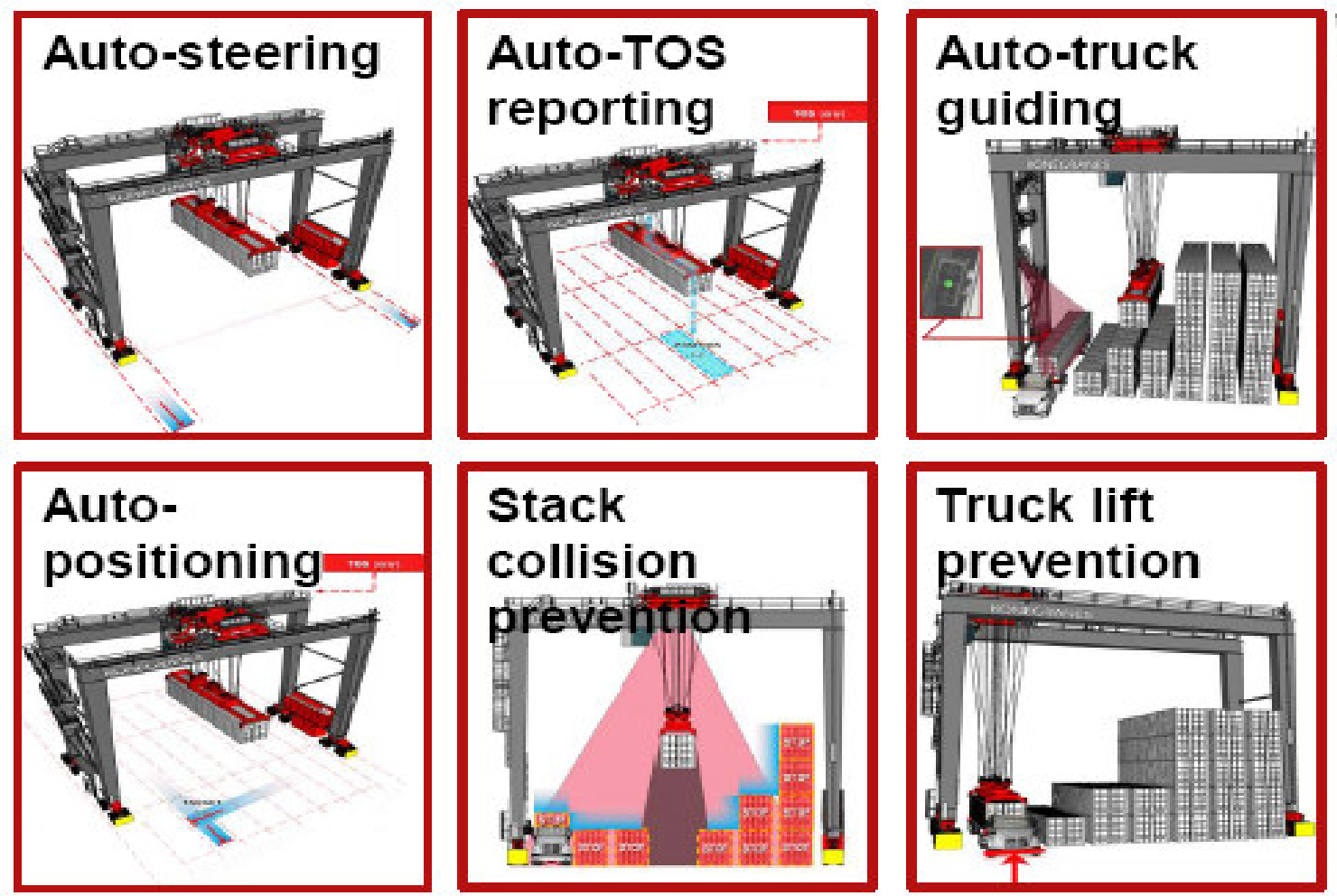

Fonte: Konecranes/ Gylling (2014)

O Tobishima Pier South Side Container no Japão possui 12 A-RTGs com os seguintes dispositivos:

- Auto-steering;

- Stack Profiling System; 
- Automated Picking and Stacking Containers chamado de "Magic Eye" e

- Remote Control.

Destacam-se nesses A-RTG, o sistema Automated Picking and Stacking Containers chamado de "Olho mágico" que possui a função de controlador de balanço (sway) dos movimentos, ajustando a velocidade de armazenagem dos locks do contêiner, com precisão é de 25 milímetros. A figura 70 ilustra essa função.

Figura 70 - Automated Picking and Stacking Containers ("Magic eye") do A-RTG no terminal de Tobishima Pier South Side Container

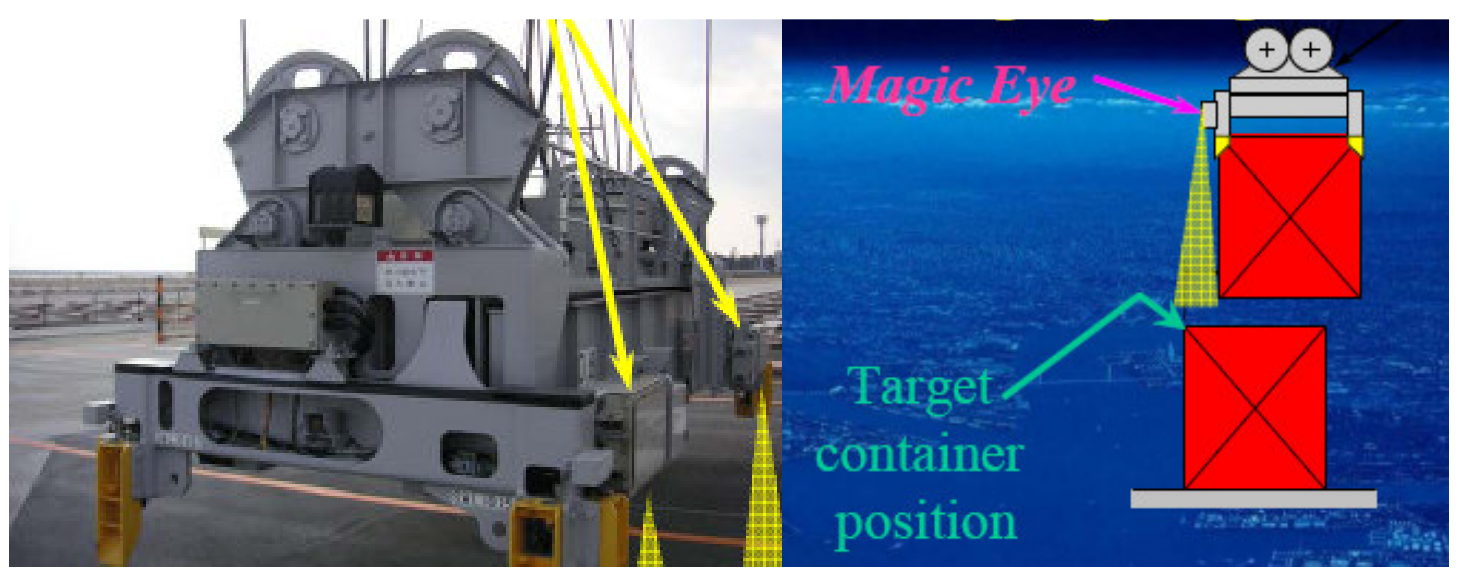

Fonte: Mitsubishi Heavy Industries / Tobishima Pier South Side Container

A figura 71 apresenta o Sistema de Controle Remoto dos A-RTG, são cinco mesas/consoles de controle remoto para 12 equipamentos; normalmente três são utilizados.

Nota-se que a ação do operador do console ocorre apenas na "Área de Operação Remota Manual", que consiste na colocação e retirada do contêiner da carreta; enquanto que o recebimento e entrega na pilha ocorre de forma automática, na "Área de Operação Automatizada".

A disposição da mesa de controle e exemplo das telas nos monitores no momento de carregamento de um contêiner do A-RTG é mostrada na figura 72. 
Figura 71 - Áreas de operação do A-RTG

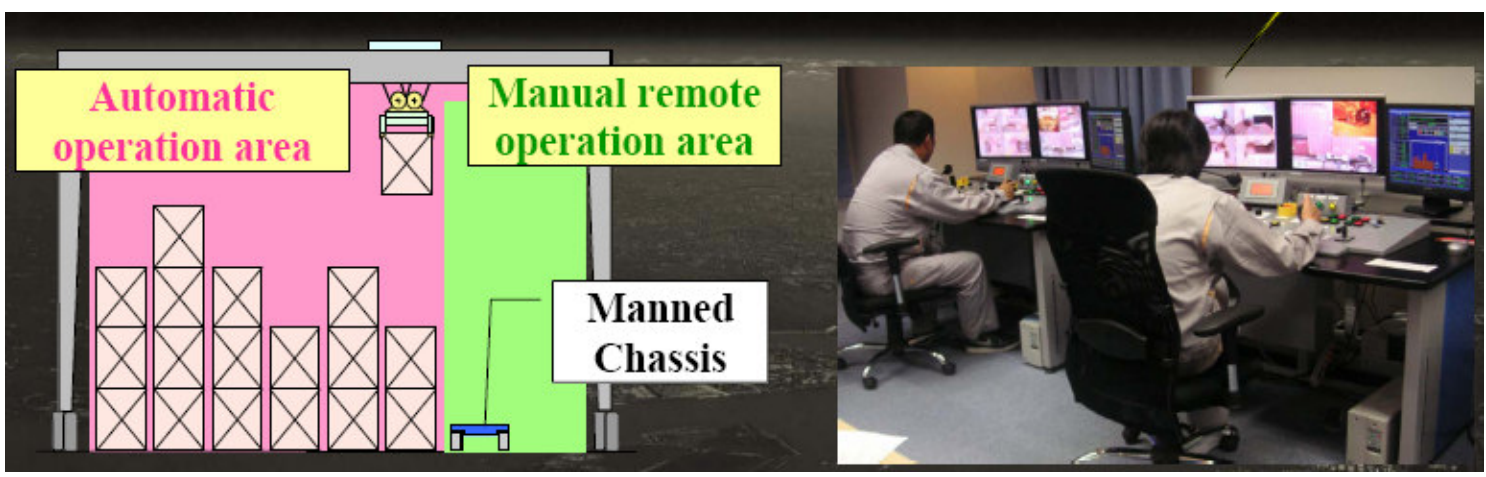

Fonte: Mitsubishi Heavy Industries / Tobishima Pier South Side Container

Figura 72 - A-RTG no terminal de Tobishima Pier South Side Container
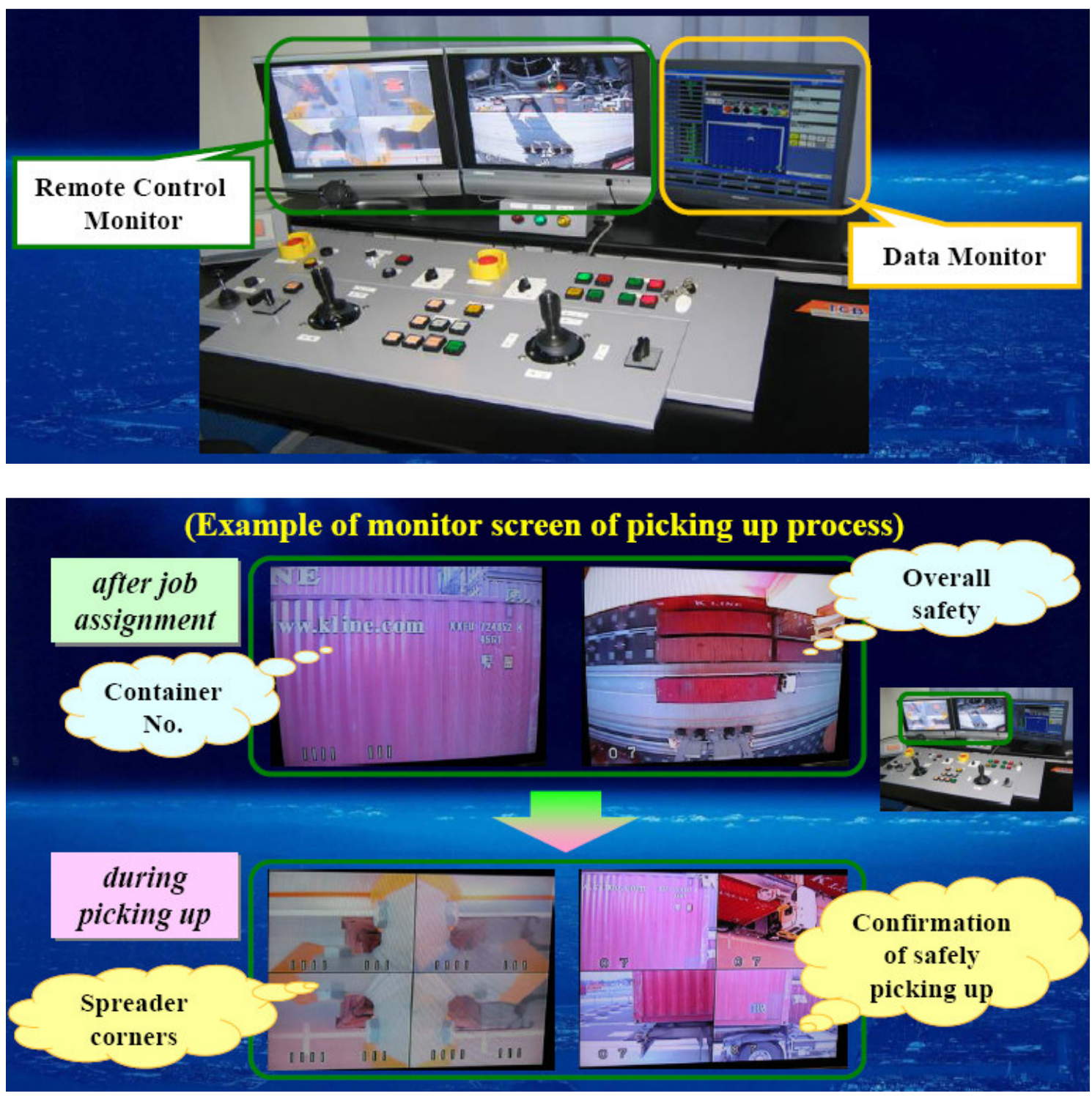

Fonte: Mitsubishi Heavy Industries / Tobishima Pier South Side Container 
Antes de discorrer sobre os Guindastes Automatizados de Pátio ou Automated Stacking Cranes (ASC), iremos fazer uma introdução nos equipamentos chamados de Rail Mounted Grantry (RMG), por serem estes os percursores do ASC.

Esses equipamentos possuem algumas vantagens com relação aos RTGs: são normalmente mais largos e altos e sua automação é considerada mais fácil por operarem sobre trilhos, por não sofrer com os problemas de posicionamento causados pelas possíveis irregularidades dos pneus e piso; contudo, há um custo considerável de investimento na implantação de trilhos. São normalmente encontrados em:

- Terminais intermodais (figura 73)

- Nas zonas de transferências de terminais, dos veículos para a pilha e das pilhas para o navio (figura 74);

- Áreas de atendimento de ferrovia nos terminais (figura 75);

Figura 73 - Terminal Intermodal IFB Central Hub Antwerp (Bélgica)

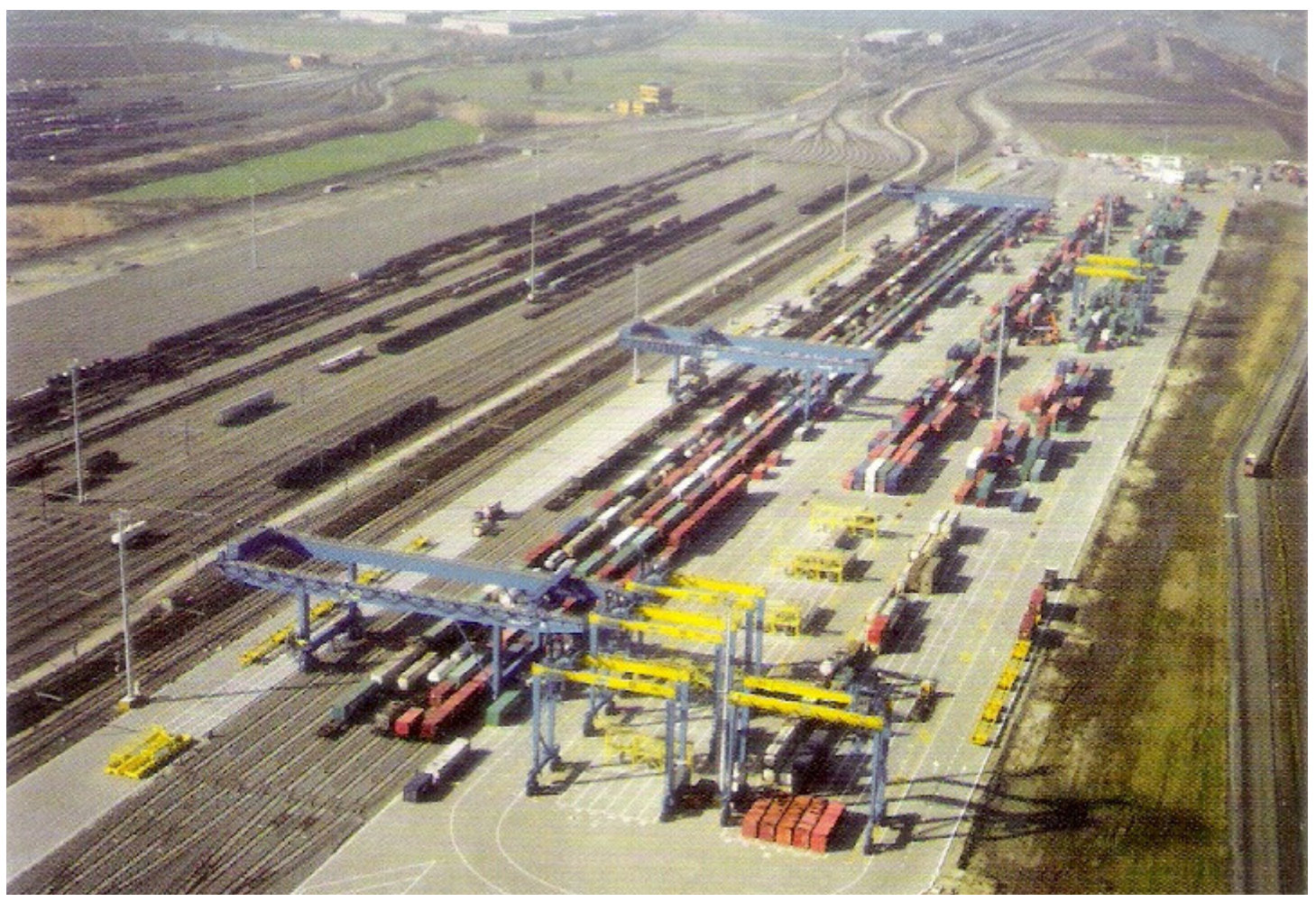

Fonte: Container Management Magazine 
Figura 74- Exemplo de A-RMG e ASC em zona de transferência de terminais
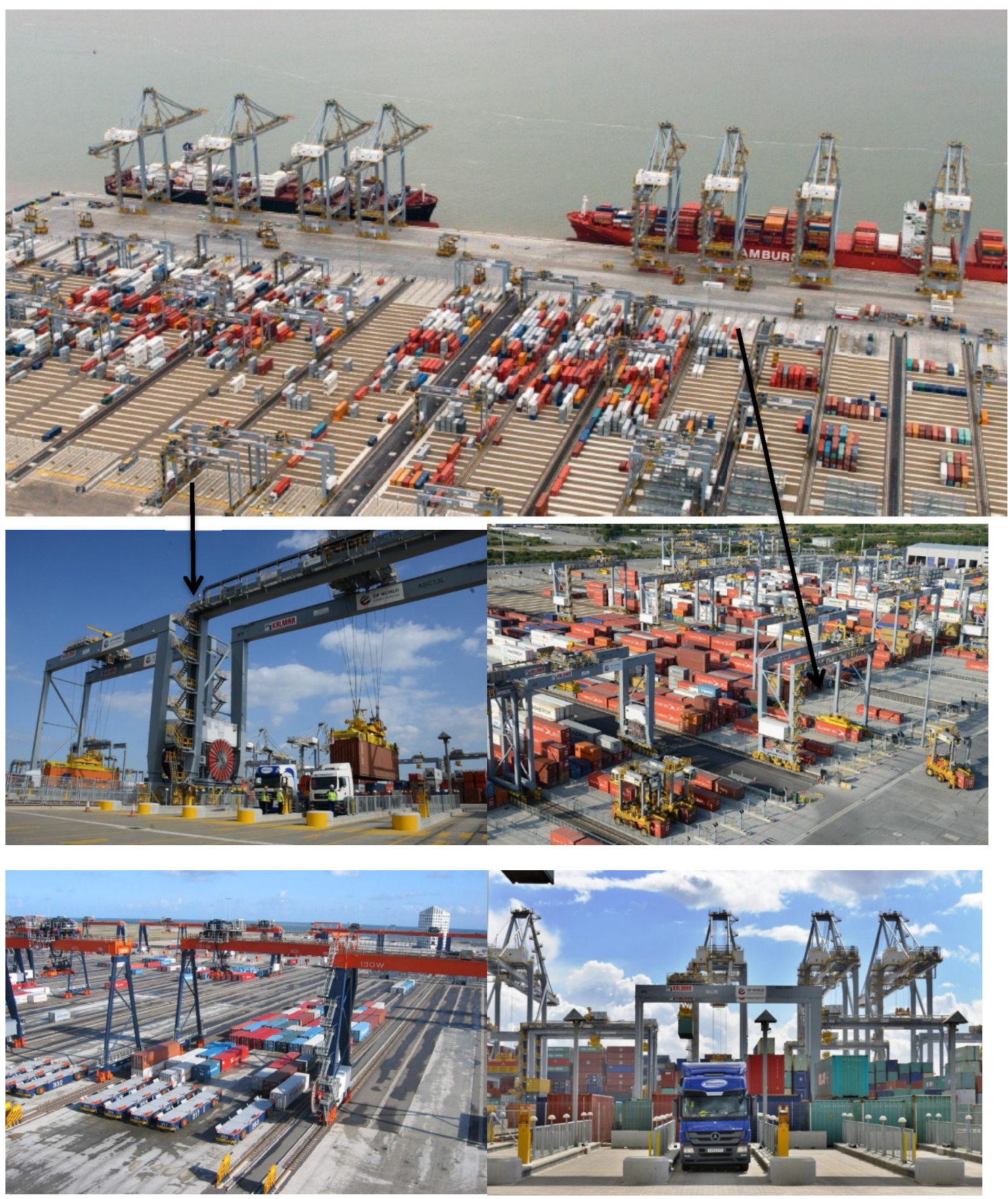

Fonte: Konecranes e DPWorld London Gateway 
Figura 75 - Exemplo de RMG em área de ferrovia

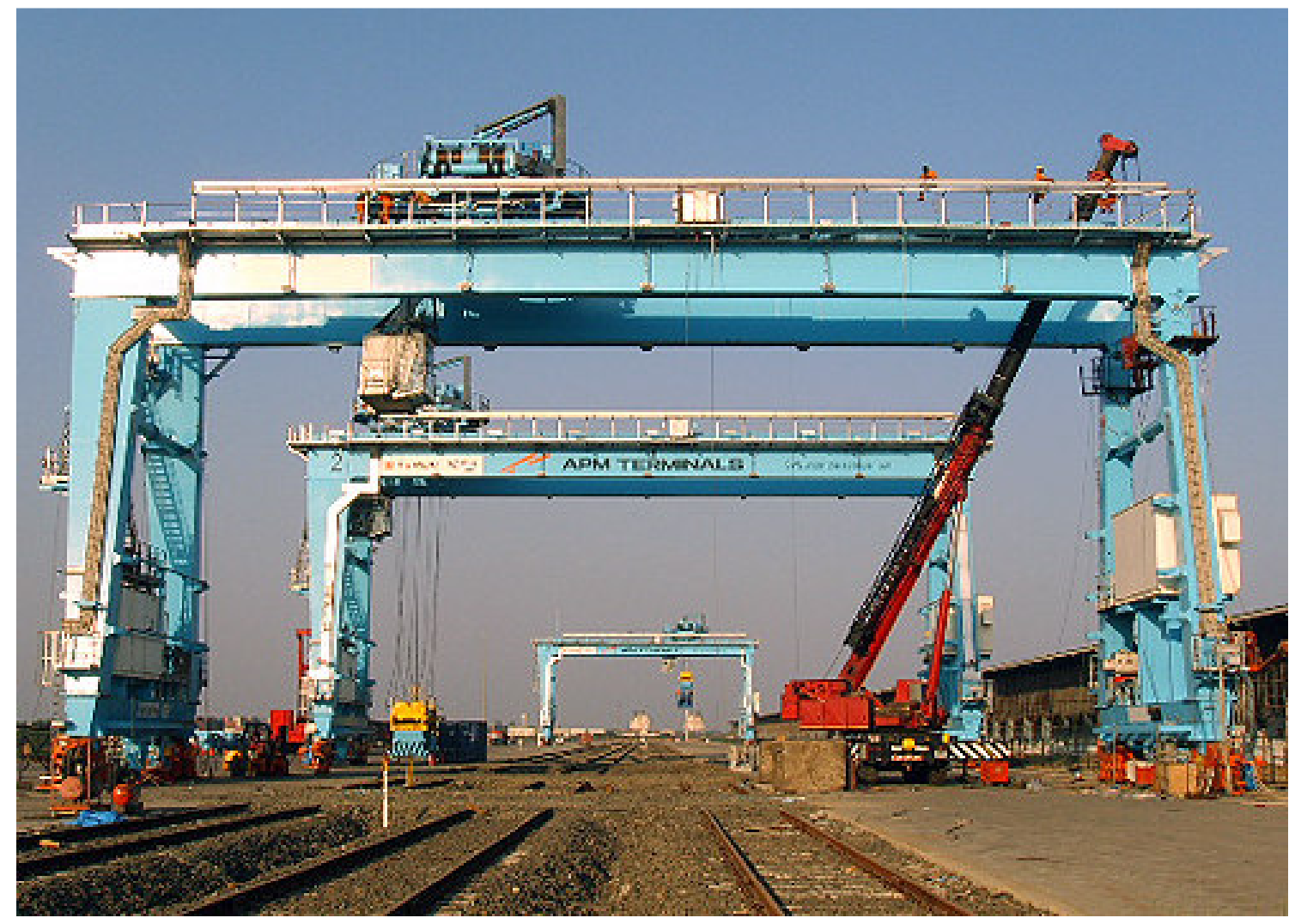

Fonte: Catálogo TEREX

Quanto aos Guindastes Automatizados de Pátio ou Automated Stacking Cranes (ASC), podemos classificá-los em:

- End-Loading ASC e

- Side Loading Cantilever ASC.

Essa classificação deve se ao layout de quadra/pátio, conforme ilustram as figuras 76 a 79 com layout End-Loading ou Front-end Loading, isto é, com o carregamento ocorrendo no início e fim da quadra ou nas suas pontas, com as quadras normalmente transversais ao cais. A figura 80 mostra exemplos de equipamento do tipo E-ASC. 
Figura 76 - Exemplo de quadra End-Loading no Euromax (Roterdã)

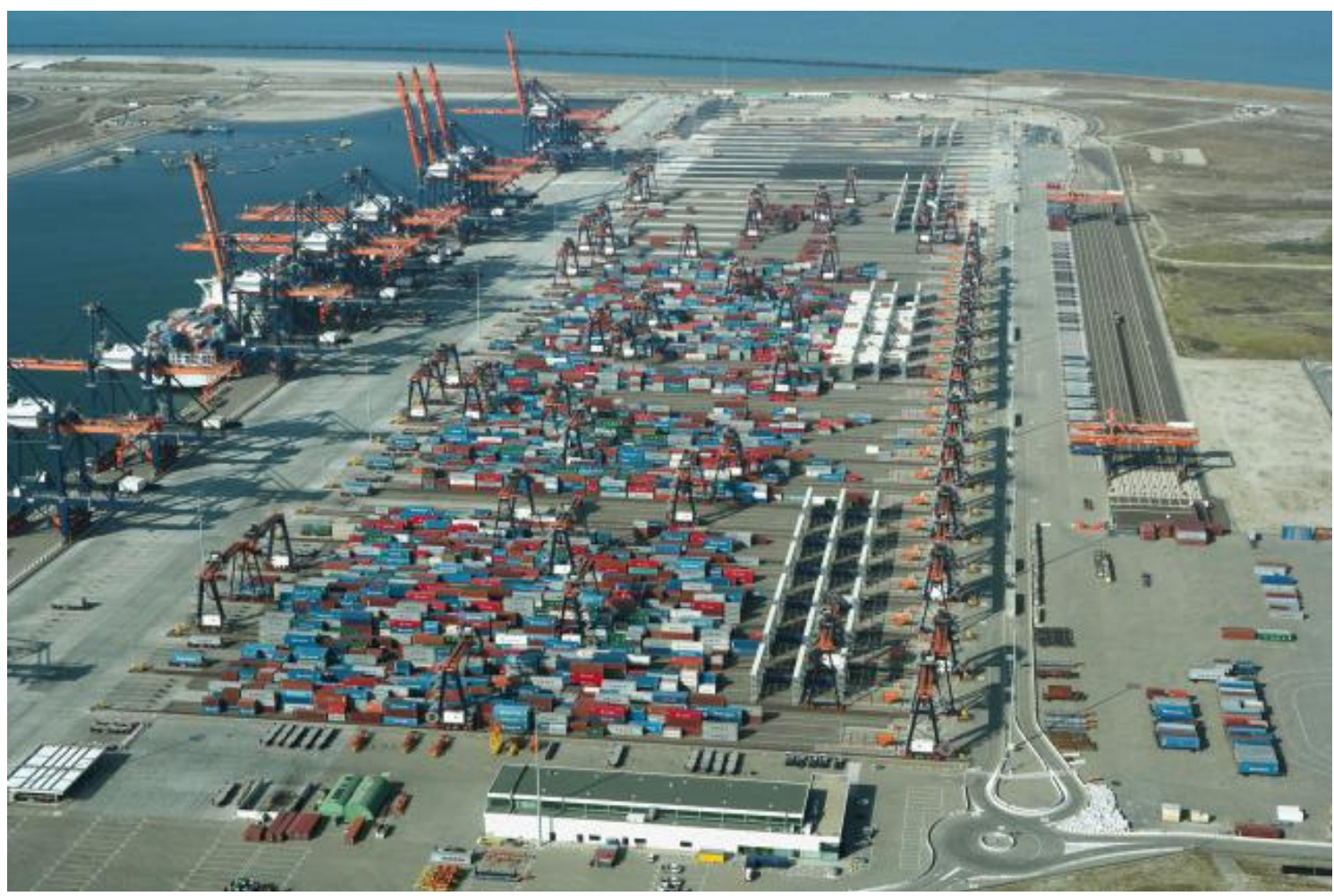

Fonte: Euromax

Figura 77 - Exemplo de quadra End-Loadingno TTI Algeciras (Espanha) e de Equipamento EASC

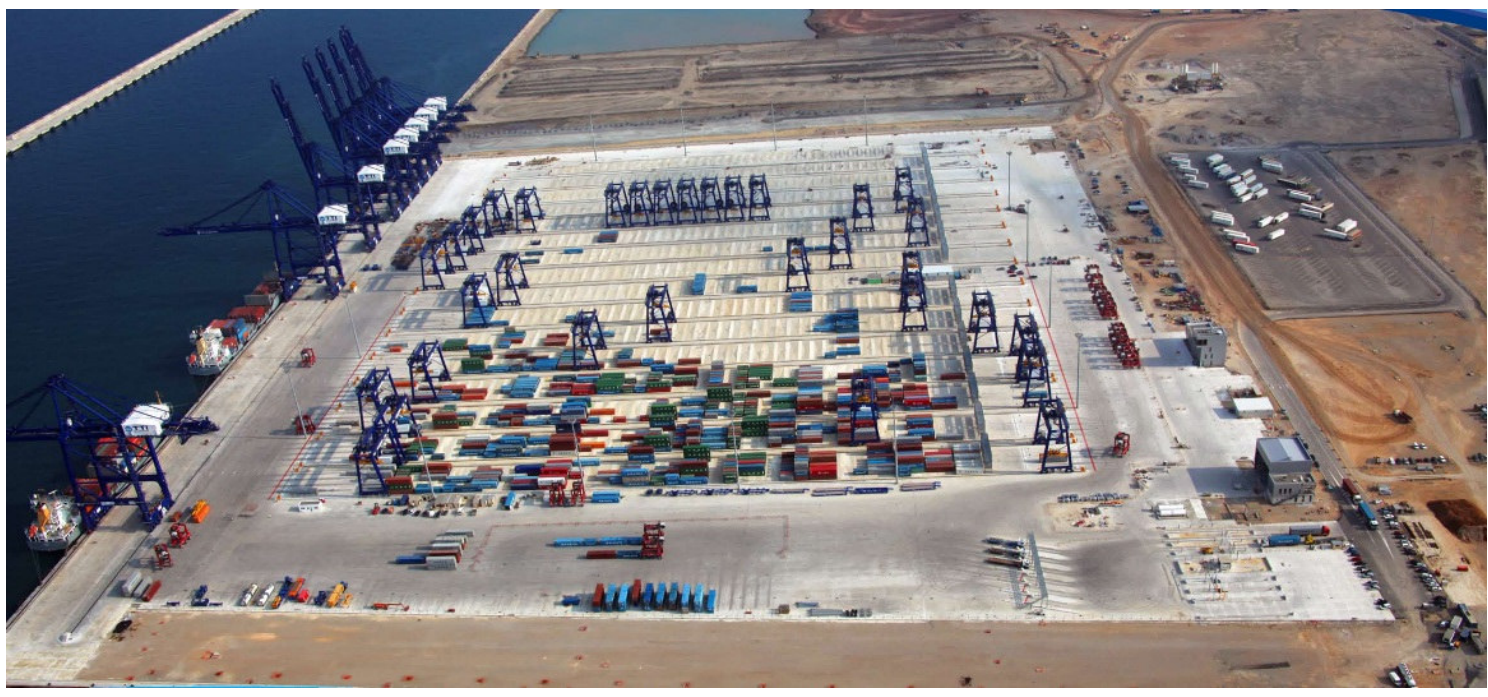

Fonte: TTI Algeciras 
Figura 78 - Exemplo de quadra End-Loading no APTM Virginia (Estados Unidos)

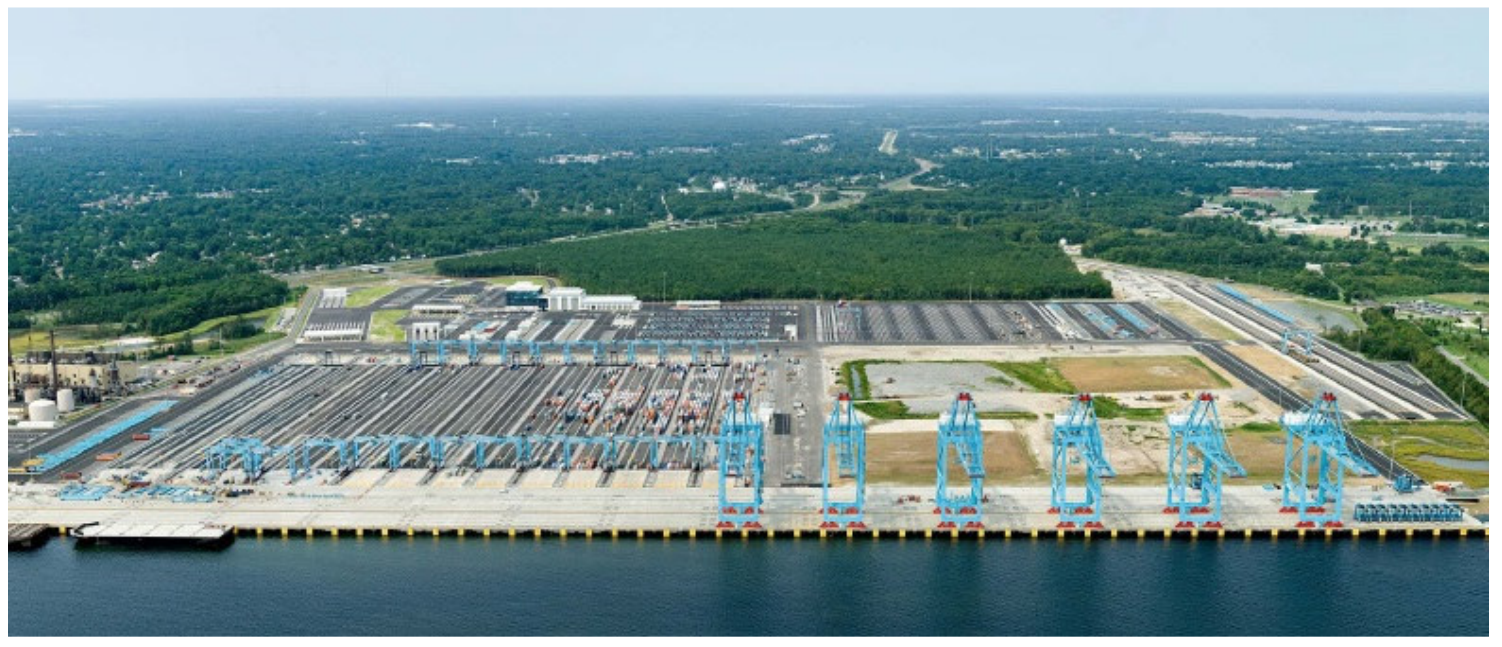

Fonte: APMT

Figura 79 - Exemplo de quadra End-Loading no London Gateway (Inglaterra)

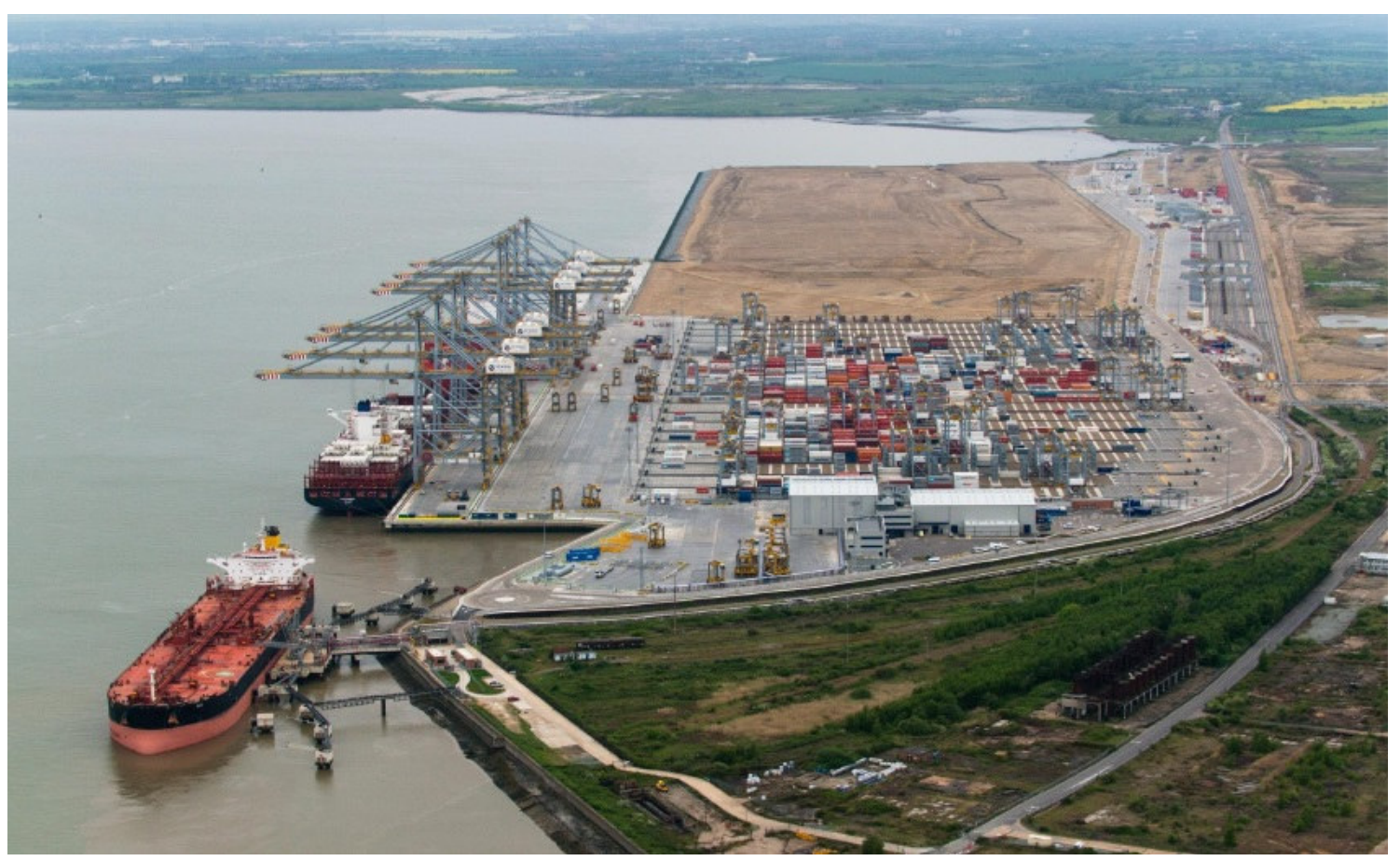

Fonte: DPWorld 
Figura 80 - Exemplos de Equipamentos E-ASC no Euromax (Roterdã), Antwerp Gateway (Deurganck Dock) (Bélgica) e CTA (Alemanha)
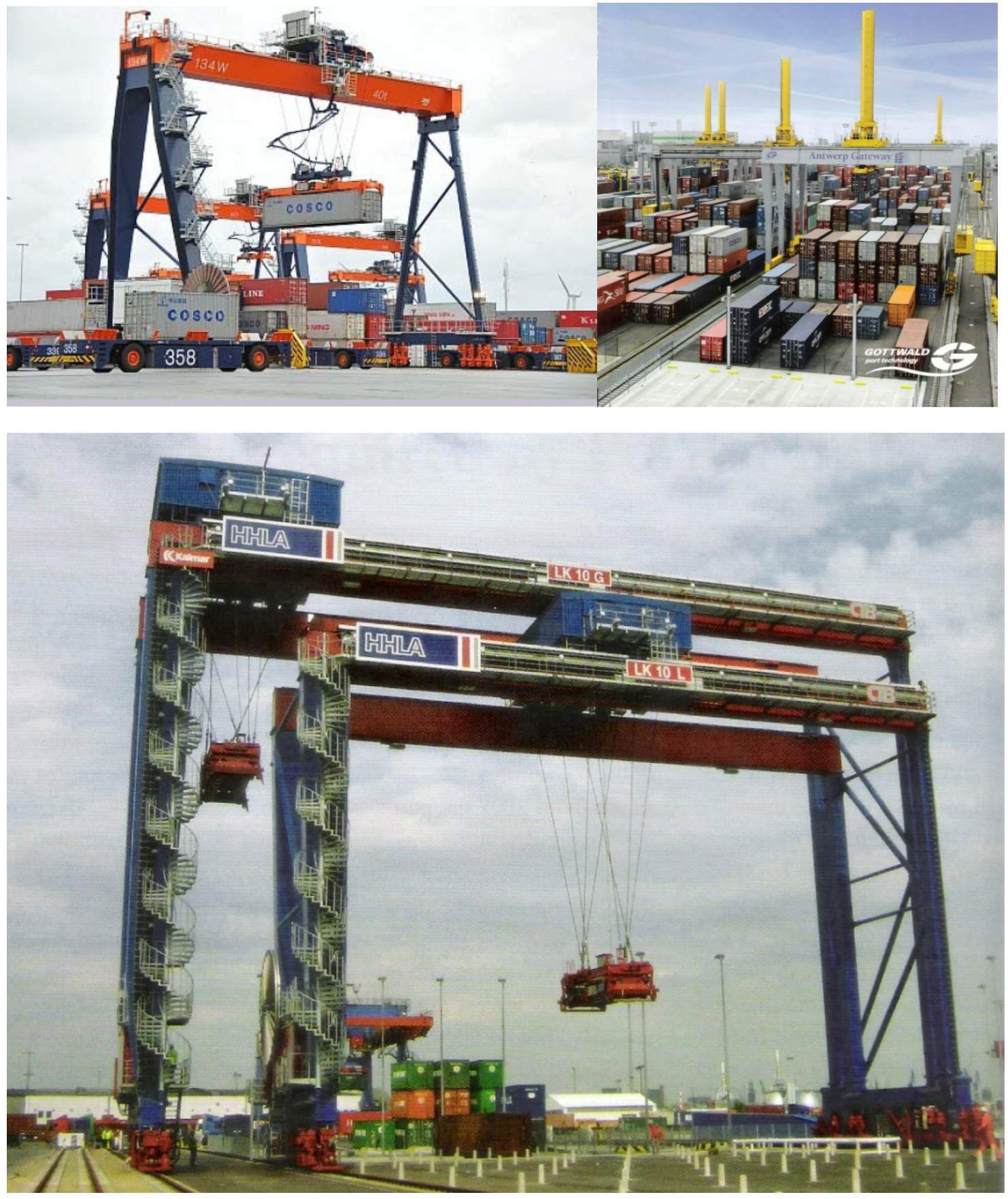

Fonte: Catálogos ABB e Gottwald (TEREX)

A figura 81 ilustra o layout Side loading com equipamento Cantilever, com carregamento paralelo às quadras, as quais também são usualmente longitudinais ao cais. E a figura 82 apresenta equipamentos do tipo C-ASC. 
Figura 81 - Exemplo de quadra Side-Loading no Terminal da Hanjin New Port Co (Busan) e de Equipamento C-ASC

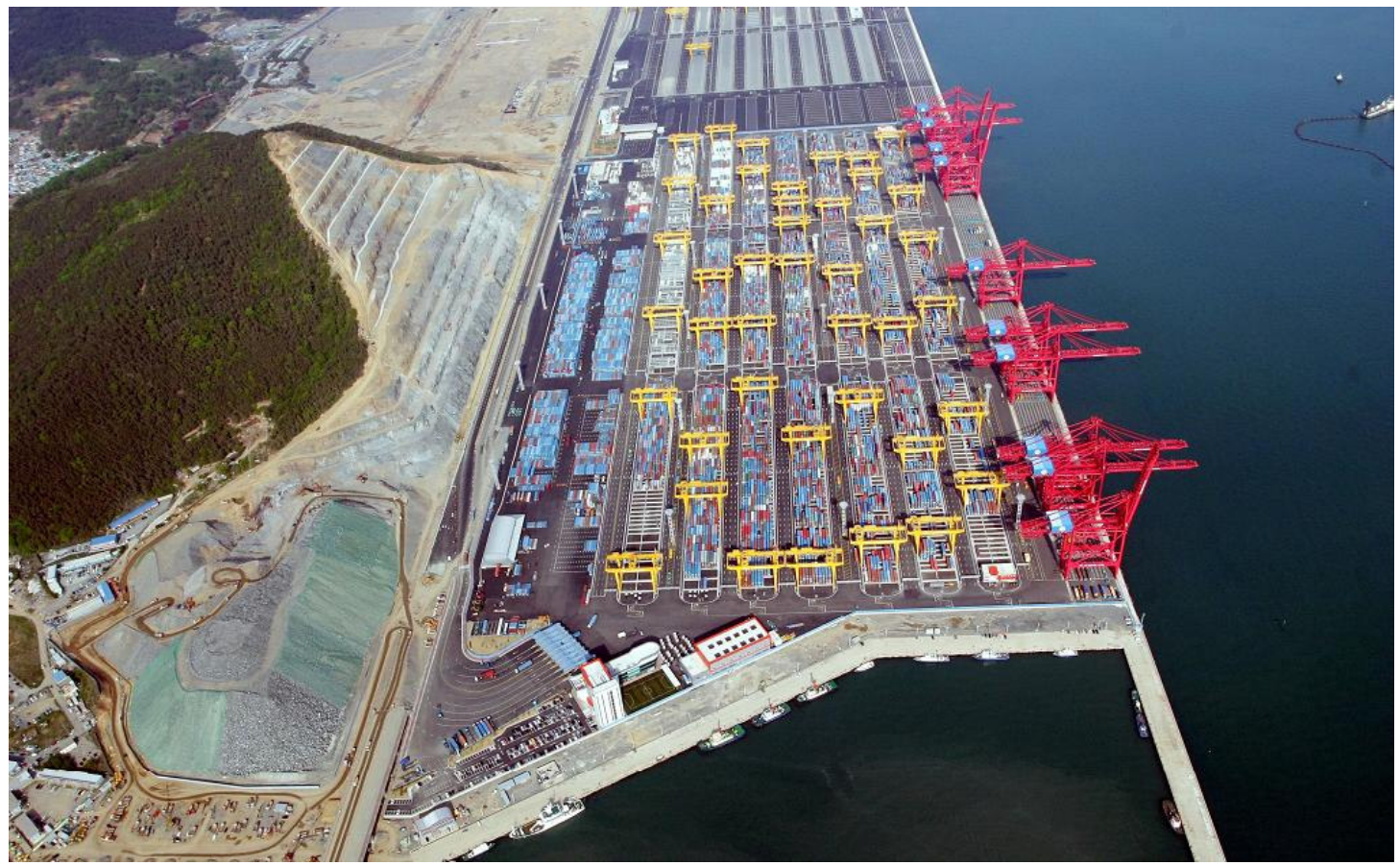

Fonte: Catálogo ABB

Figura 82 - Exemplos de Equipamentos C-ASC

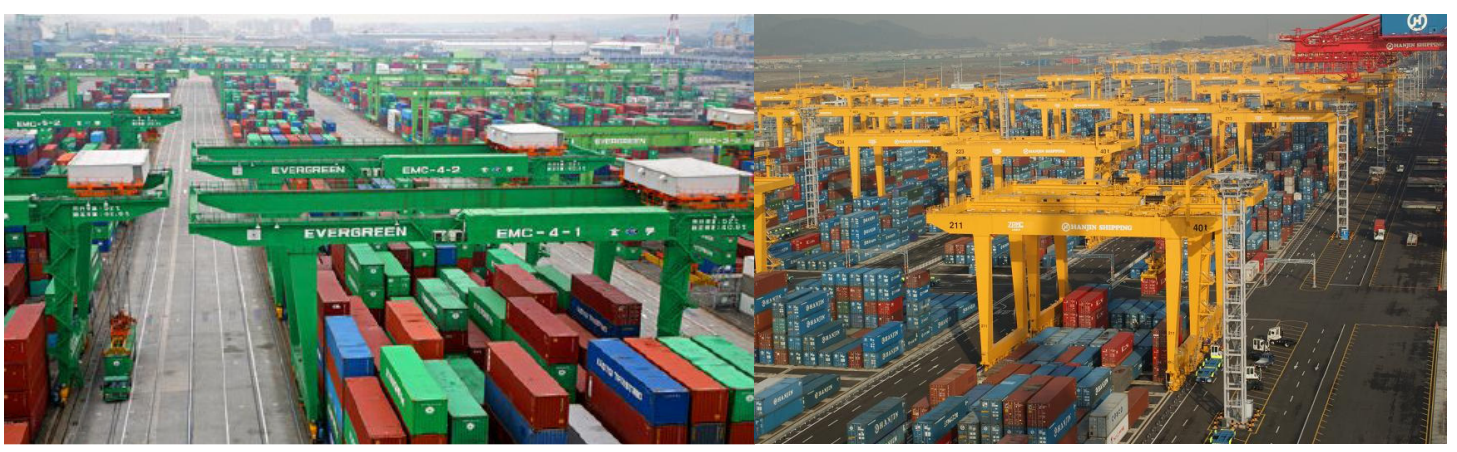

Fonte: Catálogo ABB

Completando os Equipamentos Sistemas Automatizados de Armazenamento de Contêineres estão os OHBC - Overhead Bridge Crane (figura 83), esse equipamento pode ser encontrado no PSA's Pasir Payang Terminal (Cingapura) e no Antwerp's Churchilldock (um projeto piloto de 200 metros de extensão). Trata-se de equipamento de alto investimento inicial de CAPEX, em virtude da estrutura necessária de piso e pilares que sustentam a ponte rolante; em contrapartida possui um alto potencial de automação; precisão no posicionamento e de maior velocidade 
dos que os demais equipamentos, além de ser um equipamento eletrificado, o que reduz seus custos de OPEX.

Figura 83 - Vista aérea do Pasir Payang Terminal (Cingapura) e Equipamentos OHBC
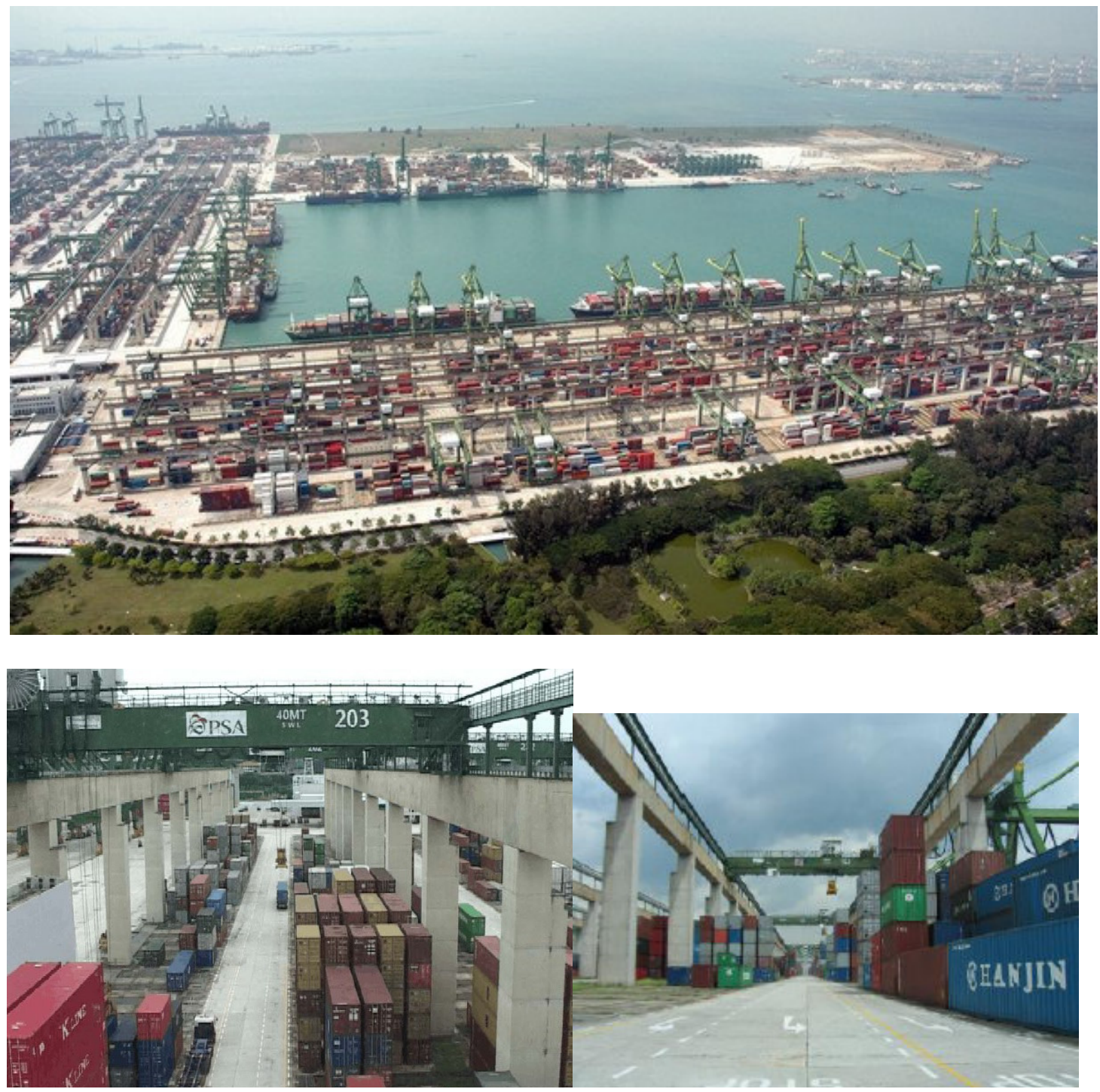

Fonte: PSA

A eletrificação de equipamentos é um item que precisa ser visto com atenção, diversos terminais eletrificaram seus RTG, os quais passaram a ser chamados de E-RTG, como o Modern Terminal Limited (Hong Kong) e Lazaro Cardenas Terminal (México). Além da questão de diminuição do custo de diesel e manutenção, há o apelo ambiental de redução de consumo e emissão de GEE e por que não indicar a eletrificação como item preliminar de automação; o que demonstra essa 
preocupação é que diversos terminais já têm encomendado seu RTGs com o Enrolador de Cabo de Alimentação (Cable Ree); a outra maneira de eletrificar um RTG é por meio do sistema de Barramento (Bus Bar), ver figura 84.

Figura 84 - Cable Reel x Bus Bar

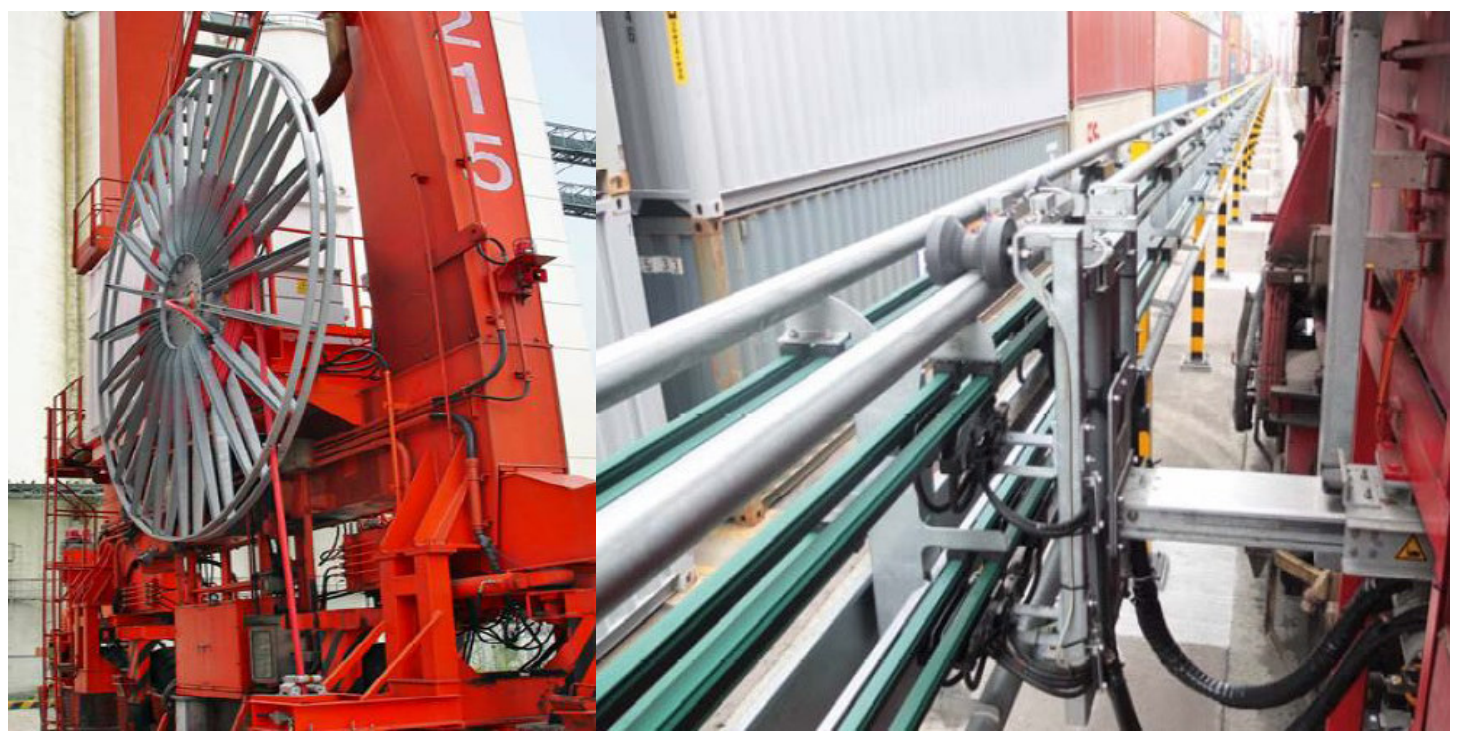

Fonte: Catálogos da Conductix Wampfler e Vahle Electrification System

Sobre conceitos e ideias inovadoras de equipamentos de movimentação (transferência e armazenamento) e de diferentes tipos de layout, apresentamos três propostas (ver figura 85):

- ASC com Trolley Duplo (ASC Double Trolley) no ASC da Konecranes;

- Dupla Linha subterrânea de transferência de contêineres do cais-pátio ferroviário (Dual lane below ground) da AECOM;

- Layout do tipo Front-Ending loanding do Global Terminal Bayonne em Nova Jersey;

- Transferência do container do ASC para o caminhão e vice nas zonas de transfêrencias do lado de terra. 
Figura 85 - Conceitos de Equipamentos de Transferência, Armazenagem e layout.
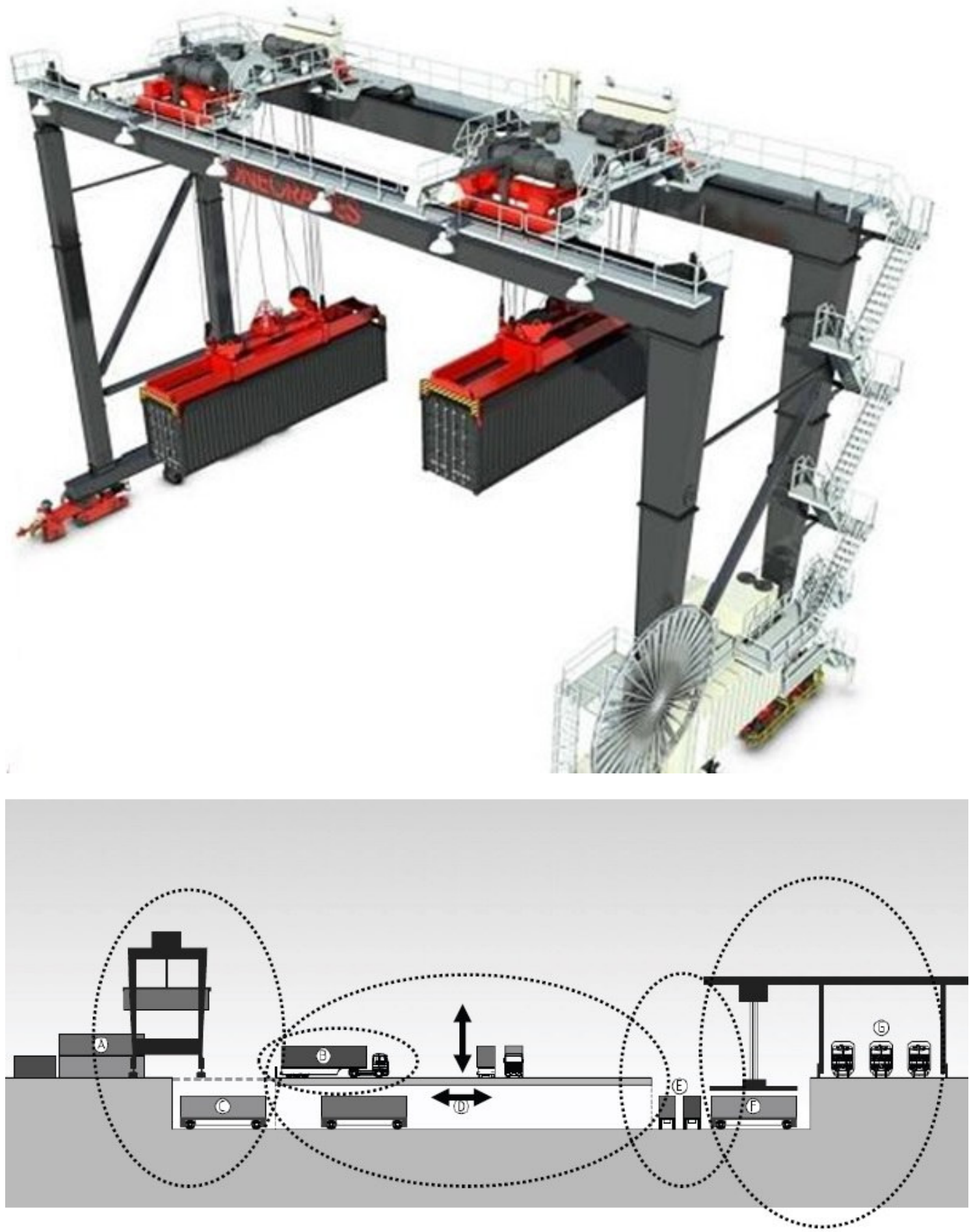

(A) AsC CONTAINER StACKS $\quad$ Bel OW GROUND OPEN ACCESS

(B) ASC/TRUCK EXCHANGE SLOTS

DUAL LANE BELOW
RAL/ASC LINK
(E) DUAL LANE BELOW GROUND OPEN

(F) RMG/AGV BELOW GROUND DPEN
(G) RAIL DPERATION (RMG) 

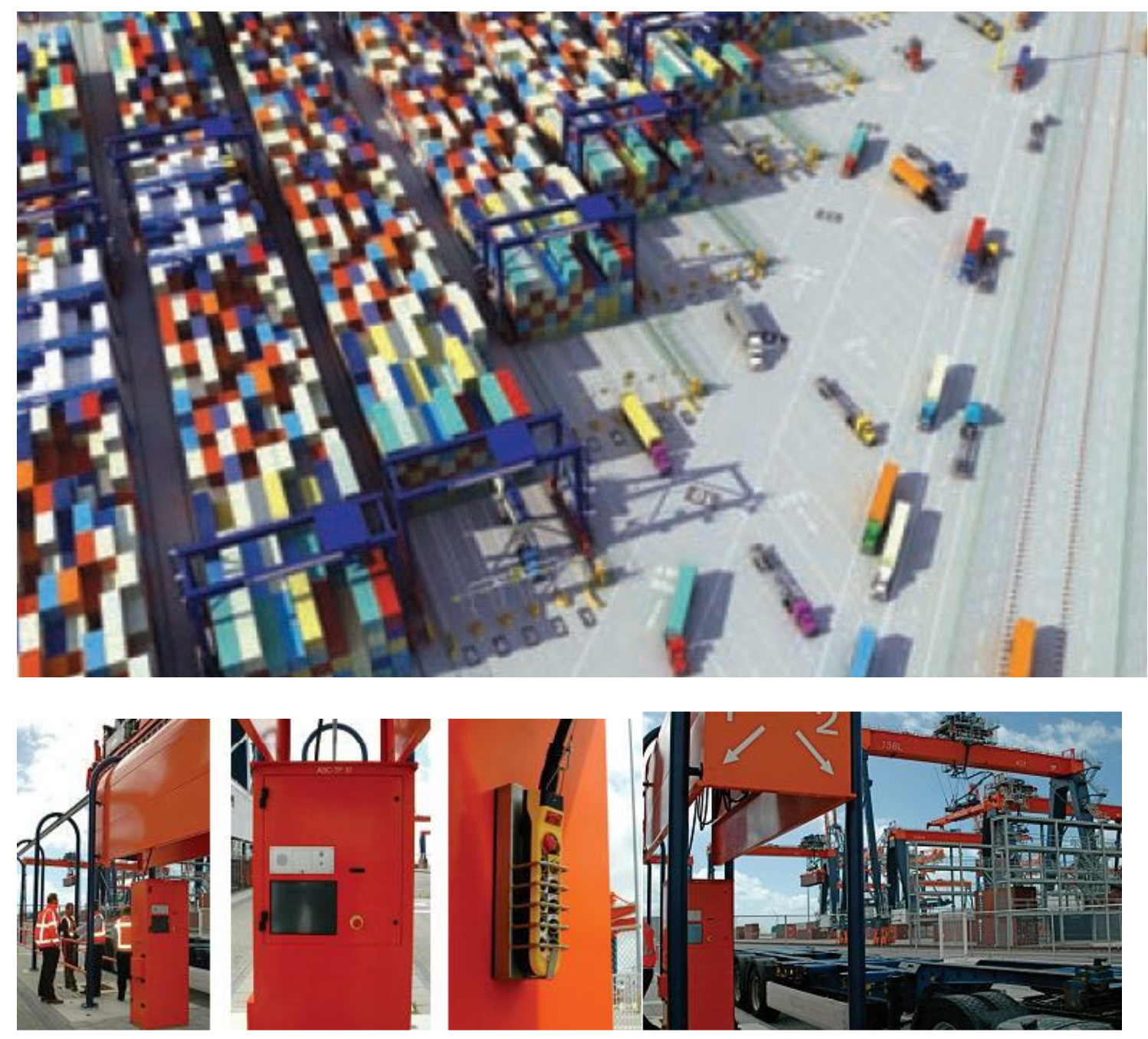

Fonte: Konecranes, AECOM, World CargoNews.

Ainda sobre conceitos inovadores de sistema de armazenamento automatizado em Racks, os quais começam a sair do papel para virar realidade, tais como:

- High Stack System (HSS), desenvolvido pela Korea Maritime Institute (KMI) em parceria com EZ-Indus Corporation; o sistema consiste em uma plataforma de transferência do cais para dentro do armazém construído, e um elevador de contêineres com a função de armazenar os contêineres nos racks;

- "Container Hangar" elaborado pela NYK, JFE Engineering Corporation e Tokyo Port Terminal Corporation no Ohi Container Terminal. A figura 86 abaixo ilustra esses dois conceitos; 
- Teustack desenvolvido pela FATA/Finmeccanica no molde de armazéns verticalizados automatizados.

Figura 86 - High Stack System, Container Hangar e Teustack
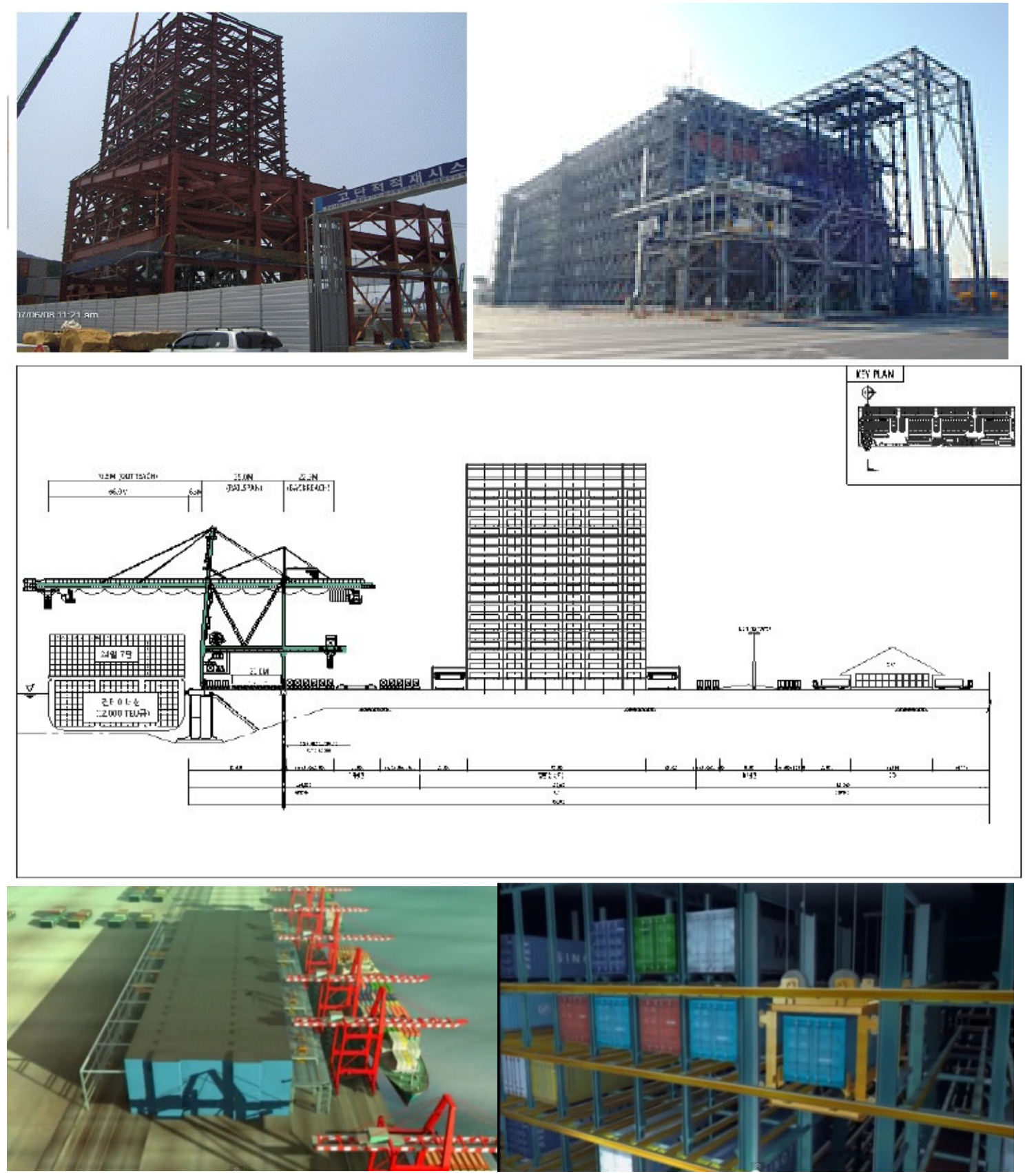

Fonte: Automation of Container Terminals (ISL) e FATA

Finalizando, a questão dos Guindastes Automatizados de Pátio ou Automated Stacking Cranes (ASC), o relatório da Port Equipment Manufacturers Association 
(PEMA) aponta que há cerca de 500 equipamentos em operação na Europa, Ásia e Estados Unidos e respondem pela movimentação de 20 milhões de TEU/ano.

Retomando os conceitos gerais de Automação, Groover (2011) indica que nem sempre há uma distinção clara entre os sistemas automatizados e os sistemas trabalhadores-máquinas, pois esses últimos, muitas vezes, operam com um determinado grau de automação.

Portanto, pode-se distinguir a automação em dois níveis:

- Semiautomatizado, no qual a máquina executa parcela do ciclo de trabalho sob algum tipo de controle de programa e o restante do ciclo é operado por um trabalhador humano;

- Totalmente automatizado, é aquele no qual a máquina opera por períodos mais longos ou maiores números de ciclos, sem a intervenção humana.

O fato de indicar-se que o processo é sem intervenção humana não é impeditivo que trabalhadores realizem o processo de monitoramento da operação, certificando que a máquina opera de acordo as especificações. Esse monitoramento, não é preciso ser realizado a cada ciclo, mas pode ser realizado com uma frequência estabelecida de ciclos completados.

Sobre os graus de automação de terminais de contêineres, Monfort (2012) separa em: terminais automatizados e terminais semiautomatizados e, em paralelo, faz uma consideração entre automações menores e automações maiores.

O termo "totalmente automatizado" ou simplesmente "automatizado" se emprega para os terminais que automatizaram seus movimentos do pátio e de conexão ou transferência cais-pátio; mesmo quando a movimentação dos portêineres continua sendo realizada manualmente.

O conceito de "semiautomatizado" ou "parcialmente automatizado" é definido para aqueles terminais que possuem as operações de pátio automatizadas e a operação de cais-pátio por meio de equipamentos convencionais tripulados. Equipamentos que são controlados via controle remoto são considerados por Monfort (2012) como semiautomatizados.

A classificação que diferencia automação maior e menor é mais rigorosa; entendendo-se como: 
- Automação maior, a automação total de um processo e movimentação do equipamento; enquanto,

- Automação menor é considerada as diversas novas tecnologias, tanto na parte lógica, operacional e administrativa, como na parte física de movimentação de equipamentos e contêineres, as quais permitem automações parciais do processo. Os portêineres são bons exemplos repletos de automação menores, normalmente suportadas por CLPs.

Figura 87 - Exemplo de CLP Siemens de portêineres

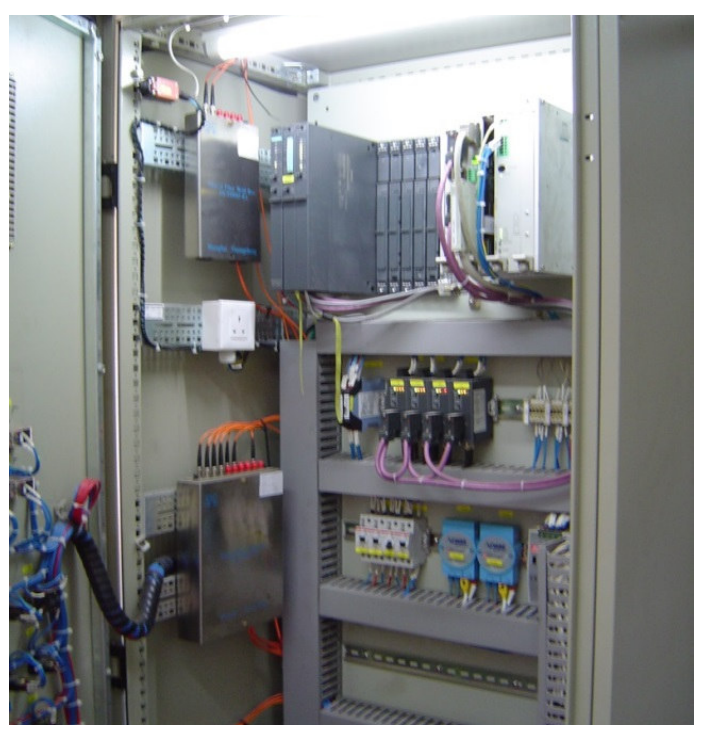

Fonte: Catálogo SIEMENS

Listamos, abaixo, uma série de funções automatizadas de portêineres indicadas por Bryfors (2013), as quais também podem ser adaptadas e instaladas nos equipamentos de pátio como o RTG e ASC. São elas:

- Load Position Sensor (LPS);

- Electronic Load Control (ELC);

- Vehicle Alignment System (VAS);

- Ship Profiling System (SPS);

- Automatic Container Lading System (ACLAS);

- Remote Control.

O Sistema de Sensores de Posicionamento (Load Position Sensor) e Controle de Embarque Eletrônico (Electronic Load Control) abrangem os controles de "sway" 
ou "anti-sway", cuja finalidade é a de minimizar os movimentos pendulares ou, como dizem os operadores, "tirar o balanço", permitindo dessa forma um posicionamento mais rápido para engatar e/ou desengatar os contêineres; ou o sistema "skew" ou "anti-skew" o qual serve para ajustar as inclinações (ou torções) transversais (list), e longitudinais (trim). Bryfors (2013) indica que o tempo natural de estabilização (sem ação de funções anti-balanço ou torção) de um container de 40' na altura do solo pode ser superior a 20 segundos. As figuras 88 e 89 ilustram as questões de sway e skew.

Figura 88 - Exemplo das funções de skew e sway a bordo de navio
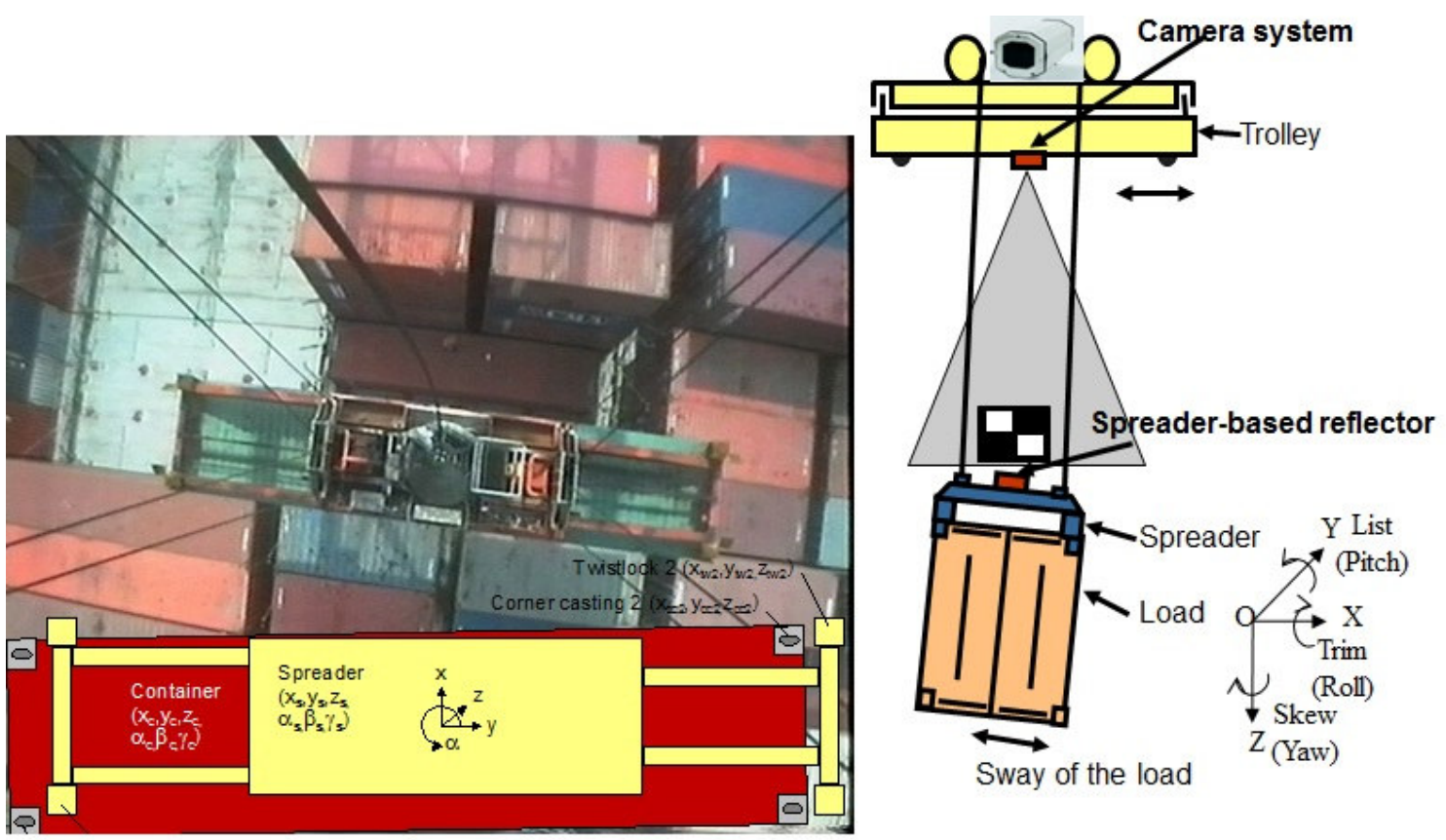

Fonte: Catálogo Siemens

Figura 89 - Exemplo das funções de skew e sway em carretas

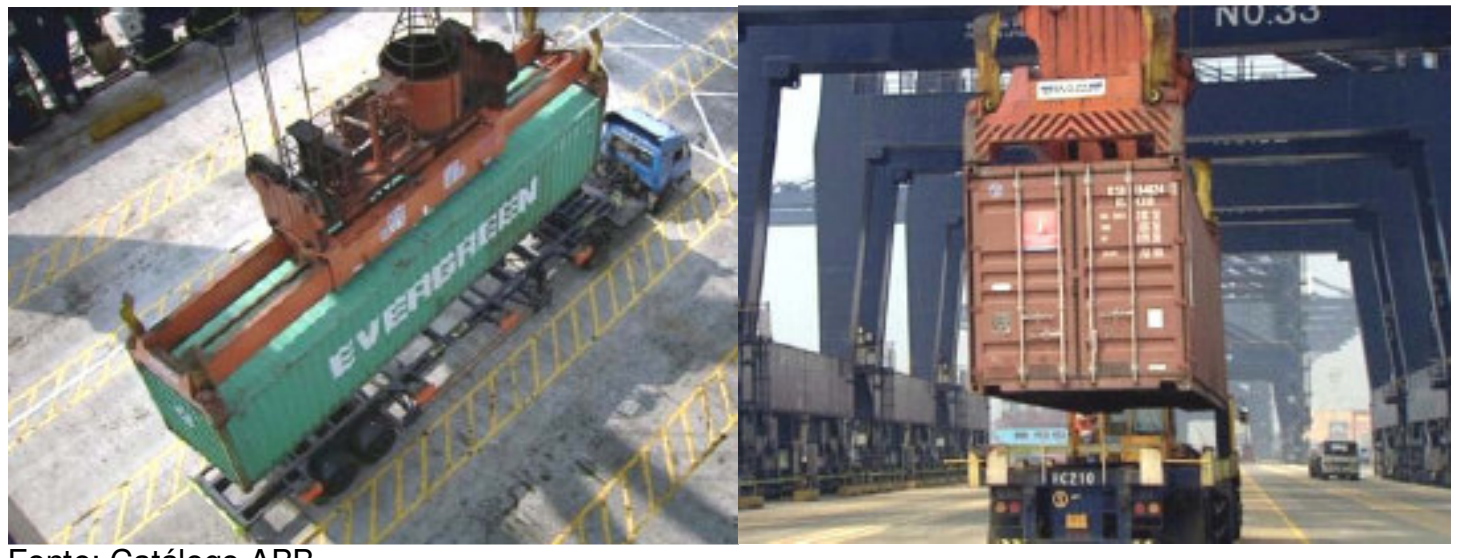

Fonte: Catálogo ABB 
Outra função indicada é o Sistema de Alinhamento de Veículos (Vehicle Alignment System) e que consiste em ser um guia para o motorista parar o veículo na posição correta; diferentemente do sistema de posicionamento de sensor anteriormente ilustrado nesse trabalho na figura 49. Esse é projetado com o uso de laser 3D instalado na principal viga do portêiner, conforme figura 90.

Figura 90 - Sistema de Posicionamento de Carreta através de Laser

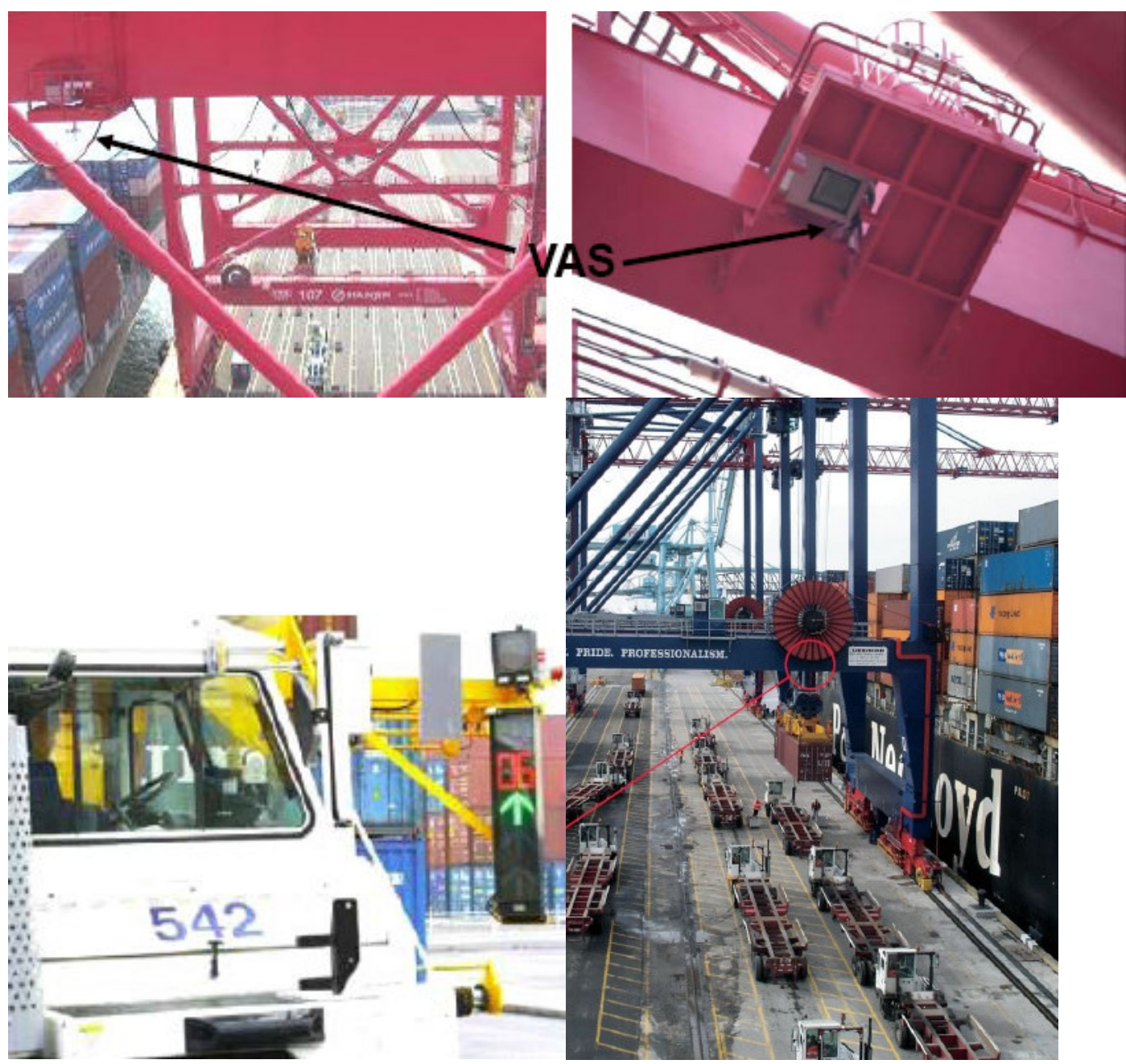

Fonte: Catálogo ABB e SICK Sensors

O Sistema de Perfil de Navio (Ship Profiling System) verifica como o próprio nome indica o perfil das alturas de cada pilha a bordo (convés e porão), esse mapeamento é feito por meio de sistema de escaneamento 3D com a supervisão de sistema de anticolisão continuo, ilustrações das figuras 91 e 92. 
Figura 91 - Sistema de Perfil do Navio (Ship Profilling System)
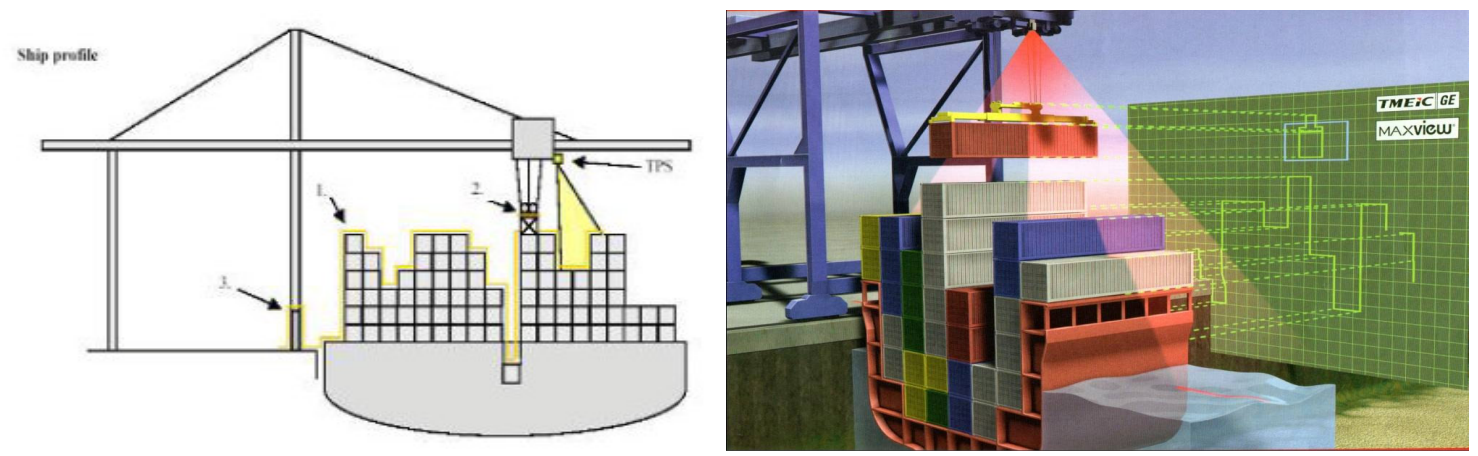

Fonte: Catálogo ABB e TMEIC

Figura 92 - Sistema de Perfil do Navio (Ship Profilling System)

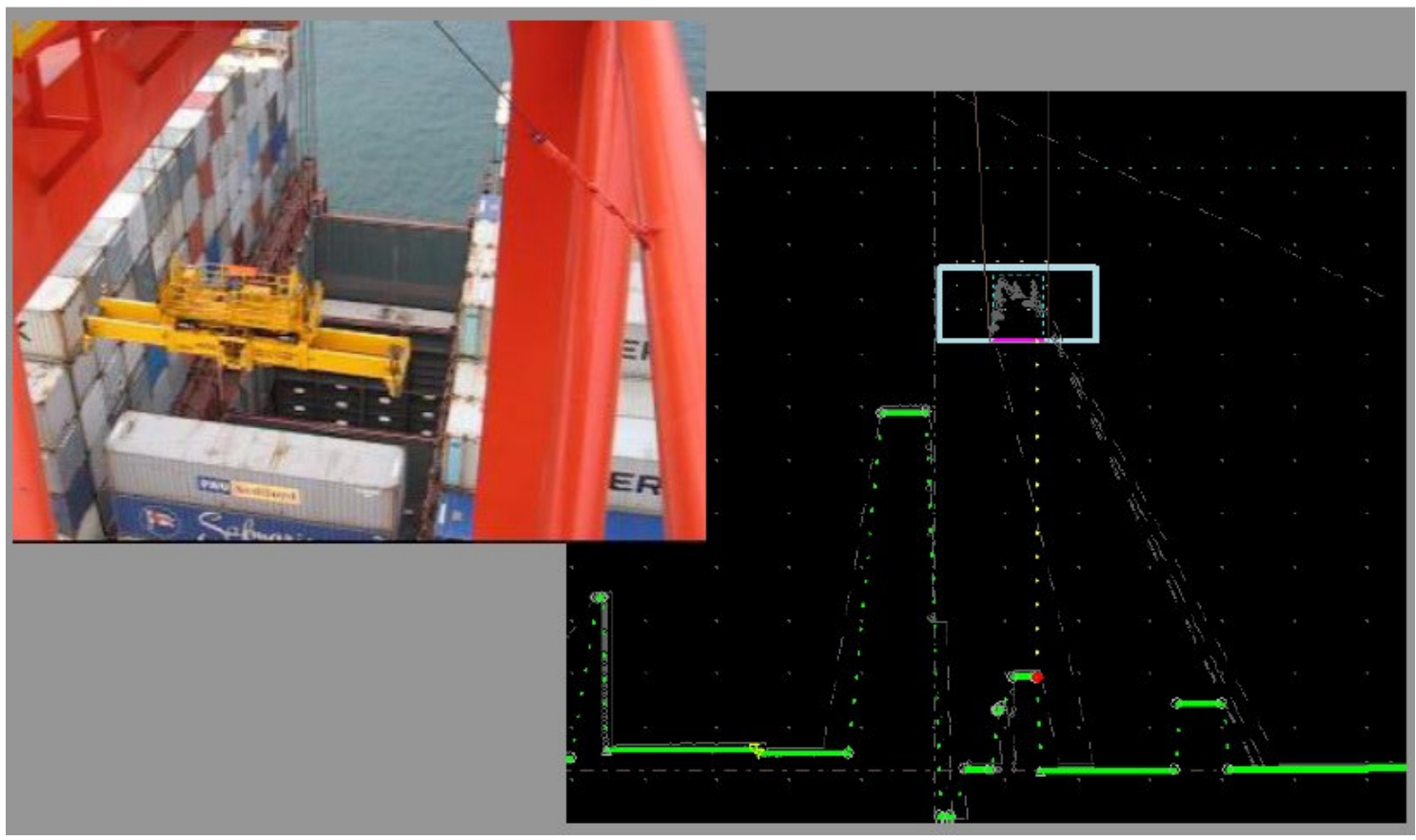

Fonte: Apresentação TMEIC no TOC Europa (Londres 2014).

Esse mesmo sistema de verificação de perfil (escâner 3D e sistema de anticolisão continuo) da pilha utilizado inicialmente em portêineres migrou recentemente para os RTGs, com o nome de Sistema ou Sensor "Anti-Topple", ou algo como sistema "antiqueda". A figura 93 representa a imagem real de armazenagem na quadra do contêiner e a tela do sistema com indicação dos obstáculos. 
Figura 93- Sistema de Perfil de Anti-Topple para RTG
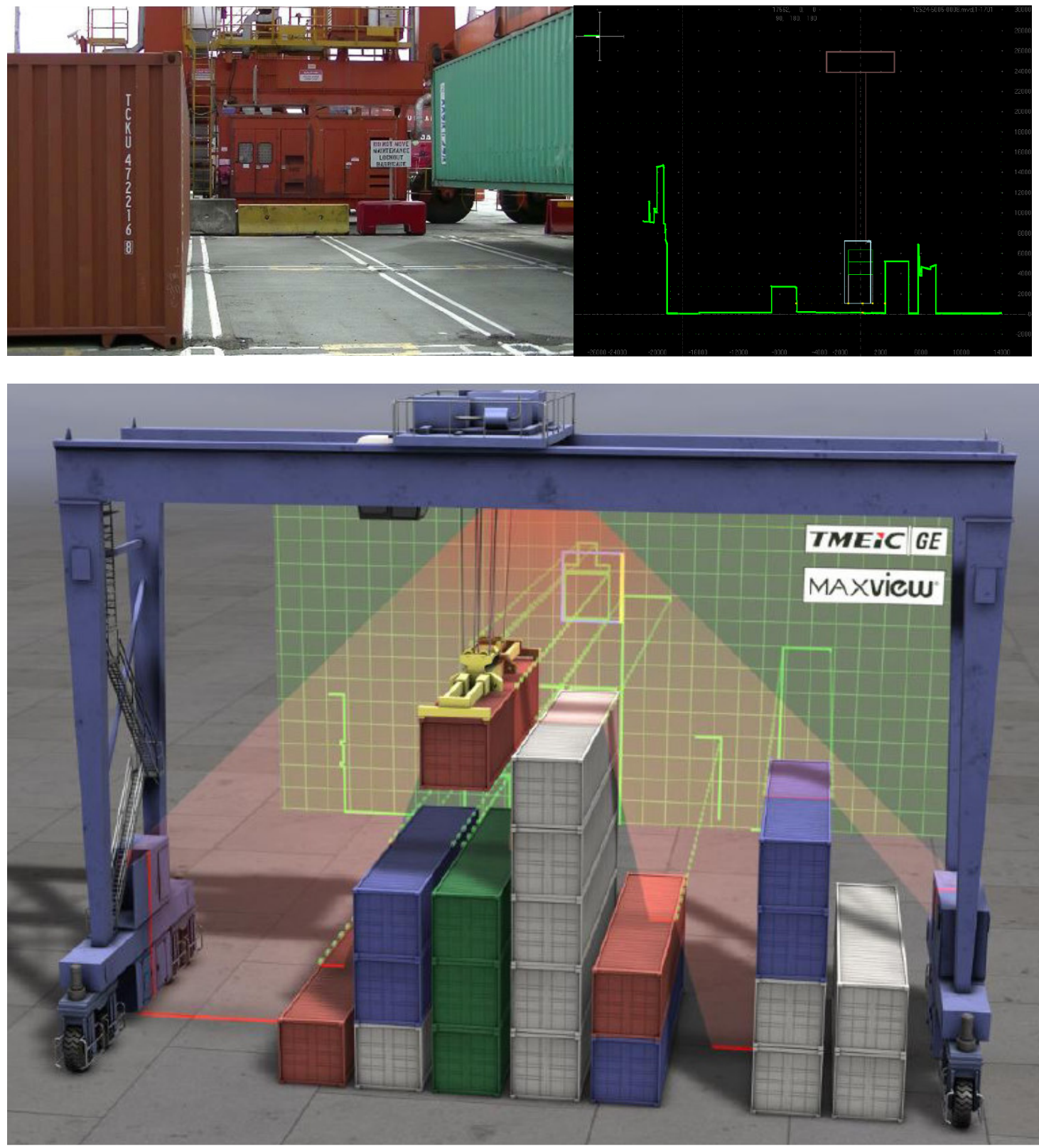


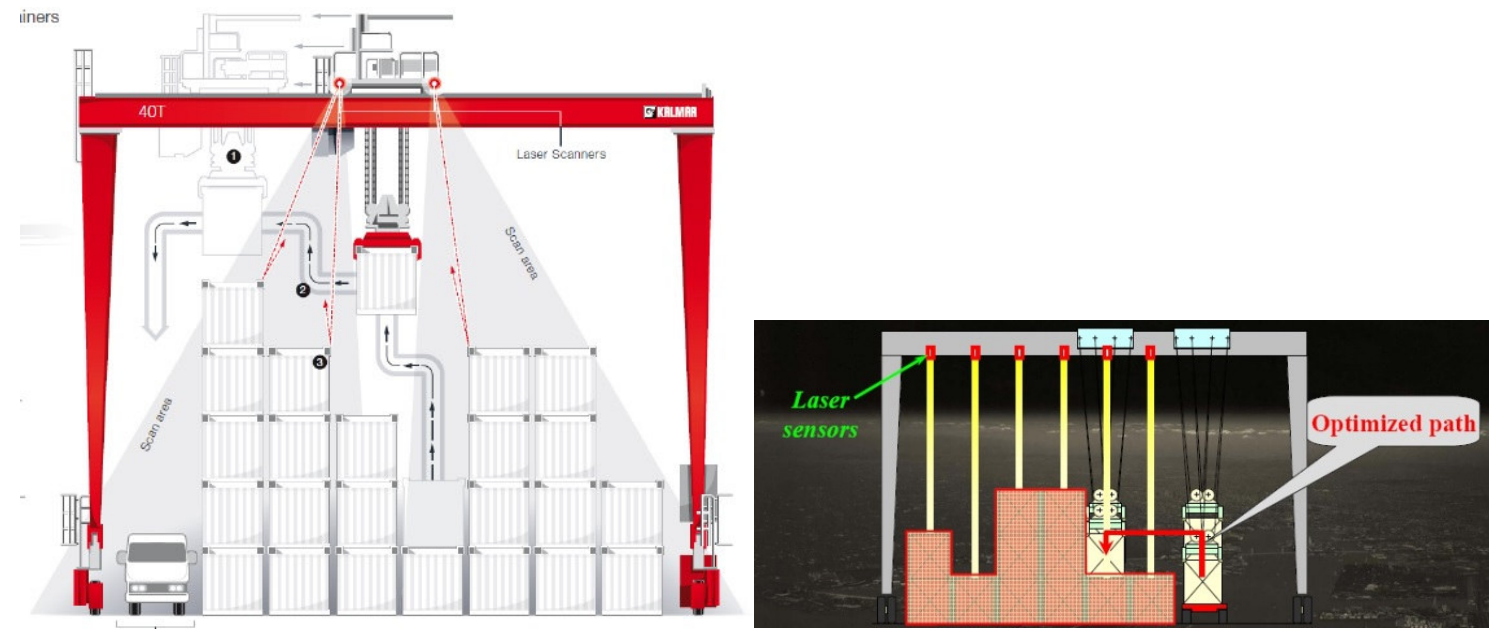

Fonte: Apresentação TMEIC, Kalmar e Mitsubishi Heavy Industries

Essa tecnologia de verificação de perfil também pode ser utilizada como parte integrante de um Sistema de Carregamento de Contêiner Automatizado (Automatic Container Lading) ou de um Sistema de Empilhamento Automatizado (Automated Container Stacking). A figura 94 ilustra a colocação de um contêiner ao lado de uma pilha existente.

Figura 94 - Sistema de Perfil de Anti-Topple para RTG

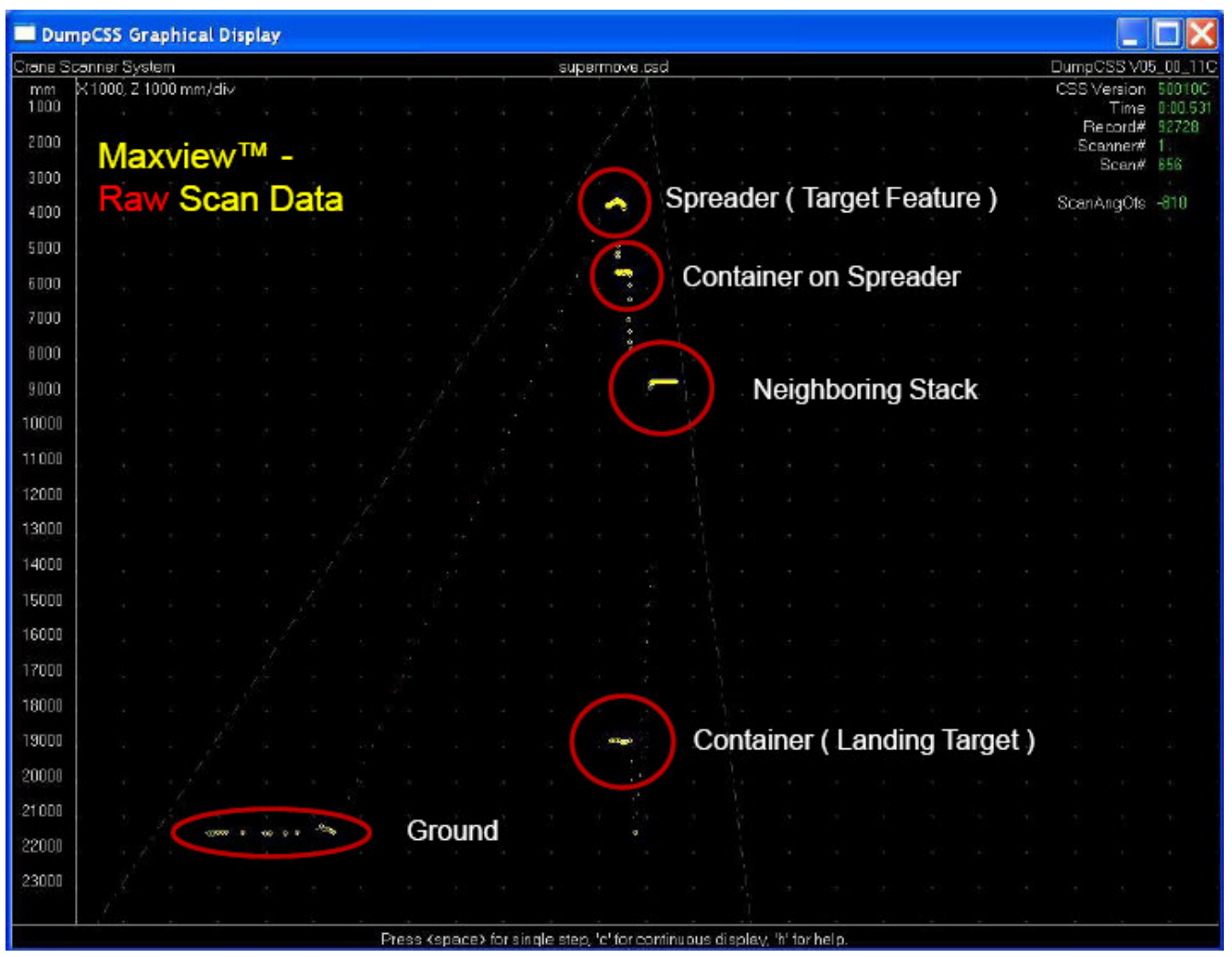




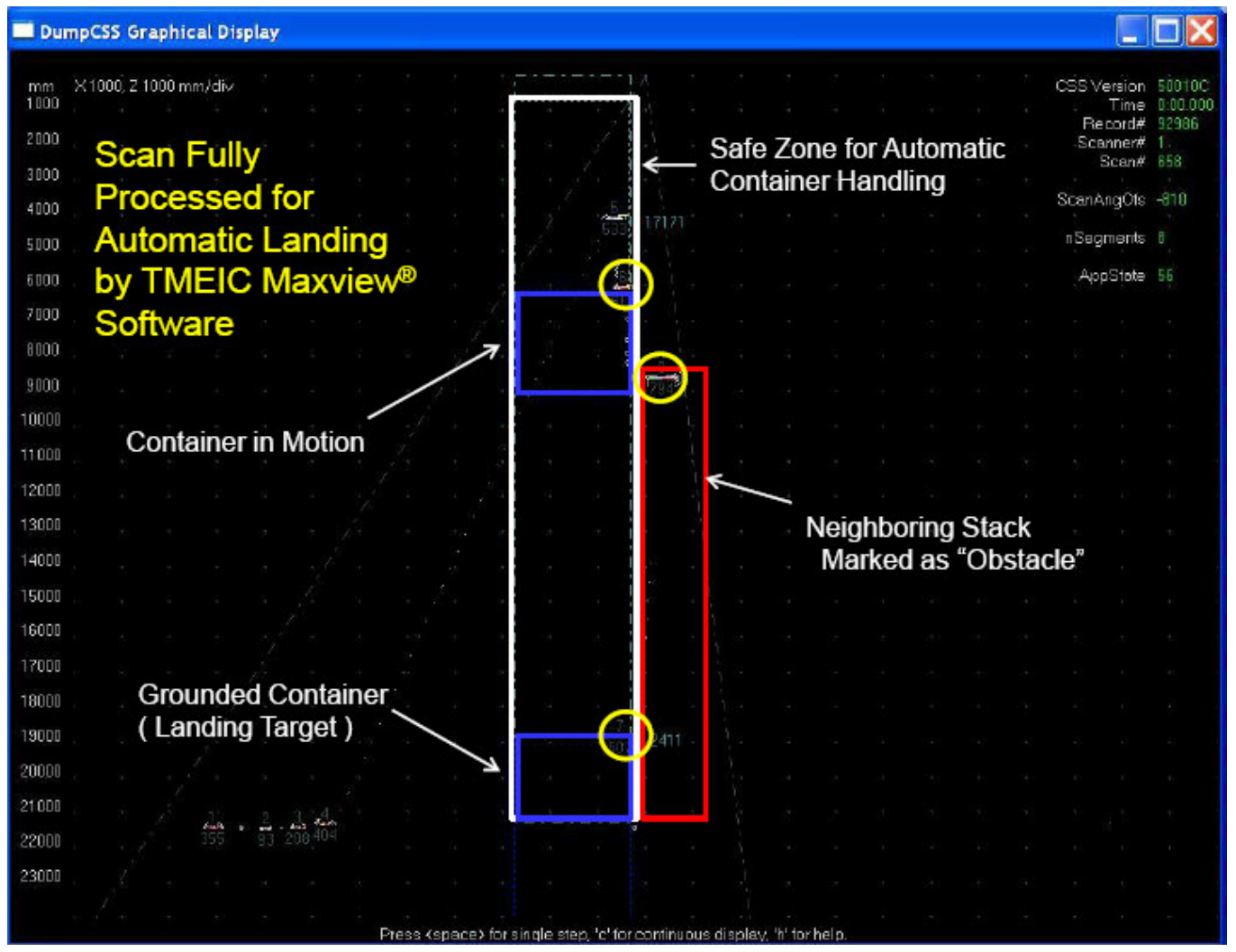

Fonte: Apresentação TMEIC no TOC Europa (Londres 2014).

A combinação dos sistemas anteriores citados, isto é, Sistema de Sensores de Posicionamento (Load Position Sensor), Controle de Embarque Eletrônico (Electronic Load Control) mais o Sistema de Alinhamento de Veículos (Vehicle Alignment System) e Sistema de Perfil de Navio (Ship Profiling System) formam um Sistema de Carregamento de Contêiner Automatizado (Automatic Container Lading System- ACLAS); um sistema auto assistido das operações de embarque e descarga, evitando o carregamento ou "aterrissagem" do contêiner de forma errada (hard landing), sobre as guias de carretas ou fora das células (cellguides) dos navios, conforme a figura 95. 
Figura 95 - Colocação (Aterrissagens) sobre carreta e a bordo de navio
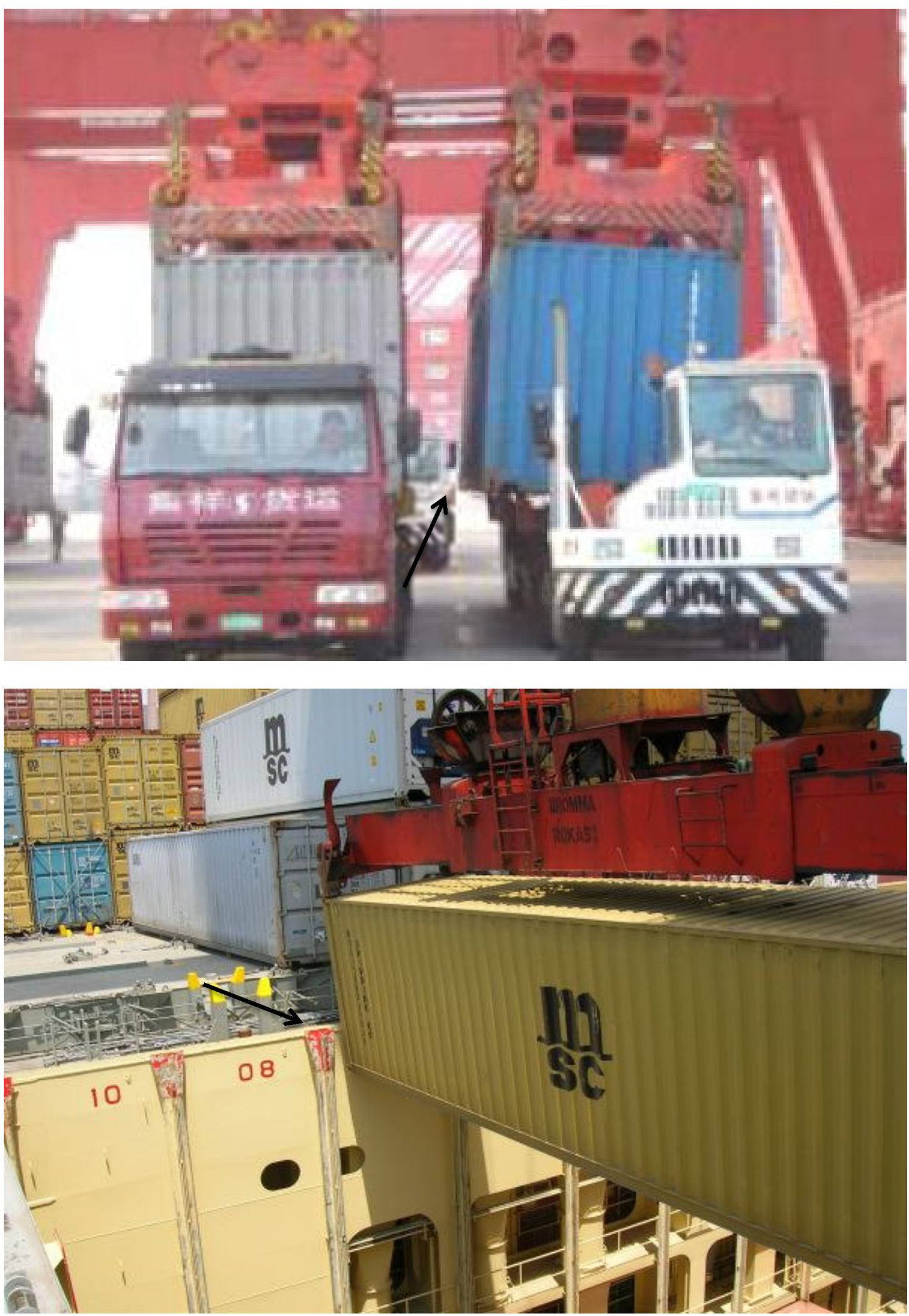

Fonte: Catálogo ABB e site www.walshsurveyor.com 
A figura 96 compara duas operações de descarga na mesma bay (porão), sendo a primeira realizada manualmente com contêineres no convés e a segunda realizada de forma assistida pelo sistema ACLAS com contêineres no porão, ou seja, operação mais complexa e de maior trajeto a ser percorrido pelo portêiner.

No período da operação manual, movimentaram-se 115 contêineres, performando ao final do período, $29 \mathrm{mph}$ (movimentos por hora) e ocorrendo 23 "hard landing" ou aterrissagens mal sucedidas. Na operação assistida pelo ACLAS, foram descarregados 106 contêineres com uma produtividade de $37 \mathrm{mph}$ e nenhuma "hard landing".

Figura 96 - Aterrissagens sobre carreta e a bordo de navio

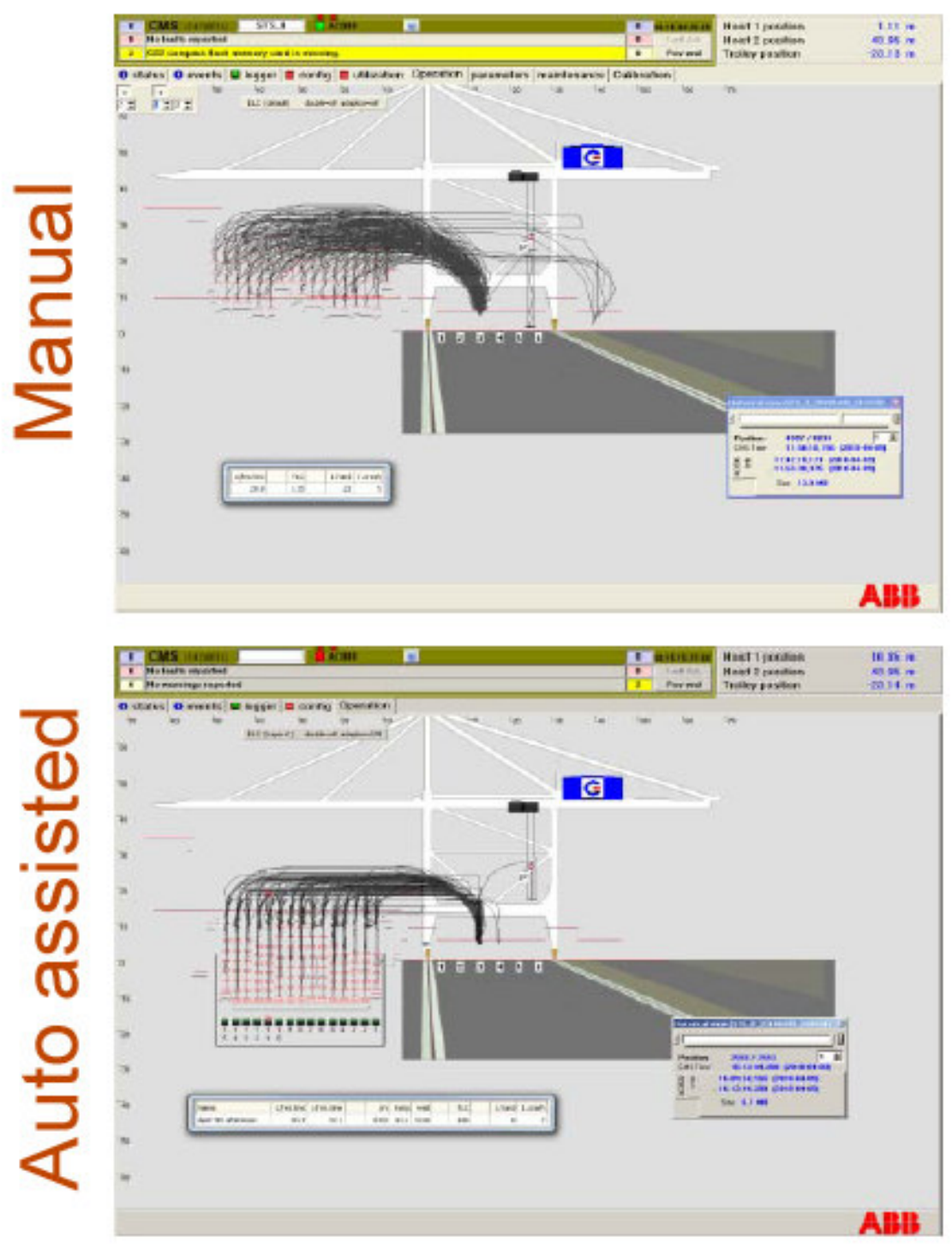

Fonte: Catálogo ABB 
A figura 97 compara a mesma operação realizada em simulador, por operadores novatos, operadores experientes e com a operação assistida pelo sistema ACLAS. É notória a falta de sensibilidade pelos operadores de realizarem os movimentos no mesmo padrão (altura, referências etc.). Supondo que cada movimento realizado de forma assistida contribua com apenas três segundos de melhoria na operação em um terminal que movimenta 500.000 contêineres/ano; isso significará ao final de um ano 17,4 dias de berços de berço livre.

Figura 97 - Comparação do uso do ACLAS entre operadores novatos, experientes e o sistema assistido.

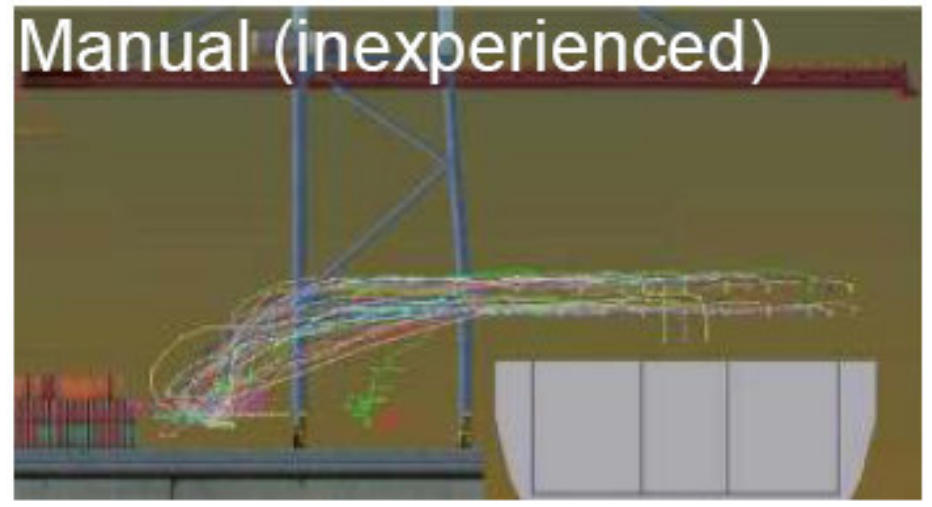

\section{Manual (experienced)}

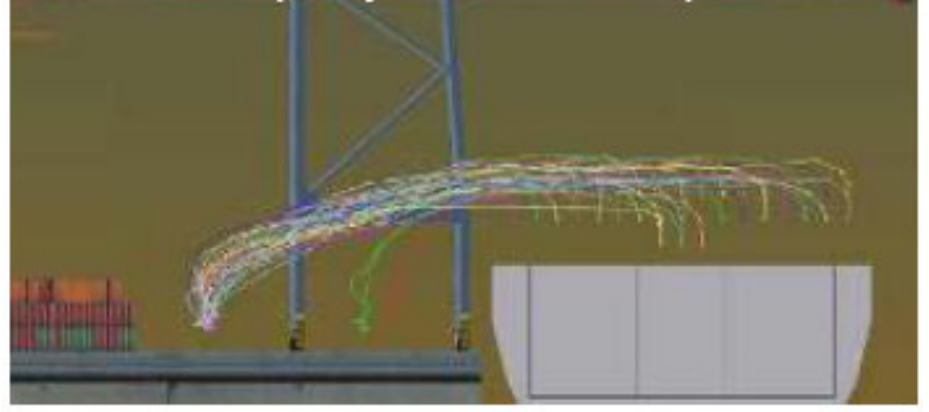

\section{ACLAS (inexperienced)}

Fonte: Catálogo ABB 
E, por derradeiro, o Sistema de Controle Remoto (Remote Control) exemplificado anteriormente através da figura 68 e abaixo pela Figura 98, que retira o operador da cabine fixa do equipamento para um ambiente de escritório com melhor ergonomia, eliminando um problema de saúde ocupacional (dores nas costas) e diminuição dos índices de afastamento por esse problema, desenvolvido sobre o conhecimento de operações, redução nos tempos de trocas de turno/operador.

Figura 98 - Comparação de Ergonomia entre a Cabine Fixa e o Controle Remoto
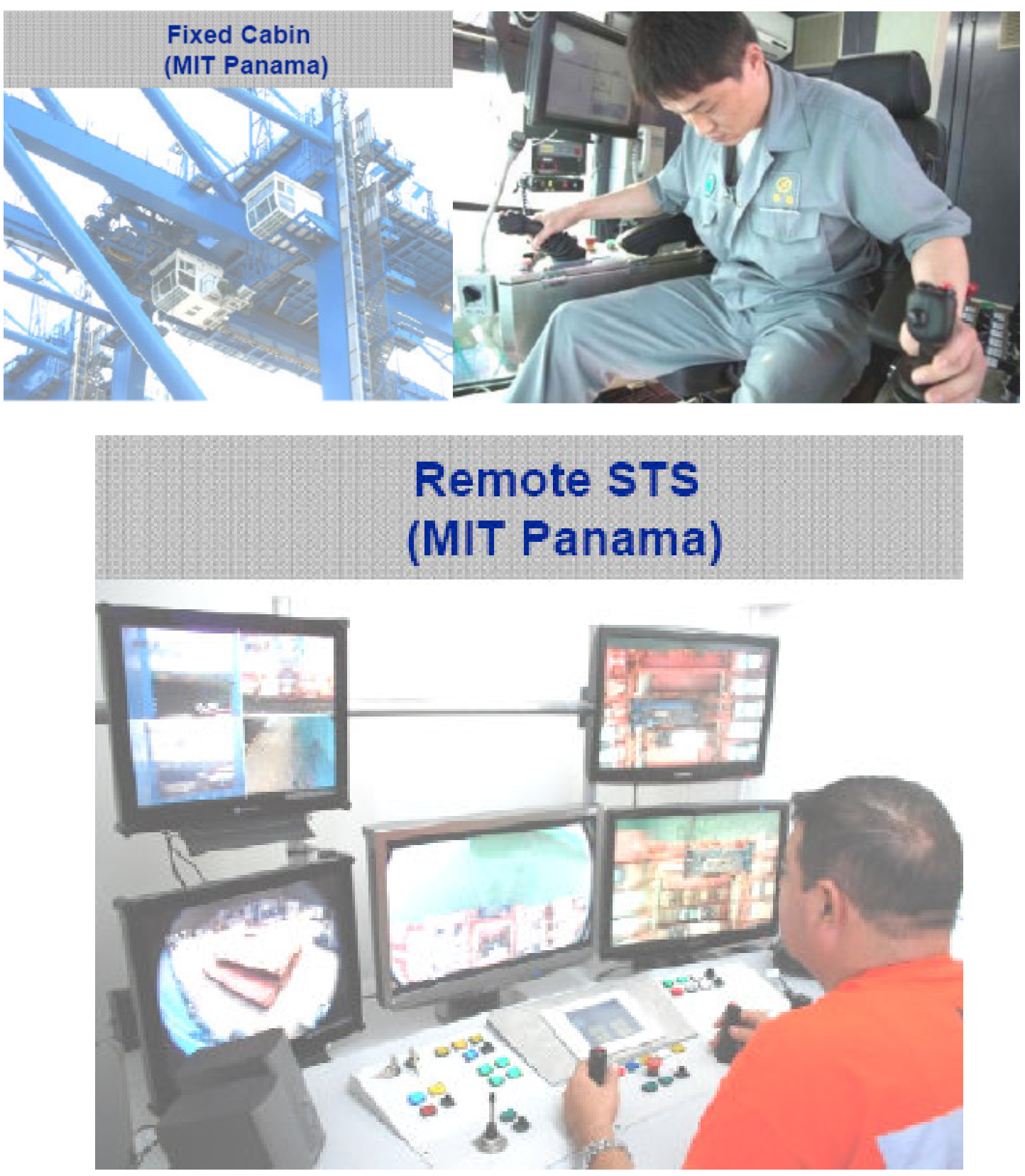

Fonte: Catálogo ABB 
O Manzanilo International Terminal no Panamá realizou esse processo de transferência do operador de portêiner da cabine a 40 metros do solo, para um ambiente de Controle Remoto no escritório de forma gradativa, trazendo o operador primeiramente para uma cabine na perna do portêiner, para depois uma mesa de controle na área de operações.

De forma análoga, a Konecranes propõe fazer o mesmo com os operadores de RTG, trazendo o operador de 18 metros de altura, para uma das pernas no RTG a 3 - 4 metros do chão; este novo conceito recebeu o nome de "Boxhunter" (ver figura 99). A cabine localizada na perna do RTG permite um acesso mais fácil e rápido do operador, além de deixar a estrutura superior do equipamento mais leve.

Figura 99- RTG Boxhunter da Konecranes

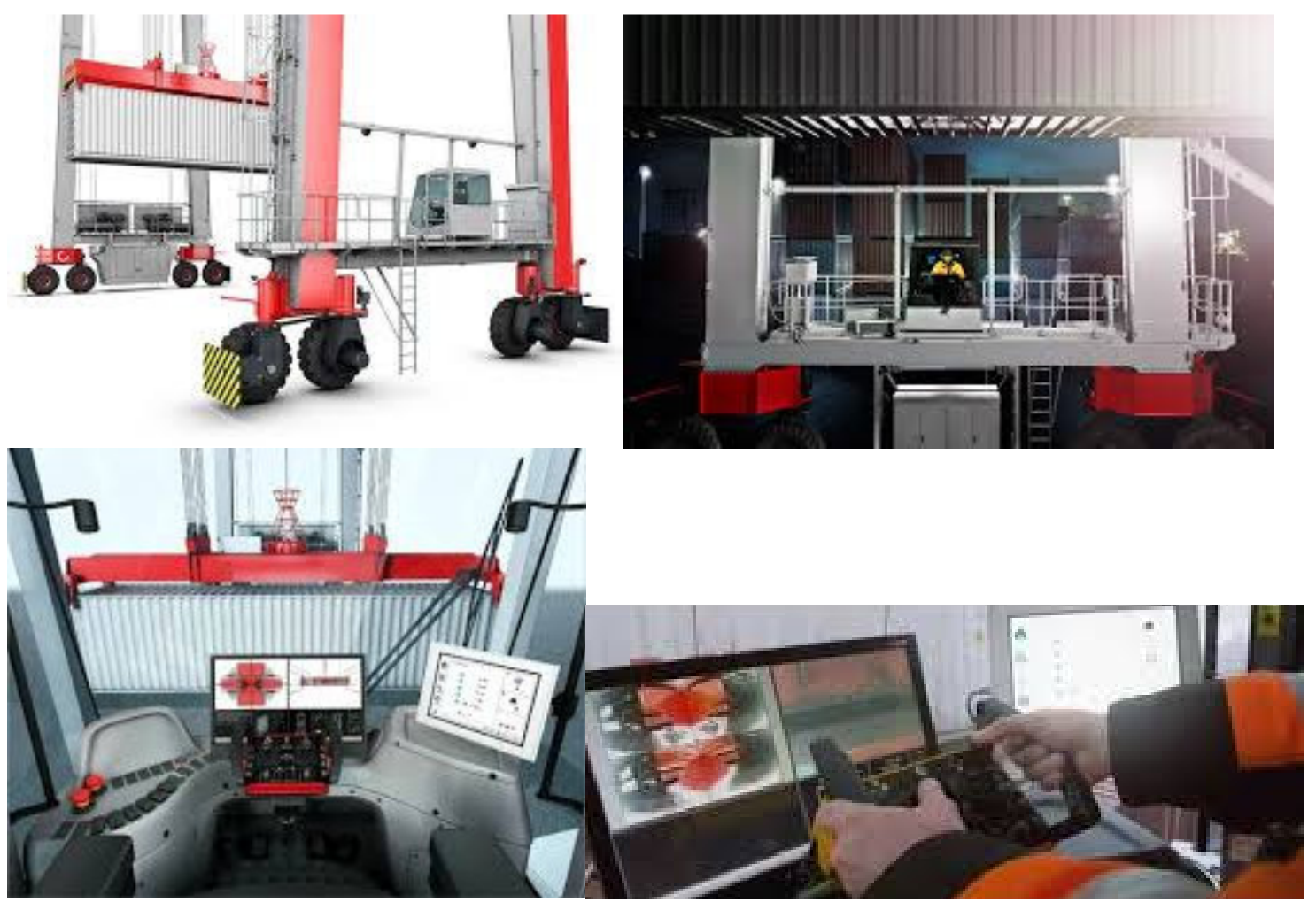

Fonte: Catálogo Konecranes 


\subsubsection{PROCESSO tRADICIONAL VERSUS AUtOMAÇÃO DE GATES, DESCRIÇÃO DAS TECNOLOGIAS PARA AUTOMAÇÃO EXISTENTES E GARGALOS OPERACIONAIS}

Dempsey (2012), em linha com o trabalho dessa tese, explica que é possível a criação de um framework para análise da viabilidade e impactos potenciais nas operações, observando as várias áreas de um terminal no qual a automação pode ser aplicada; contudo, reforça que qualquer análise deve previamente iniciar com entendimento das tecnologias disponíveis.

Sobre as tecnologias de automação, Dempsey, no mesmo texto, agrupa em três núcleos ou bases as principais tecnologias, sendo essas:

- Identificação;

- Localização ou Posicionamento; e,

- Sensoriamento ou Telemática.

Iniciando a descrição das principais tecnologias dos três núcleos pela de Identificação, pode-se afirmar que os terminais possuem necessidade de identificar contêineres, equipamentos e pessoas de forma eficiente e sem divergências. A captura automática de dados de identificação depende de três tecnologias: Reconhecimento de Caracteres Óticos (OCR), Sistemas de Imagens e Identificação via Rádio Frequência (RFID).

Utilizando os processos de gates de entrada e saída como referência de aplicação, a captura de dados por meio de OCR nos gates é a principal tecnologia para identificação de contêineres (figura 100), baseado em um padrão de numeração, permite uma leitura da identificação alfanumérica presente nas laterais e teto dos contêineres e conversão digital de dados, para entrada de dados no TOS ou em um Sistema de Gate Automatizado (Automated Gate Systems - AGS).

O mesmo OCR é utilizado para a captura das placas do conjunto (caminhão e chassis), sistema que é comumente chamado de LPR (Licence Plate Recognition). Em conjunto com o sistema de OCR, é possível agregar um sistema de imagens utilizando câmeras para verificar a existência de avarias, presença de lacre, selos de carga perigosa e numeração da UN e direção de portas. Importante destacar que um sistema de OCR isoladamente não automatiza uma linha de gate. 
Figura 100 - Exemplo de OCR em Gates Cobertos e Portais
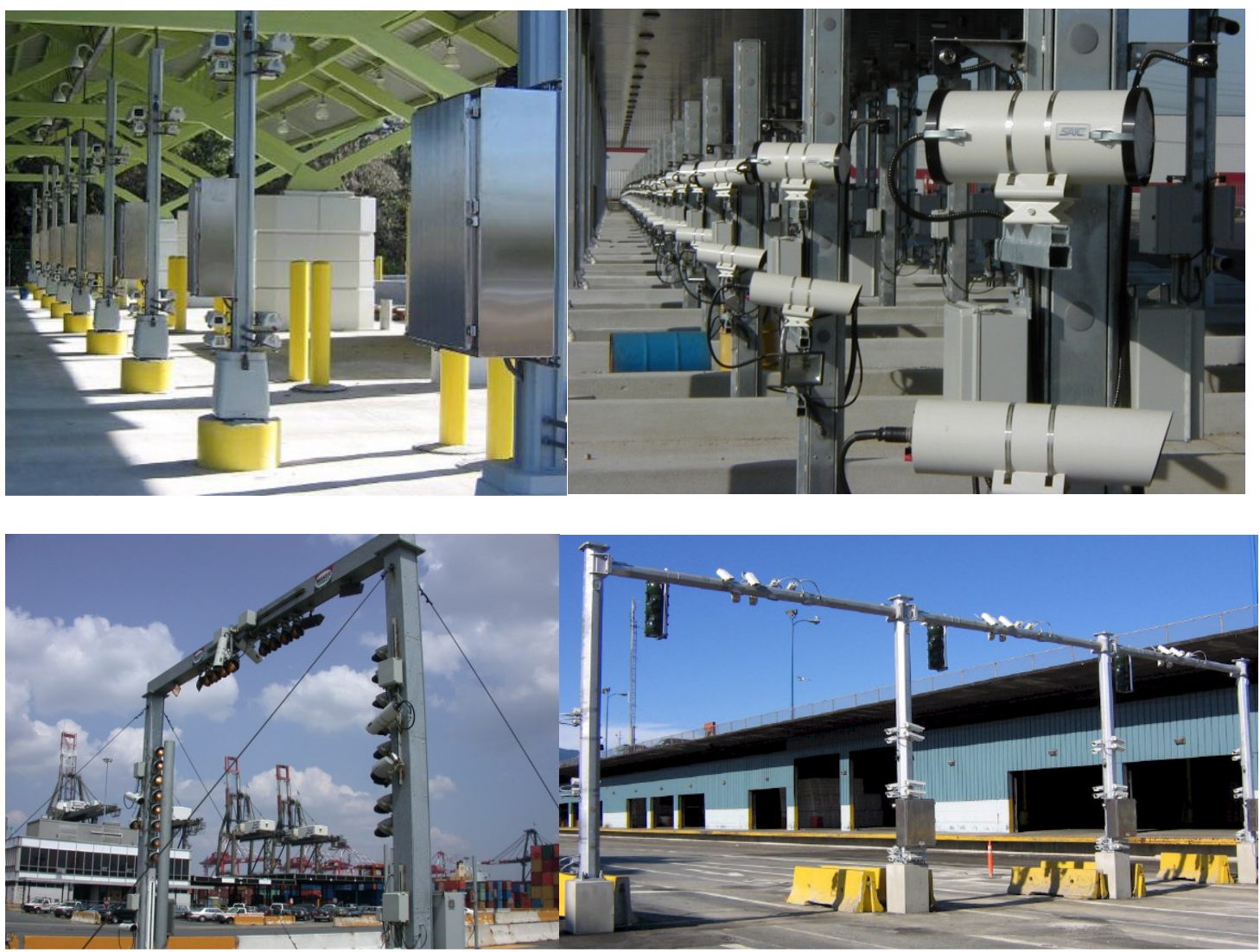

Fonte: Catálogo CAMCO e APS

Figura 101 - Exemplo de Infraestrutura de Gates com OCR
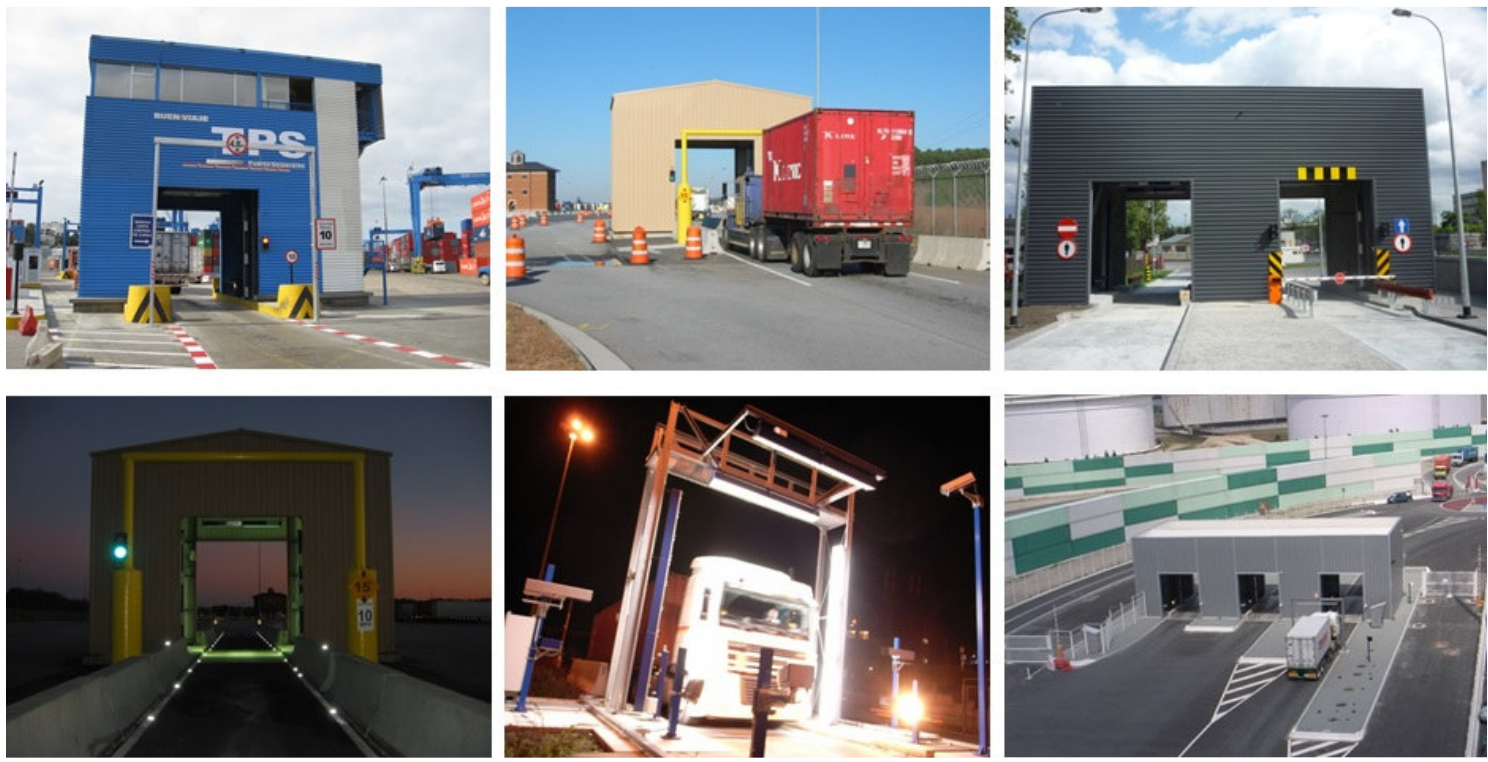

Fonte: Catálogo CAMCO 
Sistemas OCR apresentam duas tecnologias de captura de imagens, conforme ilustram a figura 102 que apresenta exemplos de imagens do tipo "Area Scan" (quadros de fotos), enquanto a figura 103 mostra o sistema "Line Scan" (digitalização da superfície do container com imagens de alta precisão).

Figura 102 - Exemplo de imagens "Area Scan"
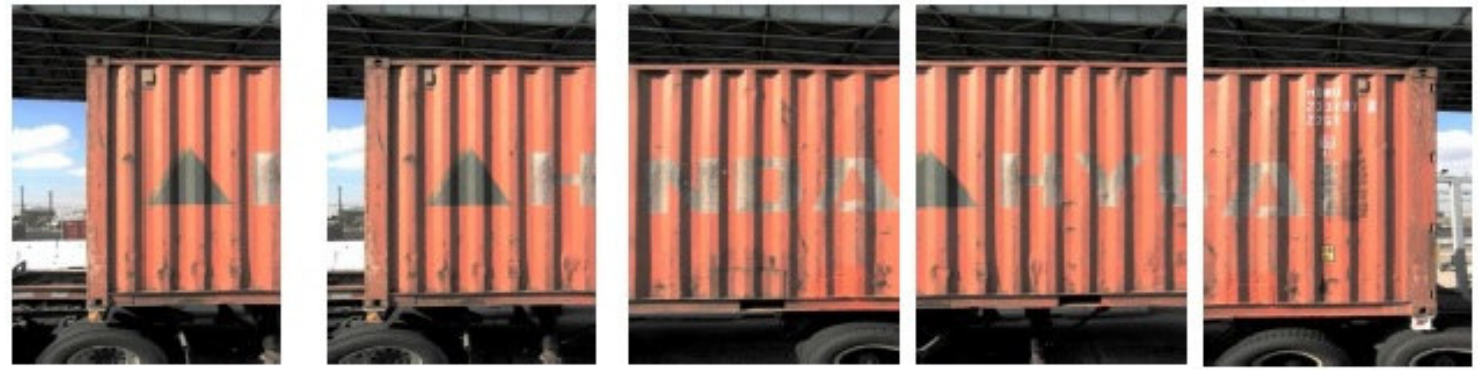

Fonte: CAMCO

Figura 103 - Exemplos de imagens "Line Scan"
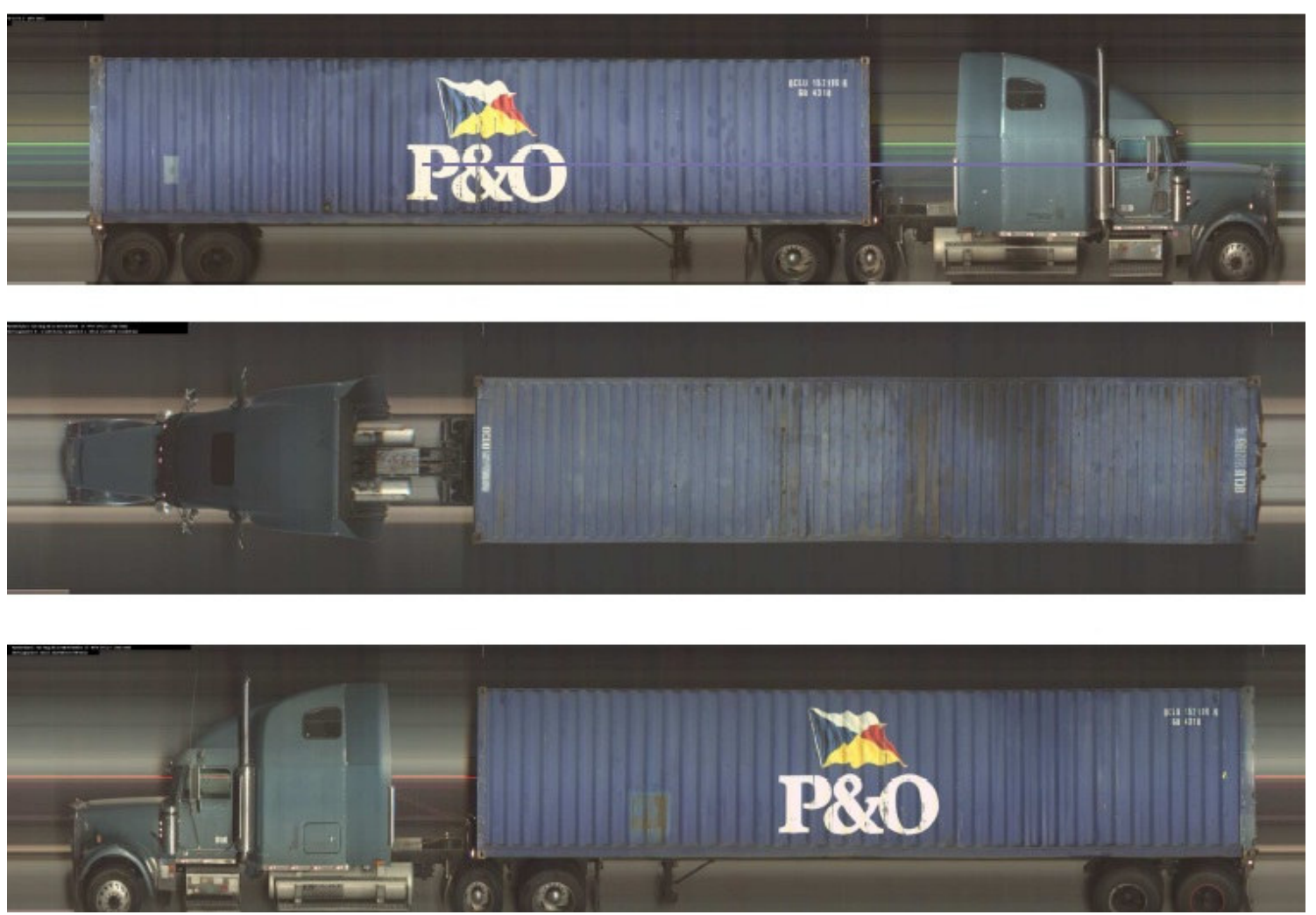

Fonte: CAMCO 
Figura 104 - Exemplos de imagens Line Scan diversas

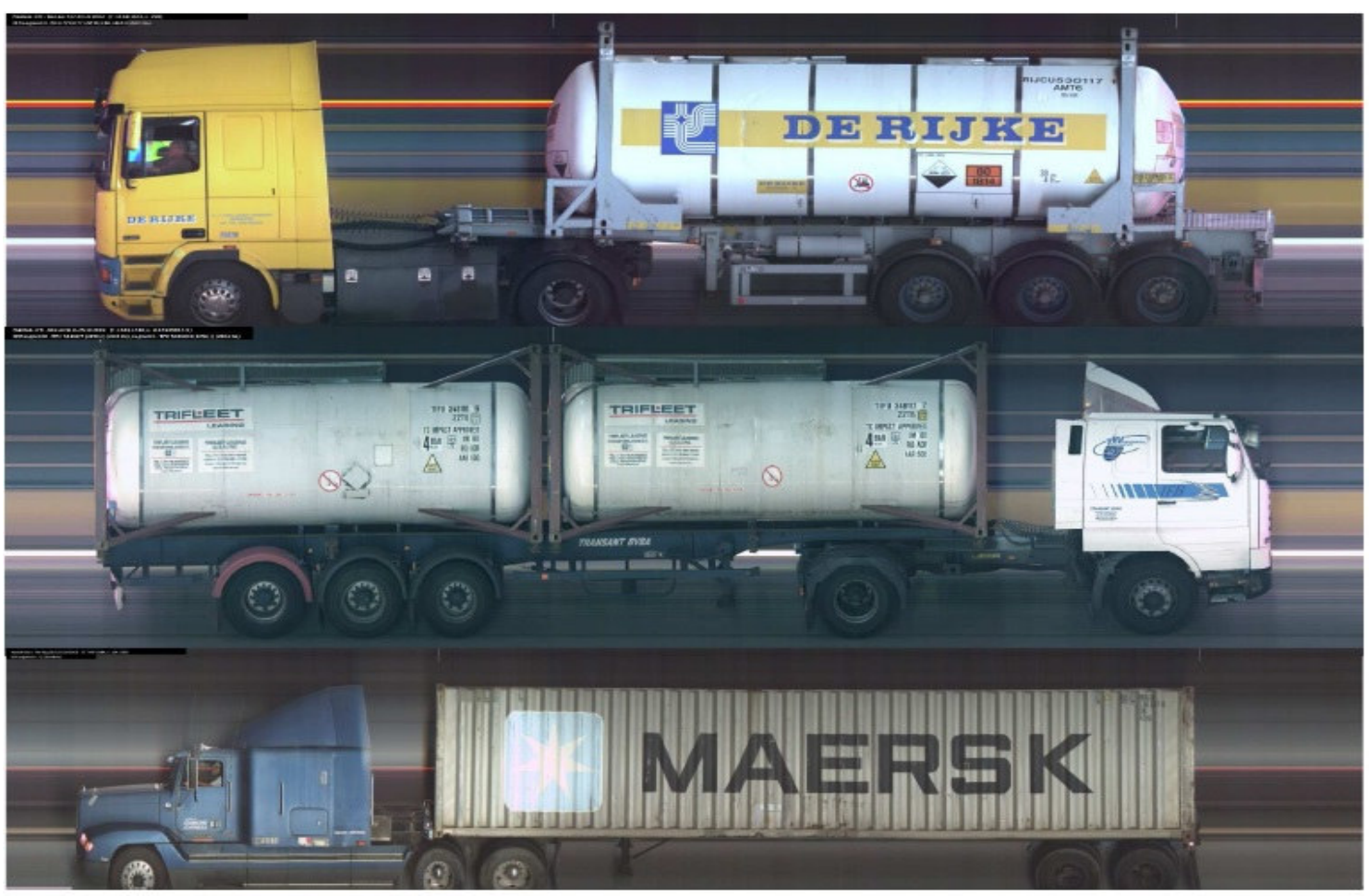

Fonte: CAMCO

O Uso de OCR não se restringe apenas aos gates dos terminais, mas tem ganhado espaço em outros processos e aplicações, como:

- Na operação de recebimento e entrega de contêineres via ferroviária, como ilustrado na figura 105;

- Instalado nos portêineres, figura 106, para auxiliar nas atividades de conferência, registro de embarque e descarga no TOS, confirmação da posição correta do container a bordo do navio.

Outras aplicações de combinação do uso do OCR com tags serão descritas mais adiante, quando da descrição das tecnologias de posicionamento e localização. 
Figura 105 - OCR na Ferrovia

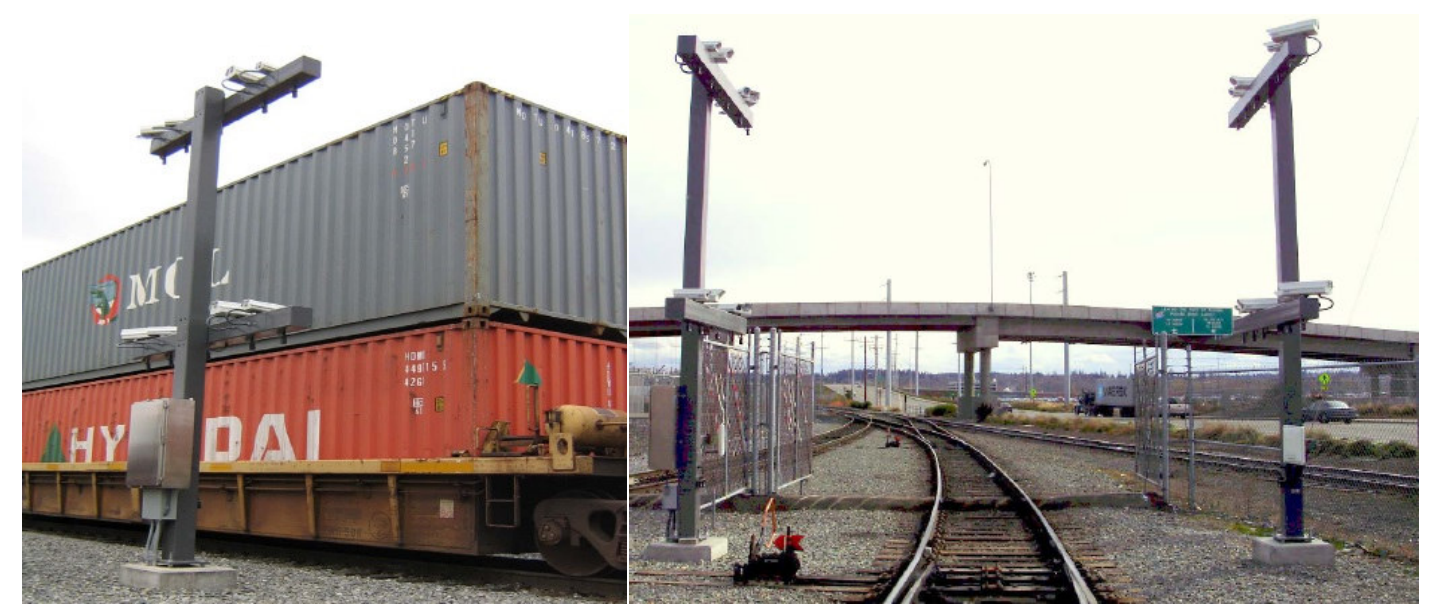

Fonte: APS

Figura 106 - OCR instalado em portêineres
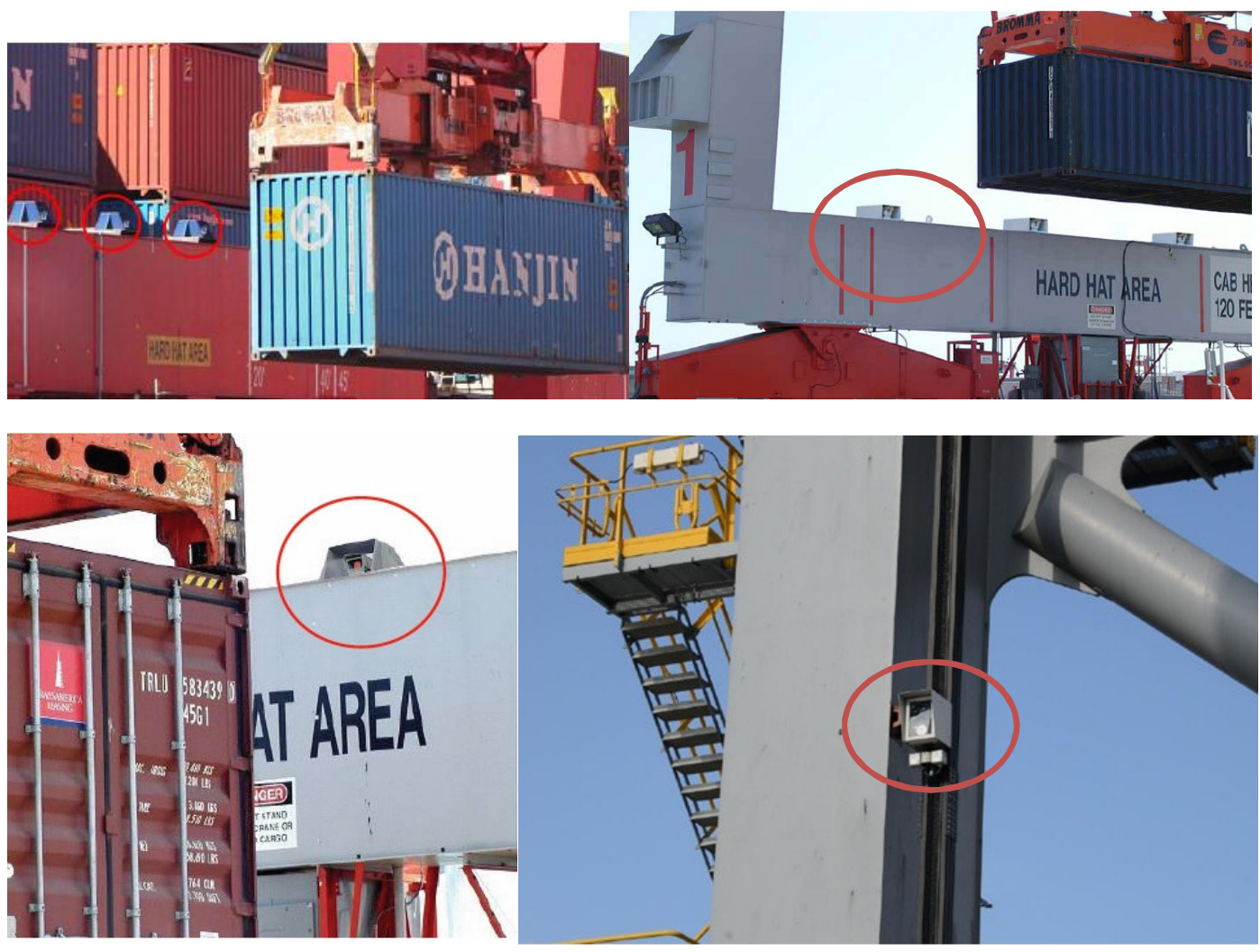

Fonte: APS e London Gateway

A figura 107 apresenta imagens de OCR dos portêineres, da lateral do contêiner, teto e porta. 
Figura 107 - Imagens de OCR instalado em portêineres
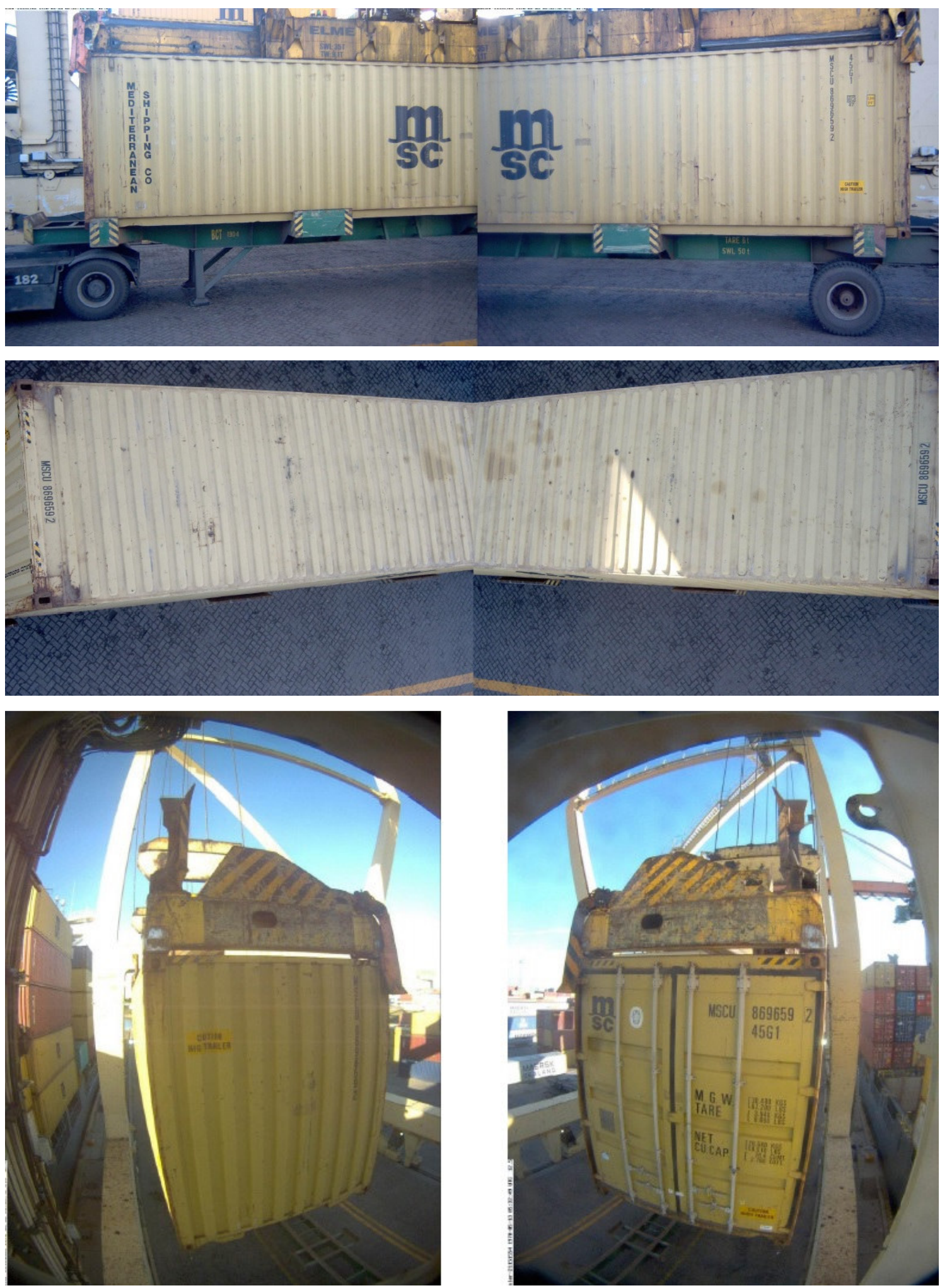

Fonte: Autepra 
Um sistema tradicional de Gate difere bastante de um Sistema de Gate Automatizado (AGS). Sistemas tradicionais de gates possuem muitas interrupções e paradas do veículo no fluxo do processo, tais como:

- Confirmação do horário de agendamento do contêiner feito pelo transportador ou exportador, conforme disponibilidade e escolha de janelas de chegada;

- Verificação de dados do conjunto (motorista, caminhão, chassis);

- Vistoria física do contêiner (avarias e lacres);

- Entrega de "Placares Identificadores" da carreta. Isso é necessário, pois os veículos não possuem a numeração da placa pintada no teto (como na Europa), o que impossibilita que o operador da máquina saiba no caso da entrega de contêineres qual o veículo;

- Motorista precisa soltar o pino lock do caminhão que prende o contêiner;

- Segregação das "missões" do veículo no terminal, onde missão é entendida como: o tipo de carga, regime aduaneiro ou atributo do contêiner. Por exemplo: recebimento de um contêiner cheio de exportação ou de um vazio de exportação; entrega de um contêiner de importação cheio para outro terminal (TRA, EADI, diretamente para o cliente, etc.), Contêiner em regime de DTA, entre outros;

- Atendimento no gate de entrada para últimas verificações (instruções de CSI ou alfândega para passagem no escâner);

- Pesagem do conjunto na entrada e saída;

- Recebimento da posição de pátio para armazenagem ou retirada do contêiner conforme o módulo de planejamento de pátio do TOS;

- Confirmação do Banco de Dados Comum de Credenciamento (BDCC), que é um sistema de cadastramento e emissão de crachá de identificação necessário para o acesso de pessoas e veículos aos recintos alfandegados e a todos os locais do Porto de Santos;

- Biometria.

Portanto, tais atividades exigem recursos humanos no Pré-gate, na área de vistoria, no controle de fluxo e segregação de missões, nos gates de entrada e saída, e adicionalmente operadores no chamado gate de problema (problem desk) ou área de suporte ao motorista, trata-se de uma área do terminal responsável pelo 
atendimento daqueles veículos que apresentaram problemas no Pré-gate, como falta de agendamento ou horário antecipado ou vencido do agendamento; problemas de avarias ou mesmo quebra do veículo.

Há ainda o aspecto de segurança patrimonial e do trabalho a ser atendido; portanto há muita interação homem-máquina, quando pensamos no trabalho do vistoriador e caminhões ou controladores de fluxos e caminhões.

Todos esses itens acabam criando problemas de implicação econômica para a organização do trabalho; pois há a dependência direta entre o ritmo de trabalho e a produtividade, uma vez que a produtividade é dependente do rendimento operacional dos equipamentos/recursos, porém nesse caso acaba ficando limitada pelo ritmo do trabalho humano. E o que poderia ser considerado e tratado como um processo contínuo, que é normalmente caracterizado pelo uso de sistemas integrados e alto nível de automação, acabam sendo dependente das interações de operadores e monitoramento e controle constante.

A Figura 108 apresenta uma comparação entre etapas de um processo de gate tradicional e de um gate automatizado (AGS).

Figura 108 - Diagramas de blocos para comparação das etapas de um processo de gate tradicional vs gate automatizado

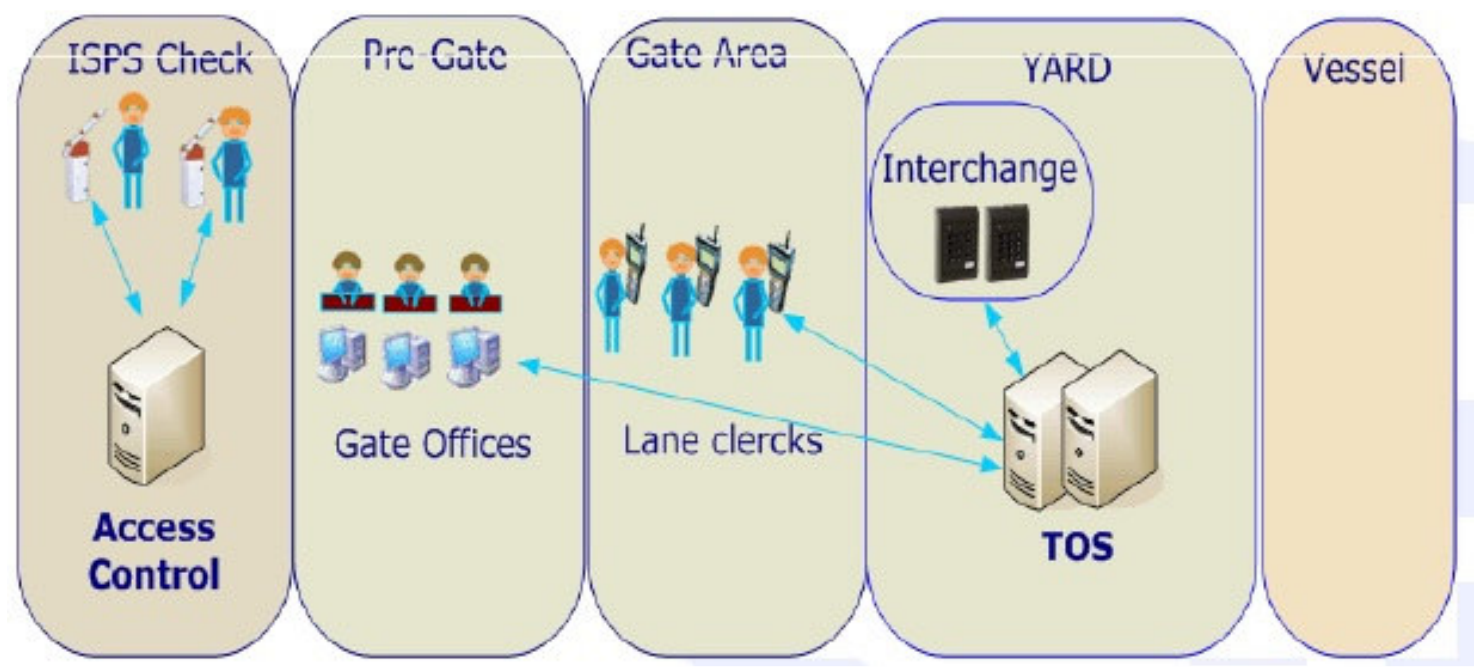




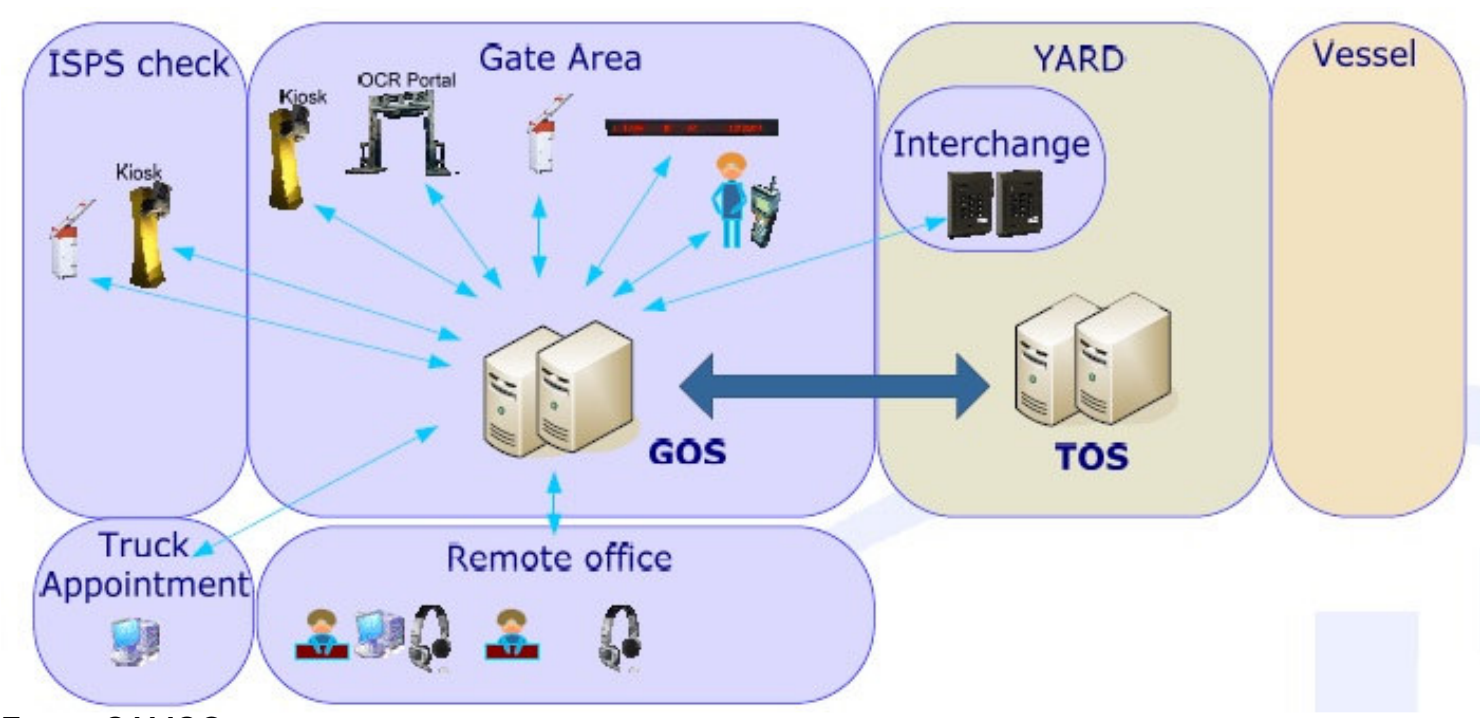

Fonte: CAMCO

Nota-se que as atividades de gates no processo tradicional são realizadas com pessoas em todos os sub-processos; há funcionários no controle de acesso, nos gates e na vistoria e não há integração do controle de acesso com o TOS e as demais interfaces ocorrem de forma ponto a ponto com cada atividade.

Enquanto os gates automatizados (ver exemplo na figura 108) são formados por diversos dispositivos, como: kiosks associados a cancelas automáticas na identificação do motorista e verificação de cartões ISPS code e BDCC; na área de gate propriamente dita, os processos ocorrem por meio do uso do OCR; vistoria através de coletores de dados; os operadores de gates trabalham de forma remota em caso de problemas e a interface do TOS é feita diretamente com o Gate Operating System (GOS) ou Sistema Operacional de Gates. Apenas vistoriados estão presentes diretamente no "chão de terminal" nesse processo. E há casos de necessidade de detecção de radiação.

A figura 109 abaixo dois gates automatizado, um no Terminal Pacifico Sur (TPS) em Valparaiso (Chile), e o segundo o novo terminal da DPW, o London Gateway em Londres (Inglaterra), pede-se notar a área utilizada para essas instalações de Gates. 
Figura 109 - Gate automatizado no TPS (Chile) e London Gateway (Inglaterra)
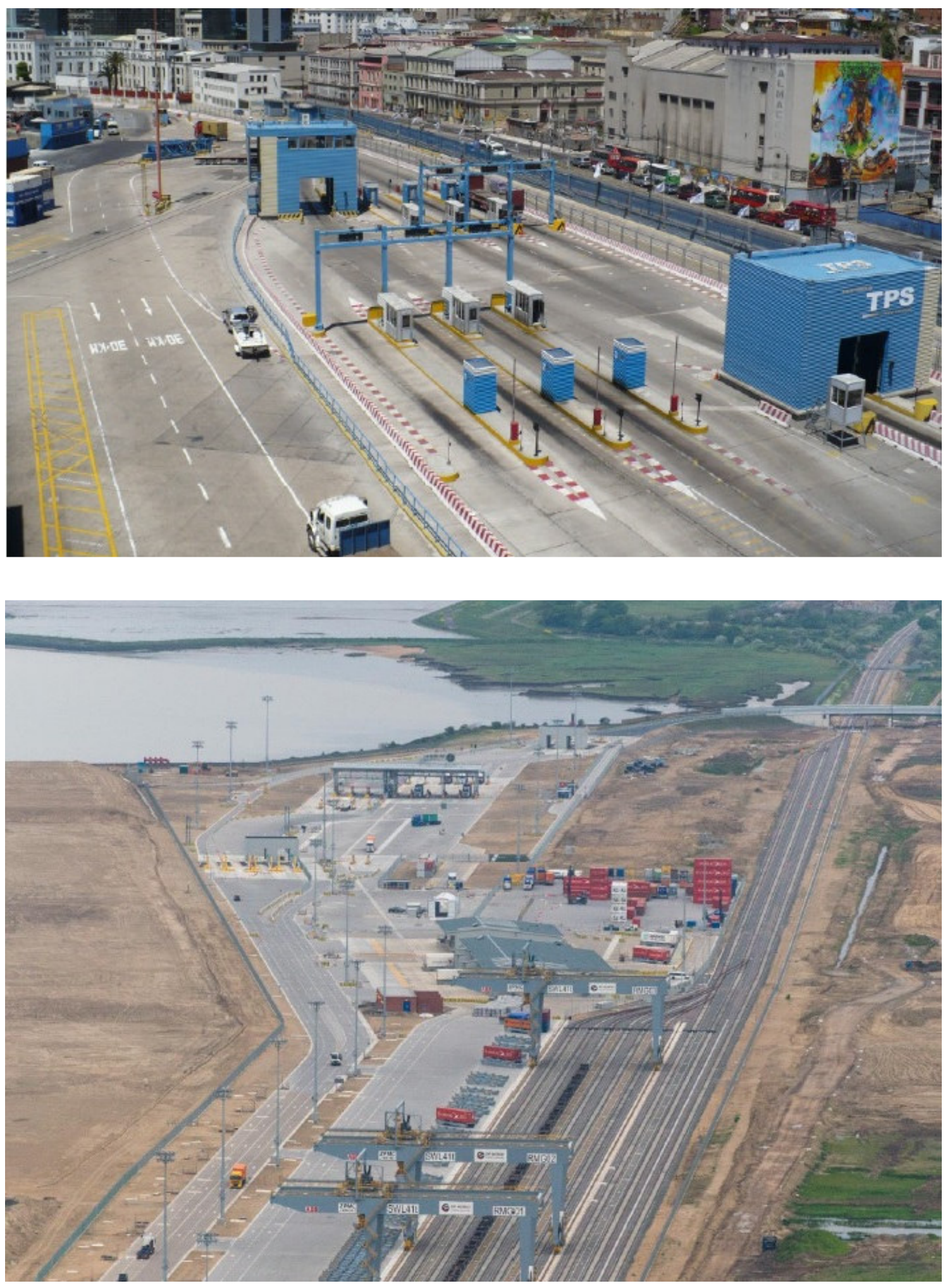

Fonte: CAMCO e London Gateway 
Cabe destacar que, além das interrupções e paradas intrínsecas do processo, existem paralizações causadas pela baixa qualidade das placas de veículos (conforme a figura 110 comprova) tais como: numeração ilegível, placas amassadas, diferentes posições na frente do caminhão, que não permite ao OCR identificar a numeração correta da placa dos caminhões, obrigando a intervenção humana.

Figura 110 - Placas de caminhões

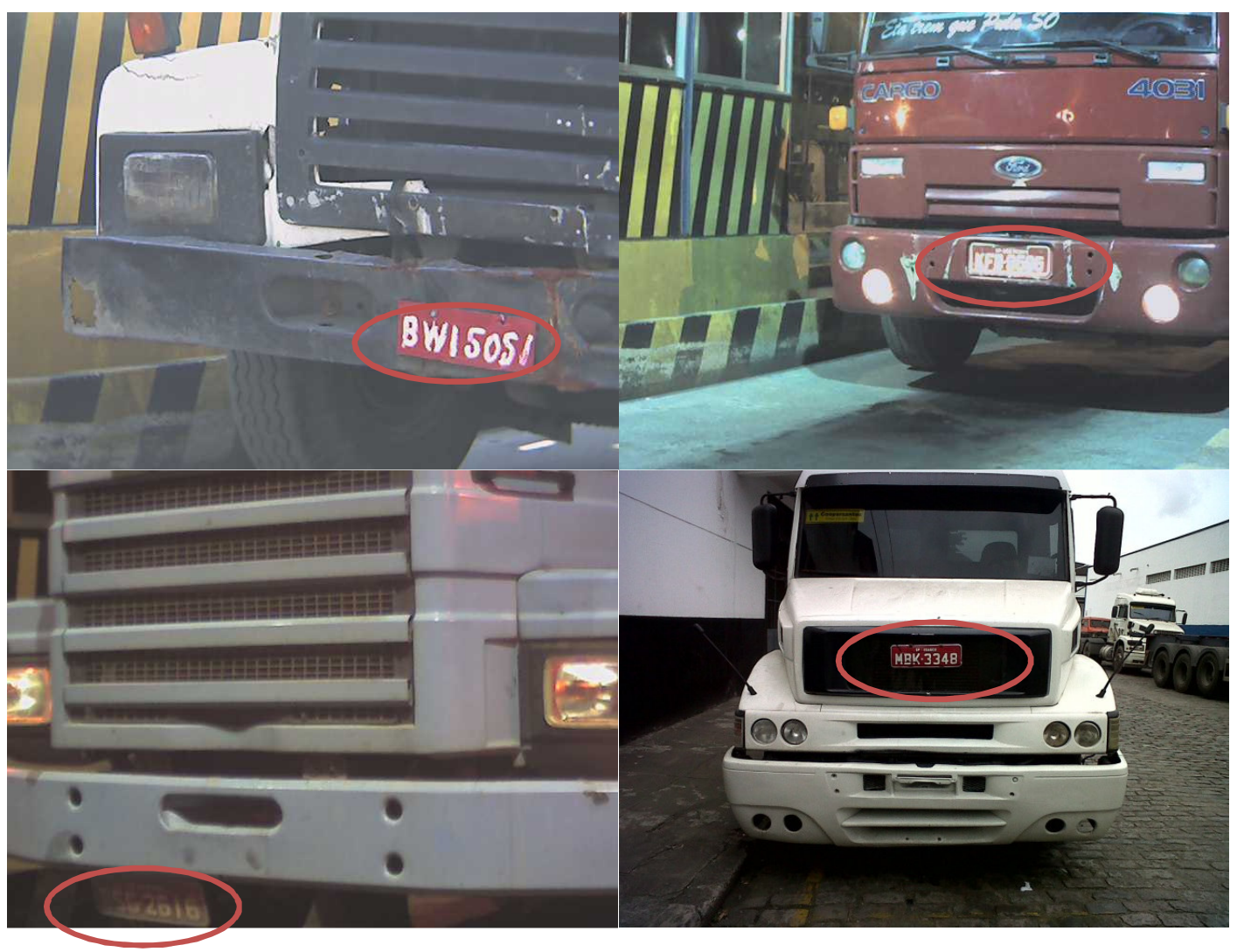

Fonte: Acervo do autor

Outra aplicação de uso do OCR, bastante recente, é o sistema de inspeção automático de avarias ou Automatic Container Damage Inspection System; esse sistema detecta as áreas avariadas dos contêineres (ver figuras 111 e 112), reportando automaticamente para o Sistema de Gates (GOS), com base no uso de um sistema robusto, com câmeras 3D e um sistema de medição laser ótico-elétrico, bem como de um algoritmo complexo que permite uma informação detalhada da estrutura do contêiner e reprodução da acurada da cena em tempo real. Em caso de necessidade de complemento de vistoria manual, o sistema reduz a área a ser inspecionada. Normalmente os terminais registram as avarias por meio de códigos, 
como, por exemplo, 00 = amassado, arranhado e enferrujado ou 01 = painel esquerdo amassado etc.; destaca-se que as vistorias de terminais são simples e a verificação e se o contêiner está bom para uso (good to service).

Figura 111 - Imagens das telas do OCR e resultado da vistoria automatizada
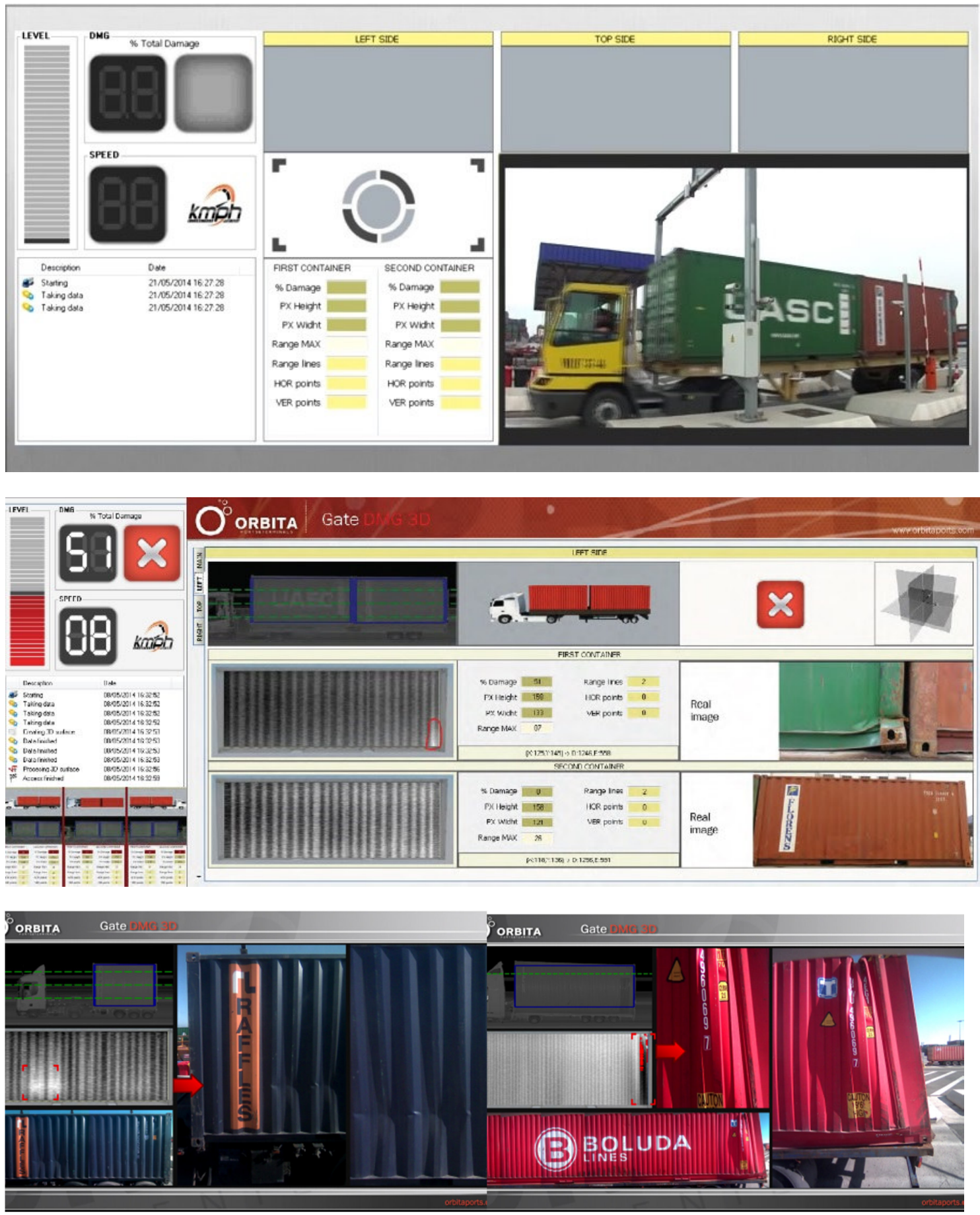

Fonte: Orbita GateDMG 3D 
Figura 112 - Imagens das telas do Sistema Visy ADDS - Active Damage Detection System
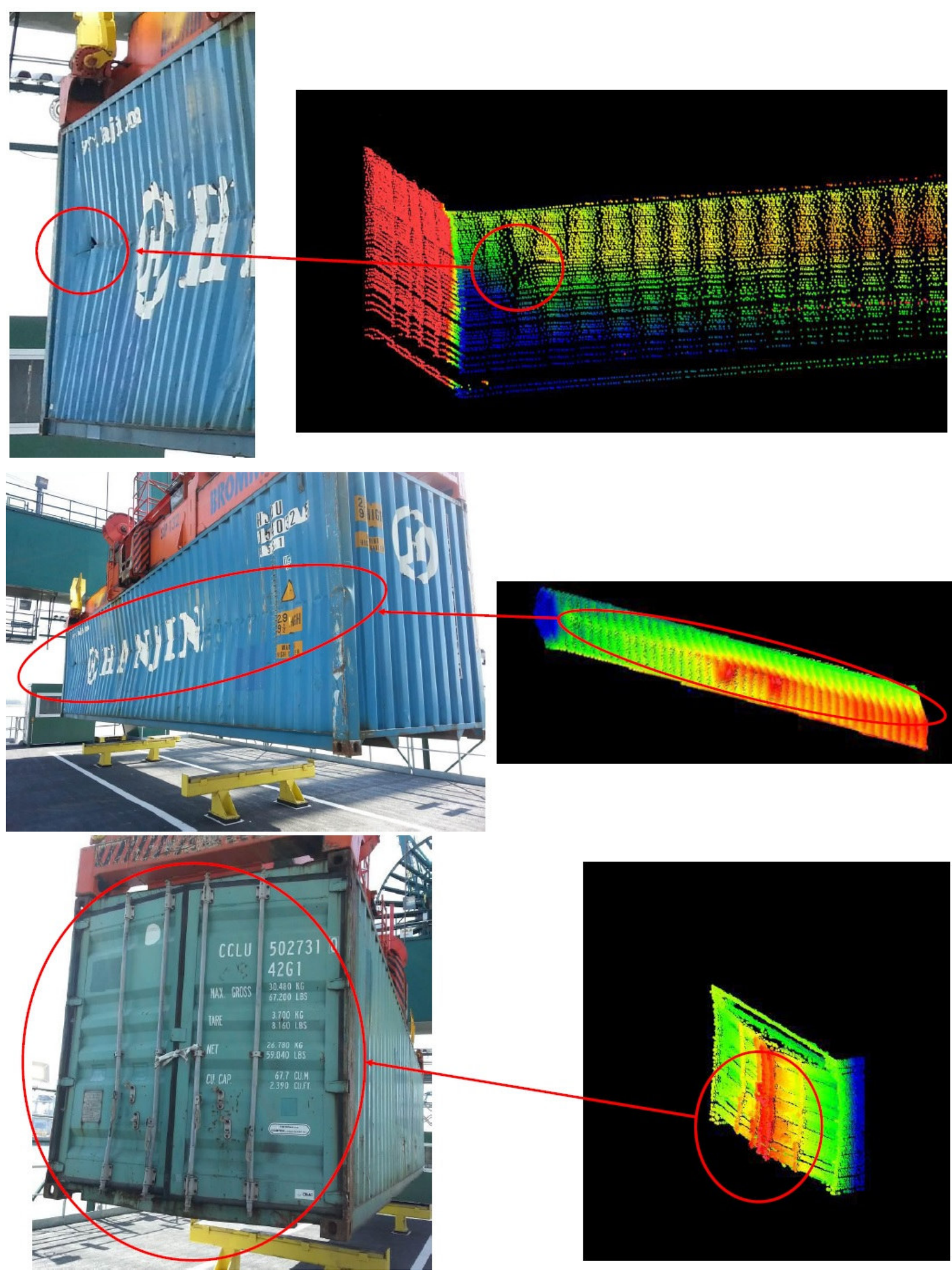

Fonte: Autepra / Visy 
Um exemplo de restrição, no caso específico das atividades de gate de saída no porto de Santos, para os contêineres de importação que serão transferidos de um recinto alfandegado para outro, há a adição de um processo de preenchimento manual por representantes dos terminais de destino, conhecido como caixeiros, de dados do veículo, avarias e lacres, além da verificação da autenticidade do documento chamado de Guia de Movimentação de Contêineres de Importação (GMCl), ver figura 113.

Figura 113 - Exemplo de uma GMCI

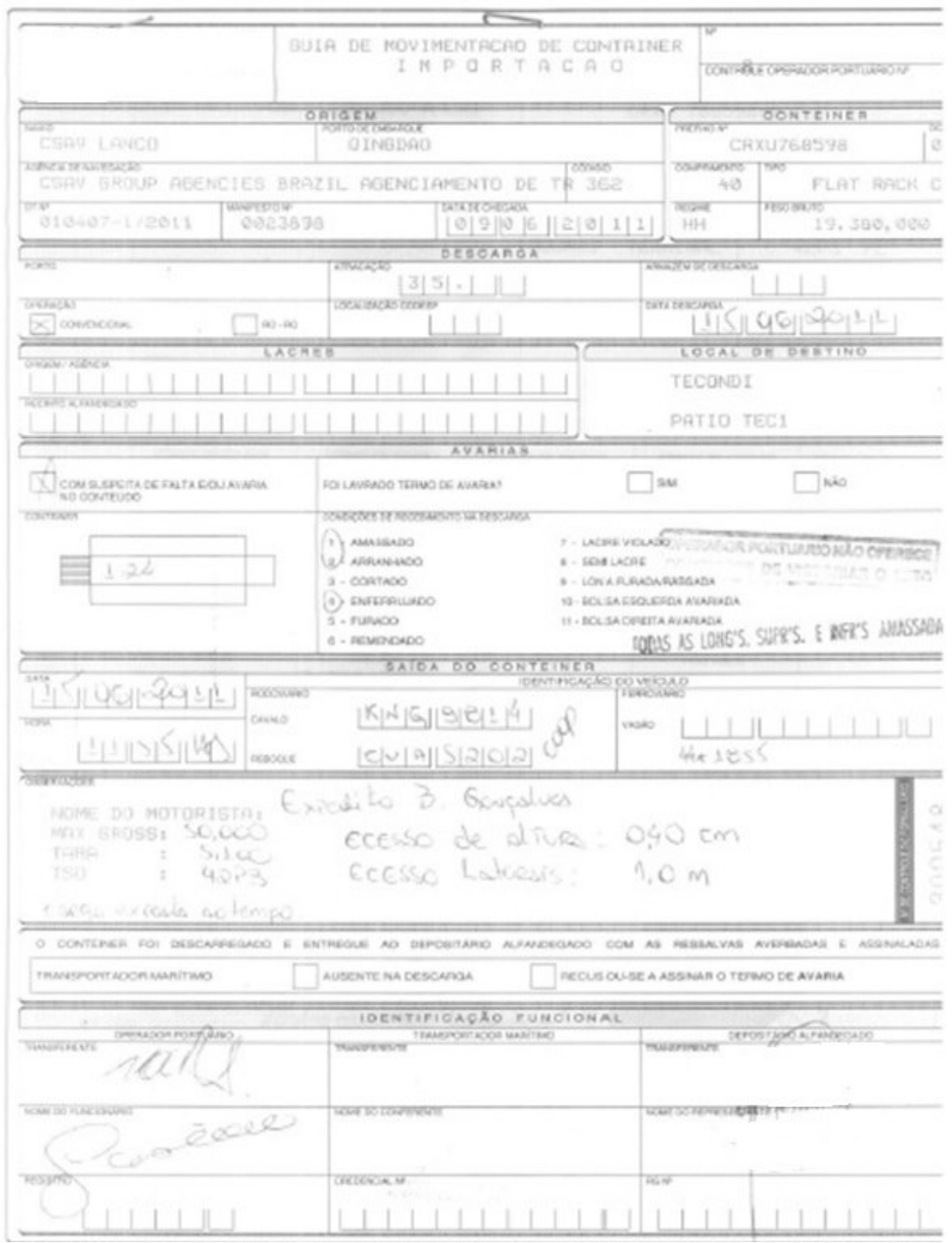

Fonte: Acervo do autor 
Assim como diversas placas apresentam baixa qualidade, alguns lacres existentes não colaboram para uma rápida inspeção (ver figura 114). Os lacres eletrônicos (figura 115), apesar de muito difundidos, ainda não são um padrão escolhido pelo mercado, isto sem falar que o custo ainda não é convidativo e há questão de processos indefinidos, tais como: como, onde e quando realizar leitura ou retirar esse lacre eletrônico para regravação/reaproveitamento.

\section{Figura 114 - Qualidade de Lacres}

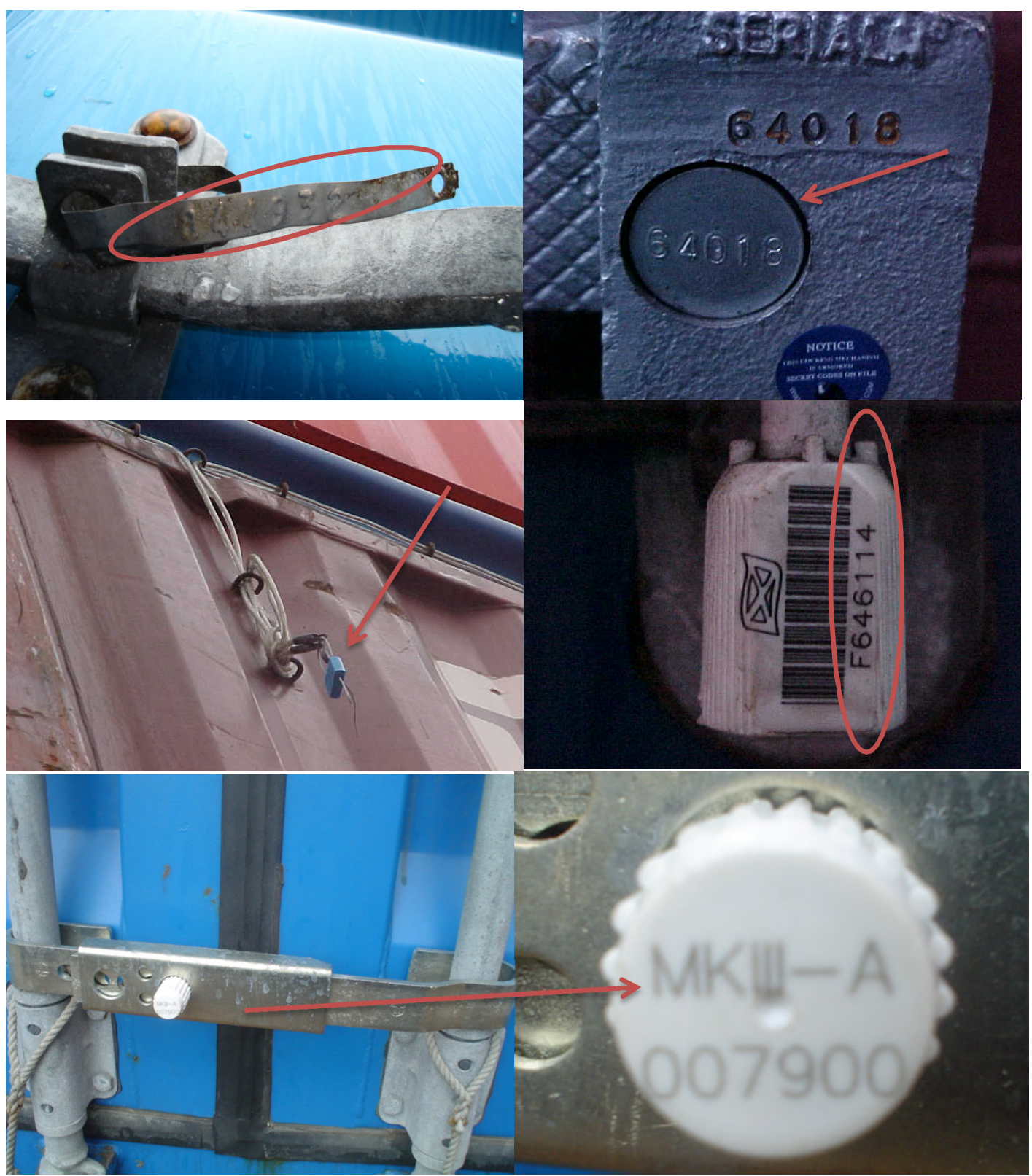

Fonte: Acervo do autor 
Figura 115 - Lacres Eletrônicos
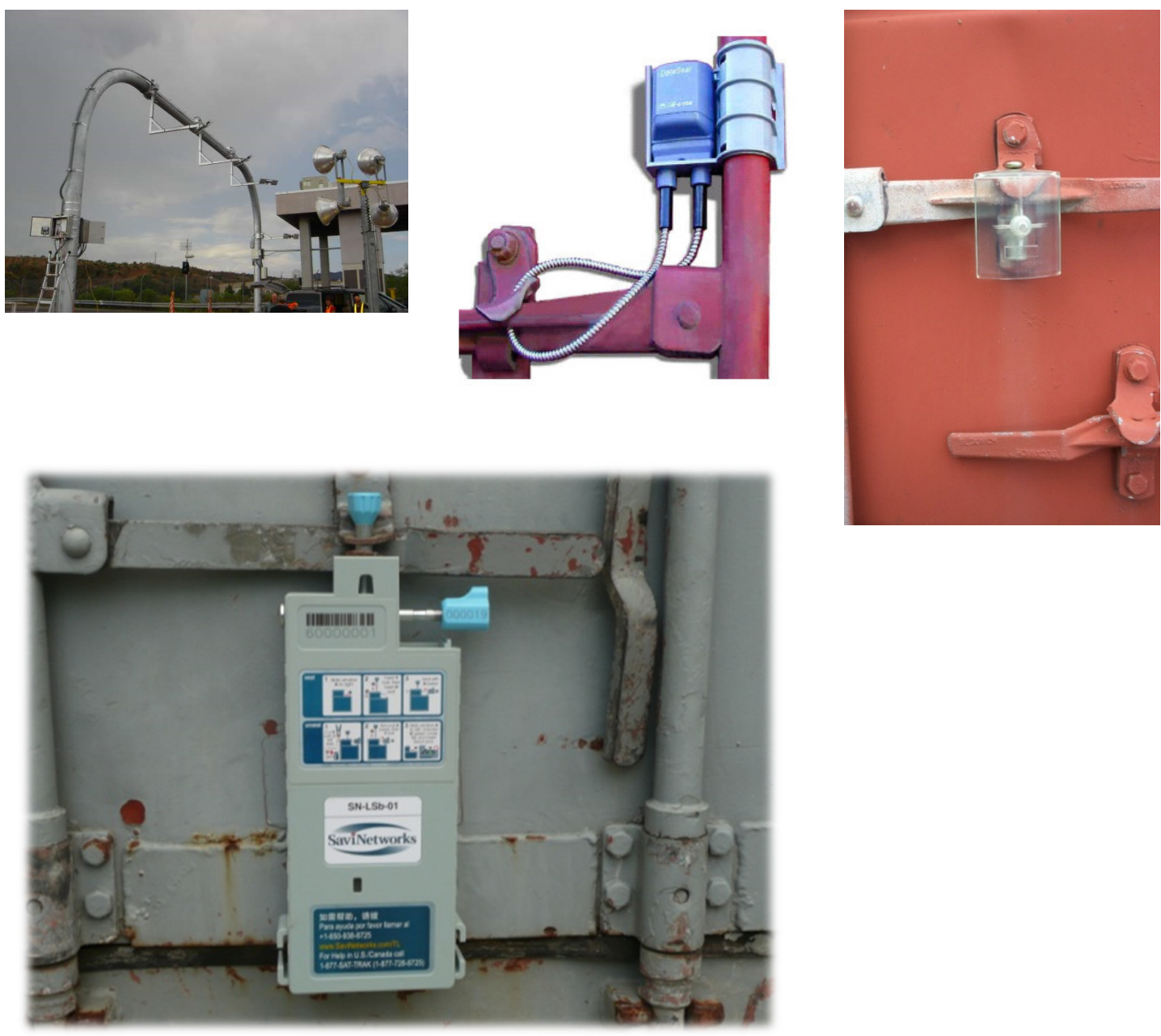

Fonte: Acervo do autor e catálogo SAVI

Esses lacres eletrônicos na sua grande maioria são compostos de Identificação por Frequência de Rádio (RFID), cujo princípio de funcionamento é simples; sendo composto por um transceptor ou leitora que transmite uma onda de frequência de rádio por meio de uma antena para um transponder, outag. $\mathrm{O}$ tag absorve a onda de RF (ou campo magnético) e responde com alguma informação que é gerenciada por um sistema computacional. São classificados em tag ativos, com alcance até 500 metros, e tags passivos, com alcances menores de 10 metros.

A figura 116 exemplifica uma aplicação de rastreabilidade de contêineres utilizando lacres eletrônicos com RFID e a camada GPRS de celular. 
Figura 116 - Exemplo de rastreamento do container utilizando lacre eletrônico e camada GPRS

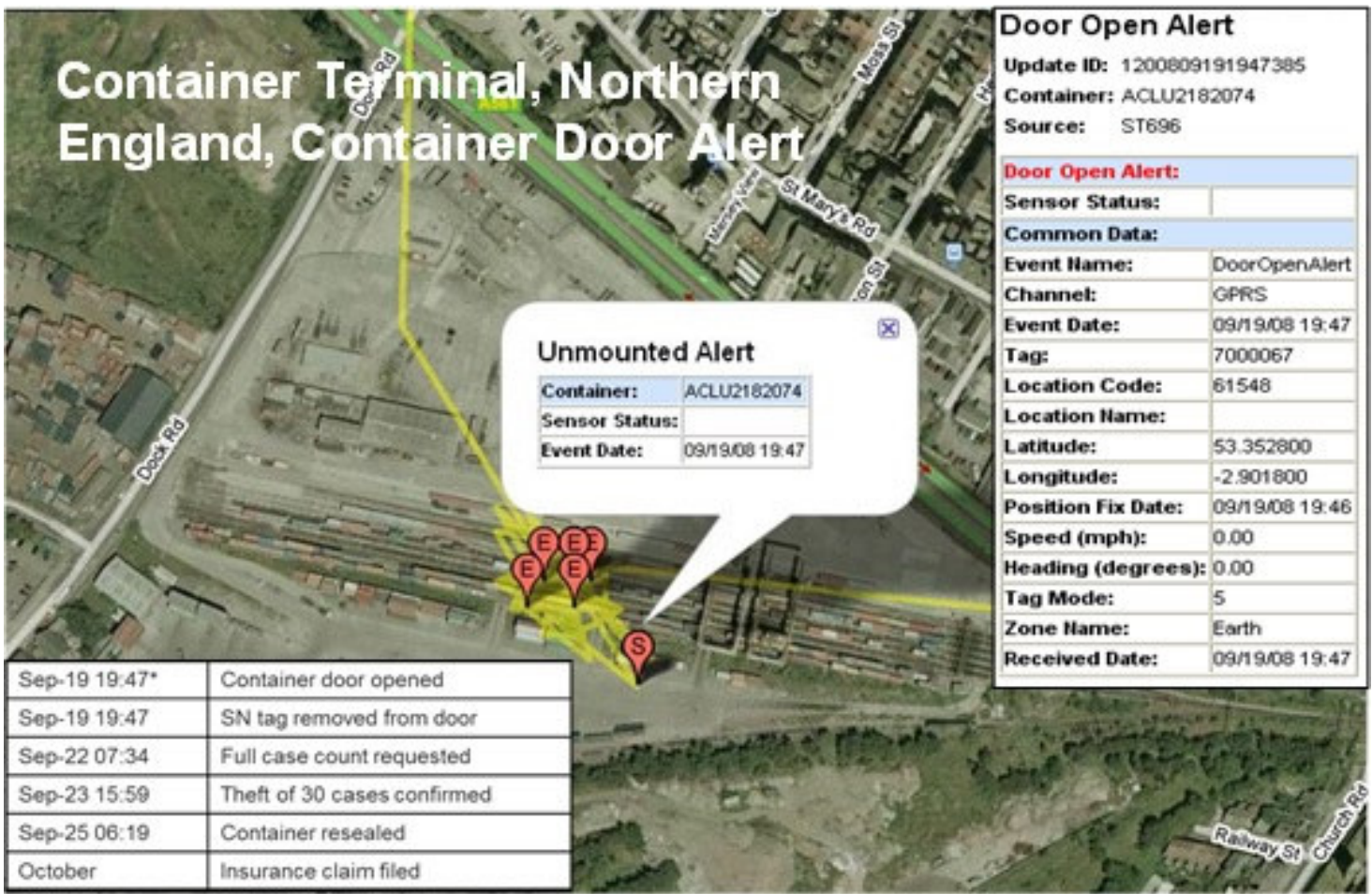

Fonte: Catálogo SAVI

Diversas são as aplicações e combinações do uso RFID em terminais de contêineres na categoria de Posicionamento e Localização; como exemplos dessas combinações têm-se: 3D Bar, 2D Optical tags, OCR etc.

A figura 117 ilustra um sistema da APS chamado de "Matchmaker", composto por OCR e câmeras posicionados embaixo da cabine do operador que realiza a verificação com os tags 2D; e a figura 118 demonstra uma aplicação pura de RFID.

Em sistemas tradicionais a atribuição e confirmação das ordens ou tarefas (jobs) processadas pelo TOS ocorrem por associação manual feita pelo conferente por meio de coletores. Por exemplo, durante a descarga, o conferente digita o contêiner descarregado (mais os lacres e avarias) e associa esse contêiner a uma carreta, para que, por sua vez, o TOS reconheça qual contêiner está em que carreta e possa planejar a posição no pátio desse contêiner; não atribuir nenhuma tarefa para essa carreta carregada e indicar para o operador do equipamento qual contêiner e/ou carreta estará sendo endereçada para armazenar. 
Figura 117 - Tecnologia MatchMaker da APS
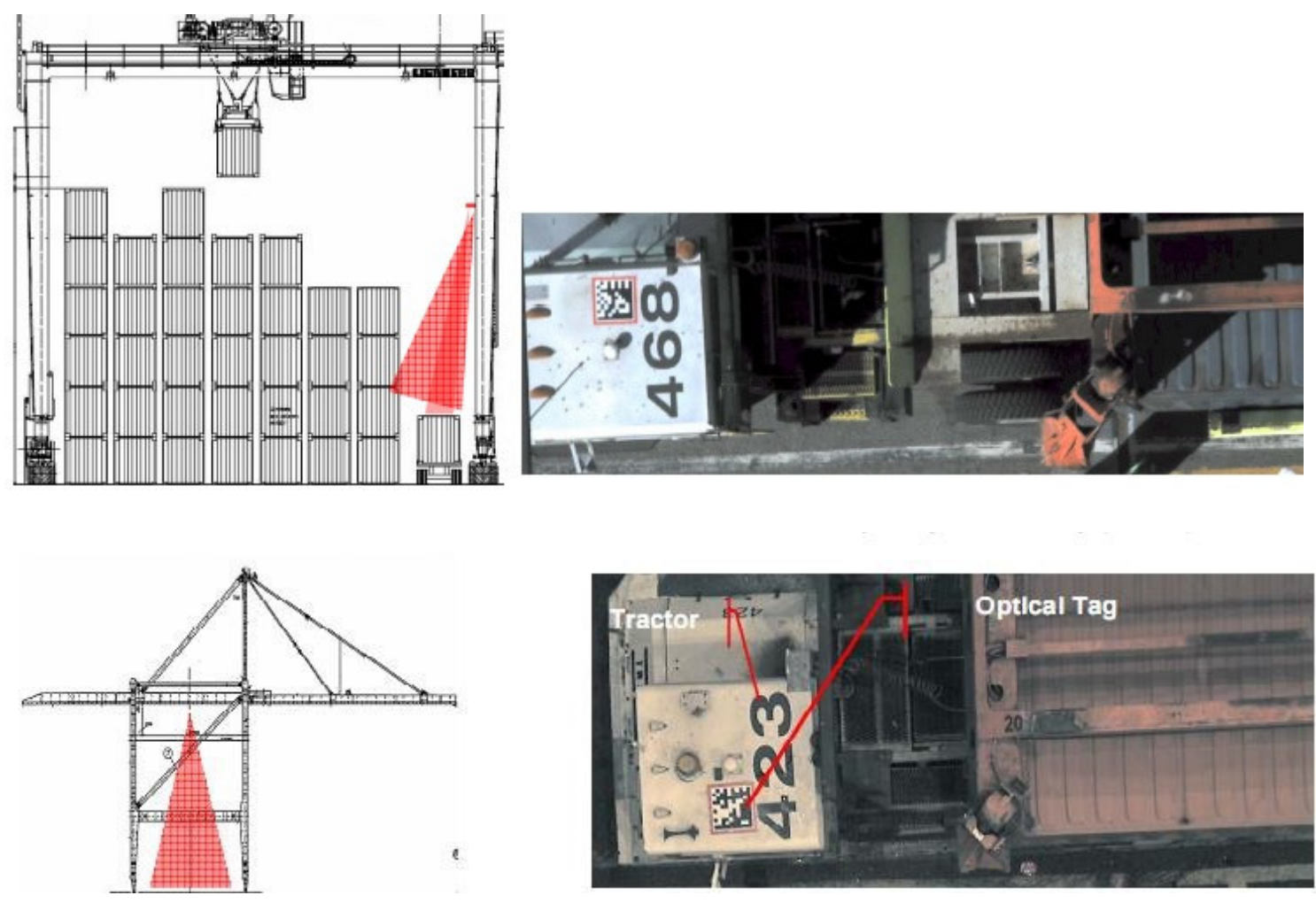

Fonte: APS

Figura 118- Identificação de carretas via RFID

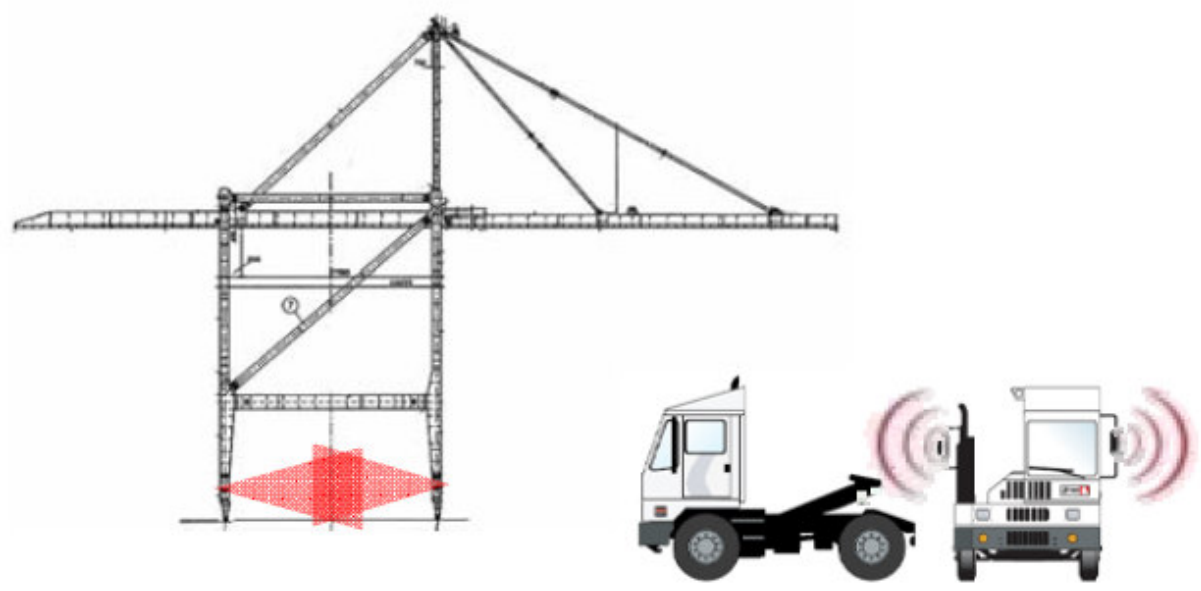

Fonte: APS

Os sistemas de GPS são a ferramenta mais utilizada nas aplicações de rastreamento e posicionamento da indústria portuária. Seu funcionamento ocorre com base na instalação do dispositivo de processamento e comunicação no 
equipamento; conforme a movimentação desses equipamentos, o receptor GPS recebe dados de posição de vários satélites, processa essas informações e envia para um servidor de aplicativos. Um exemplo dessa aplicação é o sistema Autosteering de alinhamento dos RTGs nas pistas de rolagem, como ilustra a Figura 69.

Contudo, em alguns casos, o uso de GPS no terminal não é efetivo, os sinais sofrem bloqueio ou obstrução, em virtude do "mar de aço" formado pelos contêineres nas pilhas e dos equipamentos. Muitas vezes, sistemas GPS costumam falhar embaixo dos portêineres ou têm a precisão afetada. Nessa situação, os sistemas GPS podem ser reforçados por sistemas conhecidos como Sistemas de Localização em Tempo Real ou Real Time Locating Systems (RTLS).

RTLS são sistemas tecnicamente baseados em RFID que utilizam um sistema de triangulação para localizar o contêiner ou veículo, por meio da combinação de uma infraestrutura de tags, leitores (readers) e antenas, com um software de posicionamento. Atualmente, o termo RTLS ganhou um conceito mais amplo e indica não apenas sistemas baseado em RFID, mas qualquer sistema de posicionamento não GPS.

O Terminal Sociedade Portuária Regional de Cartagena (SPRC) na Colômbia (ver figura 119) instalou uma solução RTLS da Navis que utiliza tags e infraestrutura da WhereNet, para garantir a localização exata dos contêineres, de forma a permitir que o TOS tome decisões ótimas para a seleção e expedição da tarefa (job); por exemplo, acompanhar a movimentação do caminhão de rua e identificar a ordem de entrega da fila das pilha para o RTG.

Essa visibilidade da localização dos veículos de rua permitirá ao terminal otimizaras atribuições de trabalho dos RTG, assim como priorizar corretamente os serviços e filas de trabalhos prioritários de navios e gates. 
Figura 119 - Foto do Terminal SPRC

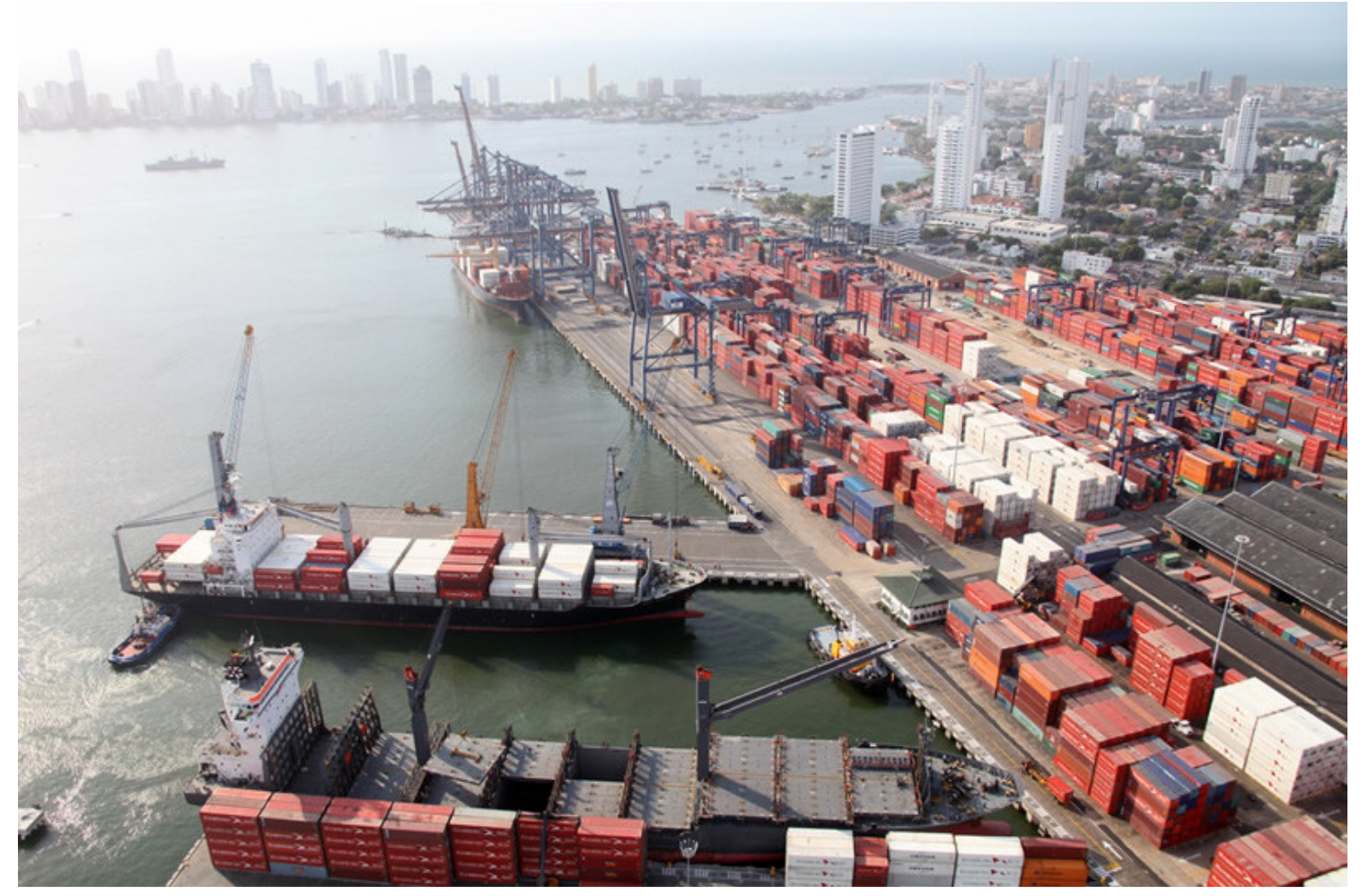

Fonte: Transmares Agência Marítima

Outro exemplo de tecnologia de localização automatizada ocorre nas operações de embarque e descarga, mais especificamente, na atualização da posição de estivagem dos planos de bordo, conforme ilustração da Figura 120. Arquivos EDI da mensagem BAPLIE (plano de pós-estivagem) contêm normalmente erros de localização de contêineres, especialmente daqueles contêineres que foram removidos em outros portos, os chamados de "Shift", quando a remoção ocorre via bordo, isto é, na mesma bay (uma simples troca da vante pela ré no porão) ou no máximo bays adjacentes; enquanto os "Restows" ocorrem via terra, ou seja, entre bays distantes do navio, por exemplo: o contêiner está na bay 05 e precisa ser removido para bay 41 ; isso implica dois movimentos, um de descarga, normalmente seguido de armazenagem temporária no pátio, para posterior embarque.

O processo tradicional ocorre com a posição final de estivagem registrada manualmente por meio do uso de coletor pelo conferente a bordo, ou sendo corrigida na folha do plano da bay que normalmente acompanha o conferente em caso de dúvidas da posição planejada ou em virtude da troca na sequência dos contêineres embaixo do portêiner. $O$ processo automatizado ocorre com uso de 
sistemas de confirmação automatizada de posição estivagem ou Automated Stowage Confirmation, também chamado de "SureStow", funciona com base na captura do dados via OCR e informe do embarque e descarga para o TOS em tempo real, comparando a posição atual com a posição planejada.

Figura 120 - Sistema de Confirmação Automatizada de Estivagem (Automated Stowage Confirmation)

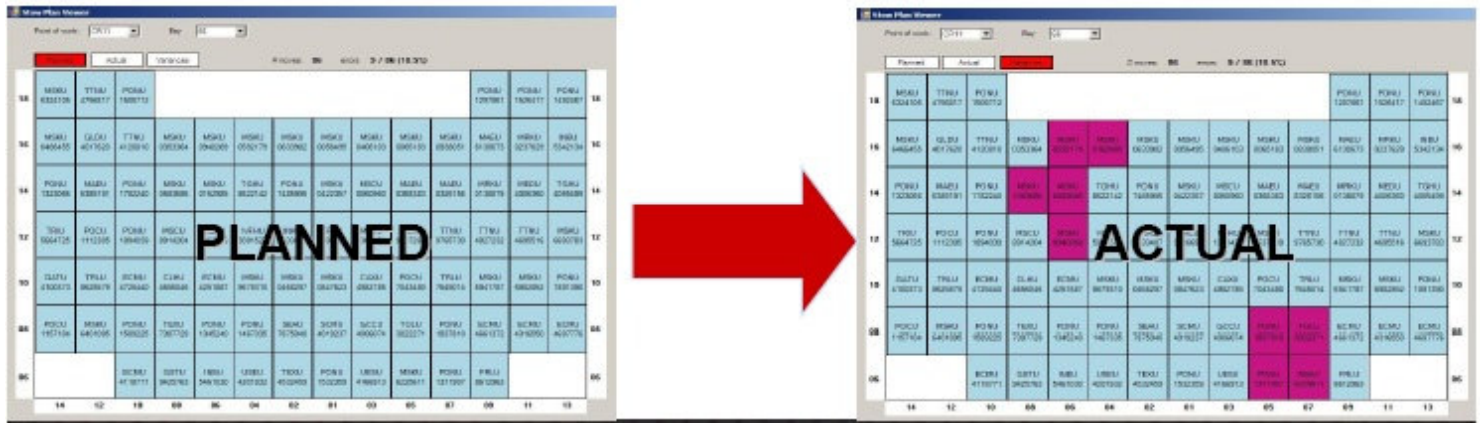

Fonte: APS

E, por derradeiro, completando as tecnologias de automação citadas por Dempsey (2012), temos o Sensoriamento e Telemática. De alguma forma, várias tecnologias e sistemas citados anteriormente possuem característica de sensoriamento, como os sensores anticolisão e de telemática. Se considerarmos telemática como todo e qualquer dispositivo ou sistema que combina tecnologia e telecomunicações, tal como os sistemas de posicionamento como RTLS.

Porém, há dois sistemas que iremos descrever: o primeiro são os Sistemas de Gerenciamento dos Equipamentos ou Crane Management System (CMS), uma vez que ele existe para Portêineres (ver figuras 121 e 122) e para RTGs (figura 123). Esses sistemas possuem como principal função o monitoramento e o diagnóstico de falhas do equipamento, indicando detalhes dos equipamentos para manutenção e operação; alarmes de defeitos; estatísticas do número de movimentos realizados e de horas trabalhadas; aplicativo de configuração e ajuste do equipamento na elevação (hoist), trolley (translação), Boom (lança), spreader, entre outros; velocidade do vento; carga e sobrecarga no equipamento. 
Figura 121 - Sistemas de Gerenciamento dos Equipamentos ou Crane Managemet System (CMS) da ZPMC

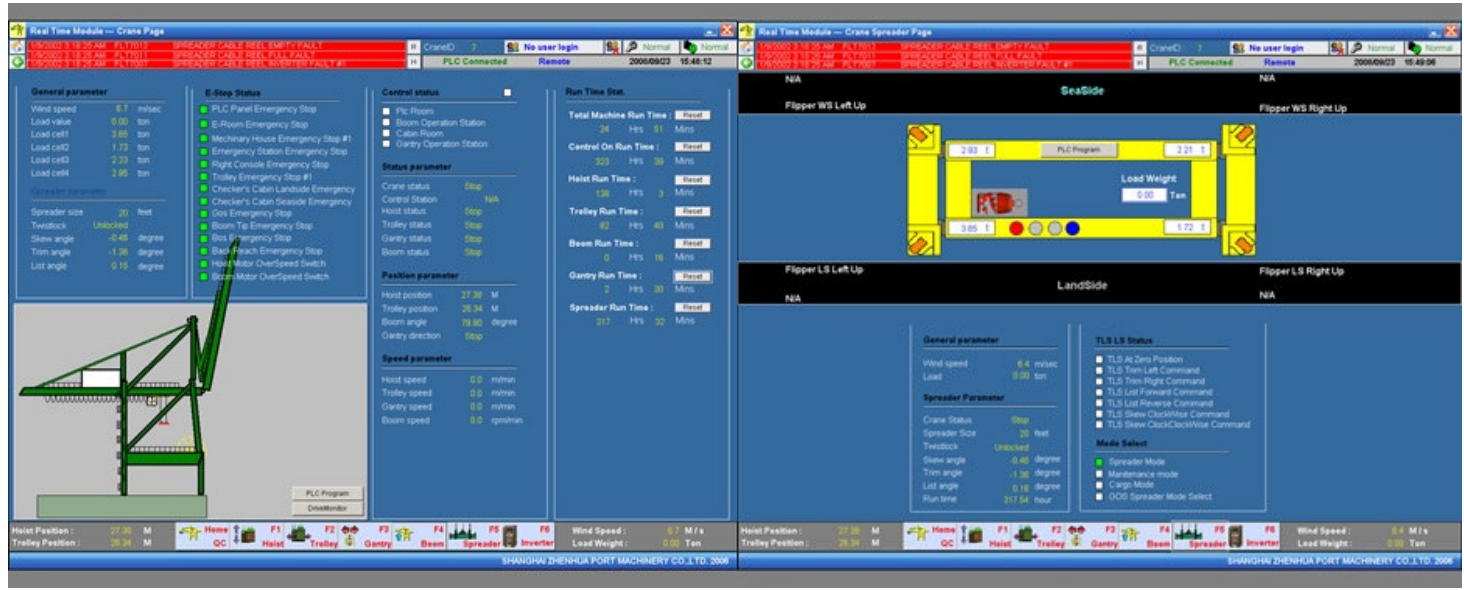

Fonte: ZPMC

Figura 122 - Sistemas de Gerenciamento dos Equipamentos ou Crane Managemet System (CMS) da TMEIC, com detalhe de telemetria e tendências do equipamento.
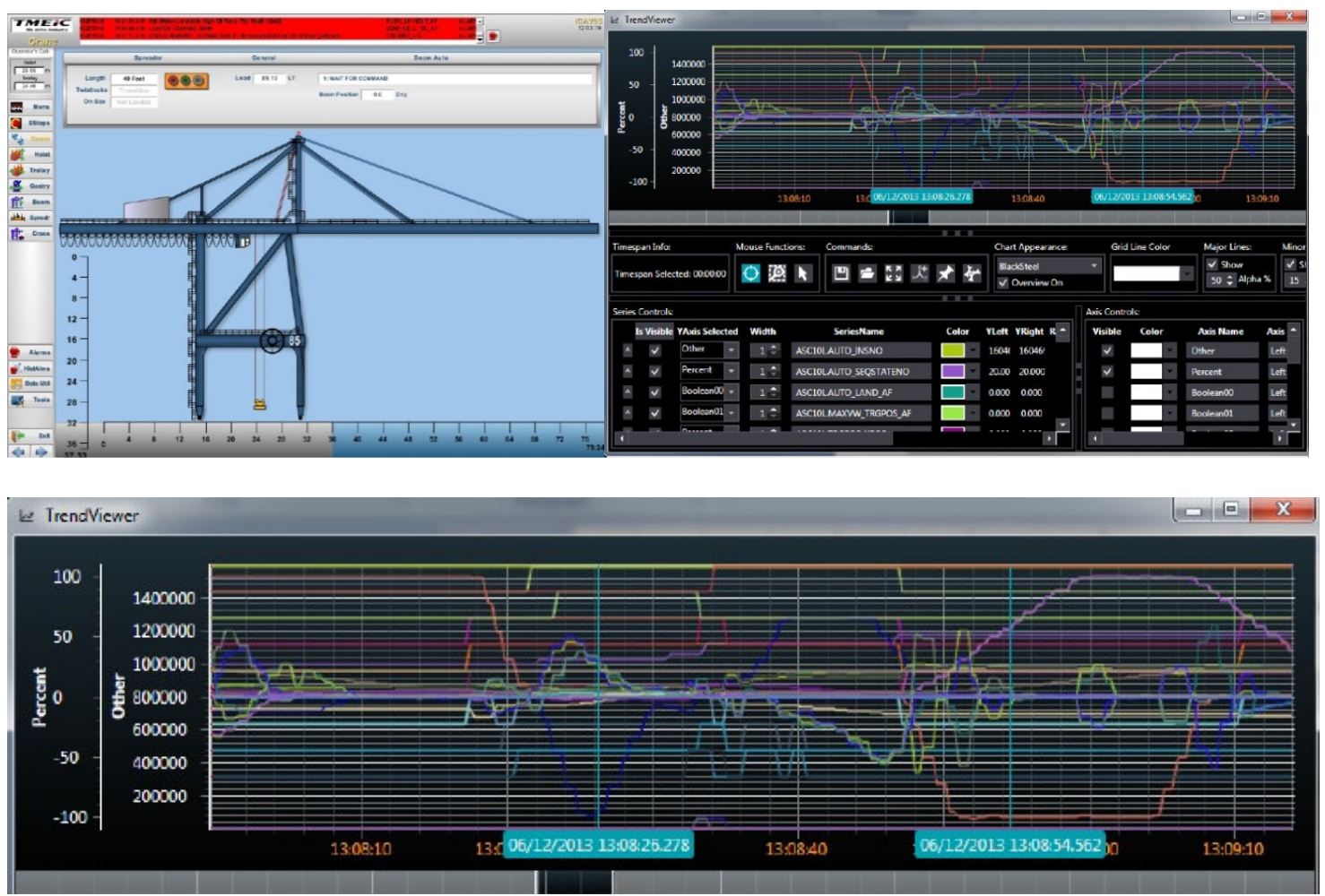

Fonte: TMEIC 
Figura 123 - Sistemas de Gerenciamento dos Equipamentos ou Crane Managemet System (CMS) da TMEIC para RTG.

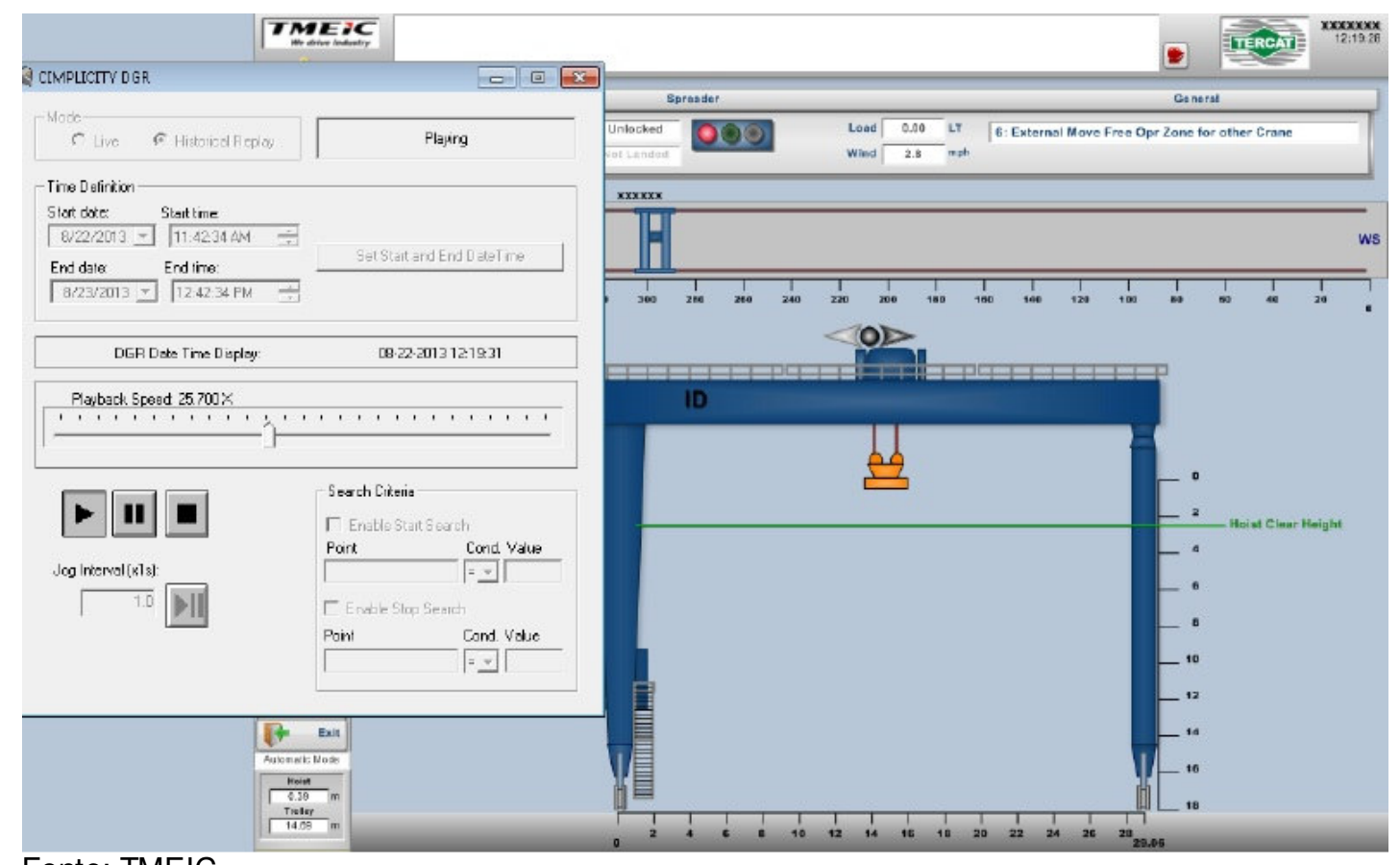

Fonte: TMEIC

E, o segundo sistema é o de Sistema de Monitoramento de Contêineres Refrigerados ou Reefer Monitoring. Esses sistemas migraram do monitoramento de contêineres refrigerados a bordo dos navios para os pátios de terminais. Salienta-se que esse sistema funciona apenas para os contêineres refrigerados que possuem modem (Figura 124) os demais continuam a ser monitorados manualmente.

As informações são trocadas por meio do cabo de energia do contêiner e codificadas em seguida para transmissão dos dados para o sistema de monitoramento (conforme Figura 125), no qual, por meio de interface, atualizam os sistemas: TOS e Billing para cobrança de conexão/desconexão; consumo de energia, se a carga estava "hotstuffing" etc. 
Figura 124 - Modems de contêineres (ISO 10368)

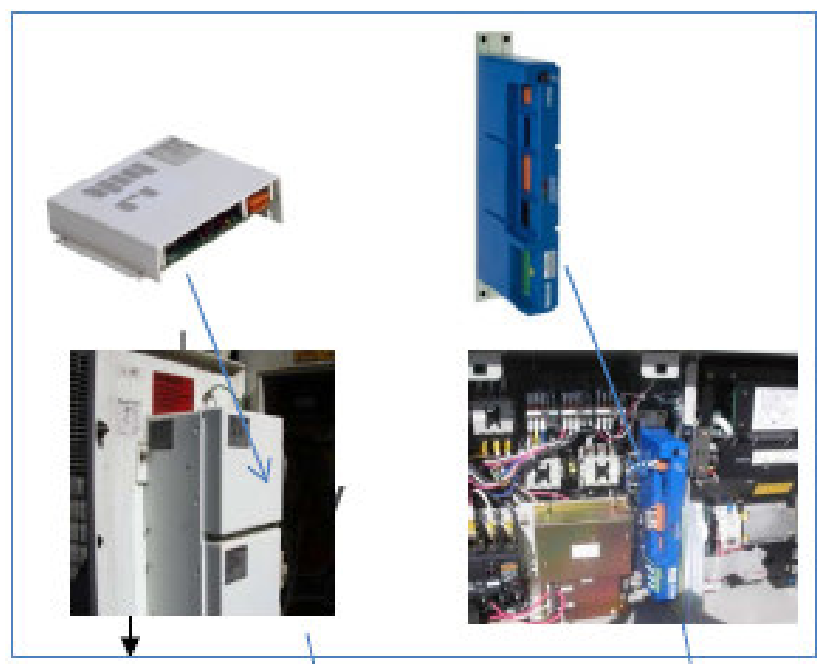

Fonte: Emerson Climate Technologies

Figura 125 - Telas do Sistema de Monitoramento de Contêineres Reefers

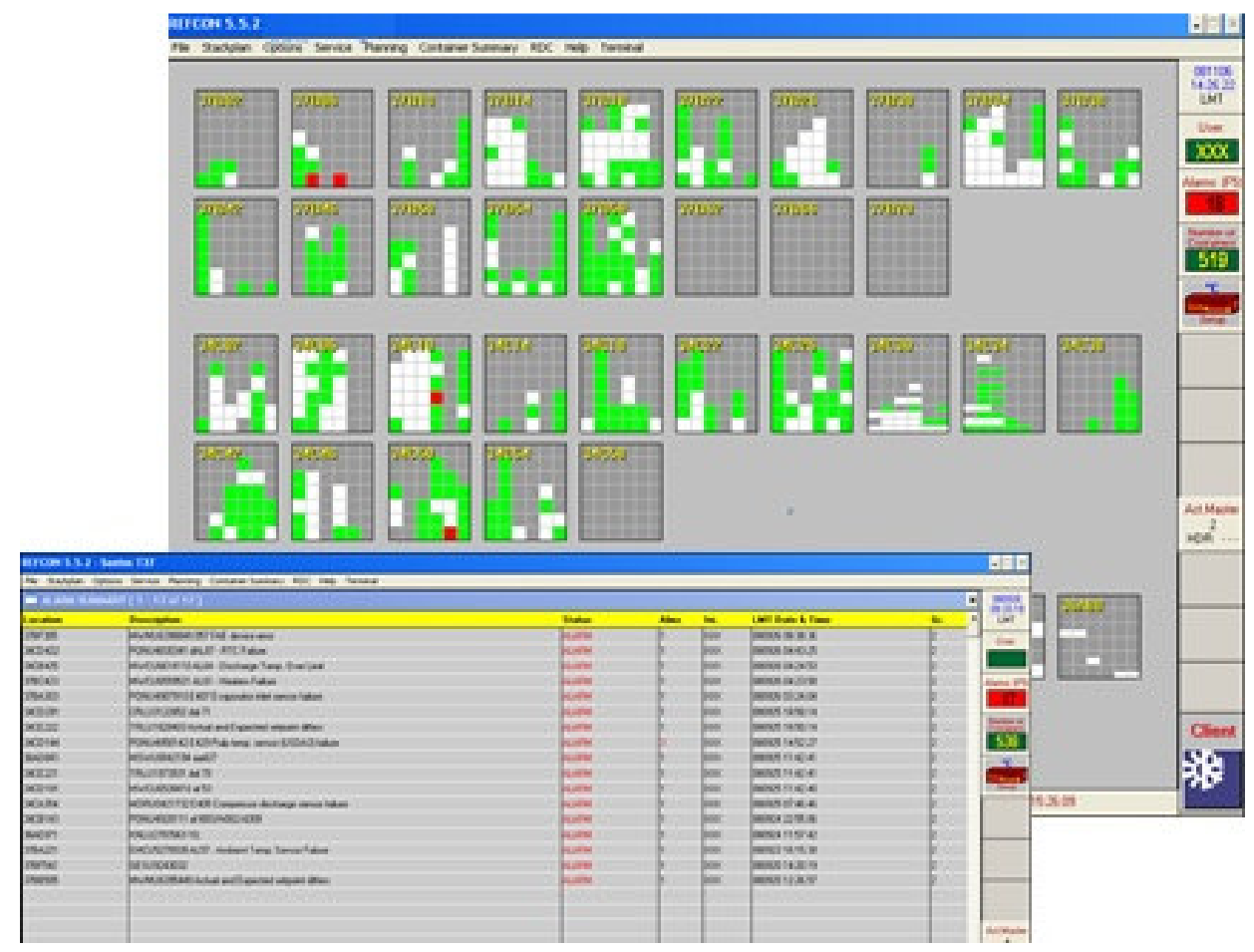

Fonte: Emerson Climate Technologies

Na tela da Figura 125, observa-se que os contêineres verdes são os reefers que possuem modem e estão sendo monitorados automaticamente; os brancos são também reefers, mas não possuem modem, e são verificados manualmente; 
enquanto os vermelhos são contêineres alarmados, isto é, possuem algum problema.

\subsection{SISTEMA OPERACIONAL DO TERMINAL - TERMINAL OPERATING SYSTEM (TOS)}

Nas seções anteriores desse capitulo, foi descrito um terminal de contêineres como um sistema de produção, por meio de comparações entre processos tradicionais e automatizados e seguindo a descrição de níveis e categorias de Glover (2011) entre Instalações e Sistemas de apoio à Operação.

Discorremos nessa seção sobre os Sistemas de Apoio à Operação, cuja divisão fundamentamos em:

- Os Procedimentos Operacionais Padrão ou Standard Operating Procedures (SOPS) e

- O Sistema Operacional do Terminal ou Terminal Operating System (TOS).

Os Procedimentos Operacionais são descrições detalhadas de todas as operações necessárias para a execução de uma atividade, ou seja, é um conjunto de instruções padronizado para realizar uma atividade ou processo. Os terminais de contêineres possuem um vasto conjunto de procedimentos escritos, normalmente com a dupla finalidade, suportar quaisquer operações no terminal e atender às certificações de qualidade ISO exigidas, seja por força de contrato de arrendamento em portos brasileiros, por questões de governança corporativa ou exigência do mercado. É importante, sempre, pensar nesses procedimentos como parte integrante de um Sistema de Gestão Integrada (SGI) para desenvolvimento de melhoria contínua do terminal. Apesar da importância desses, o texto concentra uma atenção maior nos TOS.

Busk (2009) explica que automação em terminais é primeiramente um TOS inteligente para otimização de recursos por meio de algoritmos avançados e completa que automação está longe de ser apenas equipamentos de movimentação não tripulados.

TOS são softwares de planejamento e gerenciamento operacional de um terminal, sendo basicamente formados por módulos de: 
- Planejamento de Berços;

- Planejamento de Navio;

- Planejamento de Pátio;

- Controle/Alocação de Equipamentos;

- Controle de Gates;

- Controle e Registro do Fluxo de documentação;

- Troca Eletrônica de Dados - EDI;

- Sistema de Faturamento (Billing);

- Interfaces com diversos outros sistemas e dispositivos.

A descrição do TOS será iniciada pelo módulo de planejamento e alocação de berços. O recurso berço é o mais importante dos terminais e que exigem cuidado no planejamento e, com certeza, foi o recurso que mais sofreu alterações na última década, em virtude do crescimento dos navios, da alteração do sistema de chegada de navios de FIFO para Janela Operacional ou Janela de Tempo (Time Windows) e de dragagem de aprofundamento dos canais de navegação e acesso.

Essa importância é comprovada por meio do alto número de publicações de artigos sobre os problemas de planejamento, alocação e programação de berços, conforme comprova a tabela 15 , resumo da revisão bibliográfica da dissertação de mestrado de Patricio (2005) e da tabela 16 da revisão de literatura feita pelo profs. da Universidade de Montenegro, Dragović e Park (2011) para o seminário de automação e metodologias de simulação para avaliação e melhoria dos terminais de contêineres (MASPORT Seminar) promovido pela Fundação ValenciaPort em 2011. 
Tabela 15 - Quadro resumo da revisão bibliográfica sobre planejamento de berços de atracação de Patricio (2005)

\begin{tabular}{|c|c|c|}
\hline $\begin{array}{l}\text { Problemas } \\
\text { Considerados }\end{array}$ & Abordagem & Referências \\
\hline $\begin{array}{l}\text { Planejamento e } \\
\text { Alocação de } \\
\text { Berços }\end{array}$ & $\begin{array}{l}\text { Problemas formulados por meio } \\
\text { de programação linear; onde os } \\
\text { problemas menores foram } \\
\text { resolvidos com CPLEX e os casos } \\
\text { maiores foram desenvolvidos com } \\
\text { busca tabu (Tabu search). } \\
\text { Procedimento de busca em árvore } \\
\text { (Tree search). } \\
\text { Experimentos computacionais } \\
\text { com CPLEX, nos quais o primeiro } \\
\text { modelo de DBAP foi capaz de } \\
\text { resolver problemas de } 10 \text { berços } \\
\text { e } 50 \text { navios, enquanto o modelo } \\
\text { compacto de DBAP não foi tão } \\
\text { eficiente em virtude das limitações } \\
\text { do grande M's. } \\
\text { Uso de simulação de um sistema } \\
\text { chamado BAMS (Berth Allocation } \\
\text { management System). } \\
\text { Filas de navios atendidas de } \\
\text { forma FIFO. } \\
\text { Modelo de programação inteira } \\
\text { mista (Mixed Integer Program). } \\
\text { Algoritmos Simulated Annealing } \\
\text { (SA). } \\
\text { Utilização de gráficos acíclicos } \\
\text { diretos (Directed Acyclic Graph). } \\
\text { Software LINDO, que apresentou } \\
\text { problema de tempo de } \\
\text { processamento quando o número } \\
\text { de navios era superior a sete e o } \\
\text { tempo de planejamento excedia } \\
72 \text { horas. } \\
\text { Heurística baseada em Algoritmo } \\
\text { Genético (GA). } \\
\text { Programação inteira mista (Mixed } \\
\text { Integer Program) formulando } \\
\text { versões estáticas e dinâmicas do } \\
\text { problema de alocação de berço e } \\
\text { suas relaxações lagrangianas. } \\
\text { Técnicas de otimização } \\
\text { subgradiente. }\end{array}$ & $\begin{array}{l}\text { Cordeau et al (2003); } \\
\text { Chen e Hsieh (2001); } \\
\text { Guan e Cheung (2004); } \\
\text { Hansen o Oguz (2003); } \\
\text { Henesey, Davidsson e } \\
\text { Persson (2004); } \\
\text { Imai, Nagaiwa e Chan } \\
\text { (1997); } \\
\text { Kim e Moon (2003); } \\
\text { Lai e Shih (1992); } \\
\text { Legato e Mazza (2000); } \\
\text { Li, Cai e Lee (1998); } \\
\text { Lim (2004); } \\
\text { Lim (2000); } \\
\text { Lim e Goh (2000); } \\
\text { Moon (2000); } \\
\text { Nishimura, Imai e } \\
\text { Papadimitriou (2001); } \\
\text { Park e Kim (2002); } \\
\text { Park e Kim (2003); } \\
\text { Piaw (2003). }\end{array}$ \\
\hline
\end{tabular}

Fonte: Patricio (2005) 
Tabela 16 - Quadro resumo da revisão de Literatura bibliográfica sobre planejamento e alocação de berços de atracação por Dragović e Park (2011)

\begin{tabular}{|c|c|c|}
\hline $\begin{array}{l}\text { Problemas } \\
\text { Considerados }\end{array}$ & Abordagem & Referências \\
\hline $\begin{array}{l}\text { Planejamento de } \\
\text { Berço }\end{array}$ & $\begin{array}{l}\text { Teoria das Filas. } \\
\text { Métodos básicos da teoria da } \\
\text { probabilidade em sistemas de } \\
\text { portos. } \\
\text { Distribuição discreta e continua } \\
\text { em processos operacionais de } \\
\text { portos. } \\
\text { Processos estocásticos em } \\
\text { sistemas de portos. } \\
\text { Processos Markovianos. } \\
\text { Processos Birth-death. } \\
\text { Processos Poison. }\end{array}$ & $\begin{array}{l}\text { Plumle (1966); } \\
\text { Nicolaou (1967,1969); } \\
\text { Mettam (1967); } \\
\text { Jones e Blunden (1968); } \\
\text { Miller (1971); } \\
\text { Wanhill (1974); } \\
\text { Edmond (1975); } \\
\text { Noritake e Kimura (1983, } \\
\text { 1989); } \\
\text { Noritake (1985); } \\
\text { Schonfeld e Sharafeldien } \\
\text { (1985); } \\
\text { Sabria e Daganzo (1989); } \\
\text { Radmilović (1992); } \\
\text { Berg-Andreassen e } \\
\text { Prokopowicz (1992); } \\
\text { Huang et al. (1995, 1997); } \\
\text { Zrnić et al. (1999); } \\
\text { Chu e Huang (2002); } \\
\text { Shabayek e Yeung } \\
\text { (2001); } \\
\text { Radmilović et al. (2005). }\end{array}$ \\
\hline $\begin{array}{l}\text { Alocação e } \\
\text { Programação } \\
\text { (Scheduling) de } \\
\text { Berço e }\end{array}$ & $\begin{array}{l}\text { Algoritmos DBAP (Dynamic Berth } \\
\text { Allocation Problem). } \\
\text { Algoritmos SBAP DBAP (Static } \\
\text { Berth Allocation Problem). } \\
\text { Algoritmos Genéticos. } \\
\text { Relaxação lagrangiana. } \\
\text { Busca Tabu (Tabu Search). } \\
\text { Programação inteira mista (Mixed } \\
\text { Integer Program). } \\
\text { Procedimento de Busca em } \\
\text { árvore (Tree search). } \\
\text { Simulated Annealing (SA). }\end{array}$ & $\begin{array}{l}\text { Lai e Shih (1992); } \\
\text { Imai et al.(1997); } \\
\text { Lim (1998); } \\
\text { Nishimura et al. (2001); } \\
\text { Imai et al. (2001, 2003, } \\
\text { 2005); } \\
\text { Zhou Xu (2002); } \\
\text { Kim e Moon (2003); } \\
\text { Cordeau et al (2003); } \\
\text { Guan e Cheung (2004). }\end{array}$ \\
\hline
\end{tabular}

Fonte: Dragović e Park (2011)

Alocação de berço no TOS significa planejar as visitas ou escalas dos navios por meio da reserva de espaço de berço e atribuindo os portêineres antecipadamente de forma a permitir ações preventivas em caso de falta ou avaria. 
É fato que quase a totalidade dos armadores e terminais trabalha com Janelas Operacionais, o que facilita a programação de berços; mas deve-se lembrar de que a decisão do local de atracação pode implicar o local de abertura do navio o pátio para armazenagem da carga; a definição dos cabeços e a distância dos navios.

Figura 126 - Telas do Módulo de Planejamento da Escala do Navio e Alocação de guindastes e berço
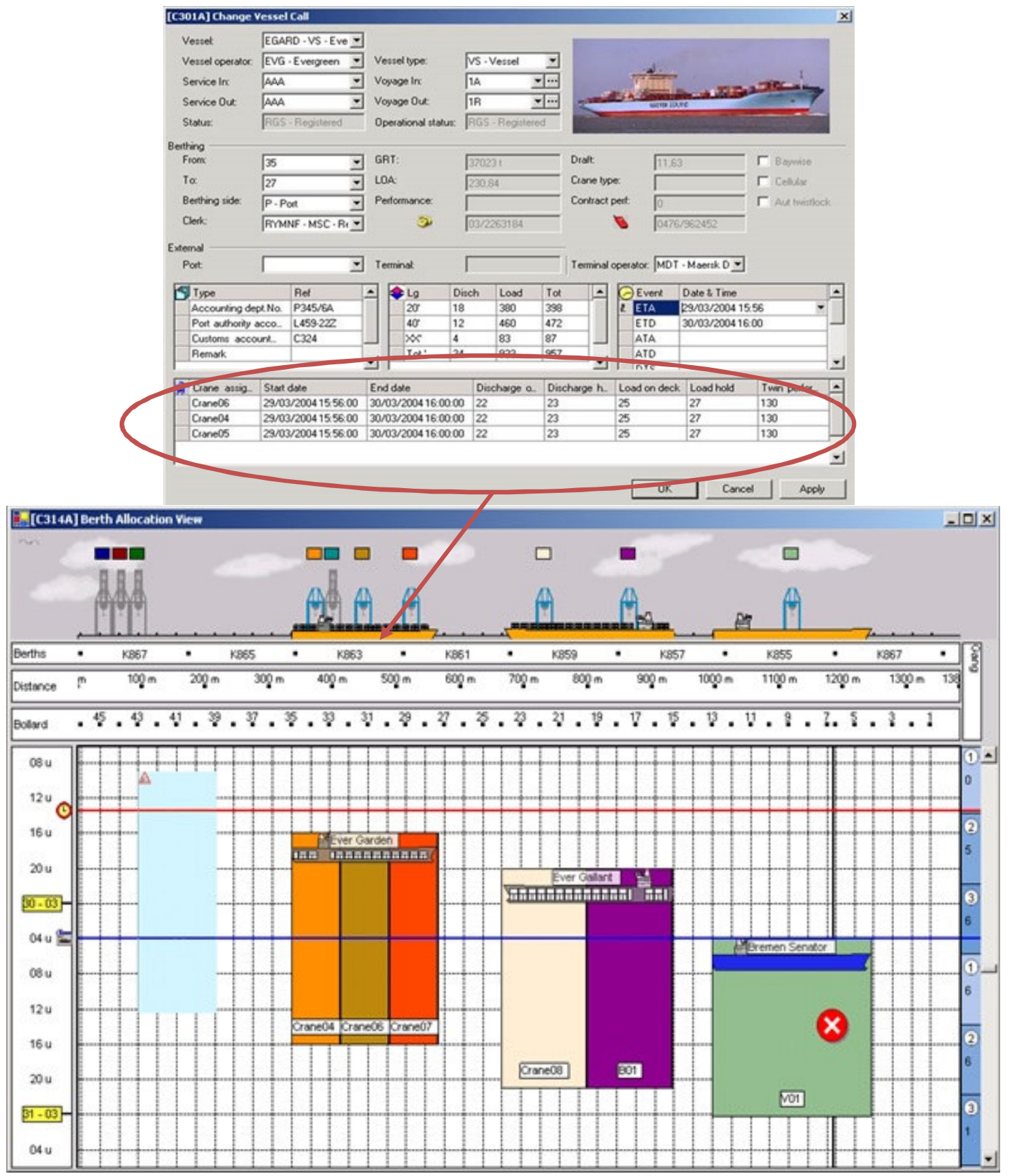

Fonte: COSMOS N.V. 
O módulo de planejamento de navios é responsável pelo planejamento e sequenciamento de embarque e descarga dos contêineres, visando à redução do número de remoções no pátio; à otimização do posicionamento dos contêineres a bordo; a garantir a estabilidade e cálculo de stress do navio respeitando os dados de características do navio (Vessel Particulars), tais como: limites de peso e altura (Stackweight e Stackheight), e verificação do cumprimento dos cálculos de esforços de peação (lashing) da Lloyds, bem como com os requisitos de peso dinâmico da Lloyds Germanisher (ver figura 127); a aplicar as informações de pré-estivagem (prestow) do arquivo MOVINS enviado pelo centro de planejamento (planner) do armador, tipo do contêiner, porto de destino, peso do contêiner, posição no pátio, instruções especiais de estivagem da carga no porão (Underdeck) ou no convés (Wetherdeck); verificação de conflito de carga perigosa (carga IMDG). A figura 128 ilustra um plano de bordo com base em um conjunto de bays. Enquanto a Figura 129 ilustra uma sequência de telas utilizadas no planejamento do sequenciamento de embarque e descarga.

Figura 127 - Tela de Overview das bays do navio

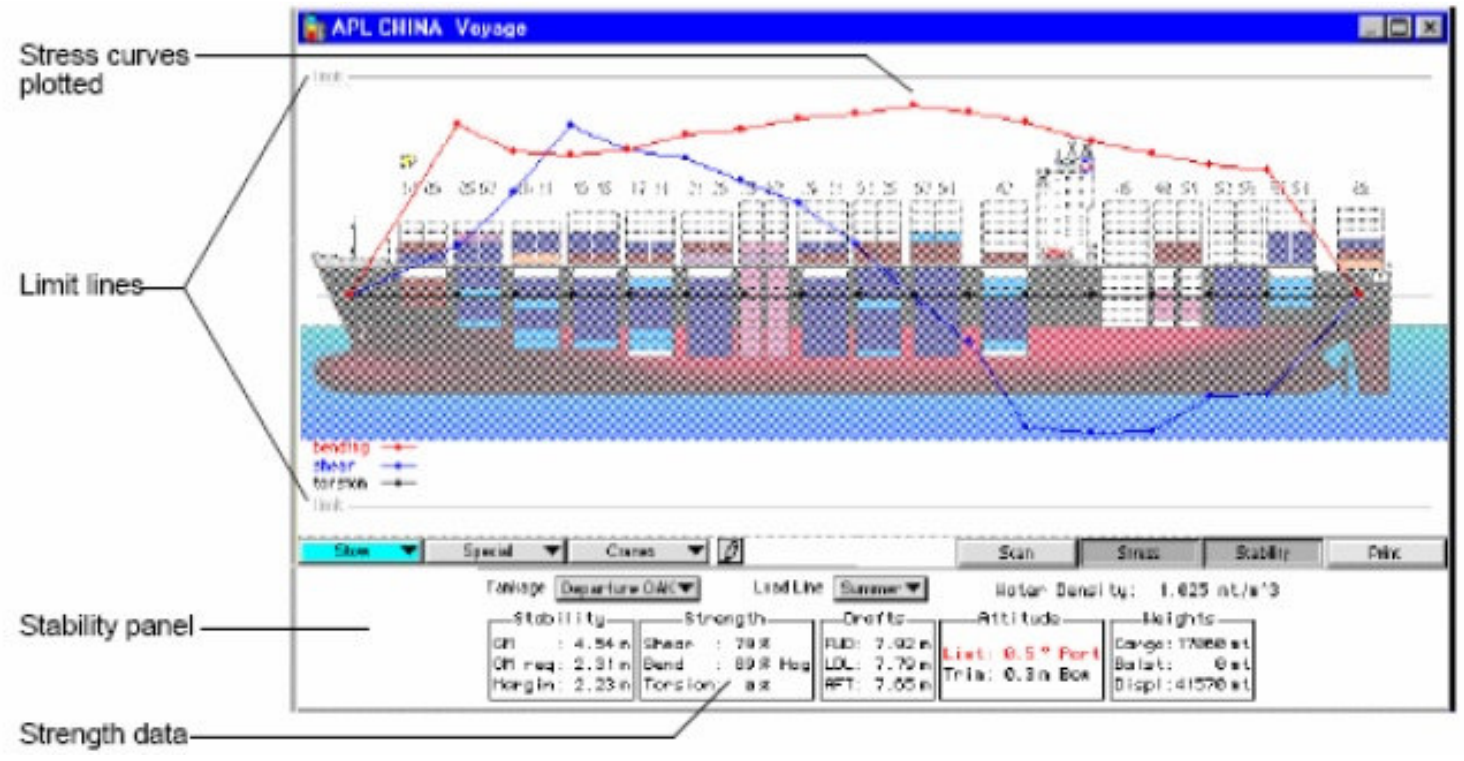

Fonte: Módulo SHIPS/COSMOS N.V. 
Figura 128 - Plano de bordo do recebido do armador e Tela de vista geral das bays do navio após aplicação dos arquivos EDI MOVINS e BAPLIE
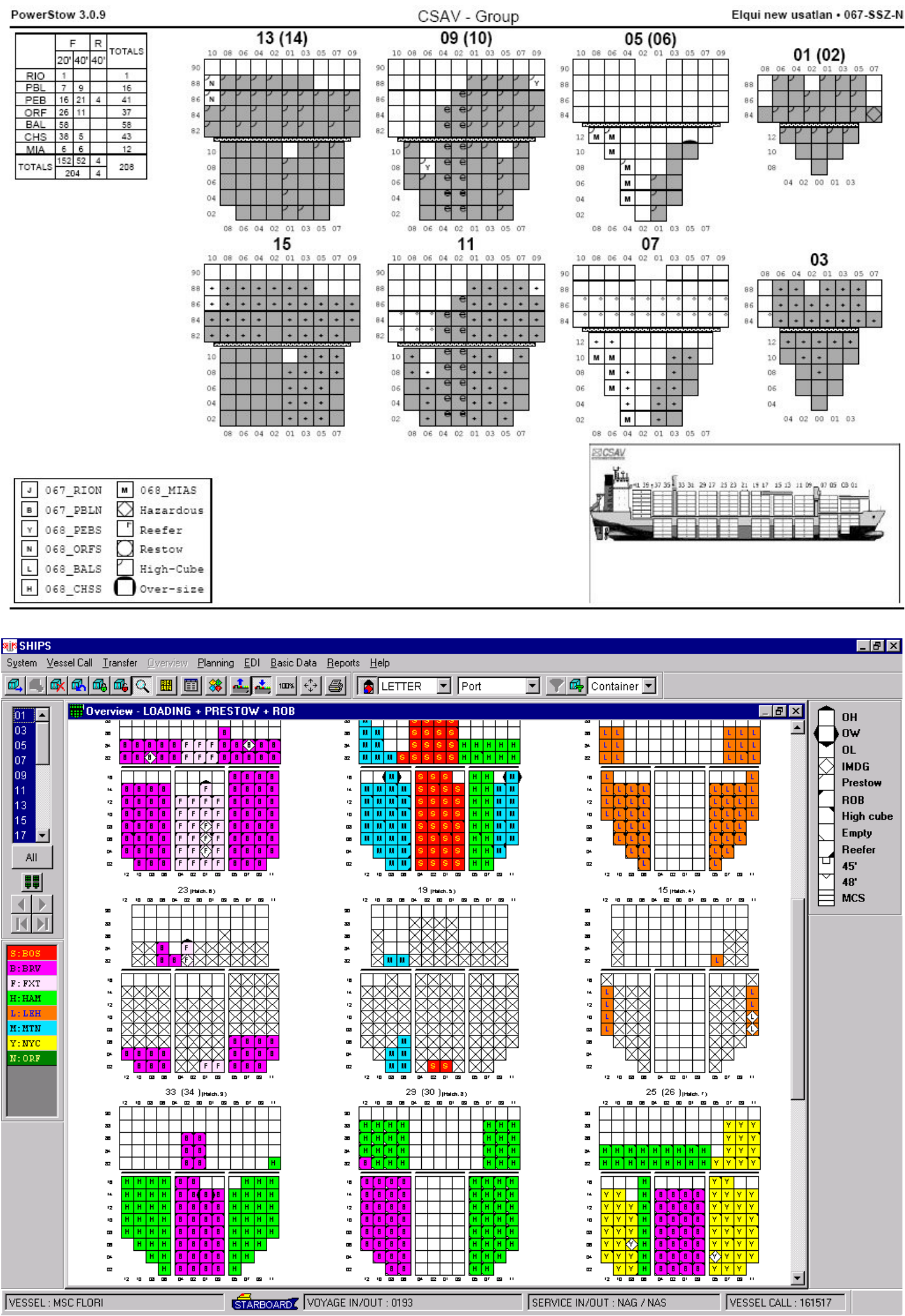

Fonte: Módulo SHIPS/COSMOS N.V. 
Figura 129 - Tela de Alocação de Portêineres e Sequência de trabalho, detalhes do planejamento das bays

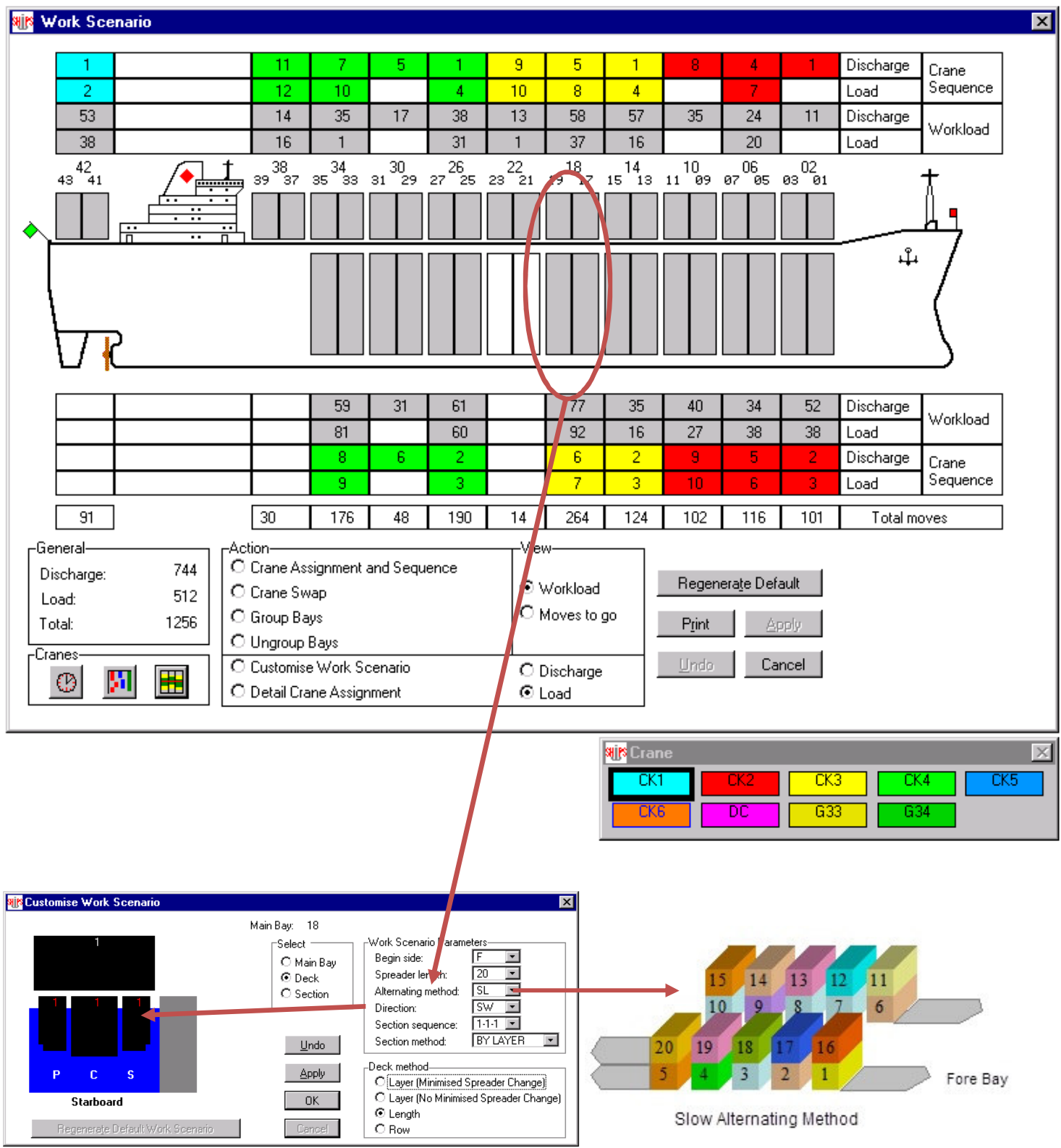

Fonte: Módulo SHIPS/COSMOS N.V.

Como é possível notar na Figura 129, há riqueza de detalhes para customizar o planejamento de cada navio, bay a bay, ou ainda detalhar o sequenciamento por seção, ou seja, trabalha o convés de uma forma e o porão de outra; indicando as variáveis de planejamento as quais serão consideradas no momento de sequenciar o navio, tais como: se inicia a bay pela vante (fore) ou ré (aft); abertura de spreader (20' ou 40'); método de alternar entre vante e ré; direção da operação se inicia de mar para terra ou de terra para mar; sequência da seção de operação começando 
pelo centro e, em seguida, faz os bordos ou começa fazendo um bordo (exemplo: boreste), seguindo para o centro e depois o outro bordo (bombordo), lastreando o navio pelas suas alturas (layers) ou levantando as colunas (rows); e ainda realizando o sequenciamento pelo comprimento dos contêineres ou minimizando ou não a abertura/ troca de spreader.

O resultado dessa alocação de equipamentos e planejamento do sequenciamento é apresentado na Figura 130 com o chamado Crane Split ou divisão de ternos ou costado. Os números na barra horizontal representam as bays dos navios, enquanto a coluna vertical o horário de início, o término previsto de cada terno/equipamento é indicado no final de cada sequência, enquanto o número de movimentos de cada bay/seção é indicado dentro das imagens que representam guindaste.

Figura 130 - Tela de Alocação de Portêineres e Sequencia de trabalho

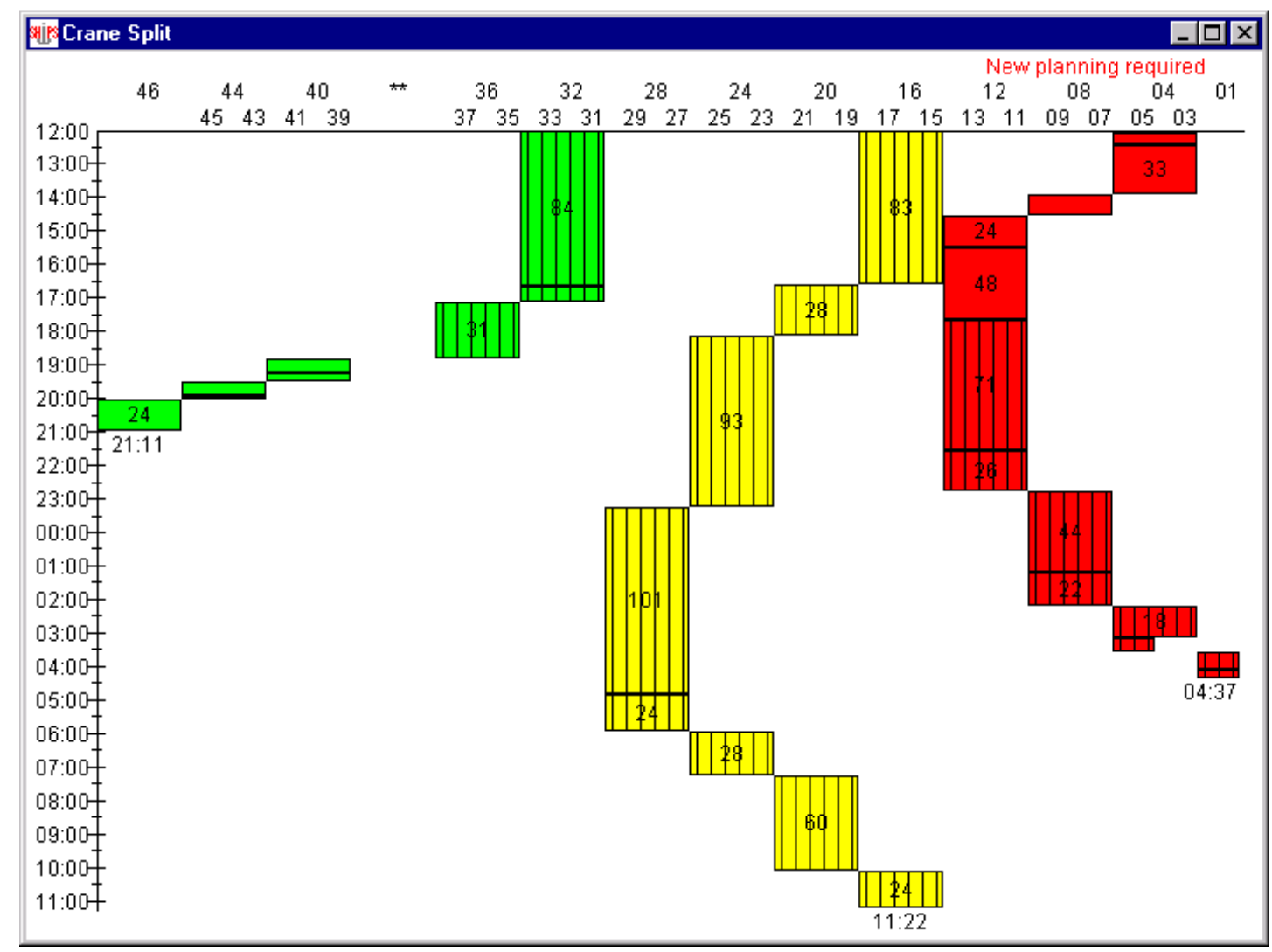

Fonte: Módulo SHIPS/COSMOS N.V.

Descrevendo um pouco mais o desenho da Figura 30 os blocos listrados representam operações de embarque, enquanto os blocos lisos a operação de 
descarga e a distância entre bumpers (amortecedores anticolisão) dos portêineres é considerada pelo sistema, pois, assim como é construída a classe do navio no sistema, os dados dos portêineres são entrada de dados do sistema, é preciso indicar alcance de lança (números de bays), capacidade single e twins, largura entre pernas com o número de linhas embaixo do portêiner, assim como a distância entre bumpers, de forma a permitir verificar a possibilidade de conflitos. Na Figura 131 nota-se a proximidade do trabalho nas bays 16 e 12; entre $14 \mathrm{~h} 30$ e 17h.

Figura 131 - Detalhe da representação dos guindastes

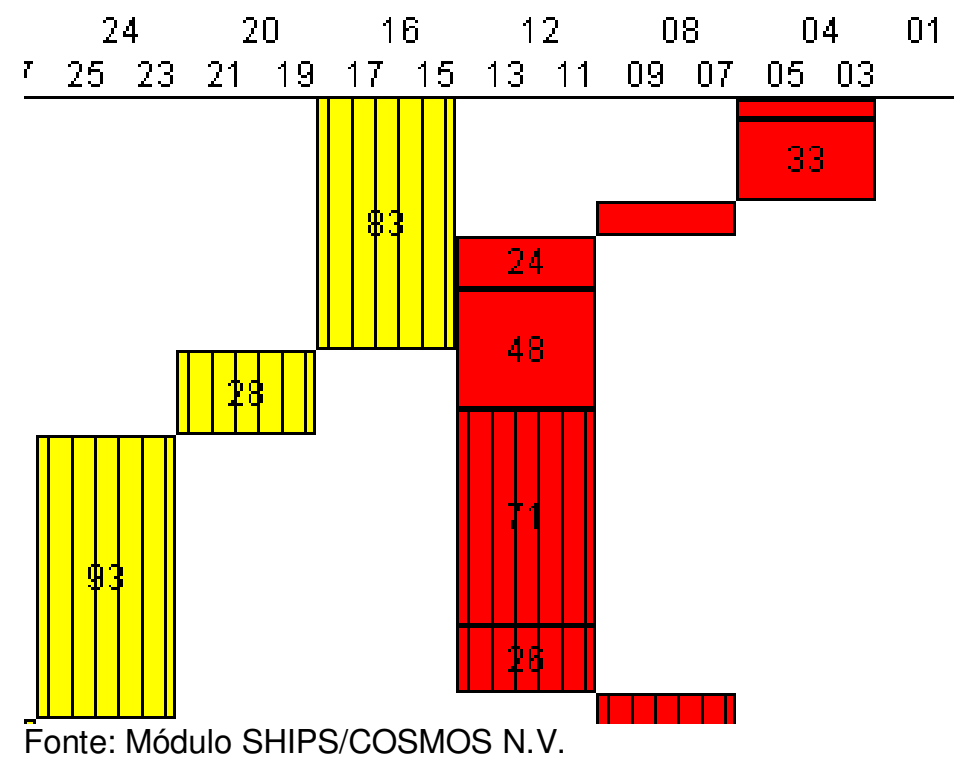

Ao término da operação, um arquivo EDI BAPLIE é gerado atualizando o plano de bordo com a retirada da carga de descarga do porto e embarque dos contêineres e ajustes das remoções eventualmente realizadas.

O módulo seguinte a ser tratado é o módulo de planejamento de pátio, que usualmente trabalha de forma conjunta com o módulo de alocação de equipamentos (RTG, Reach Stacker e Caminhões ou Terminal Tractors).

A função básica do módulo de planejamento de pátio é planejar automaticamente e garantir o posicionamento de cada contêiner no pátio; reservar espaço para a carga de exportação e importação dos navios depositados e futuros maximizando o uso de espaço (alta densidade das pilhas); otimizar as operações do terminal, aumentando a produtividade do navio e reduzindo os custos de movimentação, como: movimentos improdutivos como remoções por erro de armazenamento em quadra (mistura de navios, portos ou classes de peso); redução 
de consumo de combustível, homem-hora e desgaste de equipamento por meio da diminuição de distâncias percorridas ou dirigidas com equipamento vazio; balanceamento da movimentação entre os equipamentos alocados.

O planejamento de pátio, independente de qual TOS o terminal utilize (NAVIS, COSMOS, Tideworks, RBS, Opus, Jade, entre outros), trabalha normalmente com três conceitos de planejamento ou matriz de planejamento:

- Combinações para agrupamento dos contêineres, exemplo: agrupar todos os reefers ou carga perigosa (IMO) ou os contêineres de 40' de exportação cheios para Hamburgo na Alemanha;

- Reserva de espaço é onde serão colocados os contêineres conforme movimentação do navio; podendo ser feito de forma fixa, por exemplo, a quadra de contêineres reefers em virtude das tomadas ou de forma dinâmica, alocando aquele grupo de contêineres, conforme volume da viagem e local/ berço de atracação do navio no terminal;

- Uso de algoritmos que mostra como os contêineres serão colocados junto; isto é, Navio/Viagem; por porto; tamanho e faixa de peso; armazenar os contêineres pesados sobre os leves, etc.

A Figura 132 representa os níveis de visualização existentes de diferentes TOS, começando pela vista geral do terminal (Bird eyes view); seguidos do nível de visualização do Pátio; depois dos blocos, quadras ou pilhas e o ultimo nível de detalhe de informações do contêiner. 
Figura 132- Níveis de visualização do terminal, pátio, quadra, contêiner

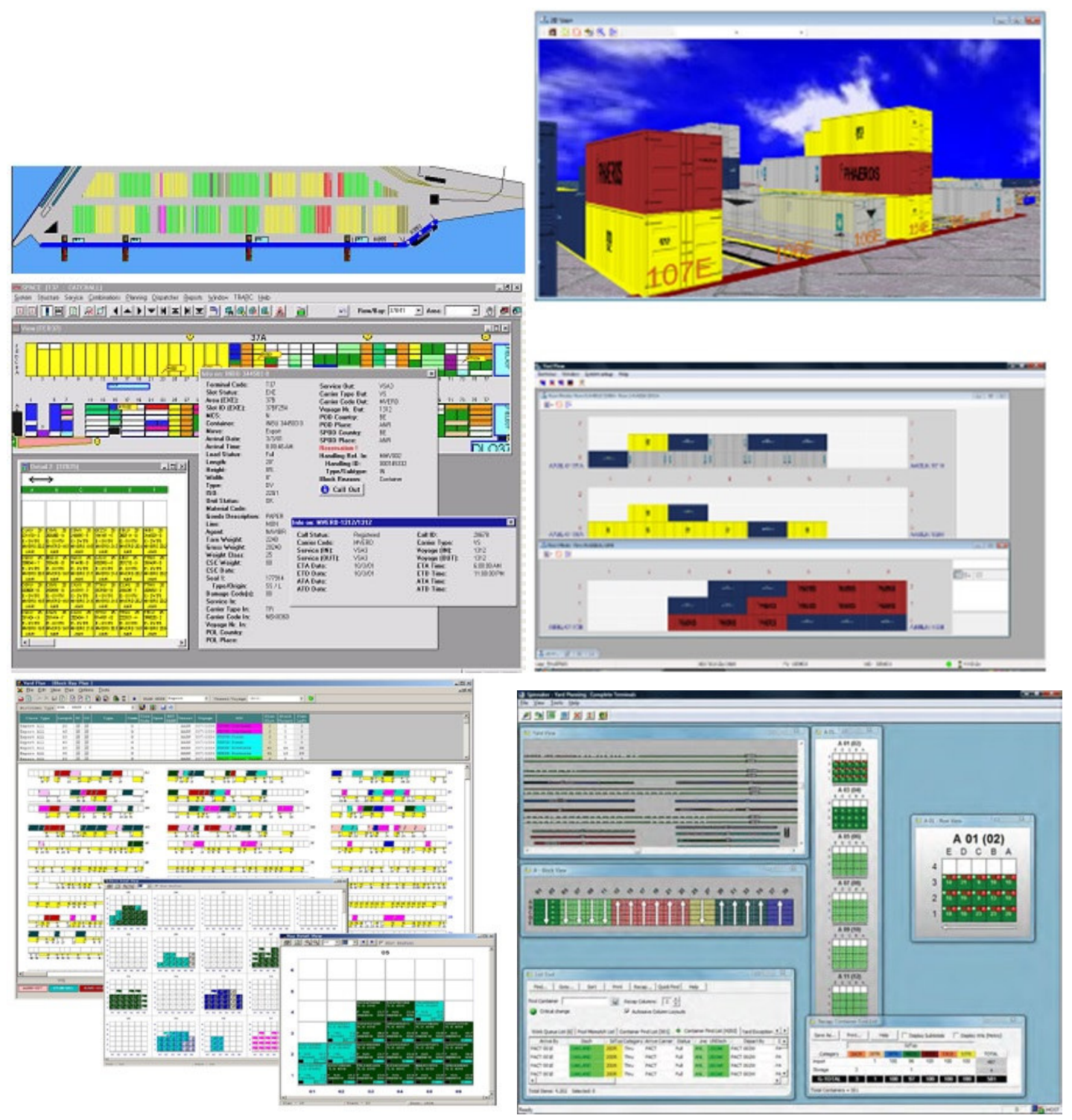

Fonte: Módulo SPACE/COSMOS N.V; Yard View Spinnaker/Tideworks; Yard View (Phaeros); Opus.

O módulo de Controle e Alocação de Equipamentos possui como finalidade otimizar o uso do transporte horizontal do terminal; reduzir o tempo de viagem sem contêineres; aumentar o número de instruções recebidas por hora para os operadores de equipamentos; rastrear os equipamentos no terminal (conforme figura 133, os pop-ups amarelos ilustram o número de identificação do equipamento). $\mathrm{Na}$ mesma Figura, é possível verificar a emulação de um coletor de dados veicular de um dos equipamentos que ilustra o recebimento de instruções do TOS. 
Figura 133 - Alocação e rastreamento de equipamentos no terminal

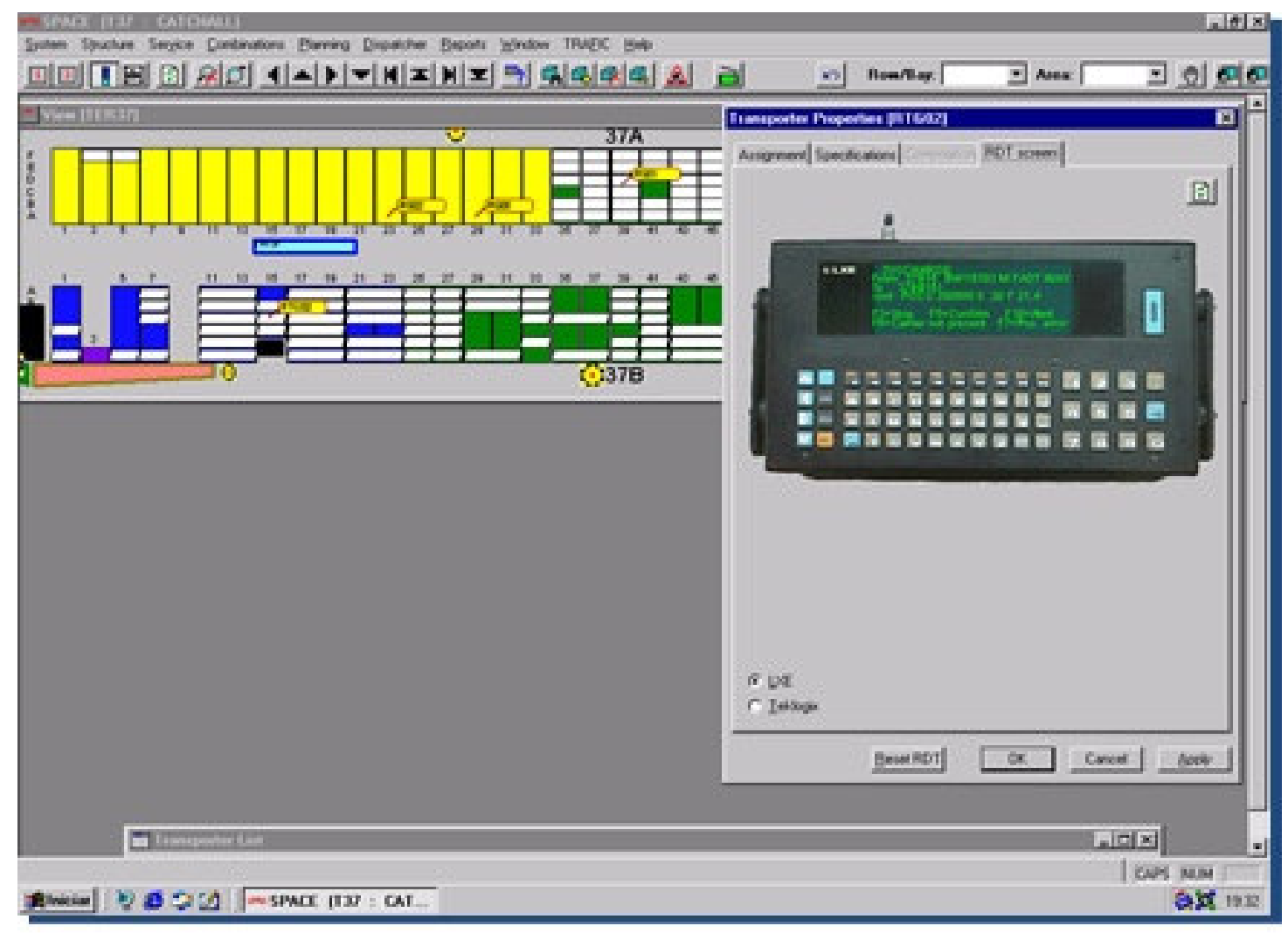

Fonte: Módulo TRAFIC/COSMOS N.V

Entre os obstáculos à otimização de equipamentos encontra-se normalmente nas regras de alocação que fixam os equipamentos por navio/terno/equipamento ou por tarefa como: no recebimento ou entrega de contêineres de importação para rua, no embarque do $1^{\circ}$ terno de um navio ou nas remoções em quadras de contêineres cancelados ou que rolaram para outro navio (housekeeping).

Há módulos de controle e alocação de equipamentos que trabalham com os equipamentos em pool, isto é, todos os equipamentos trabalham para qualquer tarefa e serão alocados conforme a prioridade da atividade ou exclusividade do movimento, por exemplo, é necessário um contêiner até 10 toneladas para o porto de Antuérpia para fechar a tampa do porão, a posição de estivagem reservada é para um contêiner de carga perigosa de uma determinada classe ou trata-se de um contêiner de embarque direto com excesso; em virtude da distância de sua última tarefa realizada para o próximo movimento; do tempo de espera da atividade e do custo daquele movimento. Normalmente, o custo do movimento está atrelado ao tempo de espera daquele contêiner no terminal ou da distância necessária para 
realizá-la; trabalhar em pool é a melhor forma a permitir a uma distribuição balanceada das filas de trabalhos.

A Figura 134 ilustra o que normalmente ocorre com a alocação fixa de equipamentos, ou seja, uma sobrecarga em alguns equipamentos e um desperdício em outros, com a alocação de mão de obra e consumo de diesel, uma vez que os equipamentos normalmente ficam ligados.

Figura 134 - Exemplo de distribuição de equipamentos com regras fixas

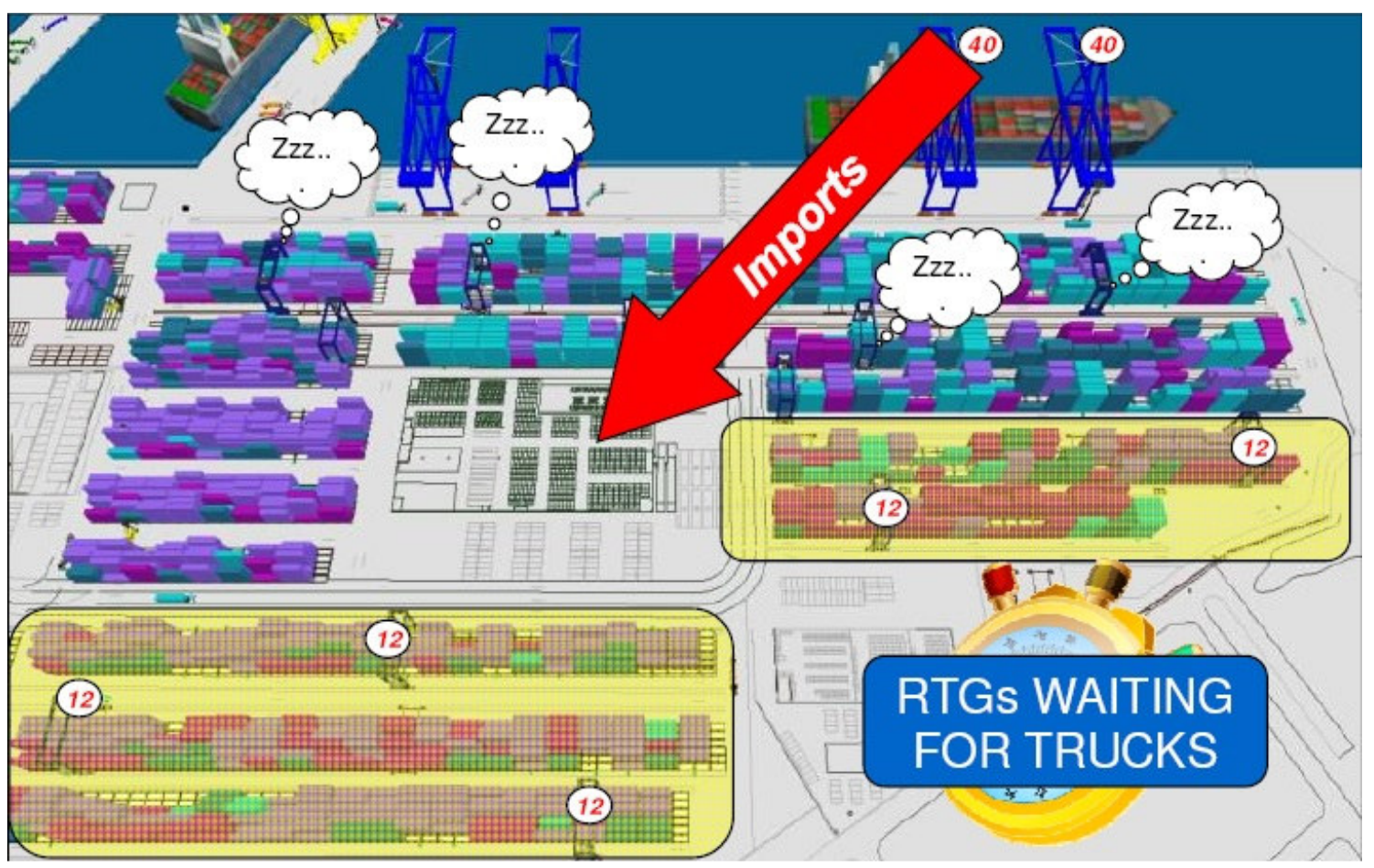

Fonte: Bustamante (2009)

Enquanto a Figura 135 demonstra uma comparação de percurso realizada por equipamentos fixos em um terno (pool dedicado) ou equipamento e equipamentos dispostos de forma geral (pool global). 
Figura 135 - Alocação e rastreamento de equipamentos no terminal

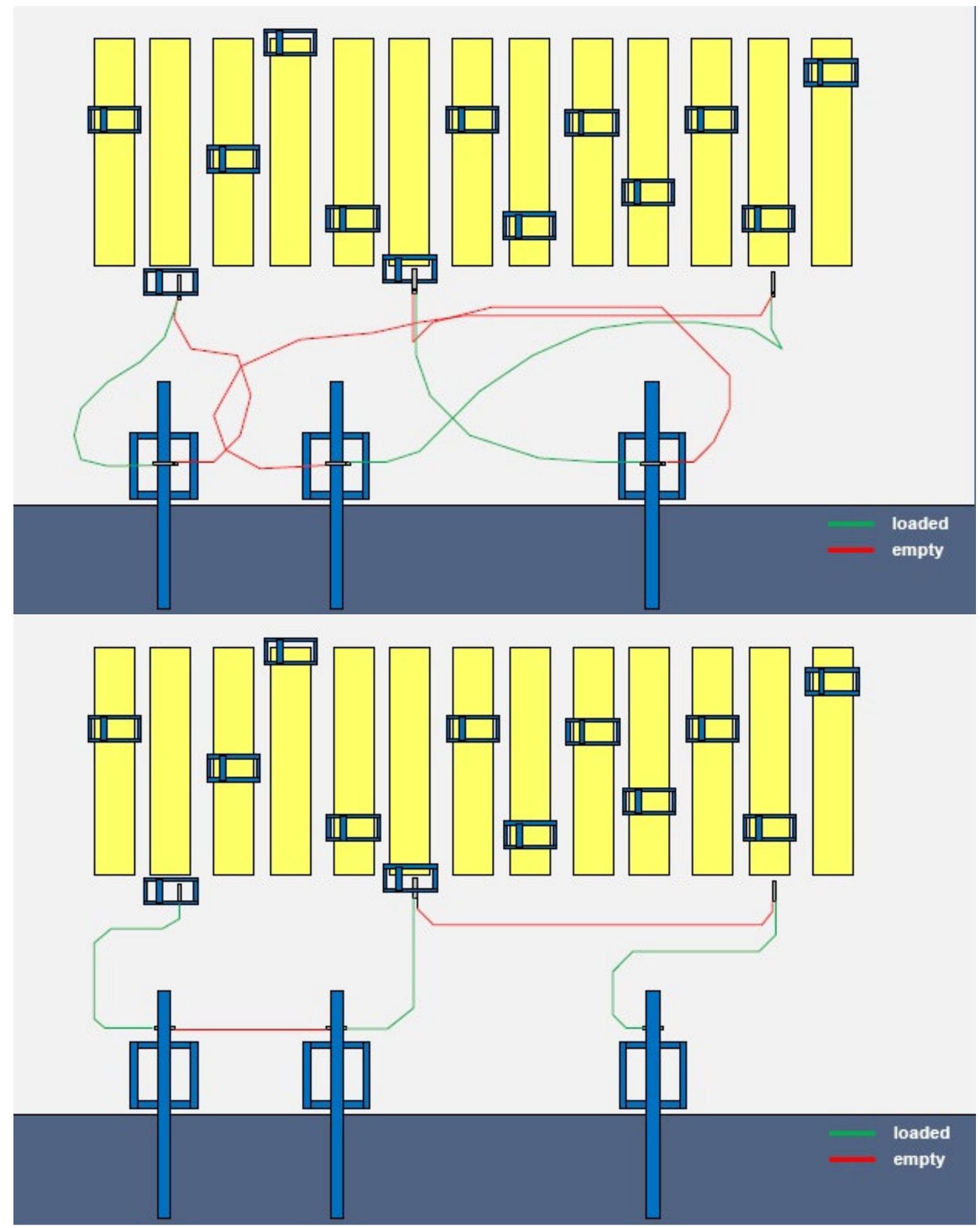

Fonte: Richter (2010)

A Figura 136 indica outra representação dos dois tipos de pool; há módulos do TOS dedicados a essa otimização, o melhor exemplo é o Prime Route da NAVIS. 
Figura 136 - Otimização de veículos através de dois tipos de Pool
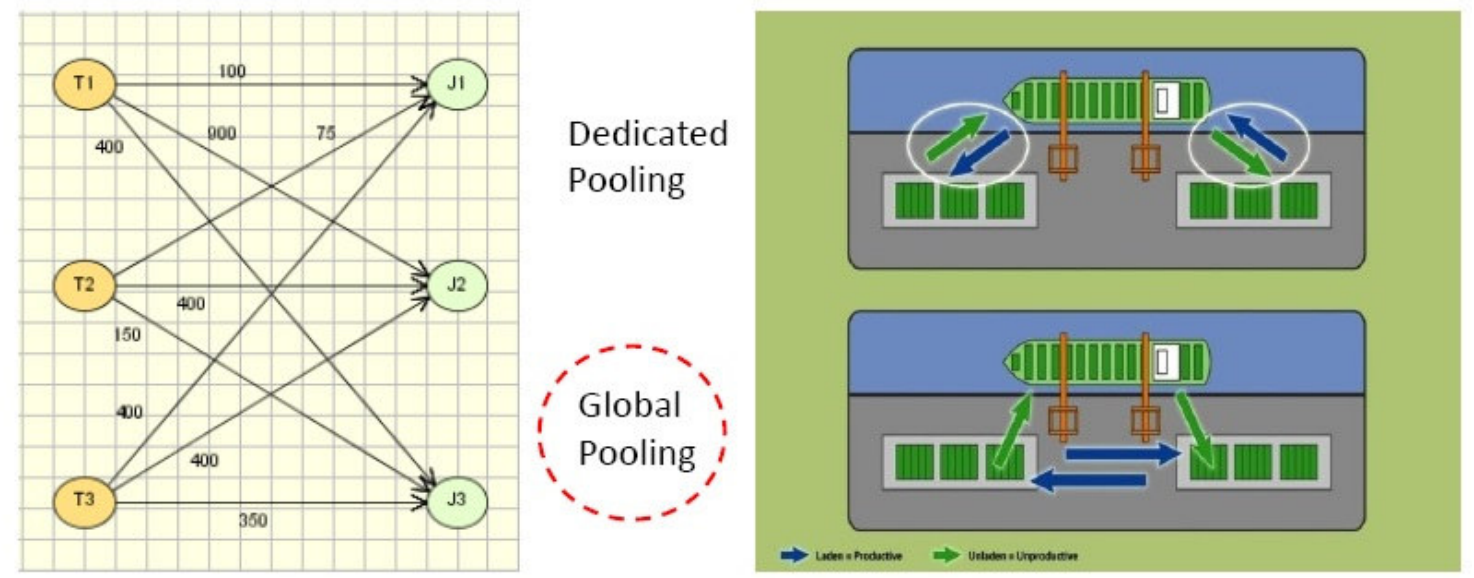

Fonte: Florez (2014) e Prime Route/NAVIS

O módulo de gates possui as funções de controle e registro de todos os caminhões que são processados no terminal; baseado nas informações précadastradas no sistema de agendamento e oriundas de informações (previsões) enviadas pelo armador, tal como os bookings e que são controlados pelo setor de prontificação de carga do terminal.

Os processos de gates foram descrito anteriormente nesse trabalho, ocorrem diversas atividades operacionais e de controle alfandegário, como pesagem e vistoria física do contêiner e de lacres. As vistorias físicas são confrontadas com as informações documentais (agendamento, cópia de documentos, EDI) enviadas pelos clientes; isso permite que em caso de erro o TOS possa corrigir o planejamento. Por exemplo, se um contêiner foi cadastrado com o código ISO 2210 para o porto de Kingston; mas esse contêiner é na realidade de código 4210 do mesmo porto; o TOS replaneja o contêiner para uma quadra de contêineres de 40', baseado nas informações físicas, pois entende que ocorreu um erro de digitação e as inspeções físicas se sobrepõem as enviadas anteriormente. Dito isso, consideram-se os gates como a última fronteira de correção de dados e é notória a forte integração com o módulo de documentação e EDI.

O módulo de documentação é usualmente gerenciado pelos setores de prontificação ou prontidão de carga e setor de captação de carga; a lista de documentos e informações transacionadas é extensa, começando pelos bookings ou arquivos EDI UN/EDIFACT COPARN, lista de vazios, B/L, ficha de mercadorias 
perigosas, carta de temperatura dos contêineres reefers, lista de remoção, Solicitações de Despacho (SD), apenas para citar alguns.

O módulo de EDI também é integrado ao sistema de documentação, o padrão de mensagens mais trocado com os armadores é o UN/EDIFACT (United Nations/Eletronic Data Interchange for Administration Commerce and Transport), tais como: COPARN (bookings), MOVINS (plano de bordo/pré-estivagem), BAPLIE (plano de bordo/pós-estivagem), COARRI (relatório de contêineres embarcados e descarregados), CODECO (transações de gates), COPRAR (criação de ordens de embarque e descarga), apenas para citar os mais utilizados. Contudo, ainda é preciso administrar as mensagens de outros padrões como: ANSI X12 ou flat files que são arquivos de padrão proprietários. Um bom exemplo são os arquivos DTE ou Declaração de Transito Aduaneira da alfandega de Santos; esses arquivos tratam dos eventos de controle das transferências de cargas do perfil operador portuário para o perfil recinto alfandegado e as informações, sobre os estoques de cargas em regime aduaneiro dessas empresas, para as autoridades responsáveis pela fiscalização do comércio exterior.

O módulo de faturamento (Billing System) é o responsável pela geração de fatura dos serviços prestados mediante a tabela negociada com o cliente, tais como: armazenagem, movimentação (handling), repesagem, conexão/desconexão de contêineres reefers, consumo de energia, enfim, todos os serviços prestados no terminal. Quanto às interfaces com os diversos outros sistemas e dispositivos, podemos indicar: Balanças estáticas e dinâmicas, GPS, OCR, RFID, RTLS, Coletores de Dados, Sistemas de monitoramento de reefer e escâneres.

Com exceção dos escâneres, os demais sistemas e dispositivos foram de alguma maneira ilustrados no texto; portanto a Figura 137 a 139 demonstra imagens desses equipamentos que foram instituídos pela Portaria RFB $n^{\circ} 3.518 / 2011$ e que obrigaram os terminais a revisarem suas regras de fluxo em virtude da Portaria $n^{\circ}$ 229/12 que disciplina o uso desses equipamentos e determina quais fluxos e prazos devem ser escaneados. Um ponto de definição importante para os terminais é encontrar qual o local ideal de instalação do escâner de forma a não prejudicar o fluxo e pelo fato de necessitar de uma área considerável para a sua instalação. Todo escâner possui OCR integrado nas suas operações. 
Figura 137 - Áreas de Instalação de Scanners

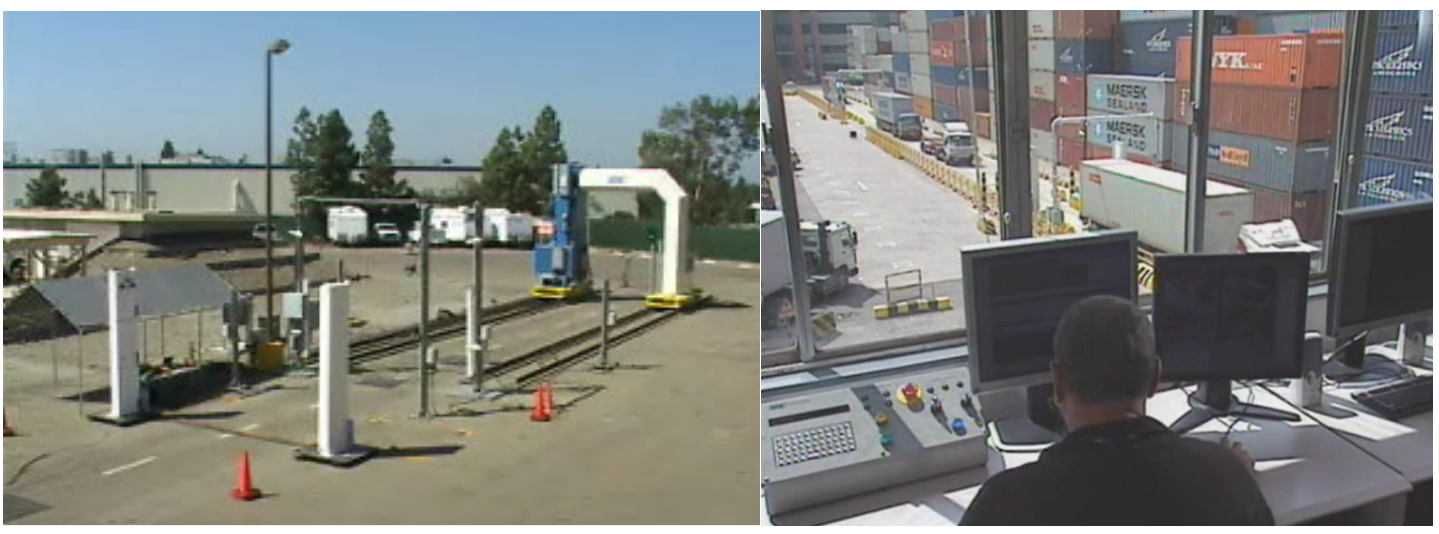

Fonte: SAIC

Figura 138 - Imagens escaneados de um contêiner com pneus
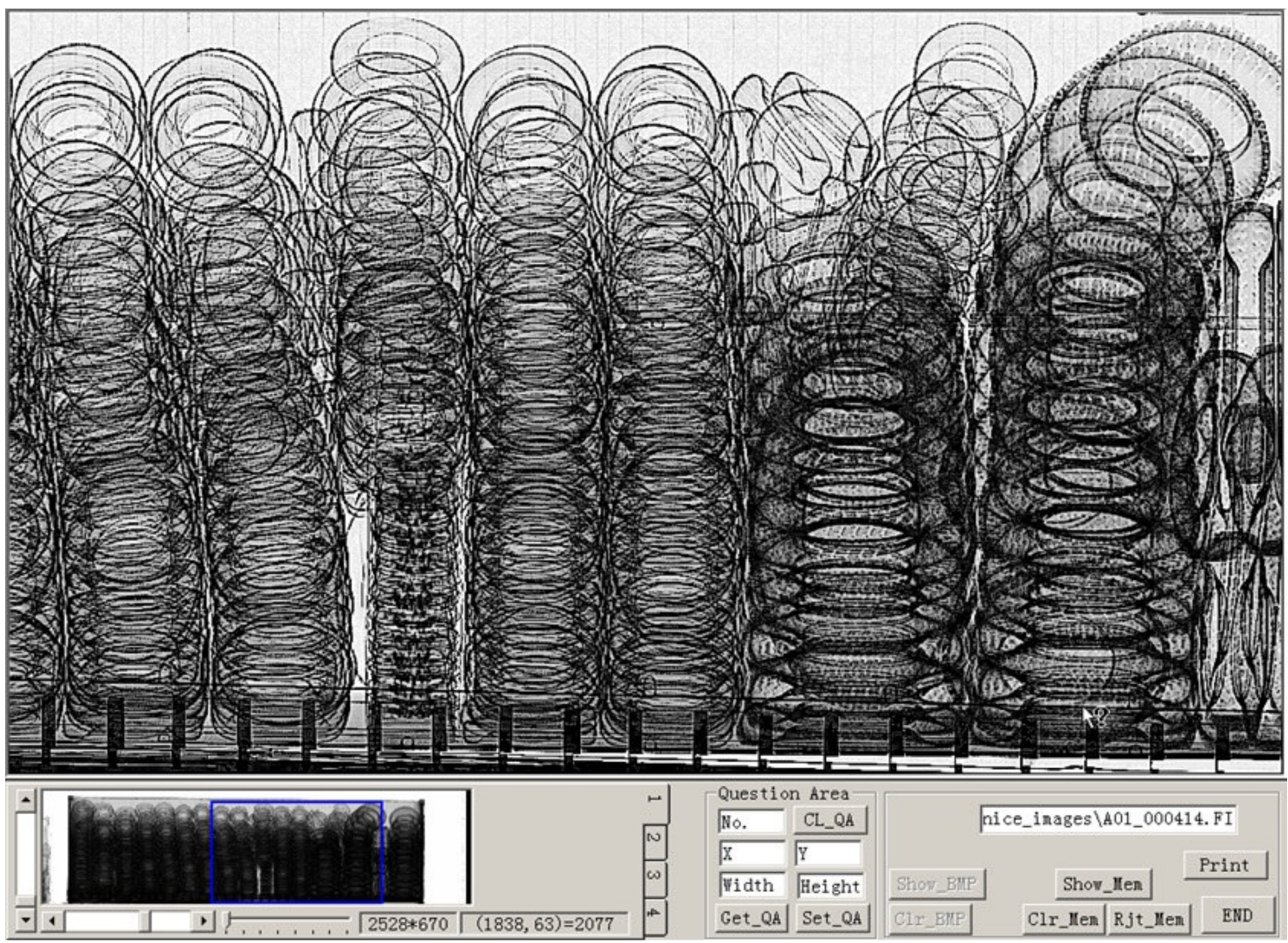

Fonte: SAIC 
Figura 139 - Imagens escaneados de um contêiner com um véiculo

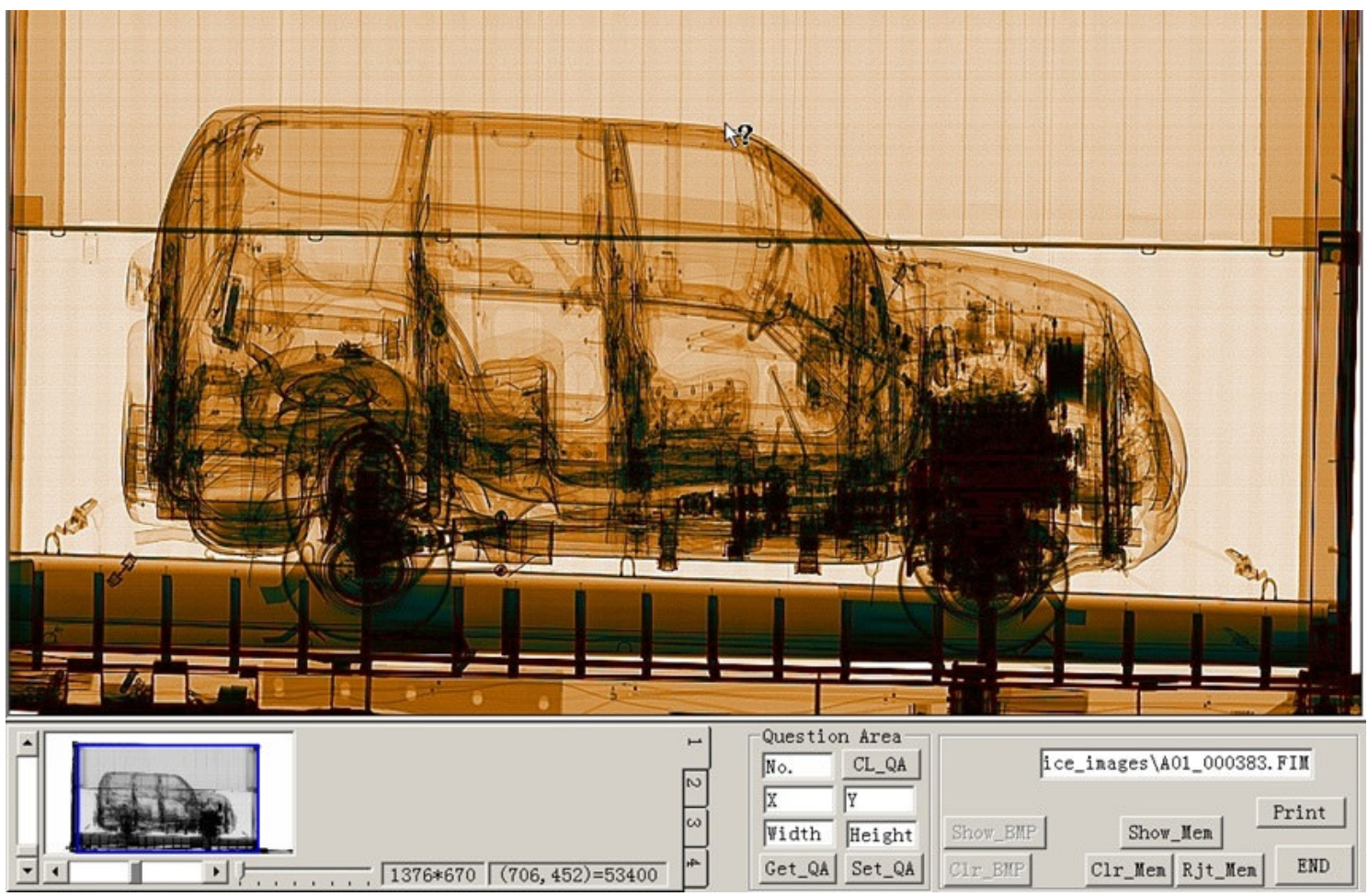

Fonte: SAIC

Deve-se notar que o TOS nos terminais não controla as cargas fracionadas dentro dos armazéns e atividades aduaneiras; para essa atividade, são necessários Sistemas de Gerenciamento de Armazéns ou Warehouse Management System (WMS).

Esse terceiro capítulo buscou apresentar os terminais de contêineres como um sistema de produção, por meio da comparação de processos manuais ou tradicionais contra automatizados e explicar a participação humana nos processos produtivos, bem como as principais tecnologias existentes para automação, seja essa maior ou menor e discorrer sobre a importância dos TOS no planejamento e automação futura de terminais.

A importância do TOS para a automação de terminais, pode ser comprovada por fato recente de que um dos maiores produtores de equipamentos portuários da indústria, a empresa Kalmar/Cargotec, adquiriu a empresa de software NAVIS, detentora do mais avançado TOS do mercado para integração de suas funções de planejamento e execução com seus equipamentos. 
O Sistema da Navis está em uso em mais de 230 terminais de contêineres marítimos em mais de 50 países do mundo e é utilizado por três dos quatro principais operadores de terminais globais; sendo que 63 sites operam seus sistemas há mais de 10 anos.

Figura 140-Localização dos terminais que utilizam NAVIS no mundo

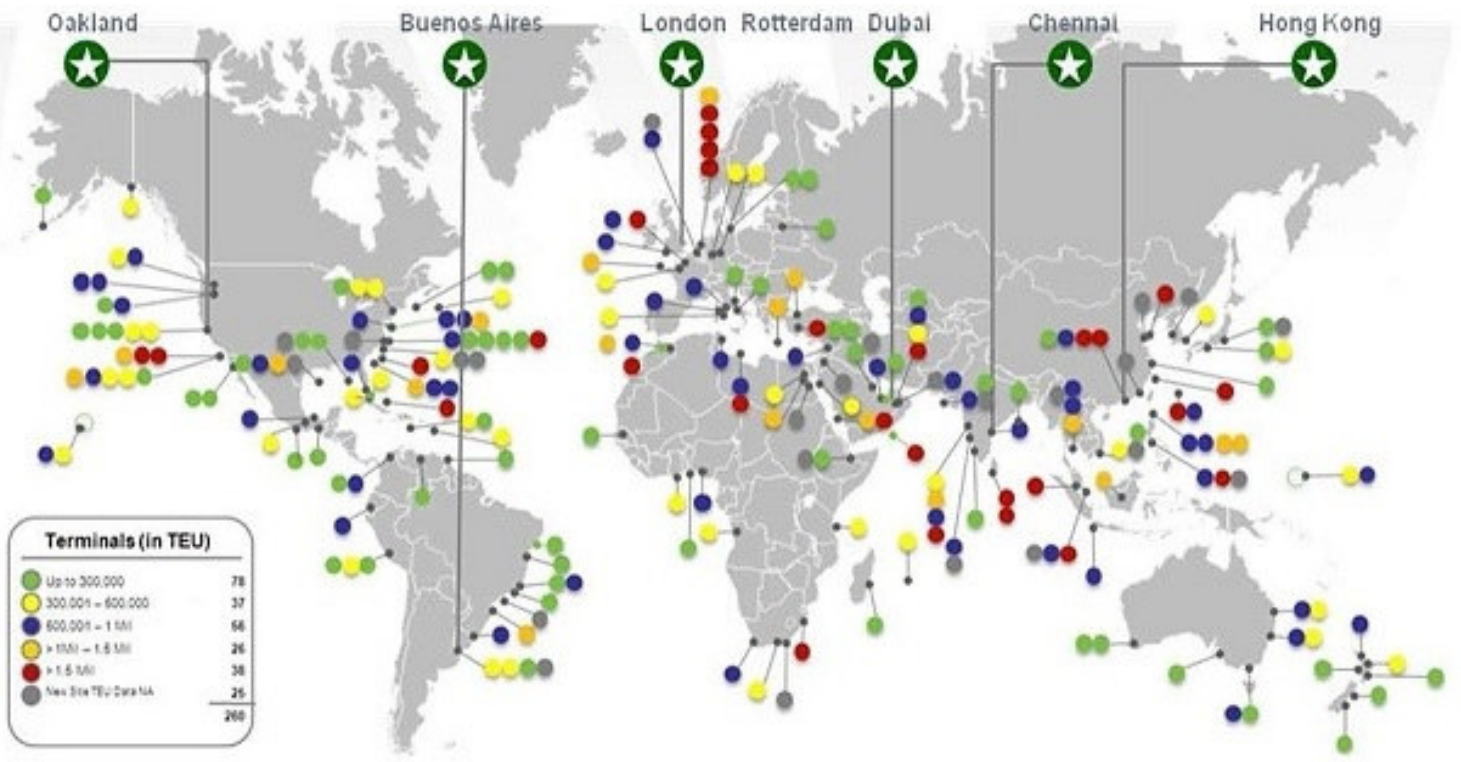

Fonte: NAVIS 


\section{REVISÃO BIBLIOGRÁFICA}

\subsection{HISTÓRIA DA AUTOMAÇÃO}

Groover (2011) relaciona a história da automação ao desenvolvimento de dispositivos mecânicos, tais como a roda por volta de 3.200 a.C, o guincho em 600 a.C, o came para transmissão de movimento aproximadamente em 1.000 a.C e outras engrenagens, as quais mais tarde foram melhoradas e utilizadas na construção de outros mecanismos como a máquina a vapor em 1765 para a geração de energia; 20 anos mais tarde, melhorado, formaria um controlador centrífugo pelo mesmo James Watt . Adventos do transporte ocorreram de forma seguida, o barco a vapor e as locomotivas em 1787 e 1803 respectivamente. Com o tear de Jacquard, por volta de 1800, nasce o que seria a primeira programação de máquina formada por placas de metal perfuradas, cujo objetivo era produzir tecidos a partir de fios. Dessa forma, os três elementos básicos necessários para automação estavam presentes: Energia, Sistema de Controle e Programa de Instruções.

Dando continuidade na linha do tempo, em 1881 tivemos o início da eletrificação e em 1913 a linha de montagem, seguidos pela linha de transferência mecanizada para a produção em massa com programação definida pela configuração do equipamento em 1924, a teoria matemática de sistemas de controle tomou praticamente as décadas de 30 e 40 em estudos, o computador eletromecânico MARK I em 1944, seguidos de importantes eventos da eletrônica como o transistor em 1948, disco rígido em 1956, os circuitos integrados em 1960 e o microprocessador em 1971.

O termo Automação foi criado em 1946, como referência aos dispositivos automáticos da linha de produção da Ford por Del Harder, mesmo ano do primeiro computador eletrônico digital; a máquina-ferramenta de controle numérico em 1952, o primeiro robô comercial em 1961 para desembarcar peças de uma fundição. No final da década de 60, surge o primeiro sistema de manufatura flexível e o Controlador Lógico Programável (CLP). Em 1978 a Apple lançaria o primeiro computador pessoal. As próximas décadas seriam fartas na criação de dispositivos e linguagens computacionais tão importantes para suportar os futuros dispositivos automatizados. E, em 1993, é inaugurado o primeiro terminal de contêineres automatizado da história, o Delta/Sea-Land Terminal (agora chamado de Delta 
Dedicated North Terminal) da Europe Container Terminal (ECT) do grupo Hutchison Port Holding (HPH) na região de Maasvlakte na Holanda; com o uso de AGVs e ASCs para a transferência de contêineres entre o cais e as pilhas.

Figura 141 - Fotos do ECT Delta Roterdã

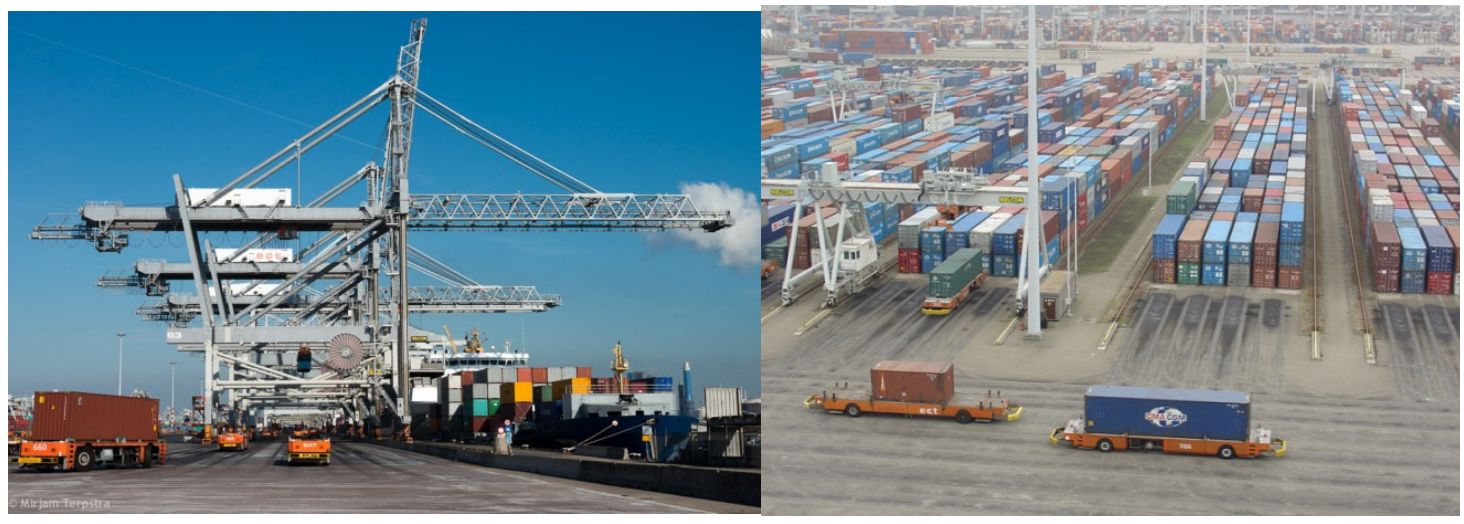

Fonte: Extraída dos sites: www.mirjam-terpstra.com e www.nieuwsbladtransport.nl

Portanto, o termo Automação está próximo de 70 anos de história e é parte integrante diária de diversas atividades humanas, seja nas residências com as lavadoras de roupas e louças automáticas, controle remoto ou abertura de portões por meio de reconhecimento da placa do veículo ou cartão com identificadores de Rádio Frequência (RFID), na rua por meio dos caixas eletrônicos automáticos ou simplesmente ATM (Automated Teller Machine), no trânsito com uso de semáforos totalmente atuados que decorrem da demanda de tráfego na interseção, mediante implantação de detectores de tráfego como: laços indutivos, sensores, câmeras de detecção de presença, nas aproximações, permitindo alteração nos tempos de estágio; nos automóveis com os controladores de velocidade de cruzeiro (Cruise Control) ou piloto automático e em praticamente todos os segmentos e processos das indústrias, por meio do uso de simples sensores de fim de curso, detectores de proximidade e nível, células fotoelétricas para detectar a passagem de partes em movimento, contadores e temporizadores, Controlador Lógico Programável (CLP) para eventos discretos de controle de processos, Processadores, Sistemas de transporte e manipulação do tipo tapetes rolantes (Conveyor Lines) ou Veículos Guiados Automaticamente (AGVs), e no uso de Robôs.

Sobre Robótica, Niku (2011) explica que a lista existente de algumas aplicações de Robótica foi realizada e não está completa por nenhum estiramento 
da imaginação; citando apenas algumas conhecidas: Soldagem, Pintura, Montagem e Fabricação são aplicações comuns na indústria automotiva; carregamento de máquinas; operações de retirada e deposição que pode incluir paletização, colocação de cartuchos, montagens simples ou retirada de peças tratadas de fornos; Inspeção de peças, placas de circuitos e circuitos integrados $(\mathrm{Cl})$, aplicações médicas em procedimentos cirúrgicos; ajuda a pessoas com deficiências; trabalhos em ambientes perigosos e confinados, como atendimento a um ambiente radiativo, pesquisa de gases em um lago de lava vulcânica ou locais subaquáticos, espaciais e inacessíveis; e, há empresas com robôs humanoides como o ASIMO da Honda ou o Nesbot da Nestlé.

Não há conhecimento do uso de robôs nas atividades de terminais de contêineres, apesar de Saanen (2004) utilizar o termo de equipamentos robotizados para os equipamentos de pátio, como os ASC (Automatic Stacking Crane), entre outros.

\subsection{CONCEITOS DE AUTOMAÇÃO}

Os conceitos e aplicações de automação nas áreas de conhecimento de engenharia são amplos, conforme Pinto (2010) é a tecnologia relacionada com a aplicação de sistemas mecânicos, elétricos, eletrônicos e computacionais nas operações e controle dos sistemas de produção.

Automação é definida por Stevenson (1999) como um maquinário que dispõe de dispositivos sensores e de controle, que the permitem funcionar automaticamente.

Seleme e Seleme (2008) cunham que Automação é distinta da mecanização e explicam que a Mecanização consiste simplesmente no uso de máquina para realizar trabalho em substituição ao esforço físico; enquanto Automação são sistemas automáticos de controle, pelos quais mecanismos verificam seu próprio funcionamento, efetuam medições e correções, sem interferência humana.

Groove (2011) explica Automação como a tecnologia por meio da qual um processo ou procedimento é alcançado sem assistência humana.

Contudo, há um conceito de que é à base do Sistema Toyota de Produção e que não deve ser confundido com a automação, esse conceito é denominado de "Autonomação" ou automação com um toque humano; normalmente essas 
máquinas estão acopladas a um dispositivo de parada automático. Segundo Ohno (1997), a Autonomação altera o conceito de gestão, pois não será necessário um operador enquanto a máquina estiver funcionando normalmente, a intervenção humana ocorre apenas em anormalidades ou defeitos.

Shingo (1996) refere-se à Autonomação também como pré-automação e explica que a ideia era de separar completamente os trabalhadores das máquinas por meio do uso de mecanismos sofisticados para detecção de anormalidades na produção. Enquanto Liker (2004) explica que Jidoka é o termo em japonês para Autonomação e significa equipamento dotado de inteligência para desligar-se quando apresenta problemas.

Os sistemas de produção são divididos, segundo Groover (2011), em Instalações (a fábrica, os equipamentos e a forma como estão organizados) e Sistemas de Apoio à Produção (conjunto de procedimentos utilizados no suporte da produção e solução de problemas técnicos e logísticos). O mesmo Groover (2011) indica que os elementos automatizados do Sistema de Produção podem ser separados em duas categorias, isto é, automação dos sistemas de produção da fábrica e controle computadorizados dos sistemas de apoio à produção. Todavia, pode-se afirmar que para os processos automatizados de terminais de contêineres e para outros diversos segmentos da indústria, essas duas categorias se sobrepõem, pois a maioria dos sistemas de produção automatizados são suportados e gerenciados por sistemas computacionais.

São três os tipos de automação que classificam os sistemas automatizados de produção. A saber, Automação Rígida; Automação Programável e Automação Flexível.

$\mathrm{Na}$ Automação rígida, a configuração do equipamento define a sequência simples das operações de processamento e como características o alto investimento CAPEX inicial em equipamentos; esse item comum aos três tipos de automação, Altas taxas de produção e uma inflexibilidade quanto à variação da produção. $\mathrm{O}$ processamento dos AGS nos terminais pode ser considerado exemplo de automação rígida.

Enquanto os CLPs dos portêineres são considerados exemplos de Automação Programável; isto é, equipamento de que são projetados com a capacidade de alterar a sequência de operações de modo a atender a alguma variação. Dentre as características, conforme dito anteriormente, o alto investimento; 
taxa de produção inferior as taxas da automação rígida; flexibilidade quanto às modificações e maior adaptabilidade para produções em lote.

Considera-se a Automação Flexível uma extensão da programável, pois este é capaz de produzir uma variedade de produtos sem grandes desperdícios de produção entre alterações de configurações do equipamento e dos produtos. Como características têm-se: o alto investimento; a produção continua de produtos; taxas médias de produção e alguma flexibilidade para lidar com variações. Por exemplo, os portêineres com os diferentes tipos de contêineres (diversos tamanhos 20', 40', 45'; tipos de contêineres, como plataforma ou flatracks com excesso; cargas de projeto e caixarias).

Há três elementos básicos necessários para automação: Energia, Sistema de Controle e Programa de Instruções; cada um desses elementos está presente em um dos cinco níveis de automação:

- Nível 1 - do dispositivo

- Exemplo: componentes como Sensores, Atuadores etc.;

- Nível 2 - da máquina

- Exemplo: máquinas individuais, tais como: AGVs, Robôs industriais;

- Nível 3 - célula ou do sistema

- Trata-se de um grupo de máquinas conectados por um sistema;

- Nível 4 - da fábrica ou da produção

- Instruções do sistema de informação corporativo que são traduzidos em planos operacionais para a produção;

- Nível 5 - do empreendimento

- Sistema formado pelo sistema de informações corporativo, que inclui funções de gerenciamento da empresa, marketing e vendas, contabilidade, projeto e pesquisa, plano mestre de produção, entre outros.

Enfim, por que automatizar? Groover (2011) apresenta algumas razões as quais listamos a seguir:

- Aumentar a Produtividade;

- Reduzir os Custos; 
- Minimizar os efeitos e falta de trabalhadores;

- Eliminar ou Reduzir das rotinas manuais;

- Realizar processos que não podem ser executados manualmente;

- Aumentar a segurança do trabalhador;

- Melhorar a qualidade do produto ou serviço;

- Diminuir do tempo de produção;

- Evitar o alto custo da não automação.

Agrega-se um item na lista de Groover, o qual se entende ser um fator relevante para a escolha da automação que é a "Consistência nas operações"; pois para a maioria dos terminais, a chave para atingir maiores produtividades, talvez não seja operar mais rápido; mas sim operar de forma mais regular, reduzindo a variabilidade nos processos. Talvez por isso, a aplicação de metodologia 6 Sigma seja tão popular em terminais.

E quem automatizou as suas operações? Desde 1993, diversos terminais tornaram as suas operações automatizadas ou semiautomatizadas, conforme a Tabela 17. 
Tabela 17 - Terminais Semiautomatizados e Automatizados em Operação e Projetos Futuros

\begin{tabular}{|c|c|c|c|c|c|}
\hline \multirow[t]{2}{*}{ Terminal } & \multirow[t]{2}{*}{ Local } & \multirow[t]{2}{*}{ Operador } & \multirow{2}{*}{$\begin{array}{l}\text { Inicio da } \\
\text { operação }\end{array}$} & \multicolumn{2}{|c|}{ Equipamentos } \\
\hline & & & & Pátio & $\begin{array}{l}\text { Transferência } \\
\text { Cais - Pátio }\end{array}$ \\
\hline Delta Terminal & Roterdã & ECT & 1993 & E-ASC & AGV \\
\hline Pasir Panjang Terminal (PPT) & Cingapura & PSA & 1997 & OHBC & TT + Chassis \\
\hline London Thamesport & Ilha de Grain (Kent) & $\mathrm{HHPH}$ & 2000 & C-ASC & TT + Chassis \\
\hline $\begin{array}{l}\text { Container Terminal Alternwerder } \\
\text { (CTA) }\end{array}$ & Hamburgo & HHLA & 2002 & E-ASC & AGV \\
\hline Ohi Terminal & Tóquio & Wan Hai & 2003 & C-ASC & TT + Chassis \\
\hline Evergreen Marine Terminal & Kaohsiung & Evergreen Marine Corp. & 2005 & C-ASC & TT + Chassis \\
\hline Antwerp Gateway & Antuérpia & DP World & 2007 & E-ASC & ShC \\
\hline $\begin{array}{l}\text { Korea Express Busan Container } \\
\text { Terminal (KBCT) }\end{array}$ & Busan & $\begin{array}{l}\text { Pusan East Container } \\
\text { Terminal Co Ltd (PECT) }\end{array}$ & 2007 & C-ASC & $\mathrm{TT}+$ Chassis \\
\hline APMT Virginia & Portsmouth, VA & $\begin{array}{l}\text { Virginia International } \\
\text { Terminals (VIT) }\end{array}$ & 2007 & E-ASC & Cassette + ShC \\
\hline Euromax Terminal & Roterdã & ECT & 2008 & E-ASC & AGV \\
\hline Tobishima Container Berth & Nagoya & $\begin{array}{l}\text { Tobishima Container } \\
\text { Berth Company (TCB) }\end{array}$ & 2008 & A-RTG & AGV \\
\hline
\end{tabular}




\begin{tabular}{|c|c|c|c|c|c|}
\hline Terminal & Local & Operador & Inicio da & \multicolumn{2}{|c|}{ Equipamentos } \\
\hline Pusan Newport & Busan & $\begin{array}{l}\text { Pusan Newport Co Ltd. } \\
\text { (DPW) }\end{array}$ & 2009 & C-ASC & TT + Chassis \\
\hline Fishermans Island Terminal & Brisbane & Patrick Stevedoring & 2009 & Autostrad & Autostrad \\
\hline $\begin{array}{l}\text { Hanjin New Port (Busan New Port } \\
\text { Phase 2-1) }\end{array}$ & Busan & $\begin{array}{l}\text { Hanjin Newport Co Ltd } \\
\text { (HJNC) }\end{array}$ & 2009 & C-ASC & TT + Chassis \\
\hline $\begin{array}{l}\text { Taipei Port Container Terminal } \\
\text { (TPCT) }\end{array}$ & Taipei & $\begin{array}{l}\text { Taipei Port Container } \\
\text { Terminal Corp. (Evergreen, } \\
\text { Yang Ming, Wan Hai) }\end{array}$ & 2010 & C-ASC & TT + Chassis \\
\hline $\begin{array}{l}\text { Container Terminal Burchardkai } \\
\text { (CTB) }\end{array}$ & Hamburgo & HHLA & 2010 & E-ASC & Straddle Carriers \\
\hline TTI Algeciras & Algeciras & $\begin{array}{c}\text { Total Terminal } \\
\text { International Algeciras } \\
\text { (Hanjin) }\end{array}$ & 2010 & E-ASC & ShC \\
\hline $\begin{array}{l}\text { Hyundai Pusan New-Port Terminal } \\
\text { (HPNT) }\end{array}$ & Busan & $\begin{array}{c}\text { Hyunsau Merchant } \\
\text { Marine }\end{array}$ & 2010 & C-ASC & $\mathrm{TT}+$ Chassis \\
\hline Kao Ming Container Terminal & Kaohsiung & $\begin{array}{c}\text { Kao Ming Container } \\
\text { Terminal Corp. (Yang } \\
\text { Ming) }\end{array}$ & 2010 & C-ASC & $\mathrm{TT}+$ Chassis \\
\hline Pusan Newport Phase 2-3 & Busan & $\begin{array}{l}\text { Pusan Newport Co Ltd. } \\
\text { (DPW) }\end{array}$ & 2012 & E-ASC & ShC \\
\hline
\end{tabular}




\begin{tabular}{|c|c|c|c|c|c|}
\hline Terminal & Local & Operador & Inicio da & \multicolumn{2}{|c|}{ Equipamentos } \\
\hline Khalifa Container Terminal & Abu Dhabi & $\begin{array}{c}\text { AD Terminals (Abu Dhabi } \\
\text { Port Co.) }\end{array}$ & 2012 & E-ASC & ShC \\
\hline Tercat & Barcelona & $\mathrm{HPH}$ & 2012 & E-ASC & ShC \\
\hline $\begin{array}{l}\text { Sydney International Container } \\
\text { Terminals }\end{array}$ & Sidnei & $\mathrm{HPH}$ & 2012 & E-ASC & \\
\hline Brisbane Container Terminals & Brisbane & $\mathrm{HPH}$ & $2012 / 2014$ & E-ASC & ShC \\
\hline London Gateway & Londres & DP World & 2013 & E-ASC & ShC \\
\hline TraPac & Los Angeles & TraPac Inc. & 2013 & E-ASC & Auto ShC \\
\hline Global Terminal & New Jersey & $\begin{array}{c}\text { Global Container } \\
\text { Terminals }\end{array}$ & 2013 & E-ASC & ShC \\
\hline APMT Maasvlakt II & Roterdã & APMT & 2014 & E-ASC & AGV \\
\hline Rotterdam World Gateway & Roterdã & $\begin{array}{l}\text { DP World/ New World } \\
\text { Alliance / CMA CGM }\end{array}$ & 2014 & E-ASC & AGV \\
\hline Vado Ligure & Vado & APMT & 2016 & E-ASC & TT + Chassis \\
\hline $\begin{array}{l}\text { Kaohsiunng Intercontinental } \\
\text { Terminal (KIT) }\end{array}$ & Kaohsiung & $\begin{array}{c}\text { Kao Ming Container } \\
\text { Terminal Co. (Evergreen) }\end{array}$ & & E-ASC & TT + Chassis \\
\hline DP World Brisbane & Brisbane & DP World & & E-ASC & ShC \\
\hline
\end{tabular}

Fonte: PEMA. Legenda: E-ASC $=$ End-loaded automated stacking crane; C-ASC $=$ Side loaded (Cantilever) automated stacking crane; OHBC $=$ Overhead Bridge Crane; SC - Straddle Carrier; ShC = Shuttle Carrier (Transport Stradlle Carrier) ; TT + Chassis $=$ Terminal Tractor (Caminhão) + Chassis 
Figura 142- TerCat ou BEST (Barcelona Europe South Terminal)

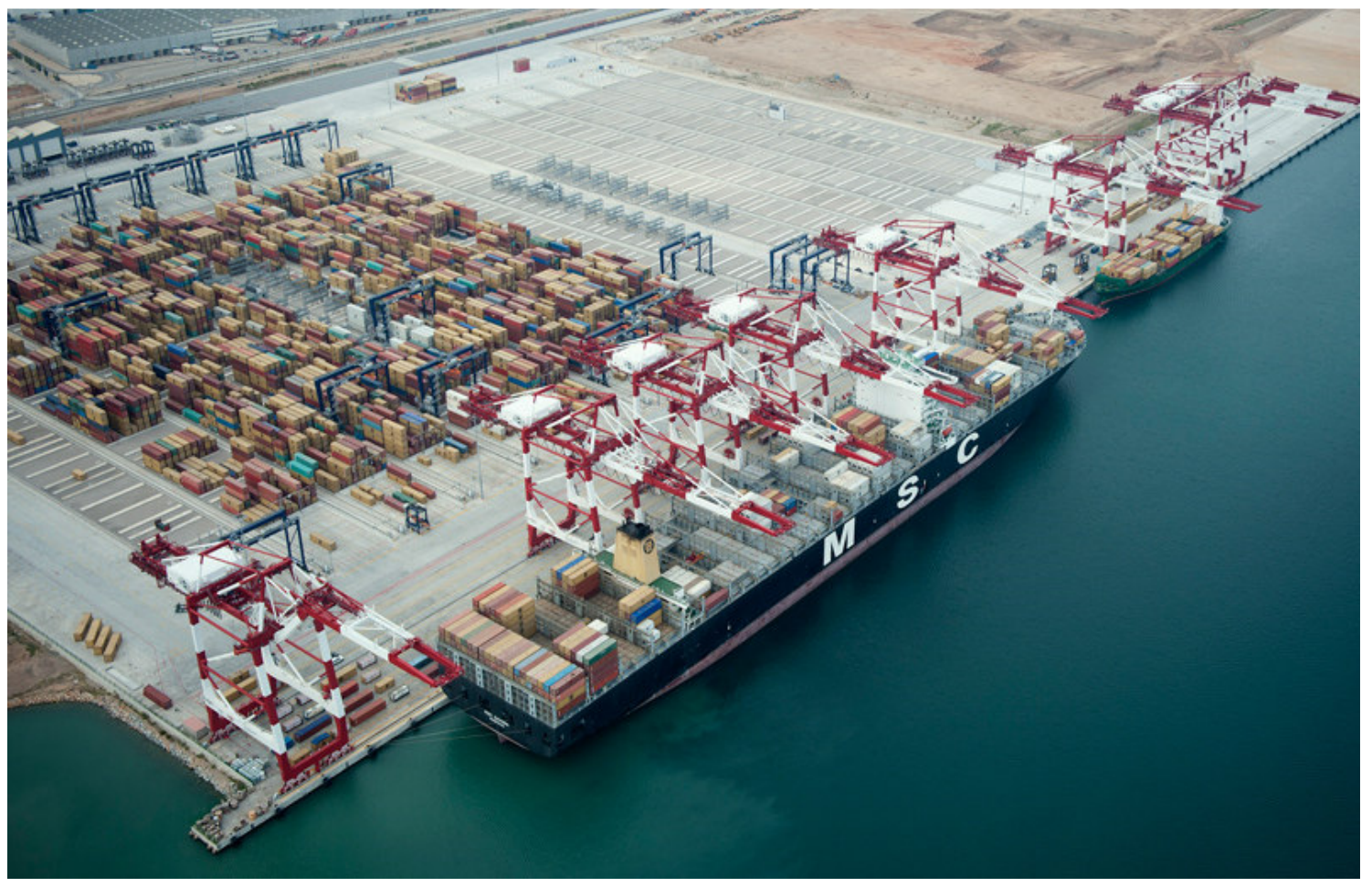

Fonte: Porto de Barcelona

Figura 143 - Rotterdam World Gateway

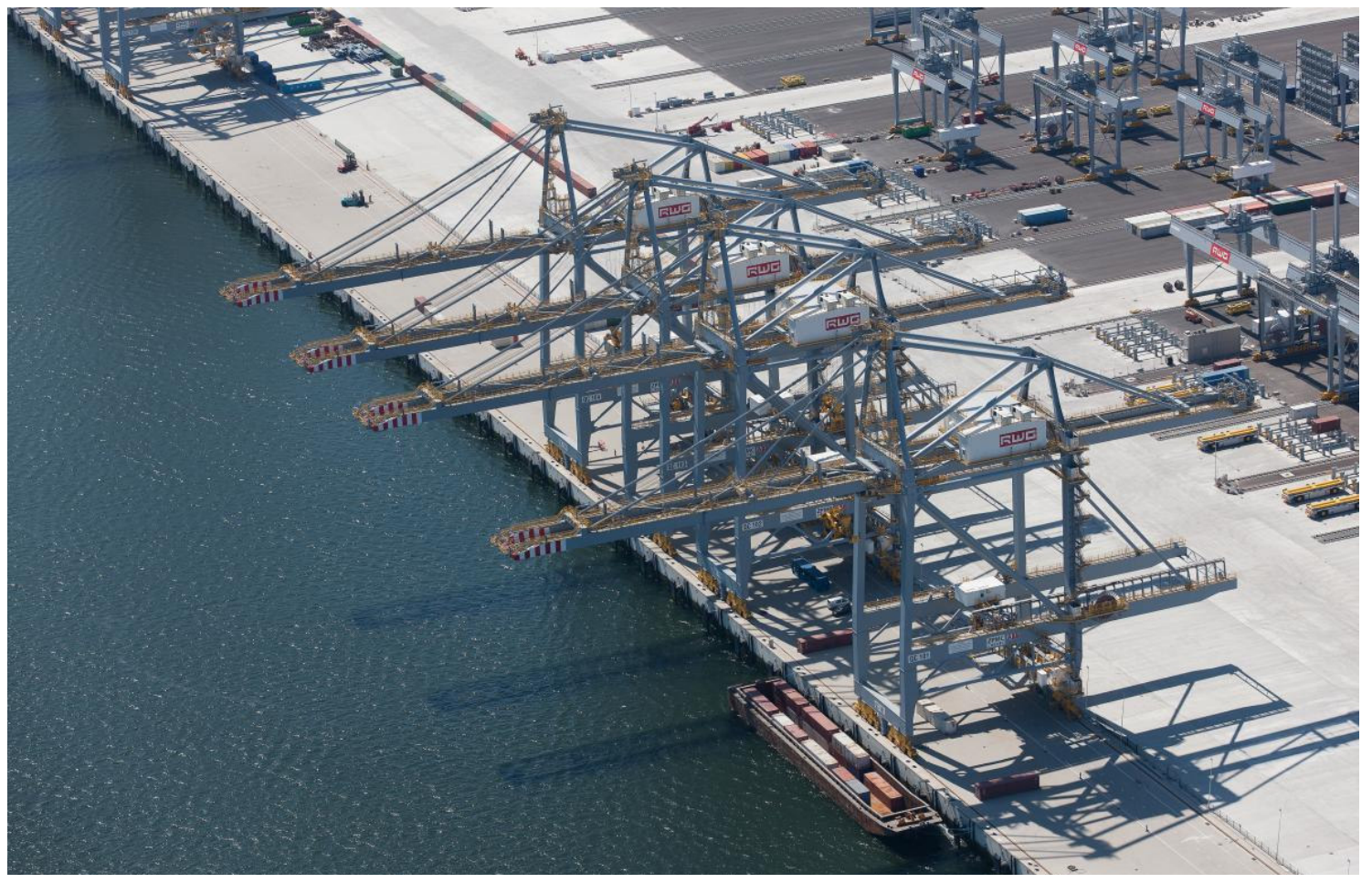

Fonte: nwg.nl 
Interessante notar que dos 33 terminais listados na Tabela 17, apenas 8 são considerados totalmente automatizados, ou seja, aproximadamente $25 \%$ apenas; os demais $75 \%$ são semiautomatizados; o que corrobora com a afirmação de Koegeboehn (2014) que após a comprovação da automação completa, a maioria das implementações recentes de terminais e projetos futuros curiosamente caminharam para semiautomação.

Verificando a comparação de produtividade da tabela 18 de Davidson (2011) entre terminais automatizados com grandes terminais e todos os terminais, observase que os terminais automatizados desempenham melhor que a média mundial, contudo não melhor do que os grandes terminais.

Tabela 18 - Benchmarking de desempenho entre terminais automatizados e convencionais

\begin{tabular}{l|ccc}
\hline \multirow{1}{*}{ Indicadores } & \multicolumn{3}{|c}{ Terminais } \\
\cline { 2 - 4 } & Automatizados & Grandes & Média (Todos) \\
TEU por metro de cais & 1.184 & 1.344 & 846 \\
TEU por portêiner & 114.833 & 131.457 & 103.224 \\
TEU por hectare & 22.799 & 30.171 & 21.004 \\
\hline
\end{tabular}

Fonte: Drewry (2009)

Comparando os números dos terminais automatizados com os dos grandes terminais, observa-se que o indicador de TEU por hectare é $24 \%$ menor; enquanto os outros dois indicadores, TEU por metro de cais e TEU por portêiner, estão na faixa de $12 \%$ a $13 \%$ abaixo respectivamente. Outro indicador interessante está relacionado ao volume movimentado pelos terminais, conforme a Tabela 19.

Tabela 19 - Quantidade de Terminais versus o tamanho do terminal

\begin{tabular}{c|cccc}
\hline Volume em TEUs & \multicolumn{3}{|c}{ Número de Terminais } & \multicolumn{2}{c}{$\%$} \\
\cline { 2 - 5 }$<100.000$ TEUs & Total & Acumulado & Individual & Acumulado \\
$100.000-250.000$ & 594 & 594 & 48 & 48 \\
$250.000-500.000$ & 256 & 850 & 21 & 68 \\
$500.000-1.000 .000$ & 160 & 1010 & 13 & 81 \\
Acima de 1.000 .000 & 126 & 1136 & 10 & 97 \\
Total & 112 & 1248 & 9 & 100 \\
\hline
\end{tabular}

Fonte: Drewry (2009)

Richter (2009), baseado no conceito de que automação de terminais e toda movimentação de contêineres realizada por sistemas sem intervenção humana; 
afirma que não há terminais completamente automatizados na indústria e talvez nunca exista; embora todos os terminais possuam elementos de automação na sua movimentação e processos operacionais, tais como as atividades de gate ou de armazenamento. Bruggeling (2011) indica que melhorias normalmente não são provenientes da automação em si, mas do fluxo de materiais e informações dos processos.

\subsection{LITERATURA SOBRE AUTOMAÇÃO NA ÁREA PORTUÁRIA}

A categoria de problemas de planejamento tratados na literatura sobre portos e terminais de contêineres (Figura 144) é extensa, principalmente na literatura internacional.

Figura 144 - Categoria de problemas de planejamento

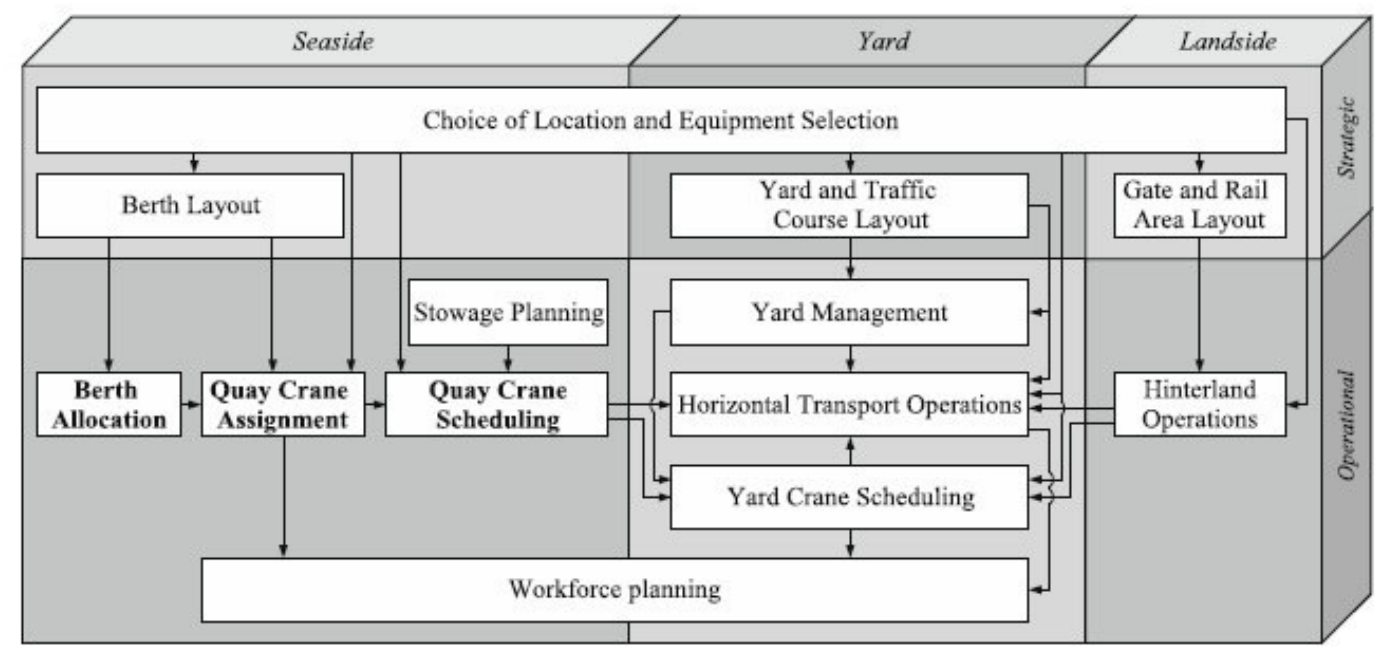

Nas Tabelas 15 e 16 no capitulo anterior foram apresentados referências bibliográficas dos Problemas de planejamento de berço, e de alocação e programação de berço; enquanto a Tabela 20 completa as referências citadas novamente por Dragović e Park (2011) para os seguintes problemas: programação de berços e guindastes/portêineres; simulação de terminais de contêineres e portos, conceitos e visão geral. 
Tabela 20 - Complemento do Quadro resumo da revisão de Literatura bibliográfica sobre planejamento e alocação de berços de atracação por Dragović e Park (2011)

\begin{tabular}{|c|c|c|}
\hline $\begin{array}{l}\text { Problemas } \\
\text { Considerados }\end{array}$ & Abordagem & Referências \\
\hline $\begin{array}{l}\text { Programação de } \\
\text { Berço e } \\
\text { Guindastes } \\
\text { (Portêineres) }\end{array}$ & $\begin{array}{l}\text { SM; } \\
\text { Programação Dinâmica, } \\
\text { Simulated Annealing (SA) }\end{array}$ & $\begin{array}{l}\text { Park e Kim (2003); } \\
\text { Dai et al (2004) }\end{array}$ \\
\hline $\begin{array}{l}\text { Programação de } \\
\text { Guindastes } \\
\text { (Portêineres) }\end{array}$ & $\begin{array}{l}\text { Método Heurística } \\
\text { Branch \& Bound (B\&B); } \\
\text { (B\&B); Simulated Annealing (SA); } \\
\text { Programação Dinamica; Tabu } \\
\text { Search; Squeaky wheel } \\
\text { B\&B ; GRASP }\end{array}$ & $\begin{array}{l}\text { Daganzo (1989); } \\
\text { Peterkofsky e Daganzo } \\
\text { (1990); } \\
\text { Zhum e Lim (2004); } \\
\text { Lim et al (2004); } \\
\text { Kim e Park (2004) }\end{array}$ \\
\hline $\begin{array}{l}\text { Simulação de } \\
\text { terminais de } \\
\text { contêineres e } \\
\text { portos }\end{array}$ & $\begin{array}{l}\text { Modsim III } \\
\text { Programação orientada a Objetos } \\
\text { (ORP), C++ } \\
\text { ARENA } \\
\text { ARENA, SLX } \\
\text { Visual SLAM } \\
\text { AweSim } \\
\text { Witness software } \\
\text { Taylor II } \\
\text { GPSS/H } \\
\text { Scenario generator } \\
\text { ORP, Java }\end{array}$ & $\begin{array}{l}\text { Gambradella et al (1998, } \\
\text { 2001); } \\
\text { Yun e Choi (1999); } \\
\text { Tahar e Hussain (2000); } \\
\text { Merkuryeva et al (2000); } \\
\text { Legato e Mazza (2001); } \\
\text { Nam et al (2002); Demirci } \\
\text { (2003); } \\
\text { Shabayek e Yeung } \\
\text { (2002); } \\
\text { Kia et al (2002); } \\
\text { Pachakis e Kiremidjian } \\
\text { (2003); } \\
\text { Hartmann (2004); } \\
\text { Bielli et al (2005). }\end{array}$ \\
\hline $\begin{array}{l}\text { Visão Geral de } \\
\text { Conceitos }\end{array}$ & $\begin{array}{l}\text { Modelos quantitativos para vários } \\
\text { problemas de decisão } \\
\text { Processos Logísticos e } \\
\text { operacionais em terminais de } \\
\text { contêineres - Métodos de } \\
\text { otimização } \\
\text { Pesquisa Operacional em } \\
\text { terminais de contêineres: uma } \\
\text { atualização da literatura } \\
\text { Terminais de contêineres e } \\
\text { operação de terminais } \\
\text { Modelos e métodos para } \\
\text { operações em terminais de } \\
\text { contêineres }\end{array}$ & $\begin{array}{l}\text { Vis e Koster (2003); } \\
\text { Steenken et al (2004); }\end{array}$ \\
\hline
\end{tabular}

Fonte: Dragović e Park (2011) 
Hennesey (2004) apresenta na Tabela 21 os diversos problemas de terminais e suas referências bibliográficas classificadas por meio de níveis estratégico, tático e operacional.

Tabela 21 - Complemento do Quadro resumo da revisão de Literatura bibliográfica sobre planejamento e alocação de berços de atracação por Dragović e Park (2011)

\begin{tabular}{|c|c|c|c|}
\hline \multirow[t]{2}{*}{ Problemas } & \multicolumn{2}{|l|}{ Controle } & Planejamento \\
\hline & Operacional & Tático & Estratégico \\
\hline $\begin{array}{c}\text { Berços e } \\
\text { Portêineres }\end{array}$ & $\begin{array}{l}\text { (Avriel et al. 1998) } \\
\text { (Böse 2000) } \\
\text { (Hensey et al. 2003a) } \\
\text { (Ling and Wen-Jing } \\
\text { 1999) } \\
\text { (Steenken 2001) } \\
\text { (Wilson and Roach } \\
\text { 2000) } \\
\text { (Wilson et al.2001) }\end{array}$ & $\begin{array}{l}\text { (Imai 2001) } \\
\text { (Imai et al.2002) } \\
\text { (Nishimura 2001) }\end{array}$ & $\begin{array}{l}\text { (Bockstael - Blok et al. } \\
\text { 2002) } \\
\text { (Bruzzone 1999) } \\
\text { (Carpenter and Ward 1990) } \\
\text { (Duinkerken 2000) } \\
\text { (Duinkerken 2001) } \\
\text { (Duinkerken et al. 2000) } \\
\text { (Gambardella et al. 1998) } \\
\text { (Gambardella et al. 2000) } \\
\text { (Gibson et al. 1992) } \\
\text { (Hartmann 2002) } \\
\text { (Henesey et al. 2003) } \\
\text { (Henesey 2004) } \\
\text { (Holguín - Veras and } \\
\text { Watson 1996) } \\
\text { (Imai et al. 2002) } \\
\text { (Kao 1996) } \\
\text { (Kia 2002) } \\
\text { (Koh et al.1994) } \\
\text { (Leathrum 1997) } \\
\text { (Leathrum 2000) } \\
\text { (Leathrum and Frith 2000) } \\
\text { (Lee et al. 2002) } \\
\text { (Legato 2001) } \\
\text { (Lim 1998) } \\
\text { (Mastrolilli 1998) } \\
\text { (Nevins 1995) } \\
\text { (Nevins 1998) } \\
\text { (Nishimura 2001) } \\
\text { (Ryan 1998) } \\
\text { (Tahar 2000) } \\
\text { (Thurston and Hu 2002) } \\
\text { (Tongzon 1995) } \\
\text { (Yun and Choi 1999) } \\
\text { (Zaffalon 1998) }\end{array}$ \\
\hline $\begin{array}{c}\text { Transferência } \\
\text { Cais - Pátio }\end{array}$ & $\begin{array}{l}\text { (Hensey et al 2003a) } \\
\text { (Zhang 2001) }\end{array}$ & $\begin{array}{l}\text { (Gambardella et } \\
\text { al.1996) } \\
\text { (Kim 2000) } \\
\text { (Kim and Park 2002) }\end{array}$ & $\begin{array}{l}\text { (Bockstael-Blok et al.2002) } \\
\text { (Bruzzone 1999) } \\
\text { (Carpenter and Ward 1990) } \\
\text { (Duinkerken 2000) } \\
\text { (Duinkerken 2001) } \\
\text { (Duinkerken et al. 2002) } \\
\text { (Gambardella et al.2000) } \\
\text { (Gibson et al.1992) }\end{array}$ \\
\hline
\end{tabular}




\begin{tabular}{|c|c|c|c|}
\hline & & & $\begin{array}{l}\text { (Hartmann 2002) } \\
\text { (Henesey et al. 2003b) } \\
\text { (Holguín-Veras and Watson } \\
\text { 1996) } \\
\text { (Kia 2002) } \\
\text { (Khoshnevis and Asef- } \\
\text { Vaziri 2000) } \\
\text { (Kozan 2000) } \\
\text { (Leathrum 1997) } \\
\text { (Leathrum 2000) } \\
\text { (Leathrum and Frith 2000) } \\
\text { (Lee et al. 2002) } \\
\text { (Mastrolilli M. 1998) } \\
\text { (Nevins 1995) } \\
\text { (Nevins 1998) } \\
\text { (Ryan 1998) } \\
\text { (Tahar 2000) }\end{array}$ \\
\hline Armazenagem & $\begin{array}{l}\text { (Bish 2003) } \\
\text { (Carrascosa et } \\
\text { al.2001) } \\
\text { (Hensey et al. 2003a) } \\
\text { (Kozan 2000) } \\
\text { (Rebollo et al. 2000) } \\
\text { (Rebollo et al. 2001) } \\
\text { (Zhang 2001) } \\
\text { (Zhang 2002) }\end{array}$ & $\begin{array}{l}\text { (Gambardella et al. } \\
\text { 1996) } \\
\text { (Gambardella 2001) } \\
\text { (Kim and Bae 1998) } \\
\text { (Kim and Hong } \\
\text { 1998) } \\
\text { (Kim et al. 2000) } \\
\text { (Kim and Kim 2002) } \\
\text { (Kim and Park 2002) }\end{array}$ & $\begin{array}{l}\text { (Bockstael-Blok et al. 2002) } \\
\text { (Bruzzone 1999) } \\
\text { (Carpenter and Ward 1990) } \\
\text { (Gambardella et al.2000) } \\
\text { (Gambardella 2001) } \\
\text { (Gibson et al. 1992) } \\
\text { (Hartmann 2002) } \\
\text { (Henesey 2003b) } \\
\text { (Holguín-Veras and Watson } \\
\text { 1996) } \\
\text { (Kim and Kim 2002) } \\
\text { (Kim and Park 2002) } \\
\text { (Khoshnevis and Asef Vaziri } \\
\text { 2000) } \\
\text { (Kia 2002) } \\
\text { (Preston and Kozan 2001) } \\
\text { (Kozan and Preston 1999) } \\
\text { (Leathrum 1997) } \\
\text { (Leathrum 2000) } \\
\text { (Leathrum and Frith 2000) } \\
\text { (Lee et al. 2002) } \\
\text { (Mastrolilli M. 1998) } \\
\text { (Nevins 1995) } \\
\text { (Nevins 1998) } \\
\text { (Ryan 1998) } \\
\text { (Shen and Khoong 1995) } \\
\text { (Tahar 2000) }\end{array}$ \\
\hline $\begin{array}{c}\text { Recebimento } \\
\text { e Entrega }\end{array}$ & (Hensey et al.2003a) & (Sideris et al. 2002) & $\begin{array}{l}\text { (Bockstael - Blok et al.2002) } \\
\text { (Bruzzone 1999) } \\
\text { (Carpenter and Ward 1990) } \\
\text { (Gambardella et al.2000) } \\
\text { (Gibson et al. 1992) } \\
\text { (Hartmann 2002) } \\
\text { (Henesey 2003b) } \\
\text { (Holguín- Veras and } \\
\text { Watson 1996) }\end{array}$ \\
\hline
\end{tabular}




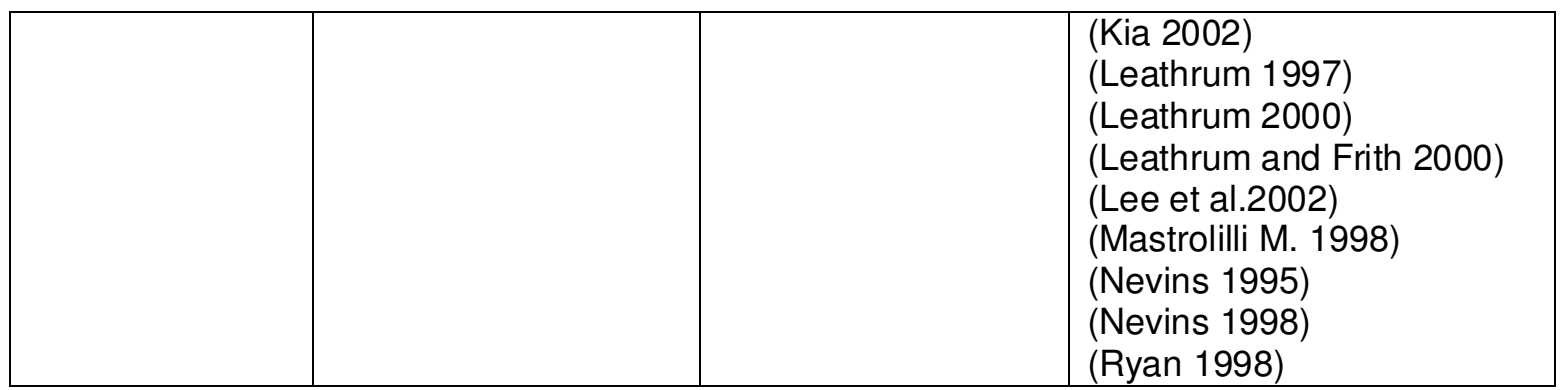

Fonte: Henesey (2004)

Contudo, há ainda diversos outros trabalhos sobre métodos de escolha de equipamentos e regras de armazenamento; análise de capacidade; alocação de espaço; programação de veículos; aplicações de 6 Sigma na gestão de processos; aplicações de tecnologia de informação; e, muito mais.

Porém, essa revisão bibliográfica, concentra-se nos trabalhos relacionados à automação de terminais de contêineres, os quais contêm os problemas de operações de transporte horizontais, em face do uso de AGVs e de problemas relacionados à gestão de pátio, dos seus equipamentos e tráfego; artigos alusivos à automação de portêineres entre outros.

\subsubsection{LITERATURA NACIONAL}

Iniciando pela literatura nacional, são numerosos os trabalhos que tratam de assunto e problemas relacionados a contêineres, tais como estudos de capacidade e simulação de dimensionamento de terminais, avaliação de viabilidade econômica, análises de regras de atracação e escolha de equipamentos, otimização de seleção e alocação de cargas, entre outros. Assim como é extensa a produção de trabalhos sobre automação nas diversas áreas da indústria; porém quando associamos as palavras: portos ou terminais de contêineres com automação, o número de publicações é limitada.

Encontram-se alguns trabalhos sobre a arquitetura de sistemas de gestão portuária, distribuição automática das informações e consequentemente a otimização de alguns processos tratados nas trocas de mensagens EDI, conforme Kurosawa (2004) ou como Vianna (2009), que trata de um modelo de gestão e automação de portos brasileiros, além de temas relacionados, também, à troca eletrônica de dados, tais como a Supervia Eletrônica de Dados (SED) e processos 
mapeados do Sistema Integrado de Gestão Portuário, denominado Portal SISPORTOS, cuja principal proposta é ser uma janela única de informações entre os participantes da indústria portuária.

Torres (2008) apresenta um modelo analítico e operacional da Supervia Eletrônica de Dados (SED) que busca integrar os intervenientes nas operações e que consiste na automação do recebimento e tratamento das informações dos documentos como a Requisição de Atracação e Prioridades (RAP), do manifesto de carga e dos boletins de carga e descarga. Cabe destacar que todas essas mensagens são flat files, não seguem nenhum padrão internacional de mensagens EDI.

Pires (2011) na sua dissertação de mestrado trata sobre metodologias de automação integradas ao Centro de Controle, Comunicação, Operações e Segurança (CCOS) para o sistema de segurança portuário utilizando o porto de Santos como estudo de caso de integração dos diversos dispositivos existentes e regras do código ISPS. Ainda na área de automação de segurança, Russo (2006) trata de um modelo, denominado de Plano de Segurança Aduaneira Portuária (PSAP), que consiste na automação de todos os processos e controles da atividade portuária, com utilização de alta tecnologia para a fiscalização da aduana, mediante inspeção não intrusiva de contêineres (uso de escâneres), sua lacração e rastreamento na zona portuária; objetivando disparar uma ação fiscal específica baseada na determinação do risco potencial da carga.

Foco similar é dado por Zancul (2006) por meio da integração de sistemas de controle de carga em ambiente portuário, utilizando os dados de movimentação física da carga, integrados aos sistemas envolvidos na fiscalização juntamente com os dados do manifesto, permitindo antecipar a fiscalização da carga para antes da descarga e por Fontana (2010) que discorre sobre a formulação de um modelo de automação de processo aplicado à cadeia logística segura em consonância com os diversos programas de segurança existentes, tais como: Código Internacional de Segurança e Proteção a Navios e Instalações Portuárias (ISPS Code) da IMO, SafeFramework of Standards da OMA, Container Security Initiative (CSI) e do Safe Ports Act ambos do governo americano e Plano Nacional de Segurança Aduaneira (PNSA) da Secretária da Receita Federal; além da normatização da ISO 28.000 para os sistemas de gestão de segurança da cadeia de suprimento. 
Sortino (2013) argumenta sobre a importância da automação de portos, isto é, a informatização de atividades, combinadas com automação de processos e equipamentos, como estratégia para a agilização e aumento das transações do comércio internacional brasileiro e apresenta alguns resultados de redução experimentada no número de dias no processamento de exportações e importações, bem como no número de documentos utilizados em portos pesquisados que recentemente embarcaram alguma automação, como a Coreia do Sul, Cingapura e Sri Lanka.

A adoção da automação nas atividades portuárias depende de fatores econômicos e políticos, como o volume de investimentos, custo e a escolha do momento da substituição da mão de obra. Indica que essa questão da mão de obra é de difícil solução e observa um círculo vicioso de investimentos e velocidade moderados, em nome da manutenção de 70.000 mil empregos diretos nos portos, defendidos pelos sindicatos e entidades públicas, afirma Sortino (2013).

A Figura 145 mostra a invasão do terminal da Embraport e navios atracados pelos estivadores, em protesto contra a nova lei dos portos (Lei 12.815/13) que muda as relações de trabalho entre os TPAs e os terminais privados, que podem contratar pela CLT, sem interferência ou uso do Órgão Gestor de Mão de Obra (OGMO).

Figura 145 - Invasão do navio pela estiva

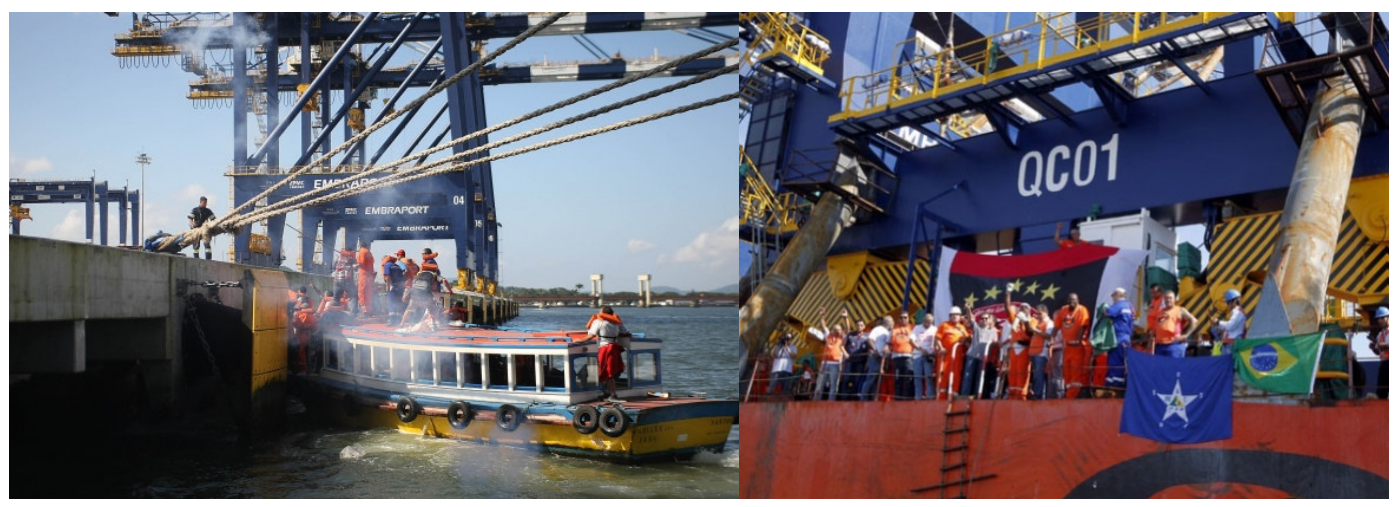

Fonte: Jornal Estado de São Paulo

Hardt et al (2003) utilizam a modelagem Empírica (ME) em três modelos: um modelo de supermercado automatizado, em terminal de contêineres automatizado, e um sistema de controle. Essa técnica é chamada de empírica porque os seus princípios de modelagem são baseados em observação e experimentação e pode-se 
definir como uma técnica para modelagem, simulação de sistemas em geral que se baseia na representação de estados pelo computador. No artigo, o modelo do supermercado automatizado (SMA) que utiliza Carrinho Autônomo (CA) foi adaptado no programa para terminais de contêineres automatizados (TCA) que trabalham com Veículos Autônomos (VA), conceito dos AGV, num alto nível de abstração.

Portanto, há um número restrito de publicações sobre um assunto tão abrangente de aplicações em terminais e na área portuária. Provavelmente a ausência de literatura ocorra pelo fato de os terminais brasileiros serem convencionais ou não automatizados; porém com elementos de automação começando a surgir.

\subsubsection{LITERATURA INTERNACIONAL}

Iniciando a revisão de Literatura internacional pelo trabalho de Saanen (2004), na sua tese de doutorado apresenta uma abordagem para o projeto de um terminal automatizado; essa abordagem consiste primeiramente na definição das características do terminal de contêineres, isto é:

- Verificação dos requisitos conflitantes, tais como: produtividade, redução de custos e maximização do uso do espaço, ou aspectos ambientais,

- Influência de eventos externos e circunstancias como a chegada de navios, caminhões e trens/vagões,

- Informações dos processos externos pobres; casos onde informações apresentam erros, fora de tempo ou em cima da hora, por exemplo: corte ou acréscimo de carga com o navio em operação,

- Vários pontos de interação entre o sistema e mundo externo,

- Processos com grandes variações de tempo; o mesmo Saanen e De Waal (2001) indicam a variação de um ciclo de embarque ou descarga de contêineres entre 40 segundos até 5 minutos, conforme figura 146, 
Figura 146 - Ciclo de tempo típico de portêineres

Average productivity $=40$ cycles per hour

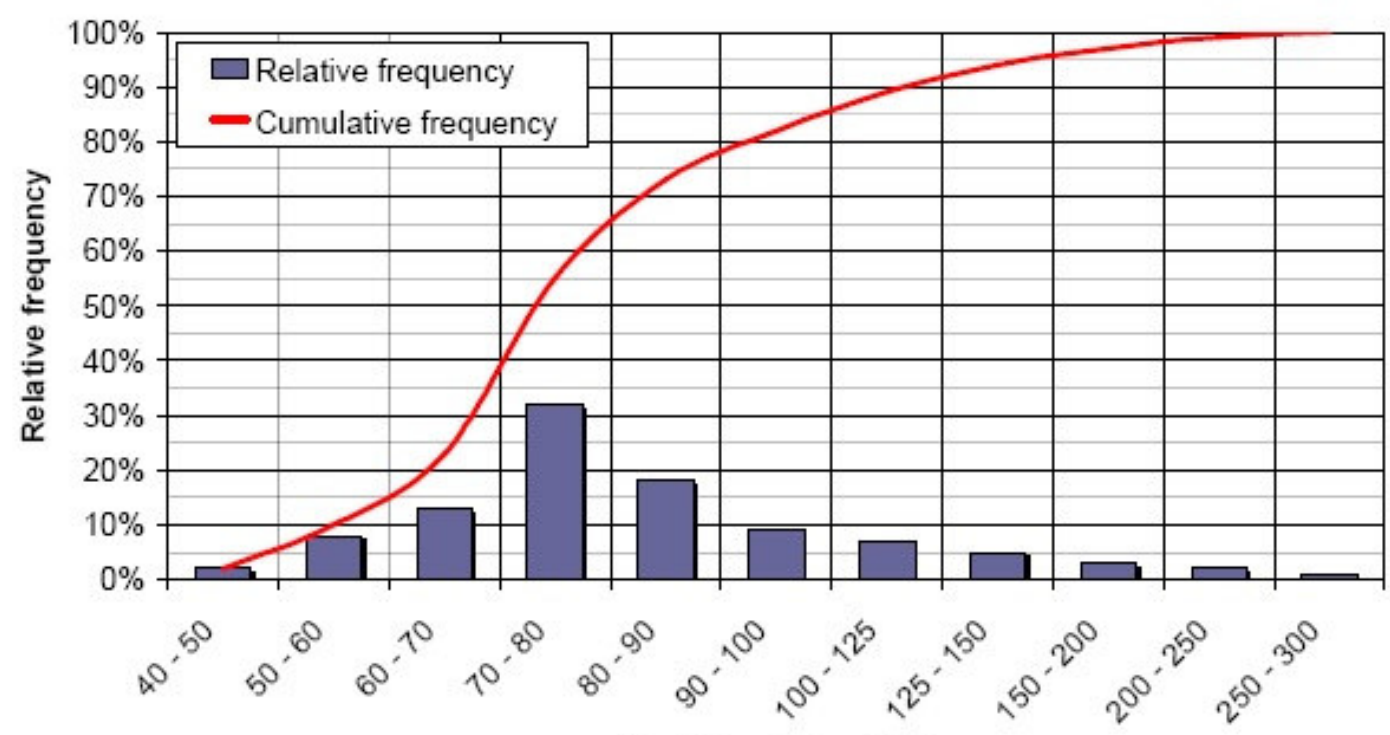

Cycletime interval (s)

Fonte: Saanen e De Wall (2001)

- Processos Interligados; os principais processos de um terminal de contêineres (transporte, transbordo, armazenagem, inspeções da alfandega, etc.) estão interligados em tempo, sequência, compartilhamento de recursos ou são entrada e saída uns do outros,

- Interações não lineares entre os processos; conforme indicado anteriormente a saída de um processo afeta outro processo, e dependendo da variação pode resultar em desperdícios (exemplo: tempo de espera, o que faz com o setor de operações adicionem mais equipamentos do que necessário, para cobrir efeitos de perda). A figura 147 representa esse efeito. Nota-se que o resultado para 16 ou 18 ASC (Guindastes de pátio) a partir de 20 AGV (Transporte horizontal) é o mesmo,

- Planejamento e Coordenação dos processos do terminal. 
Figura 147- Curvas de Produtividade para vários equipamentos de pátio (ASC) e transportes horizontais (AGV)

Berth productivity dependent on transport/stack equipment quay length $=400 \mathrm{~m}, 9$ stacks, berth contains 4 quay cranes

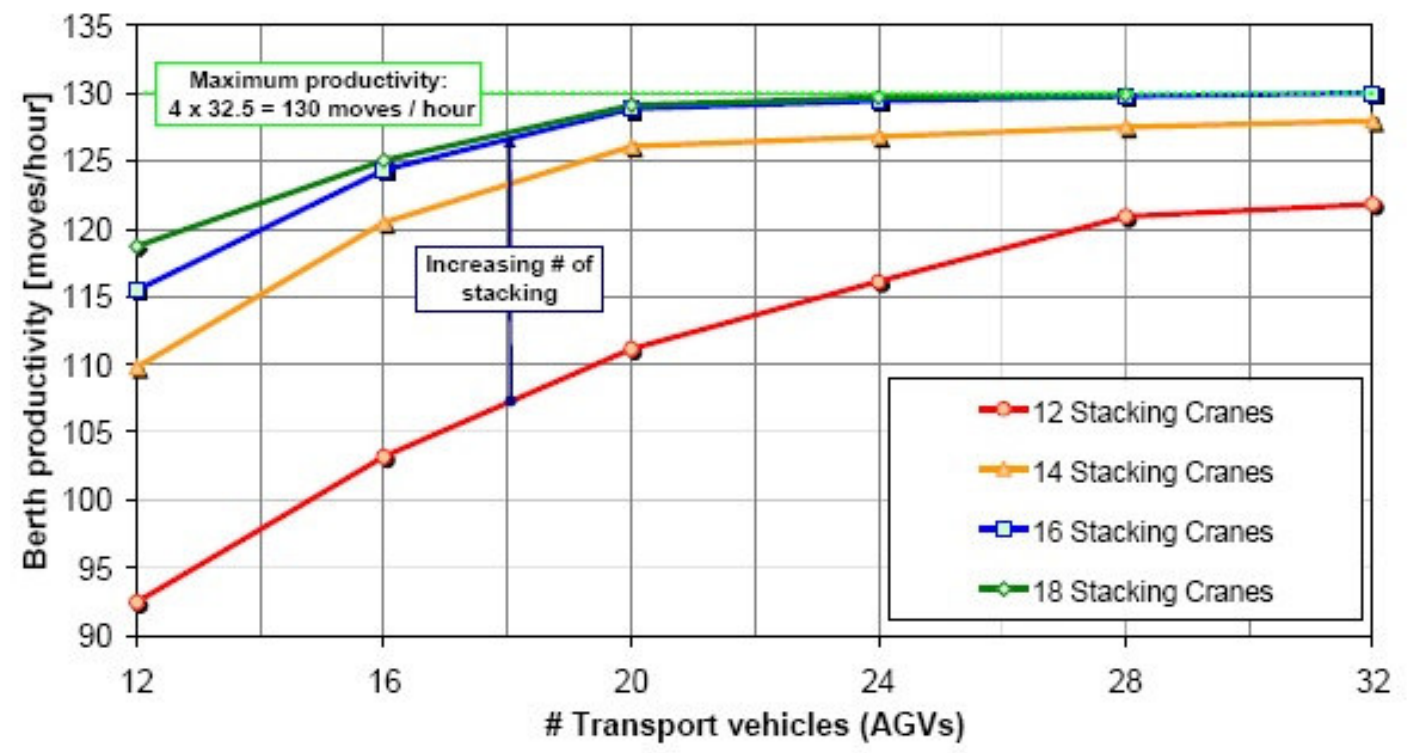

Fonte: Saanen apud Dobner et al, 2001 (estudos da Gottwald para o porto de Felixstowe)

Quanto ao Framework proposto por Saanen (2004) para projeto de terminais automatizados é formado pela seguinte estrutura:

- Projeto Funcional,

- Projeto Técnico,

- Implantação e realização, e,

- Comissionamento e operações.

Onde o projeto funcional busca responder as questões de Porque (Why) e O que (What) em alto nível, visão holística, sem entrar em detalhes do Como (How), que fica a carga da fase Técnica do projeto e de seu detalhamento, como por exemplo: fluxo logístico detalhado, tipo de equipamento de movimentação, algoritmos de expedição dos veículos, e muitos outros. A fase de implantação é caracterizada pelo desenvolvimento e construção; enquanto, os testes e avaliações na fase de comissionamento.

Liu; Jula e loannou (2002) avaliaram através de simulação, quatro conceitos de terminais automatizados de contêineres fundamentados em:

- AGV (Automated Guided Vehicle) (ver figuras 54, 55,56 e 57), 
- LMCS (Linear Motor Conveyance System) ou LMTT (Linear Motor based Transfer Technology) (figura 67),

- GR (Overhead Grid Rail System) ou OHBC (Overhead Bridge Crane), (figura 83),

- AS/RS (High-Rise Automated Storage amd Retrieval Structure), (figura 86).

Para um terminal-tipo servido por navios de 8.000 TEUs, com taxa de ocupação de 85\%, período de operação de 16 horas, onde a cada 24 horas chega um navio; distribuição da carga de 60\% rodoviária e 40\% via ferroviária, com 6 dias de abertura de gates e padrão de chegada de $80 \%$ da carga nos últimos 3 dias; e o terminal recebe 6.120 TEUS por dia de exportação e 9.520 TEUs de importação, o que exige uma capacidade diária de 15.640 TEUs. O terminal possui 5 berços e produtividade de 42 movimentos/hora por portêiner e 6 gates de entrada e 4 de saídas baseado no modelo de filas de $M(\lambda) / M(\mu) / n$; onde $\lambda$ a taxa de chegada, $\mu$ é a taxa de serviço e $n$ é o numero de gates. O resultado da simulação na Tabela 22 demonstra que o desempenho dos sistemas é quase idêntico para a maioria das medições, exceção da produtividade por acre, pelo fato do sistema AS/RS utiliza área menor dos que os sistemas, e a diferença significante entre os sistemas encontram-se na média dos custos por container.

Tabela 22 - Resultado de Custos e Desempenho para 04 diferentes

\begin{tabular}{l|cccc}
\hline \multicolumn{1}{c|}{ Conceitos } & AGV & LCMS & $\begin{array}{c}\text { GR ou } \\
\text { OHBC }\end{array}$ & AS $/ \boldsymbol{R S}$ \\
\hline Tempo de operação (h) & 16,81 & 16,83 & 16,47 & 16,24 \\
Produtividade & 40,45 & 40,40 & 41,68 & 41,7 \\
Produtividade por acre & 0,579 & 0,575 & 0,652 & 0,767 \\
\% de utilização de gate & 65,7 & 66,03 & 65,7 & 66,4 \\
Tempo de ciclo dos caminhões & 127 & 127 & 120 & 110,7 \\
(em segundos) & & & & \\
\% de Tempo ocioso dos AGVs & 36,3 & 36,2 & 31,8 & 30,9 \\
\% Tempo ocioso dos portêineres & 31,7 & 31,8 & 31,8 & 32,3 \\
Dwell Time (horas) & 19,1 & 19,1 & 19 & 18,9 \\
Custo médio por container (US\$) & 77,3 & 147,4 & 90,1 & 102,2 \\
\hline
\end{tabular}

Fonte: Liu; Jula e loannou (2002) 
Saanen; Meel; Verbraeck (2003) realizam uma comparação entre três sistemas de movimentação:

- Automated Guide Vehicle (AGV),

- Automated Lifting Vehicle (ALV), e,

- Straddle Carriers (SC) tripulada.

Para um terminal hipotético de capacidade de movimentação de 2,4 milhões de TEUs, com $10 \%$ de transbordos (transhipment) e alta movimentação de contêineres através de ferrovia. Consistiu em três partes a analise, a primeira parte é o resultado da comparação de produtividade através de simulação dinâmica, a segunda parte apresenta os custos das três alternativas de movimentação, e, finalmente, a terceira parte combina a produtividade e custos resultantes com outros aspectos em uma analise multicritério (Multi-criteria analysis).

Como resultado, os AGVs mostraram-se os mais baratos por movimento, seguidos pelos ALVs, com as ressalvas sobre o valor do equipamento no mercado, da complexidade de automação e dos custos do componente spreader; e terceiro, a SC com operador era a operação mais cara, em virtude dos custos de manutenção e mão de obra.

Saanen (2005) realiza outra comparação entre três conceitos de sistemas automatizados de armazenamento (ver figura 148) através de simulação, esses conceitos são:

- Single RMG (Rail Mounted Gantry) de 6 lastros x 4 alturas, alcance de 40 TEUs de distância (modelo ECT);

- Twin RMG de 10 lastros x 4 alturas, alcance de 40 TEUs de distância (modelo Euromax);

- Cross-over RMG (ver Figura 80) de 10 lastros x 4 alturas, alcance de 40 TEUs de distância (modelo CTA). 
Figura 148 - Três conceitos de sistemas automatizados de armazenamento

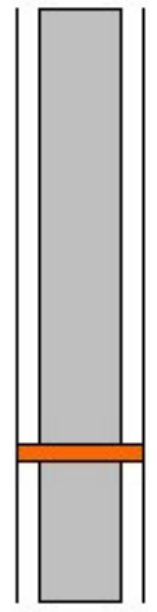

Single RMG

6 wide

4 high

40 TEU long

(ECT)

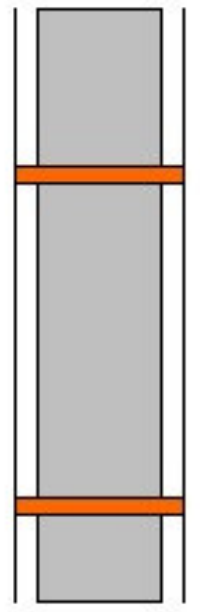

Twin RMG 10 wide 4 high 40 TEU long (Euromax)

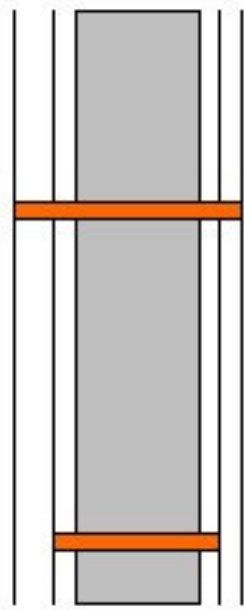

Cross-over RMG

10 wide

4 high

40 TEU long

(CTA)

Fonte: Saanen (2005)

A analise dos três conceitos respeitou os seguintes critérios: Produtividade do navio (waterside) e da recepção/expedição de caminhões/vagões (landside), capacidade (armazenamento e movimentação), custos (CAPEX e OPEX) e riscos (Complexidade e Flexibilidade); e o terminal-tipo possuía um berço único de 350 metros, área de armazenagem de largura de 300 metros e profundidade de 500 metros, alocação de quatro portêineres, com produtividade de 40 movimentos/hora, transporte horizontal feitos por AGV e gates com operações de 80 contêineres/hora.

O resultado da simulação conclui que há diferenças significativas de capacidade entre os três sistemas; o Single RMG suportou 1.500 TEUs/ metro de cais, o Cross-over 1.900 TEUs/metro de cais, enquanto o Twin-RMG elevou esse número para 2.200 TEUs/metro de cais. Foram identificados dois gargalos: a capacidade de movimentação do Single RMG e a capacidade de armazenagem do Twin RMG, o nível de serviço do Single RMG é inferior a dos outros dois sistemas, tanto nas operações de navio, quanto nas operações de caminhões/vagões, o nível de serviço do Cross-RMG se mostrou ligeiramente superior ao do Twin, em contrapartida os custos do Twin RMG são 10\% inferior. 
Vis e Carlo (2010) preocupados com a programação (Scheduling) de entrega e recebimento da movimentação contêineres dos navios e dos gates nas pilhas, que trabalham com dois Automated Stacking Cranes (ASC), apresentaram um modelo matemático utilizando Simulated-Annealing para minimizar o cruzamento (makespan) entre esses dois equipamentos.

Pirhonen (2011) realiza uma comparação entre equipamentos manuais e automatizados indicando o número necessário de operadores para cada sistema, baseado em um terminal-tipo teórico, com 6 portêineres com produtividade média de 30 contêineres por hora, sem a inclusão dos movimentos de vagões e movimentação de contêineres vazios. O número de operadores é baseado em um total de cinco operadores para cada veiculo manual / tripulado, pois se considera três turnos por dia e as questões de absenteísmo, doença, férias, etc. A tabela 23 apresenta a comparação.

Tabela 23 - Resultado de Custos e Desempenho para 04 diferentes

\begin{tabular}{lc|ccc}
\hline Composição de Equipamentos & Por porteiner & $\begin{array}{c}\text { Total para } \mathbf{6} \\
\text { ternos }\end{array}$ & $\begin{array}{c}\text { Número de } \\
\text { operadores }\end{array}$ \\
\hline RTG manual & 3 & 18 & 90 \\
Terminal Tractor & 5 & 30 & 150 \\
& & & & $\mathbf{2 4 0}$ \\
ASC & 5 & 30 & 20 \\
Automated Shuttle Carrier ${ }^{8}$ & 2 & 12 & 0 \\
& Total & & & $\mathbf{2 0}$ \\
\hline
\end{tabular}

Fonte: Piehonen (2011)

Pirhonen (2011) realiza a mesma comparação com Eco RTG, mas não há nenhuma diferença com os RTG convencionais em termos de número de operadores, a diferença está nas emissões de GEE; alias, na analise de emissões o Automated Shuttle Carrier $\AA$ mostrou-se melhor desempenho que o Eco-RTG. Na tabela 22, destaca-se o número de equipamentos por portêiner e o número de operadores para os Automatic Stacking Cranes (ASC); contudo o autor explica que a indicação de cinco equipamentos é para garantir uma operação mais tranquila, e há a necessidade de um operador para cada quatro ASC para atendimento remoto do carregamento e descarregamento de caminhões de rua. 
Ranau (2011) compara dois diferentes sistemas de operação automatizado verificando os requisitos de área/espaço necessário, são eles: AGV e Automated Straddle Carrier (utilizado no Terminal de Fishermans Island in Brisbane), ambos combinados com Automated Stacking Cranes (ASC).

Liu e loannou (2002) realizam uma comparação entre quatro diferentes regras na expedição ou envio de AGVs em terminais automatizados; entende-se como expedição ou envio (dispatching) uma regra de decisão ou metodologia de seleção para um veiculo buscar ou entregar um contêiner; o resultado da simulação atribui como a melhor regra a de fila mínima no cais, como segunda opção à regra randômica, seguida da regra de menor distância e por ultimo a maior distância percorrida.

Hoshino e Ota (2008) apresentaram um modelo para projetos de sistema de transporte automatizado que considera a manutenção do que ele chamou de robôs, isto é, os AGV e os ASC ou ATC (Automated Transfer Crane). O modelo consistiu na entrada em manutenção do robô durante a operação, com base na sua confiabilidade, e da medida de desempenho de tempo médio entre falhas (MTBF), bem como no número de robôs. A metodologia empregada busca uma solução combinatória para uma determina demanda, e considera os custos de gestão do sistema e de penalidade.

Dando continuidade nos estudos anteriores Hoshino e Ota (2008) propuseram um sistema de controle de robôs (AGV e ASC/ATC) reativo com três modelos operacionais híbridos (1. estado normal de operação, 2.em manutenção preventiva, 3. em manutenção corretiva) considerando a confiabilidade dos robôs.

Hoshino et al (2007) avaliaram dois sistemas de transportes com AGVs, um chamado de sistema de transporte de AGV Vertical (Quadra no sistema End-loading ou perpendiculares ao cais), e, sistema de transporte de AGV Horizontal (Sideloading ou paralelas ao cais), conforme ilustra a Figura 149. Para isso, utilizaram os resultados de teoria de filas em rede (queuing network theory) e um simulador de transporte para projetar uma estratégia híbrida, e definir o número de equipamentos (AGVs) adequado para dois sistemas de transporte; os quais foram avaliados com base em critérios de eficácia de custos. Para este fim, os custos totais de construção dos sistemas são comparados, e demonstraram que o sistema de transporte de AGV Horizontal foi mais eficiente. 
Figura 149 - Sistema de transporte de AGV Vertical (a) e Horizontal (b)

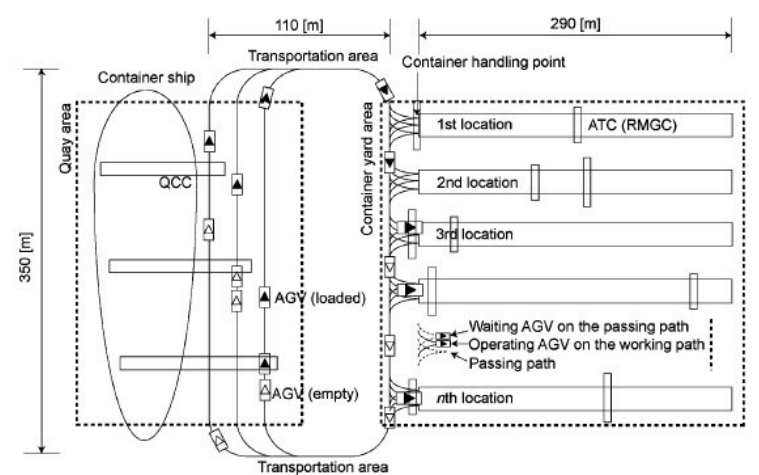

(a)

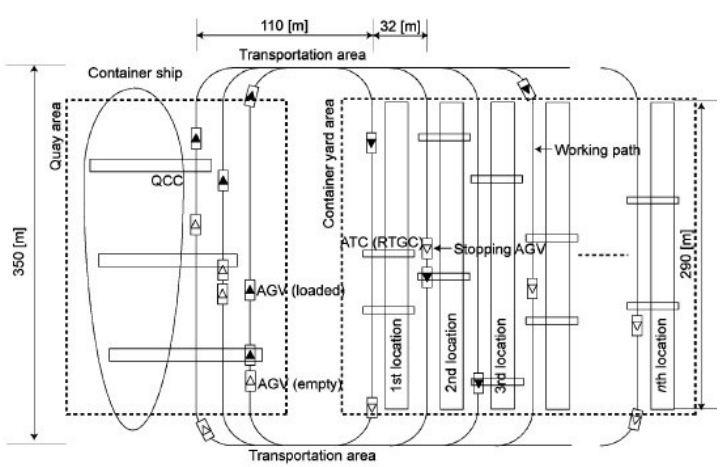

(b)

Fonte: Hoshino et al (2007)

Jula et al (2000) utilizaram o Simple Additive Weighting Method (SAWM) do método de Multiple Attribute Decision Making (MADM) para definir o número ótimo de transportadores (Shuttles) no pátio utilizando a tecnologia LMTT (ver figura 67) , assim como discutem as questões de conflitos e bloqueios (deadlocks) quando dois ou mais equipamentos solicitam o mesmo recurso.

Shinoda, Fukushi e Tachibana (2000) apresentaram uma simulação para avaliar a eficiência dos sistemas Quay Stack Transfer da ZPMC (ver figura 66) utilizando o modelo de rede Petri (Petri-net model).

Zhu et al (2010) compararam o mesmo sistema da ZPMC com sistemas convencionais através de simulação e verificaram durante a simulação que o sistema pode atingir até 102 TEUs/hora aproximadamente, contudo o sistema é sujeito a fatores e restrições como o tamanho do navio, plano de bordo, configuração caminhão/AGV e do TOS.

Ainda sobre o Quay Stack Transfer da ZPMC, Hu et al (2013) desmembraram o sistema em três partes: Ground Trolleys (GT), Transfer Plataforms (TP), Frame Trolley (FT); e analisaram o desempenho de um Transfer Plataforms (TP), o número de recursos e configuração do terminal através de modelo de Markov. O modelo demonstrou que com o aumento do desempenho dos TPs, ocorreu um aumento nas taxas de atraso dos outros subsistemas, o que obriga o balanceamento das taxas de chegada dos Frames e Ground Trolleys através da otimização da velocidade de translado e carga de trabalho. 


\subsubsection{CONCLUSÃO DA REVISÃO BIBLIOGRÁFICA}

A literatura nacional possui numerosos trabalhos que tratam de assuntos e problemas relacionados a portos e terminais nos seus diversos segmentos; contudo, pode-se afirmar que há uma enorme lacuna no tema automação em terminais de contêineres, há alguns trabalhos de informatização de sistemas de gestão portuária baseados na otimização dos processos ou na integração de sistemas de controle de carga via EDI.

A Literatura internacional possui autores expoentes como Saanen e Hoshino com vasta publicação e experiências de aplicações práticas de simulação em terminais, e uma produção diversificada de vários temas sobre automação, com prevalência para os complexos sistemas de transporte horizontal (AGV) e dos diversos sistemas de armazenagem automatizada, tais como: ASC, OHBC ou HSS; ou automações maiores.

No entanto, pouco foco tem sido dado ao beneficio da implantação de automações menores, ou no desenvolvimento de priorização e conversão de processos e terminais manuais ou convencionais para semiautomatizados ou automatizados. Em face desta constatação, o autor no capitulo seguinte, apresenta uma proposta de modelo de avaliação e decisão operacional de automação, assim como a metodologia utilizada, e um diagnostico ou uma fotografia atualizada da automação em oito importantes terminais de contêineres brasileiros. 


\section{METOdOLOGIA, DESCRIÇÂO DO MODELO E DIAGNÓSTICO DE AUTOMAÇÂO EM TERMINAIS DE CONTÊINERES NO BRASIL}

Neste capítulo será realizado um breve descritivo da metodologia aplicada, seguido da descrição do modelo de decisão de automação com suas premissas, lista de tecnologias testadas e a matriz de decisão e de segmentação. Ao termino do capitulo um diagnóstico da automação de alguns dos principais terminais de contêineres do país; em ordem alfabética será apresentado. Abaixo a lista de terminais selecionados: Brasil Terminal Portuário (BTP); Ecoporto; Embraport; Porto de Itapoá; Santos-Brasil; Tecon Salvador; Tecon Rio Grande; e, Terminal de Vila Velha (TVV). O questionário da pesquisa foi respondido por e-mail e estarão registrados no anexo.

\subsection{METODOLOGIA}

Essa pesquisa envolveu um caráter bastante pratico das atividades e problemas operacionais e estratégicos de terminais; o que está em linha com as definições de pesquisa segundo Demo (1996) e Minayo (1993). Para Demo pesquisa é uma atividade cotidiana considerada um questionamento ou dialogo permanente com a realidade em sentido teórico e pratico; enquanto Minayo (1993) define pesquisa com uma atividade de aproximação sucessiva da realidade que nunca se esgota, combinando teoria e dados.

Portanto, do ponto de vista da sua natureza, essa é uma pesquisa aplicada, que de acordo com Silva e Menezes (2001) tem o objetivo de gerar conhecimento para aplicação prática dirigida à solução de problemas específicos.

Observando o ponto de vista da forma de abordagem do problema, o mesmo possui viés de pesquisa qualitativa, quando analisa o processo e seus significados; todavia, possui também uma parcela de pesquisa quantitativa quando classifica e analisa informações através de uso de técnicas estatísticas, tais como: percentagem, média ponderada, etc.

Quanto aos objetivos, é uma pesquisa exploratória, pois visa proporcionar maior familiaridade com o problema com a finalidade de torna-lo explicito ou construir hipóteses, e envolve um levantamento bibliográfico e exemplos que 
estimulam o entendimento. Possui uma parcela de pesquisa descritiva, quando envolve o uso de técnica de coleta de dados através de questionário e forma de levantamento.

Finalmente, esse trabalho seguiu as etapas de planejamento e execução de pesquisa, a seguir:

- Escolha do tema

- Revisão da literatura nacional

- Revisão da literatura internacional

- Justificativa

- Formulação do problema

- Determinação dos objetivos

- Metodologia de realização da pesquisa

- Coleta de dados via questionário

- Tabulação de dados

- Analise dos resultados

- Conclusão dos resultados

- Sugestões para continuidade da pesquisa

Sobre a metodologia de realização da pesquisa, essa foi realizada através de questionário com perguntas fechadas com escolhas do tipo sim ou não para as aplicações de tecnologia ou dispositivo de automação, que estão tabulados na Tabela 28. Compõe ainda a metodologia a questão de observações: individual, não participante e na vida real.

\subsection{DESCRIÇÂO DO MODELO}

\subsubsection{CONTEXTO E TÉCNICAS DE AUXILIO Á TOMADA DE DECISÂO}

A partir da evolução das pesquisas sobre a tomada de decisão, Yu (2011) classifica os tipos de modelos: na Teoria Clássica (base da abordagem prescritiva) e no Modelo de racionalidade limitada (base da abordagem descritiva).

$\mathrm{Na}$ Teoria clássica os modelos possuem como principal característica as tomadas de decisões economicamente viáveis e em conformidade com os 
interesses das empresas, pressupondo problemas bem definidos e formatados, assim como objetivos conhecidos e acordados, com informações completas de forma a evitar incertezas e alcançar soluções ótimas. O Modelo da racionalidade se caracteriza pela incapacidade de tomada de decisão totalmente racional, são aqueles problemas cujos pressupostos são conflitantes, sem consenso entre as áreas da organização e possuem alternativas limitadas em função do tempo, e normalmente atingem soluções apenas satisfatórias. Ressalva-se que a moderna abordagem prescritiva, baseada na Teoria clássica, tem incorporado aspectos dos modelos da racionalidade limitada, devendo-se entender a palavra racionalidade como uma classe particular de procedimentos de tomada de decisão (preferências e consequências).

Em resumo, ainda conforme Yu (2011), quatro são as questões que devem ser respondidas, são elas:

1. Quais as alternativas viáveis?

2. Quais as consequências e probabilidades de ocorrências?

3. Qual o peso (ou valor) atribuídos às consequências relacionadas as alternativas?

4. Quais os critérios utilizados para a escolha?

No contexto de tomada de decisão, há de se destacar dificuldades adicionais relacionadas à complexidade da decisão e ao grau de risco e incerteza.

Figura 150 - Contexto da tomada de decisão

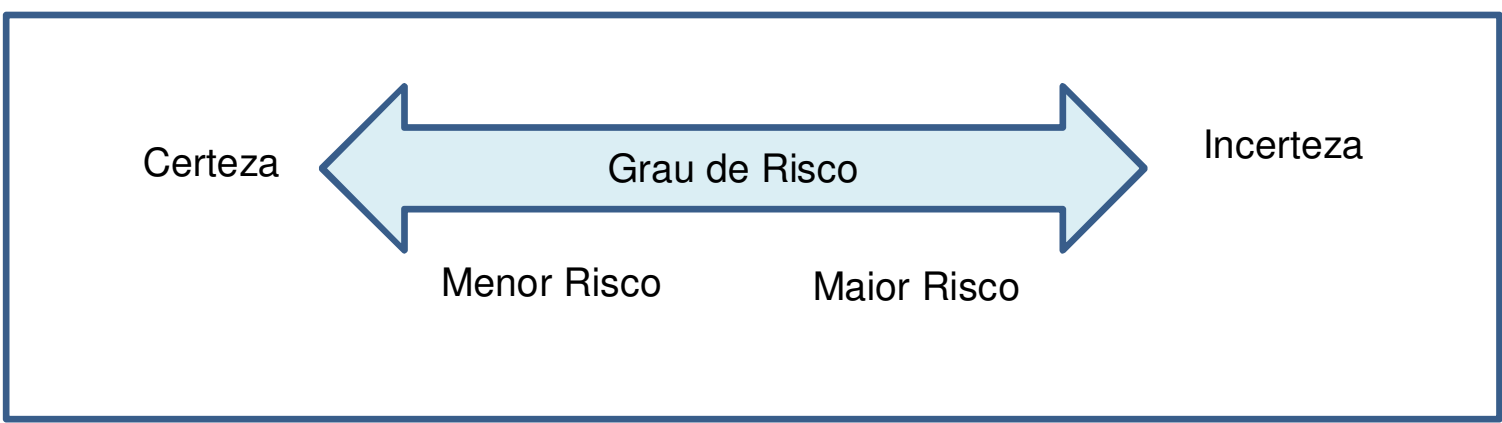

Fonte: Yu (2011)

Shimizu (2000) considera que a escolha do modelo depende da complexidade do problema, da finalidade da decisão e da limitação de tempo e custo. E considera, 
um problema complexo quando as variáveis e ou objetivos aumentam; quando a ocorrência dos valores dessas variáveis e ou objetivos está sujeita a riscos ou incertezas; e, os valores são definidos de modo impreciso.

A tabela 24 a seguir apresenta exemplos de técnicas ou softwares para suporte a tomada de decisão.

Tabela 24 - Exemplos de técnicas para suporte a tomada de decisão

\begin{tabular}{l|l|}
\hline \multicolumn{2}{c|}{ Técnicas de Auxilio } \\
\hline Énfase Quantitativa & Árvore de decisão \\
& Critérios financeiros: VPL, TIR \\
& Matriz de decisão \\
& Programação Linear \\
& Simulação \\
& Teorema de Bayes \\
& Teoria de filas \\
& Teoria da Utilidade \\
& Brainstorming \\
& Diagrama de influência \\
& Diagramas casuais \\
& Espinha de Peixe (Ishikawa) \\
& Mapas cognitivos \\
& Método Delphi \\
& Tabela de Estratégias \\
\hline & AHP \\
\hline
\end{tabular}

Fonte: Yu (2011)

Há diversos softwares multicritérios para auxilio a decisão, tais como: DPL, Electe, Promethee. 


\subsubsection{DESCRIÇÃO DO MODELO}

O Modelo de decisão foi desenvolvido em planilha Excel e sua matriz de decisão é formada por um conjunto de variáveis. O conjunto de sistemas ou dispositivos para automação existente foram inseridos no topo do quadro e avaliados conforme as variáveis e premissas estabelecidas para um determinado terminal-tipo, sendo os resultados apresentados em uma matriz de segmentação, formados pelos eixos de Impacto no negócio, e, Risco e Complexidade de implantação.

A Lista de Tecnologias e Dispositivos testados foram:

- ACLAS - Automatic Container Lading System

- AGS - Automated Gate System

- AGV - Automated Guided Vehicle

- ASC - Automated Stacking Cranes

- A-RTG - Automated RTG

- ATHS - Automated Twistlock Handling System

- Auto-Steering

- Anti-Sway/Skew

- Anti-Topple

- CMS - Crane Management System

- EDI - Eletronic Data Interchange

- Eletrificação de RTGs

- OCR - Optical Character Recognition

- Reefer Monitoring System

- Remote Control

- RFID/RTLS - Radio Frequency Identification / Real Time Locationg System

- SPS - Ship Profiling System

- TPS - Truck / Trailler Positioning System / VAS - Vehicle Alignment System

- TOS - Terminal Operating System

- Weight Scales (Instalada nos Equipamentos: RTG ou portêineres) 
O terminal-tipo escolhido para as decisões possui 1.100 metros de cais de forma a acomodar 3 navios de 335 metros de LOA de 9.000 TEUs; possui 12 portêineres, dessa forma, a alocação de 4 portêineres por equipamento e 500.000 $\mathrm{m}^{2}$ de área (sendo 60\% dedicados para armazenagem de carga, portanto 300.000 m²; os outros $40 \%$ são normalmente dedicados a edificações de apoio, como gates, prédio administrativo/operacional, estacionamentos, arruamento etc.).

Estabelecendo-se como regra a relação de 3 RTGs para cada portêiner, serão necessários 36 RTGs. Considerando 6 gates de entrada e outros 6 de saída com uma taxa de processamento de até 30 movimentos/hora e que cada RTG realiza em média 18 movimentos por hora; teremos até 180 movimentos/hora de gates o que implica 10 RTG em quadra para atendimento de rua (recebimento e entrega de contêineres), remoções em quadra, "housekeeping" e demais serviços. Uma taxa de $10 \%$ a mais de RTG é considerada em virtude das quebras e manutenções, portanto, mais 5 RTG, totalizando 51 RTGs.

Para os caminhões, a relação é de 5 para cada portêiner (considerando que as carretas trabalham em pool dedicado) ou seja, 60, outras 12 carretas são disponibilizadas para atendimentos de remoções em quadra, atendimento da área de inspeção, repesagem, passagem no scanner etc. E, nesse caso, aumentamos para $15 \%$ o número extra de carretas, em virtude de quebras e manutenção, ou seja, 83 carretas.

O conjunto de oito variáveis e suas premissas de avaliação foi separado em dois eixos:

- Impacto no negócio, e,

- Risco e Complexidade de Implantação.

Entendendo como Impacto no negócio as questões financeiras e operacionais, como exemplo de impacto financeiro, uma multa ou suspensão temporária da alfandega pela falta de um dispositivo considerado obrigatório; e um impacto operacional, a baixa produtividade na operação de navio ou formação de fila nos gates em virtude de algum bloqueio ou falha da automação; e Risco e Complexidade de Implantação a probabilidade de ocorrência do resultado real de alguma das atividades ser diferente do resultado esperado e as consequências desse evento; e, se a complexidade da implantação está relacionada com diversas interfaces com outros sistemas, e, se dispositivo ou tecnologia está exposto a algum 
perigo ou possibilidade de acidente; tal como os portais de AGS e OCR com o alto trafego de caminhões nos terminais.

As variáveis selecionadas no eixo (x) de impacto nos negócios foram:

- Investimento em CAPEX/OPEX: A implantação da Automação representa um alto investimento em CAPEX, bem como em custos de manutenção em OPEX;

- O Sistema ou Dispositivo possui Obrigatoriedade, conforme determinação de algum órgão anuente ou licenciador;

- A implantação da automação altera significativamente a Organização do Trabalho e processos da empresa;

- Reduz a necessidade parcial ou total de Uso Intensivo de mão de obra.

Enquanto que as variáveis do eixo (y) de Risco e Complexidade:

- O Layout existente dificulta ou impede a automação, o que pode implicar necessidade de alteração ou perda de área operacional útil;

- A questão de Confiabilidade dos sistemas, no qual independente da quebra, defeito ou falta é possível a substituição por sistema manual, sem risco a interrupção das operações;

- Sua Contribuição para o Meio-Ambiente e Segurança do Trabalho;

- A complexidade de Integração com os demais sistemas existentes na empresa.

Explicando a pontuação das variáveis, essas podem ser classificadas em: Baixo, Médio ou Alto; e o peso de cada pontuação é pré-definido como Baixo = 1; Médio = 3; e, Alta = 6. Enquanto o posicionamento de cada uma das tecnologias e dispositivo é dado através do somatório das multiplicações entre valores e pesos divididos pelo somatório dos pesos (média ponderada).

A figura 151 ilustra o quadro de preenchimento das variáveis na planilha Excel. 
Figura 1511 - Exemplos das Telas do Modelo em Excel

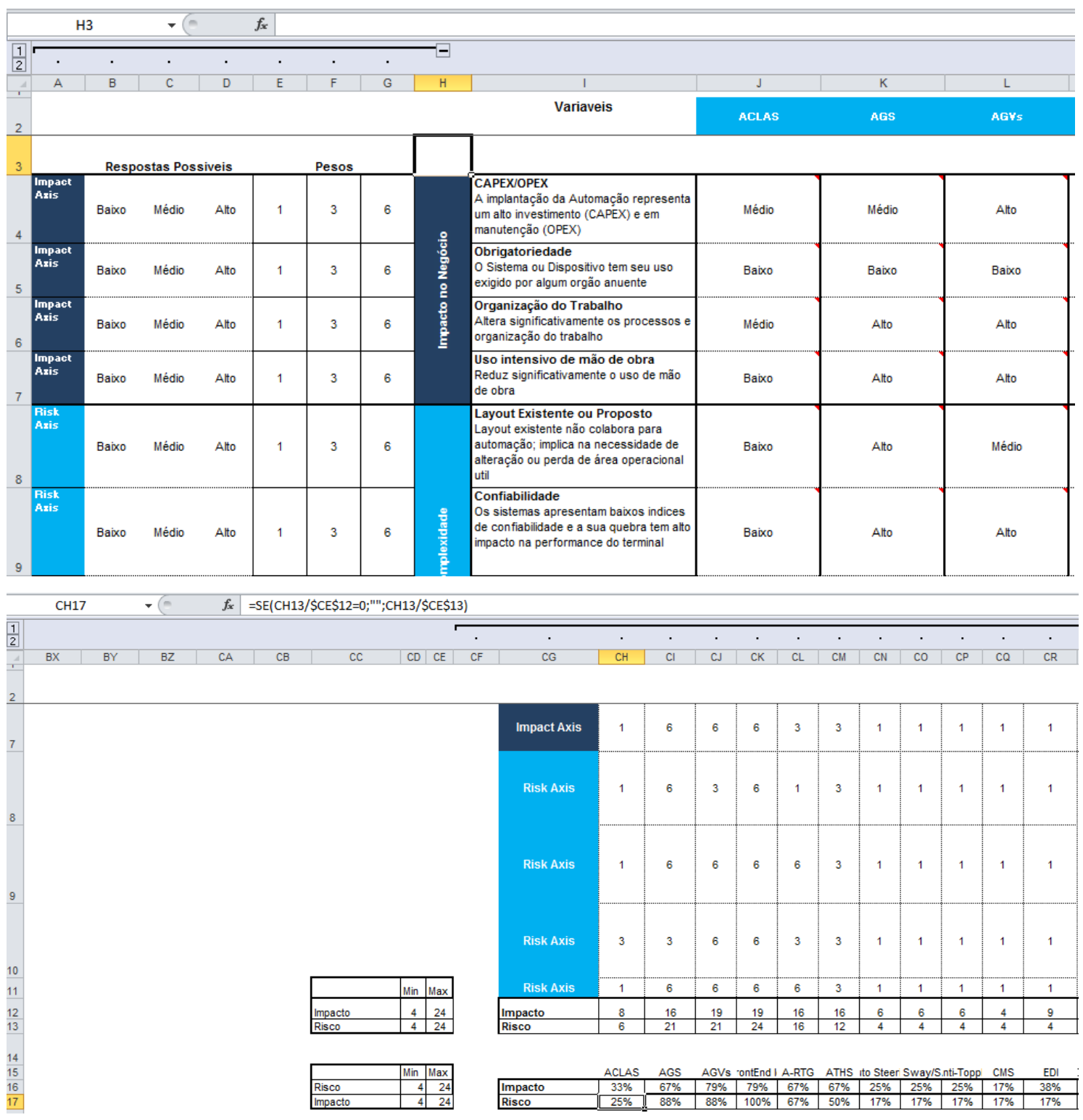

Fonte: Modelo Excel elaborado pelo autor

A tabela 25 explica as considerações e premissas de cada variável, enquanto a tabela 26 apresenta a pontuação atribuída a cada uma das tecnologias e dispositivos, observando de forma imparcial (como observador externo) as premissas, riscos e impactos.

Exemplificando o processo de pontuação de cada variável, as questões de CAPEX e OPEX foram verificadas com os fornecedores de equipamentos e com os diversos terminais que adquiriram ou negociaram alguma das tecnologias 
recentemente sobre quais os valores aplicados, e obteve-se número de ordem superior a $\mathrm{R} \$ 5$ milhões para TOS ou $\mathrm{R} \$ 580$ mil para TPC/VAS por equipamento; ou seja, pontuação alta.

A obrigatoriedade foi fundamentada sobre as resoluções e determinações de órgãos anuentes, como citado anteriormente, a Instrução normativa 3.518/11 da alfandega que exige o uso de OCR nos gates. Exigências comerciais e contratuais também foram consideradas, a exemplo da troca eletrônica de dados (EDI) com os armadores, logo pontuação alta.

A organização do trabalho e Uso de mão de obra foram analisadas conjuntamente e ponderado as alterações nos processos e na redução das equipes; bons exemplos são o AGS com um ou dois funcionários observando e tratando as exceções de gates (nos chamados "desk problems" ou "kitchens"), e o Remote Control com um operador observando e atuando na área de operação manual remota para dois ou três equipamentos (ver figura 71). A pontuação do Remote Control foi considerada média no caso de uso de mão de obra, pois não elimina a mão de obra, mas reduz no momento em que um operador é responsável por dois ou três equipamentos.

A parte do layout se preocupou com grandes alterações que impactassem diretamente nos fluxos horizontais ou perda de capacidade de área para instalação da tecnologia ou dispositivo. Por que a implantação de eletrificação foi considerada de pontuação alta? Por acarretar perda de capacidade em virtude da instalação dos barramentos ou de alteração de fluxo em virtude de alteração dos RTGs para Backto-Back.

A confiabilidade foi baseada na questão da possibilidade de substituição em caso de falha ou quebra por outro equipamento ou transferência para operações manuais, pois infelizmente, não há dados, publicações ou estatísticas que retratem o real grau de confiabilidade desses dispositivos. Sistemas como o anti sway ou anti skew em caso de falha podem ser substituídos pela pratica e sensibilidade do operador sem prejuízo as operações, portanto pontuação baixa.

A contribuição para segurança do trabalho e meio-ambiente foi verificado se a tecnologia de alguma forma reduz a possibilidade de acidentes com o trabalhador e ao meio-ambiente; o ATHS reduz a probabilidade de acidentes de mão ou dedos imprensados nos locks dos contêineres (ver figura 47), pois faz essa colocação 
automaticamente, porém não tem contribuição para o meio-ambiente, por isso foi considerado médio.

E por derradeiro, a Integração, Sistemas que possuem uma grande capilaridade de ações no terminal e possui diversas interfaces com outros sistemas, são mais suscetíveis a falhas; há diversos casos reais de implantação de TOS, que acarretaram o fechamento do terminal para reorganização interna de pátio através de auditoria de pilhas ou até Fallback (retorno) para o sistema anterior.

A figura 152 mostra o resultado da matriz de decisão do modelo, o qual serviu de orientação para escolha e posicionamento visual. 
Tabela 255 - Critérios de avaliação das variáveis

\begin{tabular}{|c|c|c|c|}
\hline Variáveis & Baixo & Médio & Alto \\
\hline CAPEX/OPEX & $\begin{array}{l}\text { Os valores de CAPEX são }<\mathrm{R} \$ 1 \\
\text { milhão }\end{array}$ & $\begin{array}{l}\text { Os valores de CAPEX estão entre } \\
\mathrm{R} \$ 1 \text { milhão e } \mathrm{R} \$ 5 \text { milhões }\end{array}$ & $\begin{array}{l}\text { Os valores de CAPEX são > R\$ } 5 \\
\text { milhões }\end{array}$ \\
\hline Obrigatoriedade & $\begin{array}{l}\text { Não existe obrigatoriedade no uso } \\
\text { por parte de órgão licenciador ou } \\
\text { anuente do setor. }\end{array}$ & $\begin{array}{l}\text { É recomendável, mas não } \\
\text { obrigatório. }\end{array}$ & É considerado obrigatório. \\
\hline Organização do trabalho & $\begin{array}{l}\text { Praticamente não ocorrem } \\
\text { alterações nos processos e } \\
\text { organização do trabalho. }\end{array}$ & $\begin{array}{l}\text { Ocorrem alterações nos } \\
\text { processos, mas sem alteração de } \\
\text { função das equipes. }\end{array}$ & $\begin{array}{l}\text { Ocorrem alterações nos processos } \\
\text { e nas funções das equipes. }\end{array}$ \\
\hline $\begin{array}{l}\text { Uso intensivo de mão de } \\
\text { obra }\end{array}$ & $\begin{array}{l}\text { Não há alteração no tamanho das } \\
\text { equipes. }\end{array}$ & $\begin{array}{l}\text { Ocorre redução significativa no } \\
\text { tamanho das equipes, mas não } \\
\text { total. }\end{array}$ & Ocorre redução total. \\
\hline Layout existente & $\begin{array}{l}\text { Não é necessária alterações ou } \\
\text { perda de área ou capacidade. }\end{array}$ & $\begin{array}{l}\text { É necessário alteração do layout, } \\
\text { mas não ocorre perda de área ou } \\
\text { capacidade. }\end{array}$ & $\begin{array}{l}\text { É necessário alteração no layout e } \\
\text { ocorre perda de área ou } \\
\text { capacidade. }\end{array}$ \\
\hline Confiabilidade & $\begin{array}{l}\text { Sistema apresenta alta } \\
\text { confiabilidade e sua falta ou } \\
\text { quebra temporária pode ser } \\
\text { substituída por outro recurso em } \\
\text { paralelo. Não apresenta riscos de } \\
\text { acidentes ou impactos em outros }\end{array}$ & $\begin{array}{l}\text { Sistema apresenta confiabilidade, } \\
\text { sua falta ou quebra pode ser } \\
\text { substituída por outros recursos } \\
\text { manualmente durante algum } \\
\text { tempo, mas perdurando o } \\
\text { problema, ocorrerá impacto na }\end{array}$ & $\begin{array}{l}\text { Sistema apresenta confiabilidade } \\
\text { e sua falta não pode ser } \\
\text { substituída por outro recurso, seja } \\
\text { pela impossibilidade ou escassez } \\
\text { dos mesmos. }\end{array}$ \\
\hline
\end{tabular}




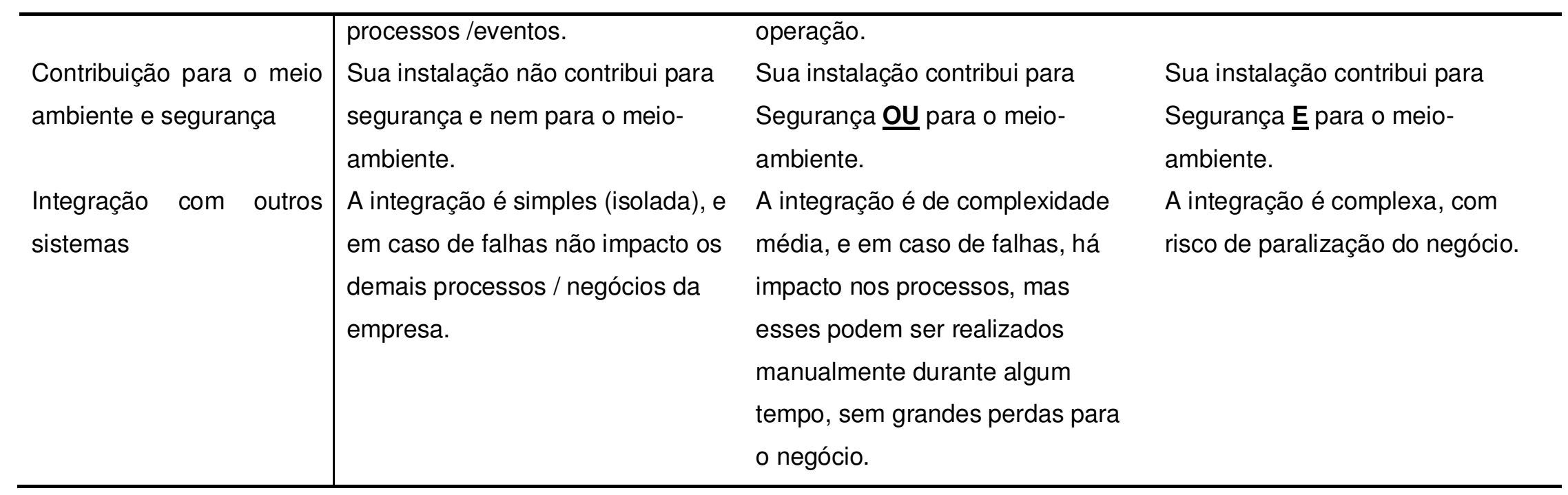

Fonte: Elaborado pelo autor 
Tabela 266 - Valor atribuído a cada uma das tecnologias/dispositivos

\begin{tabular}{|c|c|c|c|c|c|c|c|c|}
\hline Tecnologias/Variáveis & CAPEX/OPEX & Obrigatoriedade & $\begin{array}{l}\text { Organização } \\
\text { do Trabalho }\end{array}$ & $\begin{array}{l}\text { Uso de } \\
\text { mão de } \\
\text { obra }\end{array}$ & Layout & Confiabilidade & $\begin{array}{l}\text { Contribuição } \\
\text { para Seg./MA }\end{array}$ & Integração \\
\hline ACLAS & Médio & Baixo & Médio & Baixo & Baixo & Baixo & Médio & Baixo \\
\hline AGS & Médio & Baixo & Alto & Alto & Alto & Alto & Médio & Alto \\
\hline AGV & Alto & Baixo & Alto & Alto & Médio & Alto & Alto & Alto \\
\hline ASC & Alto & Alto & Alto & Alto & Alto & Alto & Alto & Alto \\
\hline A-RTG & Alto & Baixo & Alto & Médio & Baixo & Alto & Médio & Alto \\
\hline ATHS & Alto & Baixo & Alto & Médio & Médio & Médio & Médio & Médio \\
\hline Auto Steering & Médio & Baixo & Baixo & Baixo & Baixo & Baixo & Baixo & Baixo \\
\hline Anti Sway & Médio & Baixo & Baixo & Baixo & Baixo & Baixo & Baixo & Baixo \\
\hline Anti Toople & Médio & Baixo & Baixo & Baixo & Baixo & Baixo & Baixo & Baixo \\
\hline CMS & Baixo & Baixo & Baixo & Baixo & Baixo & Baixo & Baixo & Baixo \\
\hline EDI & Baixo & Alto & Baixo & Baixo & Baixo & Baixo & Baixo & Baixo \\
\hline OCR (gates) & Médio & Alto & Médio & Médio & Médio & Médio & Baixo & Médio \\
\hline OCR (portêineres) & Médio & Baixo & Alto & Médio & Baixo & Baixo & Médio & Médio \\
\hline Reefer monitoring & Baixo & Baixo & Baixo & Baixo & Baixo & Baixo & Baixo & Médio \\
\hline Remote Control & Alto & Baixo & Alto & Médio & Médio & Alto & Médio & Alto \\
\hline RFID/RTLS & Médio & Baixo & Médio & Baixo & Baixo & Baixo & Baixo & Baixo \\
\hline SPS & Médio & Baixo & Baixo & Baixo & Baixo & Baixo & Médio & Baixo \\
\hline TPS/VAS & Alto & Baixo & Médio & Baixo & Baixo & Baixo & Médio & Baixo \\
\hline TOS & Médio & Alto & Médio & Baixo & Baixo & Alto & Médio & Alto \\
\hline Weigh Scale & Baixo & Médio & Médio & Baixo & Baixo & Médio & Baixo & Médio \\
\hline Eletrificação & Alto & Baixo & Baixo & Baixo & Alto & Médio & Médio & Alto \\
\hline
\end{tabular}

Fonte: Elaborado pelo autor 


\section{Figura 152 - Resultado da matriz de decisão}

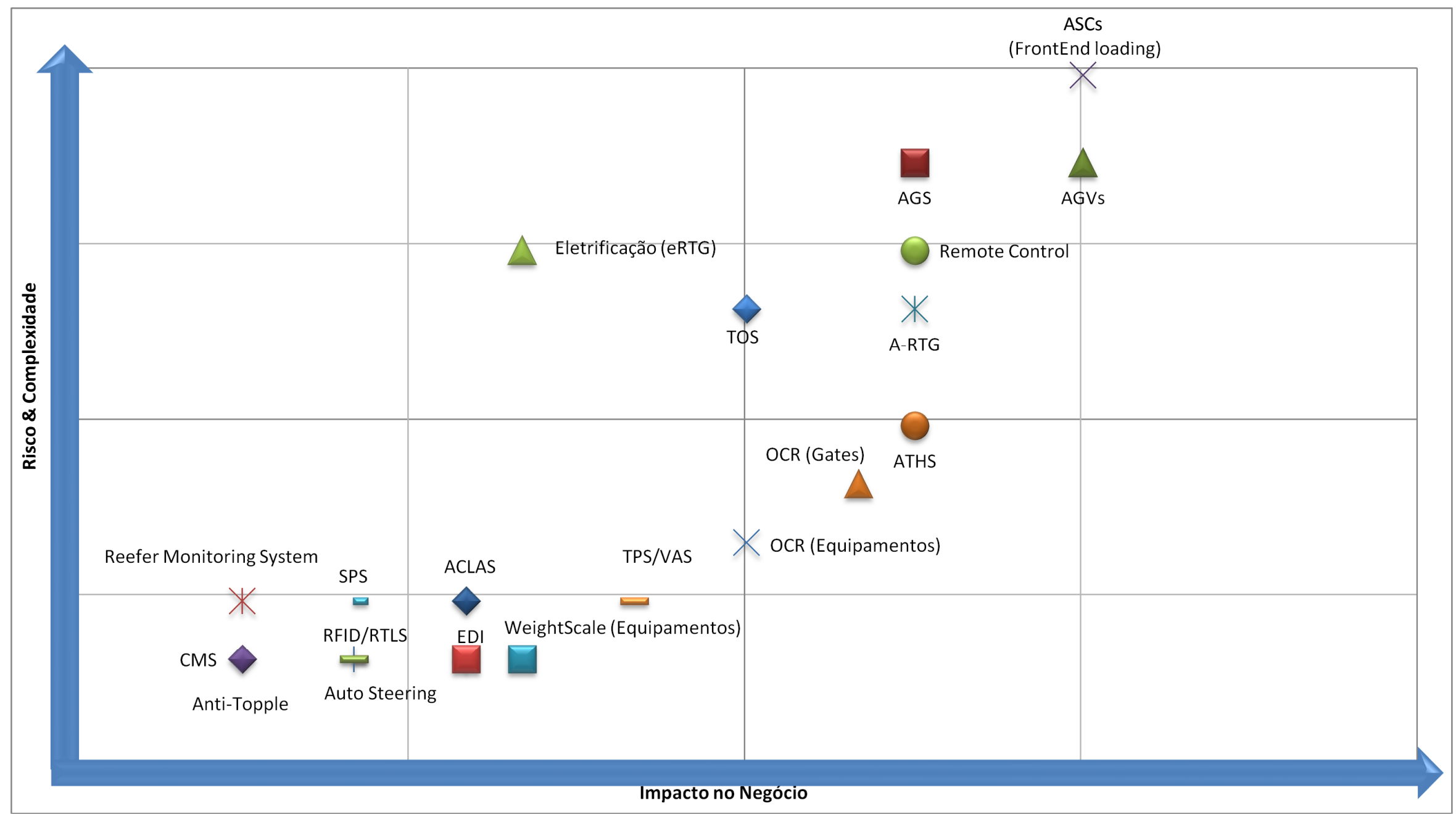

Fonte: Elaborado pelo autor 
A matriz de segmentação é o resultado "gráfico" das pontuações associadas a cada variável na guia de premissas. Os resultados dividem os sistemas e tecnologias em quatro quadrantes:

- Canto esquerdo inferior (Quadrante I): "Baixo Risco e Baixo Impacto/Complexidade";

- Canto direito inferior (Quadrante II): "Baixo Risco e Alto Impacto/Complexidade";

- Canto superior esquerdo (Quadrante III): "Alto Risco e Baixo Impacto/Complexidade";

- Canto superior direito (Quadrante IV): "Alto Risco e Alto Impacto/Complexidade".

Iniciando a análise pelo Quadrante I, no qual 10 das 20 tecnologias selecionadas foram posicionadas; na sua maioria são o que chamamos anteriormente de automação "menor" ou "parcial do processo". São tecnologias ou dispositivos cujas pontuações foram baixos ou médios; exceção do EDI quanto à obrigatoriedade que foi considera alta, em virtude da necessidade e pressão dos clientes (são itens contratuais), ou por instrução da aduana e de seus sistemas (SISCARGA, e DTE).

Agrupando as tecnologias por aplicabilidade ou similaridade, pode-se afirmar que a troca eletrônica de dados (EDI) é uma das mais antigas tecnologias de automação, nascida na década de $60 \mathrm{com}$ a indústria automobilística americana; e utilizada na indústria de terminais de contêineres no Brasil a partir de 1997, com os arquivos do tipo UN/EDIFACT - BAPLIE que são os planos de pós-estivagem de carga. Essa simples automação diminui o tempo na saída do navio em mais de $50 \%$, uma redução de aproximadamente 2 horas para 45 minutos à 1 hora, pois antes do uso da ferramenta de EDI, o imediato do navio ficava aguardando a atualização do Masterplan do navio, que era o conjunto de desenho de todas as bays do navio em folha A3. Essa atualização era realizada com correções a lápis na numeração do contêiner e posição a bordo ou por meio da colagem de etiquetas; havia, inclusive, o uso de um conferente de carga exclusivo para essa atividade. Trata-se de uma tecnologia de baixo custo de implantação e complexidade e de alto grau de maturidade. 
As tecnologias de anti-sway/anti-skew (também chamadas de anti-snag) são praticamente itens de série dos portêineres, contudo, apresentam problemas de deixar a operação mais lenta, o que faz com que os operadores, por pressão de produtividade ou por questões culturais, realizem um "by-pass" na função. O sistema Auto-steering para os RTGs (dispositivo que auxilia no equipamento nas pistas por meio de uso de GPS), não é item de série e pode ou não ser adquirido na compra do equipamento. Essas tecnologias são de baixa complexidade para instalação e alto grau de maturidade. Apesar de agrupado nessa categoria, o ACLAS, dispositivo apresentado nas figuras 95 a 97 e novamente ilustrado na figura 153, onde se percebe que o operador está supervisionando a operação no monitor e trabalha sem as mãos estarem no controle do equipamento. Essa é uma tecnologia recente e em fase de expansão; até a presente data, nenhum terminal no país tem esse dispositivo instalado. Situação semelhante dos sistemas de verificação de perfil (Ship Profile System (SPS) e Anti-Topple), a bordo do navio ou nas pilhas no pátio. São tecnologias em fase de expansão de instalação na indústria portuária, para não dizer período de amadurecimento ou testes em ambiente real de produção. As figuras de 91 a 94 exemplificam esses sistemas.

Figura 1533 - Imagem do ACLAS da ABB - operador trabalhando "handsoff"

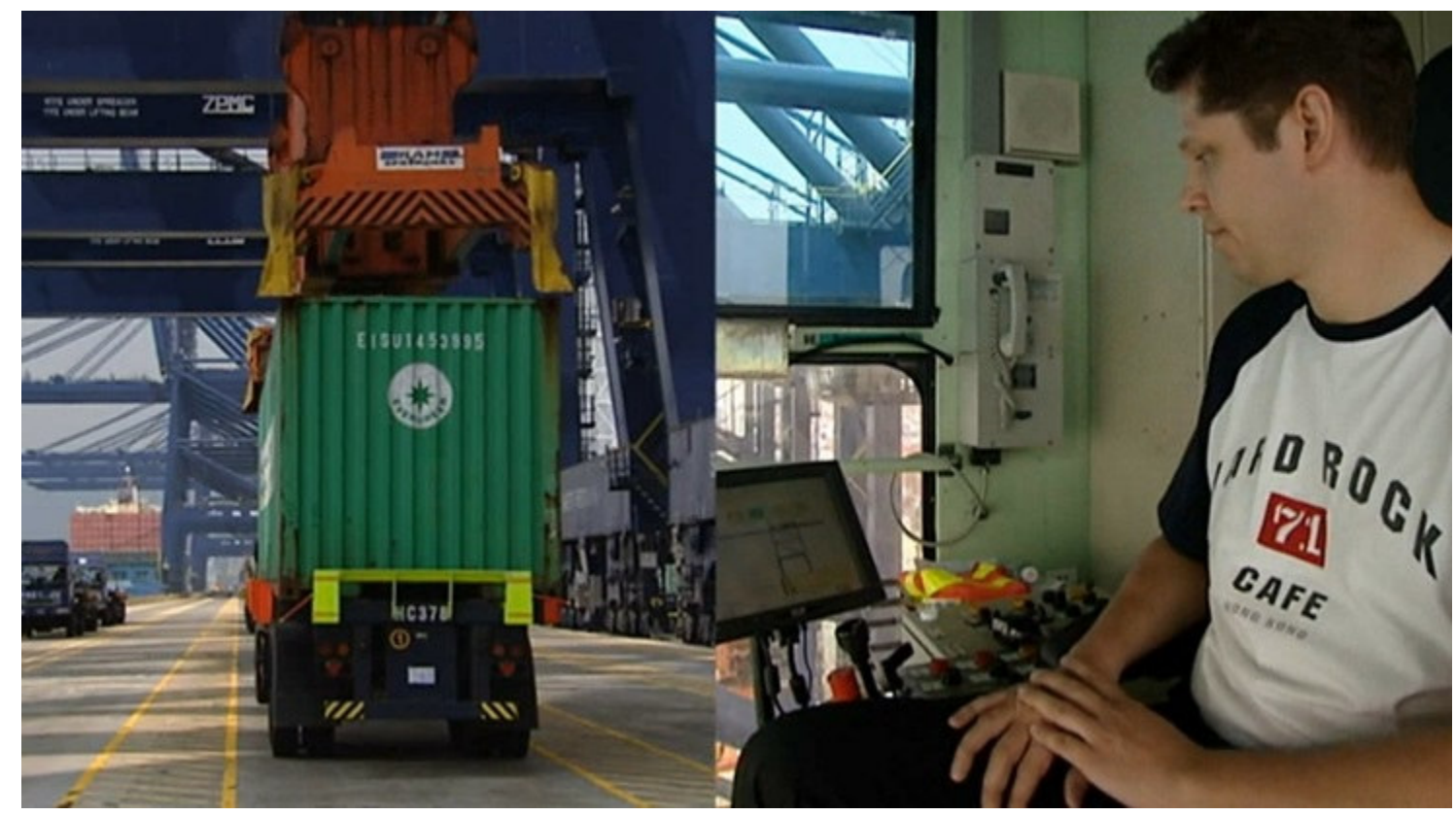

Fonte: ABB 
Os sistemas de posicionamento e alinhamento de veículos ou contêineres, representados pelos sistemas do tipo: TPS / VAS (Truck / Trailler Positioning System / Vehicle Alignment System) que inicialmente nasceram com o uso de sensores simples, passam por uma fase de substituição de componentes ou dispositivos, passando a utilizar tecnologias mais sofisticadas como o laser, OCR ou RFID, o que encareceu demais o produto; um portêiner com laser GMHB tem o valor de $\mathrm{R} \$ 580$ mil por portêiner. Há TOS no mercado que oferece o sistema do tipo RTLS (Real Time Locationg System) como um módulo nativo do sistema.

Os sistemas de gerenciamento de guindastes (CMS) e o sistema de monitoramento de contêineres refrigerados (Reefer Monitoring System) são sistemas de supervisionamento dos equipamentos, seja portêineres, RTGs ou contêineres reefers. Esses sistemas já foram amplamente testados e são de instalação e integração simples e alta confiabilidade. No caso do sistema de monitoramento dos reefers, destaca-se que o sistema migrou do controle de contêineres reefers abordo dos navios para o controle desses contêineres depositados no pátio dos terminais; portanto, alto grau de maturidade.

Foram posicionadas no Quadrante II a tecnologia de OCR (Optical Character Recognition), tanto para gates como para portêineres. O uso de OCR nos Gates é obrigatório pelos terminais de contêineres, conforme Instrução Normativa $\mathrm{n}^{\circ}$ 3.518/11, a mesma que determina o uso de escâneres. O valor do investimento de OCR por linha de gate ou portal varia entre $€ 65$ mil a $€ 90$ mil e a manutenção anual é de $€ 7$ mil por linha; esses valores são apenas para o sistema de câmeras e sensores. A implantação de gate automatizado (AGS) exige outros dispositivos como Kiosk que variam de $€ 8$ mil à $€ 12$ mil e a implantação de uma área de apoio (Back Office), cujo software completo (Gate Operating System - GOS) é da ordem de $€$ $50.000,00$ à $€ 100.000,00$. Esses dados são base 2010 da CAMCO (Bélgica) e não incluem os impostos, o que eleva em média o valor em $40 \%$.

No caso de OCR em portêineres, não existe a obrigatoriedade e a sua instalação tem ganhado aderência nos terminais no exterior, na substituição das confirmações de embarque e descarga e verificação da presença de lacres e avarias. Esse serviço no Brasil é realizado pelo conferente de carga por meio do uso de coletores de dados. No país, atualmente, dois terminais operam com OCR nos portêineres, o terminal da Santos-Brasil está em fase de comissionamento e o TECON Suape já instalado e a ordem de preço são semelhantes. 
Finalizando o Quadrante II, tem-se o Sistema Automático de Colocação e Retirada de TwistLocks (Automatic TwistLock Handling System (ATHS)), ao rever as figuras 50 e 51; pode-se notar que essa tecnologia é fronteiriça ao Quadrante IV (Alto risco e Alto impacto).

Apesar de vários testes realizados, esses não conduziram a uma aplicação em larga escala. No Brasil, não há nenhuma instalação com esse equipamento ou estação e podemos enumerar algumas razões técnicas e econômicas, citando alguns:

- O investimento necessário para uma única estação é bastante elevada (mais de US\$ 1 milhão), porém o retorno sobre investimento é demorado;

- Nem todos os tipos de castanhas (twist locks) podem ser manuseados;

- Quando a estação apresenta falha ou quebra acaba bloqueando uma área embaixo portêiner ou no backreach;

- Quando instalado no portêiner adiciona um peso significativo à estrutura do guindaste e, muito provavelmente, reduz a capacidade de elevação do guindaste;

- As estações continuam precisando de mão de obra para abastecimento dos twistlocks;

- Necessitam ser movimentadas acompanhando a translação do portêiner entre as bays do navio, e

- Requerem mão de obra especializada para a manutenção.

Como referência, o valor de uma diária de 6 horas da capatazia de segunda a sábado no horário das $07 \mathrm{~h}$ às $19 \mathrm{~h}$ é de $\mathrm{R} \$ 88,05$. Porém, deve-se dizer que o dispositivo possui oportunidades de contribuição para a segurança do trabalho e tem potencial de integração com outros equipamentos como balanças.

A eletrificação dos RTGs ou eRTG foi a única tecnologia classificada no Quadrante III; contudo, merece um destaque especial, pois pensando em automação plena ou mesmo semiautomação, principalmente dos equipamentos de pátio, ela pode ser o primeiro passo.

A frota mundial atual de RTG, segundo a World Cargo News e relatórios da ZPMC, é de cerca de 13.000 equipamentos com uma produtividade média de 8 
movimentos/hora, o que incita a busca pelo aumento de produtividade. Contudo, o consumo de diesel e manutenção ( $€ 2,55 / h)$ desses equipamentos é elevado, o que motiva a busca por redução de seus custos. A Tabela 27 demonstra os custos de diesel e energia elétrica para os diferentes tipos de RTGs existentes no mercado.

Tabela 277 - Comparação de consumo entre os tipos de RTG

\begin{tabular}{|c|c|c|c|c|}
\hline Tipo de RTG & $\begin{array}{c}R T G \\
\text { Convencional }\end{array}$ & EcoRTG® & $\begin{array}{c}\text { EcoRTG } B \\
c / \\
\text { capacitores }\end{array}$ & eRTG \\
\hline $\begin{array}{l}\text { Diesel /consumo de energia } \\
\text { (15 movimentos por hora) }\end{array}$ & $\begin{array}{l}5,52 \mathrm{gal} . / \mathrm{h} \\
\text { ou } 24,3 \mathrm{l} / \mathrm{h}\end{array}$ & $\begin{array}{l}3,45 \mathrm{gal} . / \mathrm{h} \\
\text { ou } 14,7 \mathrm{l} / \mathrm{h}\end{array}$ & $\begin{array}{l}1,8 \mathrm{gal} . / \mathrm{h} \\
\text { ou } 7,92 \mathrm{l} / \mathrm{h}\end{array}$ & $35 \mathrm{KW} / \mathrm{h}$ \\
\hline $\begin{array}{l}\text { Custos de Energia: } \\
\text { Diesel }=€ 3,13 \text { ou Kwh }=€ 0,09\end{array}$ & $€ 17,28$ & $€ 10,80$ & $€ 5,63$ & $€ 3,15$ \\
\hline $\begin{array}{l}\text { Custo de operação/ano } \\
\text { (3.600 horas) }\end{array}$ & $€ 62.199,36$ & $€ 38.874,60$ & $€ 20.282,40$ & $€ 11.340,00$ \\
\hline
\end{tabular}

Fonte: Henesey (2014), comparações para o Porto da Georgia

A figura 84 ilustra os dois tipos de tecnologias de eletrificação para RTGs: Enrolador de Cabo de Alimentação (Cable Reel) ou sistema de Barramento (Bus Bar). A adoção por um ou outro tipo está relacionada ao tipo de operação do terminal e número de quadras e suas respectivas extensões em metros. Alguns terminais brasileiros, em seus últimos pedidos de compra de equipamento, solicitaram os mesmos com o Enrolador de Cabo de Alimentação. Tal escolha se deve ao elevado custo de instalação. Segundo a Conductix, a instalação de 250 metros de quadra com três RTG tem um custo de $\mathrm{R} \$ 650$ mil por RTG e o valor de um RTG convencional é na faixa de US\$1,2 milhão, enquanto os EcoRTG® possuem um investimento adicional de US\$170 mil; aliás, o conceito de EcoRTG® foi desenvolvido pela Siemens e APMT, no qual emprega uma tecnologia que permite que o gerador a diesel funcione com velocidades variáveis, combinando a sua potência de saída para a energia requerida pelo RTG, em qualquer momento durante o ciclo de elevação e descida; de acordo com informações da APMT Algeciras (Espanha) as experiências realizadas representaram uma redução de 50\% do consumo de diesel.

Porém, como demonstrado na figura 154, é notório o crescimento pela compra de eRTG, a taxa percentual de RTG eletrificados sobre o total de RTGs em 
2006 era de 1\%, em 2013 o percentual era de 11\%; sendo que $75 \%$ os RTGs eletrificados são de barramento condutor.

Figura 1544 - Características da Frota de RTG e taxa percentual de eRTG

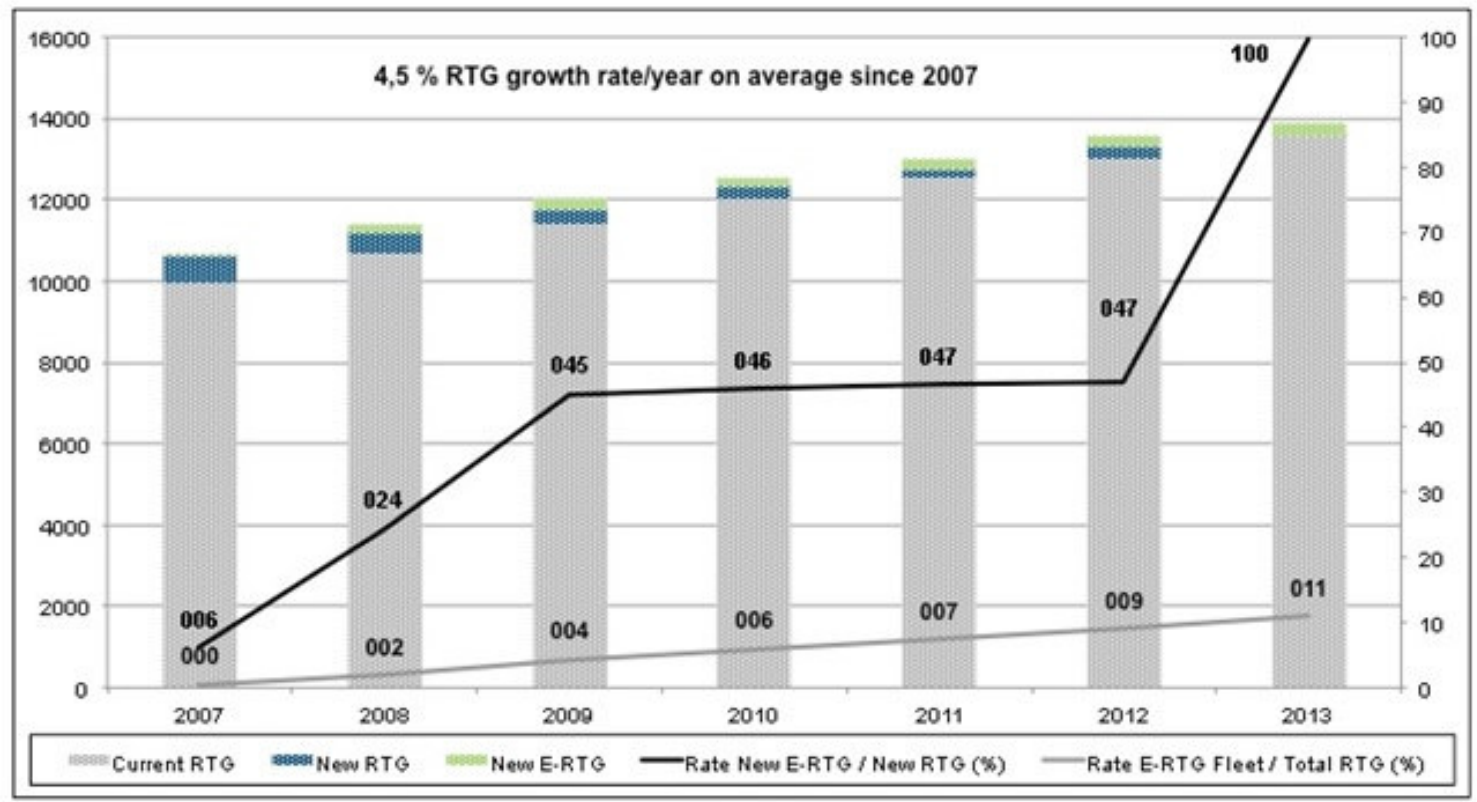

Fonte: Henesey (2014)

A outra questão que favorece o crescimento do eRTG é a redução da emissão de $\mathrm{CO}_{2}$. Henesey (2014) indica uma redução de $-52 \%$ de emissão entre os RTGs convencionais e os eletrificados. Outra vantagem da eletrificação é a redução da poluição sonora;

E, por derradeiro, no Quadrante IV, encontram-se as tecnologias de automação "maior" e de alta complexidade e risco de instalação, como: AGS, AGV, ASC, A-RTG, Remote Control e o TOS.

No modelo apresentado, o TOS foi categorizado no quadrante IV, mas teve sua posição entre os quadrantes III e IV. A instalação de TOS nos terminais é um item de grande atenção e esforços, pois mexe com a estrutura organizacional, altera processos e a organização do trabalho. Há diversos relatos nacionais e internacionais sobre Startup/Go Live de terminais ou troca de Sistema traumáticas. Um exemplo internacional, o porto da África do Sul, precisou fechar praticamente uma semana dias para auditar todas as pilhas após alguns poucos dias de trabalho e colocar o terminal em regime novamente em virtude do elevado número de contêineres depositado pelos operadores em posições erradas, o TOS indicava que 
a posição de depósito era, por exemplo, Quadra A, bay 25 , lastro $\mathrm{D}, 3^{\mathrm{a}}$ altura, porém o operador armazenava o contêiner na Quadra, bay 25, lastro E, 3a altura e confirmava como estivesse na outra no lastro D, ou seja, fisicamente estava em uma posição e virtualmente no sistema em outra; fazendo que o sistema tomasse repetidas decisões erradas de posicionamento. Houve um caso de um terminal no Brasil que, após um ou dois dias de operações com o novo TOS, precisou fazer um "fallback" para o sistema antigo.

Essa ferramenta pode atingir facilmente a cifra de $R \$ 5$ milhões, com custos de manutenção anuais na ordem de US\$ 150 mil a US\$ 300 mil; além de um percentual do valor de cada módulo, o volume do terminal entra como variável da composição desse custo. Todos os terminais de contêineres de médio e grande porte possuem um TOS instalado, é a principal ferramenta de planejamento e controle do terminal, contudo, há de se destacar que também é uma ferramenta cujo real potencial não é utilizado. Não é incomum encontrar planejadores de navios realizando sequenciamento de embarque de forma manual, retirando o contêiner da quadra e transferindo para o navio, alguns um a um; situação semelhante com o planejamento de pátio; onde o armazenador decide a localização, em vez de programar as regras de negócios e/ou filtros para tratar as regras e ficando para tratativas manuais, aqueles contêineres especiais, que merecem atenção diferenciada como carga perigosa ou com excesso.

A instalação de Gate automatizado começa a ganhar adeptos no país, após a instalação dos OCR; dito isso, Ecoporto, Embraport e TECON Rio Grande já possuem a estrutura instalada e estão realizando testes ainda com os gates tripulados; exceção da Santos-Brasil que inicia as operações automatizada dos seus gates.

As demais tecnologias são, com certeza, de maior complexidade e de necessidade de investimentos e custos altos; por exemplo, um AGV tem custo estimado de $€ 350$ mil contra $€ 90$ mil de um Terminal Tractor/Trailer e possui dois complicadores; o primeiro é a questão da eliminação, substituição ou realocação do trabalhador e o segundo é a $(R e)$ organização do trabalho.

Entende-se organização do trabalho, segundo Fleury (1997), como a definição das atividades e responsabilidades de cada pessoa ou grupo de pessoas que participa de uma organização produtora de bens ou serviços. 
Lucena (1991) explica que em ambientes competitivos, como é o caso de operações de contêineres no Brasil e mais especificamente no porto de Santos. Apenas em Santos os terminais marítimos especializados em contêineres em um trecho de estuário de nove quilômetros somam um total de sete instalações, a saber:

- Terminal da Santos--Brasil,

- Libra Terminais,

- Deicmar,

- Rodrimar,

- Ecoporto (antigo TECONDI),

- BTP e

- Embraport;

Esse número extrapolaria mais de 30 instalações se incluindo os armazéns gerais, TRAs, EADIs, etc.

Portanto, o dimensionamento do efetivo é uma atividade essencial para atender às necessidades de continuidade do negócio, sua estratégia e cumprindo os objetivos da empresa. Segundo Marx, Zilbovicius e Mello (2011), o dimensionamento de pessoas é uma decisão política, dependendo do tipo de organização, da operação e dos stakeholders envolvidos, portanto não existe método universal e nem é tarefa simples esse dimensionamento; assim a metodologia a ser empregada dependerá de diversos fatores, como a análise dos processos de produção e das variáveis que interferem na relação com a tecnologia. Os mesmos autores apresentaram um esquema dos fatores que afeta o dimensionamento de pessoal formado por: Contexto econômico e comercial, Leis e regulamentos, Organização da produção e do trabalho, Investimentos, Dimensão Social e Dimensão Tecnológica.

A Figura 155 ilustra como diferentes equipamentos e metodologias de operação afetam a organização do trabalho embaixo dos portêineres. 
Figura 1555 - Representação do posicionamento das equipes de trabalho em regime de operação com spreader single, Tandem e Tandem Double.
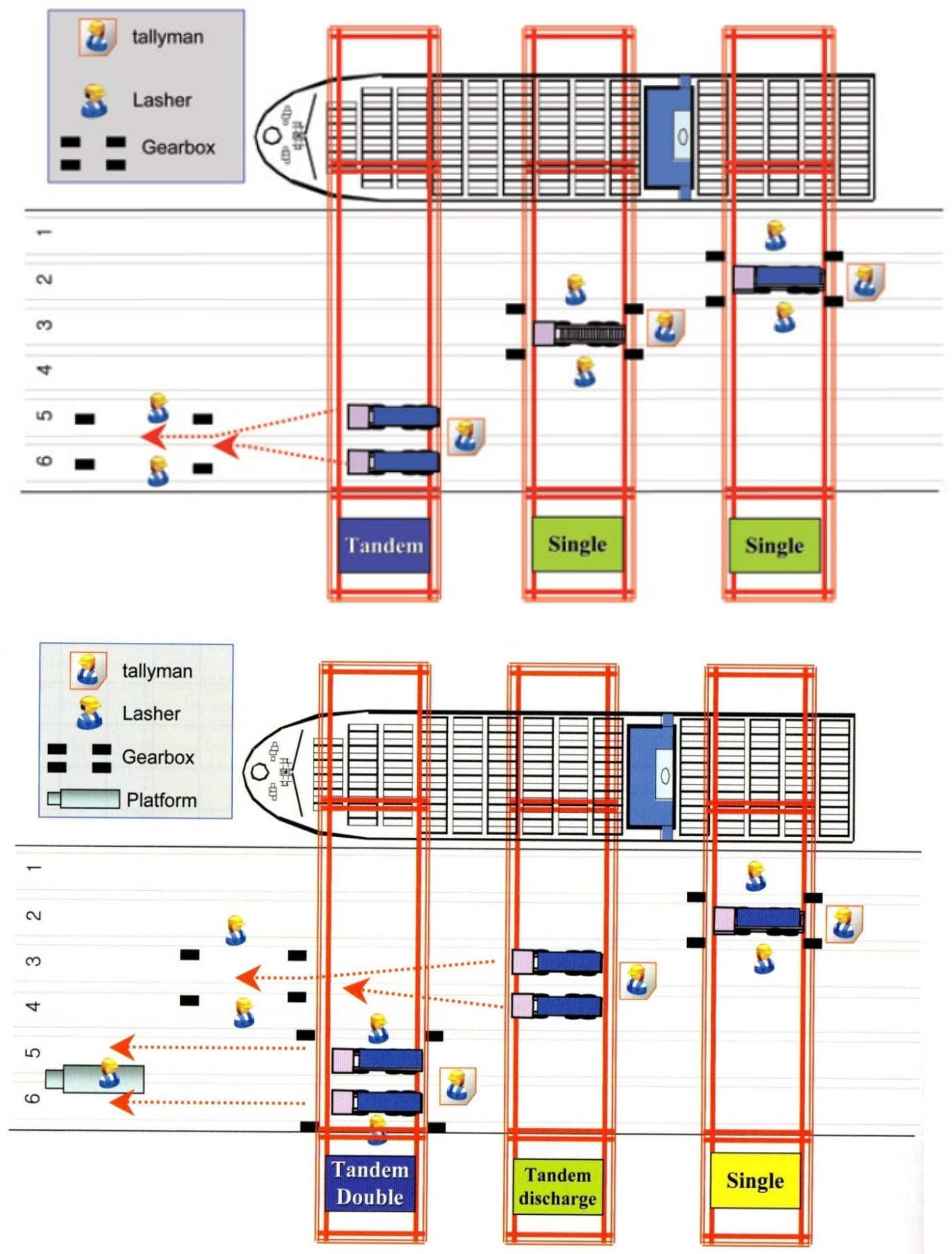

Fonte: Port Technology - edição 51

A operação com spreader single é a mais simples e tradicional, com a movimentação de um contêiner por vez; a operação com spreader tandem (ver Figura 39) ocorre a possibilidade de até 4 contêineres de 20' simultaneamente; 
enquanto que a operação tandem double cycling, que consiste basicamente no spreader viajar sempre carregado. Por exemplo, embarcam-se 2 contêineres de 40' e descarrega-se outros 2 contêineres. Song (2011) indica que essa operação de embarque e descarga é principalmente realizada no porão dos navios e deve iniciar com a operação do spreader em single, de forma que a diferença de altura das colunas (rows) do navio seja menor que 35 centímetros, ou seja, a primeira fase da operação possui restrições e compara a produtividade média de operação single com Tandem de 33,3 movimentos por hora contra 41,1 movimentos por hora respectivamente. Não há consenso entre os operadores portuários sobre o uso de técnicas do tipo double cycling.

A operação combinada de ASC com AGV com quadras do tipo "FrontEnding loading" exigem grandes áreas. A figura 156 indica um projeto da área de transferência do cais para a pilha em sentido "FrontEnding"; são recomendados quase 150 metros entre distância entre pernas, backreach e área de transferência. Há terminais no país que não possuem essa distância de retroarea.

Figura 156 - Desenho de distância recomendada para operação de AGV e ASC (FrontEnding Loading)

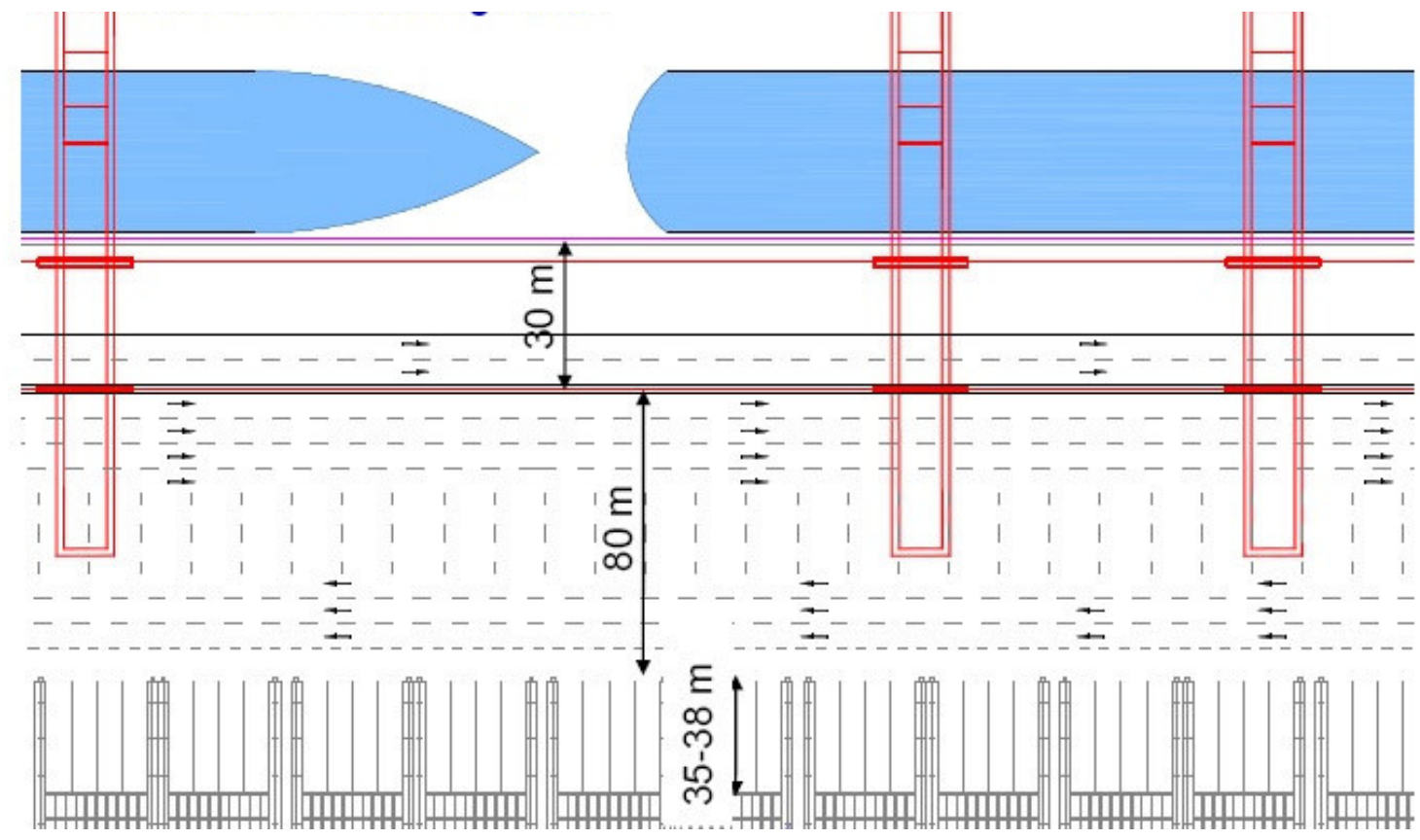

Fonte: Busk (2009) 
Dessa forma demonstra-se a importância do layout como variável de decisão. Tomando como exemplo o Terminal Pacifico Sur (TPS) no Chile, nota-se que as quadras de armazenagem iniciam imediatamente após, cerca de dois metros de distância do trilho do lado de terra do portêiner, o que impede utilização da área de backreach para operações; como é possível notar na Figura 157, os tampões são colocados entre as pernas dos portêineres o que causa restrições de fluxo.

Figura 157 - Layouts com restrições

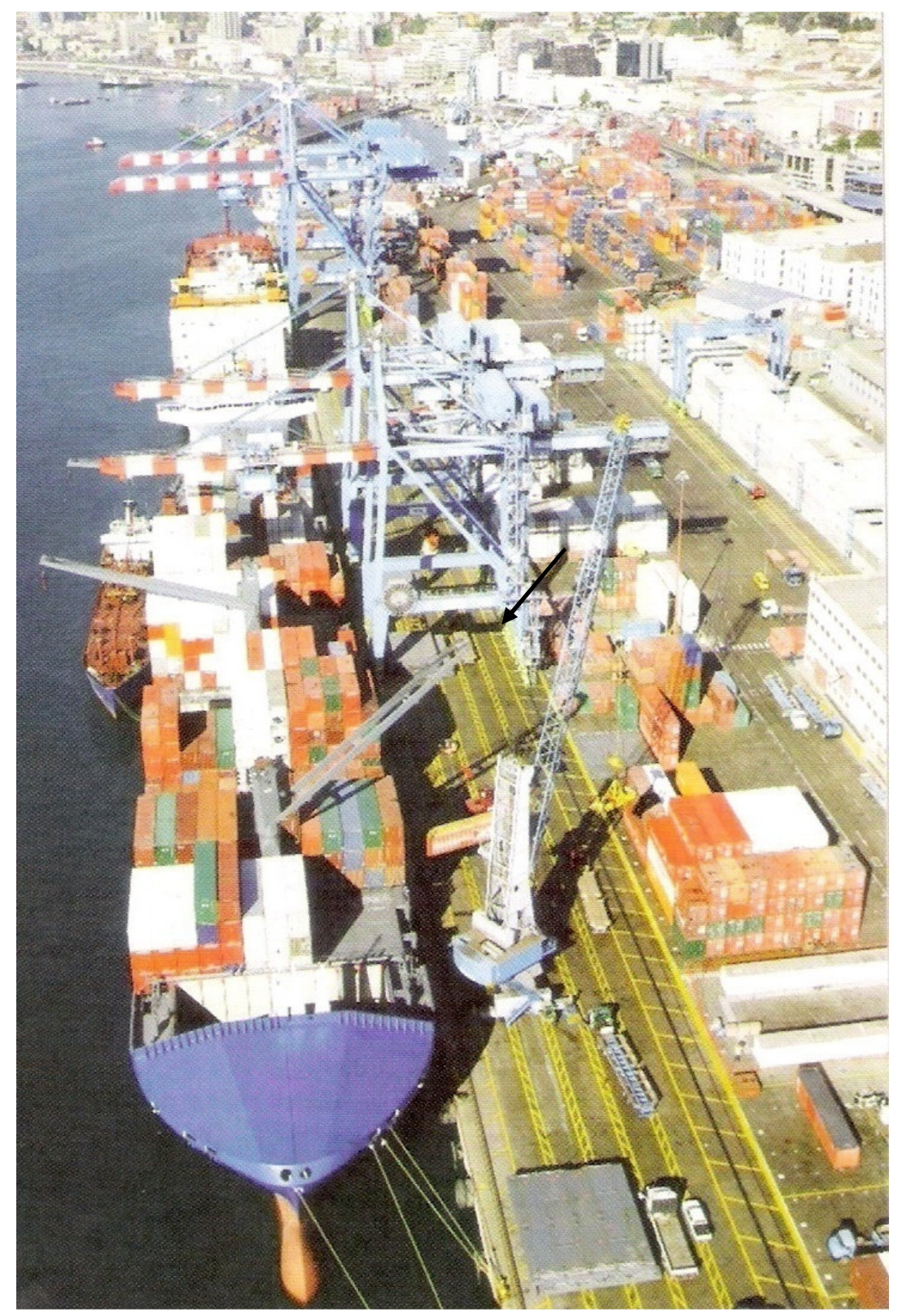

Fonte: TPS 
A seguir, um quadro diagnóstico com as tecnologias utilizadas no modelo e presentesem oito terminais brasileiros dos portos de Santos (SP), Itapoá (SC), Salvador (BA), Rio Grande (RS), Vila Velha (ES), são eles:

- Brasil Terminal Portuário (BTP);

- Ecoporto;

- Embraport;

- Porto de Itapoá;

- Santos-Brasil;

- Tecon Salvador;

- Tecon Rio Grande; e

- Terminal de Vila Velha (TVV).

Destaca-se que os terminais da BTP e Embraport possuem um pouco mais de um ano de operação, tendo iniciado suas atividades em agosto de 2013. 
Tabela 288 - Tabela Diagnostico de utilização de tecnologias

\begin{tabular}{|c|c|c|c|c|c|c|c|c|}
\hline & $\underset{\infty}{R}$ & 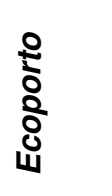 & $\begin{array}{l}\frac{1}{0} \\
\frac{0}{00} \\
\frac{0}{5} \\
\text { है }\end{array}$ & 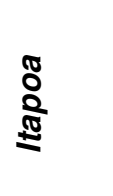 & 站 & 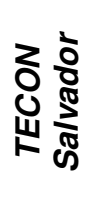 & 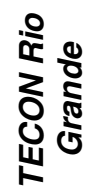 & $\vec{k}$ \\
\hline ACLAS & $\mathrm{N} / \mathrm{A}$ & $\mathrm{N} / \mathrm{A}$ & $\mathrm{N} / \mathrm{A}$ & $\mathrm{N} / \mathrm{A}$ & $\mathrm{N} / \mathrm{A}$ & $\mathrm{N} / \mathrm{A}$ & $\mathrm{N} / \mathrm{A}$ & $\mathrm{N} / \mathrm{A}$ \\
\hline AGS & $\mathrm{N} / \mathrm{A}$ & $x$ & $x$ & $\mathrm{~N} / \mathrm{A}$ & $x$ & $\mathrm{~N} / \mathrm{A}$ & $X\left(^{*}\right)$ & $x$ \\
\hline AGV & $N / A$ & $N / A$ & $\mathrm{~N} / \mathrm{A}$ & $\mathrm{N} / \mathrm{A}$ & $\mathrm{N} / \mathrm{A}$ & $\mathrm{N} / \mathrm{A}$ & $\mathrm{N} / \mathrm{A}$ & $\mathrm{N} / \mathrm{A}$ \\
\hline ASC & $\mathrm{N} / \mathrm{A}$ & $\mathrm{N} / \mathrm{A}$ & $\mathrm{N} / \mathrm{A}$ & $\mathrm{N} / \mathrm{A}$ & $\mathrm{N} / \mathrm{A}$ & $N / A$ & $\mathrm{~N} / \mathrm{A}$ & $\mathrm{N} / \mathrm{A}$ \\
\hline A-RTG & $\mathrm{N} / \mathrm{A}$ & $\mathrm{N} / \mathrm{A}$ & $\mathrm{N} / \mathrm{A}$ & $\mathrm{N} / \mathrm{A}$ & $\mathrm{N} / \mathrm{A}$ & $N / A$ & $\mathrm{~N} / \mathrm{A}$ & $\mathrm{N} / \mathrm{A}$ \\
\hline ATHS & $N / A$ & $\mathrm{~N} / \mathrm{A}$ & $\mathrm{N} / \mathrm{A}$ & $\mathrm{N} / \mathrm{A}$ & $\mathrm{N} / \mathrm{A}$ & $\mathrm{N} / \mathrm{A}$ & $\mathrm{N} / \mathrm{A}$ & $\mathrm{N} / \mathrm{A}$ \\
\hline Auto Steering & $\mathrm{N} / \mathrm{A}$ & $x$ & $x$ & $x$ & $x$ & $\mathrm{~N} / \mathrm{A}$ & $\mathrm{N} / \mathrm{A}$ & $\mathrm{N} / \mathrm{A}$ \\
\hline Anti Sway & $x$ & $\mathrm{x}$ & $x$ & $x$ & $\mathrm{~N} / \mathrm{A}$ & $N / A$ & $\mathrm{~N} / \mathrm{A}$ & $x$ \\
\hline Anti Toople & $\mathrm{N} / \mathrm{A}$ & $x$ & $\mathrm{x}$ & $\mathrm{N} / \mathrm{A}$ & $\mathrm{N} / \mathrm{A}$ & $\mathrm{N} / \mathrm{A}$ & $\mathrm{N} / \mathrm{A}$ & $\mathrm{N} / \mathrm{A}$ \\
\hline CMS & $x$ & $x$ & $x$ & $x$ & $x$ & $\mathrm{~N} / \mathrm{A}$ & $\mathrm{N} / \mathrm{A}$ & $x$ \\
\hline EDI & $\mathrm{X}$ & $x$ & $x$ & $x$ & $x$ & $x$ & $x$ & $x$ \\
\hline OCR (gates) & $x$ & $x$ & $x$ & $x$ & $x$ & $x$ & $x$ & $x$ \\
\hline OCR (portêineres) & $\mathrm{N} / \mathrm{A}$ & $\mathrm{N} / \mathrm{A}$ & $\mathrm{N} / \mathrm{A}$ & $\mathrm{N} / \mathrm{A}$ & $x$ & $N / A$ & $\mathrm{~N} / \mathrm{A}$ & $\mathrm{N} / \mathrm{A}$ \\
\hline Reefer monitoring & $\mathrm{N} / \mathrm{A}$ & $\mathrm{N} / \mathrm{A}$ & $\mathrm{N} / \mathrm{A}$ & $\mathrm{N} / \mathrm{A}$ & $x$ & $N / A$ & $\mathrm{~N} / \mathrm{A}$ & $\mathrm{N} / \mathrm{A}$ \\
\hline Remote Control & $\mathrm{N} / \mathrm{A}$ & $x$ & $\mathrm{~N} / \mathrm{A}$ & $\mathrm{N} / \mathrm{A}$ & $X(\#)$ & $\mathrm{N} / \mathrm{A}$ & $\mathrm{N} / \mathrm{A}$ & $\mathrm{N} / \mathrm{A}$ \\
\hline RFID/RTLS & $x$ & $X\left(^{*}\right)$ & $x$ & $\mathrm{~N} / \mathrm{A}$ & $x$ & $\mathrm{X}$ & $\mathrm{N} / \mathrm{A}$ & $x$ \\
\hline SPS & $\mathrm{N} / \mathrm{A}$ & $\mathrm{N} / \mathrm{A}$ & $\mathrm{N} / \mathrm{A}$ & $\mathrm{N} / \mathrm{A}$ & $\mathrm{N} / \mathrm{A}$ & $\mathrm{N} / \mathrm{A}$ & $\mathrm{N} / \mathrm{A}$ & $\mathrm{N} / \mathrm{A}$ \\
\hline TPS/VAS & $\mathrm{N} / \mathrm{A}$ & $\mathrm{N} / \mathrm{A}$ & $x$ & $\mathrm{~N} / \mathrm{A}$ & $\mathrm{N} / \mathrm{A}$ & $\mathrm{N} / \mathrm{A}$ & $\mathrm{N} / \mathrm{A}$ & $\mathrm{N} / \mathrm{A}$ \\
\hline TOS & $x$ & $X\left(^{*}\right)$ & $x$ & $x$ & $x$ & $x$ & $x$ & $x$ \\
\hline Weigh Scale & $X$ & $\mathrm{~N} / \mathrm{A}$ & $\mathrm{N} / \mathrm{A}$ & $\mathrm{N} / \mathrm{A}$ & $x$ & $X$ & $x$ & $\mathrm{~N} / \mathrm{A}$ \\
\hline Eletrificação & $\mathrm{N} / \mathrm{A}$ & $\mathrm{N} / \mathrm{A}$ & $\mathrm{N} / \mathrm{A}$ & $N / A$ & $\mathrm{~N} / \mathrm{A}$ & $\mathrm{N} / \mathrm{A}$ & $\mathrm{N} / \mathrm{A}$ & $\mathrm{N} / \mathrm{A}$ \\
\hline
\end{tabular}

Fonte: Elaborada pelo autor

Legendas: N/A = Não aplicado; X (*) Em fase de implantação; X (\#) Em estudo para RTGs (3 x1) 


\section{CONCLUSÔES}

Esse trabalho apresentou através de uma contextualização do setor, a evolução da operação portuária de contêineres no Brasil e do crescimento de navios, assim como relata esse impacto nas operações e discute a necessidade de adequação permanente dos terminais.

Em seguida, uma comparação é realizada entre os processos tradicionais ou manuais com processos automatizados, oportunidade em que o autor realiza uma detalhada e inédita descrição das tecnologias e automação aplicada as operações de terminais de contêineres; e revisão bibliográfica nacional onde se observa uma literatura restrita a tópicos como informatização, integração de sistemas de controle através de EDI. A literatura internacional, por sua vez, mostrou-se mais ampla com predominância nos tópicos de comparações entre sistemas automatizados de transporte horizonta como os AGVs, e de sistemas de armazenamento de pátio automatizado, exemplo dos ASCs.

Portanto, foi possível verificar que as operações de terminais são complexas e a automação aumenta essa complexidade, por diversas razões, tal como requerer maior confiabilidade dos sistemas; o custo de CAPEX e/ou OPEX não é desprezível, o impacto na organização do trabalho e layout pode ser um complicador da instalação da tecnologia. E não existe unanimidade sobre a questão automação e qual tecnologia é mais apropriada, porém a tendência observando os 33 terminais automatizados internacionalmente, apenas nove são automação total, os demais tenderam a semi-automação. No caso dos oito terminais brasileiros pesquisados, observou-se que todos possuem o que se classificou com "automação menor", com alguns casos incipientes de Sistema de Gate Automatizado (AGS) e uso do TOS.

Outrossim, um modelo em Excel foi desenvolvido para auxiliar na reflexão da escolha e classificação conforme risco e impacto. Foram testadas 21 tecnologias ou dispositivos considerando as variáveis de Layout existente, CAPEX e OPEX, Confiabilidade, Integração com sistemas de Tecnologia da Informação e Inteligência de Equipamento, em especial com TOS, Organização do trabalho, Contribuição para a segurança e meio ambiente, Obrigatoriedade legal do uso, Intensidade do uso de mão de obra. 
Pode-se afirmar que a automação no exterior encontra-se em um estágio de "Controle" em respostas às preocupações de elevados custos de mão de obra e necessidade de aumento de produtividade pelo aumento do tamanho dos navios e impacto nos processos do terminal; enquanto no Brasil, os terminais encontram-se em uma fase de "Adequação" tanto Institucional, em virtude do período de incerteza em face dos novos marcos regulatórios; Comercial, pela entrada de operadores globais nas operações e excesso temporário de capacidade; e, Operacional, com o aumento da complexidade da operação pelo crescimento dos navios, e pelas exigências de flexibilidade dos clientes, e rígidos controles de segurança; e um ambiente onde não é mais possível, conviver com os gargalos de infraestrutura existente (leia-se acessos terrestres e marítimos. E a questão de Automação, encontra-se em uma fase de "Iniciação" com aplicação e aprendizado de "Automações Menores", conforme demonstrado na pesquisa dos oito terminais, caminhando para uma fase de "Contágio", de aplicação de "Automação Maior" com risco controlado e de tecnologia com grau de maturidade confiável.

Em síntese, pode-se sustentar que o cenário para os próximos anos de competição, é que a tendência dos terminais brasileiros é de semi-automação em áreas de gates, planejamento, e de conferência de informações e confirmação de registros.

Por derradeiro, recomenda-se a continuidade de desenvolvimento de novos modelos de suporte a decisão para escolha de automação; e estudos mais dedicados às questões de confiabilidade da automação e organização do trabalho; em virtude da ausência destes. 


\section{BIBLIOGRAFIA}

ALDERTON, P.M. Port management and operations. London: LLP Reference Publishing, 1999. 258p.

ASHAR, A. The fourth revolution and transshipment potentials for Panama ports. Terminal Operations Conference (TOC Europa). 16 - 18 May. Rotterdam, 2000.

AMARAL, A.C.R. Direito do comercio internacional: aspectos fundamentais. São Paulo: Aduaneiras, 2004. 395p.

BALLOU, R. Logística empresarial: transporte, administração de matérias, distribuição física. São Paulo: Atlas, 1993. 388p.

BASILIO, P. S. O Trabalho Portuário. Artigo publicado na revista Atualidades Jurídicas - revista eletrônica do Conselho Federal da OAB. Brasília: Editora OAB, p. 227-248, 2009.

BAUMANN, R.; CANUTO, O.; GONÇALVES, R. Economia Internacional: teoria e experiência brasileira. Rio de Janeiro: Editora Campus, 2004. 442p.

BOTTER, R.C. Transporte marítimo internacional: natureza, evolução e tendências do setor. São Paulo, 1996. 53 p.

BRANDÃO, F.D. Avaliação dos impactos econômicos e operacionais em regime de slow steaming. Trabalho de conclusão de curso, Escola Politécnica da Universidade Federal do Rio de Janeiro (UFRJ). Rio de Janeiro, 2013. 51p.

BRUGGELING,M. Abandoning the Spherical Container Terminal - The support of container terminal berth planning by the integration and visualization of terminal information. Technische Universiteit Delft.Delft (The Nertherlands), 2011. $147 p$.

BUSK, K. Introduction to Automation and drivers for automation. Terminal Automation Seminar - Driving terminal efficiency and profitability. London (UK), 2009. 
BUSTAMANTE, E. Developing KPIs for an RTG operational model. Terminal Operations Conference (TOC Americas). Buenos Aires (Argentina), 2009.

CAMPOI, F. Comércio Exterior vs Comércio Internacional . Artigo publicado em 14.Nov.2008 .

CARVALHO, H.D. Tecnologia da Informação aplicada à automação de terminais de contêineres. Trabalho de conclusão de curso, Escola Politécnica da Universidade de São Paulo (EPUSP). São Paulo, 2012. 80p.

CASACA,A.C.P. Simulation and the Lean Port Environment. Maritime Economics \& Logistics, vol.7.p.262-280, 2005.

CLARKE, R. Ship Size Development and Cascading - How Can Terminals prepare.Terminal Management and Planning . Londres, 2014.

COELHO, W.A. A primeira norma brasileira sobre contêineres. Revista Informativo dos Portos, janeiro 2013, no 159, p.48.

CONTADOR, J.C. Gestão de Operações - A Engenharia de Produção a serviço da modernização da empresa. São Paulo: Editora Edgard Blucher Ltda, 1997.

CONTAINER MANAGEMENT. World Top container ports 2012. London, 2012, 135 p.

DAVIDSON,N. The revival of terminal automation: drivers for container terminal automation. Terminal Automation Seminar - Exploring industry trends, new technology and positioning for recovery, 15 th and $16^{\text {th }}$ September, London (UK), 2011.

DAVIDSON,N. Market Outlook - Identifying opportunities and trends in the terminal sector. Terminal Management and Planning .Londres, 2014.

DEMO, P. Pesquisa e construção de conhecimento. Rio de Janeiro: Tempo brasileiro, 1996.

DEMPSEY,M. Terminal Automation for the rest of us. TECH TOC.Panamá, 2012. 
DOBNER, M. Automated Guided Vehicles - In the past exotic, today reliable, cost-effective and environmentally friendly. Terminal Operations Conference (TOC-Europa), 24-26 June.Londres, 2014.

DRAGOVlć, B; PARK, N.K. Modeling of Ship-Berth-Yard Link Performance and Throughput Evaluation in Container Port. Masport Seminar: Automation and Simulation Methodologies for the Evaluation and Improvement of Port Container Terminals. 10-11 November ,2011.

ELOVIC,P. Implementation of Gate and Crane OCR Systems for Container Terminal Automation and Security. Terminal Operations Conference (TOC Asia). Hong Kong, 2003.

FARIA, S.F.S. Fragmentos da história dos transportes. São Paulo: Aduaneiras, 2000. 100p.

FLOREZ, G. Improving terminal performance through fine tunning and KPI's measurement.Terminal Operations Conference (TOC Europe), 24-26 June. London (UK), 2014.

FOLTZ, C; SANDPEARL, M;URRIOLA,C. Future of Transhipment in the Americas.Terminal Operations Conference (TOC-Americas), 29-31 October. Miami, 2004.

FONSECA, F. Oportunidades de Investimento Privado nos Portos. Apresentação no $8^{\circ}$ Encontro de Logística e Transporte da FIESP.São Paulo,2013.

FONTANA, C.F. Metodologia para implantação dos processos da cadeia logística segura. Tese de Doutorado, Escola Politécnica da Universidade de São Paulo (EPUSP). São Paulo, 2010. 185p.

FROYEN, R.T. Macroeconomia. São Paulo: Editora Saraiva, 1999. 664p.

FUJIMOTO.T; SHIMOKAWA,K; JURGENS, U. Transforming Automobile Assembly - Experience in automation and work organization. $U$ Jürgen e $T$. Fujimoto Ed.Cap. 4.1, Spring 1997. 
GROOVER,M.P. Automação Industrial e Sistemas de Manufatura. São Paulo: Pearson, 2011. 581p.

GRIMSTAD,A; NEUMANN-LARSEN,E. Ultra large container vessels - can the economy of scale be quantified? . Container Ship Update from DNV. Norway, 2013.

GYLLING, T. Automation for RTG Cranes.Terminal Operations Conference (TOCEuropa), 24-26 June.London, 2014.

HARDT, D.C. C; GREGIO, J.M.; LIMA, T. W. ; FISCHER, C.N. Modelagem e Simulação de ambientes automatizados usando a modelagem empírica. REIC. Revista Eletrônica de Iniciação Científica, www. sbc. org. br/reic/revista, v. III, n. II, p. 2, 2003.

HENESEY,L.E. Improving Container Terminal Performance: A literature survey. PhD Thesis, Department of Systems and Software Engineering of School of Engineering.Blekinge Institute of Technology.Karlshamn, Sweden, 2004, 120p.

HENESEY,L.E. The RTG Evolution and Electric/Automation Revolution.World Port Development, June 2014, p. 31,32.

HOSHINO, S; OTA,J. Design of an Automated Transportation System in a Seaport Container Terminal for the Reliability of Operating Robots. International Conference on Intelligent Robots and Systems, $29^{\text {th }}$ Oct. $-02^{\text {nd }}$ Nov. San Diego (USA),2007.

HOSHINO, S; OTA,J. Reactive robot control with hybrid operational models in a seaport container terminal considering system reliability. International Conference on Intelligent Robots and Systems , 22 $2^{\text {th }}-26^{\text {th }}$ Sep. Nice (France), 2008.

HOSHINO,S; OTA,J.; SHINOZAKI, A.; HASHIMOTO, H. Hybrid Design Methodology and Cost-Effectiveness Evaluation of AGV Transportation Systems. IEEE Transactions on Automation Science and Engineering, Vol.4, No.3, July,2007. 
HU,H; LEE,B.K.; HUANG, Y.; LEE,L.H.; CHEW,E.P. Performance Analysis on Transfer Platforms in Frame Bridge Based Automated Container Terminals. The Scientific World Journal.Mathematical Problems in Engineering. 2013.

JULA,H.; LIU,C.I; KOSMATOPOULOS, E.B.; IOANNOU, P.A. Container terminal using automated shuttles driven by linear motors. 9th IFAC Sym. Control in Transportation Systems, Braunschweig, Germany, June 2000.

KOEGEBOEHN, D. Analysing the development of automation: Past, present \& future. Terminal Management and Planning. London, 2014.

KOEGEBOEHN, D. Improving productivity and capacity potential develop an improvement roadmap. Terminal Management and Planning . London, 2014.

KRUGMAN, P. A Crise de 2008 e a Economia da depressão. Rio de Janeiro: Editora Campus, 2009. 201p.

KUROSAWA, R.S.S. Análise de Sistemas de Informação aplicados à Gestão Portuária. Dissertação de Mestrado, Escola Politécnica da Universidade de São Paulo (EPUSP). São Paulo, 2004. 143p.

LEVINSON,M. The Box: how the shipping container made the world smaller and world economy bigger. New Jersey: Princeton University Press, 2006. 375p.

LIKER, J.K. O modelo Toyota - 14 princípios de gestão do maior fabricante do mundo. Porto Alegre: Bookman, 2004.316p.

LIMA JUNIOR, O.F. Desempenho em serviços de transportes: conceitos, métodos e práticas. Tese de Livre Docência, Faculdade de Engenharia Civil da Universidade Estadual de Campinas, 2004. 247p.

LIMA JUNIOR, O.F. Analise e avaliação do desempenho dos serviços de transporte de carga. In: Caixeta-Filho, J.V; Martins, R.S. Gestão Logística do transporte de Cargas. São Paulo: Atlas, 2001. p.108-145. 
LIU,C.I; IOANNOU, P.A. A comparison of different AGV dispatching rules in an Automated Container Terminal. International Conference on Intelligent Robots and Systems, $3^{\text {rd }}-6^{\text {th }}$ Sep. Singapore, 2002.

LIU,C; Jula,H;IOANNOU, P.A. Design, Simulation and Evaluation of Automated Container Terminals. IEEE Transactions on Intelligent Transportation Systems, Vol.3, no.1, March, 2002.

LUCENA, M.D.S. Planejamento de Recursos Humanos. São Paulo: Atlas, 1991.

LUNARDI, A.L. Condições Internacionais de Compra e Venda - Incoterms 2000. São Paulo: Aduaneiras, 2001. 172 p.

LUZ, R. Relações Econômicas Internacionais. Rio de Janeiro: Editora Campus, 2010. 456p.

MACHADO, I.S. O Porto de Santos e a Revolução dos Contêineres. Dissertação (Mestrado), Faculdade de Filosofia, Letras e Ciências Humanas, Universidade de São Paulo, São Paulo, 2012.

MAIA, J.M. Economia internacional e comércio exterior. São Paulo: Atlas, 2001. 469p.

MÄKINEN, M. Three angles on the Navis acquisition. Kalmar Around the world Customer Magazine. Issue 1, p.8-9.

MARX, R.; ZILBOVICIUS, M. MELLO, A.M. Metodologia para apoio à decisão de dimensionamento de efetivos em operações complexas. Escola Politécnica da Universidade de São Paulo (EPUSP). São Paulo, 2011.127p

MINAYO,M.C.S. O desafio do conhecimento. São Paulo: Hucitec, 1993.

MONFORT, A. et al. Innovaciones tecnológicas y de gestión em Terminales Portuários de Contenedores. Valencia: Fundacion Valenciaport,2012.

MONFORT, A. et al. La terminal portuaria de contenedores como sistema nodal em la caderna logística. Valencia: Fundacion Valenciaport, 2011. 
MONFORT, A. et al. Manual de capacidad portuária: Aplicación a terminales de contenedores. Valencia: Fundacion Valenciaport, 2011.

MOREIRA, D.A. Administração de Produção e Operações. São Paulo: Pioneira, 1993. 619p.

NIKU, S.B. Introdução à Robótica - Análise, Controle, Aplicações. Rio de Janeiro: LTC, 2011. 382p.

OHNO,T. O Sistema Toyota de Produção - Além da Produção em Larga Escala. Porto Alegre: Bookman, 1997.151p.

PATRICIO, M. Analise de regras de regras de atracação de navios em terminais de contêineres. Dissertação de Mestrado, Escola Politécnica da Universidade de São Paulo (EPUSP). São Paulo, 2005. 127p.

PATRICIO, M.; BOTTER, R.C. Modelo de Avaliação Operacional, de Investimentos, Organização do Trabalho e Confiabilidade para Automação em Terminais de Contêineres no Brasil - Cenário atual e futuro. Artigo apresentado no 24 Congresso Nacional de Transporte Aquaviário, Construção Naval e Offshore. Rio de Janeiro, 2012.

PEIXOTO, G.S.S. Modelo para Seleção de Equipamentos de retaguarda e estratégias de formação de pilhas na armazenagem em terminais de contêineres. Dissertação de Mestrado, Escola Politécnica da Universidade de São Paulo (EPUSP). São Paulo, 2005. 151p.

PIRES, F. Metodologias de automação integradas ao Centro de Controle, Comunicação, Operações e Segurança (CCOS) para o sistema de segurança portuário.Dissertação de Mestrado, Escola Politécnica da Universidade de São Paulo (EPUSP). São Paulo, 2011. 156p.

PIRHONEN, J. Automated Shuttle Carriers Concept - Comparison to Conventional RTG Crane and Yard Tractor Concept. Handbook of Terminal Planning, Sprinder Science+Business Media, LLC, 2011. 
Port Equipment Manufacturers Association (PEMA). Container Terminal Yard Automation. 2012.

PETERS,H.J.F. Developments in global seatrade and container shipping markets: theirs effects on the port industry and private sector involvement. International Journal of Maritime Economics 3: 3 - 26. 2001

PINTO, C.P.A; FLEURY, R.C. A modernização dos portos e as relações de trabalho no Brasil: doutrina, legislação e jurisprudência. São Paulo: Síntese, 2004. 339p.

PINTO,J.R.C. Técnicas de Automação. Lisboa (Portugal): ETEP, 2010.420p.

PONTES, C.M.V. Evolução política, organizacional e sindical do sistema portuário nacional: uma aplicação ao porto de Santos. Dissertação de Mestrado, Escola Politécnica da Universidade de São Paulo (EPUSP). São Paulo, 2001. 245p.

RANAU,M. Planning approach for Dimensioning of Automated Traffic areas at Seaport Container Terminals. Handbook of Terminal Planning, Sprinder Science+Business Media, LLC, 2011.

RICHTER, M. Managing terminal automation conversion projects. Terminal Automation Seminar - Driving terminal efficiency and profitability. London (UK), 2009.

RICHTER, M. Where next for automation? Future best practice in terminal layout and operation. Terminal Operations Conference (TOC-Europa), 08-10 June.Valencia (Espanha), 2010.

RIJSENBRIJ, J.C.The Impact of Tomorrow's Ships on Landside. Terminal Operations Conference (TOC-Europa), 19-21 June.Lisbon, 2001.

RIJSENBRIJ, J. C. Double or Quit? New concepts in terminal design. Terminal Operations Conference (TOC-Europa), 11-13 June. Antwerpen, 2002. 
ROBINSON, H.J. Formação de estoques de contêineres em áreas portuárias. Dissertação de Mestrado, Instituto Militar de Engenharia (IME). Rio de Janeiro, 1985. 288p.

RUDOLF III. C.D. Mega-crane productivity:Can it Keep up with Mega-ship Size increases?. Terminal Operations Conference (TOC-Europa), 19-21 June. Lisbon, 2001.

RUSSO FILHO, A. Comercio Internacional, um modelo para segurança portuária de modernização da aduana brasileira. Dissertação de Mestrado, Escola Politécnica da Universidade de São Paulo (EPUSP). São Paulo, 2006. 118p.

SAANEN,Y.A; DE WALL,A. Simulatie PCS Nieuw. Relatório da TBA Nederland, 2001.

SAANEN,Y.A. An Approach for Designing Robotized Marine Container Terminals. Tese de Doutorado, Technische Universiteit Delft.Delft (The Nertherlands), 2004. 303p.

SAANEN,Y.A. Comparison of three automated stacking alternatives by means of simulation. Terminal Operations Conference (TOC-Ameridas), 29th November 01st December. Savannah (USA), 2005.

SAANEN,Y.A; MEEL,J.V; VERBRAECK,A. The Design and Assessment of next generation automated container terminals. $15^{\text {th }}$ European Simulation Symposium, $26^{\text {th }}-29^{\text {th }}$ October, Delft (The Netherlands), 2003.

SALGADO, M. Terminais de Contêineres: Investir continuamente: questão de sobrevivência. $1^{\circ}$ Fórum de Contêineres: Investimentos em Terminais de Contêineres: Apostando no Processo de Industrialização Nacional. São Paulo, 2012.

SHINODA, T.; FUKUCHI, N.; TACHIBABA, T.I. A Simulation of the Container Handling Operation at the Next Generation of Container Terminals.18 Congresso Nacional de Transportes Marítimos e Construção Naval (SOBENA), Rio de Janeiro, 2000. 
SHIMIZU, T. Decisão nas Organizações - Introdução aos problemas de decisão encontrados nas organizações e nos sistemas de apoio à decisão. São Paulo: Editora Atlas, 2000. 317p.

SONG,J.H. Tandem operation and double cycling in container terminal - the effective use of dual hoist tandem speaders. Port Technology International, 51th edition, 2011.

SORTINO, G.F.F. Automação de portos como estratégia para a agilização do comércio internacional do Brasil. Revista Estratégica, São Paulo: FAAP, v.12,n.1, 2013.

SELEME,R; SELEME, R.B. Automação da Produção - Abordagem gerencial. Paraná: Editora IBEX, 2008. 215p.

SHINGO,S. O Sistema Toyota de Produção do ponto de vista da Engenharia de Produção. Porto Alegre: Bookman, 1996.

SILVA,E.L.; MENEZES,E.M. Metodologia da pesquisa e elaboração de dissertação. Florianópolis: Laboratório de Ensino a distância da UFSC, 2001. 121p.

SIRKIN, H.L; HEMERLING, J.W; BHATTACHARYA, A. Globalidade a nova era da globalização: como vencer num mundo em que se concorre com todos, por tudo e em toda parte. Rio de Janeiro: Editora Nova Fronteira, 2008. 313p.

STEENKEN, D.;VOß, S.; STAHLBOCK, R. Container terminal operation and operations research - a classification and literature review. OR Spectrum,v.26, p.3- 49, 2004.

STEVENSON, W.J. Administração das Operações de Produção. Rio de Janeiro: LTC, 1999.701p.

STOPFORD, M. Is the drive for ever bigger containership irresistible? Lloyds List Shipping Forecasting Conference, 26 ${ }^{\text {th }}$ April. London, 2002.

A história dos portos brasileiros. Revista Porto S.A., setembro 2008, № 9, p. 1218. 
TORRES, L.F.R. Estudo analítico e operacional da Supervia Eletrônica de Dados: um modelo de gestão eletrônica para os portos brasileiros. Dissertação de Mestrado, Escola Politécnica da Universidade de São Paulo (EPUSP). São Paulo, 2008. 167p.

TOZER, D.; PENFOLD, A. Ultra Large Container Ships (ULCS) designing to the limit of current and projected terminal infrastructure capabilities. Proceedings of Boxships 2001 Conference, London (2001)

THOMAS, B.J. Structural changes in the maritime industry: impact on inter-port competition trades. 2001.

VALLø,N. Are the terminals ready for ULCVs - indeed they are ! Container Ship Update from DNV.Norway, 2013.

VIANNA JUNIOR, E.O. Modelo de gestão e automação dos portos brasileiros. Tese de Doutorado, Escola Politécnica da Universidade de São Paulo (EPUSP). São Paulo, 2009. 352p.

VIS,I.F.A; CARLO,H.J. Sequencing Two Cooperating Automated Stacking Cranes in a Container Terminal. Transportation Science, Vol.44 Issue 2, May 2010.169-182p.

WARD, T. Terminal Efficiency - Expectations and Responses. Terminal Operations Conference (TOC Europe), $13^{\text {th }}-15^{\text {th }}$ June. Antwepen, 2012.

WREN,H. Operators views - the productivity gains and challenges that remain with automation. Terminal Automation Seminar - Driving terminal efficiency and profitability. London (UK), 2009.

WIJNOLST, N.; WAALS, F. Malacca-Max container carrier on the Europe-Far East route by 2010.Terminal Operations Conference (TOC Europe). 16 - 18 May. Rotterdam, 2000.

YERGIN, D. O Petróleo: uma história mundial de conquistas, poder e dinheiro. São Paulo: Paz e Terra, 2010.1080p. 
Y, A.S.O Tomada de decisão nas organizações - Uma visão Multidisciplinar. São Paulo: Saraiva, 2011.336p.

ZANCUL, P.J. Integração de sistemas de controle de carga em ambiente portuário. Dissertação de Mestrado, Escola Politécnica da Universidade de São Paulo (EPUSP). São Paulo, 2006. 131p.

Zhu,M.;FAN,X.;CHENG,H.;HE,Q. Modeling and simulation of automated terminal operation. Journal of Computers, Vol.5, no.6, June, 2010.

[URL: http://jus.com.br/revista/texto/5434/trabalhadores-portuarios-avulsos-e-orgaogestor-de-mao-de-obra]

[ ]. Automation of Container Terminals. Institute of Shipping Economics and Logistics (ISL). Bremerhaven (Germany).

[ ]. Intercâmbio Comercial do Agronegócio : Principais Mercados de Destino. Ministério da Agricultura, Pecuário e Abastecimento. Secretária de Relações Internacionais do Agronegócio. Brasília: MAPA/ACS, 2012.

[ ]. Safety and Shipping review.2014.Allianz Global Corporate and Specialty.Munique (Alemanha), 2014. 
ANEXOS 
Terminal: Porto de Itapoa

Nome/Posição: Marcio Guiot / Diretor de Operações

\begin{tabular}{|c|c|}
\hline & $\begin{array}{l}\stackrel{0}{2} \\
\stackrel{2}{\Xi}\end{array}$ \\
\hline $\begin{array}{l}\text { ACLAS } \\
\text { AGS } \\
\text { AGV } \\
\text { ASC } \\
\text { A-RTG } \\
\text { ATHS } \\
\text { Auto Steering } \\
\text { Anti Sway } \\
\text { Anti Toople } \\
\text { CMS } \\
\text { EDI } \\
\text { OCR (gates) } \\
\text { OCR (portêineres) } \\
\text { Reefer monitoring } \\
\text { Remote Control } \\
\text { RFID/RTLS } \\
\text { SPS } \\
\text { TPS/VAS } \\
\text { TOS } \\
\text { Weigh Scale } \\
\text { Eletrificacão }\end{array}$ & $\begin{array}{l}x \\
x \\
x\end{array}$ \\
\hline
\end{tabular}

Observações: 
Terminal: Santos Brasil

Nome/Posição: Ricardo Filho / Diretor de TI

\begin{tabular}{|c|c|}
\hline & 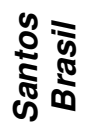 \\
\hline $\begin{array}{l}\text { ACLAS } \\
\text { AGS } \\
\text { AGV } \\
\text { ASC } \\
\text { A-RTG } \\
\text { ATHS } \\
\text { Auto Steering } \\
\text { Anti Sway } \\
\text { Anti Toople } \\
\text { CMS } \\
\text { EDI } \\
\text { OCR (gates) } \\
\text { OCR (portêineres) } \\
\text { Reefer monitoring } \\
\text { Remote Control } \\
\text { RFID/RTLS } \\
\text { SPS } \\
\text { TPS/VAS } \\
\text { TOS } \\
\text { Weigh Scale } \\
\text { Eletrificação }\end{array}$ & $\begin{array}{c}X \\
X \\
X \\
X \\
X \\
X(\#) \\
X\end{array}$ \\
\hline
\end{tabular}

Observações:

Remote control em estudo. 
Terminal: TECON Salvador

Nome/Posição: Sergio Augusto Gonçalves / Diretor de Operações

\begin{tabular}{|c|c|}
\hline & 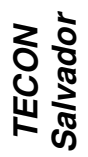 \\
\hline $\begin{array}{l}\text { ACLAS } \\
\text { AGS } \\
\text { AGV } \\
\text { ASC } \\
\text { A-RTG } \\
\text { ATHS } \\
\text { Auto Steering } \\
\text { Anti Sway } \\
\text { Anti Toople } \\
\text { CMS } \\
\text { EDI } \\
\text { OCR (gates) } \\
\text { OCR (portêineres) } \\
\text { Reefer monitoring } \\
\text { Remote Control } \\
\text { RFID/RTLS } \\
\text { SPS } \\
\text { TPS/VAS } \\
\text { TOS } \\
\text { Weigh Scale } \\
\text { Eletrificação }\end{array}$ & $\begin{array}{l}x \\
X\end{array}$ \\
\hline
\end{tabular}

Observações: 
Terminal: ECOPORTO Santos

Nome/Posição: Diogo Vasconcellos / Gerente de TI

\begin{tabular}{|c|c|}
\hline & $\begin{array}{l}\frac{0}{0} \\
\frac{0}{8} \\
\text { wे }\end{array}$ \\
\hline $\begin{array}{l}\text { ACLAS } \\
\text { AGS } \\
\text { AGV } \\
\text { ASC } \\
\text { A-RTG } \\
\text { ATHS } \\
\text { Auto Steering } \\
\text { Anti Sway } \\
\text { Anti Toople } \\
\text { CMS } \\
\text { EDI } \\
\text { OCR (gates) } \\
\text { OCR (portêineres) } \\
\text { Reefer monitoring } \\
\text { Remote Control } \\
\text { RFID/RTLS } \\
\text { SPS } \\
\text { TPS/VAS } \\
\text { TOS } \\
\text { Weigh Scale } \\
\text { Eletrificação }\end{array}$ & $\begin{array}{l}X \\
X \\
X \\
X \\
X \\
X\end{array}$ \\
\hline
\end{tabular}

Observações: 
Terminal: TVV

Nome/Posição: Vinicius de Abreu / Coordenação de Sistemas

\begin{tabular}{|c|c|}
\hline & $\vec{R}$ \\
\hline $\begin{array}{l}\text { ACLAS } \\
\text { AGS } \\
\text { AGV } \\
\text { ASC } \\
\text { A-RTG } \\
\text { ATHS } \\
\text { Auto Steering } \\
\text { Anti Sway } \\
\text { Anti Toople } \\
\text { CMS } \\
\text { EDI } \\
\text { OCR (gates) } \\
\text { OCR (portêineres) } \\
\text { Reefer monitoring } \\
\text { Remote Control } \\
\text { RFID/RTLS } \\
\text { SPS } \\
\text { TPS/VAS } \\
\text { TOS } \\
\text { Weigh Scale } \\
\text { Eletrificacão }\end{array}$ & $\begin{array}{l}X \\
X \\
X \\
X\end{array}$ \\
\hline
\end{tabular}

Observações: 
Terminal: BTP

Nome/Posição: Marcelo Patrício / Gerente de Planejamento

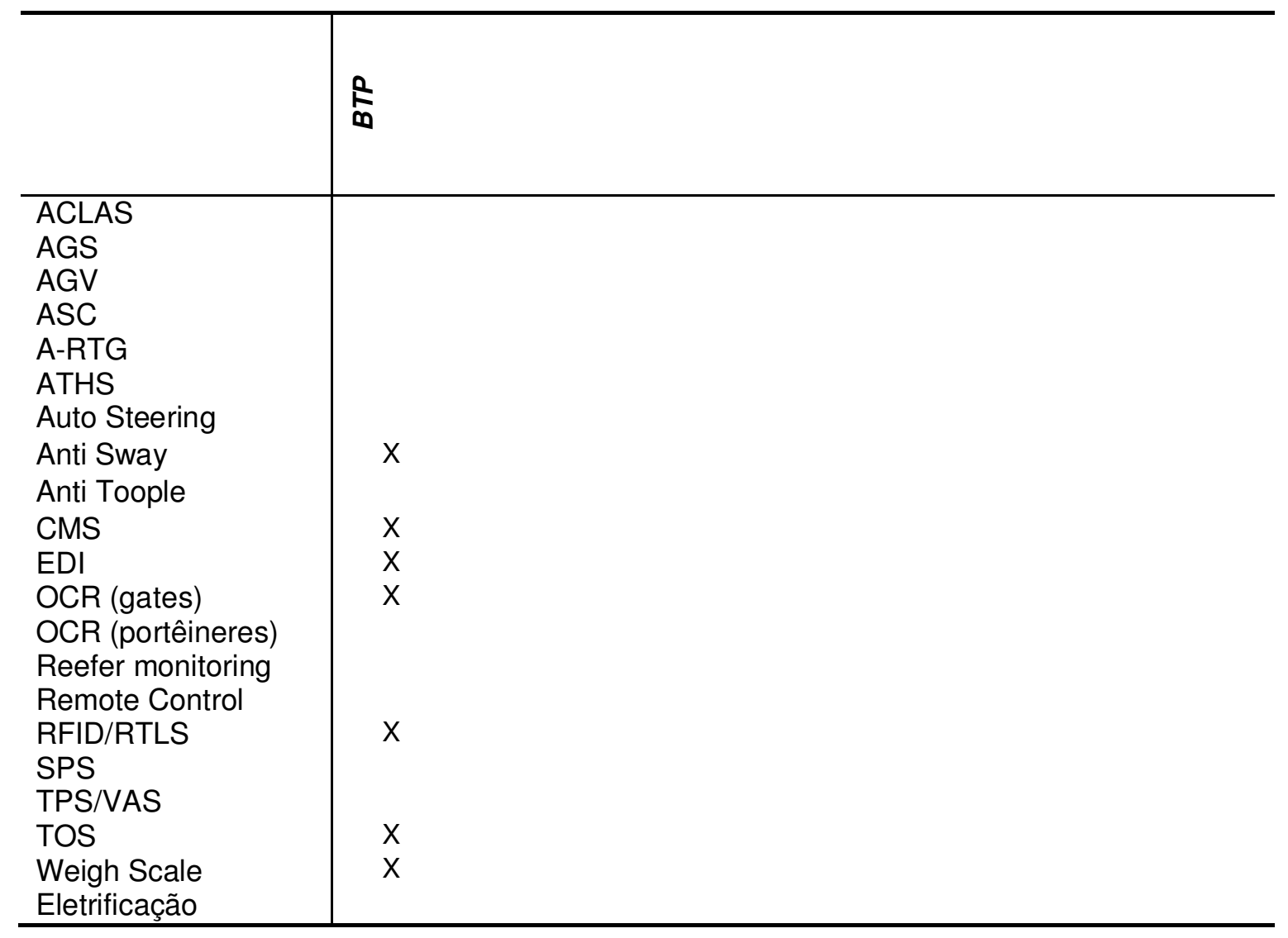

Observações: 
Terminal: Tecon Rio Grande Nome/Posição: Giovanni Pholor / Gerente de TI

\begin{tabular}{|c|c|}
\hline & 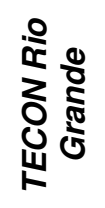 \\
\hline $\begin{array}{l}\text { ACLAS } \\
\text { AGS } \\
\text { AGV } \\
\text { ASC } \\
\text { A-RTG } \\
\text { ATHS } \\
\text { Auto Steering } \\
\text { Anti Sway } \\
\text { Anti Toople } \\
\text { CMS } \\
\text { EDI } \\
\text { OCR (gates) } \\
\text { OCR (portêineres) } \\
\text { Reefer monitoring } \\
\text { Remote Control } \\
\text { RFID/RTLS } \\
\text { SPS } \\
\text { TPS/VAS } \\
\text { TOS } \\
\text { Weigh Scale } \\
\text { Eletrificação }\end{array}$ & $\begin{array}{l}X \\
X\end{array}$ \\
\hline
\end{tabular}

Observações: 
Terminal: Embraport

Nome/Posição: Eldeer de Oliveira / Gerente de TI

\begin{tabular}{|c|c|}
\hline & 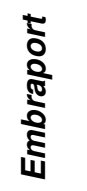 \\
\hline $\begin{array}{l}\text { ACLAS } \\
\text { AGS } \\
\text { AGV } \\
\text { ASC } \\
\text { A-RTG } \\
\text { ATHS } \\
\text { Auto Steering } \\
\text { Anti Sway } \\
\text { Anti Toople } \\
\text { CMS } \\
\text { EDI } \\
\text { OCR (gates) } \\
\text { OCR (portêineres) } \\
\text { Reefer monitoring } \\
\text { Remote Control } \\
\text { RFID/RTLS } \\
\text { SPS } \\
\text { TPS/VAS } \\
\text { TOS } \\
\text { Weigh Scale } \\
\text { Eletrificação }\end{array}$ & $\begin{array}{l}X \\
X \\
X \\
X \\
X \\
X\end{array}$ \\
\hline
\end{tabular}

Observações: 